\title{
Development of a Framework for Standardisation of Interlayer Bond of Asphalt Pavements
}

\author{
A thesis submitted to \\ the Faculty of Graduate Studies and Research \\ in Partial Fulfillment of the requirements for the degree \\ Doctor of Philosophy
}

by

Christiane Raab

Dipl.-Ing., Technical University Darmstadt

Department of Civil and Environmental Engineering

Carleton University

Ottawa-Carleton Institute of Civil and Environmental Engineering

December, 2010

C2011, Christiane Raab 
Library and Archives

Canada

Published Heritage

Branch

395 Wellington Street Ottawa ON K1A ON4 Canada
Bibliotheque et

Archives Canada

Direction du

Patrimoine de l'édition

395 , rue Wellington

Ottawa ON K1A ON4

Canada
Your file Votre reférence

ISBN: 978-0-494-79623-8

Our file Notre référence

ISBN: 978-0-494-79623-8
NOTICE:

The author has granted a nonexclusive license allowing Library and Archives Canada to reproduce, publish, archive, preserve, conserve, communicate to the public by telecommunication or on the Internet, loan, distribute and sell theses worldwide, for commercial or noncommercial purposes, in microform, paper, electronic and/or any other formats.

The author retains copyright ownership and moral rights in this thesis. Neither the thesis nor substantial extracts from it may be printed or otherwise reproduced without the author's permission.
AVIS:

L'auteur a accordé une licence non exclusive permettant à la Bibliothèque et Archives Canada de reproduire, publier, archiver, sauvegarder, conserver, transmettre au public par télécommunication ou par l'Internet, prêter, distribuer et vendre des thèses partout dans le monde, à des fins commerciales ou autres, sur support microforme, papier, électronique et/ou autres formats.

L'auteur conserve la propriété du droit d'auteur et des droits moraux qui protège cette thèse. $\mathrm{Ni}$ la thèse ni des extraits substantiels de celle-ci ne doivent être imprimés ou autrement reproduits sans son autorisation.
In compliance with the Canadian Privacy Act some supporting forms may have been removed from this thesis.

While these forms may be included in the document page count, their removal does not represent any loss of content from the thesis.
Conformément à la loi canadienne sur la protection de la vie privée, quelques formulaires secondaires ont été enlevés de cette thèse.

Bien que ces formulaires aient inclus dans la pagination, il n'y aura aucun contenu manquant. 


\section{Abstract}

A good bond between the layers of an asphalt pavement is a key factor for durable and long-lasting pavements. This fact has become more widely accepted leading to bond testing as a subject of study and the development of many different testing methods to evaluate the bond between pavement layers over the last decades. Regarding further developments in bond testing, standardisation and normalisation on an international level is very important. It is therefore crucial to come to commonly accepted methods and procedures. In this context, this thesis presented a great variety of existing shear test devices in great detail and investigated the influence of the width between the shearing rings of the Leutner test device, which has been debated during recent standardisation. Another goal of the study was to improve the phenomenological understanding of the mechanisms in interlayer bond testing. The work concentrated on the evaluation of the interlock and the combination of aggregate sizes on the interlayer bond, using a simple model material consisting of steel balls filled with $10 / 20$ penetration graded bitumen. Artificial neural network (ANN) techniques are not totally new and were used in other fields of pavement engineering. The availability and the quality of data are crucial for understanding the phenomena of interlayer bond. One of the major achievements of this thesis was that very large data describing interlayer bond over a long period of time had been collected and analysed. Subsequently, ANN was utilised to analyse the data and establish relationships. In addition to the analytical investigation laboratory tests were conducted to study the effect of moisture content, temperature and gap widths on the behaviour on the interlayer bond. 


\section{Acknowledgement}

This thesis is the outcome of collaboration between Carleton University in Ottawa, Canada and Swiss Federal Laboratories for Material Science and Technology Empa in Dübendorf, Switzerland. Therefore, I would like to express my thanks to many people in both countries and last not least to my family in my home country Germany.

First of all, I would like to thank my supervisor Prof. Abd El Halim for his advice and guidance. Especially during my stay in Canada I could always count on his support and help, which not only concerned University and scientific matters but also included practical advice and a helpful hand during every day struggles. Secondly, I thank my CoSupervisor Prof. Manfred Partl, head of the section Road Engineering/Sealing Components at Empa, for his scientific advice, help and encouragement. In Canada my thanks include all professors and staff of the Civil Engineering Department at Carleton University, especially Prof. Ata Khan, whom I will always remember for his kindness and understanding. I really enjoyed being his teaching assistant and I appreciate his friendship. Life in a foreign country is not always easy and therefore I am very grateful for all my friends and acquaintances in Canada. First of all, I have to thank Ulla ZieglerNault, who made her house my home away from home and spent a lot of her time and energy to make my stay in Canada pleasant and enjoyable. Without her support and friendship I would not have survived the hardship of the first weeks. My classmates and friends from University: Maqsooda Bibi, Maged Melmadhoon, Stephanie McNeely, Stacey Robinson and Susan Green were wonderful colleagues and I am fortunate to have spent time with them. 
In Switzerland, I appreciate the support offered by my colleagues from the section of Road Engineering and Sealing Components at Empa. My special thanks and gratitude go to my office partner Roland Takacs and my colleagues Hans Kienast and Sivotha Hean. Besides these three, many thanks to Christian Meierhofer, Markus Erb, Simon Küntzel and the two internship colleagues Guillaume Lacire and Vladan Stojadinovic for their technical support.

Finally, I would like to thank my parents and all my friends in Switzerland, Germany, South Africa and around the world, who accompanied and encouraged me. 


\section{Table of Contents}

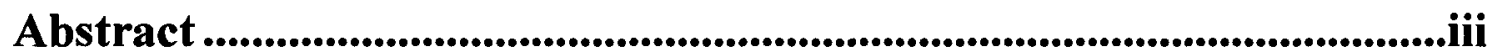

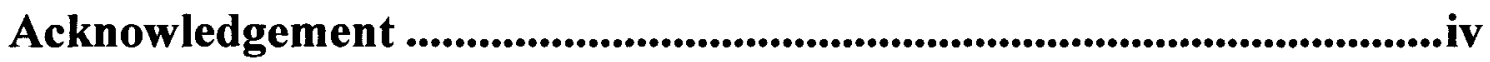

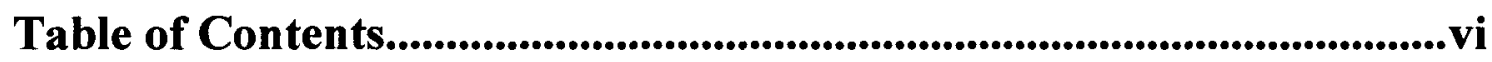

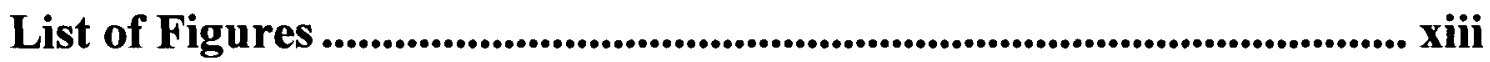

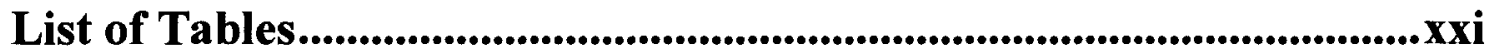

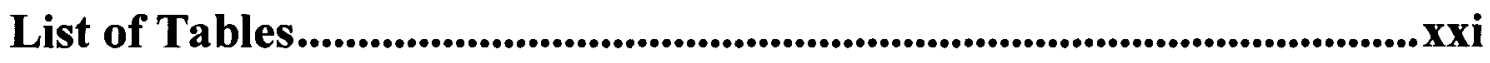

List of Appendices ........................................................................................xxiv

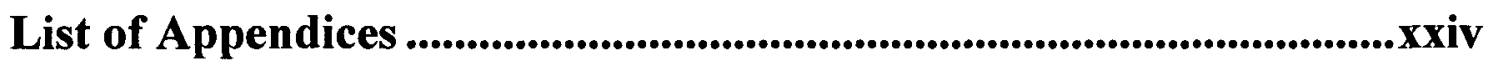

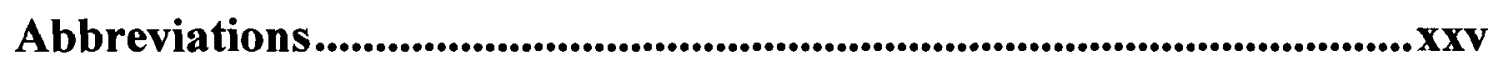

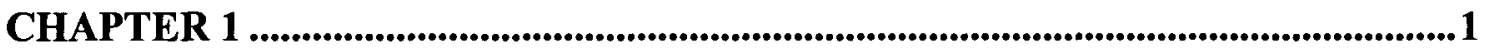

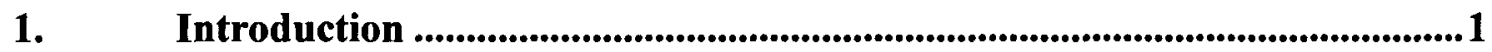

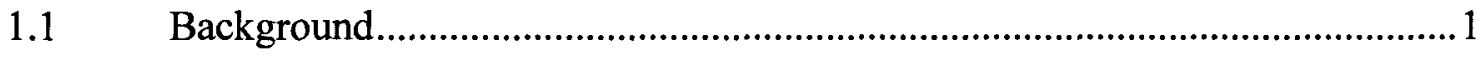

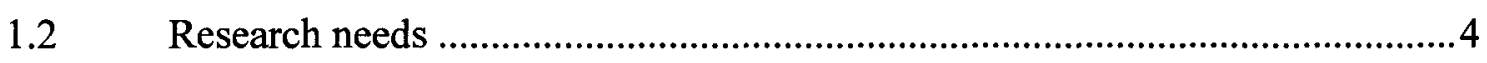

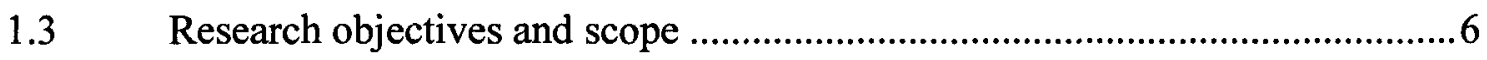

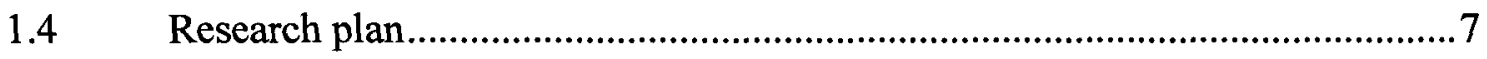

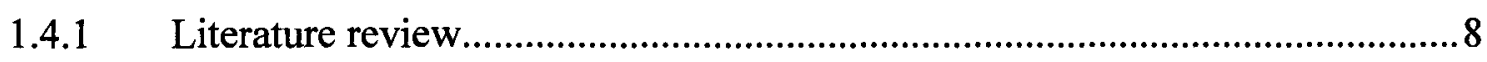

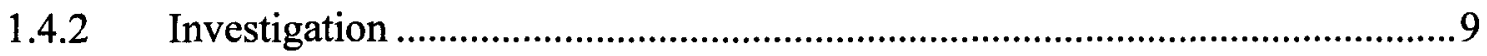

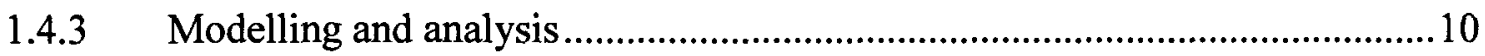

1.4.4 Conclusions and recommendations .......................................................... 
1.5 Organisation of the thesis 10

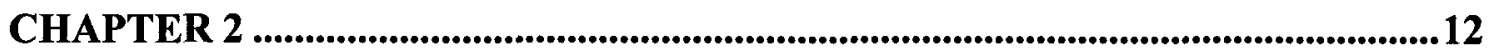

2. Literature Review ............................................................................................12

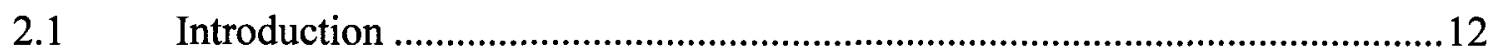

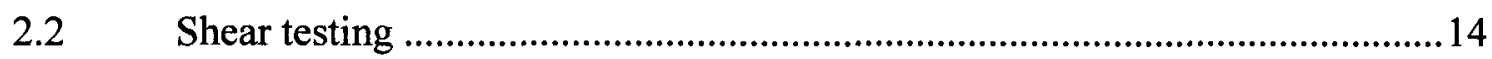

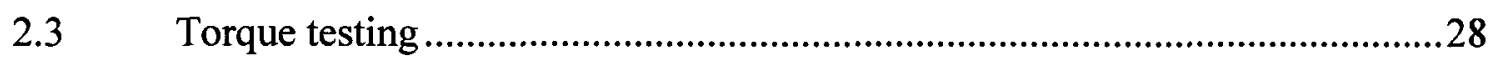

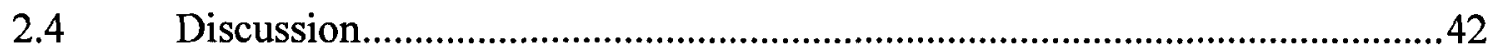

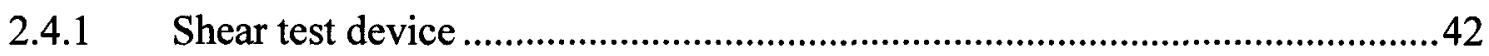

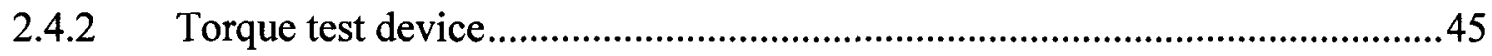

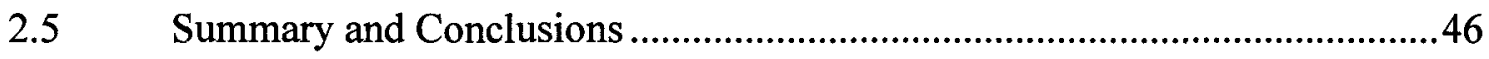

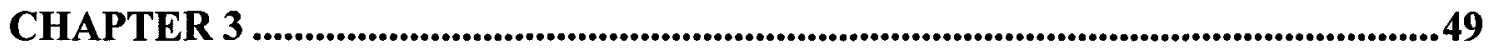

3. Experimental Investigation.................................................................................49

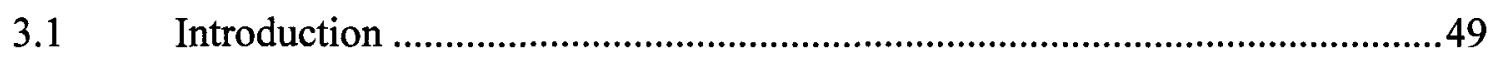

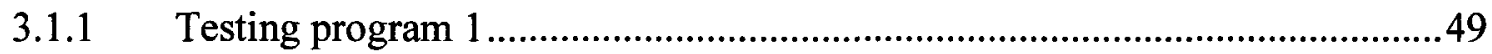

3.1.2 Testing program 2 2.....................................................................................

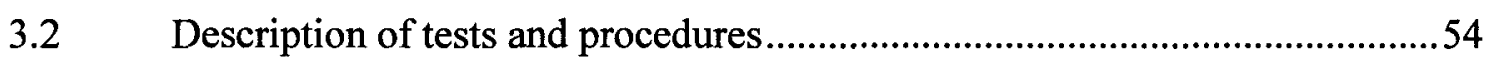

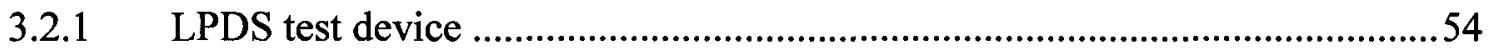

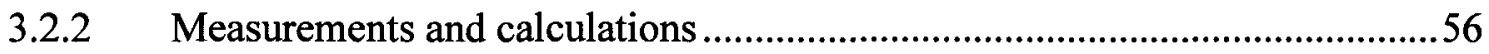

3.2.3 Determination of the mean shear curve ........................................................61

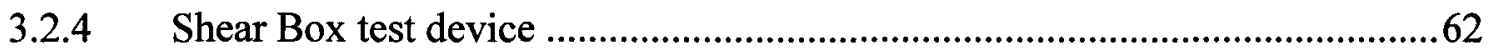

3.2.5 Measurements and calculations for Shear Box Testing...................................64

3.3 Description of materials and methods ........................................................65

3.3.1 Materials and methods for testing program 1 ….............................................65

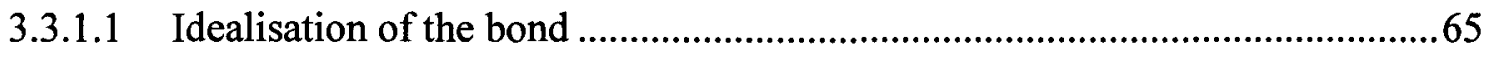

3.3.2 Materials and methods for testing program 2 2..........................................69

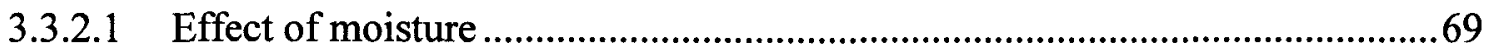




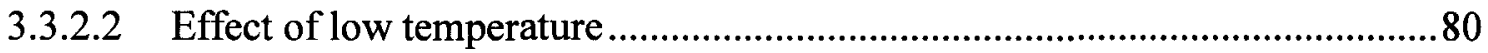

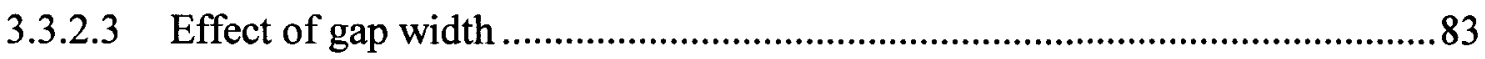

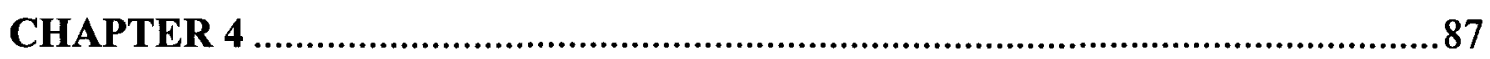

4. Results of Experimental Investigation .......................................................87

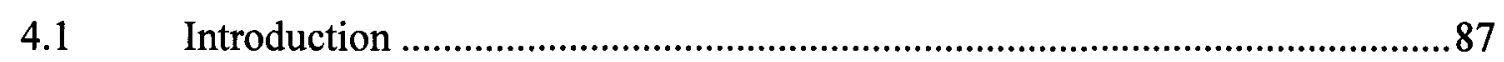

4.2 Results of the idealisation of the bond (testing program 1) ...........................87

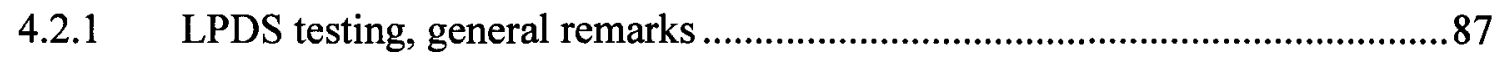

4.2.2 LPDS testing, in-layer and interlayer testing...................................................89

4.2.3 LPDS testing, influence of different steel ball combinations ...........................91

4.2.4 LPDS testing, influence of deformation rate ...................................................92

4.2.5 Shear Box, general remarks.......................................................................

4.2.6 Shear Box, influence of normal stress ...........................................................96

4.2.7 Shear Box, testing with and without binder ...................................................97

4.2.8 Comparison between LPDS and Shear Box testing ......................................102

4.3 Results of the parameter study (testing program 2).......................................104

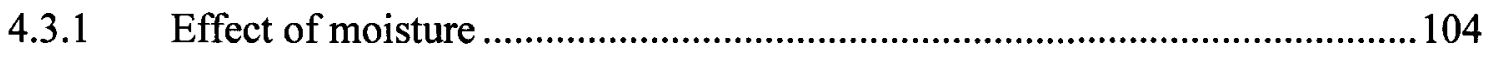

4.3.1.1 Pavements 1 and 2, interface 1: Shear Box ................................................104

4.3.1.2 Pavements 1, 2 and 3, interface 1 and 2: LPDS ..........................................111

4.3.1.3 Comparison Shear Box and LPDS, pavements 1 and 2, interface 1 .............117

4.3.2 Effect of low temperature .....................................................................118

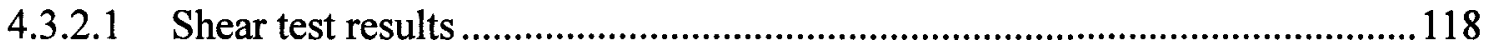

4.3.2.2 In-layer and interlayer behaviour .............................................................. 120

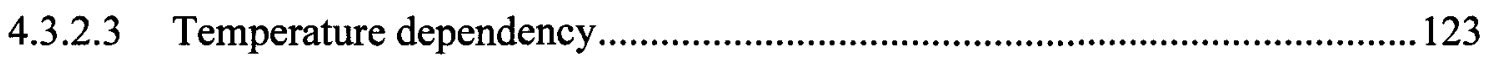

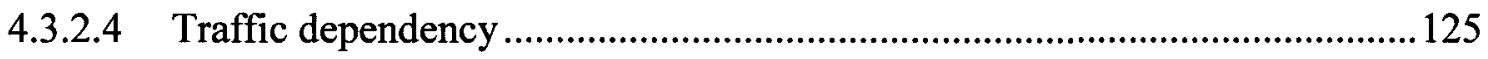

4.3.3 Effect of gap width ......................................................................................127

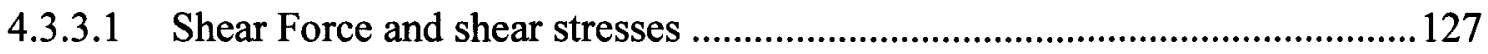

4.3.3.2 Shear stiffness (shear reaction modulus) ..........................................................129

4.3.3.3 Interlayer and in-layer shear behaviour........................................................ 130 


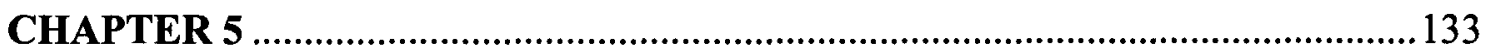

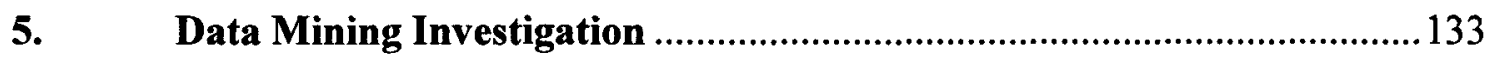

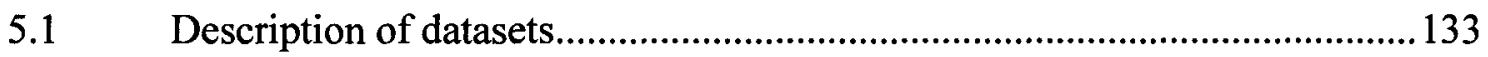

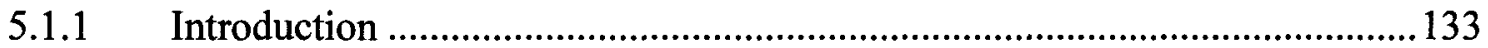

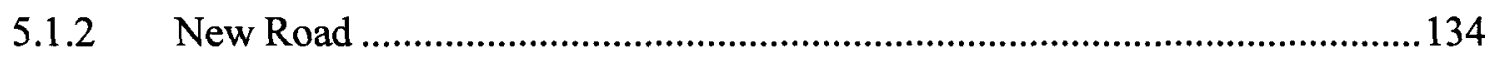

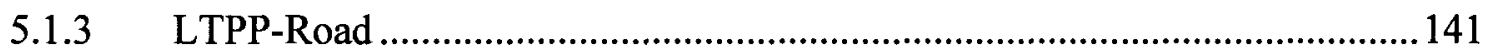

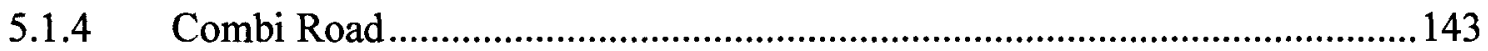

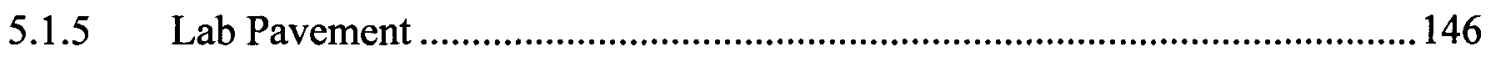

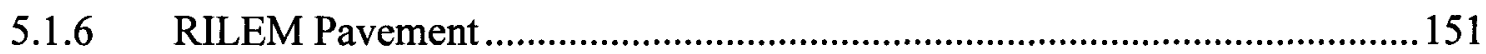

5.2 Utilisation of Artificial Neural Network ANN for the Analysis of Interlayer Shear Properties ............................................................................................. 156

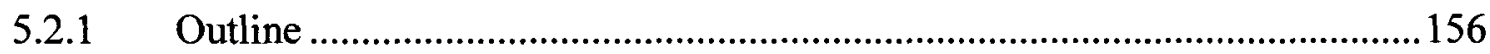

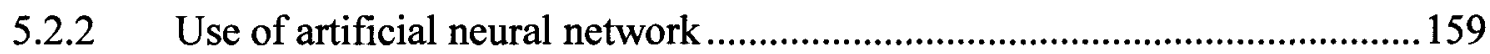

5.2.2.1 Relevance of ANN for interlayer bonding ....................................................161

5.2.2.2 Knowledge discovery using artificial intelligence ........................................ 162

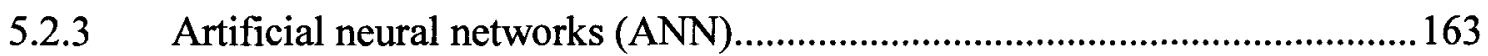

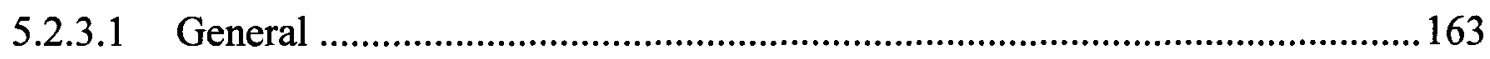

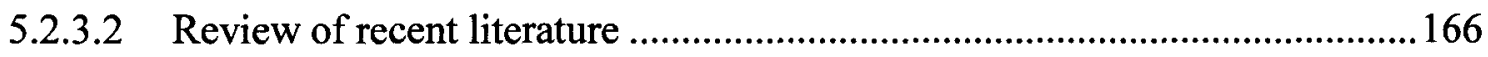

5.2.4 Problem description (interlayer bonding).....................................................167

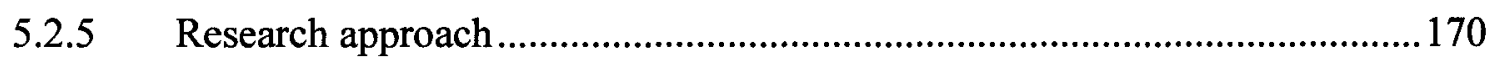

5.2.5.1 Data selection for interlayer bonding problems ...........................................171

5.2.5.2 Determination of output parameters ................................................................171

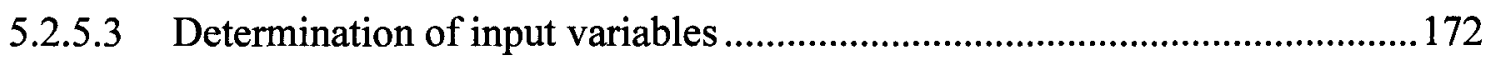

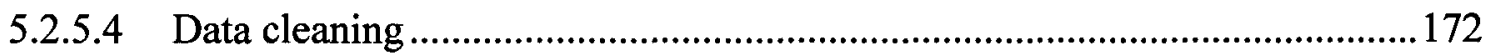

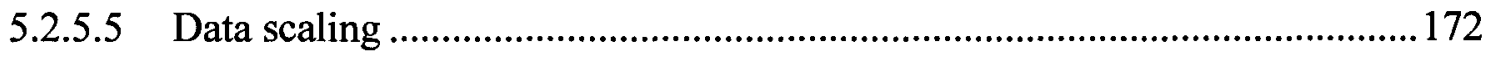

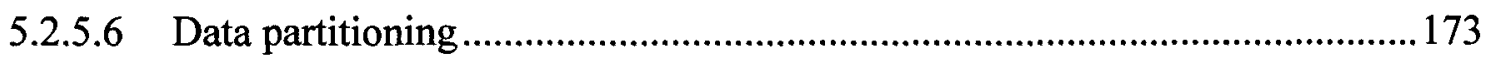

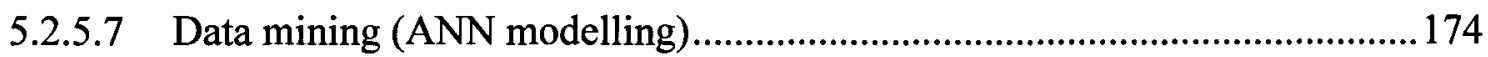

5.2.5.8 Model evaluation and interpretation.........................................................174

5.2.5.9 Analysis of relationship between actual and predicted values ......................176

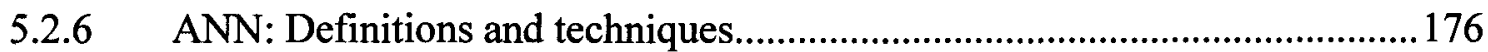




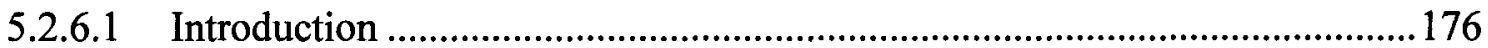

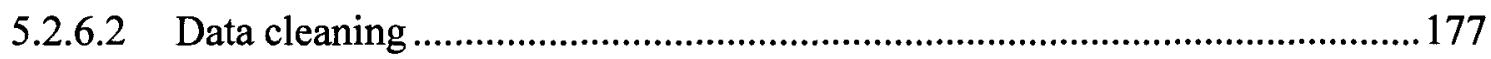

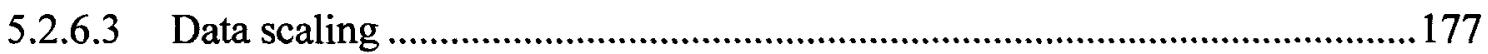

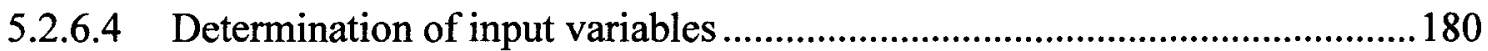

5.2.6.5 Data mining with Artificial Neural Networks: ANN Structure......................181

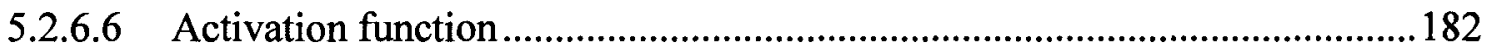

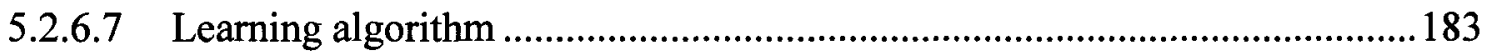

5.2.6.8 Optimisation of learning parameters ………............................................... 186

5.2.6.9 Developing ANN models - summary ..............................................................189

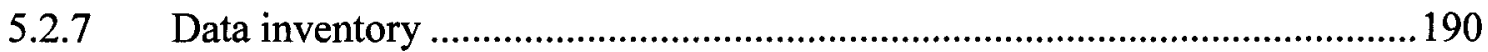

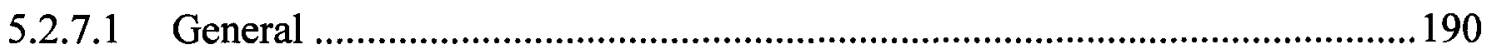

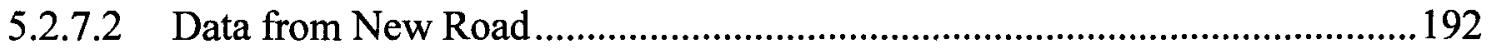

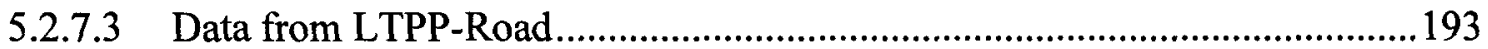

5.2.7.4 Data from Combi Road .............................................................................195

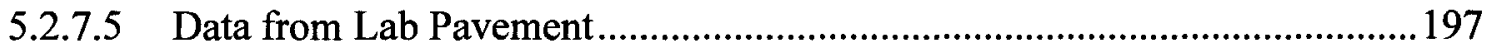

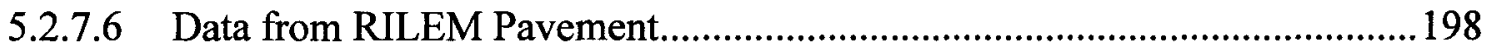

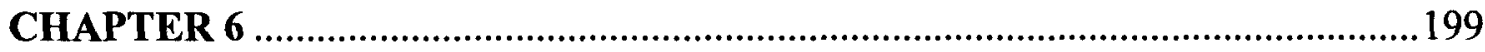

6. Interpretation and Analysis of Results ....................................................199

6.1 Influence of the tested parameters on the measured interlayer bond .............199

6.1.1 Idealisation of the bond (testing program 1) ...................................................199

6.1.2 Effect of moisture (testing program 2) ...................................................210

6.1.3 Effect of low temperature (testing program 2) ..............................................213

6.1.4 Effect of gap width (testing program 2) ........................................................214

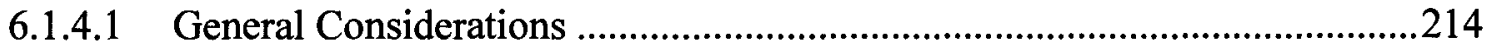

6.1.4.2 Optical measurements ...........................................................................215

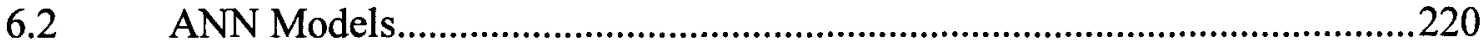

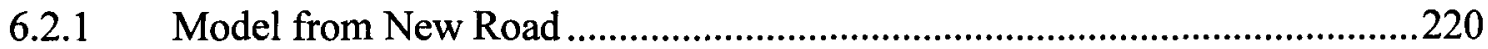

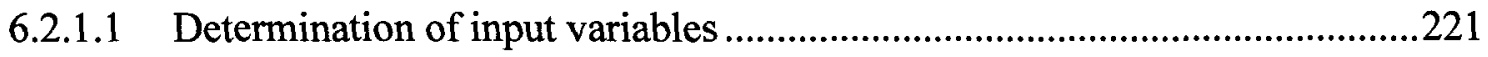

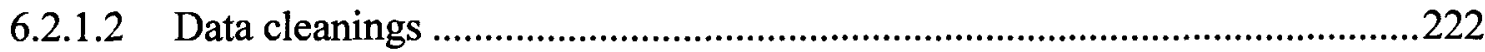




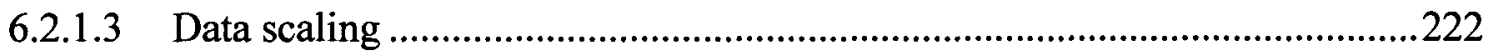

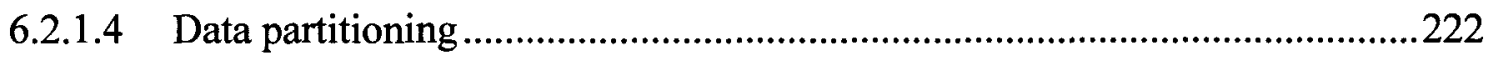

6.2.1.5 Data mining (modelling) ……………......................................................223

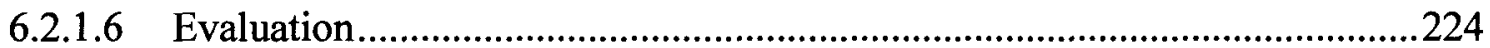

6.2.1.7 Analysis of relation between actual and predicted values.............................228

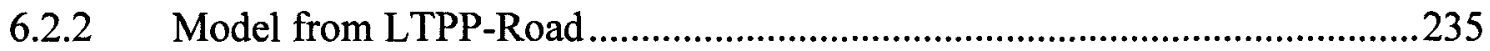

6.2.2.1 Determination of input variables ..............................................................235

6.2.2.2 Data mining (modelling) .........................................................................237

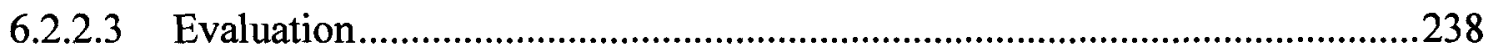

6.2.2.4 Analysis of relation between actual and predicted values..............................240

6.2.3 Model from Combi Road............................................................................247

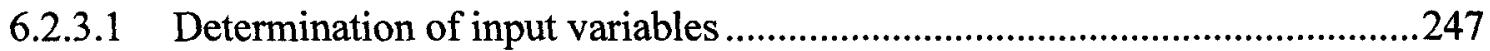

6.2.3.2 Data mining (modelling) ..............................................................................248

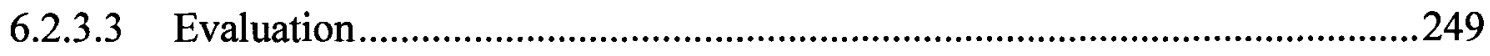

6.2.3.4 Analysis of relation between actual and predicted values............................250

6.2.4 Model from Lab Pavement ............................................................................251

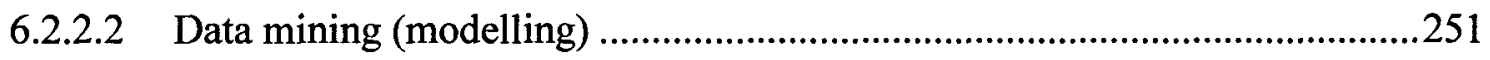

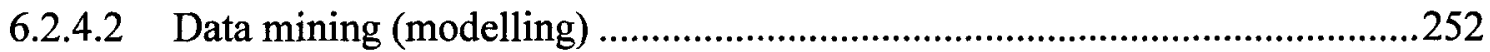

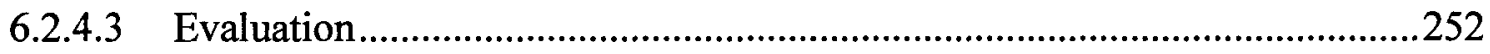

6.2.4.4 Analysis of relation between actual and predicted values.............................255

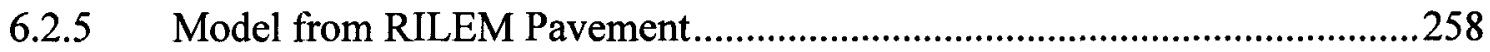

6.2.5.1 Determination of input variables .................................................................258

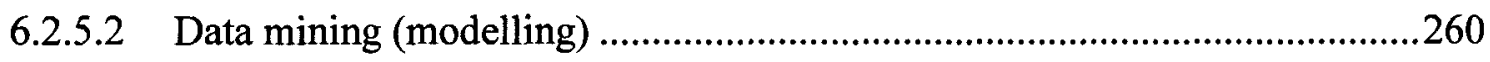

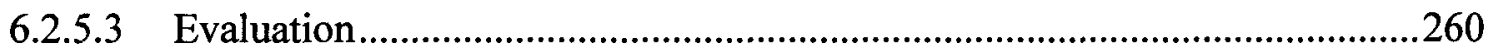

6.2.5.4 Analysis of relation between actual and predicted values............................263

6.2.6 Comparison between the different datasets ....................................................267

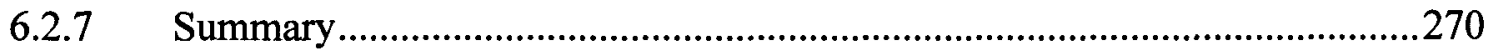

6.2.7.1 Understanding of the problem .................................................................270

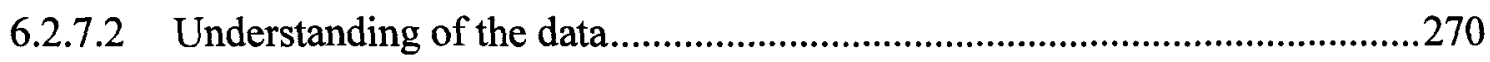

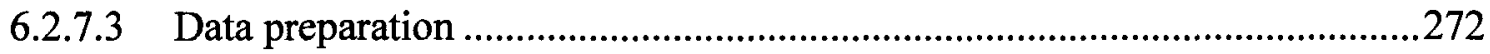




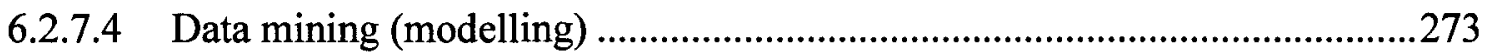

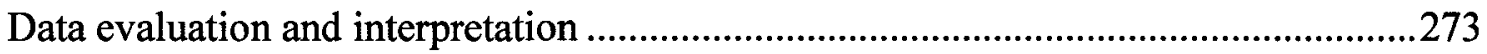

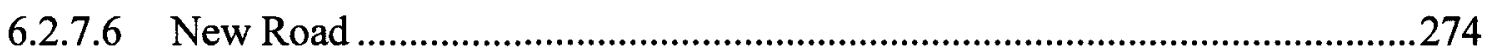

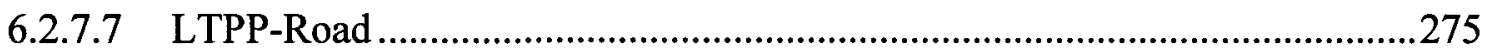

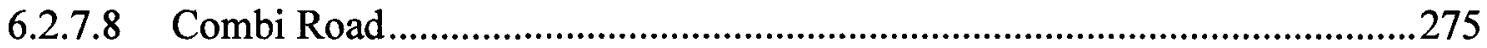

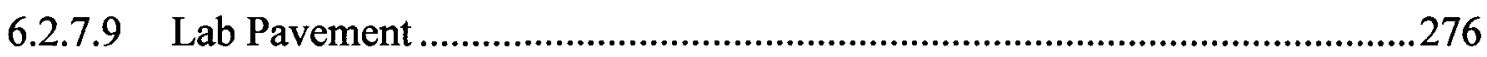

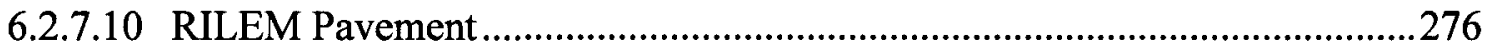

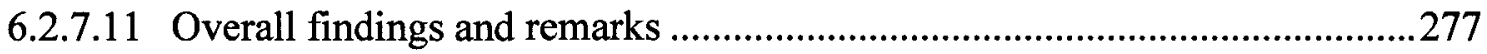

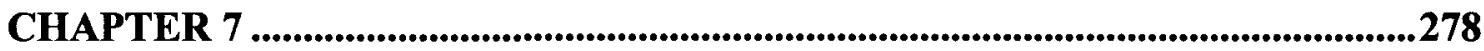

7. Conclusions and Recommendations......................................................278

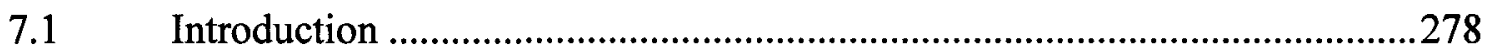

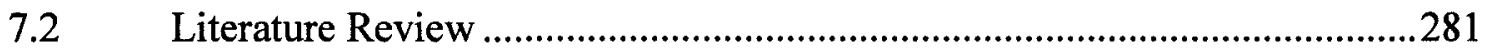

7.3 Interlayer shear data and properties..........................................................282

7.4 Utilisation of Artificial Neural Network ANN for the Analysis of Interlayer

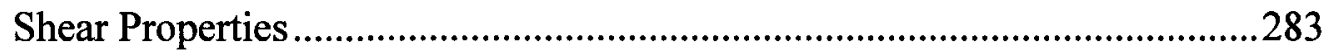

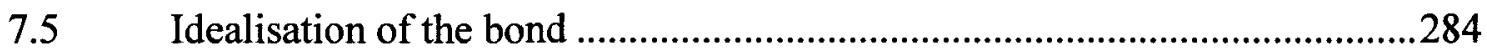

7.6 Influence of moisture on the interlayer bond of asphalt pavements ..............286

7.7 Influence of low temperature on interlayer bonding ..................................287

7.8 Influence of the gap width between the shearing rings on interlayer shear

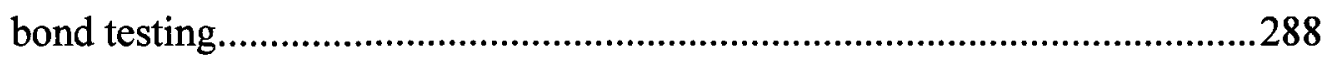

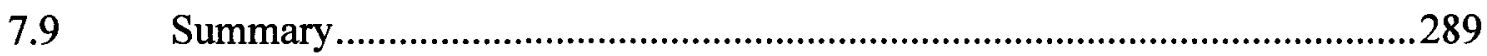

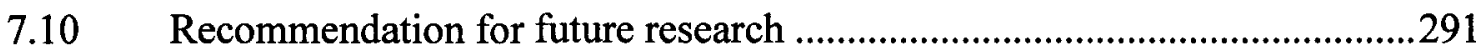

8. References..............................................................................................................295

9. Standards and Guidelines ....................................................................307 


\section{List of Figures}

Figure 1.1: Influence of air voids content (Hohlraumgehalt) and compaction

(Verdichtungsgrad) on shear force (Scherkraft) (Stöckert, 2001)

Figure 1.2: Influence of tack coat application rate and specimen age on shear strength

(Sholar et al., 2001) ...........................................................................................

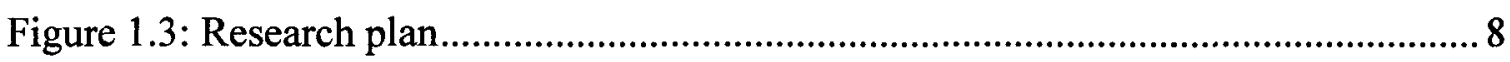

Figure 2.1: Test methods to determine interlayer bond properties in the lab and in the field (Raab and Partl, 1999) ....................................................................... 12

Figure 2.2: a) Shear stress distribution at the specimen head in the direct shear test

b) Shear stress distribution in the simple shear test ....................................... 15

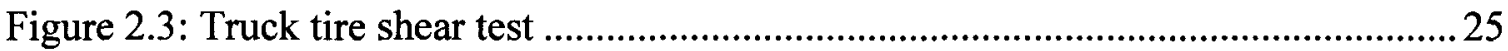

Figure 2.4: Core with glued steel plate ..........................................................................2

Figure 2.5: Photograph of the TVIST prototype machine constructed by EMPA

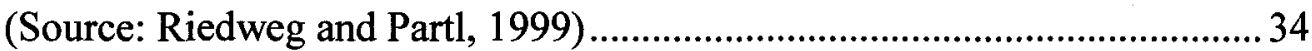

Figure 2.6: Loading and boundary conditions of CISSST .................................................

Figure 2.7: Schematic sketch of modelling and determining the bond properties for

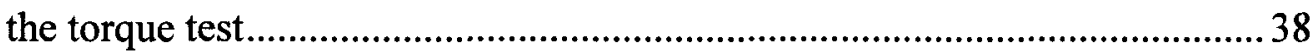

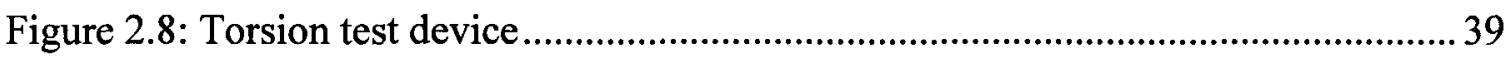

Figure 2.9: Loading plate with the remains of the porous asphalt pavement ................... 41

Figure 2.10: Arial view on the pavement, where the test was performed.......................... 41

Figure 2.11: Average deformation of the sheared part of the specimen GA2M............... 43

Figure 3.1: Layer parallel direct shear tester (LPDS), (a) photograph, (b) schematic

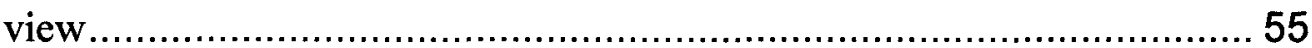

Figure 3.2: Schematic shear force-deformation curve with parameters of LPDS test...... 57

Figure 3.3: Determination of energy from shear force-shear deformation curve ..............60 60

Figure 3.4: Method to determine mean shear force - shear deformation curve.................62

Figure 3.5: ETH Shear Box device, (a) photograph, (b) schematic view ..........................63

Figure 3.6: Maximum envelope for testing at different levels of normal stress ................ 65 
Figure 3.7: Steel ball with diameters of $\emptyset 9.5 \mathrm{~mm}$ ('big') and $\varnothing 5.5 \mathrm{~mm}$ ('small'),........ 66

Figure 3.8: Specimen preparation, preparation of two layered specimen.......................... 67

Figure 3.9: Schematic drawing of different combinations, for LPDS and Shear Box testing.

Figure 3.10: Schematic drawing of interfacial bond damage caused by infiltration of

water. 70

Figure 3.11: Stripping of an open porous asphalt specimen as a result of testing under water using a traffic simulator

Figure3.12: Influence of water conditioning on interlayer shear properties (Source:

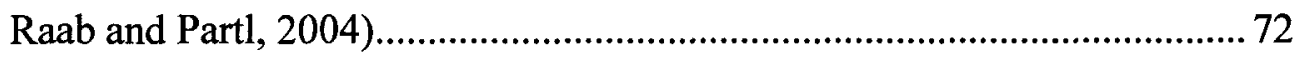

Figure 3.13: Detailed experimental program .................................................................. 73

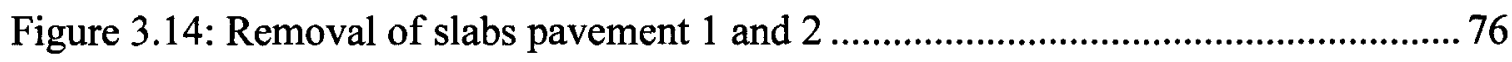

Figure 3.15: Coring of pavement 3 .......................................................................... 76

Figure 3.16: Water-pressure experiment set-up (schematic) .............................................. 79

Figure 3.17: Water-pressure experiment set-up (photograph) ............................................ 79

Figure 3.18: Slab removal and details of layers and material ............................................ 82

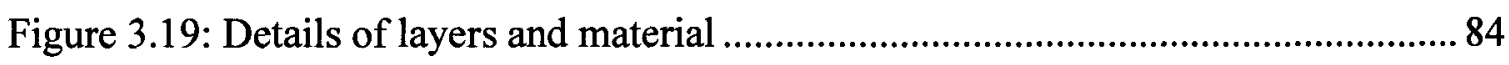

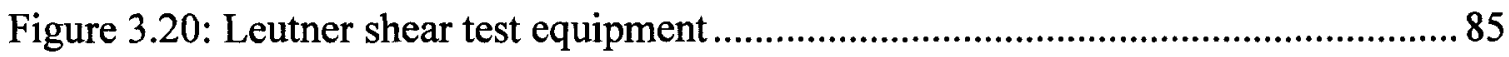

Figure 4.1: LPDS mean curves for in-layer and interlayer testing with big and small balls at a deformation rate of $50 \mathrm{~mm} / \mathrm{min}$ and a temperature of $20^{\circ} \mathrm{C}$

Figure 4.2: LPDS mean curves for interlayer testing with big and small balls at a deformation rate of $50 \mathrm{~mm} / \mathrm{min}$ (fast) and $2.5 \mathrm{~mm} / \mathrm{min}$ (slow) and a temperature of $20^{\circ} \mathrm{C}$

Figure 4.3: Shear force (shear stress) and shear stiffness for all steel ball combinations tested at a deformation rate of $2.5 \mathrm{~mm} / \mathrm{min}$ and $50 \mathrm{~mm} / \mathrm{min}$ .93

Figure 4.4: Mean shear force/stress- deformation curves for Shear Box testing with binder for all combination of steel balls at normal stresses of 0.1 and $0.4 \mathrm{MPa}$ (mean values) 97 
Figure 4.5: Mean shear force/stress- deformation curves for Shear Box testing for all combination of steel balls without binder at normal stress of 0.1 and $0.4 \mathrm{MPa}$ (mean values) 99

Figure 4.6: Max. shear stresses and envelopes at $20^{\circ} \mathrm{C}$ for the different combinations of steel balls with and without binder, all tests were conducted at $2.5 \mathrm{~mm} / \mathrm{min}$ 101

Figure 4.7: Comparison of shear stress- deformation curves for interlayer testing; LPDS with a deformation rate of $2.5 \mathrm{~mm} / \mathrm{min}$ and shear box with normal stress of $0.1 \mathrm{MPa}$ (mean values). 103

Figure 4.8: Mean shear force (stress) - deformation curves for Shear Box testing at $20^{\circ} \mathrm{C}$ of pavement 1 , interface 1

Figure 4.9: Mean shear force (stress) - deformation curves for Shear Box testing at $20^{\circ} \mathrm{C}$ of pavement 2 , interface 1 106

Figure 4.10: Maximum shear stress for different normal stresses for pavement 1 and 2 , interface 1 , Condition 1 106

Figure 4.11: Maximum shear reaction modulus $\mathrm{K}$ for different normal stresses for pavements 1 and 2 , interface 1 , Condition 1

Figure 4.12: Maximum shear forces for different normal stresses for pavement 1, interface 1, Conditions 1 and 2

Figure 4.13: Maximum shear stiffness $\mathrm{S}$ for different normal stresses for pavement 1 , interface 1 , Conditions 1 and 2

Figure 4.14: Maximum shear forces for different normal stresses for pavement 2, interface 1 , Conditions 1 and 2

Figure 4.15: Maximum shear stiffness $\mathrm{S}$ for different normal stresses for pavement 2, interface 1 , Conditions 1 and 2

Figure 4.16: Mean shear force (stress) - deformation curves for LPDS testing at $20^{\circ} \mathrm{C}$ of pavement 1 , interface 1

Figure 4.17: Mean shear force (stress) - deformation curves for LPDS testing at $20^{\circ} \mathrm{C}$ of pavement 1 , interface 2 . 
Figure 4.18: Mean shear force (stress) - deformation curves for LPDS testing at $20^{\circ} \mathrm{C}$ of pavement 2 , interface 1

Figure 4.19: Mean shear force (stress) - deformation curves for LPDS testing at $20^{\circ} \mathrm{C}$

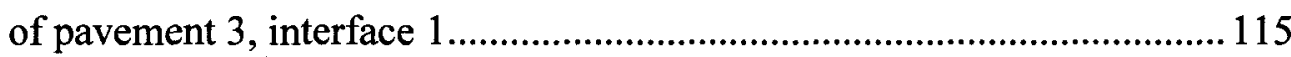

Figure 4.20: Mean shear force (stress) - deformation curves for LPDS testing at $20^{\circ} \mathrm{C}$ of pavement 3 , interface 2 .

Figure 4.21: Comparison of in-layer and interlayer shear test curves for slab 1 at $20^{\circ} \mathrm{C}$, layers 1 and 2

Figure 4.22: Comparison of in-layer and interlayer shear test curves for slab 1 at $20^{\circ} \mathrm{C}$, layers 2 and 3

Figure 4.23: Comparison of in-layer and interlayer shear test curves for slab 1 at $20^{\circ} \mathrm{C}$, layers 3 and 4

Figure 4.24: Shear forces and stresses of slab 2 at temperatures of $20^{\circ} \mathrm{C}, 0^{\circ} \mathrm{C}$ and $-20^{\circ} \mathrm{C}$

Figure 4.25: Shear stiffness and shear reaction modulus of slab 2 at temperatures of $20^{\circ} \mathrm{C}, 0^{\circ} \mathrm{C}$ and $-20^{\circ} \mathrm{C}$

Figure 4.26: Shear force and stress of slabs 1 and 2 at temperatures of $20^{\circ} \mathrm{C}$ and $-20^{\circ} \mathrm{C}$ 125

Figure 4.27: Shear stiffness and reaction modulus of slabs 1 and 2 at temperatures of $20^{\circ} \mathrm{C}$ and $-20^{\circ} \mathrm{C}$

Figure 4.28: Mean values of the maximum interlayer and in-layer shear forces and stresses with gap widths of $0 \mathrm{~mm}, 2.5 \mathrm{~mm}$ and $5.0 \mathrm{~mm}$, mean value and standard deviation

Figure 4.29: Mean values of the maximum interlayer and in-layer stiffness and shear reaction modulus with gap widths of $0 \mathrm{~mm}, 2.5 \mathrm{~mm}$ and $5.0 \mathrm{~mm}$, mean value and standard deviation.

Figure 4.30: Mean shear force-deformation curves SMA 11/AC-B 22 with standard deviation for gap widths of $0 \mathrm{~mm}, 2.5 \mathrm{~mm}$ and $5 \mathrm{~mm}$.

Figure 4.31: Mean shear force-deformation curves AC-B22/AC-T322 with standard deviation for gap widths of $0 \mathrm{~mm}, 2.5 \mathrm{~mm}$ and $5 \mathrm{~mm}$ 


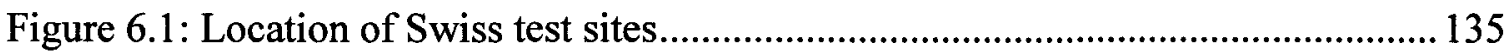

Figure 5.2: Gradation limits for AC 11 and AC 16 according to SN EN 640430 .......... 138

Figure 5.3: Gradation limits for AC 22 and AC 32 according to SN EN 640430 .......... 138

Figure 5.4: Gradation limits for SMA 11 according to SN EN 640430 ........................... 139

Figure 5.5: Gradation limits for PA 11 according to SN EN 640430 …………………... 139

Figure 5.6: Gradation for MA 11 and MA 16 according to SN EN 640441.................... 140

Figure 5.7 :Gradation limits for AC 11 and SMA 11 according to SN EN 640430 ....... 144

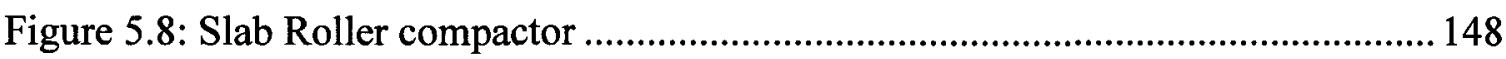

Figure 5.9: Gradation with limits for AC 11 according to SN EN 640430 .....................149

Figure 5.10: Gradation with limits for AC 22 according to SN EN 640430 ................... 150

Figure 5.11: Schematic drawing of coring schema ....................................................... 151

Figure 5.12: Schematic view of the RILEM trial pavement (Ferrotti, 2007)................... 152

Figure 5.13: RILEM trial pavement in summer 2005 (Ferrotti, 2007) ............................ 153

Figure 5.14: Coring the test specimens (Ferrotti, 2007, Piber 2009) …………………... 154

Figure 5.15: Gradation for surface layer AC11 of RILEM trial pavement....................... 155

Figure 5.16: Gradation for second layer AC16 of RILEM trial pavement ...................... 155

Figure 5.17: Outline for the utilisation of Artificial Neural Network ANN for the Analysis of Interlayer Shear Properties (described in Section 5.2 and

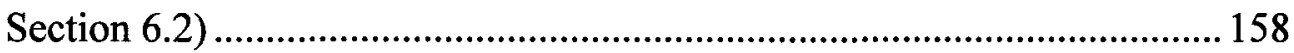

Figure 5.18: Steps of knowledge discovery according to Fayyad .................................... 163

Figure 5.19: Schematic of an artificial neuron (left) and a three layer ANN (right) ...... 165

Figure 5.20: Factors influencing a durable bond between asphalt pavement layers....... 169

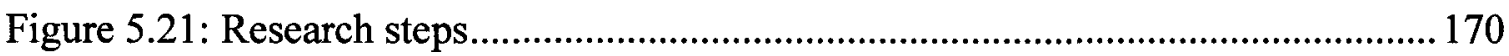

Figure 5.22: Evaluation of the developed model .......................................................... 175

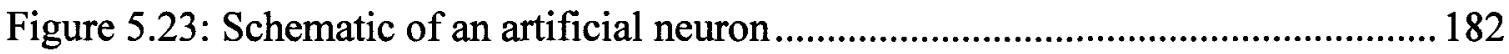

Figure 5.24 - Logistic function (a) and Hyperbolic tangent function (b) ......................... 183

Figure 6.1: Comparison of interlock in case of the two specimen structures, left: small/big (s/b), right: big/small (b/s)

Figure 6.2: Small/big specimen after LPDS test; left: small steel balls, right: big steel balls with some small steel balls remaining from top layer 200 
Figure 6.3: Comparison of roughness in case of the two specimen structures, left: big steel balls, right: small steel balls .

Figure 6.4: Schematic drawing of the roughness capacity curve. 203

Figure 6.5: Fracture surfaces after LPDS testing (slow), (a) small/small, (b) big/big and (c) small/big 206

Figure 6.6: Comparison of calculated ranking and LPDS ranking for the different steel ball combinations

Figure 6.7: Schematic drawing of test set-up (left), Photograph of image processing unit (right)

Figure 6.8: LPDS test device: Test specimen with markings for optical measurements in the shearing zone (left). To the right specimen fixed in the test device...217

Figure 6.9: Optical measurements during inter-layer and in-layer shear testing of a pavement with SMA 11 surface and AC 22 base courses at $20^{\circ} \mathrm{C}$. View of the situation at the start of the test and when cracks appear.

Figure 6.10: Network architecture used for data mining from New Road 224

Figure 6.11: Prediction of Fmax_red10 and tmax_red10, for training (left) and test (right) dataset.

Figure 6.12: Prediction of Fmax_red and $\tau$ max_red, for training (left) and test (right) dataset. 226

Figure 6.13: Prediction of $\mathrm{w}_{-}$red10 at Fmax for training (left) and test (right) dataset.. 227

Figure 6.14: Prediction of Smax_red10 and Kmax_red 10 for training (left) and test (right) dataset. 227

Figure 6.15: Prediction of Fmax_red10 and tmax_red10 for independent query test dataset red 10 . 228

Figure 6.16: Prediction of max. shear force Fmax_red and tmax_red for independent query test dataset red 10 229

Figure 6.17: Prediction of max. shear deformation wmax_red10 for independent test dataset red 10 229

Figure 6.18: Prediction of max. shear stiffness Smax_red10 for independent test dataset red 10 230 
Figure 6.19: Response graphs of the input variables as a function of max. shear force and max. shear stress: temperature (a), air void content first and second layer (b), (c), binder content first and second layer (d), (e), passing-\% for first and second layer and the sieve $8 \mathrm{~mm}, 2 \mathrm{~mm}$ and $0.09 \mathrm{~mm}$ (f) - (k) ....234

Figure 6.20: Network architecture used for data mining for LTPP-Road........................ 237 Figure 6.21: Prediction of Fmax and $\tau$ max, for training (left) and test (right) dataset ...238 Figure 6.22: Prediction of $w$ at Fmax for training (left) and test (right) dataset.............239

Figure 6.23: Prediction of Smax and Kmax for training (left) and test (right) dataset ...239 Figure 6.24: Prediction of Fmax and $\tau$ max, for independent query test dataset 241

Figure 6.25: Prediction of $\mathrm{w}$ at Fmax for independent query test dataset......................... 241

Figure 6.26: Prediction of Smax and Kmax for independent query test dataset..............242 Figure 6.27: Response graphs of the input variables as a function of max. shear force and max. shear stress: average daily traffic ADT (a), percentage of vehicles $>3.5 \mathrm{t}(\mathrm{b})$, age (c), aggregates passing the sieve $8 \mathrm{~mm}, 2 \mathrm{~mm}$ and $0.09 \mathrm{~mm}$ for first and second layer (d) - (i) 244

Figure 6.28: Response graphs of the input variables as a function of max. shear stiffness and shear reaction modulus: average daily traffic ADT (a), percentage of vehicles $>3.5 t$ (b) and age (c) .................................................246

Figure 6.29: Network architecture used for data mining for Combi-Road ...................... 248

Figure 6.30: Prediction of Fmax and tmax, for training (left) and test (right) dataset ...249

Figure 6.31: Prediction of max. shear force Fmax and max. shear stress and $\tau$ max, for independent query test dataset 250

Figure 6.32: Network architecture for data from laboratory pavements using cationic tack coats 252

Figure 6.33: Prediction of Fmax and tmax, for training (left) and test (right) dataset ...253

Figure 6.34: Prediction of $\mathrm{w}$ at Fmax for training (left) and test (right) dataset.............254 Figure 6.35: Prediction of Smax and Kmax for training (left) and test (right) dataset...254 Figure 6.36: Prediction of Fmax and $\tau$ max, for independent query test dataset ..............255

Figure 6.37: Prediction $w$ at Fmax for independent query test dataset........................... 256

Figure 6.38: Prediction of Smax and Kmax for independent query test dataset..............256 
Figure 6.39: Response graphs of the input variables as a function of max. shear force and max. shear stress: age (a), air void content of the first (b) and air void content of the second layer (c)

Figure 6.40: Response graphs of the input variable age as a function of max. shear stiffness and max. shear reaction modulus.............................................. 258

Figure 6.41: Network architecture for RILEM Pavement .......................................260

Figure 6.42: Prediction of Fmax and $\tau \max$, for training (left) and test (right) dataset ... 261

Figure 6.43: Prediction of $\mathrm{w}$ at Fmax for training (left) and test (right) dataset............. 262

Figure 6.44: Prediction of Smax and Kmax for training (left) and test (right) dataset ... 262

Figure 6.45: Prediction of Fmax and $\tau \max$, for independent query test dataset ............ 263

Figure 6.46: Prediction of $\mathrm{w}$ at Fmax for independent query test dataset....................... 264

Figure 6.47: Prediction of Smax and Kmax for independent query test dataset............. 264

Figure 6.48: Response graphs of the input variables as a function of max. shear force and max. shear stress: temperature (a), deformation rate (b), age (c), air void content of the first (d) and air void content of the second layer (e) .... 266

Figure 6.49: Response graphs of the input variables as a function of max. shear stiffness and max. shear reaction modulus: temperature (a), deform. rate (b) and age (c) 267

Figure 7.1: Developed framework for standardisation of interlayer bond of asphalt pavements 279 


\section{List of Tables}

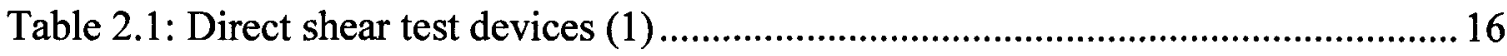

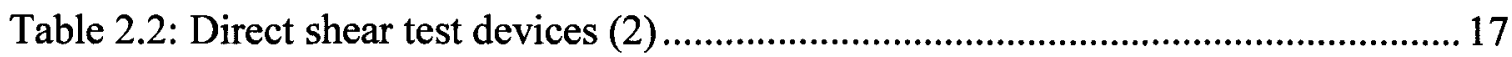

Table 2.3: Simple shear test devices ............................................................................. 18

Table 2.4: Torque test devices (1): Lab devices .............................................................29

Table 2.5: Torque test devices (2): In situ devices.......................................................... 30

Table 3.1: Test program for LPDS and Shear Box testing .................................................68

Table 3.2 :Material characteristics of pavements 1 and 2 ............................................... 75

Table 3.3: Material characteristics of pavement 3 …………………………………....... 77

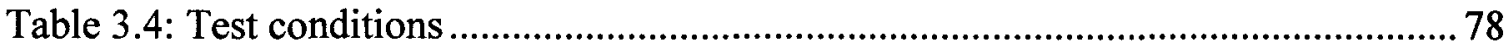

Table 3.5: Information on pavement, construction, removal and testing.......................... 82

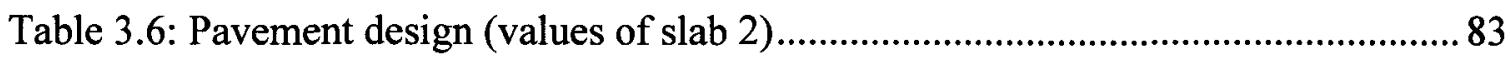

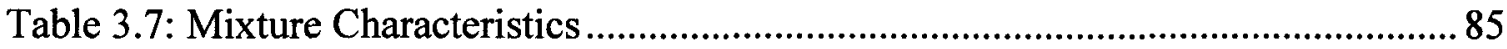

Table 4.1: Results of LPDS interlayer shear testing, single values, average (bold), standard deviation in brackets and coefficient of variation $\mathrm{CV}$ [\%]................ 88

Table 4.2: Results of LPDS in-layer shear testing, single values, average (bold), standard deviation in brackets and coefficient of variation CV [\%] .90

Table 4.3: Results of Shear Box testing with binder, single values, average (bold), standard deviation in brackets and coefficient of variation CV [\%] ................ 95

Table 4.4: Results of Shear Box testing without binder single values, average (bold), standard deviation in brackets and coefficient of variation CV [\%]...............98

Table 4.5: Area under the shear force-displacement curves (shear box) for all steel ball combinations with and without binder.

Table 4.6: Mean values of Shear Box test results for pavements 1 and 2, interlayer 1; standard deviation in brackets

Table 4.7: LPDS test results at $20^{\circ} \mathrm{C}$ for pavements 1,2 and 3, interlayers 1 and 2 (standard deviation in brackets) 
Table 4.8: Shear Box (without normal stress) and LPDS test results for pavements 1 and 2 , interlayer 1 (standard deviation in brackets)

Table 4.9: Mean values of LPDS test results (standard deviations in brackets) 119

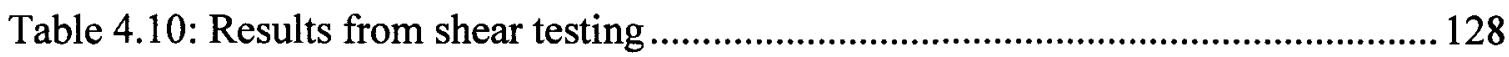

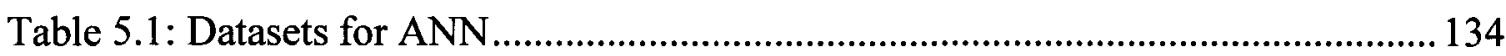

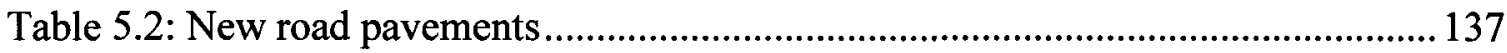

Table 5.3: Sites with pavement characteristics and traffic data ......................................... 142

Table 5.4: Test sections with different intermediate layers .............................................. 145

Table 5.5: Number of core and test date for all test sections ............................................ 146

Table 5.6: Laboratory pavement specimens.................................................................... 147

Table 5.7: Material characteristics of AC 11 and AC 22 ............................................... 149

Table 5.8: Mixture characteristics of the RILEM trial pavement ...................................... 154

Table 5.9: Testing program ......................................................................................... 156

Table 5.10: Range of output layer activation functions .............................................. 178

Table 5.11: List of general variables influencing the interlayer bond .............................. 191

Table 5.12: List of variables influencing interlayer bond of New Road........................... 193

Table 5.13: List of variables influencing interlayer bond of LTPP Road ......................... 194

Table 5.14: List of variables influencing interlayer bond of Combi Road ....................... 196

Table 5.15: List of variables influencing interlayer bond of Lab Pavement.................... 197

Table 5.16: List of variables influencing interlayer bond of RILEM Pavement ............. 198

Table 6.1: Area in \% of total cross section area under the shear force-displacement curves (shear box) for all steel ball combinations with and without binder . 206

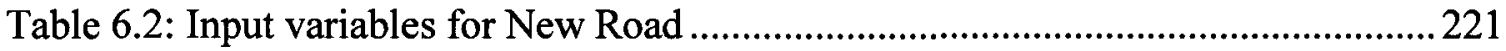

Table 6.3: Test results for all output parameters for data from New Road.......................225

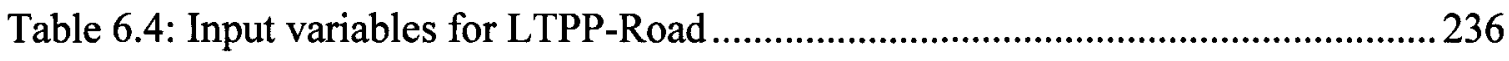

Table 6.5: Test results for all output variables for LTPP-Road .........................................238

Table 6.6: Input variables for data from Combi Road ......................................................248

Table 6.7: Test results for all output variables for data from Combi Road...................... 249

Table 6.8: Input variables for Lab Pavement ................................................................... 251

Table 6.9: Test results for all output variables for Lab Pavement .....................................253 
Table 6.10: Input variables for RILEM Pavement ............................................................259

Table 6.11: Test results for all output variables for RILEM Pavement ............................261

Table 6.12: Comparison of normalised response graphs as a function of max. shear force and stress and max. shear stiffness and shear reaction modulus...........269 


\section{List of Appendices}

Appendix A: Data from Data mining investigation (ANN) ..................................310

Appendix B: Data from testing program 2 (moisture influence).....................329

xxiv 


\section{Abbreviations}

A area

$\mathrm{AC} \quad$ asphalt concrete

AC B asphalt concrete binder course

AC T asphalt concrete base course

AC S asphalt concrete subbase course

ADT average daily traffic

AE absolute error

AI artificial intelligence

ANN artificial neural network

ARE absolute relative error

ASTRA $\quad$ Swiss Federal Road Administration

AV air void content

BBA British Board of Agreement

$b_{k} \quad$ bias

BV binder content

$\mathrm{c}_{0} \quad$ cohesion

CEN European commission for standardisation

CISSST Carleton In-Situ Shear Strength Test

d diameter, diameter of lower layer

D diameter of upper layer

E error 


$\begin{array}{ll}\text { Empa } & \text { Swiss Federal Laboratories for Materials testing and research } \\ \text { EN } & \text { European standard } \\ \text { ETH } & \text { Swiss Federal Institute of Technology } \\ \text { FANN } & \text { Feed forward ANN } \\ \text { F }_{\max } & \text { maximum shear force, in the text often only F } \\ \text { FEM } & \text { Finite Element Method } \\ \text { h } & \text { height } \\ \text { HR } & \text { hot rolled asphalt } \\ \text { K } & \text { maximum shear reaction modulus, in the text often only K } \\ \text { LCPC } & \text { Laboratoire Central des Ponts et Chaussées (F) } \\ \text { LOP } & \text { Limit of Proportionality } \\ \text { LPDS } & \text { Layer parallel direct shear } \\ \text { M } & \text { secant modulus } \\ \text { MA } & \text { mastic asphalt } \\ \text { MCS } & \text { Modified Compact Shearing } \\ \text { MRA } & \text { Multi Regression Analysis } \\ \text { MR } & \text { special Swiss low noise pavement } \\ \text { ÖNORM } & \text { Austrian standard } \\ \text { PA } & \text { porous asphalt } \\ \text { r } & \text { Radius } \\ \text { linear regression coefficient } \\ \end{array}$




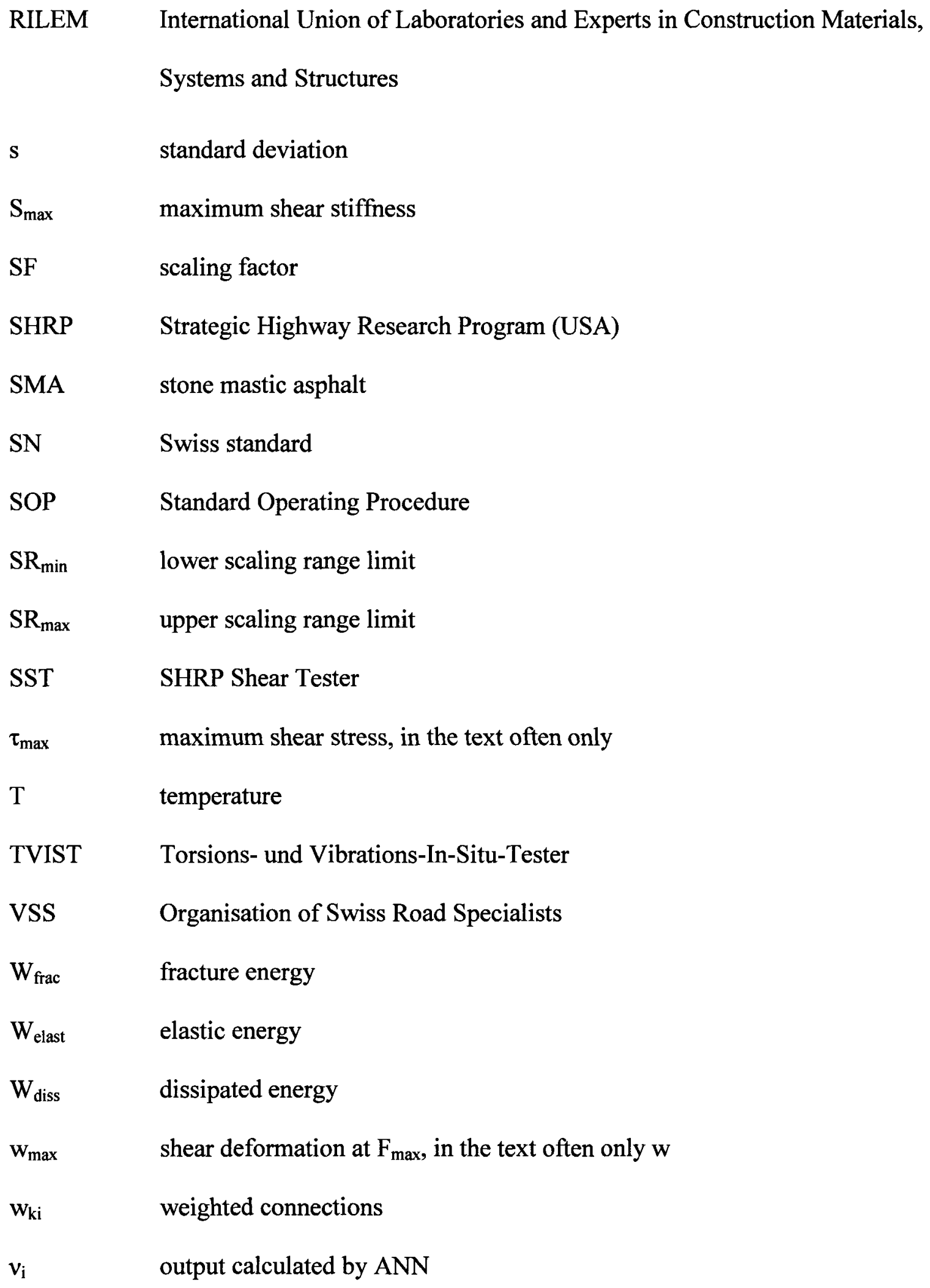




$\begin{array}{ll}\mathrm{x}, \mathrm{x}_{\mathrm{i}} & \begin{array}{l}\text { coordinate, actual numerical value, input variable } \\ \mathrm{x}_{\max }\end{array} \\ \mathrm{x}_{\min } & \text { maximum actual value of the column } \\ \mathrm{x}_{\mathrm{S}} & \text { scaled value } \\ \mathrm{y}, \mathrm{y}_{\mathrm{i}} & \text { coordinate, output variable } \\ \sigma_{\mathrm{n}} & \text { normal stress } \\ \varphi_{\mathrm{p}} & \text { maximum friction angle } \\ \tau_{\mathrm{max}} & \text { maximum shear stress }\end{array}$




\section{CHAPTER 1}

\section{Introduction}

\subsection{Background}

As a result of increasing demands of the road users and increasing rehabilitation costs as well as decreasing budgets the design and construction of long lasting asphalt pavements is becoming more and more important. Extensive research efforts are still underway worldwide, focusing on the optimisation of the mechanical properties of mixes in the individual layers.

However, in this context, it was often neglected, that not only the material properties of the individual layers but also the interlayer bond play an important role in achieving optimal long-term structural performance of a pavement.

The bond between asphalt layers is extremely important for the bearing capacity and the long term performance of pavements, a fact that became more widely accepted during recent years and led to adhesion testing as a subject of study and a development of many different test methods and procedures to evaluate the bond between pavement layers over the last decades.

Besides the development of test devices and test configurations (Leutner, 1978, Santagata and Canestrari, 1994, Raab and Partl, 1999, Ascher and Wellner, 2006), the research regarding interlayer bond properties between pavement layers has been mainly concentrated on the mechanistic-empirical evaluation of bond properties by conducting 
bond failure tests on asphalt specimens using different test methods (i.g. Canestrari et al., 2005, Ferotti, 2007, Sholar et al., 2002, Stöckert, 2001, Sutanto, 2009).

As demonstrated in Figures 1.1 and 1.2, these tests showed the influence of various parameters (aggregate distribution, binder and air void content, surface roughness, use and type of tack coat, age etc.) on the magnitude of the adhesion values. But in most cases, these findings have only been shown to be valid for certain test configurations and materials.

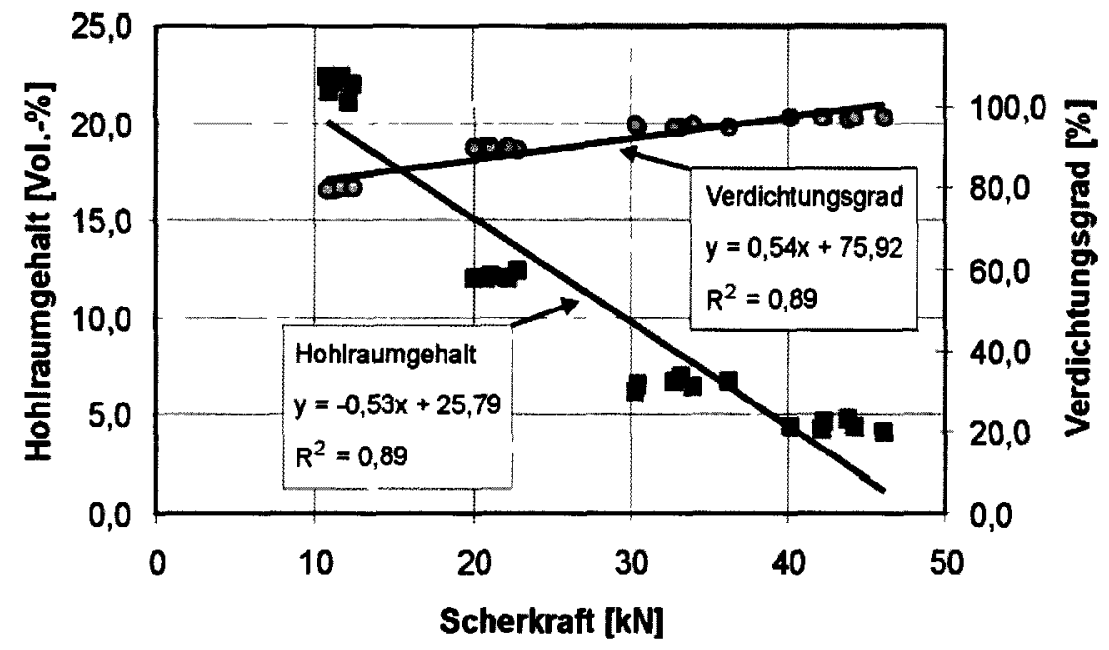

Figure 1. 1: Influence of air voids content (Hohlraumgehalt) and compaction (Verdichtungsgrad) on shear force (Scherkraft)

(Source: Stöckert, 2001) 


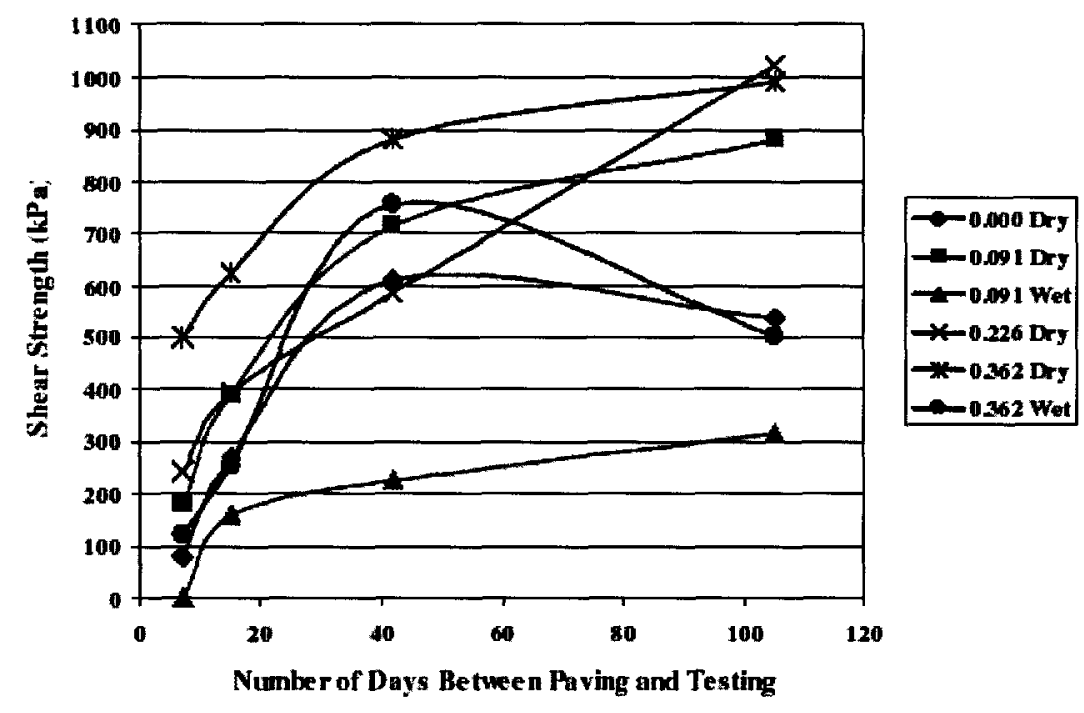

Figure 1.2: Influence of tack coat application rate and specimen age on shear strength

(Source: Sholar et al., 2001)

However, these findings have not led to characterising the interface in a satisfying way and, apart from a few statistical evaluations (e.g. Stöckert, 2001) interlayer shear bond properties have also not been the focus of computational considerations.

Hence, questions such as the following could not be answered so far:

- How can databases be established and used for predicting and assessing the interlayer shear properties?

- What is the influence of surface "roughness" on surface conditions?

- How does moisture and temperature influence the interlayer performance?

This thesis intends to contribute to answering these questions by means of artificial intelligence tools. It also includes the experimental investigation of moisture and 
climate on the interlayer shear bond and considerations regarding the understanding of fundamental mechanisms of geometrical surface conditions at the interface.

\subsection{Research needs}

During resent years, data collection has gained more and more importance in the field of pavement engineering, especially in the field of pavement management, where data collection has always been an essential tool for analysis and interpretation of field and laboratory findings. Enormous amounts of data have been gathered and numerous databases have been established. This does not apply for data from interlayer bond testing. In this field, comprehensive databases are lacking, and if available, they are not comparable or cannot be used for analysis and computational modelling. Hence, artificial intelligence tools such as artificial neural network (ANN) despite their potential for knowledge discovery have not been in the focus of researchers.

ANN techniques are not totally new and have been used in other fields of pavement engineering. However, it became obvious that the existence and the quality of available data are a crucial factor. Therefore, the availability of large amount of high quality interlayer shear data collected over several years offered the opportunity to perform ANN evaluation in the field of interlayer bonding for the first time. In particular, data from new roads, long term performance data, data for combined concrete/asphalt pavements with different intermediate layers and data from different laboratory pavements were available and could be further evaluated.

There are many factors influencing the bond between the layers of an asphalt pavement. A very important one is the interlock as a result of "roughness" in form of 
geometrical surface conditions of the interface. Although some research on this topic is available (e.g. Ferotti, 2007), the influence of the geometrical interlock and the combination of different aggregate sizes still needs further evaluation. Hence, this work studies a model material seeking insight on the influence of the geometrical interlock and the aggregate combination on the shear bond.

Although it is known that moisture has a great effect on the mechanical properties of asphalt pavements and is therefore one of the most important parameters regarding bearing capacity and durability of pavements there are not many investigations and research projects dealing with the problem of moisture induced bond failure. Moreover, the connection between interlayer bond and its relation to moisture and temperature have not been studied in detail. Hence, in this study the influence of moisture and low temperatures on the interlayer shear properties is also investigated.

Regarding the further development of interlayer shear testing, standardisation and normalisation on a worldwide level, is very important. In this context it is crucial, to come to commonly accepted and evaluated test methods and procedures. Since different countries have been developing and using their own test setups over a long period of time, the discussion on the most suitable ones should be encouraged. Research is therefore needed not only for establishing and developing common standards and methods but to improve the phenomenological understanding of the mechanisms of interlayer shear testing. In this context, the study investigates the influence of the width between the shearing rings of the Leutner shear test device, which has been debated during recent standardisation. 


\subsection{Research objectives and scope}

The main goal of this research is to develop a framework for understanding the mechanisms that operate and govern the mechanical behaviour of the interlayer bond between the layers of asphalt pavements, mainly the top asphalt layer and the one immediately underneath it. The development of this framework is crucial to achieve the following specific objectives:

1. Performing a comprehensive experimental investigation to quantify the bond between the pavement layers

2. Utilising the artificial neural network (ANN) technique to analyse and predict the relationship between the measured bond and the critical influencing factors

3. Providing sufficient information for the standardisation of the evaluation and testing of the interlayer bond.

For the bond between asphalt pavement layers, not only the interlayer bond properties of the binder but also the interlock and therefore the geometrical surface conditions of the interface were included. The influence of the geometrical surface and the combination of aggregate sizes on the shear bond was simulated using a simple model material consisting of steel balls (representing the aggregates) filled with 10/20 penetration graded bitumen.

It is also important to investigate the influence of moisture on the interlayer shear properties, since moisture is known to have an important influence on the damage process of asphalt pavements. 
Temperature is known to be one of the most critical parameters for interlayer bond testing. Therefore, temperature was included in the parameter study of testing program 2 . The temperature range for testing was limited between $-20^{\circ} \mathrm{C}$ and $20^{\circ} \mathrm{C}$.

The scope of this research is focussed on the investigation of the interlayer bond of asphalt layers of different road pavements in the field. More specifically the thesis investigates the variables that govern the bond and the parameters which affect it by performing experimental and analytical studies.

\section{$1.4 \quad$ Research plan}

In this thesis the research plan depicted in Figure 1.3 was designed and implemented to achieve the objectives discussed earlier. As shown in the figure, the research plan consists of 4 phases:

1. Literature Review

2. Investigation

3. Modelling and Analysis

4. Conclusions and Recommendations 


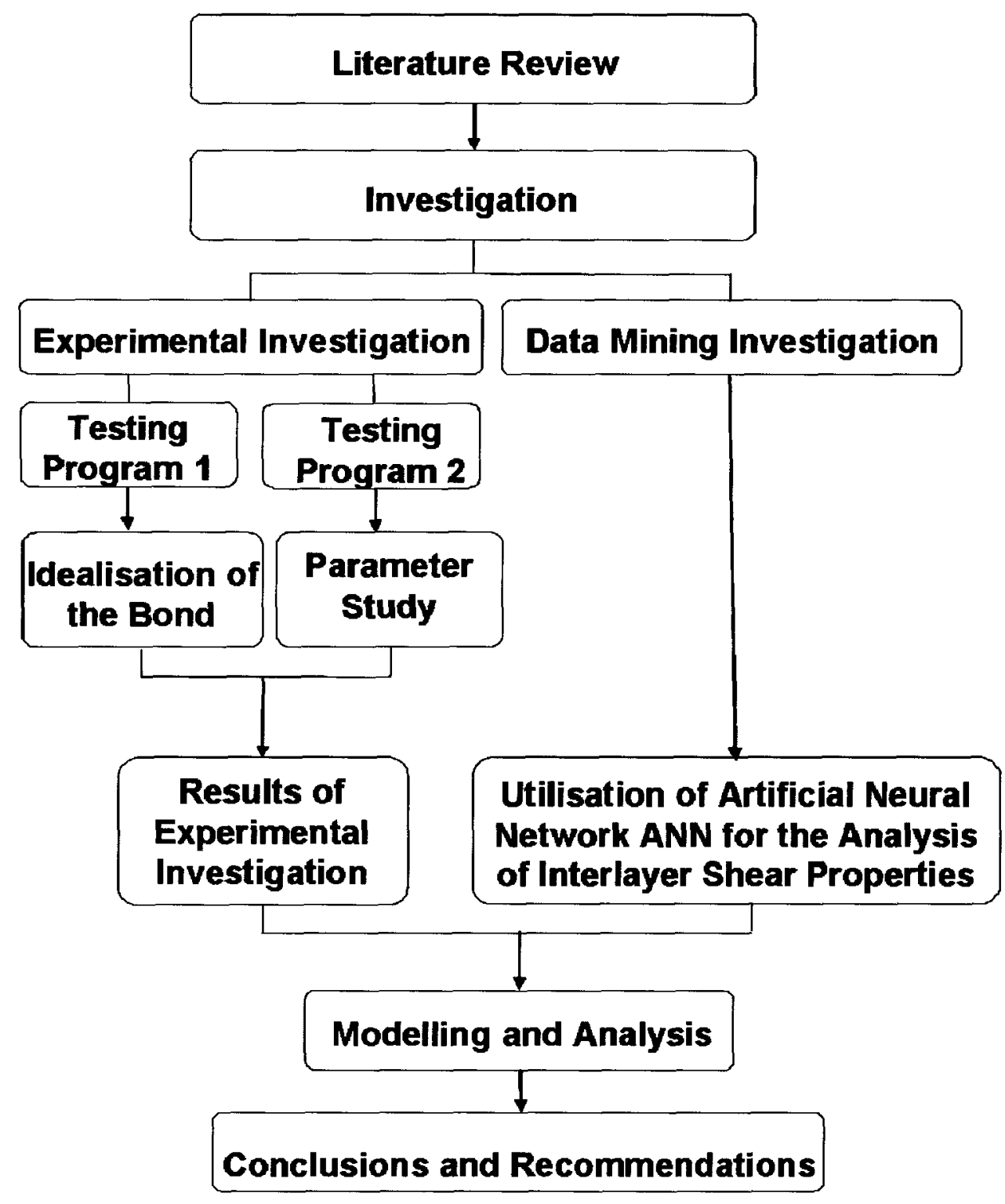

Figure 1. 3: Research plan

\subsubsection{Literature review}

The Literature review on interlayer bond test devices presents an extended overview on selected existing shear and torque test devices and gives detailed information on their functioning mechanisms and test specifications. From literature research it became clear 
that the mechanisms influencing the interlayer shear bond have not been investigated sufficiently so far and that often even the importance and the factors for having a good and durable bond are under debate. Although the development of normalisation of interlayer bond testing was taken further during the last decades, sufficient information for the standardisation of the evaluation and testing is often not available.

Further, regarding the topic of interlayer bond, comprehensive databases are lacking, and if available, they are not comparable or cannot be used for analysis and computational modelling. Hence, artificial intelligence tools such as artificial neural network (ANN) despite their potential to predict interlayer shear properties have not been in the focus of researchers.

\subsubsection{Investigation}

The Investigation is divided into two parts, an Experimental Investigation and a Data Mining Investigation.

The Experimental investigation presents the experimental research and the test results for all experimental investigations carried out this thesis. The experimental investigation further consists of two testing programs.

Testing program 1 was intended for the idealisation of the interlayer bond. This was done to better understand the mechanisms that operate and govern the bond, in particular, the geometrical surface between the layers that determines the interlock. The investigation was carried out using a model material consisting of equally sized steel balls with diameters of $\varnothing 9.5 \mathrm{~mm}$ ('big') and $\varnothing 5.5 \mathrm{~mm}$ ('small') and a hard penetration graded bitumen 10/20. 
Testing program 2 represents a parameter study on some of the main influencing parameters for the interlayer bond of the layers between asphalt pavements. This testing program had the aim to quantify the bond between asphalt layers and to show in which way the bond is influenced by the investigated factors. The outcome was also intended to provide information for further standardisation of the evaluation and testing of the interlayer bond. In the course of this testing program, experimental studies on the influence of moisture, low temperature and the gap width between the shearing rings were carried out.

\subsubsection{Modelling and analysis}

In the phase Modelling and Analysis the results and findings from the idealisation of the bond, the parameter study and the ANN evaluations were analysed and interpreted.

\subsubsection{Conclusions and recommendations}

The last phase Conclusions and Recommendation summarises the outcome of the investigations conducted in this thesis, presenting the main conclusions and the recommendations for future research.

\subsection{Organisation of the thesis}

This thesis consists of a literature review on interlayer bond test devices (Chapter 2) followed by four chapters regarding the research undertaken and a final chapter (Chapter 7) presenting the main conclusions and recommendations for future research. 
Chapter 3 outlines the experimental investigation in terms of the two different testing programs. For testing programs 1 and 2 all background information and material characteristics are shown. Chapter 3 further explains the two methods for interlayer shear testing which were used for the experimental investigation in this thesis: The Layer Parallel Shear test (LPDS) and the Shear Box test.

Chapter 4 presents all results from LPDS and Shear Box testing carried out in testing programs 1 and 2 of the experimental investigation.

Chapter 5 presents the data mining investigation dealing with the utilisation of Artificial Neural Network ANN for the analysis of interlayer shear properties. In Section 5.1 the databases determined earlier by the author of this thesis are described in detail. Section 5.2 gives some basis explanations of artificial neural networks and their technique, focussing on the applied commercial evaluation program Alyuda Neurointelligence. A data inventory visualises and describes the available databases regarding to the problem of interlayer bonding.

Chapter 6 finally, analyses and interprets the influence of the tested parameters on the measured interlayer bond for the whole investigation undertaken in this thesis, e.g. experimental investigation and data mining investigation. 


\section{CHAPTER 2}

\section{Literature Review}

\subsection{Introduction}

Many different methods and devices have been proposed for testing the bond between pavement layers. Figure 2.1 gives an overview on the methods commonly used to assess the interlayer bond of pavements and other interfaces.
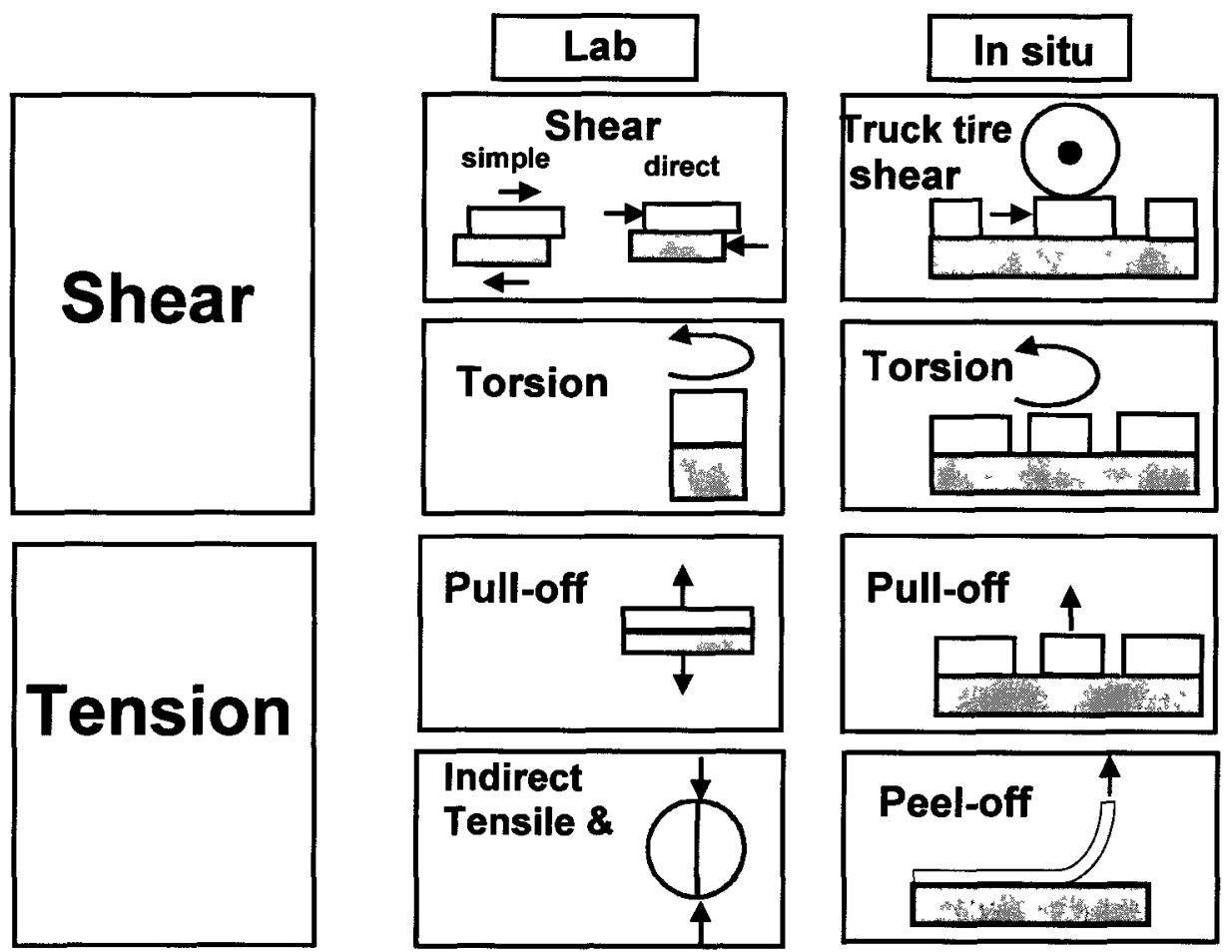

Figure 2.1: Test methods to determine interlayer bond properties in the lab and in the field

(Source: Raab and Partl, 1999) 
The choice of a certain test methods depends on the assumed loading mode and the type of application (e.g. in-situ, laboratory), the problem area (e.g. bond failure due to tensile stresses, in case of blisters or failure due to shear stresses) as well as the accuracy and repeatability of a certain test method.

During recent years, many European countries as well as the United States and Canada have established methods and equipment for testing interlayer bond of pavement layers. On the one hand, there are methods commonly used in different countries, such as the Leutner shear test (Leutner, 1979) which was taken into the national test specifications in Germany shortly after its standardisation in Switzerland and Austria and is also going to be standardised in the European Commission for Standardisation CEN (EN 12697-48, 2009). On the other hand specific solutions such as the wedge splitting test (Tschegg et al., 2007) or the torsion test (BBA, SG3/05/234, 2004) were proposed. In Italy, the Ancona Shear Testing Research and Analysing Apparatus ASTRA shear apparatus (Canestrari and Santagata, 2005) was developed and became a national specification (UNI/TS 11214, 2007). In USA, interlayer bond testing has become a serious issue. As a potential option for testing the bond between asphalt layers, Mohammad (Mohammad et al., 2002) designed a custom made shearing apparatus for use in the Superpave Shear Tester. In Canada, Carleton University has been working for many years on the development of an in-situ shear tester (Abd El Halim, 2004).

The different test methods, including various equipments, have been presented in numerous publications (Raab and Partl, 1999, Canestrari et al., 2005, Stöckert, 2001, West et al., 2005) in such a way that photographs of the various devices were depicted. However, from these photographs, the functioning of the devices is often not clear and 
sufficiently detailed information regarding test devices (e.g. gap width) and test conditions (e.g. loading function, normal force) are difficult to obtain.

This Chapter tries to give an overall overview of the most important test methods for the shear interlayer bond testing, highlighting the differences in terms of test devices, test specifications and test results for the different devices in various countries. Shear testing was considered due to the fact that this test method has been by far the most common method for determining the bond between asphalt pavements layers. Although, there are many different devices, some of them have already been standardised in several countries for some time. Tension bond testing, such as pull-off testing was not considered, although it has been adopted by some countries (e.g. Austria), because the debonding in pavements is normally connected to shear failure and not to tensile stresses.

\subsection{Shear testing}

The construction of shear testing devices for asphalt pavements originally was derived from shear testing in soil mechanics and already in the late 1970ied different equipment such as the Leutner test in Germany (Leutner, 1979) or similar tests in the US was developed for road pavements (Uzan et al., 1978). There are two fundamentally different systems: The direct and the simple shear test.

The direct shear test, in general, is a guillotine type test where the shear force is induced directly at one side and not at the front surface of the specimen (Figure 2.2, Raab and Partl, 1999). 


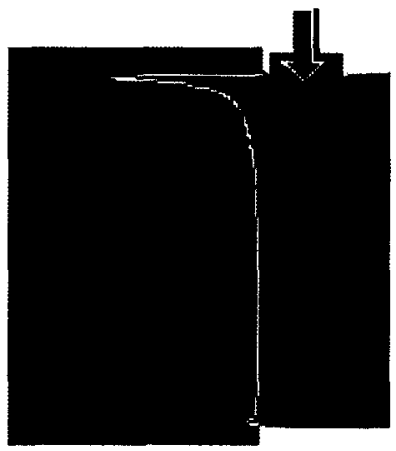

a)

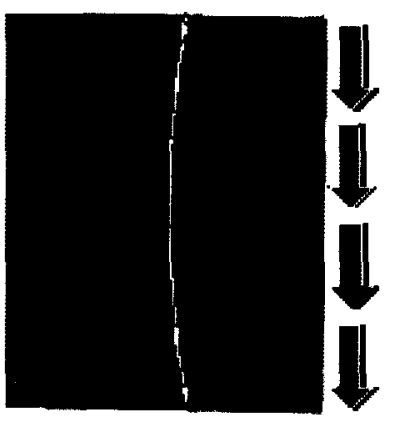

b)

Figure 2.2: a) Shear stress distribution at the specimen head in the direct shear test b) Shear stress distribution in the simple shear test

(Source: Raab and Partl, 1999)

The direct shear testing devices, as depicted in Tables 2.1 and 2.2, can be divided into devices which use a clamping or fitting system to hold the test specimen (Partl and Raab, 1999, Sholar et al., 2004, West et al., 2005, Romanoschi and Metcalf, 2002, Zeng et al., 2008) and devices which utilise a bending mechanism (three or four point shear tests) to apply the shearing (Miro et al., 2003, De Bondt, 1999).

In the simple shear tests (Figure $2.2 b$ ), the upper part of the test specimen is sheared against the bottom part of the test specimen and the shear force is induced at the specimen front surface of the specimen. In case of a three layered specimens (De La Roche, 1996, Milien et al., 1996) the middle part is sheared against both outer parts. For the simple shear test, as depicted in Table 2.3, the mechanism of the different devices is similar, differing mainly in the way the shear forces are applied and how both parts of the test specimen are moved against each other (Canestrari et al., 2005, Sanders et al., 1999). 
Table 2.1: Direct shear test devices (1)

(Source: Raab et al., 2009)

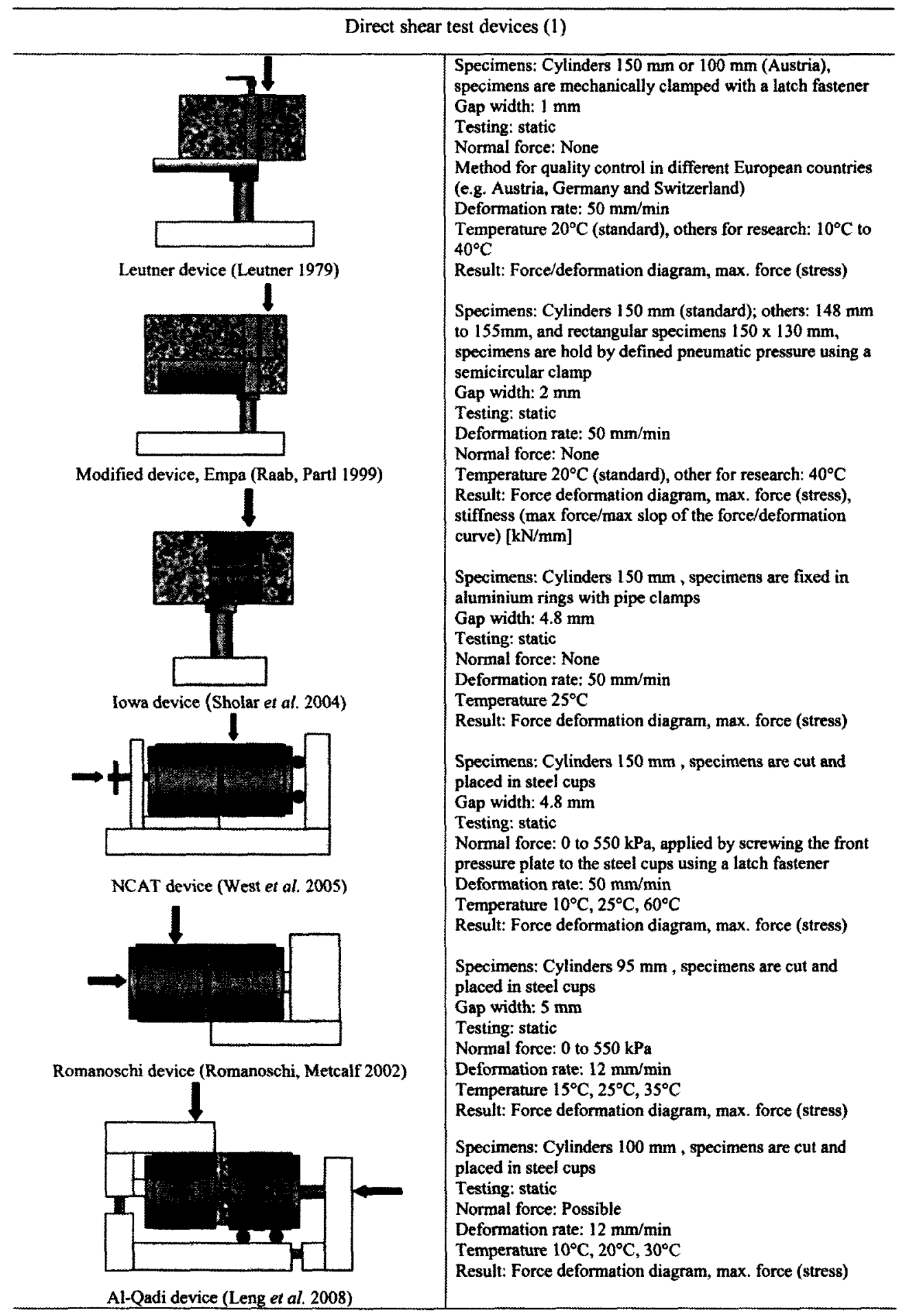


Table 2.2: Direct shear test devices (2)

(Source: Raab et al., 2009)

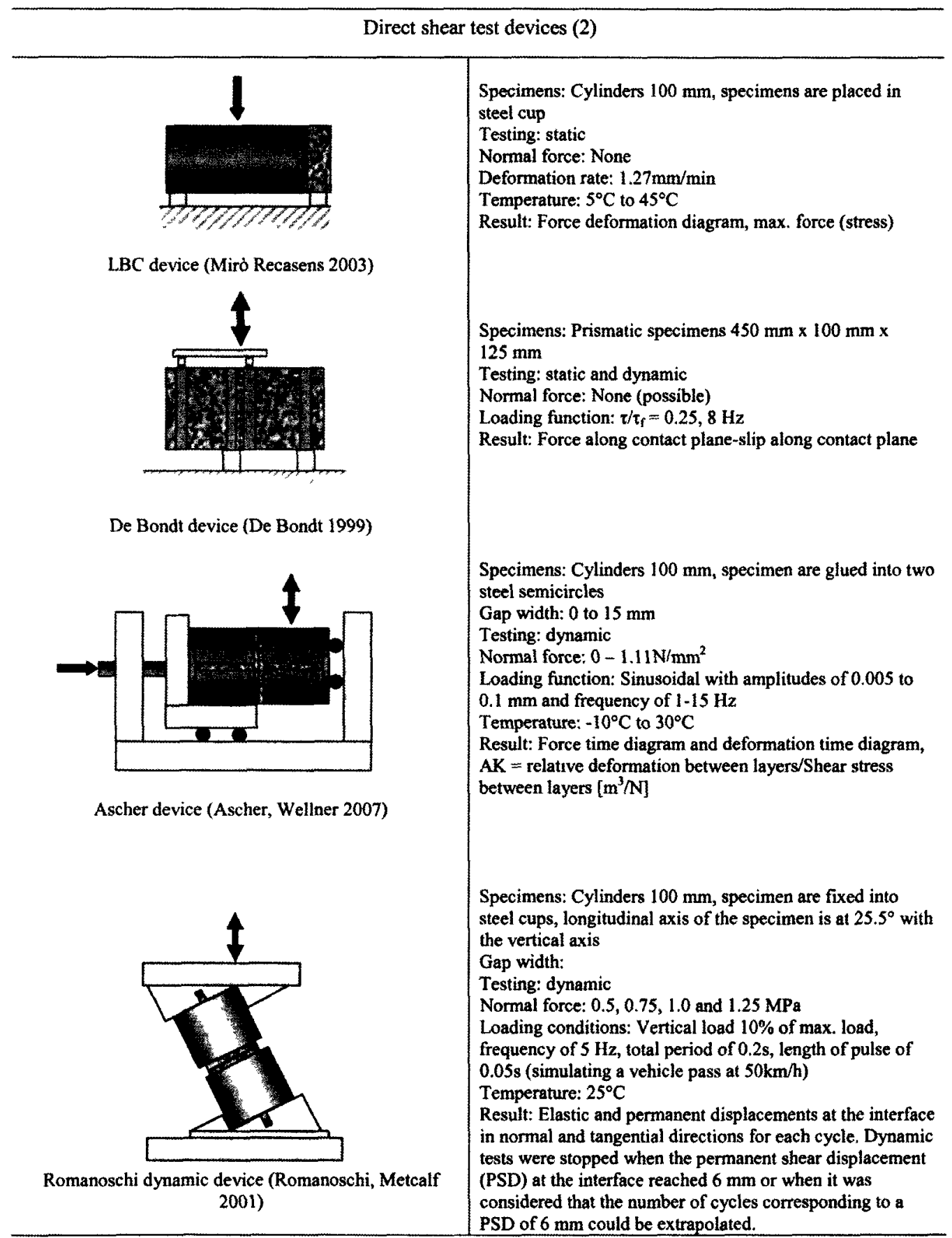




\section{Table 2.3: Simple shear test devices}

\section{(Source: Raab et al., 2009)}

Simple shear test devices

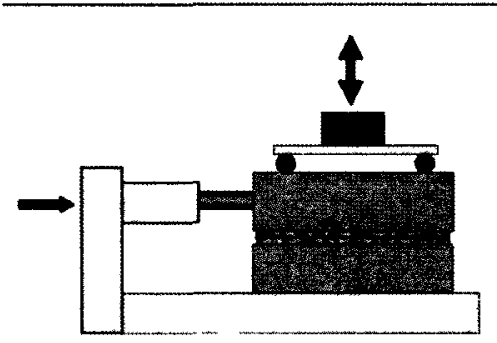

Shear Box (Sanders et al 1999)

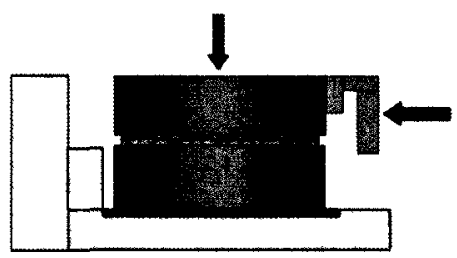

ASTRA device (Santagata, Canestrar, 1993)

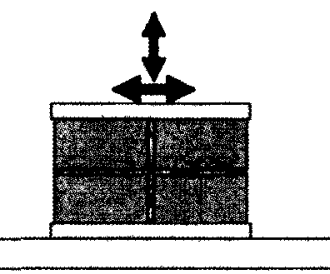

SHRP shear test device SST (Harrigan 1994)

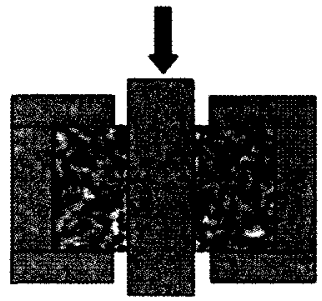

MCS device (Milien et al 1996)
Specimens Prismatic $(320 \mathrm{~mm} \times 200 \mathrm{~mm})$, specimens are in the mould fixed using an epoxy glue

Gap widh appr 10-20 times the mean particle diameter of the test specimen

Testing dynamic and static, if dynamic test does not result in fallure

Deformation rate $15 \mathrm{~mm} / \mathrm{mm}$

Normal force applied servo hydraulically, $0,50,100,200$ and $250 \mathrm{kN} / \mathrm{m}^{2}$

Loading function Sinusoidal shear stress with frequency of $2 \mathrm{~Hz}$, vertical load $200 \mathrm{kN} / \mathrm{m}^{2}$

While vertical stress was kept constant, shear stress was uncreased in 5 levels untıl the specimen fails If the specimen did not fail dunng dynamic testing, a static test was performed with constant deformation rate Temperature

Result dynamic shear stress-relative displacement diagram

Specimens Rectangular, $\max$ cross section of $100 \mathrm{~mm} x$ $100 \mathrm{~mm}$ and cylindrical with diameters 95 to $99 \mathrm{~mm}$, specimen are fixed in two steel cups

Gap width diameter of particle diameter of the test specimen

Testung static

Normal force 0,02 and $04 \mathrm{MPa}$, applied by a lever and weight system

Deformation rate $25 \mathrm{~mm} / \mathrm{mm}$

Temperature Vanable in climatic chamber

Result Data-file with shear force $T$, horizontal $\xi$ and

vertical $\eta$ displacement related to time

Specimens Cylundrical with diameters $150 \mathrm{~mm}$, specimen are glued onto aluminum "caps"

Testung static or dynamic

Loading function Constant load mode (222 $4 \mathrm{~N} / \mathrm{min}$ )

Normal force None, possible

Temperature $25^{\circ} \mathrm{C}$ and $55^{\circ} \mathrm{C}$

Result Shear stress-deformation diagram

Specimens Three layered specimens test specimens with the dimension of $70 \mathrm{~mm} \times 100 \mathrm{~mm} \times 30 \mathrm{~mm}$, specimen are placed in a metal frame where the side parts of the sample are fixed while the central part is subjected to a sinusoidal displacement

Testing dynamic

Loading function Sinusoidal displacement , $1 \mathrm{~Hz}$

Normal force None

Temperature $5^{\circ} \mathrm{C}$

Result Shear force time and deformation tume diagrams 
As opposed to the direct shear tests, where the test specimens can either be clamped or fitted into steel moulds, the test specimens in the simple shear test are always fitted into the shear mould by glue or tight fixtures. Therefore, the application of a normal force vertical to the shear plane is always an option, whereas in shear test devices with clamping mechanisms, normal forces are often not taken into consideration. Another possibility to include a normal force was developed by Romanoschi whose testing device allowed for the longitudinal axis of the test specimen being at a $25.5^{\circ}$ angle with the vertical (Romanoschi and Metcalf, 2001).

While some shear tests, mainly those used for quality assessment, only allow for static testing, others can be used either in a static or a dynamic mode (Romanoschi and Metcalf 2002, Crispino et al., 1997, Ascher and Wellner, 2007, Sanders et al., 1999).

Since in Europe most direct shear devices were designed to be mounted in a servo-hydraulic Marshall testing machine, tests were normally conducted deformation controlled at a rate of $50 \mathrm{~mm} / \mathrm{min}$.

Mostly, cylindrical test specimens of $100 \mathrm{~mm}$ (Austria) or $150 \mathrm{~mm}$ (Germany, Switzerland) taken either directly from the road or laboratory specimens were tested (Stöckert, 2001). Some devices, such as the modified Empa direct shear device LPDS, could also be used to measure the bonding of rectangular test specimens (Raab and Partl, 2007). Normally the specimens were conditioned for a minimum of 6 hours at test temperatures between $20^{\circ} \mathrm{C}$ and $25^{\circ} \mathrm{C}$. Only for some research projects other temperatures between $10^{\circ} \mathrm{C}$ and $40^{\circ} \mathrm{C}$ were evaluated (e.g. Partl and Raab, 1999). However, they were found inappropriate for quality assessment, since the higher the temperature, the more difficult to find distinct differences between the different asphalt 
pavements. Furthermore, specimens might already be damaged during conditioning or during testing (clamping of the specimen).

Germany, Austria, Switzerland, the UK and most other European countries adopted the Leutner equipment, modifying it slightly, for quality assurance at construction sites (ÖNORM B 3639-1, 1997). Bending type test setups were developed for research purposes in Spain and the Netherlands (de Bondt, 1999). The Spanish device known as the LCB shear test was developed at the Technical University of Catalonia, Spain (Miro et al., 2003). Here, cylindrical test specimens were tested at a deformation rate of only $1.27 \mathrm{~mm} / \mathrm{min}$. At the Technical University of Delft in the Netherlands, de Bondt (de Bondt, 1999) developed a four point shear test where bending effects were minimized through special arrangement of loading and supporting points.

At the Technical University of Dresden a dynamic version of the Leutner shear test was developed. This dynamic device was constructed by Ascher and allows for a normal force (Ascher and Wellner, 2007). In the dynamic testing of the bond, different parameters such as temperature $\left(-10^{\circ} \mathrm{C},+10^{\circ} \mathrm{C}\right.$ and $\left.+30^{\circ} \mathrm{C}\right)$, normal load $(0$ to $1.11 \mathrm{~N} / \mathrm{mm} 2$ ) and the loading function (sinusoidal function with amplitudes from 0.005 to $0.1 \mathrm{~mm}$ and frequencies from 1 to $15 \mathrm{~Hz}$ ) were included. The purpose of the project was to find a "bonding factor" which can be used for pavement design in BISAR or in finite element programs.

For the simple shear test, deformation rates between $1.5 \mathrm{~mm} / \mathrm{min}$ in the UK (Sanders et al., 1999), and $2.5 \mathrm{~mm} / \mathrm{min}$ in Italy (Canestrari and Santagata, 2005) were used. In UK, the direct shear test was normally conducted in the dynamic mode, where the specimens were tested under a sinusoidal shear stress with a frequency of $2 \mathrm{~Hz}$. 
While the normal stress was kept constant at $200 \mathrm{kN} / \mathrm{m}^{2}$, the shear stress was increased in 5 levels $\left(50,100,200\right.$ and $\left.250 \mathrm{kN} / \mathrm{m}^{2}\right)$ until the specimen failed. If the specimen did not fail during dynamic testing, a static test was performed using the above mentioned deformation rate of $1.5 \mathrm{~mm} / \mathrm{min}$. In Italy, shear tests were conducted in a static mode using different normal loads $(0,0.2$ and $0.4 \mathrm{MPa})$.

The specimens in the simple shear test, were found to be either prismatic $(320 \mathrm{~mm}$ x $200 \mathrm{~mm}$ ) (Sanders et al., 1999) or rectangular (max. cross section of $100 \mathrm{~mm} \times$ $100 \mathrm{~mm}$ ) and cylindrical with a diameter between $95 \mathrm{~mm}$ and $99 \mathrm{~mm}$ (Canestrari et al., 2005).

A simple dynamic shear test for glued three layered specimens, known as the Modified Compact Shearing (MCS) test (Millien et al., 1996, Diakhate et al., 2006) was developed at the Laboratory "Mechanic and Modelling of Materials and Structures in Civil Engineering (3MsCE) of the University of Limoges in France. The device allowed conducting static or dynamic tests on glued three layered specimens test specimens with the dimension of $70 \mathrm{~mm} \times 100 \mathrm{~mm} \times 30 \mathrm{~mm}$. The specimen was placed in a metal frame where the side parts of the sample was fixed while its central part was subjected to a sinusoidal displacement, causing a shear force at both interfaces. The aim of the test program was the investigation of shear fatigue tests of asphalt concrete layer interfaces with emulsions at a constant temperature of $5^{\circ} \mathrm{C}$ and a frequency of $1 \mathrm{~Hz}$.

In US, direct shear testing was generally used in quality assessments and research projects, where the main focus was on the evaluation of bonding properties of different tack coat types applied at application rates. Different DOTs, asphalt pavement institutes or universities evaluated or modified various guillotine type shear test devices using 
different clamping and fixing mechanism (West et al., 2005, Sholar et al., 2004, Leng et al., 2008). As depicted in Table 2.1, the devices differed in the fixing mechanism of the specimen as well as in the specimen diameter and the deformation rate of the testing machine. The Iowa Department of Transportation shearing device, a modification of the shearing device for Portland cement concrete (Method of Test for Determining the Shearing Strength of Bonded Concrete. Test Method No IOWA 406-B, Iowa Department of Transportation Highway Division), was built for $100 \mathrm{~mm}$ diameter cylindrical specimens (either roadway cores or laboratory specimens) and with a gap width of $3.175 \mathrm{~mm}$ between its steel shearing platens. Further modifications used aluminium rings of $150 \mathrm{~mm}$ and a width of $4.8 \mathrm{~mm}$ between them to hold the specimen (Sholar et al., 2004).

Some devices, such as the so called NCAT bond strength device (West et al., 2005), where the specimen was held in metal half cups, also allowed the application of normal forces, which were chosen between 0 and $550 \mathrm{kPa}(80 \mathrm{psi})$. For direct shear testing, specimen diameter generally varied between $95 \mathrm{~mm}$ and $150 \mathrm{~mm}$ and the deformation rate between $2.5 \mathrm{~mm} / \mathrm{min}, 12 \mathrm{~mm} / \mathrm{min}$ and $50 \mathrm{~mm} / \mathrm{min}$, often depending on the available testing machine.

In the course of another research project Romanoschi (Romanoschi and Metcalf, 2002) used a direct shear test device with normal load. The cores (diameter $95 \mathrm{~mm}$ ) were first fixed in a steel split ring, with the interface positioned at the end of the ring. The part of the core outside the steel ring was then placed and fixed in a steel cup positioned vertically and welded to a vertical supporting plate. The position of the interface was adjusted at the rim of the cup using a screwing piston placed inside the cup. To generate 
the shear at the interface, the vertical actuator pushed on top of the steel split ring with the constant displacement $(12 \mathrm{~mm} / \mathrm{min})$ until a shear displacement of $12 \mathrm{~mm}$ was reached. To this day in the United States, different modified Leutner type shear test devices such as (Leng et al., 2008) have been developed and various research projects are still underway. For his research Al-Qadi (Leng et al., 2008) developed a fixture where the test specimens were housed in a special steel chamber with a diameter of about $100 \mathrm{~mm}$. The device was designed to apply shear force in the vertical and normal force in the horizontal direction.

Mohammad et al. (Mohammad et al., 2009) developed the so called Louisiana state shear strength tester (LISST) consisting of two main parts, a shearing and a reaction frame. While the reaction frame remains stationary, the shearing frame applies the loading. Cylindrical specimens of either $100 \mathrm{~mm}$ or $150 \mathrm{~mm}$ diameter can be placed in the frames and locked with collars. Shearing load is applied with a constant rate of $2.54 \mathrm{~mm} / \mathrm{min}$. Application of a normal load is also possible. The gap between the shearing and the reaction frame measures $12.7 \mathrm{~mm}$.

To simulate the repetitive load of moving vehicles, in another study Romanoschi (Romanoschi and Metcalf, 2002) proposed a test configuration for conducting shear fatigue tests on asphalt concrete layer interfaces. The longitudinal axis of the specimen was tilted $25.5^{\circ}$ to the vertical. A vertical load was applied with $10 \%$ of the maximum load and with a frequency of $5 \mathrm{~Hz}$. So, the total period was $0.2 \mathrm{~s}$ and the length of the pulse was $0.05 \mathrm{~s}$, simulating the pass of a vehicle at $50 \mathrm{~km} / \mathrm{h}$. The corresponding normal stresses at the interface, $0.5,0.75,1.0$ and $1.25 \mathrm{MPa}$ were within the range of normal stress values for interfaces of road and airfield pavements. 
The elastic and permanent displacements at the interface in normal and tangential directions were recorded for each cycle and the dynamic tests were stopped when the permanent shear displacement (PSD) at the interface reached $6 \mathrm{~mm}$ or when it was considered that the number of cycles corresponding to a PSD of $6 \mathrm{~mm}$ could be extrapolated.

In the course of the American research program SHRP (Sousa et al., 1994), a relatively complicated test device for performing simple shear tests, the so called Superpave shear tester SST, was developed. Originally the device was not used to evaluate the interlayer shear properties between pavement layers, but to determine permanent deformation and the modulus of asphalt layers.

The SST consists of shear and axial actuators, load cells and deformation measurement systems, computer control and data acquisition systems, a temperature control and a hydraulic pump. This machine uses closed-loop computer driven control hydraulic pistons connected to vertically and horizontally operating platens. The specimen was normally glued onto aluminum "caps" which were hydraulically clamped to platens inside the temperature control chamber (West et al., 2005).

Mohammad (Mohammad et al., 2002) performed simple direct shear tests on various types of tack coat materials at several application rates using laboratory fabricated asphalt specimens. A custom made shearing apparatus was designed and fabricated for use in the Superpave Shear Tester. Specimens were fabricated in the gyratory compactor in two layers with a tack coat applied prior to compaction of the second layer. The apparatus was mounted inside the SST and the tests were conducted in 
constant load mode $(222.4 \mathrm{~N} / \mathrm{min})$. No normal load was applied to the specimens. The tests were conducted at $25^{\circ} \mathrm{C}$ and $55^{\circ} \mathrm{C}$.

As opposed to bond testing using pull-off or torque devices, shear testing is generally performed in the laboratory. In the early 1980s, Empa developed a method for shear testing in situ. The shear test with a truck tire was used to test the adhesion between bituminous surface courses and cement concrete layers (see Figure 2.3). Additional to the horizontal shear force, a vertical force induced by a single truck tire was applied during the test and resulting horizontal deformations were measured (Empa Test Report No. $51872,1985)$.

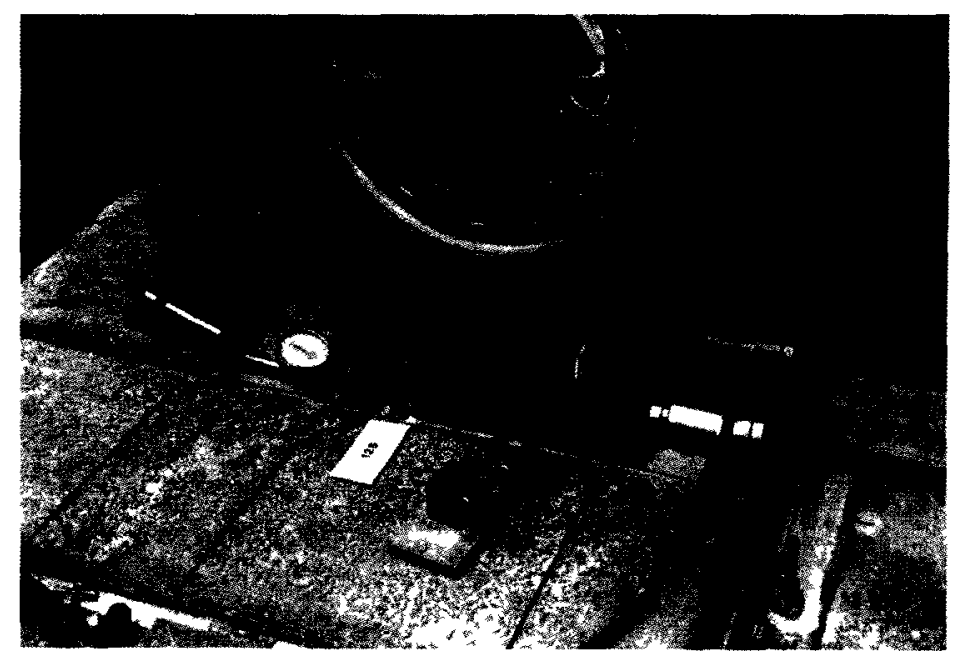

Figure 2.3: Truck tire shear test

(Source: Empa Test Report No. 51872, 1985)

In some European countries, bond testing was standardised during the 1990s. Although the requirements in standards often stayed below the proposed values suggested in different research projects, these standardisation efforts were first steps using shear bond testing on a regular bases in quality control. Research by Raab and Partl 
(Raab and Partl, 1999, Raab and Partl, 2008), for example, showed that for pavements with stone mastic asphalt SMA and asphalt concrete surface courses, a maximum shear force of $21 \mathrm{kN}$ or $18 \mathrm{kN}$ for the adhesion between the base courses could easily be obtained with $150 \mathrm{~mm}$ cores. Nevertheless, Swiss specification only required a maximum shear force of $15 \mathrm{kN}$ between surface and binder course and $12 \mathrm{kN}$ between a binder and a base course or between two base courses. Theses values correspond to a maximum nominal shear stress of $1.3 \mathrm{~N} / \mathrm{mm}^{2}$ for the adhesion between surface and base course and $1.1 \mathrm{~N} / \mathrm{mm}^{2}$ between two base courses.

In Germany, a research project launched by the German Road Authorities in 2001 (Stöckert, 2001) studied approximately 500 cores with SMA or AC surface courses. It delivered similar results and proposed the following requirements for the adhesion forces between the layers:

$25 \mathrm{kN}$ for the adhesion surface course/binder course

$20 \mathrm{kN}$ for the adhesion binder course/base course

$16 \mathrm{kN}$ for the adhesion surface course/base course.

In Austria, adhesion testing according to Leutner was conducted on $100 \mathrm{~mm}$ specimens at a test temperature of $20^{\circ} \mathrm{C} \pm 1^{\circ} \mathrm{C}$. According to the specification (Austrian standard 2004) for SMA or AC surface courses and non modified tack coats, a minimum shear stress of $0.8 \mathrm{~N} / \mathrm{mm}^{2}$ was required and $1.2 \mathrm{~N} / \mathrm{mm}^{2}$ for modified binder tack coat. For the adhesion of binder and base courses or two base course layers, the requirements were $0.5 \mathrm{~N} / \mathrm{mm}^{2}$ for non modified and $1.0 \mathrm{~N} / \mathrm{mm}^{2}$ for polymer modified tack coats. The shear stress in Austria had to be measured parallel to the traffic direction. 
Unlike torque testing (see Section 2.3), shear testing (especially the Leutner shear test) is not suitable for determining the bond strength of asphalt pavements with layer thicknesses over $25 \mathrm{~mm}$.

In order to overcome this deficiency, in a research conducted at Empa in 2004, it was proposed to extend the layer thickness by gluing steel plates of $25 \mathrm{~mm}$ on the specimen core head (Raab and Partl, 2004a, Raab and Partl, 2005, see Figure 2.4). This approach was later adapted by Sultanto (Sultanto, 2009) in his PhD studies, when also investigating the practicability of this method for comparison with torque testing.
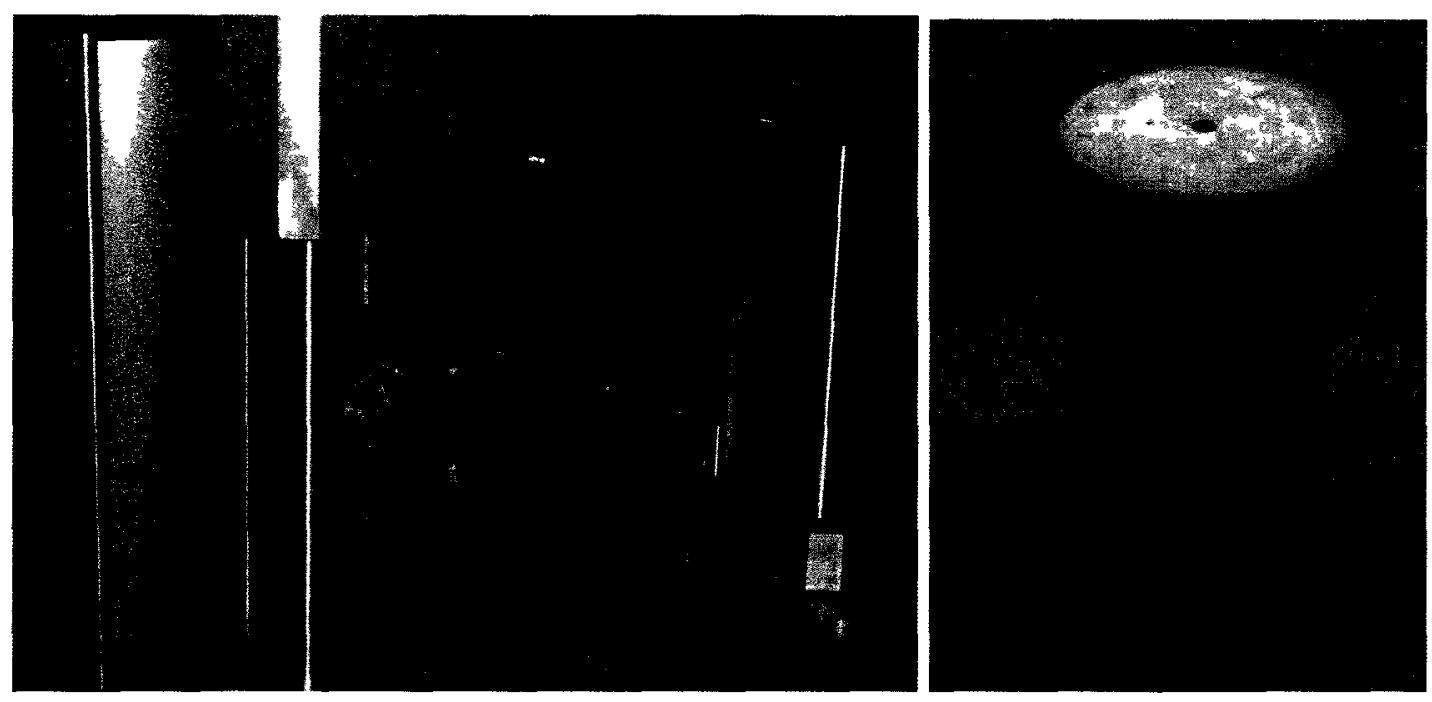

Figure 2.4: Core with glued steel plate

(Source: Raab and Partl, 2004a)

In Tables 2.1 to 2.3 schematic drawings of different direct and simple shear devices are presented. The main test parameters such as specimen dimension (core diameter), deformation rate (test speed), test mode (static, dynamic), normal load, temperature, and others parameters such as the gap width between the shearing rings are also given. 


\subsection{Torque testing}

Torque testing is another way to determine the bond between pavement layers (Choi et al., 2005, Choi et al., 2005a, West et al., 2005, Zahw, 1995). This method has not been as extensively used as direct shear testing. This might be contributed to the fact that torsion testing is in most cases more cumbersome compared to shear testing since the specimens often must be glued before testing. Furthermore, torque testing provides a non uniform shear stress distribution, varying between zero in the centre of the interface cross section to a maximum value at its outside.

Torque test devices are quite similar compared to one another. In principle, they consist of a plate which is glued or fixed to the test specimen and a torque cell applying the torque moment. As depicted in Table 2.4 the devices mainly differ in the way the test specimens are hold (gluing, gripping or clamping) and in the construction of the test frame. The test specimens for laboratory testing are in all cases cylinders with diameters between $100 \mathrm{~mm}$ and $150 \mathrm{~mm}$.

Torque testing offers a good possibility for in situ testing. Here, various devices and test set-up have been developed by different institutes and universities in Europe and North America (Kruntcheva et al., 2005, Abd El Halim et al., 1997, and Riedweg and Partl, 1999). For in situ testing, the upper layer of the pavement has to be cored below the upper layer to ensure that the specimens separate at the interface. 
Table 2.4: Torque test devices (1): Lab devices

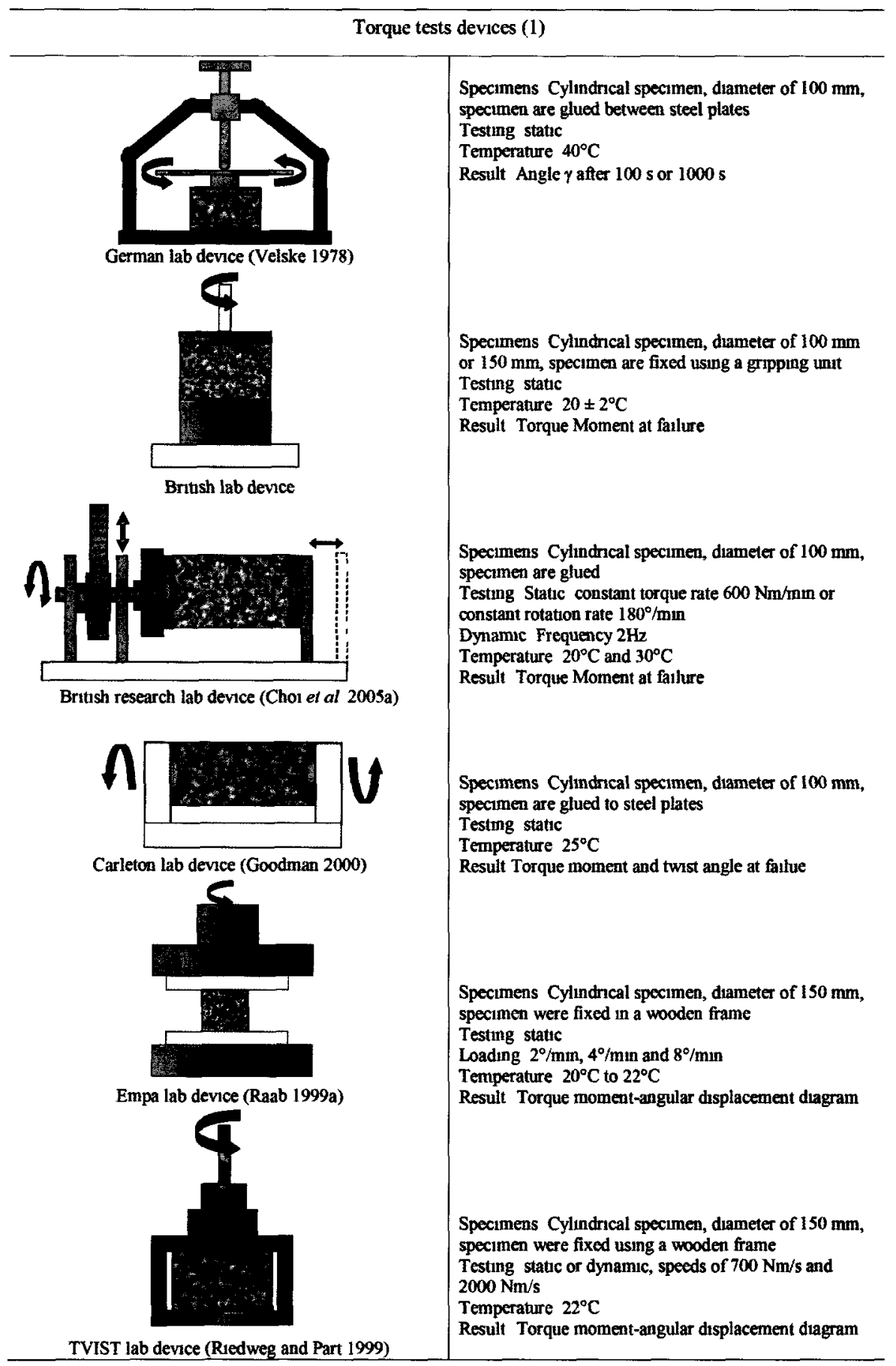


Table 2.5: Torque test devices (2): In situ devices

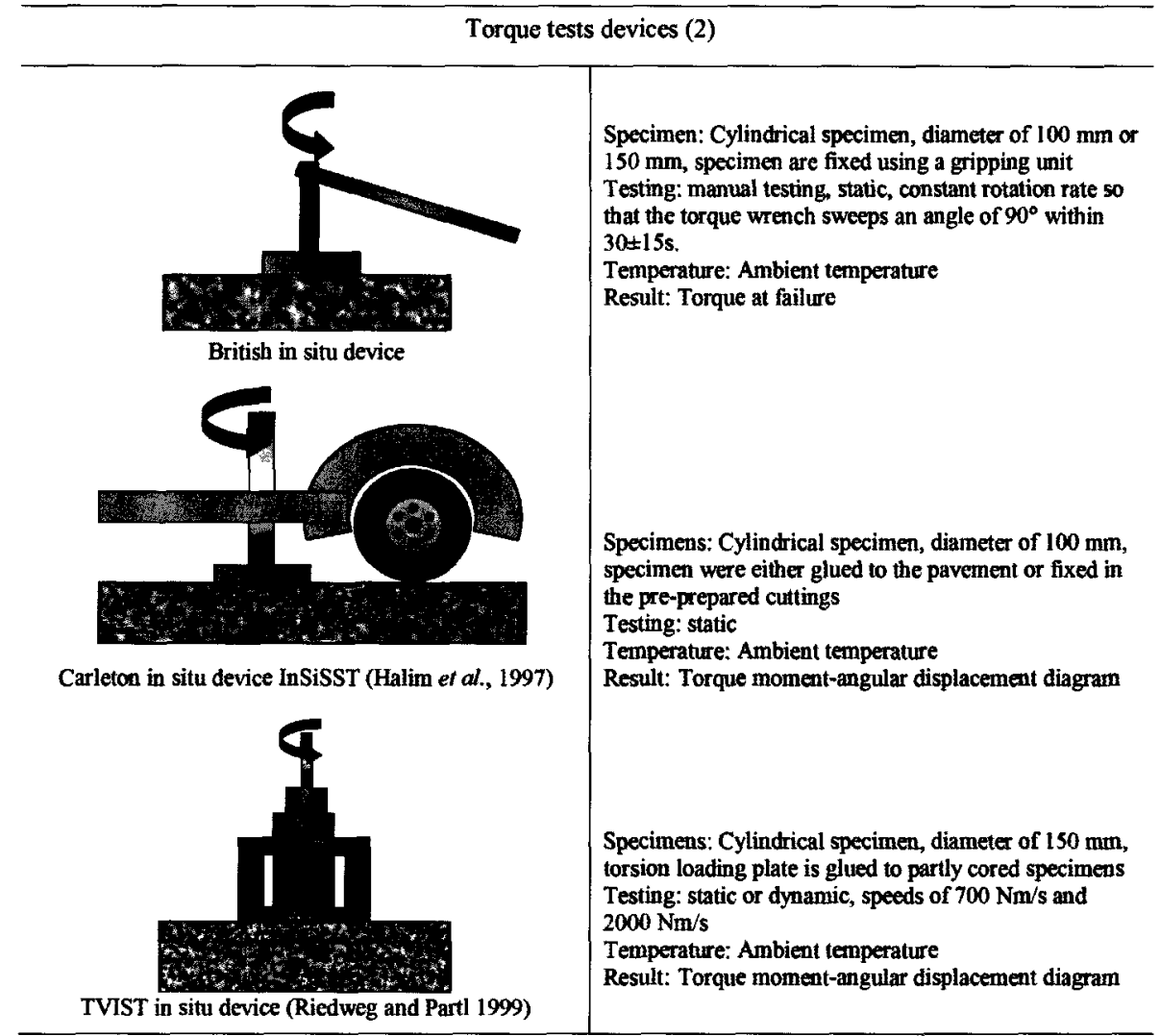


For the evaluation of deformations of cylindrical asphalt specimens due to shear stresses, Velske (Velske, 1978) developed a device, working on a similar principle as the one used for ring shear tests in soil mechanics. The specimen was subjected to torsion only. Further, a vertical force could be applied. In the torsion testing according to Velske, cylindrical specimens of $100 \mathrm{~mm}$ diameter were fixed with epoxy glue on both ends and these ends were twisted against each other. The tests were conducted at a temperature of $40^{\circ} \mathrm{C}$. The result given is the angle $\gamma$ after $100 \mathrm{~s}$ or $1000 \mathrm{~s}$.

In the British guidelines (Document SG3/05/234, 2004) a manual torque bond test is included as a mandatory test which is routinely used to measure the bond strength of thin surfacing.

In addition to the field testing Choi (Choi et al., 2005, Choi et al., 2005a) developed a laboratory torque bond test in Great Britain that allowed the test to be conducted in a more controlled environment. For the laboratory testing, double layered cores were clamped using a gripping unit, which was rigidly fixed on the floor. Then a steel plate was glued on top of the core. This plate acted as an adapter between core and torque wrench, which was attached to the plate. A torque was applied until failure and the bond strength calculated using the measured peak torque moment at failure.

In 2005 the Washington state Department of Transportation WSDOT used the torque equipment to evaluate the influence of tack coat construction factors (e.g. rain during paving operation) on the bond strength (West et al., 2005).

Diakhaté developed a more controlled torque apparatus, with a chain-sprocket mechanism to transfer a tensile force generated by a tension testing machine and convert 
it into a torque moment. This apparatus which he used to investigate the shear behaviour of tack coats, allowed the loading rate to be controlled accurately (Diakhaté et al., 2006).

Simultaneously, Sutanto (Sutanto, 2009) used the automatic torque test apparatus developed at the University of Nottingham for research purposes. Although similar to the French apparatus (Diakhate et al., 2006), the Nottingham device used a rack and piston mechanism which was capable of transferring either tensile or compressive force into positive and negative torsional load and therefore perform a cyclic zero-mean torsional load.

At Carleton University (Ottawa, Canada) torsion testing was studied not to evaluate the interlayer properties, but to determinate shear strength and stiffness of different asphalt mixes (Zahw, 1995). Mix shear strength and modulus were determined through laboratory torsion testing of cylindrical specimens to failure. The torsion testing machine was a laboratory device which evaluated the torque of cylindrical specimens (Goodman, 2000). The specimens were glued on steel plates and installed into the device. All testing was completed at $25^{\circ} \mathrm{C}$. Torque and twist angle at failure were recorded and the specimens failed in shear with a characteristic $45^{\circ}$ failure surface.

During the evaluation of a suitable test method for the adhesion testing at Empa, torsion testing was investigated. Therefore cores with a diameter of $150 \mathrm{~mm}$ were tested on an Instron torsion machine at temperatures between $20^{\circ} \mathrm{C}$ and $22^{\circ} \mathrm{C}$. The cores were fixed in a specially constructed wooden frame and installed in the testing machine. The moment necessary for the separation of the two layers was evaluated at $2 \% \mathrm{~min}, 4 \% \mathrm{~min}$ und $8 \%$ min (Raab, 1999a). 
Currently in the UK, bond strength is often assessed with the in situ torque test. Normally, the test is used on thin surfacing systems (BBA, SG3/05/234, 2004). For testing, the pavement is cored below the interface of interest and left in place. A plate is glued to the surface of the core, then a torque wrench is attached to the plate and a torque is applied manually at a constant torque rate so that the torque wrench covers an angle of $90^{\circ}$ within $30 \pm 15 \mathrm{~s} .100 \mathrm{~mm}$ cores are used to limit the magnitude of the moment to break the bond. However, this procedure resulted in the difficulty to control the torque rate, because the maximum torque strength is unknown and affected by the torque rate. Hence, Choi (Choi et al., 2005a) used a constant torque rate of $600 \mathrm{Nm} / \mathrm{min}$, which was achieved by synchronising the moment of the torque dial gauge with the second hand of an analogue clock.

Researchers at Carleton University successfully developed the In-Situ Shear Stiffness Test (InSiSST) facility (Abd El Halim et al., 1997, Goodmann, 2000, Abd El Halim, 2004) which allowed the evaluation of shear strength and stiffness properties of asphalt pavements in the field. Using a cutting tool consisting of a steel main frame and a mobile cutter, cross cuts were made in the pavement. In these cuts, plates were installed, on which the torque cell was adjusted and the torsion test was performed.

Torque testing has been conducted mainly for research purposes since the results seem to depend very much on the specimen preparation such as the gluing or fixing of laboratory specimens and the coring or cutting in case of in situ testing. Furthermore, the lack of standardised devices led to the development of a great variety of different and individual devices and test protocols. Only in the UK, torque testing was taken as a measure of quality control for the bond of thin surfaces and described in testing 
specifications (BBA, SG3/05/234, 2004). Despite the remarkable developments in the construction of torque devices for in situ testing, so far, none of these devices has been produced on a regular basis or standardised for quality control.

In Tables 2.4 and 2.5 schematic drawings of different torque test devices are presented.

In 1997 Empa developed and built a Torsion-Vibration In-Situ Tester (TVIST) - a servo-hydraulic device for evaluating the properties of asphalt concrete including the dynamic complex shear modulus $\left(\mathrm{G}^{*}\right)$ shown in Figure 2.5, (Riedweg and Partl, 1999).

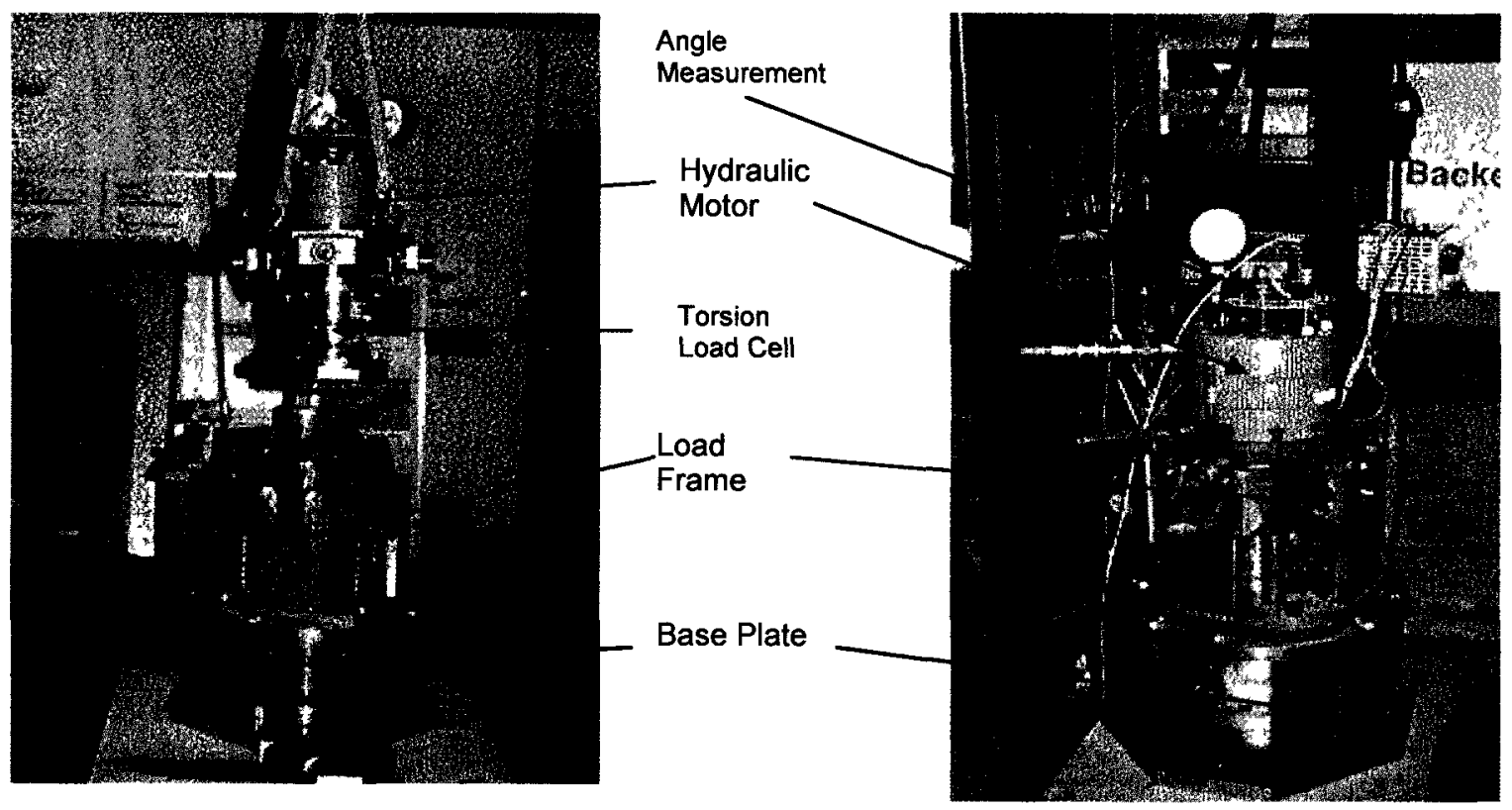

Figure 2.5: Photograph of the TVIST prototype machine constructed by EMPA

(Source: Riedweg and Partl, 1999) 
This torsion testing prototype device allowed both static and cyclic testing in angle and load controlled mode of bituminous pavement materials in situ and in the laboratory. It consisted of a rigid steel frame that was fixed on the pavement surface and a hydraulic swivel torsion motor sitting on a special bearing to allow free axial movement of the motor. In order to determine the torsion properties, the torsion loading plate was glued to partly cored specimens in the road of $150 \mathrm{~mm}$ in diameter or, in case of testing in the lab, on equivalent $150 \mathrm{~mm}$ cores. Testing at room temperature $\left(\mathrm{ca} .22^{\circ} \mathrm{C}\right.$ ) was typically done applying a torsion moment of $1800 \mathrm{Nm}$ at speeds of $700 \mathrm{Nm} / \mathrm{s}$ or if necessary at $2000 \mathrm{Nm} / \mathrm{s}$.

The concept of testing the shear strength of asphalt pavement surfaces using a rotational load in the field was first conceived by Abd El Halim and Nabi in the early 1990's. To investigate the feasibility of this concept, the Carleton In-Situ Shear Tester (CISSST) facility, mentioned earlier, was constructed.

Equation 2.1 was developed by Nabi (Abd El Halim et al., 1997) for calculating the mix shear strength with the CISSST device based on the assumption that the failed surface formed the frustum of a cone as shown in Figure 2.6. 


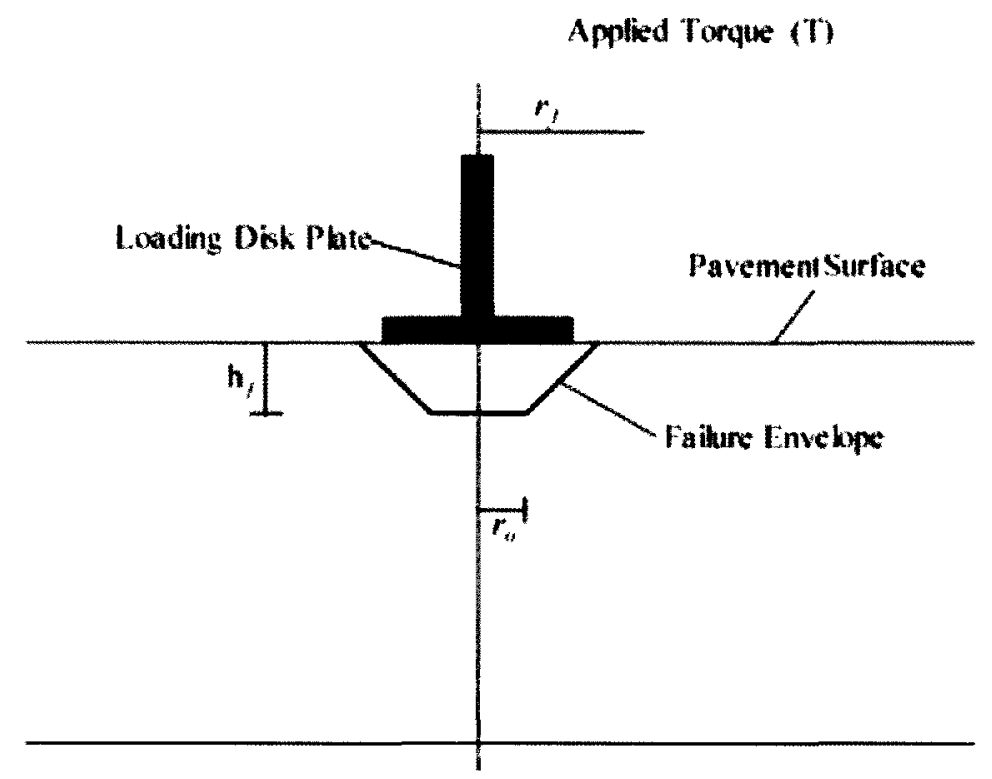

Figure 2.6: Loading and boundary conditions of CISSST

(Source: Abd El Halim et al., 1997)

$T=\frac{2}{3} \pi \tau\left[\left(\frac{r_{f}^{3}-r_{0}^{3}}{r_{f}-r_{0}} h_{f}\right)+r_{0}^{3}\right]$

where:

$\mathrm{T}=$ the maximum applied torque $[\mathrm{Nm}]$

$\tau=$ the in-situ shear stress $[\mathrm{MPa}]$

$\mathrm{h}_{\mathrm{f}}=$ the failure depth $[\mathrm{mm}]$

$r_{f}=$ the upper radius of the frustum of the failed cone [mm]

$\mathrm{r}_{0}=$ the lower radius of the frustum of the failed cone [mm]

By using the theory and modelling of the Carleton In-Situ Shear Tester (CISSST) it was planned in this study to evaluate in-layer and interlayer shear properties by testing pavement specimens supported on a circular bearing. As illustrated in Figures 2.7(a) and 
2.7(c) the fracture cone in the torque test ideally consists of the flank areas with the shear stress $\tau_{1}$ and the bottom area of the fracture cone with the shear stress $\tau_{2}$. The hypothesis of the investigation was to separate the shear contribution of each area. The idea was, to change the thickness of the layer as shown in Figure 2.7(b). In this way, different types of fracture cones would be formed exclusively consisting of the flank area (the bottom area does not contribute as it is in the air). Hence, $\mathrm{r}_{0}=0$ and equation 2.1 for the torque or the shear stress of the material would transform into:

$T_{m}=\frac{2}{3} \pi \tau_{1}\left(\frac{r_{f}^{3}-r_{0}^{3}}{r_{f}-r_{0}} h_{f}\right) \quad$ (a) and $\tau_{1}=\frac{T_{m}}{\frac{2}{3} \pi\left[\left(\frac{r_{f}^{3}-r_{0}^{3}}{r_{f}-r_{0}} h_{f}\right)\right]}$ (b) (equations 2.2a and 2.2b)

In case of a two layer pavement, the interlayer shear stress $\tau_{2}$ could be obtained by subtracting the contribution $\tau_{1}$ of the flank area of the cone with the height of the top layer (as determined in tests with the bottom area in air) from the total torque moment (Figure 2.7d). 


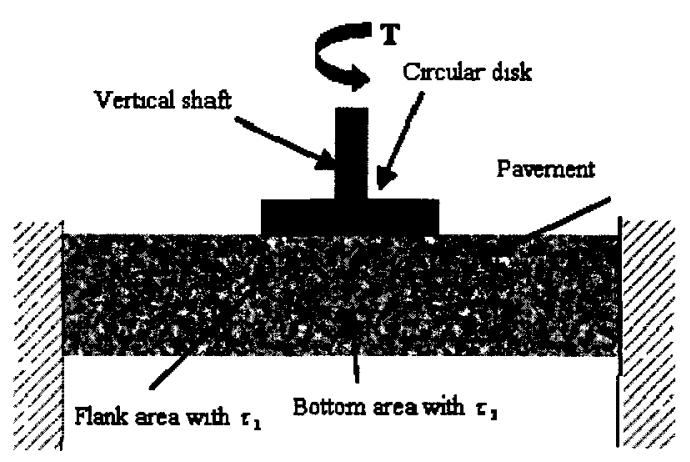

(a)

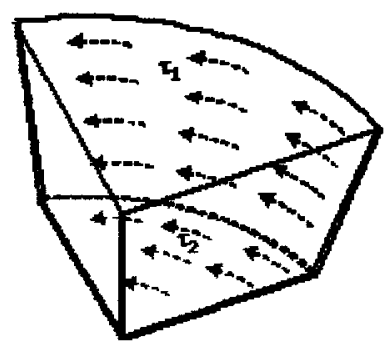

(c)

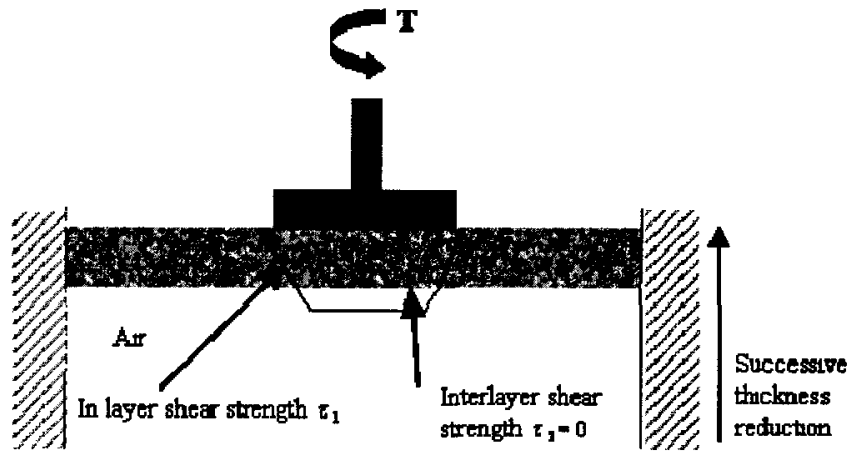

(b)

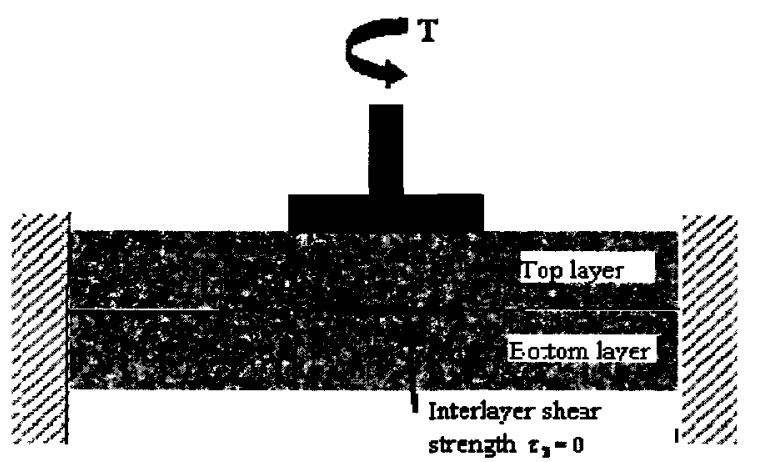

(d)

Figure 2.7: Schematic sketch of modelling and determining the bond properties for the torque test

For the torque and the shear stress at the interface equation $2.3 \mathrm{a}$ and $2.3 \mathrm{~b}$ is received:

$$
\begin{aligned}
& T_{s}=\frac{2}{3} \pi \tau_{1}\left(\frac{r_{f}^{3}-r_{0}^{3}}{r_{f}-r_{0}} h_{f}\right)+\frac{2}{3} \pi \tau_{2} r_{0}^{3} \\
& \tau_{2}=\frac{T_{s}}{\frac{2}{3} \pi r_{0}^{3}}-\frac{\tau_{1}}{r_{0}^{3}}\left(\frac{r_{f}^{3}-r_{0}^{3}}{r_{f}-r_{0}} h_{f}\right)
\end{aligned}
$$


Inserting equation $2.3 \mathrm{~b}$ leads to

$\tau_{2}=\frac{T_{s}}{\frac{2}{3} \pi r_{0}^{3}}-\frac{T_{m}}{\frac{2}{3} \pi r_{0}^{3}}=3 \frac{T_{s}-T_{m}}{2 \pi r_{0}^{3}}$

Since the Carleton Shear Tester was not available at the time of this study, preliminary tests were performed using a simple torsion device developed and constructed at Empa in order to evaluate if the hypothesis mentioned above was realistic and could be used as a basis for more elaborate investigation in this thesis. The Empa device is depicted in Figures 2.8.

The device consists of a metal ring which is based on three pillars and connected to a spindle. The torsion without normal force is applied via a metal rope connected to a pulling motor. The three pillars are sitting on a big metal plate $(0.70 \mathrm{~m} \times 1.2 \mathrm{~m})$ which has a hole where the loading plate can be glued to the specimen.

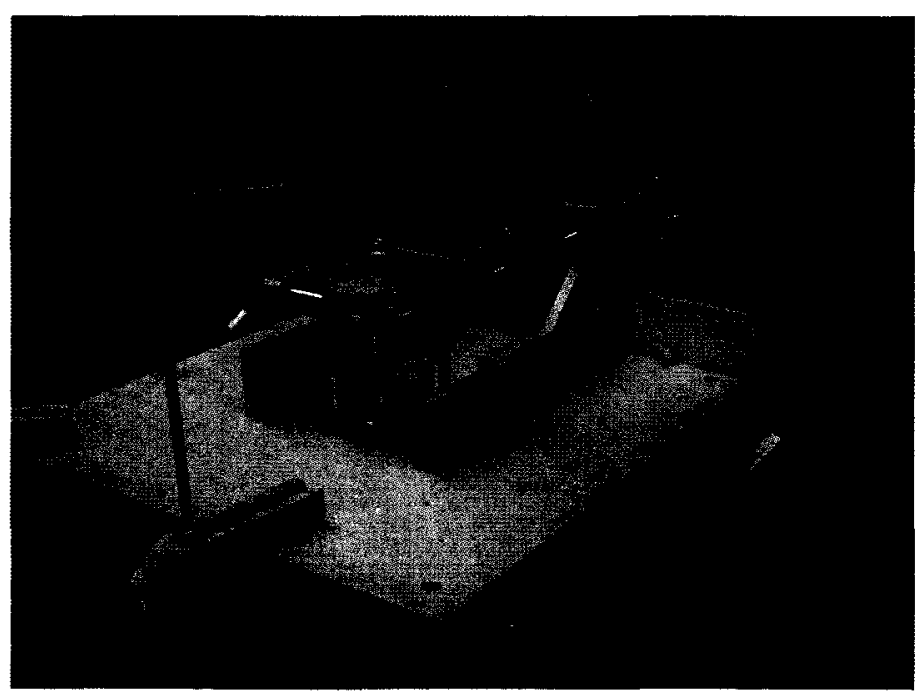

Figure 2.8: Torsion test device 
There are two sorts of loading plates, one with a diameter of $100 \mathrm{~mm}$ and another with a diameter of $150 \mathrm{~mm}$ so that size effects could be evaluated. The whole equipment is placed on a pavement slab and fixed with screw clamps. The loading plate is glued to the pavement surface.

For the first evaluation, a pavement slab $(0.70 \mathrm{~m} \times 1.1 \mathrm{~m})$ cut from a Swiss motorway pavement was taken. The pavement had four layers and a total thickness of ca. $320 \mathrm{~mm}$. The surface layer (thickness $40 \mathrm{~mm}$ ) consisted of porous asphalt PA 11 with a nominal maximum aggregate size of $11 \mathrm{~mm}$ and an air void content of ca. 20 vol-\%. The idea of using a porous asphalt slab was that this pavement is mechanically relative weak and therefore the expected cone would form more easily.

The testing was conducted according to the configuration depicted in Figure 2.7a, where the cone was expected to form in the pavement. The test was performed with a diameter of $100 \mathrm{~mm}$, a test speed of $1 \mathrm{~mm} / \mathrm{s}$ and at a temperature of $23^{\circ} \mathrm{C}$ (ambient temperature).

The test was repeated several times on different positions on the slab and a slower test speed of $0.1 \mathrm{~mm} / \mathrm{s}$ was also investigated.

As opposed to the hypothesis, no fracture cone developed, but the pavement broke in an irregular way somewhere beneath the surface with a maximum thickness of $10 \mathrm{~mm}$ compared to the layer thickness of $40 \mathrm{~mm}$ as shown in Figures 2.9 and 2.10 . 


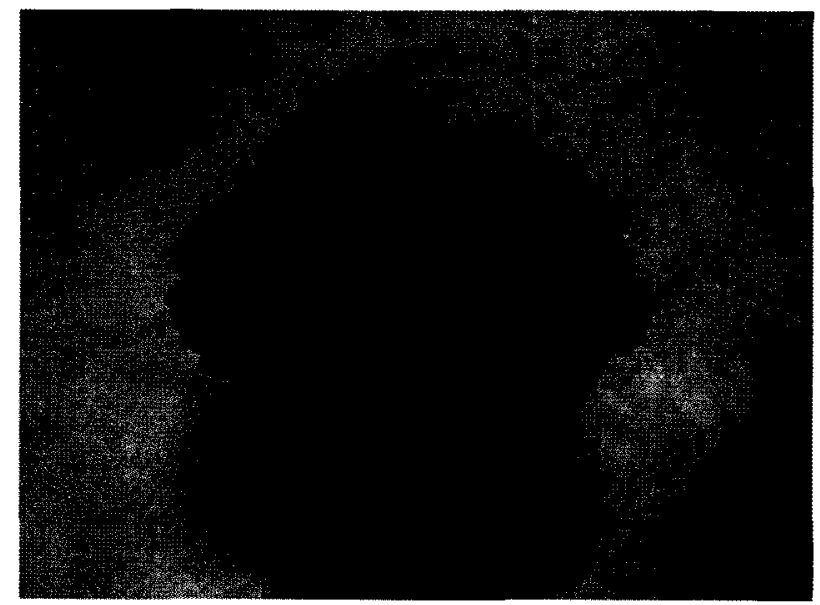

Figure 2.9: Loading plate with the remains of the porous asphalt pavement

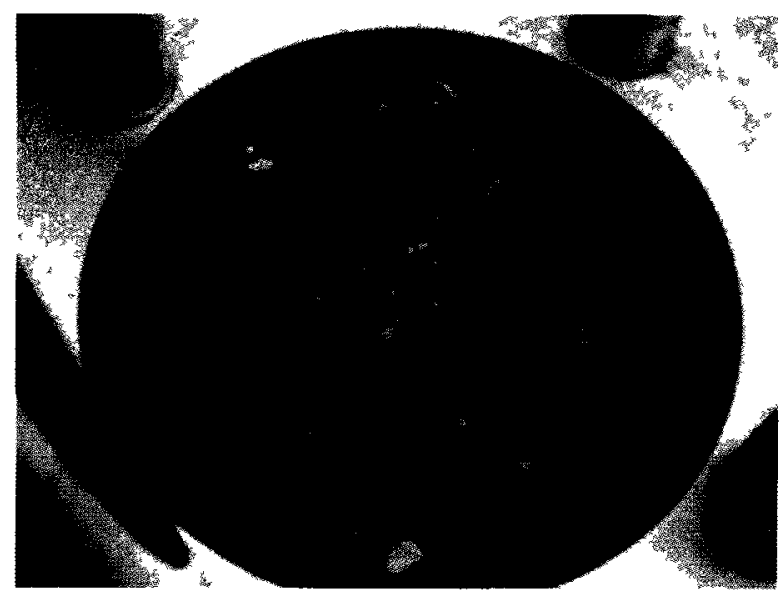

Figure 2.10: Arial view on the pavement, where the test was performed

Since the hypothesis of a fracture cone could not be verified in this case, the planned evaluation and determination of the interlayer shear stress $\tau_{2}$ as described earlier was not considered possible and the experiments were stopped. If no cones formed in porous asphalt as a mechanically relatively weak pavement, it was concluded that there would be only little chance for other pavement types. 


\subsection{Discussion}

\subsubsection{Shear test device}

From Tables 2.1 to 2.3 follows that there is a great variety of devices for testing the interlayer shear bond of asphalt pavements. The shear tests are inspired by shear testing in soil mechanics. Equipment with or without normal stress are used. The application and influence of normal stress is one of the issues which have been under debate for quite some time. Many researchers argue that the normal stress, representing the wheel load on the road, has to be included in interlayer bond testing. Regarding its influence (e.g. the magnitude of normal stress) different opinions and findings are being discussed (Uzan $e t$ al., 1978, Romanoschi and Metcalf, 2002).

It is a well-known fact that the shear test suffers from insufficiencies, since the specimen is subjected not only to shear, but a bending moment is introduced due to an eccentric load induction. By using optical measurements (see Section 6.1.4) it was shown that the specimen during shearing experiences not only a vertical shift in the direction of the shear plane, but also a horizontal or axial shift due to dilation and eccentricity effects as shown in Figure 2.11, (Raab and Partl, 1999). In fact, the deformation in the dilation direction was even twice as much as in the vertical direction. 


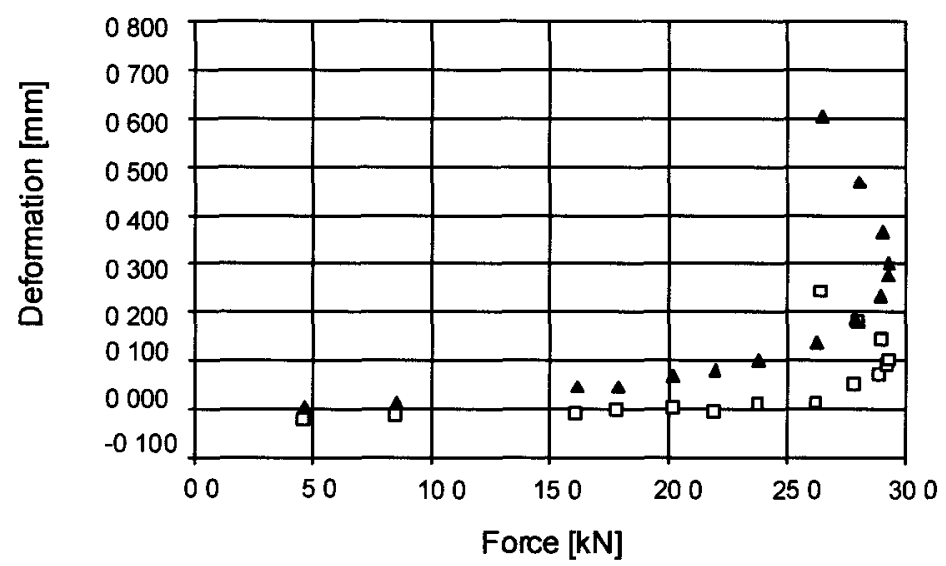

Figure 2.11: Average deformation of the sheared part of the specimen GA2M

$\triangle \mathrm{x}$-deformation $\square \mathbf{y}$-deformation (in direction of shear)

(Source: Raab and Partl, 1999)

Furthermore, when looking at the presentation and interpretation, as well as the comparison of the test results from different shear devices, no convergence exists. Although some common statements such as the dependency of adhesion tests on temperature or deformation rate are not debated among researchers, there are many divergent results regarding the influence of normal stress, tack coat and surface roughness on the adhesion properties (Uzan et al., 1978, Romanoschi and Metcalf, 2002, Raab and Partl, 2004, Ziari and Khabiri, 2007).

Another distinction between different test devices is their handling and simplicity. Here, devices using defined clamping mechanisms are preferable over devices where the test specimens have to be glued into moulds or to plates. The more time is needed for specimen preparation, and the more complicated a test setup becomes (e.g. the MCS 
device), the greater is the influence of unknown variables on the test results. Hence, such test devices are not likely to be used for daily quality assurance.

As for the guillotine devices, the different clamping mechanisms play an important role not only for the handling for producing a defined clamping pressure to hold the specimens during the test (e.g. as in the Empa LPDS test device). Furthermore, devices using cylindrical specimens are more practical especially for quality assurance since field specimens are mostly drilled cores and even a lot of laboratory specimens such as Marshall and gyratory specimens are cylindric. Some devices are flexible in a way that they allow for the testing both, cylindrical and rectangular specimens (e.g. Empa test device, ASTRA test device). Guillotine (Leutner) type devices have also the advantage to be very flexible since they can be installed in a common universal testing machine requiring no special test setups and fittings.

As shown in later, the gap width between the shearing rings is also an important variable which can not be neglected. A big gap width will lead to an increased eccentricity resulting in a combined bending-shear stress situation. Furthermore, especially when shearing specimens with intermediate layers, such as geotextiles or steel meshes, the diameter of the test devices has to be big enough to provide for the mesh width of the geotextile.

The comparison of different test devices as well as their results and outcome becomes a more and more important issue, This was demonstrated by an interlaboratory test program initiated by RILEM (Piber et al., 2009). In the course of the project, research and materials testing institutions from Europe and North America were asked to perform shear tests on pre-selected and defined material under certain test conditions 
using their specific shear test equipment. First investigations confirmed, that the direct shear test was easier to perform, as compared to torque testing, where specimen preparation (i.e. gluing) was necessary. Generally good agreement existed between different unidirectional monotonic static shear tests. As for the influence of the diameter, it was found, that the shear stress values for all temperatures tested with cores of $150 \mathrm{~mm}$ diameter were lower than the results of the test carried out with $100 \mathrm{~mm}$ cores.

\subsubsection{Torque test device}

Tables 2.4 and 2.5 depict the torque test devices, which represent a distinct smaller variety compared to the shear test devices.

In principle, torque test devices consist of a plate glued or fixed to the test specimen and a torque cell applying the torque moment. They mainly differ in the way the test specimens are hold (gluing, gripping or clamping) as well as in the construction of the test frame. As opposed to the similarity in device construction, the torque test protocols offer a great variability which does not simplify the comparison between different tests. This is a fact which made it impossible to conduct an interlaboratory test in the same manner as for shear testing (Piber et al., 2009).

Torque testing provides a non-uniform shear stress distribution, varying between zero in the centre of the interface cross section to a maximum value at its outside.

Since torsion testing is in most cases more cumbersome compared to shear testing as the specimens often must be prepared e.g. glued before testing, this test method is rather used for research purposes instead of quality control and assurance on a routine 
base. So far, only the UK torque testing was taken as a measure of quality control for the bond of thin surfaces and described in testing specifications (BBA, SG3/05/234, 2004).

Despite some disadvantages such as the cumbersome handling, torque testing offers a good possibility for in situ testing and testing of thin surfacings. Regarding in situ testing, various devices and test setup have been developed by different institutes and universities in Europe and North America (Kruntcheva et al., 2005, Abd El Halim et al., 1997 and Riedweg and Partl, 1999). However, these tests are not used on a standardised basis.

As shown in the Empa study torque can also be used to determine the shear properties within the material or for thin surfacings, while it is not easily possible to determine the shear bond between thick layers.

\subsection{Summary and Conclusions}

This Chapter presented an overview on selected existing shear and torque test devices and gives detailed information on the functioning mechanisms (device figures) and test specifications.

With respect to the different publications and devices, the following statements and conclusions can be drawn.

1. Shear testing seems to be a good and effective method for testing the interlayer bond of asphalt pavements, whereby direct shear test devices are commonly preferred to torque test devices. 
2. In many publications these test methods and devices are described by presenting photographs and sketches. Often photographs show the functioning of the devices only insufficiently and detailed information regarding the test devices (e.g. gap width) and test conditions (e.g. loading function, normal force) are difficult to retrieve. One can also observe that there is no common understanding of the relevant test conditions. Therefore, detailed drawings showing the mechanism of a device as depicted in this thesis are preferable.

3. For the construction of shear test devices it is important that the test setup is not complicated and the installation of test specimens is simple. Clamping mechanisms are often preferable over setups where specimens have to be glued or fixed into special moulds. When clamping the specimen, care has to be taken that this procedure does not damage the specimen and does not influence the test results. Therefore, it is important that a defined pressure is used and that the specimen is not tilted during the test. Incorrect clamping may also lead to loosening of the specimen or cause additional creep effects when testing at elevated temperatures.

4. Although shear failure normally occurs in warm climate, moderate test temperatures (around $20^{\circ} \mathrm{C}$ ) seem to be preferable. As compared to testing at hot temperature, the danger of damaging the specimen during testing is smaller.

5. For the comparison of different test devices, it is important that test parameters such as torque moment and deformation rate and normal load are comparable.

6. Torque test devices offer a good possibility for in situ testing and testing of thin surfacings. This is rather difficult with direct shear testing. 
7. Regarding the results from interlayer shear bond testing, it is important to compare the outcome of different devices and methods in a detailed way. The above mentioned Rilem interlaboratory test provides a first step in this direction. 


\section{CHAPTER 3}

\section{Experimental Investigation}

\subsection{Introduction}

When Chapter 2 describes how test devices and protocols have been developed during recent years and refers to still ongoing developments (e.g. CEN standardisation), this Chapter explains in detail the experimental investigation performed in this thesis. As shown earlier in Figure 1.4, the experimental investigation is hereby divided into two parts: an investigation of the idealisation of the bond (testing program 1) and a parameter study intended to investigate different influence parameters such as moisture, temperature and gap width (testing program 2).

Besides the presentation of the experimental investigation carried out in the two testing programs, this chapter also introduces in more detail the test methods LPDS and Shear Box testing which were applied for the experimental investigation. In addition to these test methods and their parameters, the calculated characteristic values and the data processing are presented and discussed.

\subsubsection{Testing program 1}

The literature review revealed that the bond properties between asphalt pavement layers have attracted more and more attention during recent years due to the continuous refinement of pavement design methodologies and increasing requirements on long term 
performance under ever increasing traffic. This led to the development of different bond test devices and the evaluation of a variety of test procedures, where the influence of different parameters, such as temperature, tack coat application or normal stress has been discussed in numerous papers and scientific contributions (Abd El Halim, 1997; Mohammad, 2001; Diakhate, 2006; Choi, 2005).

Due to the fact that a basic understanding of the interface interaction and the influencing parameters is necessary for investigating the bond between asphalt pavement layers, different views and concepts have been presented, which in most cases either described the interface surface or the influence of the tack coat (Mohammad, 2001; Kruntcheva, 2006; Canestrari, 2005).

Although there are many parameters contributing to the bond strength it is assumed that the two most critical ones are the asphalt binder and the relative size of the aggregates. The relative size of the aggregates or the geometrical surface conditions are major parameters for the interlock regardless of the mechanical and/or chemical properties of the binder (or tack coat) film at the interface of the asphalt pavement layers as well as the mechanical properties of the aggregate. In order to investigate the influence of the relative size of aggregates, the aggregates in real asphalt mixture were substituted by a combination of two different diameters of steel balls; small and large sizes. This approach had the advantages of studying the influence of the relative aggregate sizes and avoiding interconnections of real material. Furthermore, Shear Box testing provided the possibility to distinguish between the influence of relative aggregate size and that of the binder by testing the aggregates separately. Hard binder (10/20 penetration graded bitumen) was taken to replace the mastic (filler binder composite) in order to eliminate 
the influence of the filler while ensuring the stability of the material. The objective of this investigation was to understand the effect of the particle size on the operating mechanism that governs the bond between different layers and examining the influence of that specific variable on the interlayer bond properties. Once this understanding is developed it was easier to quantify other secondary variables such as shape and general gradation of aggregates used in asphalt mixes.

The author is fully aware of this fact, but decided to investigate this idealised unconventional model material based on the hypothesis that by investigating extreme situations, some effects, that may be hidden or ignored in reality, could be understood in a clearer way. In this sense, the approach chosen here is comparable to idealisation and simplification found in numerical modelling, with the difference that an idealised testing methodology has been chosen. It is therefore expected that the experimental results can directly be used for evaluating idealised models. Whereas theoretical idealisation is a common technique, experimental idealisation is comparatively scarce in the field of asphalt research.

\subsubsection{Testing program 2}

Beside the geometrical properties and aggregate interlock, a variety of other influence parameters and factors governing the interlayer bond have not been given enough attention so far:

Moisture is known to accelerate the reduction of the long term performance of asphalt pavements caused by rutting, ravelling or cracking. In fact, numerous investigations and research projects dealt with this subject by focussing on the behaviour 
and moisture resistance of asphalt mixtures and pavement materials (Partl et al., 2008, Little and Jones, 2003, Mostafa et al., 2003, Birgisson and Roque, 2003, Kandhal, 1992, Hicks 1991). However, focus of research is surprisingly different with respect to the influence of moisture on interlayer bonding: Here the connection between interlayer bonding and its relation to moisture and climate have not often been studied in great detail.

Temperature is known to be one of the most critical factors affecting interlayer bond testing. Interlayer bond testing in the laboratory is normally conducted at an ambient temperature between $20^{\circ} \mathrm{C}$ and $25^{\circ} \mathrm{C}$ and therefore, the specific knowledge of the effect of other temperatures, especially temperature below $0^{\circ} \mathrm{C}$ is often not available. The reason for testing at ambient temperature is manifold. At elevated temperatures $\left(30^{\circ} \mathrm{C}\right.$ to $40^{\circ} \mathrm{C}$ ), shear force and shear deformation are critical. However, testing and specimen handling becomes more difficult and may lead to measurement errors or specimen damage (Raab and Partl, 1999). Furthermore, at elevated temperatures, the difference in shear force between the different asphalt types becomes smaller and less distinguishable for different asphalt mixes, especially, when the binder gradually looses its binding properties due to loss of viscosity. Reduced distinguishability between different mixes can also occur at temperatures below $0^{\circ} \mathrm{C}$ when the interlocking effect at low temperature is supposed to play a minor role due to increased stiffness and bonding properties of the asphalt binder. At low temperatures, shear force is also expected to increase, which, on the one hand is less critical and on the other hand, may exceed the capacity of the testing machine. Nevertheless, it was found important to investigate the effects of low temperature on the interlayer bond testing in more detail. 
Regarding the further development of interlayer bond testing, standardisation and normalisation on a worldwide level is very important. In this context it is crucial to come to commonly accepted and evaluated test methods and procedures. Developed in the late 1970s, the so called Leutner (Leutner, 1979) direct shear test has become the most important test for determining the interlayer bond between asphalt pavement layers (see also Chapter 2). Although the test arrangement suffers from non-uniform interface shear stresses and the fact that no load perpendicular to the test plain can be applied, its simplicity and easy handling have contributed to its worldwide adoption. Over the years several countries and laboratories have made modifications or have built their own equipment (e.g. Raab and Partl, 1999; Scholar et al., 2004 and Leng, 2008). Initiated by a modification made in the United Kingdom (Choi et al., 2005, Choi et al., 2005a) the question about the gap width between the shearing rings of the device was raised in the process of European standardisation. The reason for the UK modification was due to the difficulty to perfectly align the interface to the shear plane, especially for specimens having irregular interfaces (due to coarse aggregates interlocking or uneven bottom layer surface) (Choi et al., 2005). Although the authors state that the modification using a gap width of $5 \mathrm{~mm}$ was beneficial for the testing, no comparison of tests results with different gap widths was given. Therefore, it was considered important to investigate the influence of the gap width in more detail.

When it was found to be beneficial to investigate the geometrical properties by idealising the contact surface using a model material, the influence of the above mentioned factors such as moisture, low temperature and gap width had to be 
investigated for the real asphalt material in order to take material characteristics, e.g. binder, air voids into consideration.

\subsection{Description of tests and procedures}

In the course of the interlayer bond testing, mainly the Layer Parallel Direct Shear device LPDS, a modification of the German Leutner shear device (Raab and Partl, 1999, Leutner, 1979) was used. Since the LPDS device is not able to apply horizontal and normal forces, a Shear Box at the Swiss Federal Institute of Technology (ETH) Institute of Geotechnical Engineering in Zurich was also utilised.

\subsubsection{LPDS test device}

The Layer-Parallel Direct Shear (LPDS) test device (Figure 3.1) is an EMPA modified version of equipment developed in Germany by Leutner, being more versatile in geometry and more defined in the clamping mechanism.

One part of the pavement core (up to the shear plane to be tested) is laid on a circular u-bearing and held with a well defined pressure of $0.5 \mathrm{MPa}$ by a semicircular pneumatic clamp. The other part, the core head in Figure 3.1, remains unsuspended. Shear load is induced to the core head by a semicircular shear yoke with a deformation rate of $50 \mathrm{~mm} / \mathrm{min}$, thus producing fracture within the pre-defined shear plane. The LPDS has a long clamping and supporting length such that the clamping of the specimen is simple, fast and well-defined. This is particularly beneficial when testing different shear layers in a core or when testing pre-heated test specimens as it minimizes temperature loss. 


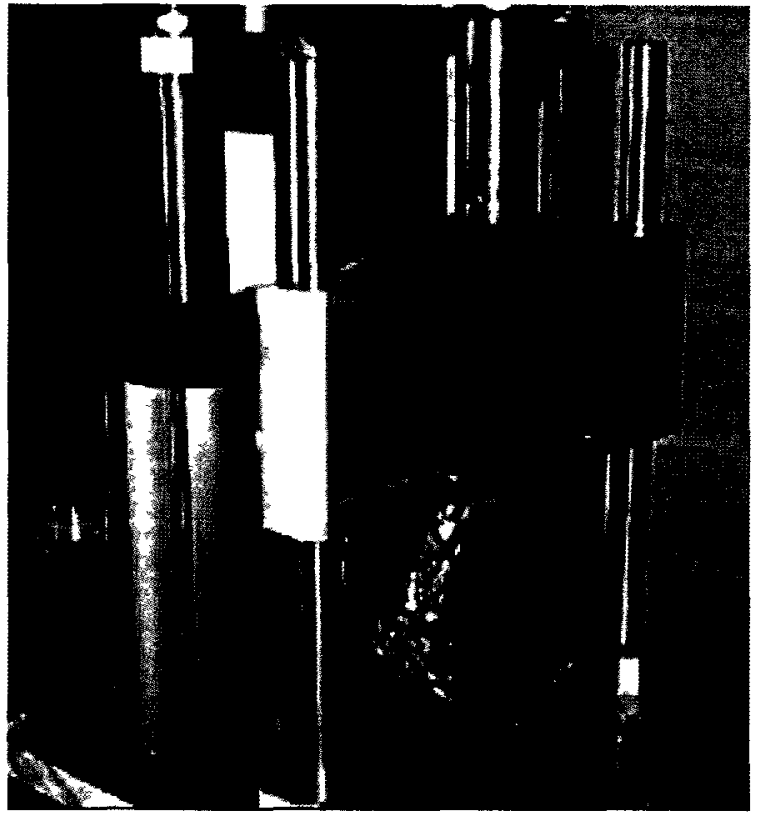

(a)

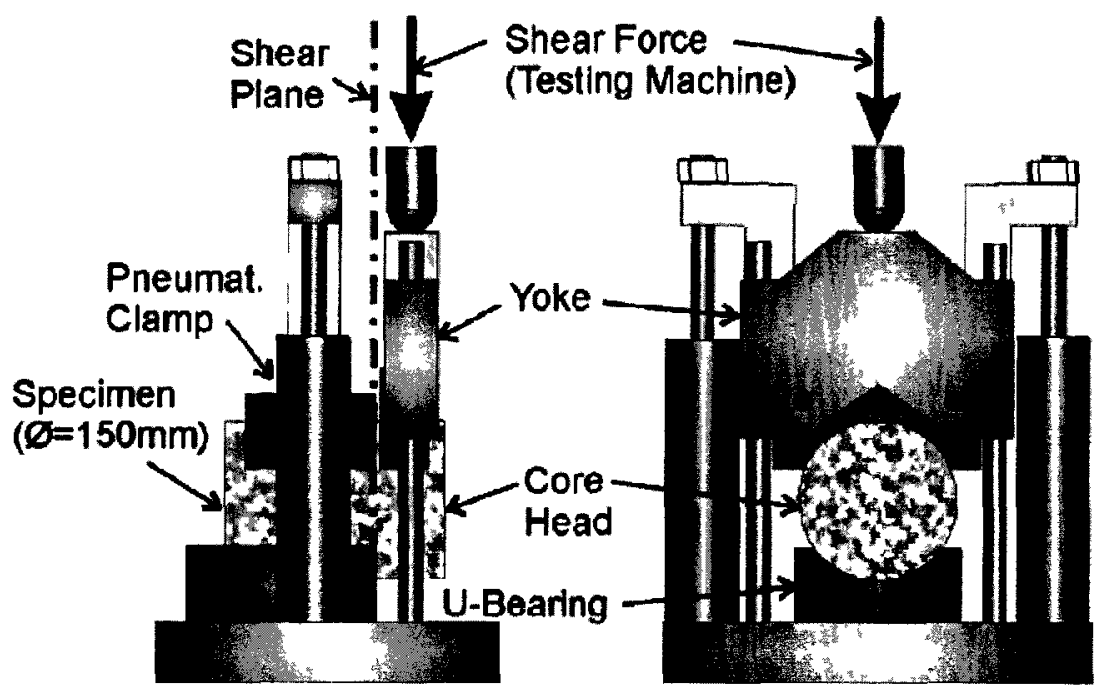

(b)

Figure 3.1: Layer parallel direct shear tester (LPDS), (a) photograph, (b) schematic view

(Source: Raab and Partl, 1999, Partl and Raab, 1999) 
In order to achieve a homogeneous load distribution, the yoke and clamps are adjustable to accommodate core diameters from $148 \mathrm{~mm}$ to $155 \mathrm{~mm}$ (normally $150 \mathrm{~mm}$ ) as well as rectangular specimens. The LPDS test device fits into an ordinary servohydraulic testing machine (Raab and Partl, 1999, Partl and Raab, 1999). The gap width between the shearing rings is $2 \mathrm{~mm}$ and therefore different from the original Leutner device with a gap width of $0 \mathrm{~mm}$. The modified gap width was selected to provide for a better alignment of the specimen.

The LPDS test is easy to perform and requires no gluing or time consuming specimen preparation. With minimal experimental effort various layers of a pavement core can be sheared one after another, provided that the layer thickness is not too small $(>20 \mathrm{~mm})$. Another benefit is that the shear resistance of cores can be determined for any shear plane parallel to the road surface. This allows determining the in-layer and interlayer shear properties, i.e. the shear properties between layers (Partl and Raab, 1999).

\subsubsection{Measurements and calculations}

This section introduces the governing equations which define the relationship between the shear parameters obtained from the LPDS test.

The LPDS test is a deformation controlled test. As a result, for each deformation value a force is obtained, until maximum shear force is reached.

Figure 3.2 shows a schematic shear force vs. shear deformation curve and the determined characteristics such as maximum force $F_{\max }$, the maximum shear stiffness $\mathrm{S}_{\max }$ and the deformation at maximum shear force $\mathrm{w}^{\circ}{ }_{\max }$ which is calculated as: 
$\mathrm{W}_{\max }^{\circ}=\mathrm{W}_{\max }-\mathrm{W}_{\mathrm{t}}$.

where $\mathrm{w}_{\mathrm{t}}=$ intersection point of $\mathrm{S}_{\max }$ and $\mathrm{x}$-axis

Nominal maximal shear stress, i.e. the average shear stress in the cross section, can be determined by dividing the max. shear force by the cross section area of the core.

$$
\tau_{\max }=\frac{F_{\max }}{A}=\frac{4 \mathrm{~F}_{\max }}{d^{2} \pi}
$$

where:

$\mathrm{F}_{\max }=$ maximal force,

$\mathrm{A}=$ nominal cross section area, and

$\mathrm{d}=$ specimen diameter.

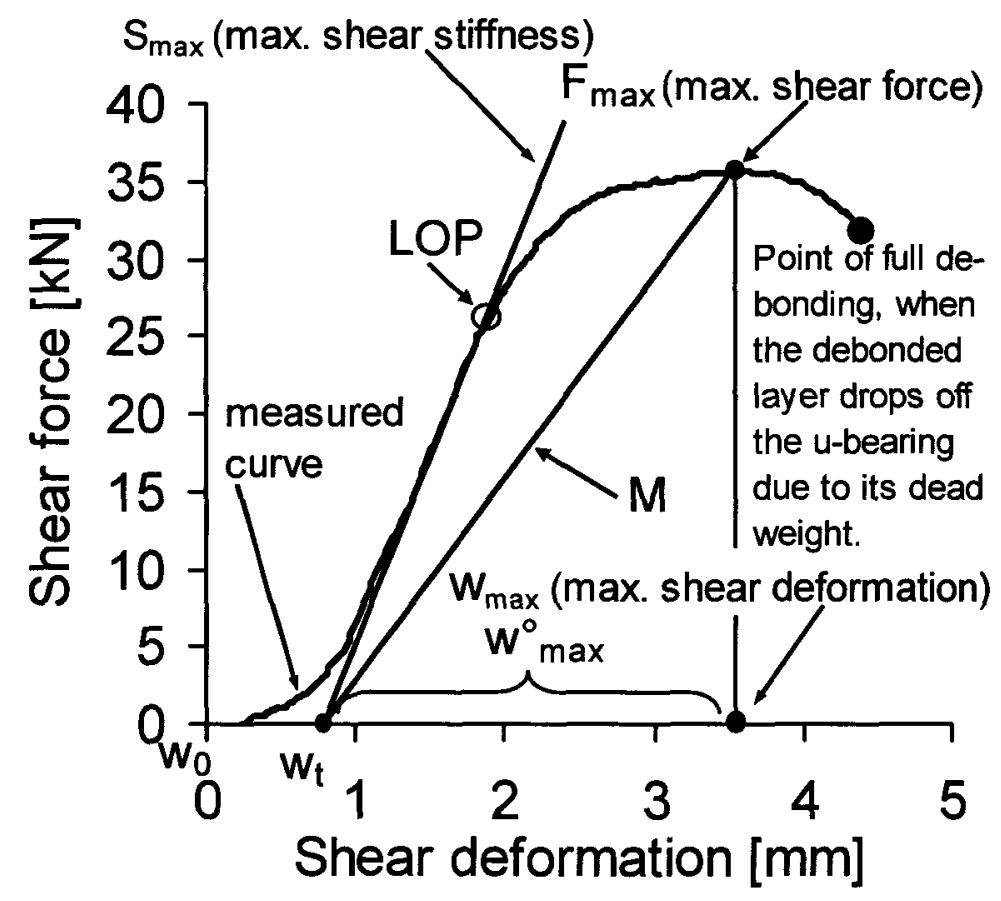

Figure 3.2: Schematic shear force-deformation curve with parameters of LPDS test 
In addition to the max. shear force, the maximum slope from Figure 3.2 is used to define the maximum shear "stiffness" value $S_{\max }$ as follows:

$S_{\max }=\frac{d F}{d w(F)} \quad$ at $\quad \frac{d^{2} F}{d w^{2}}=0 \quad$ and $\quad \frac{d^{3} F}{d w^{3}}<0$

where:

$\mathrm{dF}=$ differential shear force

$\mathrm{dw}=$ differential shear deformation

In order to be able to compare "stiffness values" for different specimen diameters the shear reaction modulus $\mathrm{K}_{\max }$ (Goodman, 1968) is used:

$K_{\max }=\frac{d \tau}{d w(\tau)} \quad$ at $\quad \frac{d^{2} \tau}{d w^{2}}=0 \quad$ and $\quad \frac{d^{3} \tau}{d w^{3}}<0$

(equation 3.3)

where:

$\mathrm{d} \tau=$ differential nominal shear stress

$\operatorname{dw}(\tau)=$ differential shear deformation

Another value is the so called secant stiffness $M$, which is calculated as the ratio between the maximum shear force and the deformation $\mathrm{w}^{\circ}{ }_{\max }$ at $\mathrm{F}_{\max }$ as given in equation 3.4 : 


$$
M=\frac{F_{\text {max }}}{w_{\text {max }}^{\circ}}
$$

where:

$\mathrm{F}_{\max }=$ maximal force

$\mathrm{w}_{\text {max }}^{\mathrm{o}}=$ deformation at $\mathrm{F}_{\max }$

The change of the secant stiffness during the test, compared to the original one can be taken as damage measure.

$$
\begin{aligned}
& \frac{M\left(w^{\circ}\right)}{S_{\max }}=1 \quad \text { no damage } \\
& 0<\frac{M\left(w^{\circ}\right)}{S_{\max }}<1 \quad \text { damage }
\end{aligned}
$$

where:

$M\left(w^{\circ}\right)=$ secant stiffness at shear deformation $w^{\circ}$

In case of LPDS it is difficult to calculate the damage since it is not possible to obtain a closed shear force/shear deformation curve without a minimum of normal force support.

In this thesis the secant stiffness $M$ according to equation 3.4 is given in the Appendix A, but it was not used for further evaluations.

It is also possible to determine the Limit of Proportionality (LOP) and the work to produce failure. 
Another possibility to evaluate the shear force vs. shear deformation curve is to calculate the fracture energy $\mathrm{W}_{\text {frac }}$ represented by the area under the curve up to the maximum shear force as shown in Figure 3.3. Fracture energy can be divided in an elastic "stored" energy part $\mathrm{W}_{\text {elast }}$ (diagonally shaded area) and a dissipated "lost" energy part $\mathrm{W}_{\text {diss }}$ (horizontally shaded area). The elastic energy is determined by drawing a parallel line to the maximum shear stiffness $S_{\max }$ (see Figure 3.2) through the point at maximum shear force $\mathrm{F}_{\max }$. In this thesis the fracture energy was not used because this parameter is closely correlated to other parameters such as $\mathrm{w}, \mathrm{F}, \mathrm{S}$, or $\tau$ and $\mathrm{K}$ and therefore does not provide important new information.

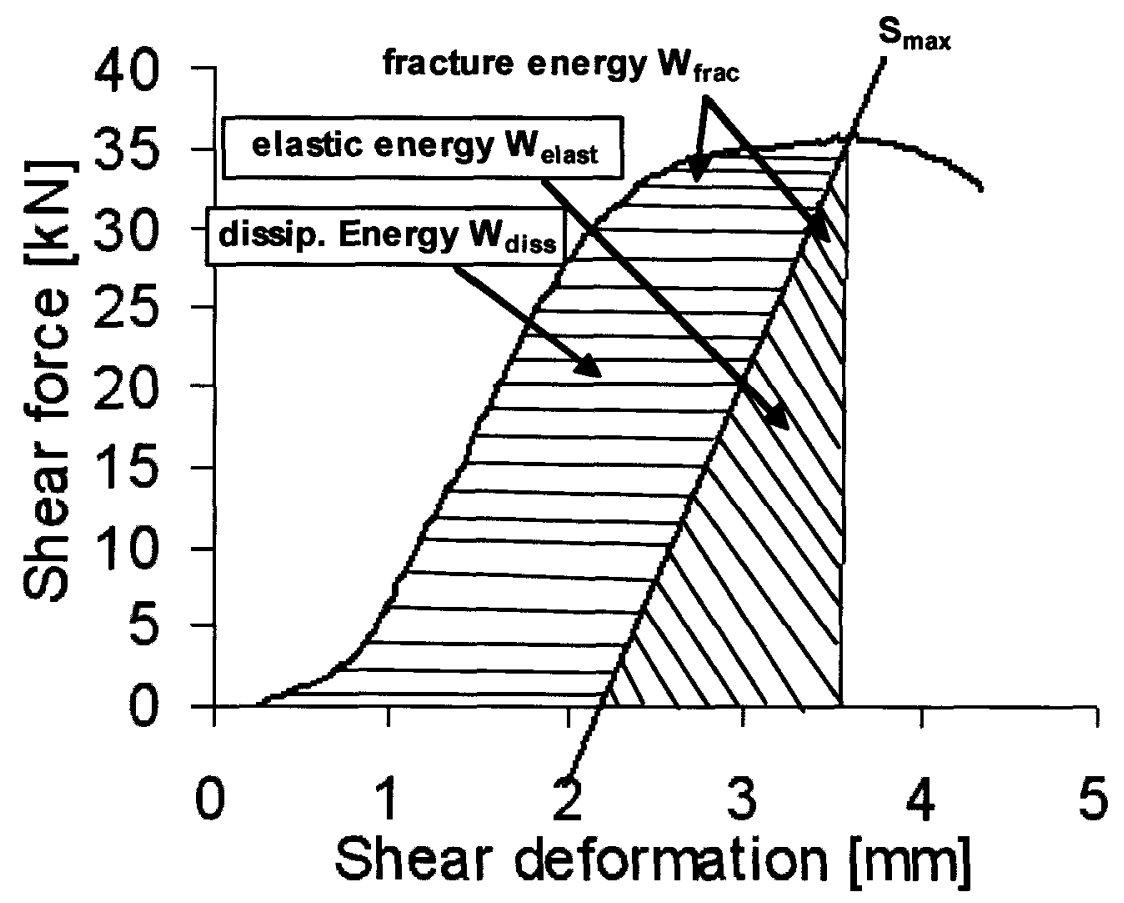

Figure 3.3: Determination of energy from shear force-shear deformation curve 
Note that, this thesis always talks about the maximum values, such as maximum shear force $F_{\max }$ or maximum shear stiffness $S_{\max }$ etc. For simplicity, the notation maximum or max. was therefore often neglected in the following text.

\subsubsection{Determination of the mean shear curve}

From the single measurements of shear force, shear stress, shear deformation and shear stiffness the mean values and standard deviation as well as the mean shear forcedeformation curves were determined. In order to determine the mean curves, the following 3-step procedure was applied:

In a first step, the flat starting phase of the measured original curves was replaced by the tangent defined as the calculated maximum shear stiffness value from equation (3.2). The intersection point of the tangent and the $\mathrm{x}$-axis defines a point $\mathrm{w}_{\mathrm{t}}$. The whole curve was then horizontally shifted from wt into the origin of the coordinate system w0 as shown schematically in Figure 3.4 (a). This was done for all single curves.

In a second step, the single curves were normalised such that both a maximum shear force and corresponding deformation of " 1 " was obtained. This was done by dividing the coordinates of the individual shear force and deformation points of each curve through maximum shear force and the corresponding deformation coordinate as shown in Figure 3.4 (b). Next, all normalised curves were summed up and divided by the number of curves (average).

In a last step, the mean curve was determined by multiplying the normalised mean curve with the mean maximum shear force and the associated mean deformation wmax- 
wt. The maximum shear stiffness value was calculated from linear regression in the steepest part of the curve as indicated by the cluster of points in Figure 3.4(a).

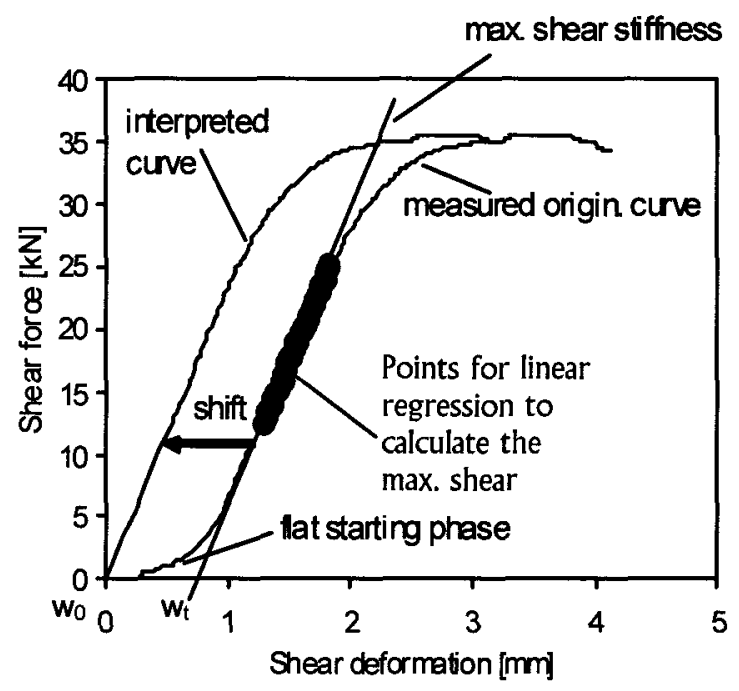

(a)

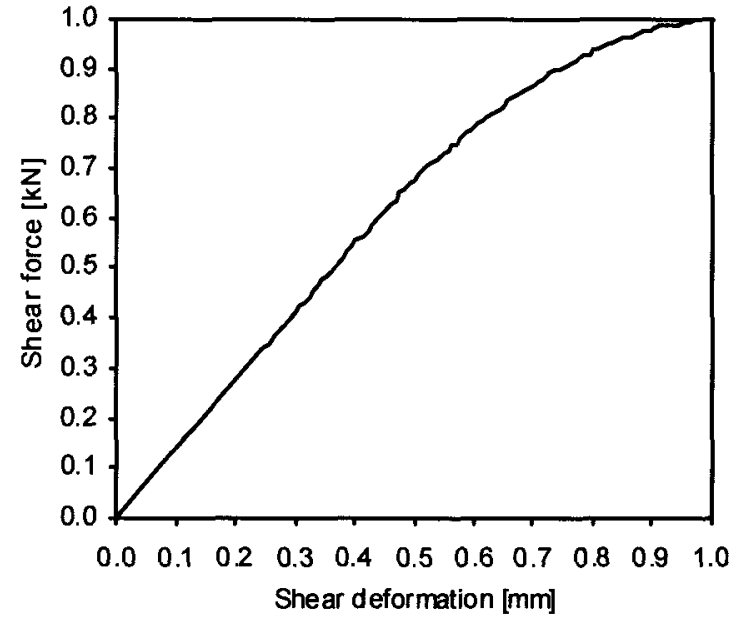

(b)

Figure 3.4: Method to determine mean shear force - shear deformation curve

\subsubsection{Shear Box test device}

For Shear Box testing Shear Box at the ETH Institute of Geotechnical Engineering as shown in Figure 3.5 was used.

The ETH Shear Box operates on the same principle as the Ancona Shear Testing Research and Analysing Apparatus ASTRA which was constructed for the determination of the shear bond between asphalt pavements in the early 1990ties (Santagata and Canestrari, 1993). As opposed to the ASTRA device, the Shear Box at ETH is normally used for testing of soil samples. Therefore, the attainable forces as well as the applicable normal loads are limited to the needs of this type of application. 


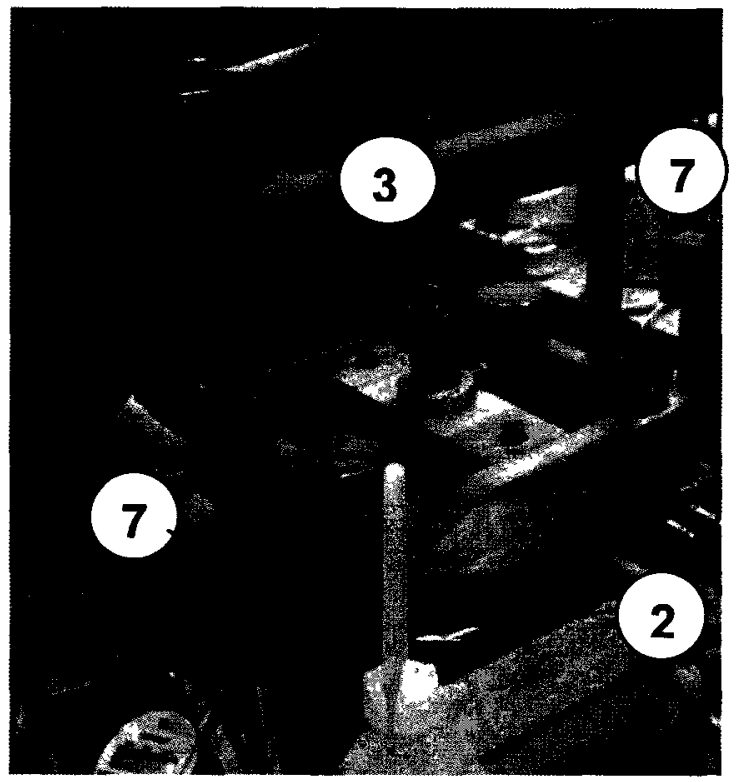

(a)

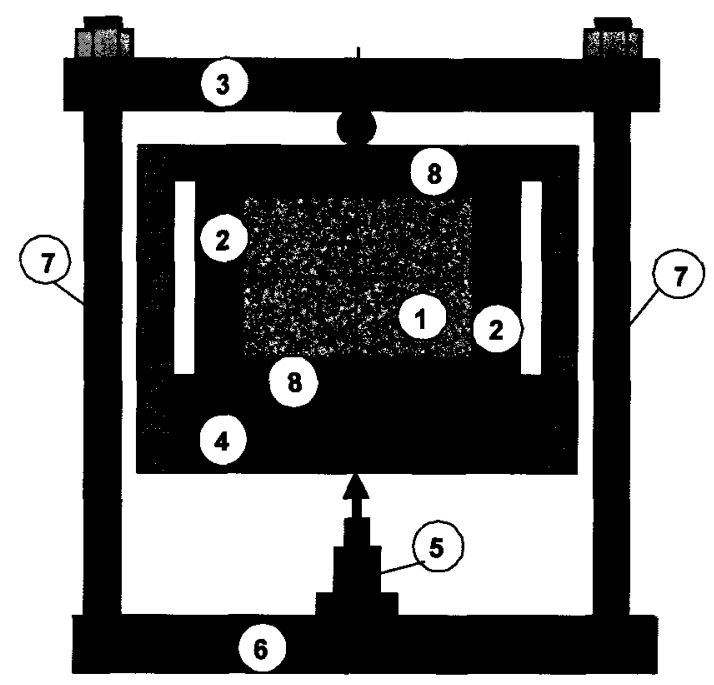

(b)

(1) Specimen

(2) Rings

(3) Yoke
(4) Base plate

(5) Jack cylinder

(6) Foundation

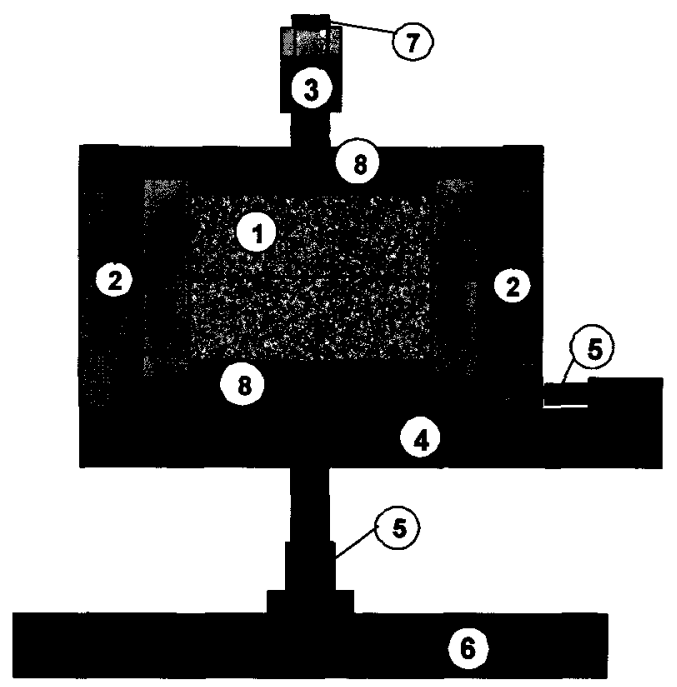

(7) Tie bar

(8) Pressure plate

Figure 3.5: ETH Shear Box device, (a) photograph, (b) schematic view 
The Shear Box test device (see Figure 3.5) consists of two metal rings (2) of $100 \mathrm{~mm}$ diameter in which the specimen (1) is placed. These rings are placed and fixed inside a lower and an upper pressure plate (8). The lower pressure plate is shifted horizontally with a constant displacement rate of $2.5 \mathrm{~mm} / \mathrm{min}$ while the upper plate is fixed. The normal load perpendicular to the shear plane is applied hydraulically by a jack cylinder (5) which presses the pressure plates against a yoke (3) as shown in Figure 3.5.

\subsubsection{Measurements and calculations for Shear Box Testing}

From Shear Box testing, shear stress, shear stiffness and shear reaction modulus can be obtained, as described earlier for the LPDS testing, and the mean force/stressdeformation curves can be calculated in the same manner.

Shear Box testing can be carried out at different normal stress levels. Hence, by recording the maximum shear stress versus the corresponding normal stress in the Mohr plane, it is possible to determine the maximum envelopes representing the failure criterion according to Coulomb's law (see Figure 3.6).

$$
\tau_{\max }=c_{0}+\sigma_{n} \tan \varphi_{p}
$$

where:

$$
\begin{aligned}
& \sigma_{\mathrm{n}}=\text { normal stress } \\
& \varphi_{\mathrm{p}}=\text { maximum friction angle } \\
& c_{0}=\text { cohesion (pure friction) }
\end{aligned}
$$




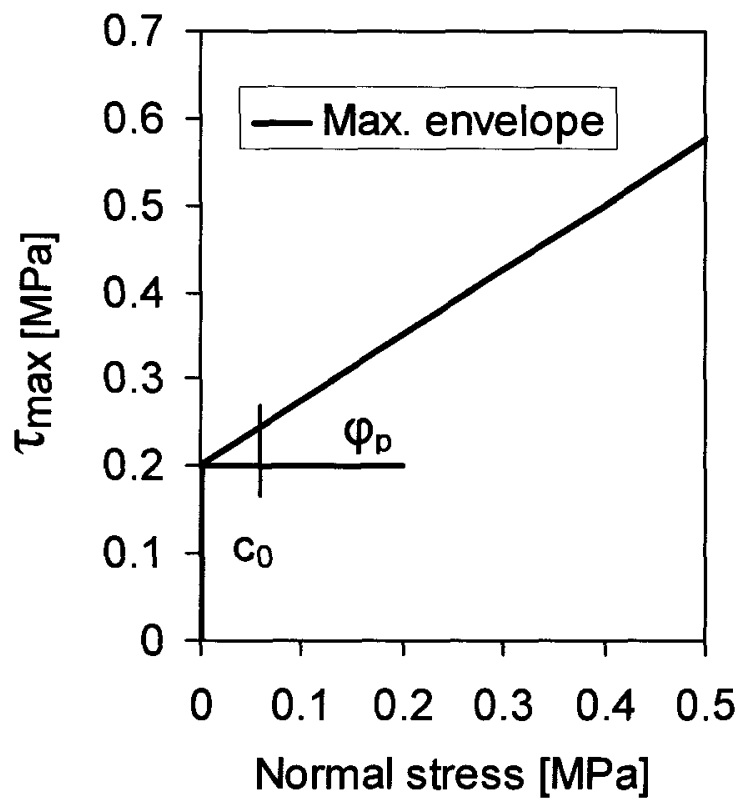

Figure 3.6: Maximum envelope for testing at different levels of normal stress

This procedure has been explained in detail for example by Canestrari and Santagata (Santagata and Canestrari, 1994, Bocci and Canestrari, 1997).

\subsection{Description of materials and methods}

\subsubsection{Materials and methods for testing program 1}

\subsubsection{Idealisation of the bond}

The model material consisted of equally sized steel balls with diameters of $\varnothing 9.5 \mathrm{~mm}$ ('big') and $\varnothing 5.5 \mathrm{~mm}$ ('small') as shown in Figure 3.7. A hard penetration graded bitumen 10/20 was used as binder. This was necessary in order to provide sufficient stability for the specimens during testing at room temperature. The ratio of the steel ball 
diameters was chosen with about $1: 2$ since in reality this combination is the most relevant combination for surface and binder courses.

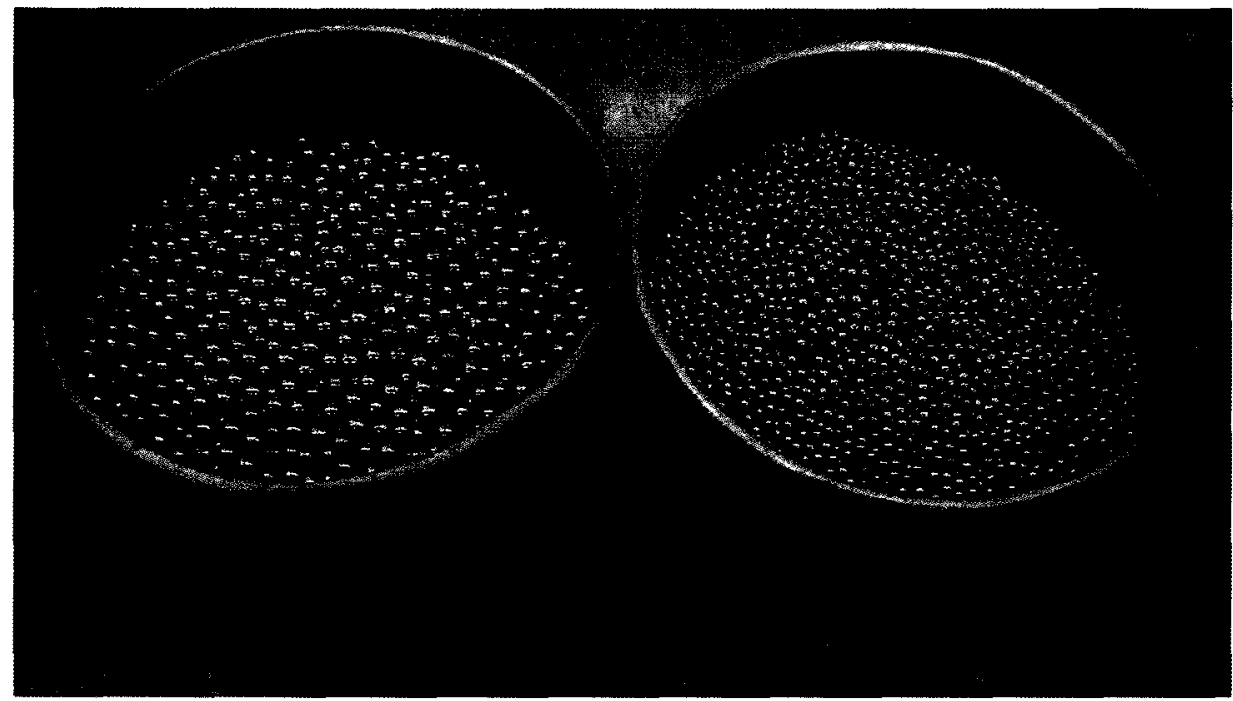

Figure 3.7: Steel ball with diameters of $\varnothing 9.5 \mathrm{~mm}$ ('big') and $\varnothing 5.5 \mathrm{~mm}$ ('small')

Specimens were prepared as follows:

Hot $\left(160^{\circ} \mathrm{C}\right)$ moulds with a diameter of either $\emptyset 100 \mathrm{~mm}$ for Shear Box testing and $\varnothing 150 \mathrm{~mm}$ for LPDS testing and a height of $35 \mathrm{~mm}$ were filled with hot $\left(160^{\circ} \mathrm{C}\right)$ degreased clean steel balls before pouring hot $\left(160^{\circ} \mathrm{C}\right)$ bitumen into the moulds. For each ball size the weight of balls and bitumen needed was determined, in order to make sure that for every specimen the same quantity of components was used. The binder content was approx. 37.5 vol- $\%$. Air void content of the specimens was approx. $0 \%$ by weight. This is different to asphalt concrete. However, when using tack coat locally on a sufficiently small scale a similar situation can be observed and given the fact that the influence of binder was expected to be most relevant, the configuration used in this study was considered the most interesting one. 
The two layered specimens were prepared in two steps: Having produced the first layer, it was allowed to cool down to ambient temperature and then turned over with the original upper side facing down in order to obtain a clear flat interface for the second layer. Since the original upper side was not totally plane it was placed on a bed of wet sand before applying the second layer onto the first.

Figure 3.8 depicts the specimen preparation of a two layered specimen.
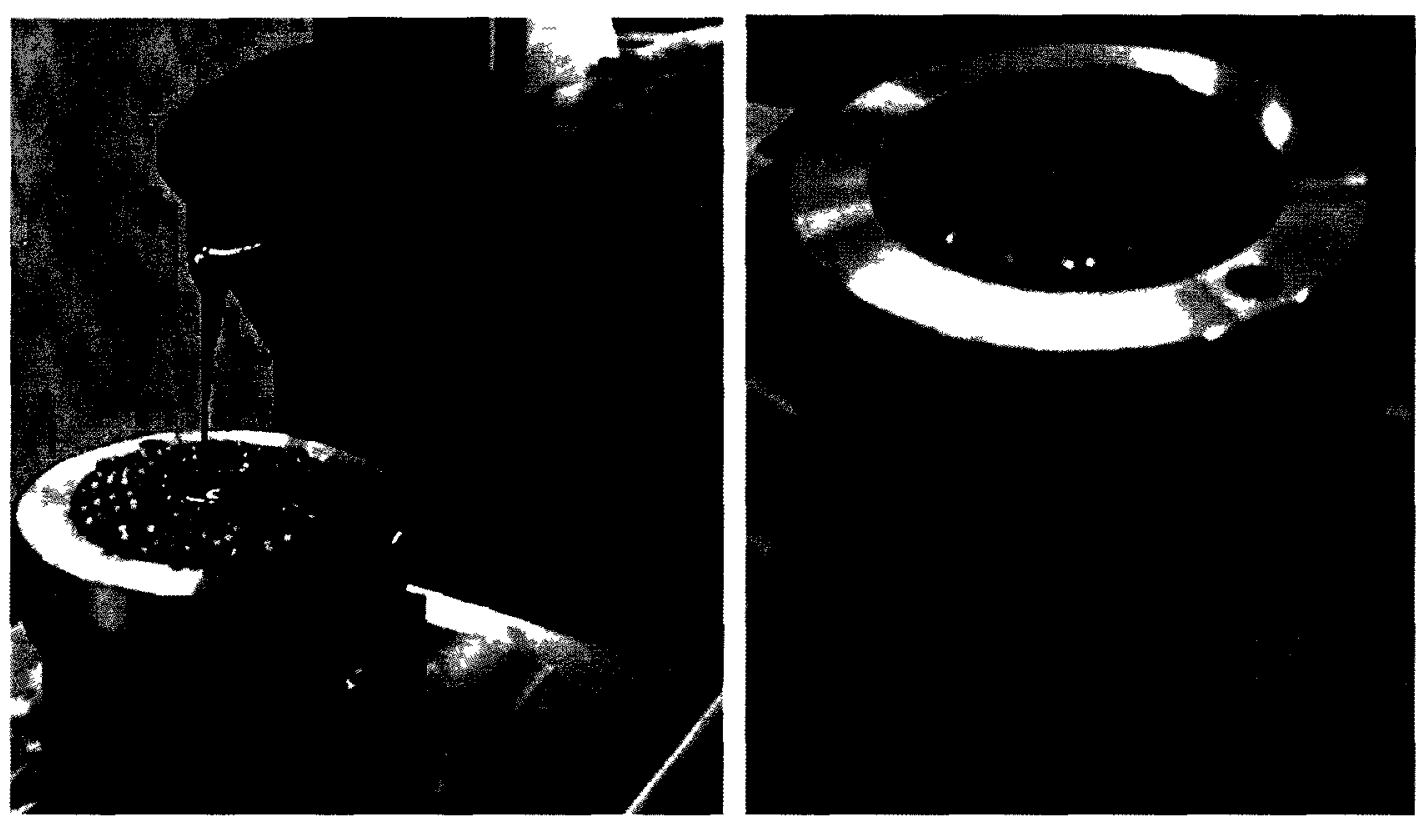

Figure 3.8: Specimen preparation, preparation of two layered specimen

In case of the specimens without binder, the two layers of steel balls were filled into the moulds directly.

Figure 3.9 shows schematic drawings of the different types and combinations of steel balls for interlayer and in-layer shear testing with LPDS and Shear Box. 


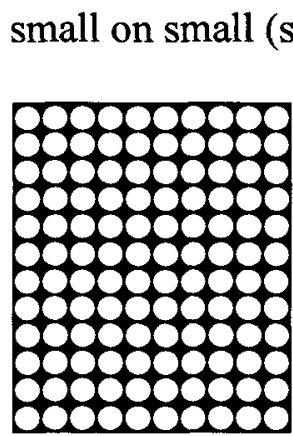

big on big (b/b)

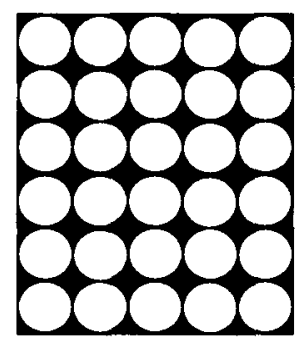

small on big (s/b) big on small (b/s), (only LPDS)
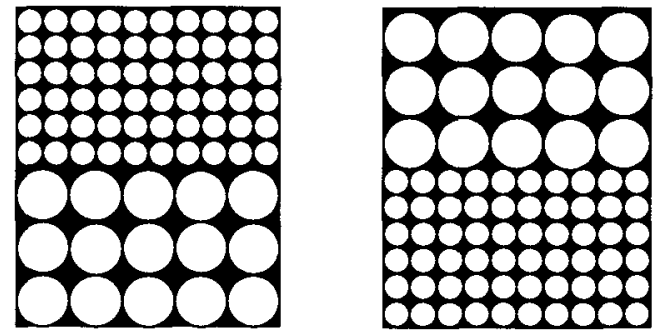

Figure 3.9: Schematic drawing of different combinations, for LPDS and Shear Box testing

In Table 3.1, the test program for both test devices is depicted. Although the combination "big" on "small" (b/s) is for surface and binder courses not relevant in practice it was tested with LPDS (not Shear Box) to investigate its effect on the bond strength.

Table 3.1: Test program for LPDS and Shear Box testing

\begin{tabular}{|l|c|c|c|c|}
\hline $\begin{array}{c}\text { Type of } \\
\text { test }\end{array}$ & No. of tests & $\begin{array}{c}\text { Test speed } \\
{[\mathrm{mm} / \mathrm{min}]}\end{array}$ & $\begin{array}{c}\text { Normal stress } \\
{[\mathrm{MPa}]}\end{array}$ & Layer arrangement \\
\hline \multirow{5}{*}{ LPDS } & $3+3$ & $2.5,50$ & 0.0 & $(\mathrm{~s} / \mathrm{s})$ \\
& $3+3$ & $2.5,50$ & 0.0 & $(\mathrm{~b} / \mathrm{b})$ \\
& $3+3$ & $2.5,50$ & 0.0 & $(\mathrm{~s} / \mathrm{b})$ \\
& $3+3$ & $2.5,50$ & 0.0 & $(\mathrm{~b} / \mathrm{s})$ \\
\hline \multirow{5}{*}{ Shear Box } & $6+2$ & 2.5 & 0.1 & $(\mathrm{~s} / \mathrm{s})+$ no binder \\
& $6+3$ & 2.5 & 0.4 & $(\mathrm{~s} / \mathrm{s})+$ no binder \\
& $6+2$ & 2.5 & 0.1 & $(\mathrm{~b} / \mathrm{b})+$ no binder \\
& $6+3$ & 2.5 & 0.4 & $(\mathrm{~b} / \mathrm{b})+$ no binder \\
& $6+2$ & 2.5 & 0.1 & $(\mathrm{~s} / \mathrm{b})+$ no binder \\
& $6+2$ & 2.5 & 0.4 & $(\mathrm{~s} / \mathrm{b})+$ no binder \\
\hline
\end{tabular}


Shear bond testing was done using the Layer Parallel Shear Test (LPDS) with two different test speeds as well as a Shear Box with varying normal stresses.

Since Shear Box testing allows testing of unbound steel ball configurations, different combinations of steel ball specimens without bitumen were also tested. This was done in order to obtain information on the influence of binder.

In order to evaluate the influence of the deformation rate and for comparison to Shear Box testing, both standard deformation rates of $50 \mathrm{~mm} / \mathrm{min}$ and $2.5 \mathrm{~mm} / \mathrm{min}$ were applied in LPDS testing. As for Shear Box testing, the influence of stress normal to the shear plane was determined applying stresses of $0.1 \mathrm{MPa}$ and $0.4 \mathrm{MPa}$. In case of Shear Box testing, the steel ball combinations were also tested without binder using either 3 or 2 repetitions.

Prior to testing, all specimens were conditioned in a climatic chamber for 8 hours and all tests were conducted at a temperature of $20^{\circ} \mathrm{C}$.

\subsubsection{Materials and methods for testing program 2}

\subsubsection{Effect of moisture}

In this Section the influence of moisture, temperature and pressure on the interlayer shear bond is investigated for three different pavements. In all cases, the interlayer shear properties were evaluated as explained in Section 3.2 and compared for dry and wet conditions.

Moisture has an important influence on the damage process of asphalt pavements. On the one hand, water penetrating through holes and cracks into the pavement structure can weaken or destroy the adhesion between the different pavement layers as shown 
schematically in Figure 3.10, and on the other hand, there is the so-called stripping effect that acts locally within the material but can also lead to a deterioration of the bond.

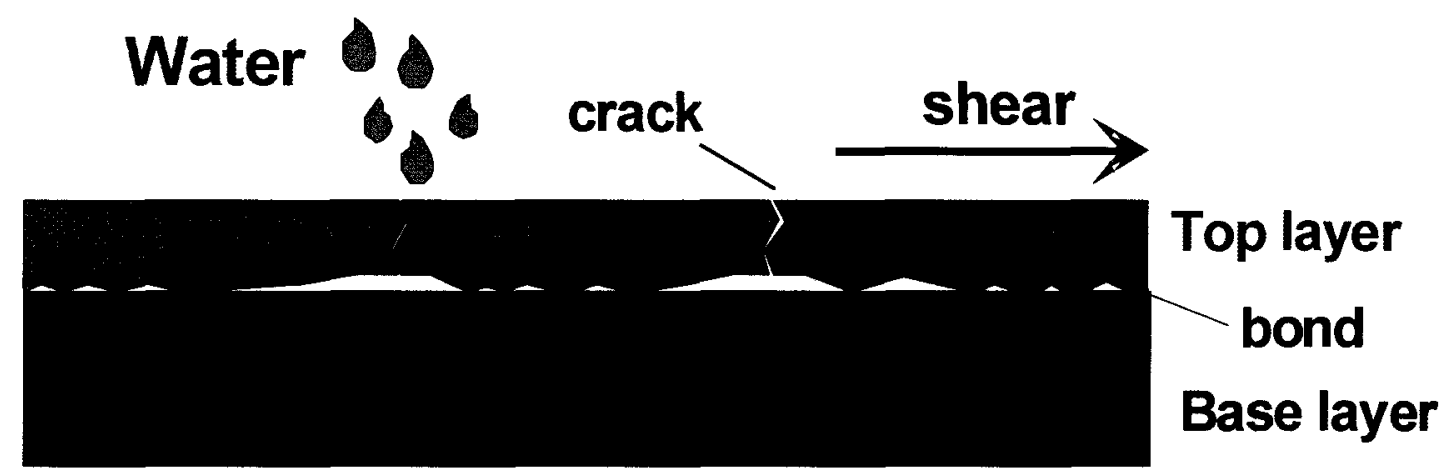

Figure 3.10: Schematic drawing of interfacial bond damage caused by infiltration of water

Stripping, which has been defined as the progressive loss of the adhesive bond between the bituminous binder film and the aggregate surface and/or the loss of cohesive resistance within the asphalt cement (mastic) caused by the action of water (Kiggundu and Roberts, 1988, Mostafa et al., 2003) can lead to a deterioration of the pavement structure including a derogation of the bond between the pavement layers as depicted in Figure 3.11. 


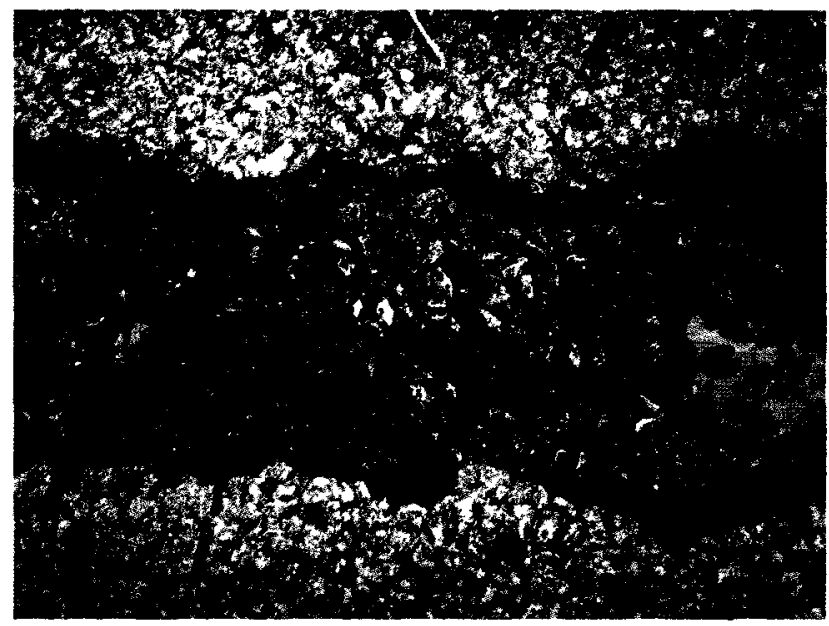

Figure 3.11: Stripping of an open porous asphalt specimen as a result of testing under water using a traffic simulator (Source: Sokolov and Partl, 2007)

It has been shown in an investigation by Raab and Partl (Raab and Partl, 2004) that the influence of moisture had a negative effect on interlayer bonding and that moisture led to a decrease in shear force between $15 \%$ and $27 \%$ as shown in Figure 3.12 . The material in this investigation were field cores from a motorway construction consisting of a SMA 11 surface and a AC 22 base course. For both layers the air void content was about 4 vol- $\%$.

Further, it was found that the reduction in shear force caused by long term water storage of $75 \mathrm{~h}$ at $40^{\circ} \mathrm{C}$ was equal to short term storage of $8 \mathrm{~h}$ combined with a pressure of 0.05 MPa (Lieberman and Raab, 2001, Raab and Partl, 2004). 


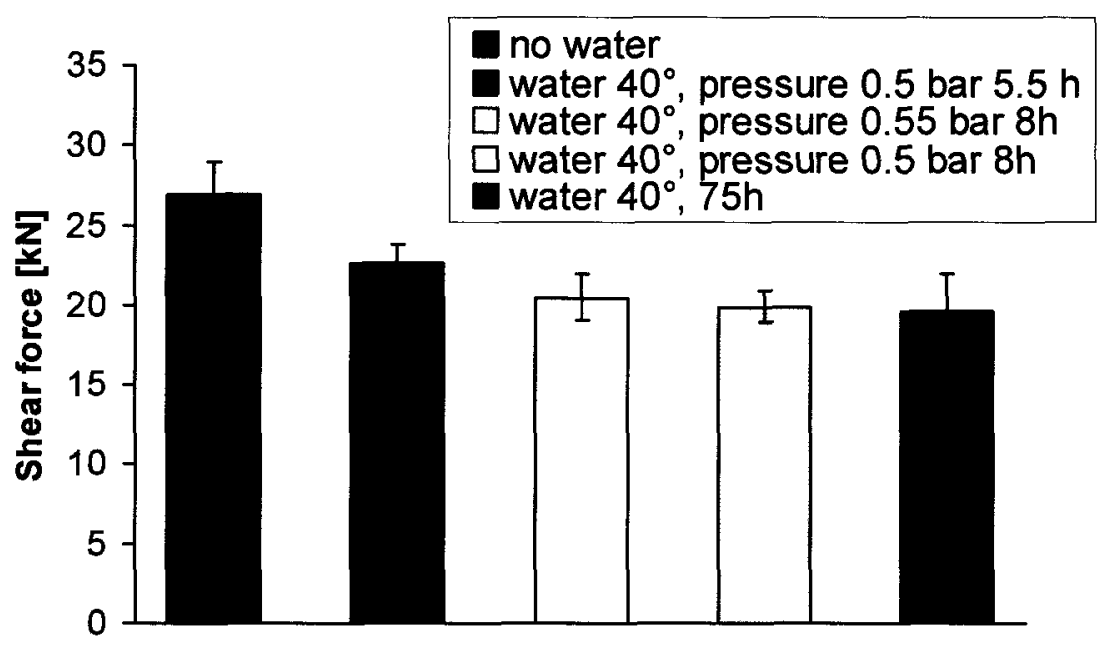

Figure 3.12: Influence of water conditioning on interlayer shear properties

(Source: Raab and Partl, 2004)

The objective of the investigation presented in this thesis was to verify the finding that moisture has a negative effect on the bond force leading to a reduction of the mean maximum shear force up to $30 \%$ for long term water storage or combined pressure and short term water storage at $40^{\circ} \mathrm{C}$. Additionally, the influence on maximum shear stiffness will be investigated. Furthermore, it was assumed that the reduction of shear properties will increased with higher applied temperature. 
In order to verify the above mentioned hypothesis the LPDS shear test and the Shear Box were used. Figure 3.13 shows the experimental program in detail:

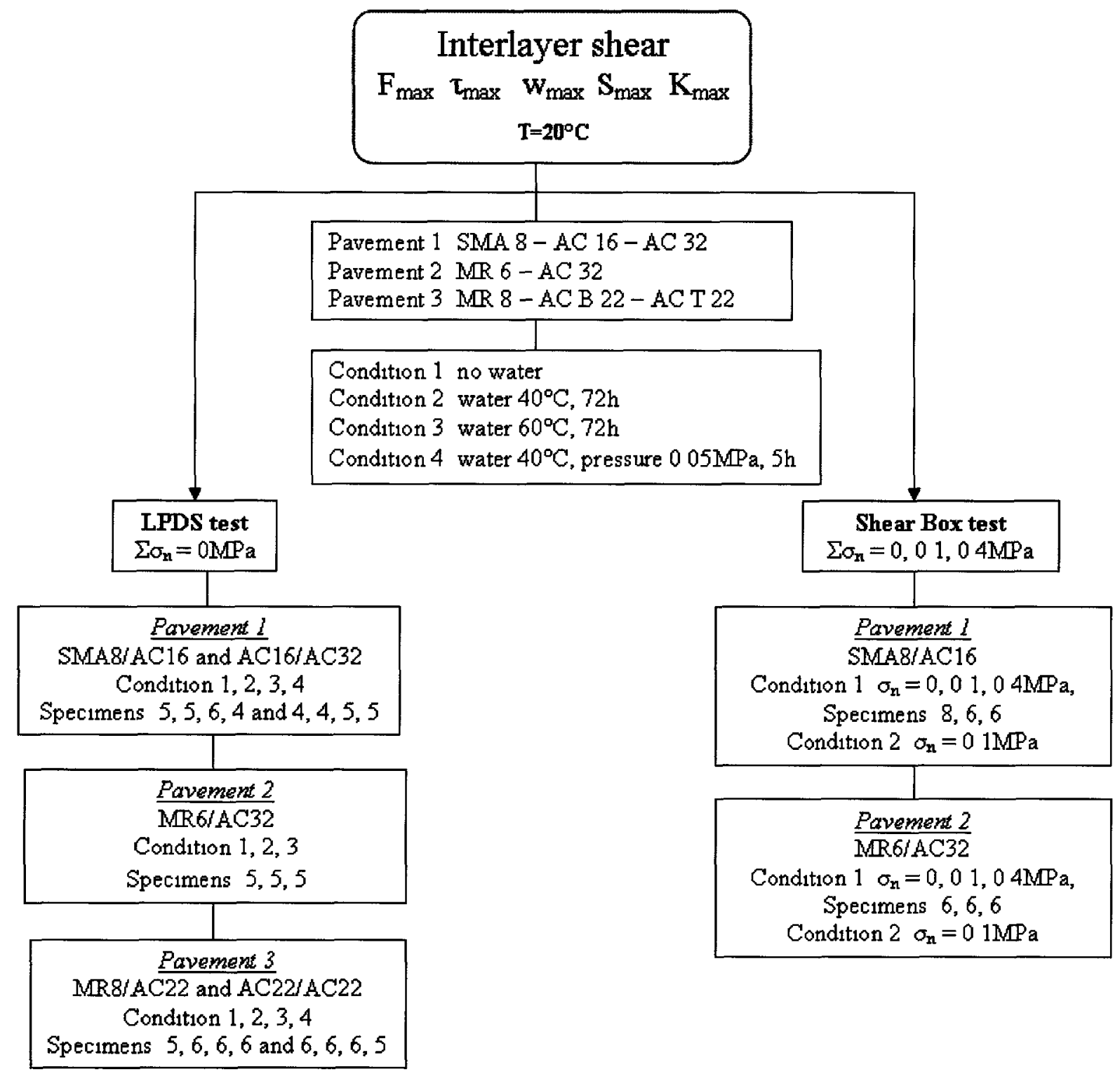

Figure 3.13: Detailed experimental program

Since the material for the previous investigation was taken from an old remaining pavement slab, the investigation was conducted using different up to date pavement 
structures for urban roads and heavy trafficked motorways. The chosen material represented the actual Swiss construction practise favouring relatively open graded low noise surface courses.

The use of urban pavement structures with comparatively thin $(30 \mathrm{~mm})$ surface courses further allowed the application of the Shear Box as an additional measure for the shear properties. For the urban pavement structures (Pavements 1 and 2), material was taken from two or three layered pavement slabs of $1.10 \mathrm{~m}$ by $0.70 \mathrm{~m}$, which had been taken prior to trafficking. The urban pavements had been constructed in 2001 and slabs had been stored thereafter at $20^{\circ} \mathrm{C}$ and $60 \%$ humidity until 2009 . Figure 3.14 shows the removal of the slabs.

Both urban pavements had been constructed according to the Swiss standard (Swiss standard SN 640431b, 1997). The surface courses were thin hot mix surface courses. The surface course of pavement 1 consisted of a stone mastic asphalt SMA with a maximum aggregate size of $8 \mathrm{~mm}$ and the one of the second pavement of a special low noise pavement MR with a maximum aggregate size of $6 \mathrm{~mm}$. The second layer of pavement 1 was an asphalt concrete $\mathrm{AC}$ with a nominal maximum aggregate size of $16 \mathrm{~mm}$. For pavement 2 an asphalt concrete $\mathrm{AC}$ with a nominal maximum aggregate size of $32 \mathrm{~mm}$ was used. Pavement 1 had a third layer consisting of asphalt concrete $\mathrm{AC}$ with a nominal maximum aggregate size of $16 \mathrm{~mm}$. All material characteristics are given in Table 3.2.

In case of LPDS testing the interlayer shear properties were determined at all existing interfaces, while Shear Box testing could only be done between the thin surface and the binder course. 
Table 3.2 :Material characteristics of pavements 1 and 2

\begin{tabular}{|c|c|c|c|c|c|c|}
\hline \multirow{3}{*}{\multicolumn{2}{|c|}{$\begin{array}{l}\text { Pavement No. } \\
\text { Layer No. } \\
\text { Layer Type }\end{array}$}} & \multicolumn{3}{|c|}{1} & \multicolumn{2}{|c|}{2} \\
\hline & & 1 & 2 & 3 & 1 & 2 \\
\hline & & SMA 8 & AC 16 & $\mathrm{AC} 22$ & MR 6 & $\mathrm{AC} 32$ \\
\hline \multicolumn{2}{|c|}{ Layer thickness [mm] } & 30 & 50 & 60 & 30 & 100 \\
\hline \multirow{3}{*}{\multicolumn{2}{|c|}{$\begin{array}{l}\text { Binder Type } \\
\text { Additives } \\
\text { Binder Content [mass-\%] }\end{array}$}} & $70 / 100$ & $55 / 70$ & $55 / 70$ & $70-100$ & $55 / 70$ \\
\hline & & none & none & none & NAF501* & none \\
\hline & & 6.9 & 5.3 & 6.0 & 6.5 & 3.7 \\
\hline \multirow{16}{*}{$\begin{array}{l}\text { Aggregates } \\
\text { Passing [mass-\%] }\end{array}$} & {$[\mathrm{mm}]$} & & & & & \\
\hline & 45.0 & & & & & 100 \\
\hline & 31.5 & & & & & 99.0 \\
\hline & 22.4 & & 100 & & & 78.0 \\
\hline & 16.0 & & 98.3 & 100 & & 65.2 \\
\hline & 11.2 & 100 & 83.6 & 91.1 & 100 & 52.4 \\
\hline & 8.0 & 94.4 & 74.4 & 83.7 & 100 & 45.0 \\
\hline & 5.6 & 56.7 & 55.3 & 57.1 & 98.9 & 36.5 \\
\hline & 4.0 & 36.9 & 43.8 & 41.6 & 68.9 & 20.6 \\
\hline & 2.8 & 29.0 & 36.1 & 33.9 & 33.3 & 25.7 \\
\hline & 2.0 & 25.4 & 31.2 & 29.3 & 24.2 & 21.8 \\
\hline & 1.0 & 20.4 & 22.8 & 22.4 & 19.9 & 15.9 \\
\hline & 0.5 & 17.3 & 17.2 & 17.30 & 17.3 & 12.4 \\
\hline & 0.25 & 15.1 & 13.0 & 14.0 & 14.8 & 9.3 \\
\hline & 0.125 & 12.9 & 10.1 & 11.6 & 11.1 & 6.8 \\
\hline & 0.009 & 11.8 & 8.8 & 10.4 & 9.4 & 5.9 \\
\hline \multicolumn{2}{|l|}{ Marshall Test } & & & & & \\
\hline \multicolumn{2}{|l|}{ Stability [kN] } & 7.9 & 14.6 & 14.0 & 13.0 & 13.0 \\
\hline \multicolumn{2}{|l|}{ Flow [mm] } & 2.3 & 2.2 & 2.5 & 2.7 & 2.5 \\
\hline \multicolumn{2}{|c|}{ Air void content [vol-\%] } & 3.4 & 4.6 & 3.1 & 11.2 & 4.7 \\
\hline \multicolumn{2}{|c|}{$\begin{array}{l}\text { Air void content of cores } \\
\text { [vol-\%] }\end{array}$} & 10.2 & 5.1 & 4.8 & 11.5 & 2.0 \\
\hline
\end{tabular}

* Trinidad lake asphalt and fibres 

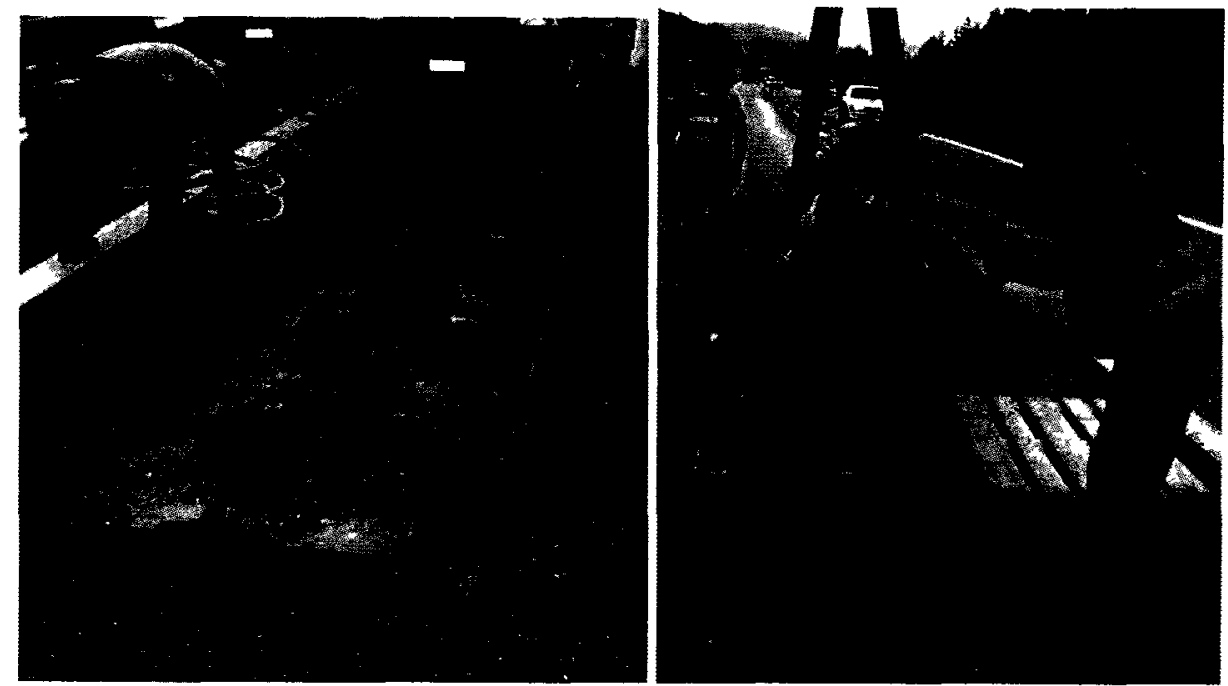

Figure 3.14: Removal of slabs pavement 1 and 2

The material from pavement 3 was taken from a newly constructed motorway in autumn 2009 (see Figure 3.15).
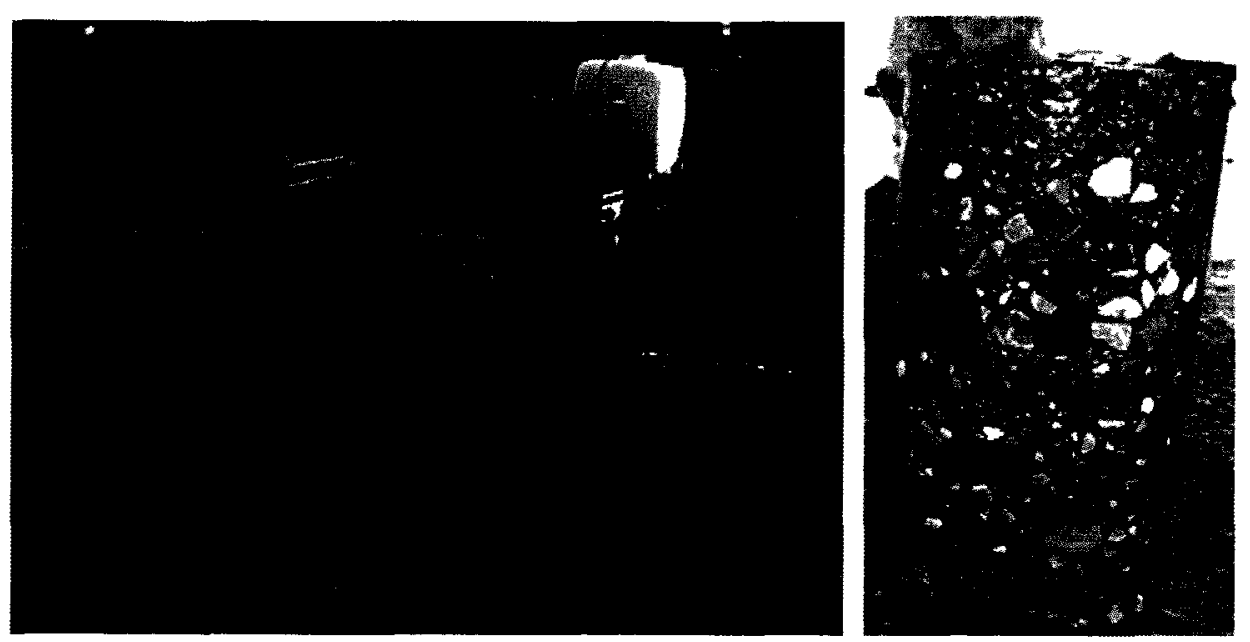

Figure 3.15: Coring of pavement 3

The surface course of pavement 3 consisted of a low noise pavement MR with a maximum aggregate size of $8 \mathrm{~mm}$. The second layer was an asphalt concrete binder course AC B with a nominal maximum aggregate size of $22 \mathrm{~mm}$ and for the third layer an 
asphalt concrete base course AC T with a nominal maximum aggregate size of $22 \mathrm{~mm}$ was used. Since the pavement consisted of three layers, the interlayer shear properties were determined with LPDS at the interface between surface and binder (interface 1) and between binder and base course (interface 2). The material properties of pavement 3 are shown in Table 3.3.

Table 3.3: Material characteristics of pavement 3

\begin{tabular}{|c|c|c|c|c|}
\hline \multirow{3}{*}{\multicolumn{2}{|c|}{$\begin{array}{l}\text { Pavement No. } \\
\text { Layer No. } \\
\text { Layer Type }\end{array}$}} & \multicolumn{3}{|c|}{3} \\
\hline & & 1 & 2 & 3 \\
\hline & & MR 8 & AC B $22 \mathrm{H}$ & $\mathrm{AC} \mathrm{T} 22 \mathrm{H}$ \\
\hline \multicolumn{2}{|c|}{ Layer thickness [mm] } & 40 & 80 & 80 \\
\hline \multicolumn{2}{|c|}{$\begin{array}{l}\text { Binder Type } \\
\text { Additives } \\
\text { Binder Content [mass-\%] }\end{array}$} & $\begin{array}{c}\text { PmB-E } 45 / 80-65 \\
\text { none } \\
6.0\end{array}$ & $\begin{array}{c}\text { PmB-E } 10 / 30-70 \\
\text { none } \\
4.8\end{array}$ & $\begin{array}{c}\text { PmB-E } 10 / 30-70 \\
\text { none } \\
4.4\end{array}$ \\
\hline \multirow{13}{*}{$\begin{array}{l}\text { Aggregates } \\
\text { Passing [mass-\%] }\end{array}$} & {$[\mathrm{mm}]$} & & & \\
\hline & 22.4 & & 100 & 100 \\
\hline & 16.0 & & 98.0 & 98.0 \\
\hline & 11.2 & & 84.0 & 84.0 \\
\hline & 8.0 & 100 & 71.0 & 71.0 \\
\hline & 5.6 & 98.0 & 62.0 & 62.0 \\
\hline & 4.0 & 69.0 & 53.0 & 53.0 \\
\hline & 2.0 & 27.5 & 32.0 & 32.0 \\
\hline & 1.0 & 23.5 & 21.5 & 21.5 \\
\hline & 0.5 & 19.0 & 15.0 & 15.0 \\
\hline & 0.25 & 16.0 & 12.0 & 12.0 \\
\hline & 0.125 & 12.5 & 9.5 & 9.5 \\
\hline & 0.0063 & 10.0 & 7.0 & 7.0 \\
\hline \multirow{3}{*}{\multicolumn{2}{|c|}{$\begin{array}{l}\text { Marshall Test } \\
\text { Stability }[\mathrm{kN}] \\
\text { Flow }[\mathrm{mm}] \\
\text { Air void content }[\mathrm{vol}-\%] \\
\end{array}$}} & 10.1 & 15.0 & 15.0 \\
\hline & & 3.1 & 4.5 & 4.5 \\
\hline & & 6.5 & 5.5 & 5.5 \\
\hline \multicolumn{2}{|c|}{$\begin{array}{l}\text { Air void content of cores } \\
\text { [vol-\%] }\end{array}$} & 10.2 & 4.3 & 4.7 \\
\hline
\end{tabular}


For shear testing, the LPDS test device was used for all three pavements and all existing interfaces. The investigation of the shear properties between the first and second layer of pavements 1 and 2 without and with water conditioning at $40^{\circ} \mathrm{C}$ (without pressure) was also done using the Shear Box. In case of LPDS shear testing the air void content was determined for every single core and layer.

In order to evaluate the influence of moisture on the interlayer shear properties, the following conditions according to Table 3.4 were chosen.

Table 3.4: Test conditions

\begin{tabular}{|c|c|c|c|}
\hline Condition No. & $\begin{array}{c}\text { Water temperature } \\
{\left[{ }^{\circ} \mathrm{C}\right]}\end{array}$ & Storage time $[\mathrm{h}]$ & Pressure [MPa] \\
\hline 1 & no water & none & none \\
2 & 40 & 72 & none \\
3 & 60 & 72 & none \\
4 & 40 & 5 & 0.05 \\
\hline
\end{tabular}

In case of pure water conditioning (conditions No. 2 and No. 3), the specimens were first stored in a water bath at $40^{\circ} \mathrm{C}$ or $60^{\circ} \mathrm{C}$, where they remained for the given amount of time according to Table 3.4. After this, they were sealed in plastic bags to prevent the evaporation of moisture and conditioned at $20^{\circ} \mathrm{C}$ for at least $8 \mathrm{~h}$ in a temperature chamber.

For the pressure conditioning (condition No. 4) a special test set-up was used. To allow the water action between the layers, a hole of $25 \mathrm{~mm}$ was drilled onto the interface of each core to be tested and a short length of pipe was glued inside. In order to ensure that the glue would not seal the pipe off, a small plastic ring was inserted. The pipes were 
connected to a pump by hoses, as seen in Figures 3.16 and 3.17. The specimens were then placed in a bath containing water at $40^{\circ} \mathrm{C}$ and water pressure of $0.05 \mathrm{MPa}$ was applied to the interface. After conditioning, the specimens were again put into plastic bags and stored for at least $8 \mathrm{~h}$ in a temperature chamber at the LPDS test temperature of $20^{\circ} \mathrm{C}$.

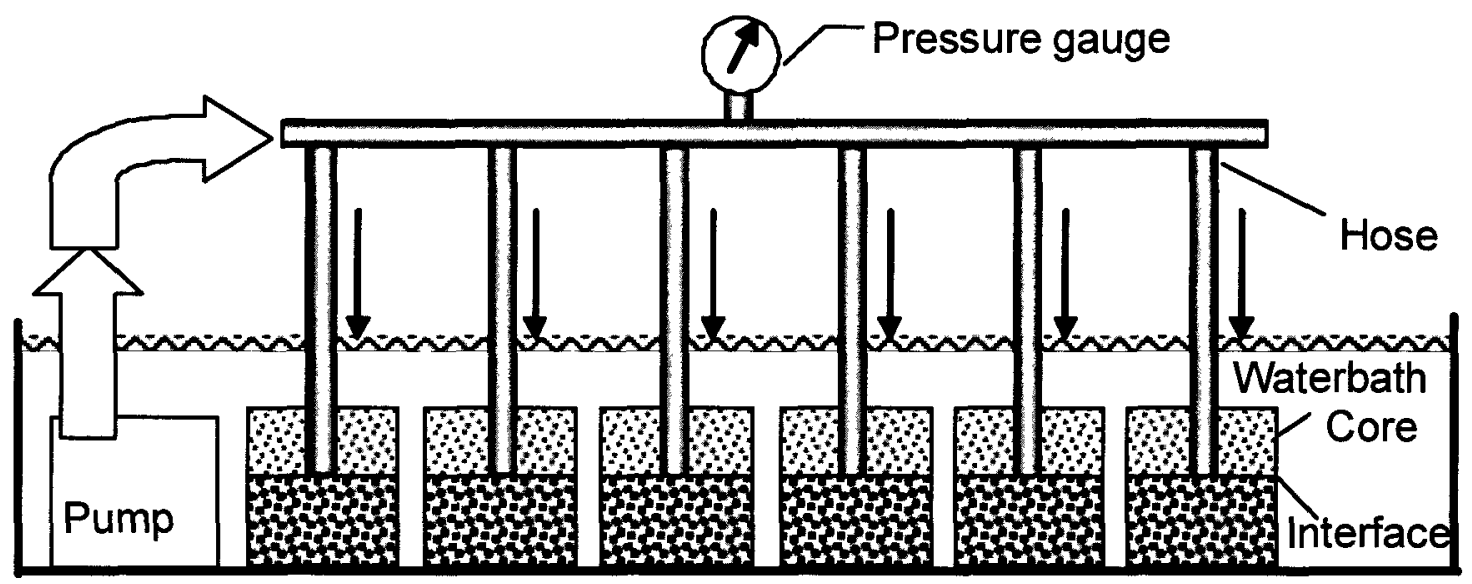

Figure 3.16: Water-pressure experiment set-up (schematic)

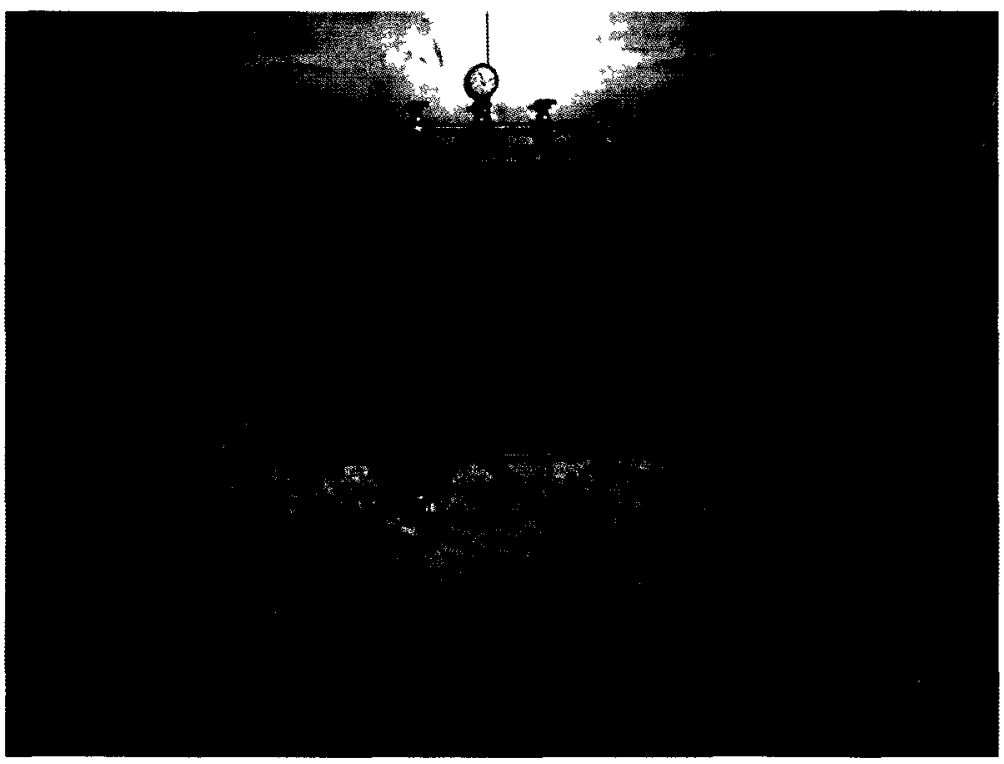

Figure 3.17: Water-pressure experiment set-up (photograph) 
Apart from pavement 2, which, because of a lack of material, could not be tested at condition No. 4 (pressure) all pavements were tested at all interfaces and all test conditions using LPDS. As mentioned earlier, the first interface of pavements 1 and 2 were additionally tested with the Shear Box for conditions No. 1 and No. 2.

\subsubsection{Effect of low temperature}

In the course of an investigation to characterise the interlayer behaviour of double layered asphalt pavement specimens where co-axial shear tests (CAST) and Leutner shear tests (LPDS) were used to determine complex modulus, shear stiffness and shear bond it was found that from both CAST and LPDS results, the ranking of overall stiffness in double layered asphalt specimens was different at different test temperatures and frequencies (Sokolov et al., 2005, Kim et al., 2010).

Based on the LPDS results it was concluded that interlayer shear behaviour should be investigated at different temperatures and not just at one temperature. In order to confirm this finding, to draw conclusions and to give recommendations, a new series of shear tests was conducted at temperatures of $+20^{\circ} \mathrm{C}, 0 \mathrm{C}^{\circ}$ and $-20^{\circ} \mathrm{C}$.

This Section will present both the shear test results from the earlier investigation and the results from the new series of shear tests conducted at temperatures of $+20^{\circ} \mathrm{C}$, $0 \mathrm{C}^{\circ}$ and $-20^{\circ} \mathrm{C}$.

In both cases, specimens were cored from two slabs of a four-layered Swiss motorway pavement. The locations where the slabs had been taken were only few kilometres apart and were of the same design. The pavement consisted of a stone mastic asphalt surface course SMA 11 with a nominal maximum aggregate size of $11 \mathrm{~mm}$, an 
asphalt concrete binder course AC 22, and an asphalt concrete base course AC 32 with nominal maximum aggregate sizes of $22 \mathrm{~mm}$ and $32 \mathrm{~mm}$ respectively, according to the Swiss Standard SN 640420. The subgrade material consisted of asphalt concrete AC S 22 with a nominal maximum aggregate size of $22 \mathrm{~mm}$ (see Figure 3.18, right).

The pavement of slab 1 and 2 was constructed in 1998. Slab 1 was extracted in 2006, while slab 2 had already been removed prior to trafficking in 1998 (see Figure 3.18 , left). The daily traffic volume on the motorway increased from about 52'000 in 2000 to $60^{\prime} 000$ in 2005 , while the percentage of heavy vehicles in 2005 was given with $8.6 \%$.

In case of slab 1, LPDS interlayer shear tests at $20^{\circ} \mathrm{C}$ were already conducted in 2006. Both the in-layer LPDS shear testing and LPDS interlayer shear testing at 0 and $20^{\circ} \mathrm{C}$ were carried out in 2009 using cores from the same pavement slab, which had been stored under ambient room temperature condition since 2006. All testing on slab 2 was conducted in 2009. Table 3.5 summarises the information on pavement construction and removal, time of testing and traffic. 

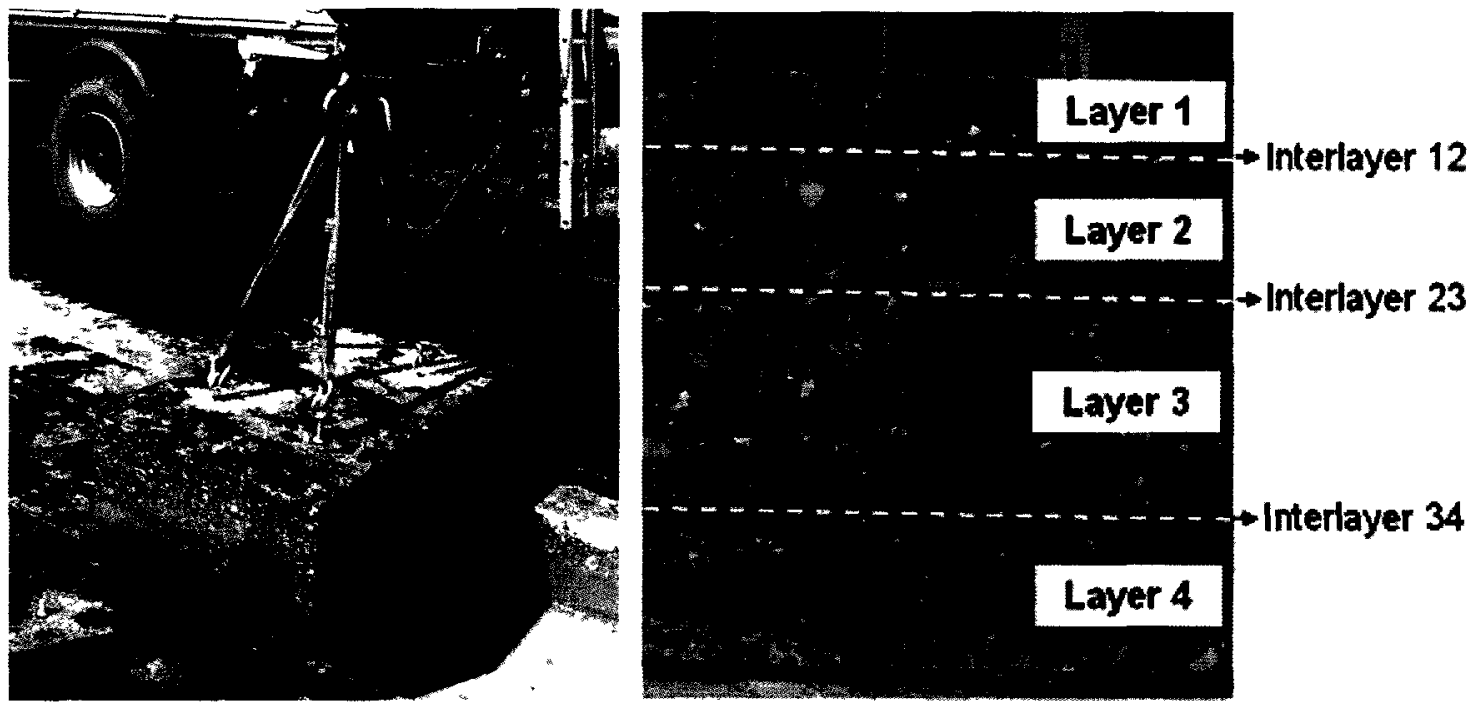

Figure 3.18: Slab removal and details of layers and material

Table 3.5: Information on pavement, construction, removal and testing

\begin{tabular}{|l|c|c|cc|c|}
\hline & Year of construction & Year of removal & \multicolumn{2}{|c|}{ Year of testing } & $\begin{array}{c}\text { Traffic } \\
\text { [vehicle/day] }\end{array}$ \\
\hline Slab 1 & 1998 & 2006 & 2006 & 2009 & 0 \\
\hline Slab 2 & 1998 & 1998 & 2009 & 2009 & $52000-60000$ \\
\hline
\end{tabular}

Further details of the mixtures are given in Table 3.7. Note that Layer 1 contained natural asphalt and Layers 2 and 3 were composed of SBS polymer modified binder. Binder and air void content results, given in Table 3.6, represent results of an investigation on slab 2, carried out in 1998 immediately after construction. The values in the table can be taken as representative for all other slabs.

In the following, the interfaces between Layer 1, Layer 2, Layer 3, and Layer 4 will be denoted by Interlayer 12, Interlayer 23 and Interlayer 34. 
Table 3.6: Pavement design (values of slab 2)

\begin{tabular}{|c|c|c|c|c|c|}
\hline Layers & Mixture type & $\begin{array}{c}\text { Binder grade } \\
\text { [pen] }\end{array}$ & $\begin{array}{c}\text { Binder } \\
\text { content } \\
\text { [mass-\%] }\end{array}$ & $\begin{array}{c}\text { Air void } \\
{[\text { vol-\%] }}\end{array}$ & $\begin{array}{c}\text { Thickness } \\
{[\mathrm{mm}]}\end{array}$ \\
\hline Layer 1 & SMA 11 & $\begin{array}{c}55 / 70+ \\
\text { Trinidad lake } \\
\text { asphalt+fibres }\end{array}$ & 5.8 & 3.2 & 40 \\
\hline Layer 2 & AC 22 & Mixelf 10/20 & 4.8 & 4.0 & 70 \\
\hline Layer 3 & AC 32 & Mixelf 10/20 & 4.8 & 4.3 & 120 \\
\hline Layer 4 & AC S 22 & $80 / 100$ & 4.4 & 6.5 & 95 \\
\hline
\end{tabular}

\subsubsection{Effect of gap width}

This Section presents load-deformation properties for different gap widths focusing on maximum stiffness values and maximum shear stress with corresponding shear deformation. In addition to the shear characteristics at the interface, shear properties were also determined for the material itself in order to discuss the difference between in-layer and interlayer shear behaviour, taking into consideration also optical measurement results of an earlier investigation (Raab and Partl, 1999).

It is important to note that the investigation presented here does not claim to provide a broad statistical data basis but intends to improve the phenomenological understanding of the mechanisms of interlayer shear testing for establishing and developing common standards. It also tries to gather evidence for the following two hypotheses:

a) The influence of gap width becomes more important in case of weak interlayer shear bond. 
b) In case of different maximum aggregate sizes of two comparable layers, the layer with the smaller aggregate size should be on top of the one with the larger aggregate size for improved interlayer shear bond

For the investigation of the shear bond characteristics, cores from a four layered Swiss motorway pavement were taken (see Figure 3.19).

The pavement consisted of a stone mastic surface course material SMA with a nominal maximum aggregate size of $11 \mathrm{~mm}$ placed on an asphalt concrete binder course material AC B 22 and an asphalt concrete base course material AC T 32 with nominal maximum aggregate sizes of $22 \mathrm{~mm}$ and $32 \mathrm{~mm}$ respectively, according to the Swiss standard SN 640420. The subgrade material was asphalt concrete AC S 22 with a nominal maximum aggregate size of $22 \mathrm{~mm}$. Further details of the mixtures are given in Table 3.7.

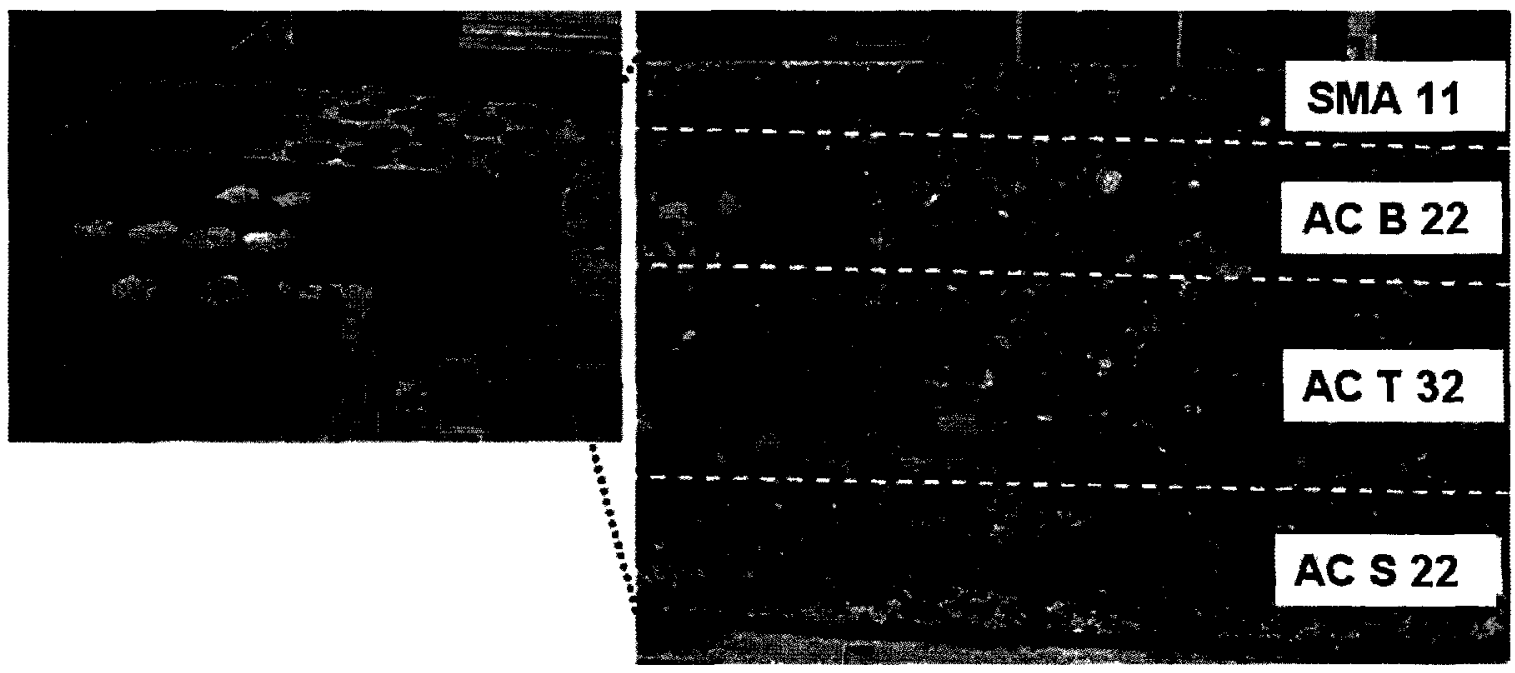

Figure 3.19: Details of layers and material 
Table 3.7: Mixture Characteristics

\begin{tabular}{|l|c|c|c|c|}
\hline $\begin{array}{c}\text { Mixture } \\
\text { type }\end{array}$ & $\begin{array}{c}\text { Binder grade } \\
\text { [pen] }\end{array}$ & $\begin{array}{c}\text { Binder content } \\
{[\text { mass-\%] }}\end{array}$ & $\begin{array}{c}\text { Air void content } \\
{[\text { vol-\%] }}\end{array}$ & $\begin{array}{c}\text { Layer thickness } \\
{[\mathrm{mm}]}\end{array}$ \\
\hline SMA 11 & $\begin{array}{c}80 / 100 \text { and Trindad } \\
\text { lake asphalt }\end{array}$ & 6.4 & 4.7 & 40 \\
\hline AC B 22 & $55 / 70$ & 3.9 & 4.1 & 80 \\
\hline AC T 32 & $55 / 70$ & 3.6 & 3.8 & 105 \\
\hline AC S 22 & $80 / 100$ & 3.3 & 6.2 & 90 \\
\hline
\end{tabular}

As opposed to the other shear tests in this research and the optical measurements described later, when the LPDS device (see Figure 3.1) was used, the tests were conducted with the original Leutner shear test equipment shown in Figure 3.20 because gap width could be manipulated more easily. That both test devices delivered comparable results had been shown in an earlier study (Raab and Partl, 1999).

Although this shear device according to the original setup has no gap between the shearing rings, the gap width could be modified for test purpose using a bolt spacer. In addition to the original $0 \mathrm{~mm}$, gap widths of $2.5 \mathrm{~mm}$ and $5.0 \mathrm{~mm}$ were used for testing.

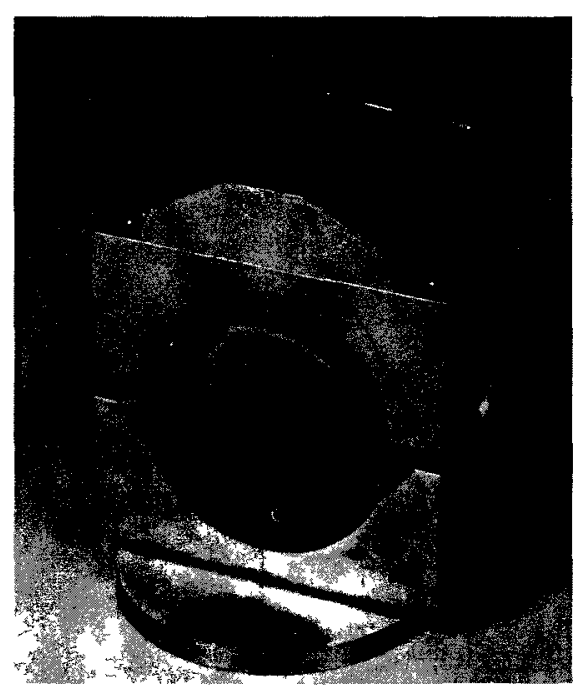

Figure 3.20: Leutner shear test equipment 
The tests were carried out at standard loading rate of $50 \mathrm{~mm} / \mathrm{min}$ and standard temperature of $20^{\circ} \mathrm{C}$ as described earlier.

Both, the shear characteristics at the interface and within the individual layers (inlayer shear testing) were determined in order to see the influence of the gap width. For every gap width configuration, between 5 and 7 cores were tested. Testing was done by successively shearing at the interfaces of each core. The in-layer shear tests for the lower layers were conducted on the remaining core parts, while the surface layers were glued onto concrete cores to enlarge the specimens and enable the testing of layer thicknesses beneath $30 \mathrm{~mm}$. 


\section{CHAPTER 4}

\section{Results of Experimental Investigation}

\subsection{Introduction}

In this Chapter the results and the experimental investigation for testing program 1 and 2 are presented.

\subsection{Results of the idealisation of the bond (testing program 1)}

\subsubsection{LPDS testing, general remarks}

Table 4.1 summarises the LPDS interlayer shear results. It shows the single and the mean values (bold) of 3 tests for maximum shear force $F_{L P D S}$, shear stress $\tau_{L P D S}$, shear reaction modulus $\mathrm{K}_{\mathrm{LPDS}}$ and shear deformation $\mathrm{w}_{\mathrm{LPDS}}$ at maximum shear force for a temperature of $20^{\circ} \mathrm{C}$. The standard deviations and the coefficient of variation $\mathrm{CV}[\%]$ are also given. 
Table 4.1: Results of LPDS interlayer shear testing, single values, average (bold), standard deviation in brackets and coefficient of variation CV [\%]

\begin{tabular}{|c|c|c|c|c|c|c|c|c|c|c|}
\hline & $\begin{array}{l}F_{\text {LPDS }} \\
{[\mathrm{kN}]}\end{array}$ & $\begin{array}{l}\tau_{\text {LPPS }} \\
\text { [MPa] }\end{array}$ & $\begin{array}{l}\mathbf{w}_{\text {LPDS }} \\
{[\mathrm{mm}]}\end{array}$ & $\begin{array}{c}S_{\mathrm{LPDS}} \\
{[\mathrm{kN} / \mathrm{mm}]}\end{array}$ & $\begin{array}{c}\mathrm{K}_{\mathrm{LPDS}} \\
{[\mathrm{MPa} / \mathrm{mm}]}\end{array}$ & $\begin{array}{l}\mathrm{F}_{\text {LPDS }} \\
{[\mathrm{kN}]}\end{array}$ & $\begin{array}{c}\tau_{\text {LPDS }} \\
\text { [MPa] }\end{array}$ & $\begin{array}{l}\mathrm{w}_{\text {LPDS }} \\
{[\mathrm{mm}]}\end{array}$ & $\begin{array}{c}\mathrm{S}_{\mathrm{LPDS}} \\
{[\mathrm{kN} / \mathrm{mm}]}\end{array}$ & $\begin{array}{c}\mathrm{K}_{\mathrm{LPDS}} \\
{[\mathrm{MP} / \mathrm{mm}]}\end{array}$ \\
\hline \multicolumn{6}{|c|}{ Interlayer, $50 \mathrm{~mm} / \mathrm{min}$} & \multicolumn{5}{|c|}{ Interlayer, $2.5 \mathrm{~mm} / \mathrm{min}$} \\
\hline \multirow{6}{*}{$\mathrm{s} / \mathrm{s}$} & 18.5 & 1.05 & 1.04 & 21.0 & 1.2 & 14.7 & 0.84 & 1.7 & 10.3 & 0.6 \\
\hline & 20.2 & 1.14 & 1.41 & 23.8 & 1.3 & 14.8 & 0.83 & 1.5 & 11.2 & 0.6 \\
\hline & 18.2 & 1.03 & 1.48 & 17.9 & 1.0 & 14.6 & 0.83 & 1.9 & 8.9 & 0.5 \\
\hline & 19.0 & 1.1 & 1.31 & 20.9 & 1.2 & 14.7 & 0.8 & 1.7 & 10.1 & 0.6 \\
\hline & (1.1) & $(0.06)$ & $(0.24)$ & (3.0) & $(0.2)$ & $(0.1)$ & $(0.006)$ & $(0.12)$ & $(1.2)$ & $(0.1)$ \\
\hline & $5.8 \%$ & $5.5 \%$ & $18.3 \%$ & $14.4 \%$ & $14.1 \%$ & $0.7 \%$ & $0.7 \%$ & $7.1 \%$ & $11.9 \%$ & $11.4 \%$ \\
\hline \multirow{6}{*}{$\mathrm{b} / \mathrm{b}$} & 20.3 & 1.15 & 1.14 & 16.1 & 0.9 & 13.2 & 0.74 & 1.8 & 10.5 & 0.6 \\
\hline & 16.2 & 0.92 & 1.43 & 22.5 & 1.3 & 11.3 & 0.63 & 1.8 & 6.9 & 0.4 \\
\hline & 17.2 & 0.97 & 0.92 & 23.8 & 1.3 & 11.2 & 0.62 & 1.2 & 11.8 & 0.7 \\
\hline & 17.9 & 1.0 & 1.16 & 20.8 & 1.2 & 11.9 & 0.7 & 1.6 & 9.7 & 0.6 \\
\hline & (2.1) & $(0.12)$ & $(0.26)$ & (4.1) & $(0.2)$ & (1.1) & $(0.06)$ & $(0.36)$ & $(2.5)$ & $(0.1)$ \\
\hline & $11.7 \%$ & $12.0 \%$ & $22.4 \%$ & $19.7 \%$ & $19.8 \%$ & $9.2 \%$ & $10.0 \%$ & $22.7 \%$ & $25.8 \%$ & $26.1 \%$ \\
\hline \multirow{6}{*}{$\mathrm{s} / \mathrm{b}$} & 22.0 & 1.24 & 1.40 & 18.5 & 1.0 & 13.6 & 0.80 & 1.72 & 11.7 & 0.7 \\
\hline & 21.9 & 1.24 & 1.48 & 20.6 & 1.2 & 16.0 & 0.91 & 1.70 & 11.4 & 0.6 \\
\hline & 18.0 & 1.02 & 1.05 & 19.2 & 1.1 & 18.6 & 1.05 & 1.60 & 11.9 & 0.7 \\
\hline & 20.6 & 1.2 & 1.31 & 19.4 & 1.1 & 16.2 & 0.9 & 1.7 & 11.7 & 0.7 \\
\hline & (2.3) & $(0.13)$ & $(0.23)$ & (1.1) & $(0.1)$ & (2.3) & $(0.13)$ & $(0.06)$ & $(0.22)$ & $(0.01)$ \\
\hline & $11.2 \%$ & $10.8 \%$ & $17.6 \%$ & $5.7 \%$ & $5.5 \%$ & $14.2 \%$ & $14.4 \%$ & $3.5 \%$ & $1.8 \%$ & $2.2 \%$ \\
\hline \multirow{6}{*}{$\mathrm{b} / \mathrm{s}$} & 16.5 & 0.93 & 0.9 & 22.1 & 1.3 & 12.9 & 0.73 & 1.6 & 11.5 & 0.7 \\
\hline & 17.2 & 0.97 & 0.9 & 20.4 & 1.2 & 13.8 & 0.78 & $2 . .0$ & 10.3 & 0.6 \\
\hline & 15.6 & 0.88 & 0.9 & 22.1 & 1.3 & 12.3 & 0.73 & 1.7 & 10.1 & 0.6 \\
\hline & 16.4 & 0.9 & 0.9 & 21.5 & 1.2 & 13.2 & 0.75 & 1.8 & 10.6 & 0.6 \\
\hline & $(0.8)$ & $(0.05)$ & $(0.04)$ & (1.0) & $(0.1)$ & $(0.5)$ & $(0.03)$ & $(0.2)$ & $(0.8)$ & $(0.04)$ \\
\hline & $4.9 \%$ & $5.6 \%$ & $4.4 \%$ & $4.7 \%$ & $4.6 \%$ & $3.8 \%$ & $4.0 \%$ & $11.1 \%$ & $7.5 \%$ & $7.1 \%$ \\
\hline
\end{tabular}

Table 4.1 summarises the LPDS interlayer shear results. It shows the single and the mean values (bold) of 3 tests for maximum shear force $F_{L P D S}$, shear stress $\tau_{L P D S}$, shear reaction modulus $\mathrm{K}_{\mathrm{LPDS}}$ and shear deformation $\mathrm{w}_{\mathrm{LPDS}}$ at maximum shear force for a temperature of $20^{\circ} \mathrm{C}$. The standard deviations and the coefficient of variation $\mathrm{CV}[\%]$ are also given. 
However, regarding statistical evaluation, the limited amount of tests has to be kept in mind.

Additional to the deformation rate of $50 \mathrm{~mm} / \mathrm{min}$ which is standard for LPDS testing, a deformation rate of $2.5 \mathrm{~mm} / \mathrm{min}$ was also selected. This was done to evaluate the influence of test speed and to compare the results with the Shear Box test, which is performed at this test speed.

The coefficient of variation CV [\%] for shear force and shear stress lies between $0.7 \%$ and $14 \%$ and has a mean value of $8.4 \%$. According to the $\mathrm{CV}$, the steel ball combinations $\mathrm{s} / \mathrm{s}$ and $\mathrm{b} / \mathrm{s}$ have a lower scatter for shear force and stress than the combinations $\mathrm{b} / \mathrm{b}$ and $\mathrm{s} / \mathrm{b}$.

For the shear stiffness, the coefficient of variation CV is slightly higher, showing a mean value of $11.4 \%$ and single values from $2.2 \%$ to $26 \%$. The same applies for the deformation, with a coefficient of variation $\mathrm{CV}$ between $3.5 \%$ and $23 \%$.

\subsubsection{LPDS testing, in-layer and interlayer testing}

Table 4.2 shows the LPDS in-layer shear results. It shows the single and the mean values (bold) of 3 tests for maximum shear force $F_{L P D S}$, shear stress $\tau_{L P D S}$, shear reaction modulus $K_{\mathrm{LPDS}}$ and shear deformation $\mathrm{w}_{\mathrm{LPDS}}$ at maximum shear force for a temperature of $20^{\circ} \mathrm{C}$. The standard deviations and the coefficient of variation $\mathrm{CV}[\%]$ are also given.

The comparison between in-layer and interlayer curves in Figure 4.1 reveals the difference in the failure behaviour. While the interlayer specimens failed suddenly, the in layer specimens still had some reserve in terms of deformation and shear force (stress) after the first damage occurred. The first peak for the shear force seemed to be a little bit 
higher in case of in layer testing for the small balls compared with the behaviour for the big balls. Overall, the in-layer maximum shear forces are about $10 \%$ higher than the interlayer ones. The in-layer shear stiffness is in both cases less than the interlayer stiffness, a fact that was already observed during an earlier study on asphalt concrete (Partl and Raab, 1999).

Table 4.2 - Results of LPDS in-layer shear testing, single values, average (bold), standard deviation in brackets and coefficient of variation CV [\%]

\begin{tabular}{|c|c|c|c|c|c|}
\hline & $\begin{array}{c}\mathrm{F}_{\text {LPDS }} \\
{[\mathrm{kN}]}\end{array}$ & $\begin{array}{c}\tau_{\mathrm{LPDS}} \\
{[\mathrm{MPa}]}\end{array}$ & $\begin{array}{c}\mathrm{w}_{\mathrm{LPDS}} \\
{[\mathrm{mm}]}\end{array}$ & $\begin{array}{c}\mathrm{S}_{\mathrm{LPDS}} \\
{[\mathrm{kN} / \mathrm{mm}]}\end{array}$ & $\begin{array}{c}\mathrm{K}_{\mathrm{LPDS}} \\
{[\mathrm{MPa} / \mathrm{mm}]}\end{array}$ \\
\hline \multicolumn{6}{|c|}{ In-layer, 50 $\mathrm{mm} / \mathrm{min}$} \\
\hline & 23.8 & 1.3 & 3.6 & 17.2 & 1.0 \\
& 20.9 & 1.2 & 1.8 & 15.1 & 0.9 \\
& 24.0 & 1.3 & 2.5 & 16.2 & 0.9 \\
& $\mathbf{2 2 . 9}$ & $\mathbf{1 . 3}$ & $\mathbf{2 . 6}$ & $\mathbf{1 6 . 2}$ & $\mathbf{0 . 9}$ \\
& $(1.72)$ & $(0.10)$ & $(0.94)$ & $(1.1)$ & $(0.06)$ \\
& $7.5 \%$ & $7.6 \%$ & $36.2 \%$ & $0.6 \%$ & $0.6 \%$ \\
\hline \multirow{6}{*}{$\mathrm{b}$} & 19.4 & 1.1 & 1.3 & 15.0 & 0.8 \\
& 20.2 & 1.1 & 1.4 & 22.6 & 1.3 \\
& 19.1 & 1.1 & 2.1 & 24.5 & 1.4 \\
& $\mathbf{1 9 . 6}$ & $\mathbf{1 . 1}$ & $\mathbf{1 . 6}$ & $\mathbf{2 0 . 7}$ & $\mathbf{1 . 2}$ \\
& $(0.56)$ & $(0.03)$ & $(0.45)$ & $(5.0)$ & $(0.28)$ \\
& $2.9 \%$ & $2.8 \%$ & $28.1 \%$ & $24.1 \%$ & $23.3 \%$ \\
\hline
\end{tabular}

Furthermore, it is interesting to note that in-layer specimens have higher max. deformation which means that they require clearly higher fracture energy than interlayer specimens which have less potential to dissipate energy. 


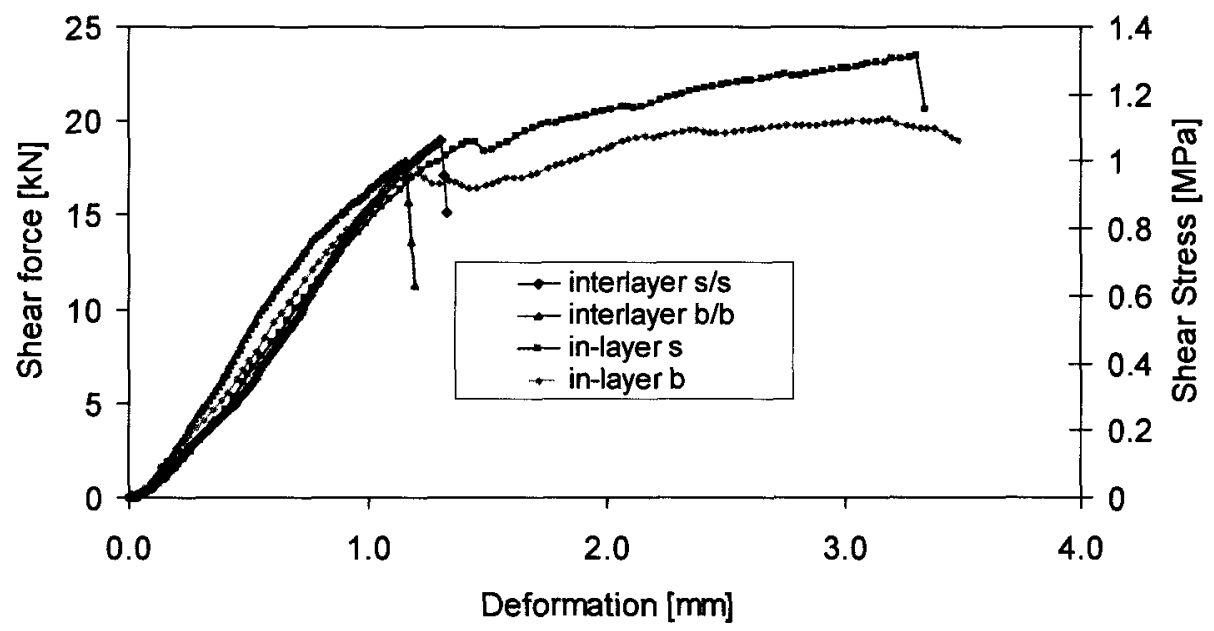

Figure 4.1: LPDS mean curves for in-layer and interlayer testing with big and small balls at a deformation rate of $50 \mathrm{~mm} / \mathrm{min}$ and a temperature of $20^{\circ} \mathrm{C}$

\subsubsection{LPDS testing, influence of different steel ball combinations}

Considering the mean values of the interlayer tests at $50 \mathrm{~mm} / \mathrm{min}$ in Figure 4.2 , the steel ball combination $\mathrm{s} / \mathrm{b}$, followed by the combination $\mathrm{s} / \mathrm{s}$, led to the highest shear forces.

The lowest results for the maximum shear forces were obtained for the combination $\mathrm{b} / \mathrm{s}$ and $\mathrm{b} / \mathrm{b}$. Regardless of the steel ball combination, the shear force values seemed to be higher when the top layer consisted of small steel balls.

A difference in the maximum shear stiffness could not be determined, i.e. all shear reaction modulus values at a deformation rate of $50 \mathrm{~mm} / \mathrm{min}$ were between $1.1 \mathrm{MPa} / \mathrm{mm}$ and $1.2 \mathrm{MPa} / \mathrm{mm}$.

Regarding the maximum shear deformation, values between $0.9 \mathrm{~mm}$ and $1.3 \mathrm{~mm}$ were determined with a deformation rate of $50 \mathrm{~mm} / \mathrm{min}$. Again, the deformation at failure was larger when the top layer consisted of small steel balls. 


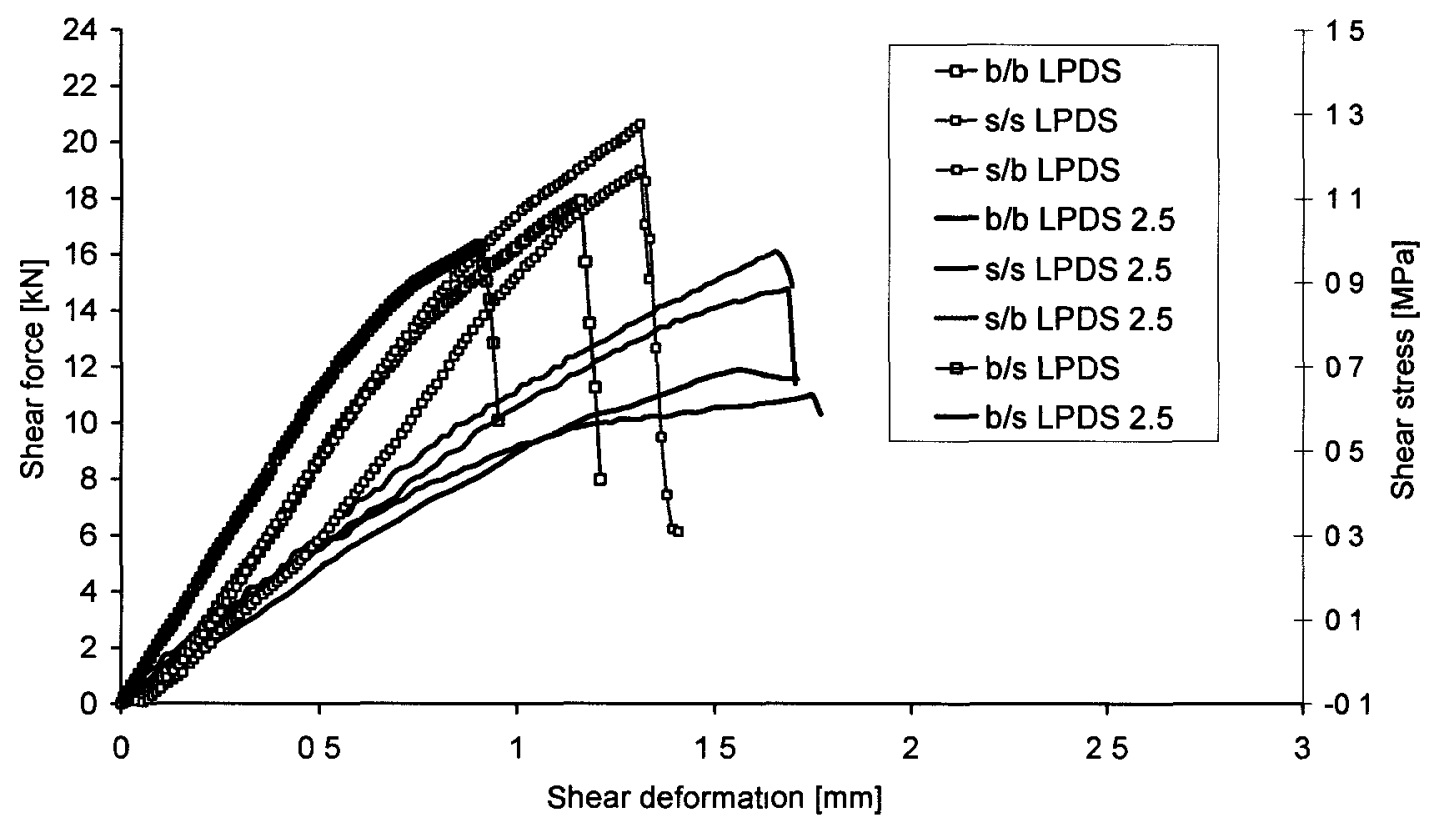

Figure 4.2: LPDS mean curves for interlayer testing with big and small balls at a deformation rate of $50 \mathrm{~mm} / \mathrm{min}$ (fast) and $2.5 \mathrm{~mm} / \mathrm{min}$ (slow) and a temperature of $20^{\circ} \mathrm{C}$

\subsubsection{LPDS testing, influence of deformation rate}

Figures 4.3 reveals that, as expected, due to viscoelastic properties, testing at a lower deformation rate of $2.5 \mathrm{~mm} / \mathrm{min}$ results in clearly lower maximum shear stresses and tremendously reduced shear stiffness.

Despite of the lower maximum shear stresses, ranking of the different steel ball combinations remained the same or quite similar, resulting in the highest shear values for $\mathrm{s} / \mathrm{b}$ followed by $\mathrm{s} / \mathrm{s}$. The values for $\mathrm{b} / \mathrm{s}$ were $\mathrm{a}$ bit higher than the value for $\mathrm{b} / \mathrm{b}$, when testing with a deformation rate of $2.5 \mathrm{~mm} / \mathrm{min}$. In case of the fast deformation rate of 
$50 \mathrm{~mm} / \mathrm{min}$ there was no significant difference between the shear forces of the combinations $\mathrm{b} / \mathrm{b}$ and $\mathrm{b} / \mathrm{s}$.
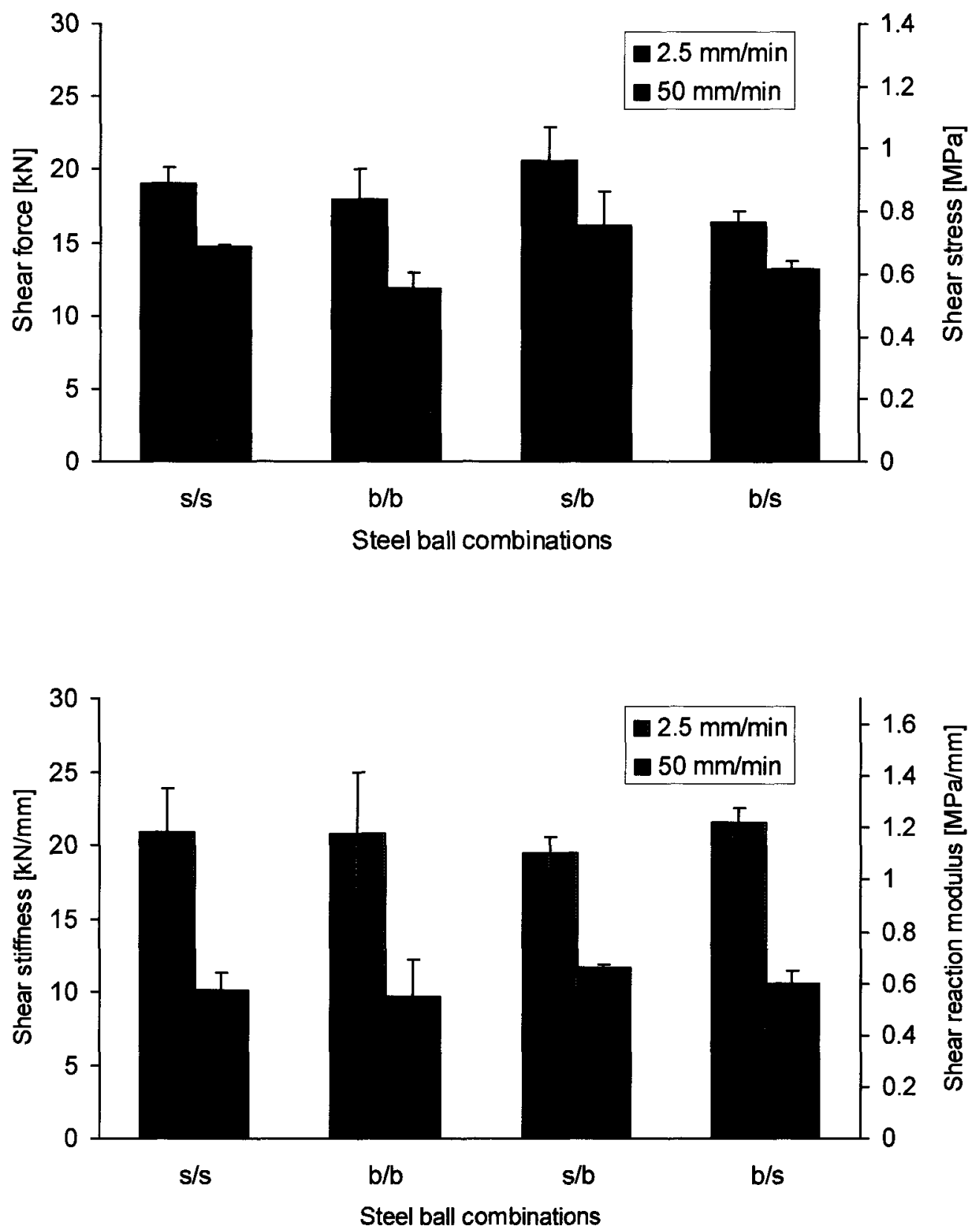

Figure 4.3: Shear force (shear stress) and shear stiffness for all steel ball combinations tested at a deformation rate of $2.5 \mathrm{~mm} / \mathrm{min}$ and $50 \mathrm{~mm} / \mathrm{min}$ 
The shear reaction modulus values for all steel ball combinations at a deformation rate of $50 \mathrm{~mm} / \mathrm{min}$ ranged between 1.1 and $1.2 \mathrm{MPa} / \mathrm{mm}$. These values were considerably higher than those obtained for a deformation rate of $2.5 \mathrm{~mm} / \mathrm{min}$ where values between 0.6 to $0.7 \mathrm{MPa} / \mathrm{mm}$ were measured.

The maximum deformation was between $0.9 \mathrm{~mm}$ and $1.5 \mathrm{~mm}$ at a deformation rate of $50 \mathrm{~mm} / \mathrm{min}$ and between $1.5 \mathrm{~mm}$ and $2.0 \mathrm{~mm}$ for $2.5 \mathrm{~mm} / \mathrm{min}$. These findings can be explained with the more ductile behaviour at a slower speed due to viscoelastic behaviour.

Although, differences in the magnitude of the shear stresses for the different combinations could be found, it is interesting to see that the values for all combinations were lying closely together, a fact that clearly showed the influence of the binder viscosity.

\subsubsection{Shear Box, general remarks}

Table 4.3 summarises the Shear Box results. It shows the single results and the mean values (bold) of 6 tests for maximum shear force $F_{\text {ShearBox, }}$ shear stress $\tau_{\text {ShearBox, }}$ shear

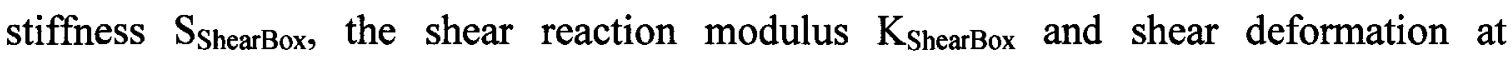
maximum shear force $w_{\text {ShearBox }}$ for a temperature of $20^{\circ} \mathrm{C}$ for the normal stresses of 0.1 $\mathrm{MPa}$ and 0.4 MPa. These values were determined using equations (1) and (2). The standard deviations and the coefficient of variation $\mathrm{CV}[\%]$ are also given. 
Table 4.3: Results of Shear Box testing with binder, single values, average (bold), standard deviation in brackets and coefficient of variation CV [\%]

\begin{tabular}{|c|c|c|c|c|c|c|}
\hline & $\begin{array}{c}\text { F }_{\text {ShearBox }} \\
{[\mathrm{kN}]}\end{array}$ & $\begin{array}{c}\tau_{\text {ShearBox }} \\
{[\mathrm{MPa}]}\end{array}$ & $\begin{array}{c}\text { W }_{\text {ShearBox }} \\
{[\mathrm{mm}]}\end{array}$ & $\begin{array}{c}\mathrm{S}_{\text {ShearBox }} \\
{[\mathrm{kN} / \mathrm{mm}]}\end{array}$ & $\begin{array}{c}\mathrm{K}_{\text {ShearBox }} \\
{[\mathrm{MPa} / \mathrm{mm}]}\end{array}$ & $\begin{array}{c}\sigma_{\mathrm{n}} \\
{[\mathrm{MPa}]}\end{array}$ \\
\hline \multirow{18}{*}{$s / s$} & 8.67 & 1.10 & 3.39 & 3.29 & 0.4 & 0.1 \\
\hline & 6.50 & 0.83 & 3.67 & 3.18 & 0.4 & 0.1 \\
\hline & 7.70 & 0.98 & 2.99 & 3.62 & 0.5 & 0.1 \\
\hline & 7.90 & 1.01 & 4.18 & 3.64 & 0.5 & 0.1 \\
\hline & 7.79 & 0.99 & 3.02 & 3.08 & 0.4 & 0.1 \\
\hline & 7.67 & 0.98 & 3.14 & 4.78 & 0.6 & 0.1 \\
\hline & 7.7 & 1.0 & 3.4 & 3.6 & 0.5 & \\
\hline & $(0.70)$ & $(0.09)$ & $(0.46)$ & $(0.63)$ & $(0.08)$ & \\
\hline & $9.1 \%$ & $9.0 \%$ & $13.5 \%$ & $17.5 \%$ & $17.3 \%$ & \\
\hline & 8.97 & 1.14 & 3.80 & 3.71 & 0.5 & 0.4 \\
\hline & 9.03 & 1.15 & 4.11 & 3.25 & 0.4 & 0.4 \\
\hline & 9.20 & 1.17 & 3.06 & 5.01 & 0.7 & 0.4 \\
\hline & 8.79 & 1.12 & 3.54 & 3.70 & 0.5 & 0.4 \\
\hline & 8.61 & 1.10 & 3.70 & 3.40 & 0.4 & 0.4 \\
\hline & 9.14 & 1.16 & 3.95 & 4.39 & 0.6 & 0.4 \\
\hline & 9.0 & 1.1 & 3.7 & 3.9 & 0.5 & \\
\hline & $(0.37)$ & $(0.03)$ & $(0.37)$ & $(0.67)$ & $(0.09)$ & \\
\hline & $2.5 \%$ & $2.7 \%$ & $10 \%$ & $17.2 \%$ & $17.0 \%$ & \\
\hline \multirow{17}{*}{$\mathrm{b} / \mathrm{b}$} & 6.97 & 0.89 & 5.05 & 1.91 & 0.2 & 0.1 \\
\hline & 6.57 & 0.84 & 5.93 & 1.92 & 0.2 & 0.1 \\
\hline & 6.56 & 0.84 & 4.17 & 2.5 & 0.3 & 0.1 \\
\hline & 7.60 & 0.97 & 5.29 & 2.69 & 0.3 & 0.1 \\
\hline & 5.50 & 0.70 & 2.94 & 3.77 & 0.5 & 0.1 \\
\hline & 6.02 & 0.77 & 4.28 & 3.35 & 0.4 & 0.1 \\
\hline & 6.5 & 0.8 & 4.6 & 2.6 & 0.3 & \\
\hline & $(0.70)$ & $(0.09)$ & $(1.0)$ & $(0.77)$ & $(0.1)$ & \\
\hline & $10.8 \%$ & $11.3 \%$ & $21.7 \%$ & $29.6 \%$ & $29.2 \%$ & \\
\hline & 10.26 & 1.36 & 3.25 & 4.07 & 0.5 & 0.4 \\
\hline & 8.89 & 1.18 & 3.87 & 2.90 & 0.4 & 0.4 \\
\hline & 9.08 & 1.20 & 3.93 & 4.27 & 0.6 & 0.4 \\
\hline & 8.40 & 1.11 & 4.22 & 5.01 & 0.7 & 0.4 \\
\hline & 7.40 & 0.98 & 4.86 & 5.29 & 0.7 & 0.4 \\
\hline & 8.8 & 1.2 & 4.1 & 4.3 & 0.6 & \\
\hline & $(1.04)$ & $(0.14)$ & $(1.23)$ & $(0.94)$ & $(0.1)$ & \\
\hline & $11.8 \%$ & $11.6 \%$ & $30 \%$ & $21.9 \%$ & $20.7 \%$ & \\
\hline \multirow{16}{*}{$\mathrm{s} / \mathrm{b}$} & 7.96 & 1.01 & 3.57 & 3.14 & 0.4 & 0.1 \\
\hline & 7.50 & 0.95 & 3.94 & 4.21 & 0.5 & 0.1 \\
\hline & 7.98 & 1.02 & 3.76 & 3.40 & 0.4 & 0.1 \\
\hline & 10.17 & 1.30 & 4.76 & 3.31 & 0.4 & 0.1 \\
\hline & 12.27 & 1.56 & 4.62 & 2.64 & 0.3 & 0.1 \\
\hline & 10.17 & 1.30 & 5.50 & 3.21 & 0.4 & 0.1 \\
\hline & 9.3 & 1.2 & 4.4 & 3.3 & 0.4 & \\
\hline & (1.69) & $(0.21)$ & $(0.67)$ & $(0.51)$ & $(0.07)$ & \\
\hline & $18.2 \%$ & $17.5 \%$ & $15.2 \%$ & $15.7 \%$ & $15.4 \%$ & \\
\hline & 10.17 & 1.30 & 4.76 & 3.14 & 0.4 & 0.4 \\
\hline & 10.48 & 1.35 & 3.98 & 4.49 & 0.6 & 0.4 \\
\hline & 11.43 & 1.46 & 4.15 & 4.77 & 0.6 & 0.4 \\
\hline & 10.59 & 1.35 & 4.49 & 3.81 & 0.5 & 0.4 \\
\hline & 10.7 & 1.4 & 4.3 & 3.7 & 0.5 & \\
\hline & $(0.53)$ & $(0.07)$ & $(0.35)$ & $(0.8)$ & $(0.1)$ & \\
\hline & $5.0 \%$ & $5.0 \%$ & $8.1 \%$ & $23.2 \%$ & $23.0 \%$ & \\
\hline
\end{tabular}


The coefficient of variation CV [\%] for shear force and shear stress lies between $9 \%$ and $18 \%$, when testing with a normal stress of $0.1 \mathrm{MPa}$, and between $2.5 \%$ and $12 \%$, when testing with a normal stress of $0.4 \mathrm{MPa}$. According to the $\mathrm{CV}$, the steel ball combination $\mathrm{s} / \mathrm{s}$ and $\mathrm{b} / \mathrm{b}$ have a lower scatter for shear stress, than the combinations $\mathrm{s} / \mathrm{b}$ tested with normal stress of $0.1 \mathrm{MPa}$. Testing with normal stress of $0.4 \mathrm{MPa}$ reveals considerably smaller shear stress scatter for the combinations $s / \mathrm{s}$ and $\mathrm{s} / \mathrm{b}$ than for the combination $\mathrm{b} / \mathrm{b}$.

Regarding the shear stiffness for all test configurations and normal stresses, the coefficient of variation $\mathrm{CV}$ is noticeably higher than for shear stress showing a mean value of $22 \%$ and single values from $17.5 \%$ to $30 \%$. This is a fact, which can be understood since the shear stiffness consists of two values, each one showing its own scatter. In case of the combination $\mathrm{s} / \mathrm{s}$, no difference between testing with normal stresses of $0.1 \mathrm{MPa}$ and $0.4 \mathrm{MPa}$ can be found, while for big/big the $\mathrm{CV}$ is higher and for $\mathrm{s} / \mathrm{b}$ lower when testing at $0.1 \mathrm{MPa}$.

\subsubsection{Shear Box, influence of normal stress}

Figure 4.4 depicts the shear stress - shear deformation curves with normal stress of 0.1 and $0.4 \mathrm{MPa}$ for all tested steel ball combinations (mean values). As expected testing with higher normal stress results for all combinations of steel balls in higher shear stress.

The potential of an increase in shear stress is higher in case of lower initial values (testing with a normal force of $0.1 \mathrm{MPa}$ ). 
In case of steel ball combination $\mathrm{s} / \mathrm{s}$ the shear stiffness is not much affected by the magnitude of the normal stress, while for the combination $\mathrm{s} / \mathrm{b}$ a little and for the combination $\mathrm{b} / \mathrm{b}$ a bigger change can be found. The shear deformation is not much affected by the magnitude of normal stress.

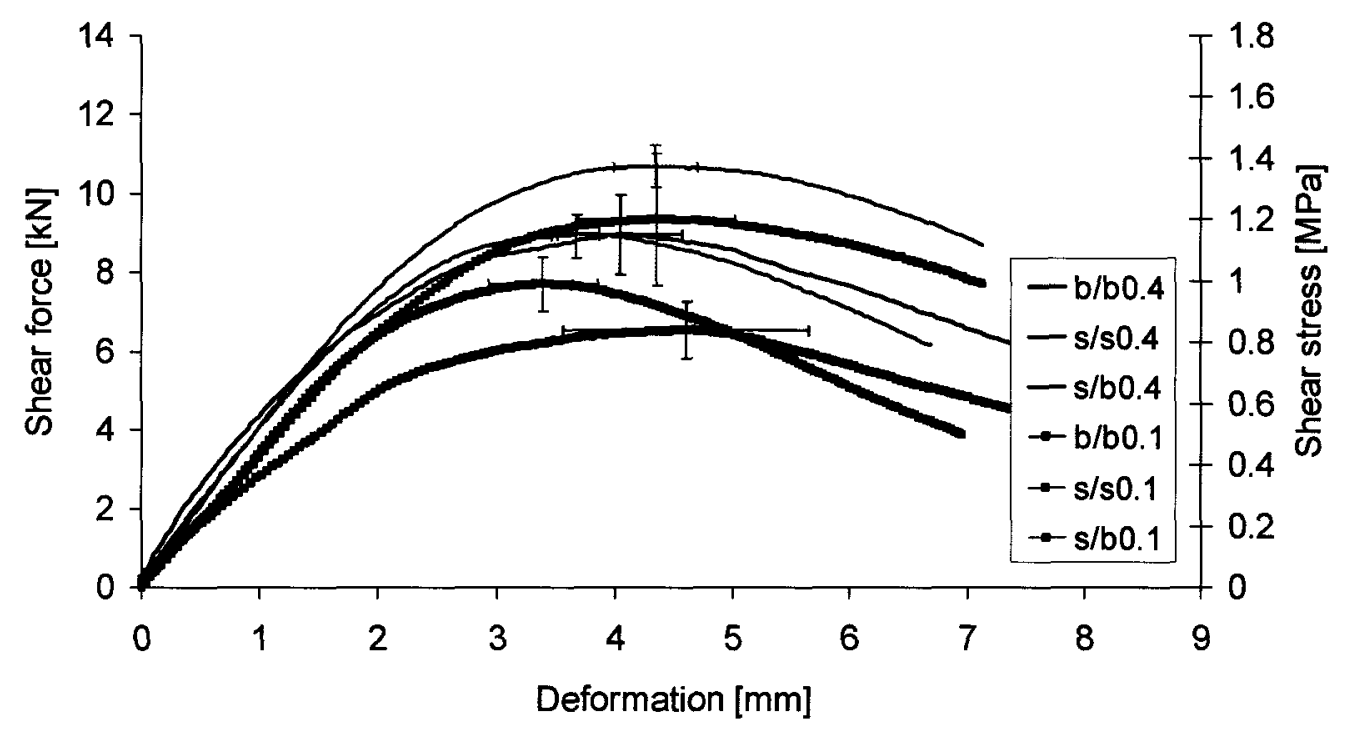

Figure 4.4: Mean shear force/stress- deformation curves for Shear Box testing with binder for all combination of steel balls at normal stresses of 0.1 and 0.4 MPa (mean values)

\subsubsection{Shear Box, testing with and without binder}

In Table 4.4 and Figure 4.5, the results for testing steel balls without binder are also depicted, showing the mean values for all combinations of steel balls with normal stresses of $0.1 \mathrm{MPa}$ and $0.4 \mathrm{MPa}$.

Again, the results demonstrate the relationship between shear stress and normal stress resulting in higher values for higher normal stress. When testing without binder, a 
distinction between the different steel ball combinations is less obvious. For both normal stresses, shear stress still seems to have the highest values when testing the combination $\mathrm{s} / \mathrm{b}$, whereas the combinations $\mathrm{s} / \mathrm{s}$ and $\mathrm{b} / \mathrm{b}$ do not have a distinct tendency.

Table 4.4: Results of Shear Box testing without binder single values, average (bold), standard deviation in brackets and coefficient of variation CV [\%]

\begin{tabular}{|c|c|c|c|c|c|c|}
\hline & $\begin{array}{c}\text { F }_{\text {ShearBox }} \\
{[\mathrm{kN}]}\end{array}$ & $\begin{array}{c}\tau_{\text {ShearBox }} \\
{[\mathrm{MPa}]}\end{array}$ & $\begin{array}{c}\text { WShearBox }_{\text {Shm] }} \\
\text { [mm }\end{array}$ & $\begin{array}{c}\mathrm{S}_{\text {ShearBox }} \\
{[\mathrm{kN} / \mathrm{mm}]}\end{array}$ & $\begin{array}{c}\mathrm{K}_{\text {ShearBox }} \\
{[\mathrm{MPa} / \mathrm{mm}]}\end{array}$ & $\begin{array}{c}\sigma_{\mathrm{n}} \\
{[\mathrm{MPa}]}\end{array}$ \\
\hline \multirow{11}{*}{$\mathrm{s} / \mathrm{s}$} & 0.52 & 0.07 & 3.90 & 1.0 & 0.06 & 0.1 \\
\hline & 0.48 & 0.06 & 1.38 & 0.77 & 0.04 & 0.1 \\
\hline & 0.5 & 0.06 & 2.64 & 0.89 & 0.05 & \\
\hline & $(0.03)$ & $(0.002)$ & (1.77) & $(0.16)$ & $(0.009)$ & \\
\hline & $6.0 \%$ & $6.0 \%$ & $67 \%$ & $17.8 \%$ & $17.3 \%$ & \\
\hline & 2.50 & 0.33 & 4.01 & 1.90 & 0.3 & 0.4 \\
\hline & 2.17 & 0.29 & 4.88 & 0.73 & 0.2 & 0.4 \\
\hline & 2.09 & 0.28 & 6.0 & 1.11 & 0.2 & 0.4 \\
\hline & 2.25 & 3.0 & 5.0 & 1.25 & 0.2 & \\
\hline & $(0.22)$ & $(0.03)$ & $(0.98)$ & $(0.60)$ & $(0.06)$ & \\
\hline & $11.1 \%$ & $10.0 \%$ & $19.6 \%$ & $48 \%$ & $30 \%$ & \\
\hline \multirow{11}{*}{$\mathrm{b} / \mathrm{b}$} & 0.53 & 0.07 & 3.09 & 0.36 & 0.02 & 0.1 \\
\hline & 0.59 & 0.08 & 5.04 & 0.57 & 0.03 & 0.1 \\
\hline & 0.56 & 0.08 & 4.10 & 0.46 & $\mathbf{0 . 0 3}$ & \\
\hline & $(0.04)$ & $(0.005)$ & (1.38) & $(0.15)$ & $(0.0085)$ & \\
\hline & $7.1 \%$ & $6.9 \%$ & $21.7 \%$ & $32.6 \%$ & $28 \%$ & \\
\hline & 2.60 & 0.34 & 7.04 & 1.12 & 0.1 & 0.4 \\
\hline & 2.66 & 0.35 & 3.00 & 1.00 & 0.1 & 0.4 \\
\hline & 2.18 & 0.29 & 6.52 & 1.83 & 0.1 & 0.4 \\
\hline & 2.48 & 0.33 & 5.5 & 1.3 & 0.1 & \\
\hline & $(0.26)$ & $(0.03)$ & $(2.20)$ & $(0.44)$ & $(0.025)$ & \\
\hline & $10.5 \%$ & $9.9 \%$ & $40 \%$ & $33 \%$ & $25 \%$ & \\
\hline \multirow{10}{*}{$\mathrm{s} / \mathrm{b}$} & 0.69 & 0.09 & 3.91 & 0.85 & 0.05 & 0.1 \\
\hline & 0.65 & 0.09 & 2.88 & 0.61 & 0.03 & 0.1 \\
\hline & 0.66 & 0.09 & 3.40 & 0.73 & 0.04 & \\
\hline & $(0.03)$ & $(0.004)$ & $(0.72)$ & $(0.17)$ & $(0.009)$ & \\
\hline & $4.5 \%$ & $4.4 \%$ & $21.1 \%$ & $23 \%$ & $22 \%$ & \\
\hline & 2.96 & 0.39 & 4.63 & 1.09 & 0.1 & 0.4 \\
\hline & 2.60 & 0.34 & 4.87 & 1.19 & 0.1 & 0.4 \\
\hline & 2.78 & 0.37 & 4.75 & 1.14 & 0.1 & \\
\hline & $(0.26)$ & $(0.03)$ & $(0.17)$ & $(0.07)$ & $(0.06)$ & \\
\hline & $9.0 \%$ & $9.0 \%$ & $3.6 \%$ & $6.1 \%$ & $6 \%$ & \\
\hline
\end{tabular}




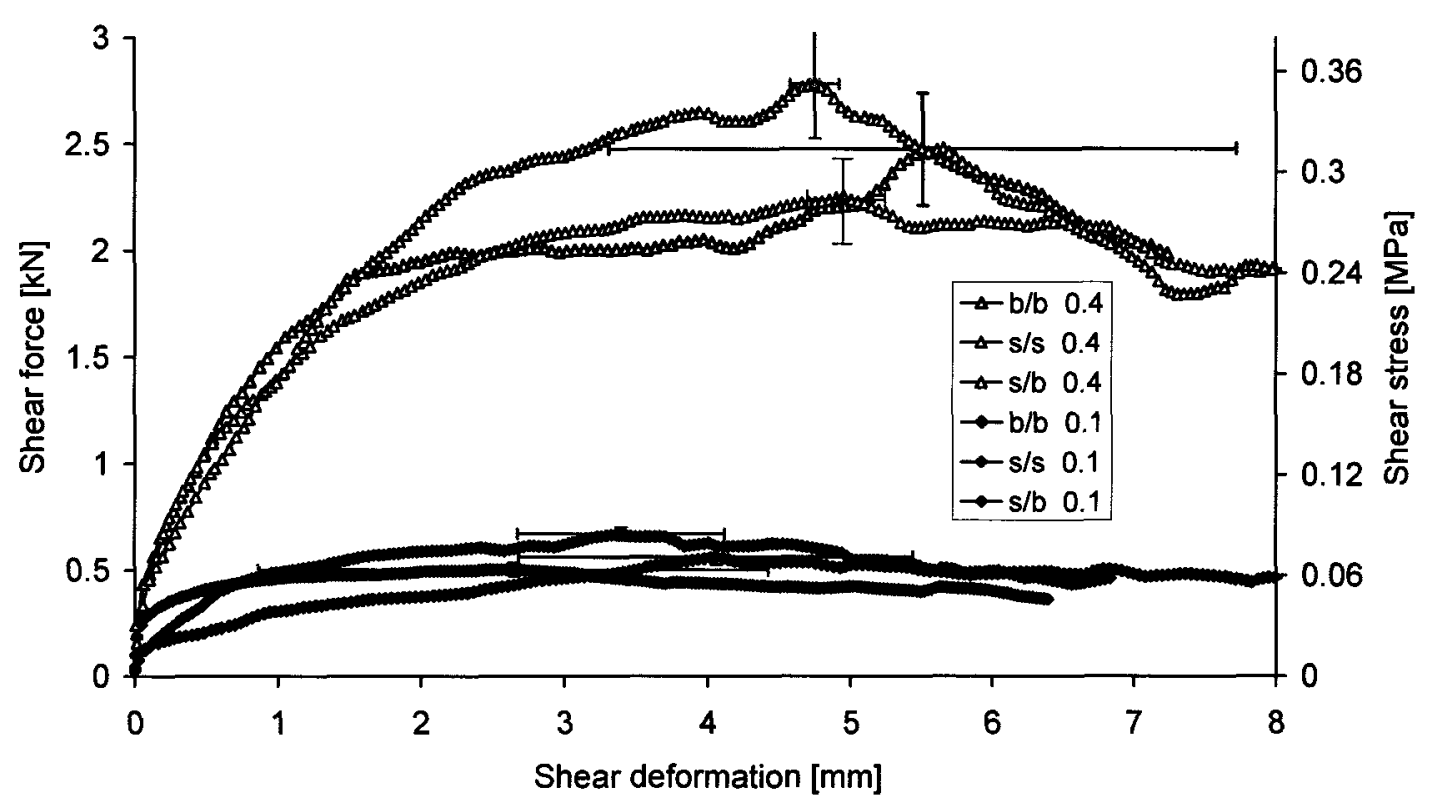

Figure 4.5 - Mean shear force/stress- deformation curves for Shear Box testing for all combination of steel balls without binder at normal stress of 0.1 and $0.4 \mathrm{MPa}$ (mean values)

Since the individual curves are quite unsteady and reveal an extended region of almost constant flow, it is not easy to determine a single maximum point. When testing at $0.4 \mathrm{MPa}$, the maximum shear stresses for the combination $\mathrm{s} / \mathrm{b}$ lay in the range of $0.35 \mathrm{MPa}$, while for $\mathrm{s} / \mathrm{s}$ and $\mathrm{b} / \mathrm{b}$ maximum values around $0.26 \mathrm{MPa}$ were achieved. When testing at $0.1 \mathrm{MPa}$ the combination $\mathrm{s} / \mathrm{b}$ reached values of $0.08 \mathrm{MPa}$ compared to about $0.07 \mathrm{MPa}$ for the other two combinations.

Especially for testing at $0.1 \mathrm{MPa}$, the shear stiffness was comparatively low (less than $0.08 \mathrm{MPa} / \mathrm{mm}$ ) and a maximum is difficult to determine. When testing at $0.4 \mathrm{MPa}$ the maximum shear stiffness achieved values in the range of $0.1 \mathrm{MPa} / \mathrm{mm}$ and 
$0.2 \mathrm{MPa} / \mathrm{mm}$ and the difference between the different combinations were bigger within single test sets (single values) than between the different combinations.

Table 4.5 presents the fracture energy, as the area under the mean shear force/deformation curve up to the maximum shear stress for all steel ball combinations at 0.1 and $0.4 \mathrm{MPa}$ with and without binder (see also Chapter 3). Subtracting the mean area without binder from the mean area with binder at $0.1 \mathrm{MPa}$ and $0.4 \mathrm{MPa}$ respectively, leads for all combinations to relative similar areas under the mean shear stress/deformation curves ranging between 13.3 and $19.5[\mathrm{kNmm}]$. Only for the combination $\mathrm{s} / \mathrm{b}$ at $0.4 \mathrm{MPa}$ a higher value of $25.8[\mathrm{kNmm}]$ was achieved.

Table 4.5: Area under the shear force-displacement curves (shear box) for all steel ball combinations with and without binder

\begin{tabular}{|c|c|c|c|}
\hline$\sigma_{\mathrm{n}}[\mathrm{MPa}]$ & $\mathrm{s} / \mathrm{s}[\mathrm{kNmm}]$ & $\mathrm{b} / \mathrm{b}[\mathrm{kNmm}]$ & $\mathrm{s} / \mathrm{b}[\mathrm{kNmm}]$ \\
\hline 0.4 & 22.1 & 25.7 & 35.4 \\
0.4, no binder & 8.8 & 7.3 & 9.6 \\
difference & $\mathbf{1 3 . 3}$ & $\mathbf{1 8 . 4}$ & $\mathbf{2 5 . 8}$ \\
\hline 0.1 & 16.9 & 21.2 & 26.5 \\
0.1, no binder & 1.2 & 1.5 & 2.3 \\
difference & $\mathbf{1 5 . 7}$ & $\mathbf{1 9 . 7}$ & $\mathbf{2 4 . 2}$ \\
\hline
\end{tabular}

From Table 4.5 it becomes clear, that the binder really increases the fracture energy that can be taken by the specimen. The increase is in the order of 3 in case of $\sigma_{\mathrm{n}}=0.4 \mathrm{MPa}$ and in the order of 13 for $\sigma_{\mathrm{n}}=0.1 \mathrm{MPa}$. This means that the gluing effect is 
dominant in case of small or no normal stress (e.g. in LPDS most energy is dissipated by the binder). When the influence of the binder becomes smaller, one can imagine that the ranking between the different steel ball combinations (roughness) changes; a fact that was confirmed in Figure 4.6.

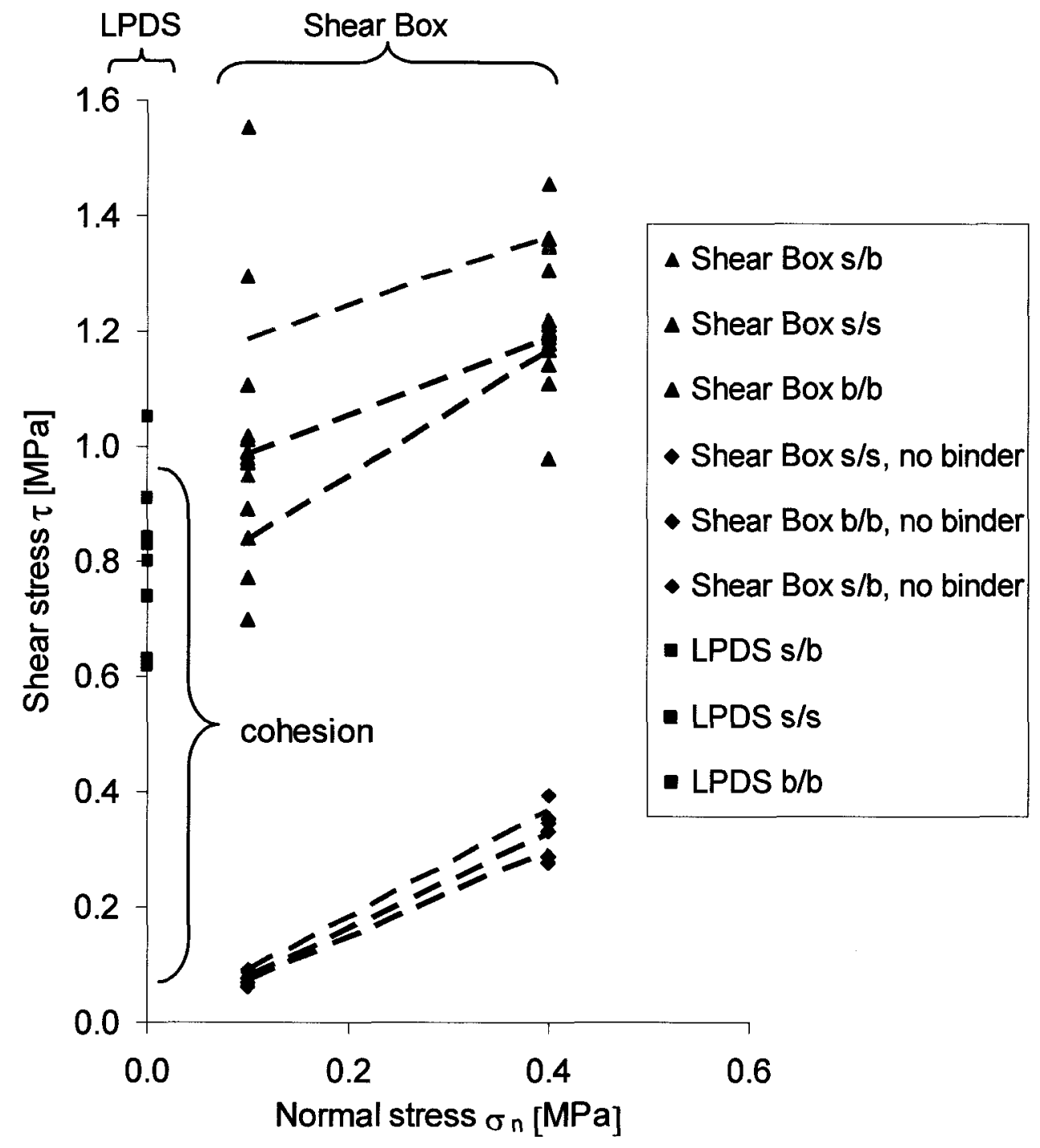

Figure 4.6: Max. shear stresses and envelopes at $20^{\circ} \mathrm{C}$ for the different combinations of steel balls with and without binder, all tests were conducted at $2.5 \mathrm{~mm} / \mathrm{min}$ 
In Figure 4.6 the maximum envelopes for all shear box test combinations with and without binder are depicted representing the failure criterion according to Coulomb's law as given in equation 3.6.

For comparison, the LPDS shear test results (single values) determined with a deformation rate of $2.5 \mathrm{~mm} / \mathrm{min}$ are also depicted.

Figures 4.5 and 4.6 clearly show that the shear bond is highly influenced by adding binder to the steel balls. Binder increases cohesion significantly, leading to an average increase in shear stress in the order of $1 \mathrm{MPa}$.

\subsubsection{Comparison between LPDS and Shear Box testing}

Comparing the shear stress values from LPDS with a deformation rate of $2.5 \mathrm{~mm} / \mathrm{min}$ and Shear Box testing with a normal force of $0.1 \mathrm{MPa}$ (see Figure 4.7) shows quite consistent results for both test methods, although the shear stress values are lower for LPDS testing.

Both test methods lead to an identical ranking for the different steel ball combinations, where highest shear force and stiffness values can be found for the combination $\mathrm{s} / \mathrm{b}$, followed by the combination $\mathrm{s} / \mathrm{s}$, while the combination $\mathrm{b} / \mathrm{b}$ achieves the lowest ones.

Extrapolating the Shear Box stress values for no normal stress $\left(\sigma_{n}=0\right)$ in Figure 4.6 makes it possible to compare the stress values between Shear Box and LPDS testing at a deformation rate of $2.5 \mathrm{~mm} / \mathrm{min}$ directly. Hence, for the combination $\mathrm{s} / \mathrm{b}$, the shear stress values are $\tau_{\text {LPDS }} / \tau_{\text {ShearBox }}=0.9 \mathrm{MPa} / 1.1278 \mathrm{MPa}$, which shows that in this case the Shear Box values are approx. 20\% higher. For the combination s/s, values of 
$\tau_{\mathrm{LPDS} /} / \tau_{\text {ShearBox }}=0.8 \mathrm{MPa} / 0.9316 \mathrm{MPa}$ result in slightly higher shear stress values for the Shear Box, while for the combination $\mathrm{b} / \mathrm{b}$, with shear stress values of $\tau_{\mathrm{LPDS} /} / \tau_{\text {ShearBox }}=$ 0.7 MPa /0.71 MPa LPDS and Shear Box results are in very good agreement.

As for the shear stress - shear deformation curves (see Figure 4.7) it seems obvious, that the shear behaviour in both tests is totally different. While in the LPDS test, failure occurs suddenly with an immediate drop of the shear force, gradual failure develops in the Shear Box test. It is also typical for Shear Box tests that the stress gradually decreases after reaching the peak (maximum) stress. This is due to the fact that in LPDS testing, deformation control can no longer be maintained after the maximum load had been reached because the pushed layer tends to drop to the bottom by its dead weight.

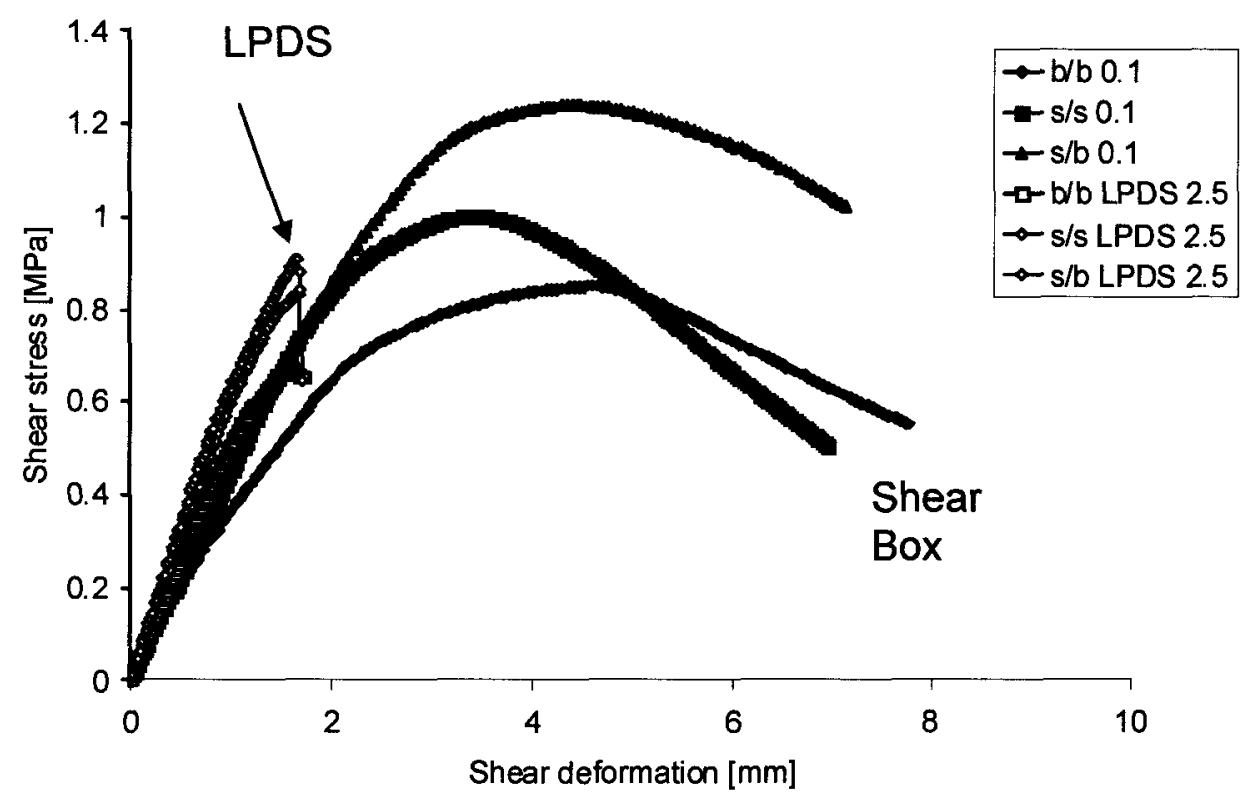

Figure 4.7: Comparison of shear stress- deformation curves for interlayer testing; LPDS with a deformation rate of $2.5 \mathrm{~mm} / \mathrm{min}$ and shear box with normal stress of 0.1 MPa (mean values) 


\subsection{Results of the parameter study (testing}

program 2)

\subsubsection{Effect of moisture}

\subsubsection{Pavements 1 and 2, interface 1: Shear Box}

Shear Box testing without water conditioning was conducted without and with 2 different normal stresses of $\sigma_{\mathrm{n}}=0.1$ and $0.4 \mathrm{MPa}$. For condition No. 2 (water storage at $40^{\circ} \mathrm{C}, 72 \mathrm{~h}$ ) a normal stress of $\sigma_{\mathbf{n}}=0.1 \mathrm{MPa}$ was applied. The test results (mean values, standard deviation in brackets are given in Table 4.6.

Table 4.6: Mean values of Shear Box test results for pavements 1 and 2, interlayer 1; standard deviation in brackets

\begin{tabular}{|c|c|c|c|c|c|c|}
\hline $\begin{array}{l}\text { Condition } \\
\text { No. }\end{array}$ & $\begin{array}{c}\sigma_{\mathrm{n}} \\
{[\mathrm{MPa}]}\end{array}$ & $\begin{array}{c}\mathrm{F}_{\max } \\
{[\mathrm{kN}]}\end{array}$ & $\begin{array}{c}\tau_{\max } \\
{[\mathrm{MPa}]}\end{array}$ & $\begin{array}{c}\mathrm{w}^{2} \mathrm{~F}_{\max } \\
{[\mathrm{mm}]}\end{array}$ & $\begin{array}{c}\mathrm{S}_{\max } \\
{[\mathrm{kN} / \mathrm{mm}]}\end{array}$ & $\begin{array}{c}\mathrm{K}_{\max } \\
{[\mathrm{MPa} / \mathrm{mm}]}\end{array}$ \\
\hline \multirow{2}{*}{1} & 0 & $9.1(1.42)$ & $1.2(0.19)$ & $3.5(0.43)$ & $3.5(0.75)$ & $0.2(0.04)$ \\
& 0.1 & $8.9(0.90)$ & $1.2(0.12)$ & $2.7(0.31)$ & $3.8(0.42)$ & $0.2(0.06)$ \\
& 0.4 & $10.6(1.67)$ & $1.4(0.22)$ & $3.2(0.52)$ & $4.5(0.14)$ & $0.3(0.1)$ \\
\hline 2 & 0.1 & $8.7(1.95)$ & $1.1(0.25)$ & $3.9(0.29)$ & $3.0(0.59)$ & $0.2(0.06)$ \\
\hline \multirow{2}{*}{1} & 0 & $9.2(1.02)$ & $1.2(0.13)$ & $2.9(0.31)$ & $3.7(0.24)$ & $0.2(0.02)$ \\
& 0.1 & $10.3(1.28)$ & $1.3(0.17)$ & $3.9(0.56)$ & $3.0(0.44)$ & $0.2(0.02)$ \\
& 0.4 & $10.6(0.97$ & $1.4(0.13)$ & $3.3(0.47)$ & $3.9(0.69)$ & $0.2(0.04)$ \\
\hline \multirow{2}{*}{2} & 0.1 & $7.4(0.71)$ & $1.0(0.09)$ & $3.3(0.66)$ & $2.7(0.38)$ & $0.2(0.04)$ \\
\hline
\end{tabular}


Figures 4.8 and 4.9 depict the mean shear force (stress) - deformation curves.

Figures 4.10 and 4.11 show the maximum shear stress and the shear reaction modulus $\mathrm{K}$ linear regression lines for the Shear Box testing of pavement 1 and 2 at different normal stresses. All single values can be found in Appendix B.

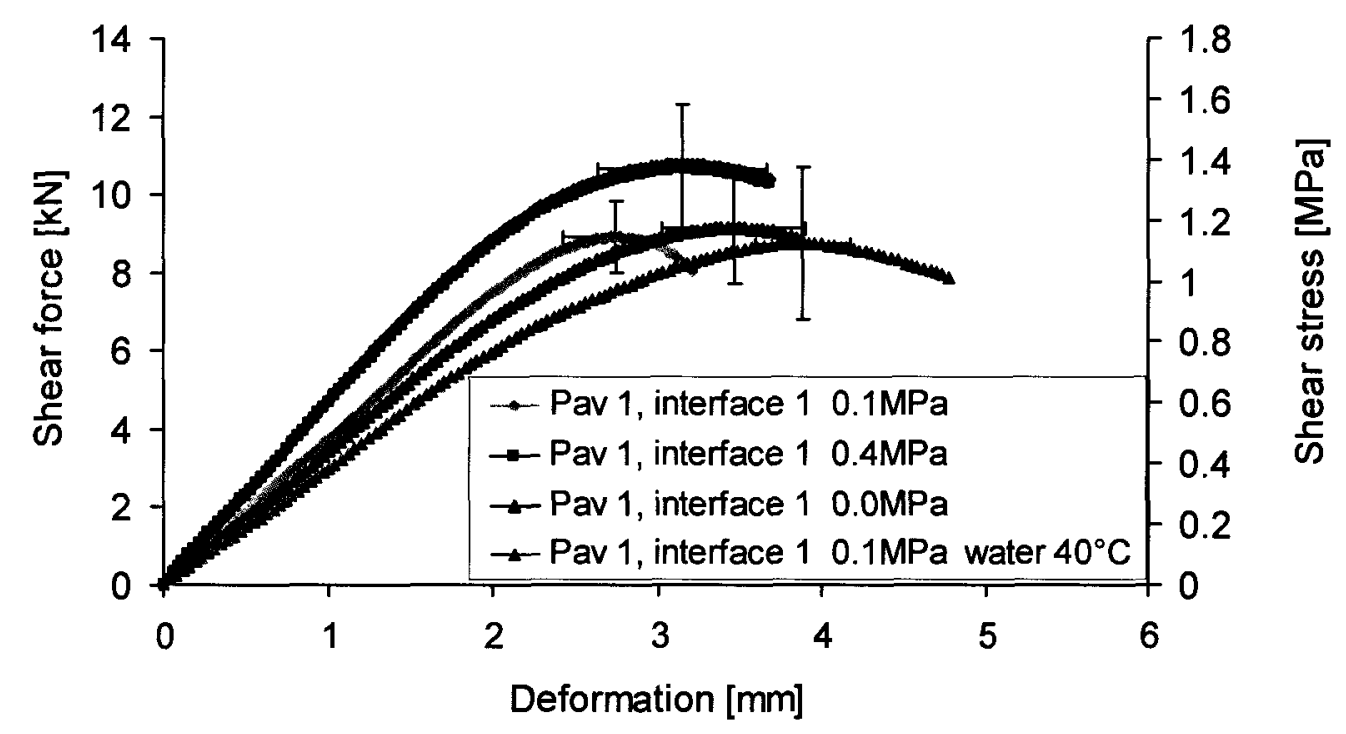

Figure 4.8: Mean shear force (stress) - deformation curves for Shear Box testing at $20^{\circ} \mathrm{C}$ of pavement 1 , interface 1 


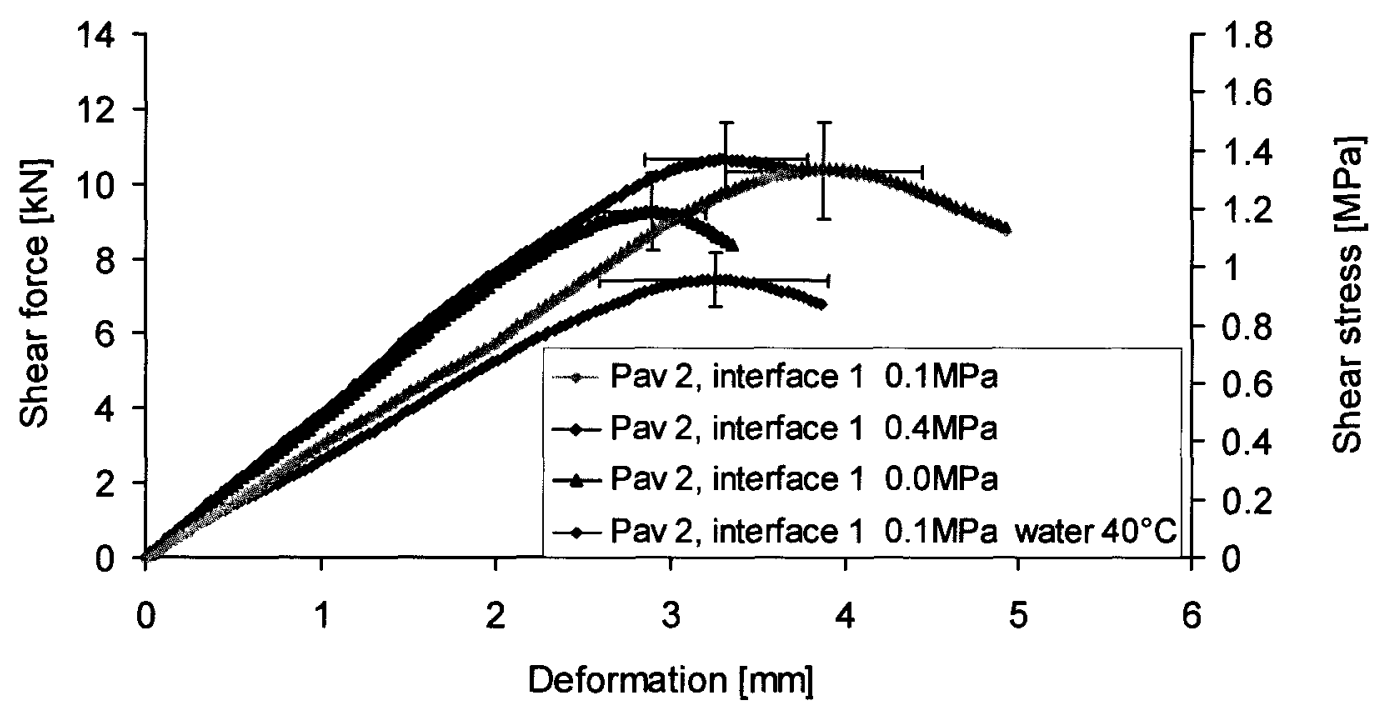

Figure 4.9: Mean shear force (stress) - deformation curves for Shear Box testing at $20^{\circ} \mathrm{C}$ of pavement 2 , interface 1

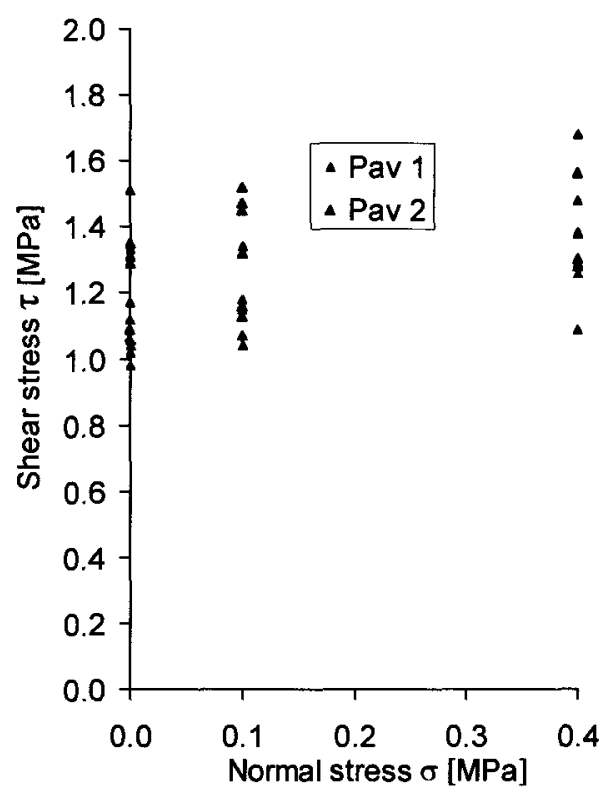

Figure 4.10: Maximum shear stress for different normal stresses for pavement 1 and 2, interface 1, Condition 1 


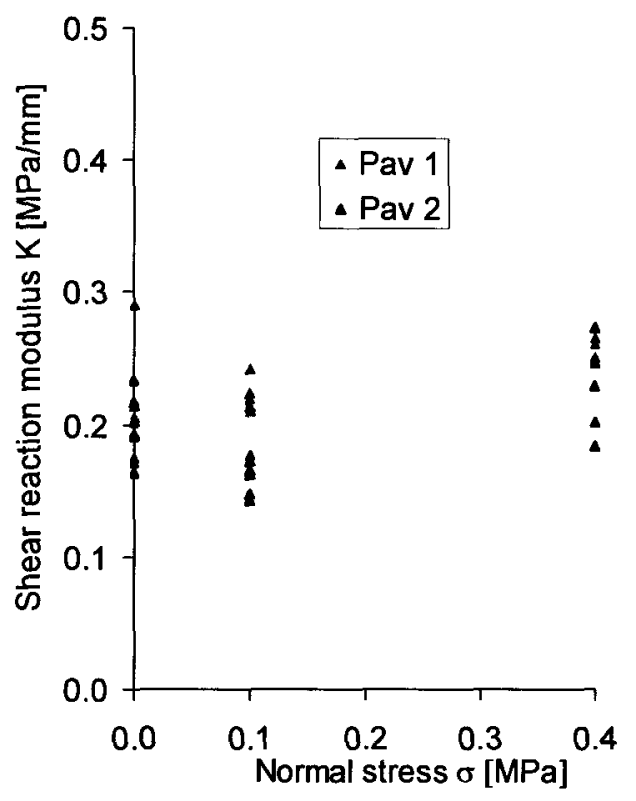

Figure 4.11: Maximum shear reaction modulus $K$ for different normal stresses for pavements 1 and 2, interface 1, Condition 1

According to Figure 4.10, the scatter between the single shear stress test results for both pavements is quite large and therefore the coefficient of determination $R^{2}$ is extremly low. As mentioned earlier for pavement 1 , the difference between results at normal stresses $0 \mathrm{MPa}$ and $0.1 \mathrm{MPa}$ is not big, whereas for testing at $0.4 \mathrm{MPa}$ there is a clear increase compared to $\sigma_{\mathrm{n}}=0 \mathrm{MPa}$ or $0.1 \mathrm{MPa}$.

The test results for pavement 1 show no big differences for testing without and with normal stress $\sigma_{\mathrm{n}}$ of $0.1 \mathrm{MPa}$ as shown in Figure 4.12. The shear force (stress) when testing at normal stress $\sigma_{\mathrm{n}}=0.1 \mathrm{MPa}$ is even a little bit lower $(8.9 \mathrm{kN} / 0.9 \mathrm{MPa})$ than the test results without normal stress $(9.1 \mathrm{kN} / 1.42 \mathrm{MPa})$. When testing with a normal stress of $0.4 \mathrm{MPa}$ the shear force (stress), and the shear stiffness $\mathrm{S}$ increase to $10.6 \mathrm{kN}$ 
respectively from $3.5 / 3.8 \mathrm{kN} / \mathrm{mm}$ to $4.5 \mathrm{kN} / \mathrm{mm}$ (see Figure 4.13 ). Testing after water conditioning and with a normal stress of $0.1 \mathrm{MPa}$ leads to $8.7 \mathrm{kN}(1.1 \mathrm{MPa})$, i.e. the lowest shear force (stress) values. However, this decrease is not statistically significant since the difference is smaller than the standard deviation. This is different in case of the shear stiffness (shear reaction modulus), where the change after moisture immersion is more distinct.

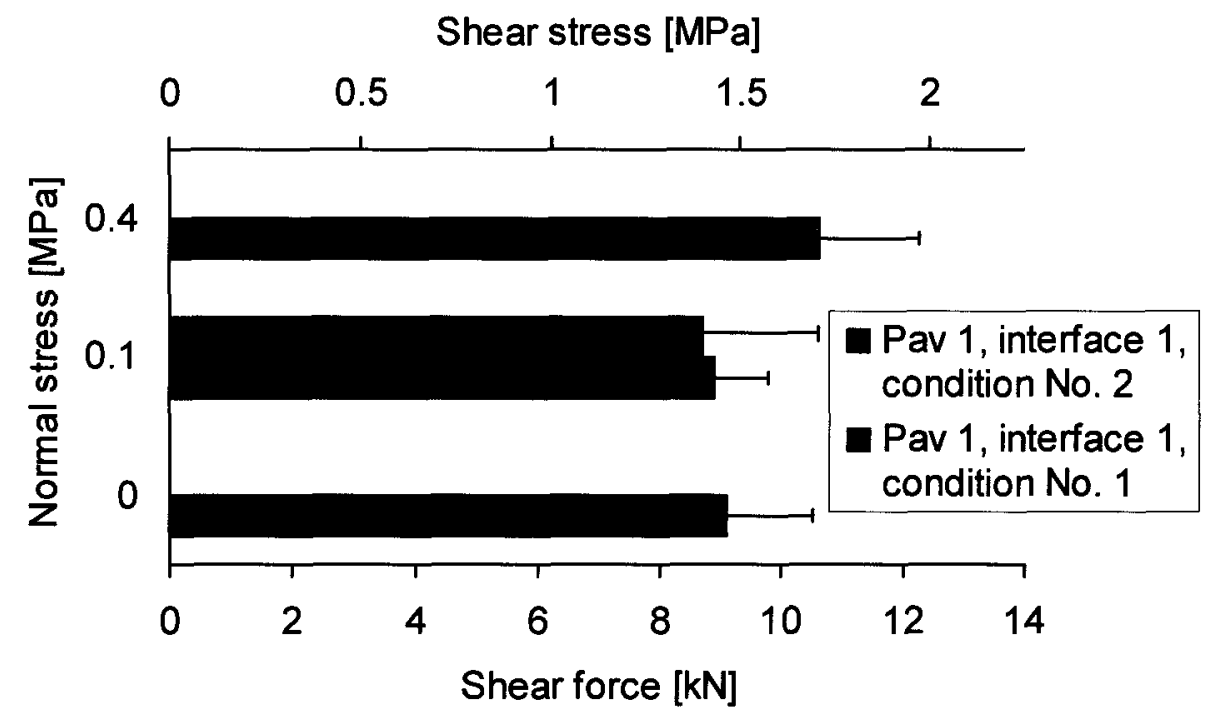

Figure 4.12: Maximum shear forces for different normal stresses for pavement 1, interface 1, Conditions 1 and 2 


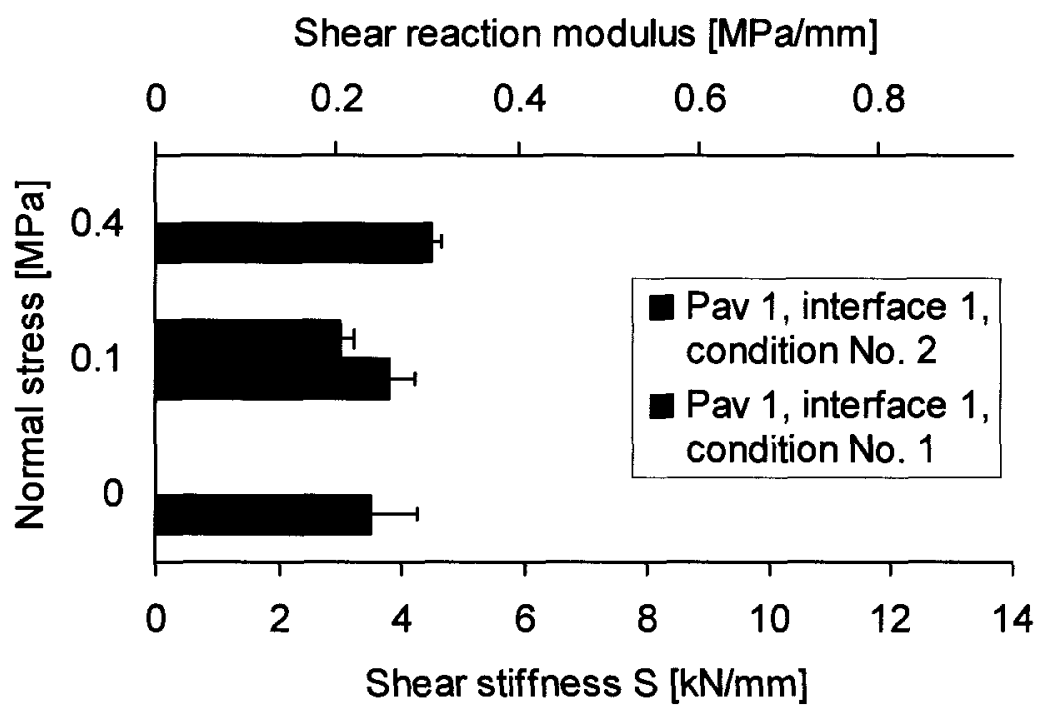

Figure 4.13: Maximum shear stiffness $S$ for different normal stresses for pavement 1, interface 1, Conditions 1 and 2

As visible in Figure 4.14, pavement 2 reveals a ranking for the shear force (shear stress) from the lowest value $9.2 \mathrm{kN}(1.2 \mathrm{MPa})$ without normal stress, to the highest shear forces (stresses) $10.3 \mathrm{kN}(1.3 \mathrm{MPa})$ with a normal stress of $0.1 \mathrm{MPa}$ and $10.6 \mathrm{kN}$ (1.4 MPa) with normal stress of 0.4 MPa. Again, the shear force (stress) test results after water conditioning achieve the lowest shear force (shear stress) values with $7.4 \mathrm{kN}$ resp. 1.0 MPa compared to pavement 1 . As opposed to pavement 1 , here the difference is statistically significant.

Regarding the shear stiffness (shear reaction modulus) there is no difference for testing at normal stresses of $\sigma_{\mathrm{n}}=0 \mathrm{MPa}$ and $\sigma_{\mathrm{n}}=0.4 \mathrm{MPa}$, while the shear stiffness at $\sigma_{\mathrm{n}}=0.1 \mathrm{MPa}$ is lower, although not statistically significant. In case of pavement 2 , the difference between testing with and without water conditioning is significant, with lower values for testing of the water conditioned specimens. 


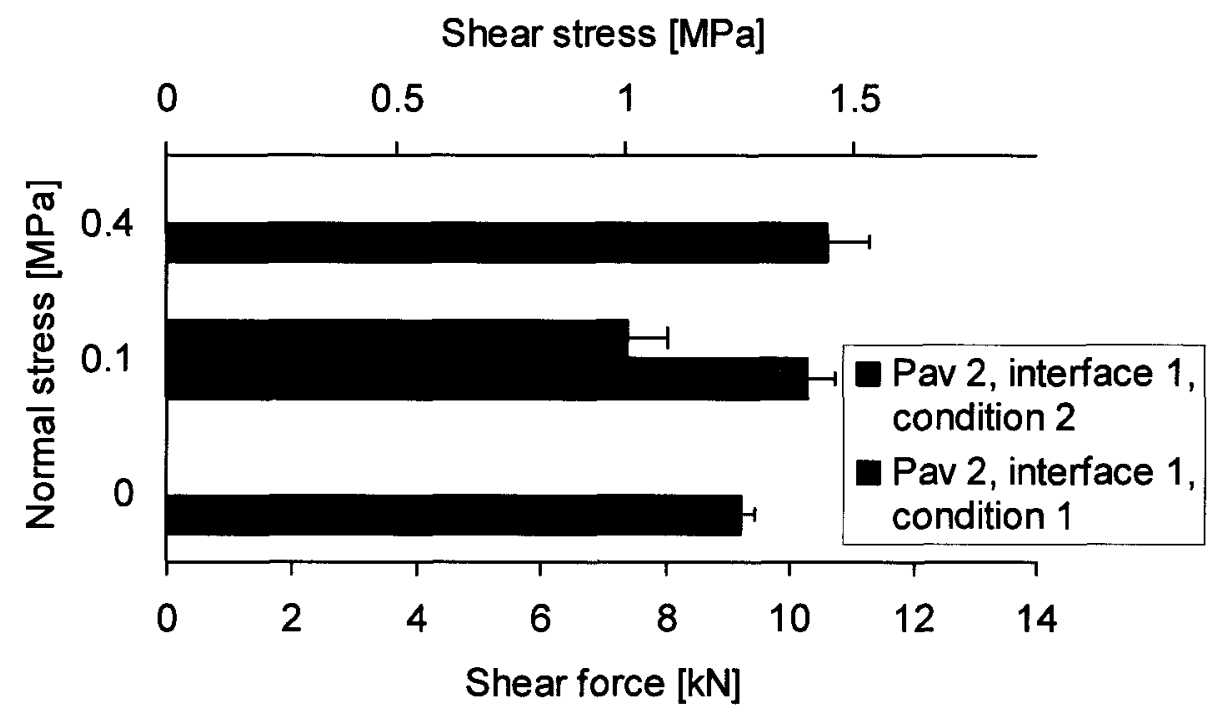

Figure 4.14: Maximum shear forces for different normal stresses for pavement 2, interface 1, Conditions 1 and 2

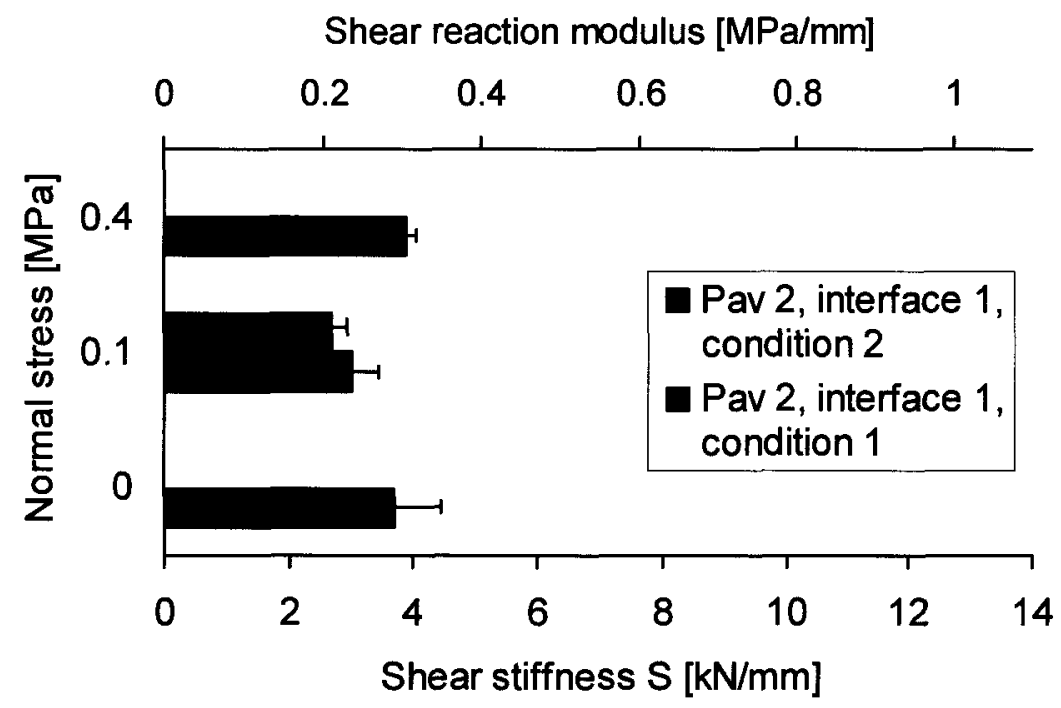

Figure 4.15: Maximum shear stiffness $S$ for different normal stresses for pavement 2, interface 1, Conditions 1 and 2 
For pavement 2, already for testing at $0.1 \mathrm{MPa}$, an increase in shear force (shear stress) compared to testing without normal stress is visible, although not significant, while for testing at a normal stress of $0.4 \mathrm{MPa}$ the increase is only marginal and lies within the standard deviation (see Figure 4.14).

Overall, the shear force (shear stress) results for interface 1 of pavements 1 and 2 are in a similar range and show no significant difference, a fact that might be attributed to their similar air void content. Similar findings are true for the shear stiffness (shear reaction modulus) and the shear deformation at maximum shear force.

\subsubsection{Pavements 1, 2 and 3, interface 1 and 2: LPDS}

LPDS testing for pavement 1 was conducted for both interfaces and all test conditions according to Table 3.5. Pavement 2, which consisted of two layers only, was tested at conditions No. 1 to No. 3. LPDS testing for pavement 3 was conducted for both interfaces and all four test conditions according to Table 3.5.

All LPDS test results (mean values, standard deviation in brackets) can be found in Table 4.7 and Figures 4.16 to 4.18. All individual values are given in Appendix B. 
Table 4.7: LPDS test results at $20^{\circ} \mathrm{C}$ for pavements 1,2 and 3, interlayers 1 and 2 (standard deviation in brackets)

\begin{tabular}{|c|c|c|c|c|c|}
\hline Condition No. & $\begin{array}{l}\mathrm{F}_{\max } \\
{[\mathrm{kN}]}\end{array}$ & $\begin{array}{c}\tau_{\max } \\
{[\mathrm{MPa}]}\end{array}$ & $\begin{array}{c}\mathrm{W} \text { at } \mathrm{F}_{\max } \\
{[\mathrm{mm}]}\end{array}$ & $\begin{array}{c}\mathrm{S}_{\max } \\
{[\mathrm{kN} / \mathrm{mm}]}\end{array}$ & $\begin{array}{c}\mathrm{K}_{\max } \\
{[\mathrm{MPa} / \mathrm{mm}]}\end{array}$ \\
\hline & \multicolumn{5}{|c|}{ Pavement 1 , interface 1} \\
\hline 1 & $30.6(2.07)$ & $1.7(0.12)$ & $2.6(0.26)$ & $17.2(2.04)$ & $1.0(0.13)$ \\
\hline 2 & $25.2(2.29)$ & $1.4(0.12)$ & $2.6(0.36)$ & $18.3(1.87)$ & $1.0(0.13)$ \\
\hline 3 & $22.8(1.34)$ & $1.3(0.07)$ & $2.2(0.29)$ & $16.0(2.44)$ & $1.0(0.16)$ \\
\hline \multirow[t]{2}{*}{4} & $25.7(0.96)$ & $1.5(0.05)$ & $2.4(0.27)$ & $16.7(3.27)$ & $0.9(0.15)$ \\
\hline & \multicolumn{5}{|c|}{ Pavement 1, interface 2} \\
\hline 1 & $27.4(3.91)$ & $1.5(0.22)$ & $2.0(0.21)$ & $22.6(6.69)$ & $1.3(0.4)$ \\
\hline 2 & $25.4(0.52)$ & $1.4(0.64)$ & $2.2(0.19)$ & $19.1(2.36)$ & $1.1(0.11)$ \\
\hline 3 & $21.9(2.04)$ & $1.2(0.12)$ & $2.4(0.25)$ & $15.4(0.20)$ & $0.9(0.14)$ \\
\hline \multirow[t]{2}{*}{4} & $18.4(4.02)$ & $1.0(0.23)$ & $2.0(0.17)$ & $14.7(1.38)$ & $0.8(0.09)$ \\
\hline & \multicolumn{5}{|c|}{ Pavement 2 , interface 1} \\
\hline 1 & $32.8(3.19)$ & $1.9(0.18)$ & $2.5(0.10)$ & $21.8(3.65)$ & $0.2(0.21)$ \\
\hline 2 & $37.2(2.95)$ & $2.1(0.17)$ & $2.7(0.23)$ & $21.3(3.29)$ & $0.2(0.20)$ \\
\hline \multirow[t]{2}{*}{3} & $33.4(3.77)$ & $1.9(0.21)$ & $2.6(0.42)$ & $20.9(1.07)$ & $0.2(0.08)$ \\
\hline & \multicolumn{5}{|c|}{ Pavement 3 , interface 1} \\
\hline 1 & $33.2(4.99)$ & $1.9(0.23)$ & $1.9(0.16)$ & $25.4(3.62)$ & $1.4(0.21)$ \\
\hline 2 & $31.8(5.91)$ & $1.9(0.33)$ & $2.2(0.22)$ & $23.7(4.44)$ & $1.4(0.26)$ \\
\hline 3 & $28.3(9.31)$ & $1.6(0.63)$ & $2.1(0.50)$ & $17.1(3.86)$ & $1.0(0.25)$ \\
\hline \multirow[t]{2}{*}{4} & $31.5(7.35)$ & $1.8(0.42)$ & $2.2(0.33)$ & $21.6(7.00)$ & $0.8(0.08)$ \\
\hline & \multicolumn{5}{|c|}{ Pavement 3 , interface 2} \\
\hline 1 & $35.2(4.5)$ & $2.0(0.25)$ & $1.5(0.24)$ & $30.5(1.93)$ & $1.6(0.13)$ \\
\hline 2 & $31.8(4.02)$ & $1.9(0.22)$ & $1.45(0.23)$ & $28.6(5.4)$ & $1.6(0.30)$ \\
\hline 3 & $29.8(5.65)$ & $1.7(0.32)$ & $1.3(0.18)$ & $26.3(4.43)$ & $1.5(0.29)$ \\
\hline 4 & $22.9(4.03)$ & $1.3(0.23)$ & $1.4(0.37)$ & $21.5(6.99)$ & $1.2(0.45)$ \\
\hline
\end{tabular}




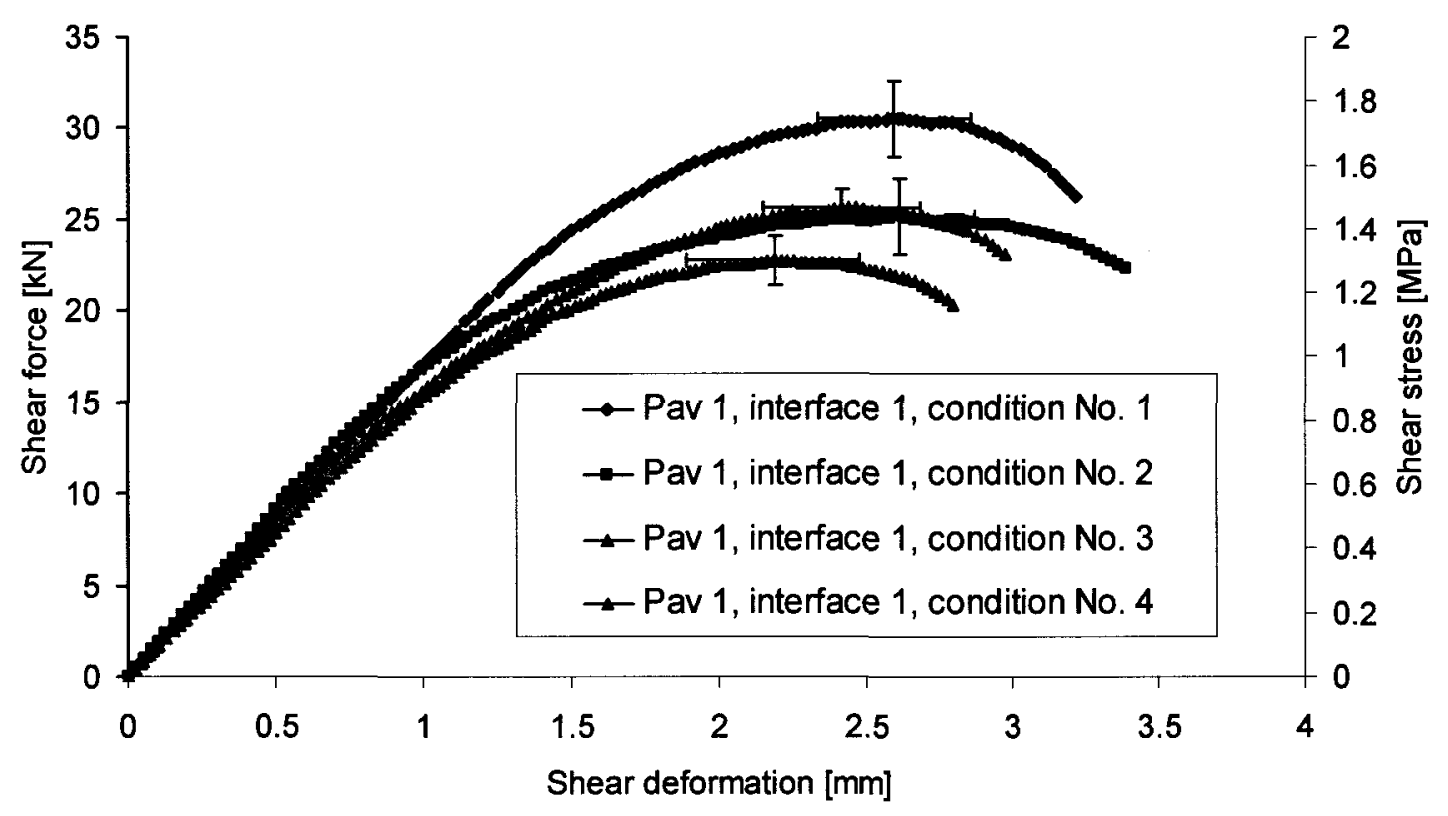

Figure 4.16: Mean shear force (stress) - deformation curves for LPDS testing at $20^{\circ} \mathrm{C}$ of pavement 1 , interface 1

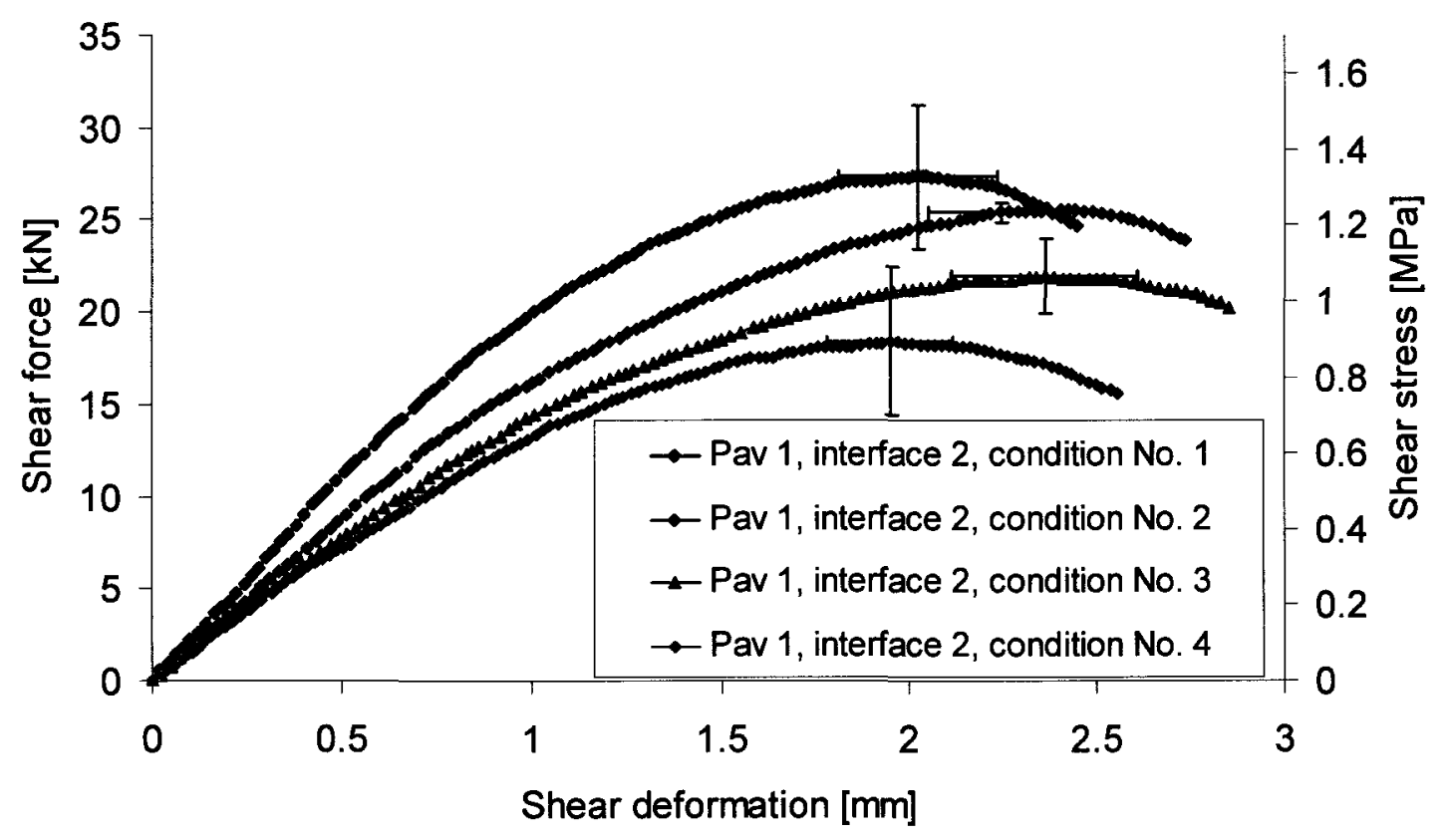

Figure 4.17: Mean shear force (stress) - deformation curves for LPDS testing at $20^{\circ} \mathrm{C}$ of pavement 1 , interface 2 


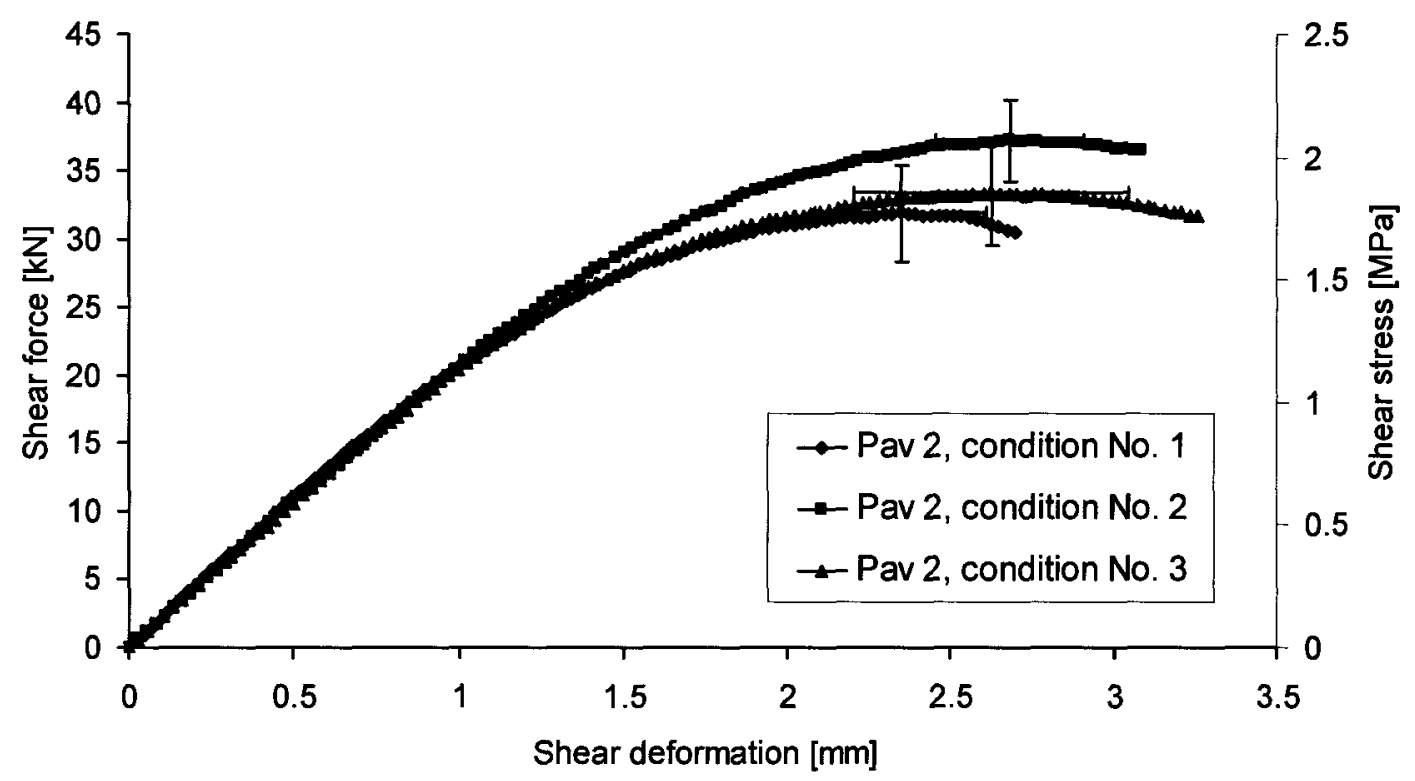

Figure 4.18: Mean shear force (stress) - deformation curves for LPDS testing at $20^{\circ} \mathrm{C}$ of pavement 2 , interface 1

According to Figure 4.16 the shear force (stress) and the shear stiffness at the first interface of pavement 1 show a clear decline and therefore a weakening from condition No. 1 (without water) to condition No. 3 (water $60^{\circ} \mathrm{C}$ ). When tested at condition 4 (water $40^{\circ} \mathrm{C}$ and pressure), the shear force (stress) results are comparable to that of condition No. 2 while the shear stiffness achieves a value comparable to condition No. 3 (water at $60^{\circ} \mathrm{C}$ ). The shear deformation at $\mathrm{F}_{\max }$ does not seem to be influenced by the different conditioning situations.

At the second interface pavement 1 shows, apart from condition No. 2 (water $40^{\circ} \mathrm{C}$ ), where the highest values for shear force (stress) and shear stiffness can be found, a decrease in shear force (stress) and stiffness from condition No. 1 to condition No. 3 and 
No. 4. Again, the shear deformation at maximum shear stress is not really effected by the different conditioning procedures (see Figure 4.17).

For pavement 2 (Figure 4.18), which was only tested for conditions No. 1 to 3 , water conditioning has nearly no impact on the shear stiffness and shear deformation, while the shear force (stress) increases from condition No. 1 (no water) to condition No. 2 (water $40^{\circ} \mathrm{C}$ ) and for condition No. 3 is comparable to condition No. 1 .

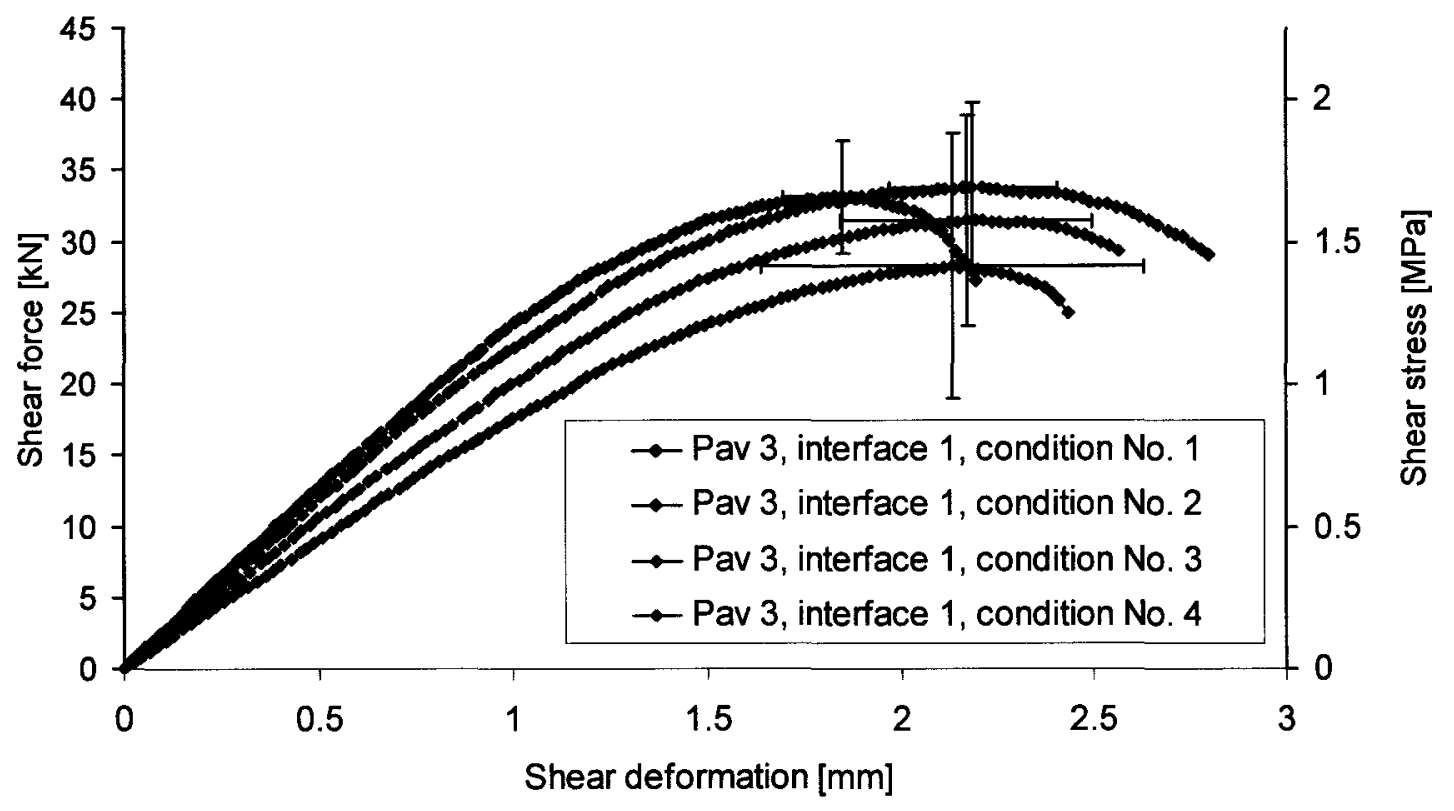

Figure 4.19: Mean shear force (stress) - deformation curves for LPDS testing at $20^{\circ} \mathrm{C}$ of pavement 3 , interface 1 


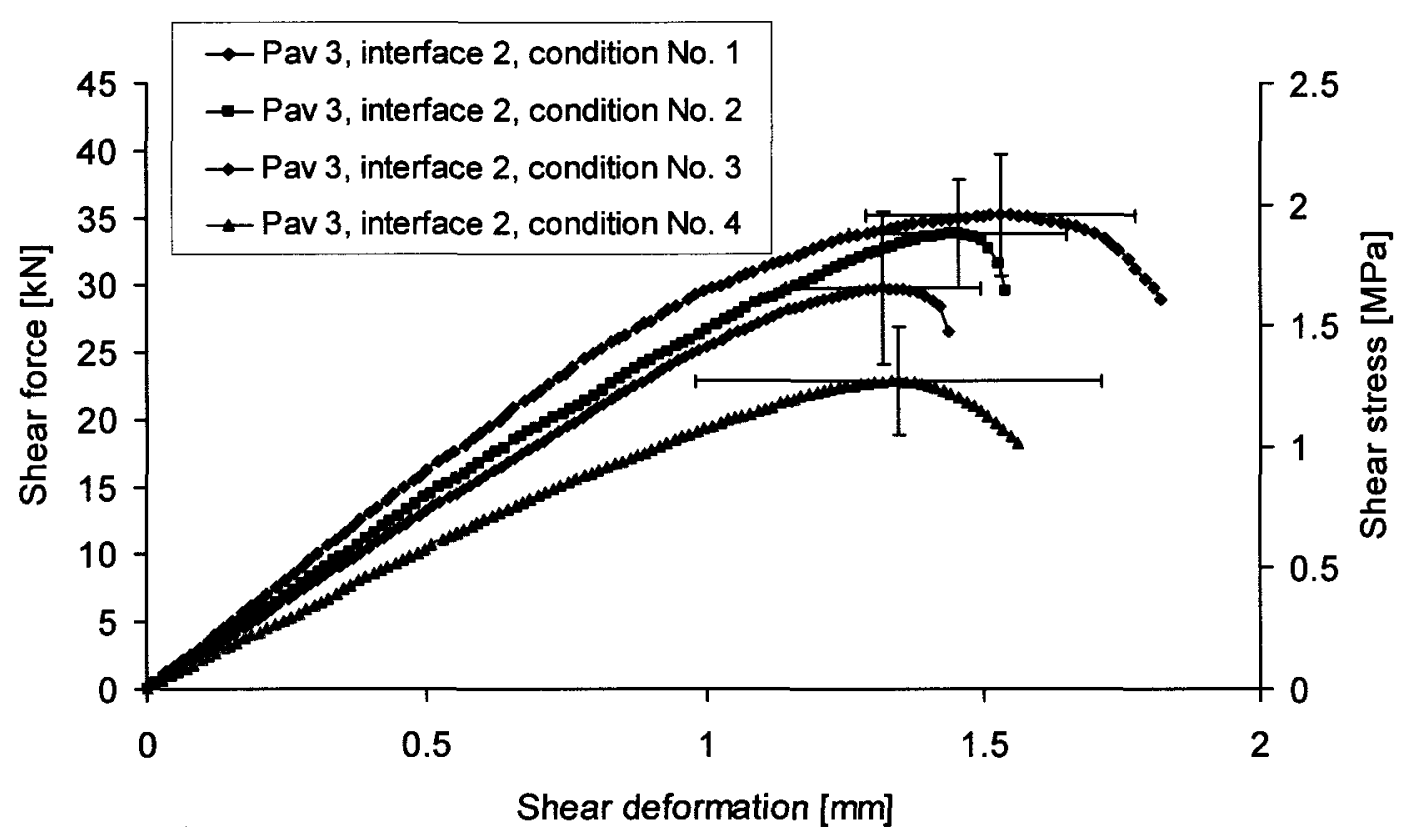

Figure 4.20: Mean shear force (stress) - deformation curves for LPDS testing at $20^{\circ} \mathrm{C}$ of pavement 3 , interface 2

For the first interface of pavement 3 (see Figure 4.19), the shear force (stress) and shear stiffness results are similar to those for the first interface of pavement 1. A clear decrease from condition No. 1 (no water) to condition No. 3 (water $60^{\circ} \mathrm{C}$ ) can be found. Again, the results for condition No. 4 (water $40^{\circ} \mathrm{C}$ and pressure) are similar to those of condition No. 2. Shear deformation values at $\mathrm{F}_{\max }$ are between $1.9 \mathrm{~mm}$ and $2.2 \mathrm{~mm}$.

For the second interface of pavement 3 (Figure 4.20), the influence of water conditioning is leading to a decrease in both shear force (stress) and shear stiffness from condition No. 1 (no water) to condition No. 4 (water $40^{\circ} \mathrm{C}$ and pressure). For pavement 3 the decrease for condition No. 4 is found to be the biggest for all pavements which were tested at that condition. 


\subsubsection{Comparison Shear Box and LPDS, pavements 1 and 2, interface 1}

For the first interface of pavements 1 and 2, a comparison between the maximum shear stress results from Shear Box without normal stress and LPSD is possible. However, one has to keep in mind that both tests were conducted at different deformation rates (Shear Box: $2.5 \mathrm{~mm} / \mathrm{min}$, LPDS: $50 \mathrm{~mm} / \mathrm{min}$ ) - a fact that will definitely have an influence on the magnitude of the maximum shear stress. The mean values of the maximum shear stress for both test methods are compared in Table 4.8.

Table 4.8: Shear Box (without normal stress) and LPDS test results for pavements 1 and 2, interlayer 1 (standard deviation in brackets)

\begin{tabular}{|c|c|c|}
\hline & Shear stress [MPa] & Shear stress [MPa] \\
\hline & Pavement 1, interface 1 & Pavement 2, interface 1 \\
\hline Shear Box & $1.2(0.19)$ & $1.2(0.13)$ \\
\hline LPDS & $1.7(0.12)$ & $1.9(0.18)$ \\
\hline
\end{tabular}

The comparison between the maximum shear stress determined with the Shear Box and with LPDS shows that the maximum shear stress achieved from LPDS testing is for both pavements about 1.5 times higher than the one from Shear Box testing. This finding can be explained with the different deformation rates and other differences between both test methods, but it is not totally in agreement with the results from other researchers who found a value of 2 to 3 to convert maximum Shear Box stresses into maximum LPDS stresses (Canestrari et al., 2005). A reason for this difference could be found in the different Shear Box equipment and in the difference of the investigated 
mixtures. While in this investigation the Shear Box from the Geotechnical Institute at ETH (Swiss Federal Institute of Technology) in Zurich was applied, Canestrari et al. used the Ancona Shear Testing Research and Analysing apparatus ASTRA (Santagata and Canestrari, 1993). There was also a difference in materials: The material investigated by Canestrari et al. consisted of two dense asphalt layers, while the specimens in the present research had always a surface layer with air void contents of more than 10 vol- $\%$.

\subsubsection{Effect of low temperature}

\subsubsection{Shear test results}

Shear testing and the evaluation of shear force and shear stiffness values as well as the construction of mean shear force - shear deformation curves was conducted. As described earlier, both, the shear characteristics at the interface and within the individual layers (inlayer shear testing) were determined.

Table 4.9 shows all results of in-layer and interlayer shear testing for slabs 1 and 2 at different temperatures. The Table gives the mean values from 4 to 8 (normally 6) repetitions and the standard deviation is given in brackets. 
Table 4.9: Mean values of LPDS test results (standard deviations in brackets)

\begin{tabular}{|c|c|c|c|c|c|c|c|}
\hline \multirow[t]{3}{*}{ Layer } & \multirow{3}{*}{$\begin{array}{l}\text { Temp } \\
{\left[{ }^{\circ} \mathrm{C}\right]}\end{array}$} & \multirow{2}{*}{\multicolumn{2}{|c|}{ 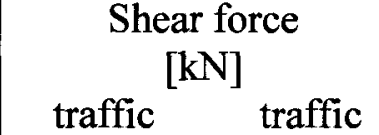 }} & \multicolumn{2}{|c|}{$\begin{array}{c}\text { Shear stress } \\
{[\mathrm{MPa}]}\end{array}$} & \multicolumn{2}{|c|}{$\begin{array}{l}\text { Shear deformation at } \\
\mathrm{F}_{\max }[\mathrm{mm}]\end{array}$} \\
\hline & & & & traffic & no traffic & traffic & no traffic \\
\hline & & slab 1 & slab 2 & slab 1 & slab 2 & slab 1 & slab 2 \\
\hline Layer 1 & 20 & $30.7(3.6)$ & - & $1.8(0.2)$ & - & $2.8(0.6)$ & - \\
\hline Layer 2 & 20 & $85.7(7.2)$ & $\begin{array}{ll}- \\
-\end{array}$ & $4.9(0.4)$ & - & $2.5(0.4)$ & - \\
\hline Layer 3 & 20 & $89.6(7.3)$ & - & $5.1(0.4)$ & - & $1.6(0.2)$ & - \\
\hline Layer 4 & 20 & $40.6(6.7)$ & - & $2.3(0.4)$ & - & $2.0(0.6)$ & - \\
\hline $\begin{array}{c}\text { Interlayer } \\
12\end{array}$ & $\begin{array}{c}20 \\
0 \\
-20\end{array}$ & $\begin{array}{c}42.0(3.2) \\
- \\
69.0(9.5)\end{array}$ & $\begin{array}{l}34.1(6.3) \\
75.1(6.1) \\
70.6(15)\end{array}$ & $\begin{array}{c}2.4(0.2) \\
- \\
3.9(0.5)\end{array}$ & $\begin{array}{l}1.9(0.4) \\
4.3(0.3) \\
4.0(0.9)\end{array}$ & $\begin{array}{c}2.0(0.4) \\
- \\
0.7(0.05)\end{array}$ & $\begin{array}{l}2.7(0.2) \\
1.2(0.1) \\
1.0(0.2)\end{array}$ \\
\hline $\begin{array}{c}\text { Interlayer } \\
23\end{array}$ & $\begin{array}{c}20 \\
0 \\
-20\end{array}$ & $\begin{array}{c}29.5(5.3) \\
- \\
-\end{array}$ & $\begin{array}{l}27.4(9.6) \\
30.3(6.6) \\
17.7(7.2)\end{array}$ & $\begin{array}{c}1.7(0.3) \\
- \\
-\end{array}$ & $\begin{array}{l}1.5(0.5) \\
1.7(0.4) \\
1.0(0.4)\end{array}$ & $\begin{array}{c}0.7(0.1) \\
- \\
-\end{array}$ & $\begin{array}{c}0.8(0.2) \\
0.6(0.05) \\
0.5(0.2)\end{array}$ \\
\hline $\begin{array}{c}\text { Interlayer } \\
34\end{array}$ & $\begin{array}{c}20 \\
0 \\
-20\end{array}$ & $\begin{array}{c}36.5(1.0) \\
- \\
27.0(7.4)\end{array}$ & $\begin{array}{l}14.9(2.9) \\
21.6(5.5) \\
17.2(5.2)\end{array}$ & $\begin{array}{c}2.1(0.1) \\
- \\
1.5(0.3)\end{array}$ & $\begin{array}{l}0.8(0.2) \\
1.2(0.3) \\
1.0(0.3)\end{array}$ & $\begin{array}{c}1.1(0.1) \\
- \\
0.5(0.05)\end{array}$ & $\begin{array}{c}0.8(0.1) \\
0.5(0.1) \\
0.5(0.08)\end{array}$ \\
\hline
\end{tabular}

\begin{tabular}{|c|c|c|c|c|c|}
\hline \multirow{2}{*}{ Layer } & \multirow{2}{*}{$\begin{array}{c}\text { Temp } \\
{\left[{ }^{\circ} \mathrm{C}\right]}\end{array}$} & \multicolumn{2}{|c|}{$\begin{array}{c}\text { Shear stiffness } \\
\text { traffic }\end{array}$} & \multicolumn{2}{c|}{ Shear reaction } \\
& & no traffic & \multicolumn{2}{c|}{\begin{tabular}{c}
\multicolumn{2}{c|}{ tradulus $[\mathrm{MPa} / \mathrm{mm}]$} \\
traffic
\end{tabular}} \\
& & slab 1 & slab 2 & slab 1 & slab 2 \\
\hline Layer 1 & 20 & $17.5(2.9)$ & - & $1.0(0.2)$ & - \\
\hline Layer 2 & 20 & $45.0(6.3)$ & - & $2.6(0.4)$ & - \\
\hline Layer 3 & 20 & $64.0(7.2)$ & - & $3.6(0.4)$ & - \\
\hline Layer 4 & 20 & $30.3(8.0)$ & - & $1.7(0.5)$ & - \\
\hline Interlayer & 20 & $30.6(6.3)$ & $20.2(9.6)$ & $1.7(0.4)$ & $1.1(0.5)$ \\
12 & 0 & - & $62.6(2.8)$ & - & $3.5(0.2)$ \\
& -20 & $92.0(10)$ & $71.6(12.7)$ & $5.2(0.6)$ & $4.1(0.7)$ \\
\hline Interlayer & 20 & $42.0(3.2)$ & $31.7(9.6)$ & $2.3(0.2)$ & $1.8(0.5)$ \\
23 & 0 & - & $52.1(9.4)$ & - & $3.0(0.5)$ \\
& -20 & - & $40.3(10.4)$ & - & $2.3(0.6)$ \\
\hline Interlayer & 20 & $39.1(2.5)$ & $20.8(5.2)$ & $2.2(0.1)$ & $1.2(0.3)$ \\
34 & 0 & - & $39.6(4.1)$ & - & $2.2(0.2)$ \\
& -20 & $51.0(12.8)$ & $35.2(9.4)$ & $2.9(0.7)$ & $2.0(0.5)$ \\
\hline
\end{tabular}




\subsubsection{In-layer and interlayer behaviour}

Since in-layer testing was only conducted for slab 1 (after trafficking), Figures 4.21 to 4.23 depict the comparison of in-layer and interlayer shear testing for this slab at a temperature of $20^{\circ} \mathrm{C}$.

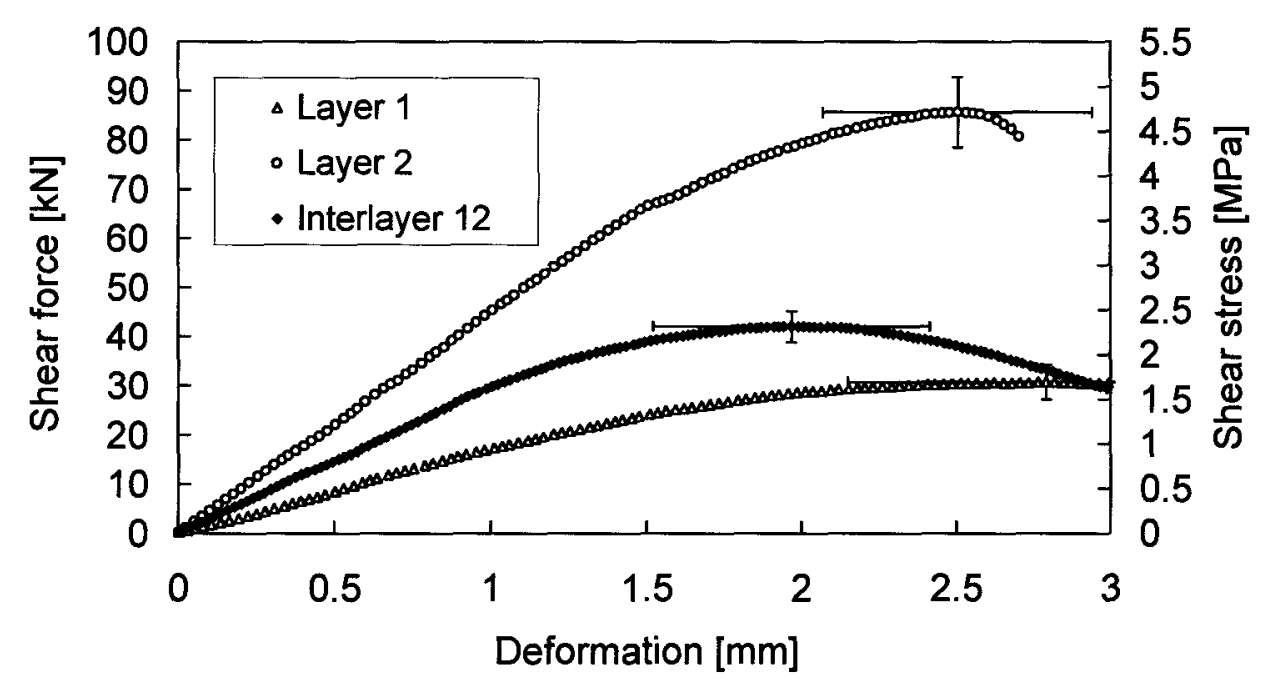

Figure 4.21: Comparison of in-layer and interlayer shear test curves for slab 1 at $20^{\circ} \mathrm{C}$, layers 1 and 2 


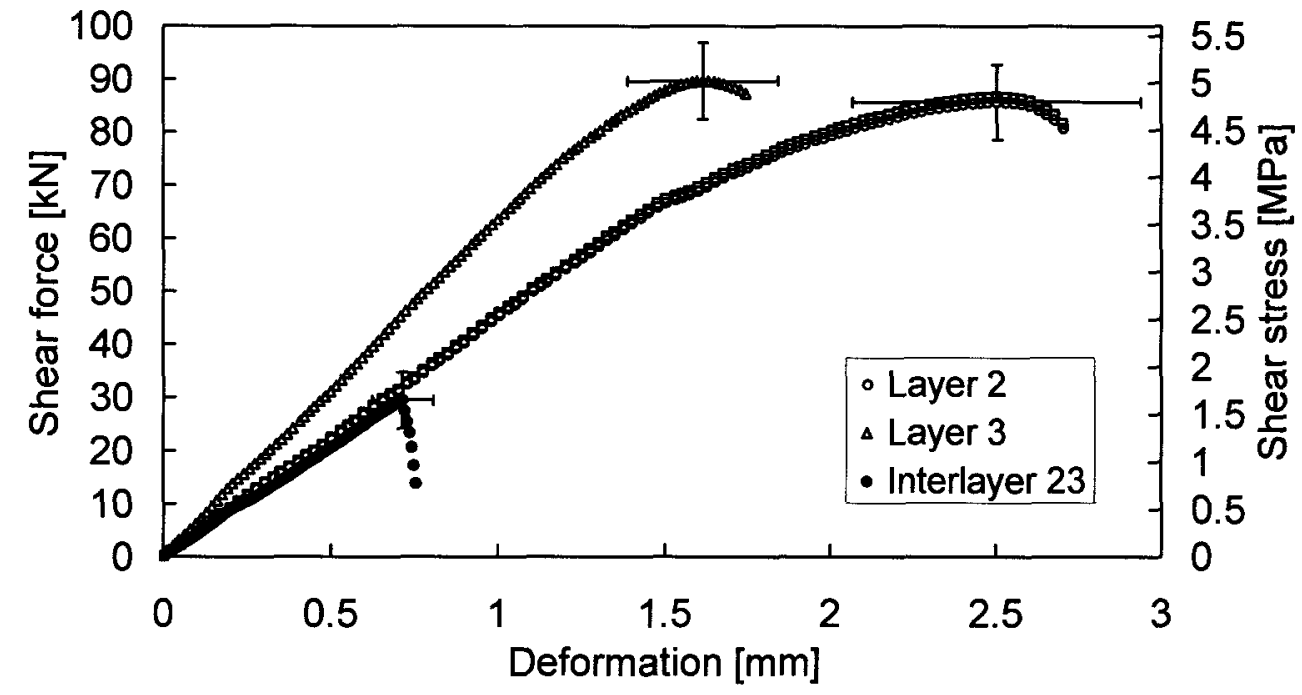

Figure 4.22: Comparison of in-layer and interlayer shear test curves for slab 1 at $20^{\circ} \mathrm{C}$, layers 2 and 3

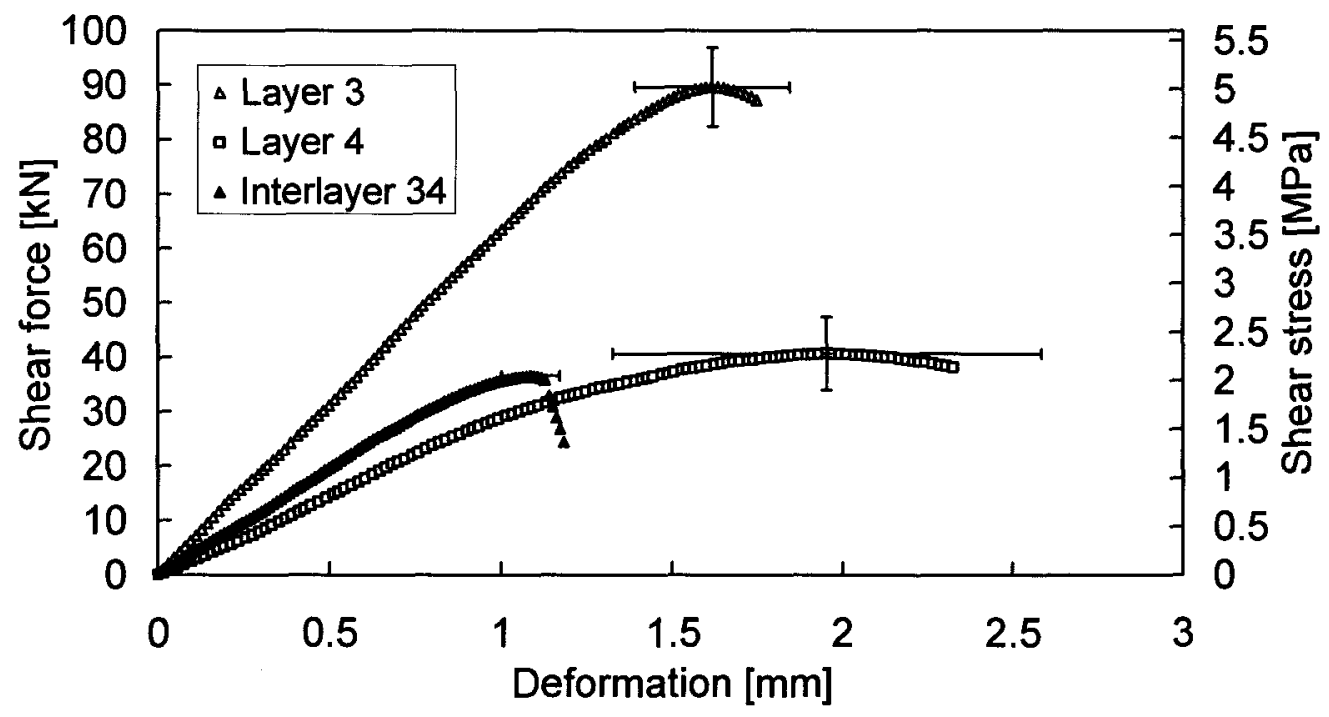

Figure 4.23: Comparison of in-layer and interlayer shear test curves for slab 1 at $20^{\circ} \mathrm{C}$, layers 3 and 4 
Comparing mean in-layer and interlayer results in form of the shear force - shear deformation curves for Layer 1 shows that both the maximum shear force of $42 \mathrm{kN}$ (or stress of $2.4 \mathrm{MPa}$ ) and the shear stiffness of $30.6 \mathrm{kN} / \mathrm{mm}$ are higher in the interface than in the material itself (maximum shear force of $30.7 \mathrm{kN}$, stress of $1.8 \mathrm{MPa}$ and stiffness of $17.5 \mathrm{kN} / \mathrm{mm}$ ). A similar observation was already reported for surface course materials in an earlier investigation (Partl and Raab, 1999).

The shear test for Layer 2 produced a maximum shear force of $85.7 \mathrm{kN}$ (or shear stress of $4.85 \mathrm{MPa}$ ) and a stiffness of $45 \mathrm{kN} / \mathrm{mm}$. These values are significantly higher than those of Layer 1 and of Interlayer 12. Layer 3 has the highest shear force and stiffness (maximum shear force of $89.6 \mathrm{kN}$, stress of $5.1 \mathrm{MPa}$, and stiffness of $64 \mathrm{kN} / \mathrm{mm}$ ), while bottom Layer 3, reveals the lowest inlayer behaviour of the two base courses, with mean values of $40.6 \mathrm{kN}$ for the maximum shear force, $2.3 \mathrm{MPa}$ for stress, and $30 \mathrm{~N} / \mathrm{mm}$ for stiffness.

For the Interlayer 23 , with a maximum shear stress of $1.7 \mathrm{MPa}$ and a shear stiffness of $42 \mathrm{kN} / \mathrm{mm}$ both being similar to Layer 2, a conclusion is difficult to draw since the interface experienced severe bonding problems. When compared to Interlayer 23, Interlayer 34 achieves a slightly higher maximum shear stress of $2.1 \mathrm{MPa}$ and a shear stiffness of $39 \mathrm{kN} / \mathrm{mm}$, which is between the stiffness of Layers 3 and 4 .

Generally, it was observed that the in-layer curves can normally be found between the interlayer curves, often tending to be closer to the one with the lower shear stiffness. 


\subsubsection{Temperature dependency}

Since, in the first investigation (slab 1), Interlayer 23 was found to have broken when testing Interlayer 12 at $-20^{\circ} \mathrm{C}$, for slab 2, Interlayer 23 was tested first. Therefore, in case of slab 2 shear forces and stresses are available for all three temperatures.

Figure 4.24 depicts the interlayer shear forces and shear stresses of slab 2 at temperatures of $+20^{\circ} \mathrm{C}, 0^{\circ} \mathrm{C}$ and $-20^{\circ} \mathrm{C}$, while Figure 4.25 shows the shear stiffness and shear reaction modulus results.

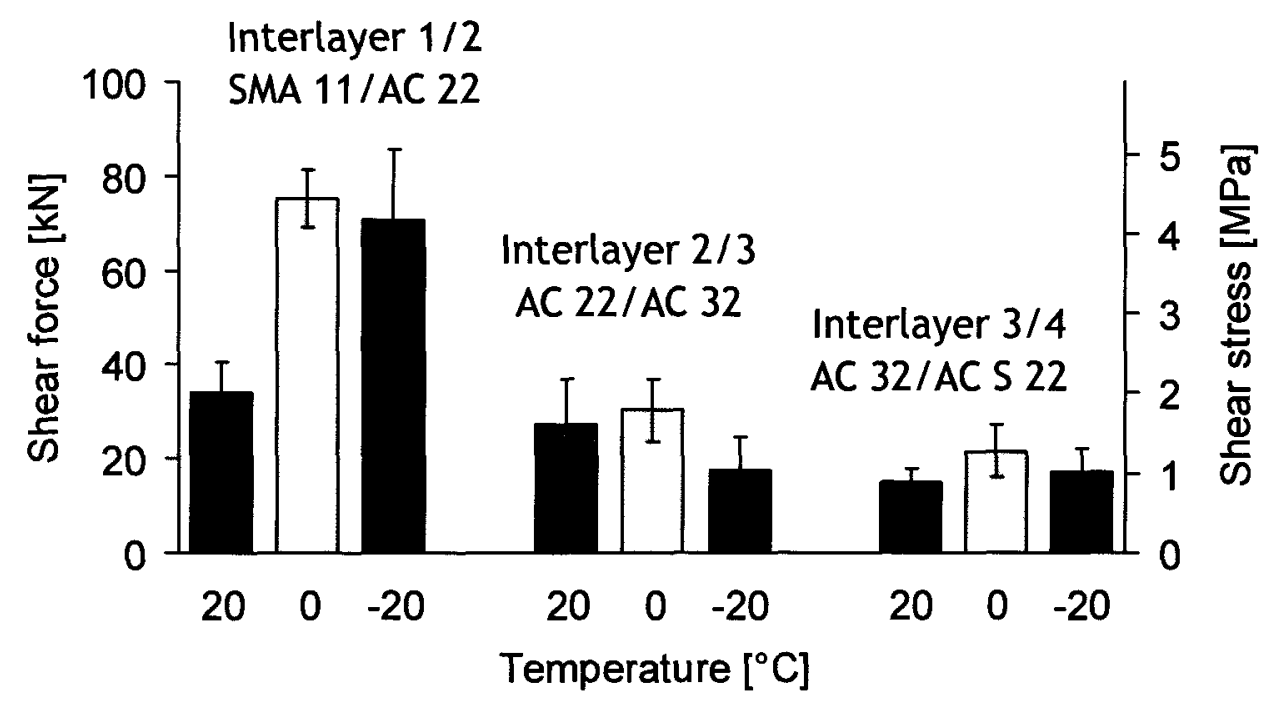

Figure 4.24: Shear forces and stresses of slab 2 at temperatures of $20^{\circ} \mathrm{C}, 0^{\circ} \mathrm{C}$ and $-20^{\circ} \mathrm{C}$ 


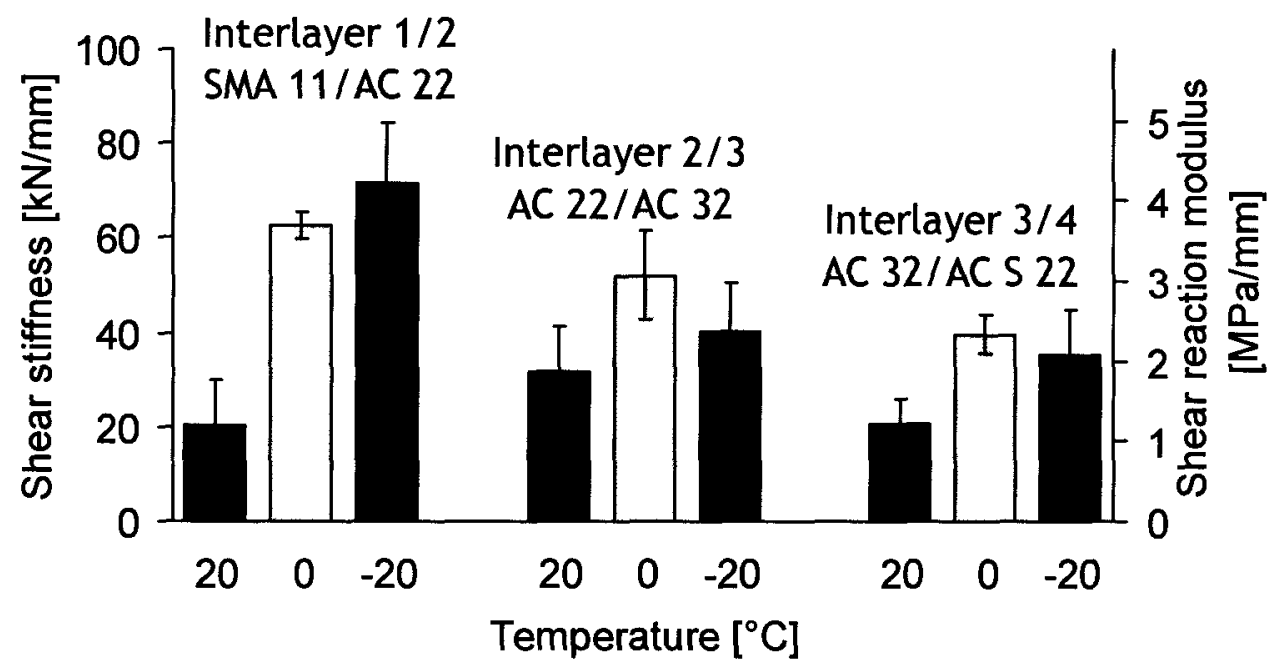

Figure 4.25: Shear stiffness and shear reaction modulus of slab 2 at temperatures of $20^{\circ} \mathrm{C}, 0^{\circ} \mathrm{C}$ and $-20^{\circ} \mathrm{C}$

Testing at lower temperature $\left(0^{\circ} \mathrm{C}\right.$ and $\left.-20^{\circ} \mathrm{C}\right)$ compared to testing at $+20^{\circ} \mathrm{C}$ leads as expected, to a more brittle behaviour resulting in generally higher shear forces and stiffness.

As for the results of slab 2 which was tested at three different temperatures, shear force, and in most cases shear stiffness are highest at $0^{\circ} \mathrm{C}$, whereas $-20^{\circ} \mathrm{C}$ seems to be a more critical temperature for shear testing. While for Interlayer 12 (slabs 1 and 2) the test results at $-20^{\circ} \mathrm{C}$ compared to the results at $+20^{\circ} \mathrm{C}$ lead to a significantly higher maximum shear force and shear stiffness, it is interesting to note that the rankings of shear test results for interlayer 34 (slab 1) and interlayer 23 (slab 2) are opposed (i.e. lower shear forces at $-20^{\circ} \mathrm{C}$ ). It seems that interlayer bond deficiencies or defects as observed with Interlayer 23 are made more obvious when testing is performed at very low temperature, i.e. $-20^{\circ} \mathrm{C}$. 
It is interesting to note, that the shear force between the lower layers, especially layers $3 / 4$ is less influenced by the test temperature. The reason for this could be found in the fact that, these layers are composed of larger aggregates and show lower binder content and shear stress therefore mainly depends on the aggregate interlock.

\subsubsection{Traffic dependency}

Figure 4.26 depicts the interlayer shear forces and shear stresses of slabs 1 and 2 at temperatures of $+20^{\circ} \mathrm{C}$ and $-20^{\circ} \mathrm{C}$, while Figure 4.27 shows the shear stiffness and shear reaction modulus results.

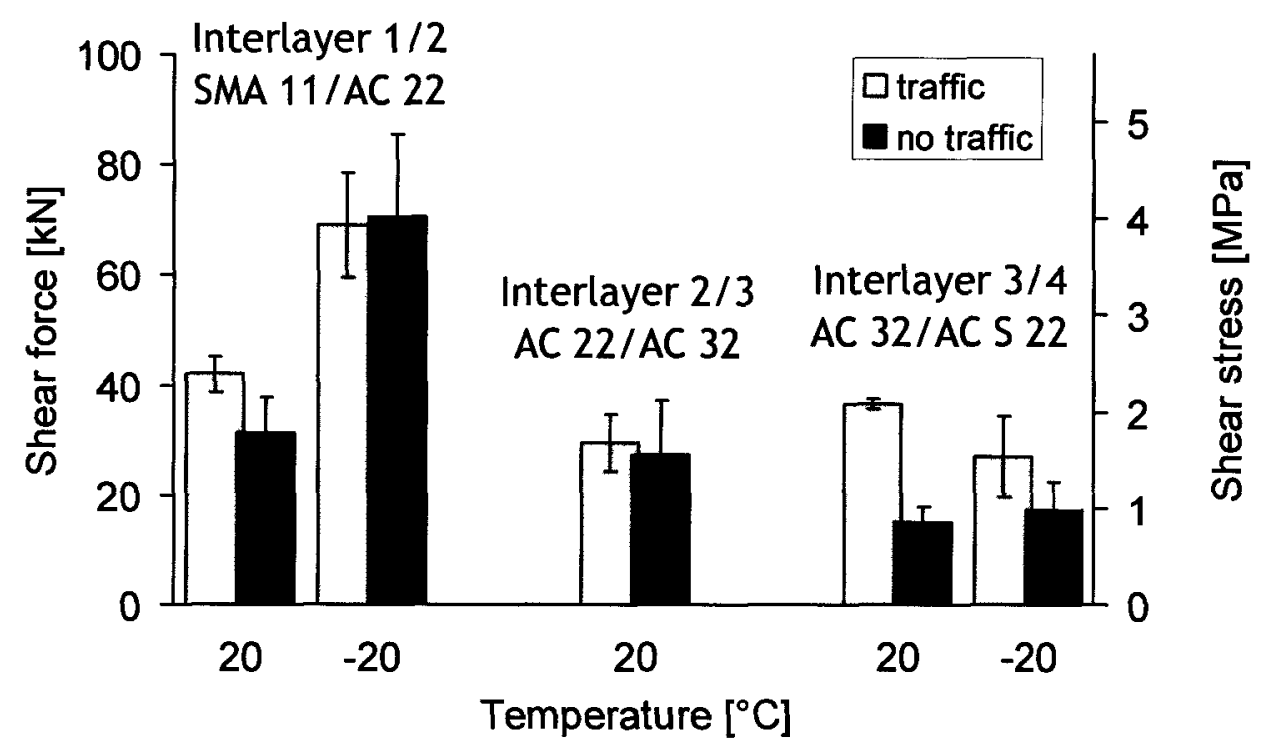

Figure 4.26: Shear force and stress of slabs 1 and 2 at temperatures of $20^{\circ} \mathrm{C}$ and $20^{\circ} \mathrm{C}$ 


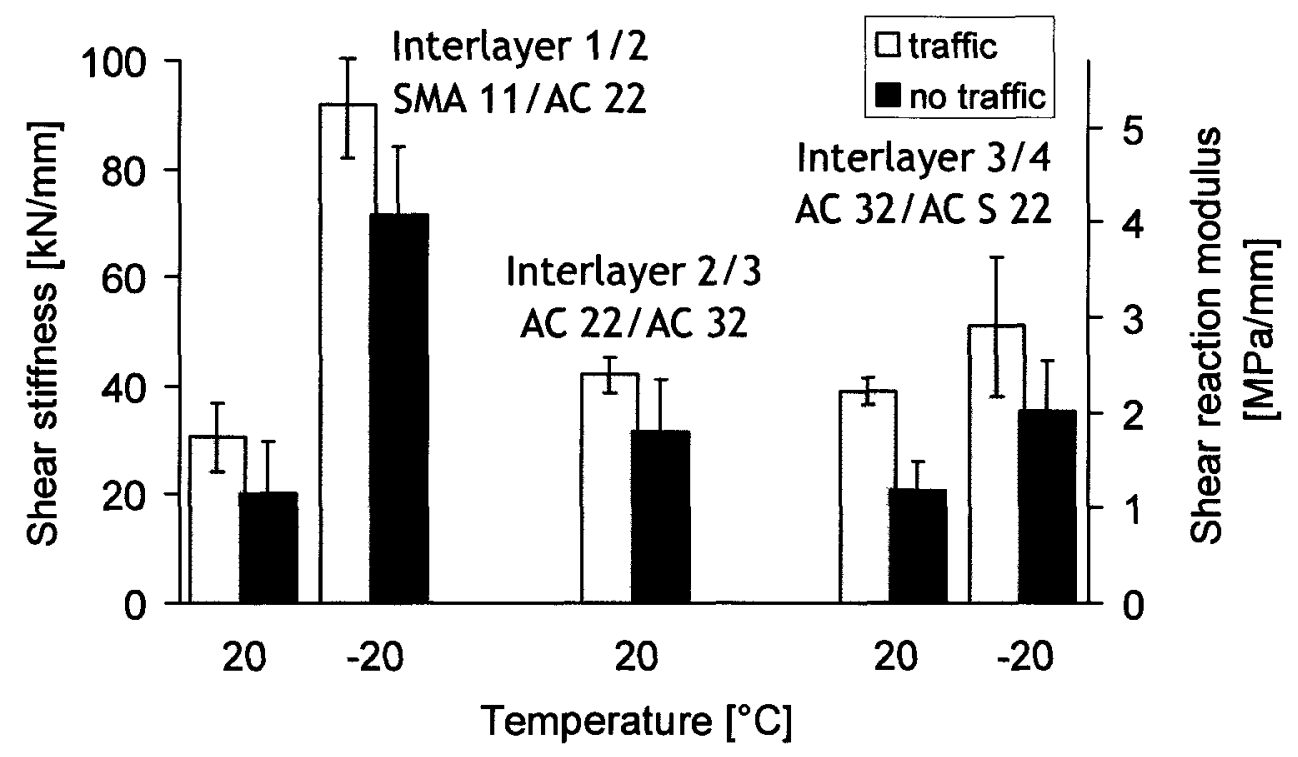

Figure 4.27: Shear stiffness and reaction modulus of slabs 1 and 2 at temperatures of $20^{\circ} \mathrm{C}$ and $-20^{\circ} \mathrm{C}$

That the shear force and stiffness results for slab 1 are generally higher than the ones for slab 2 (although the asphalt design and material is identical) can be attributed to the fact that the slab 1 had been taken 8 years after construction and trafficking (2006). This confirms the findings of other investigations by Raab and Partl which showed that there is an increase of shear force and stiffness in case of intact and well designed pavements after trafficking (Raab and Partl, 2008, Raab and Partl, 2009). 


\subsubsection{Effect of gap width}

\subsubsection{Shear Force and shear stresses}

In Table 4.10 and Figure 4.28 the mean maximum interlayer and in-layer shear forces and stresses for all investigated interfaces and mixture types for gap widths of $0 \mathrm{~mm}, 2.5 \mathrm{~mm}$ and $5.0 \mathrm{~mm}$ are shown. In Figure 4.28 the standard deviations are also given.

For the interface between SMA and AC B the shear forces decrease with increasing gap width, while for the interface between $\mathrm{AC} B$ and $\mathrm{AC} T$ the values show no significant difference. In case of the AC T/AC S interface a tendency towards a decrease at a gap width of $5.0 \mathrm{~mm}$ can be found. The observation of decreasing shear forces and shear stresses with increasing gap width could be explained by the fact that with increasing gap width, the shear plain is less concentrated at a certain location and therefore the failure happens at the weakest place of the specimens leading to lower shear forces.

It is interesting to note, that in the presented case, the gap width appears to play a more dominant role for interlayer shear properties in cases where both layers show comparatively clear differences in composition and mechanical properties. This is true for SMA 11 and AC B 22, which are very different in terms of aggregate size, binder grade, binder content and also show different in-layer shear properties, as well as in case of $\mathrm{AC}$ T 32 and AC S 22, which are different in terms of binder grade and air void content. For AC B 22 and AC T 32 with similar air void and binder contents this is not the case. 


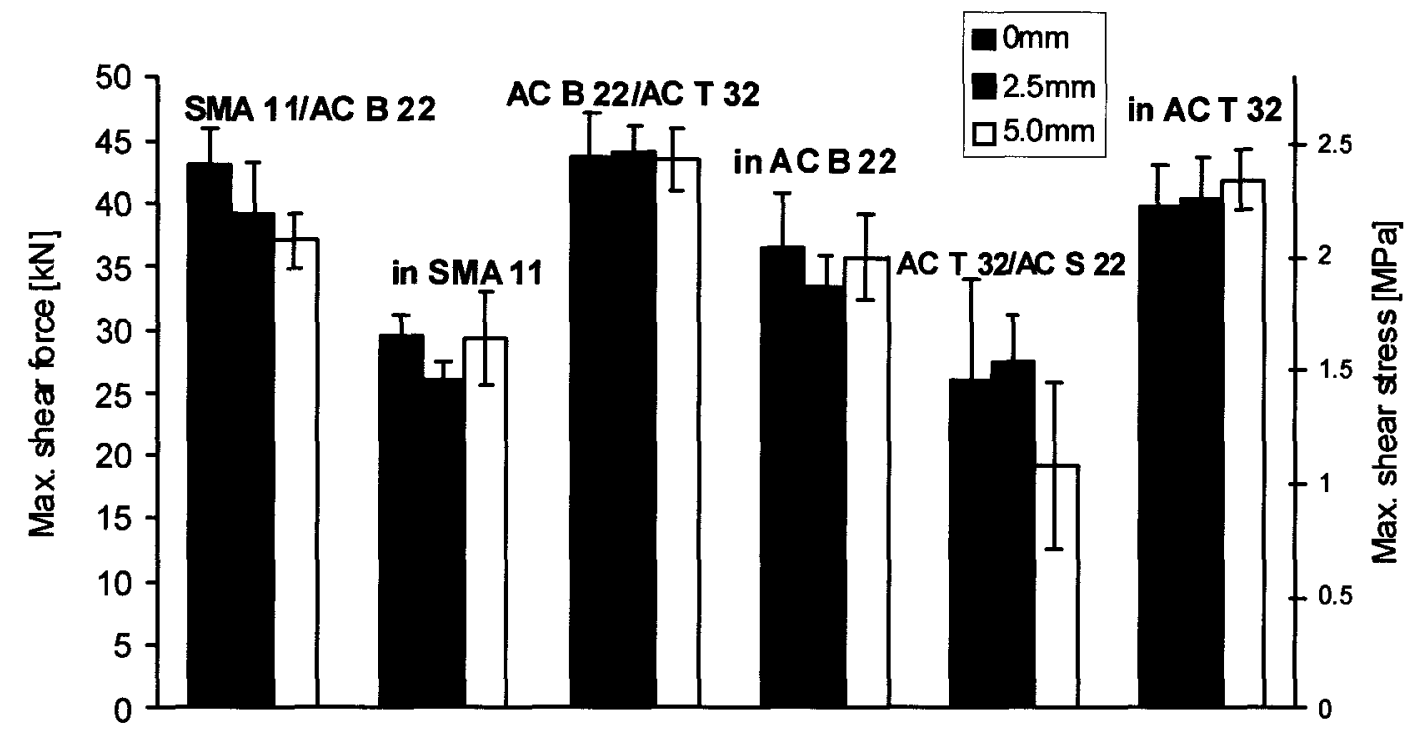

Figure 4.28: Mean values of the maximum interlayer and in-layer shear forces and stresses with gap widths of $0 \mathrm{~mm}, 2.5 \mathrm{~mm}$ and $5.0 \mathrm{~mm}$, mean value and standard deviation

\subsubsection{Shear stiffness (shear reaction modulus)}

Table 4.10 and Figure 4.29 show the mean maximum interlayer and in-layer shear stiffness values $S$ and the shear reaction modulus $K$ for all investigated interfaces and mixture types for gap widths of $0 \mathrm{~mm}, 2.5 \mathrm{~mm}$ and $5.0 \mathrm{~mm}$. In Figure 4.29 the standard deviations are also given.

Regarding the shear stiffness value, the findings are similar to the ones for the shear forces: For the SMA/AC B and the AC T/AC S interface the shear stiffness value determined with a $5 \mathrm{~mm}$ gap width was lower than the one with $0 \mathrm{~mm}$ gap width. Again, for the AC B/AC T interface, no dependency on the gap width can be observed.

For in-layer testing, the differences are negligible: The in-layer shear stiffness value within the $\mathrm{AC} T 32$ appears slightly higher than for a $0 \mathrm{~mm}$ gap when testing with 
Table 4.10: Results from shear testing

\begin{tabular}{|c|l|l|l|c|c|c|}
\hline \multicolumn{1}{|c|}{ Shear plane } & $\begin{array}{c}\text { Gap } \\
\text { width } \\
{[\mathrm{mm}]}\end{array}$ & $\begin{array}{c}\text { Shear } \\
\text { force } \\
{[\mathrm{kN}]}\end{array}$ & $\begin{array}{c}\text { Shear } \\
\text { stress } \\
{[\mathrm{MPa}]}\end{array}$ & $\begin{array}{c}\text { Shear } \\
\text { deformation } \\
{[\mathrm{mm}]}\end{array}$ & $\begin{array}{c}\text { Shear } \\
\text { stiffness } \\
\mathrm{S} \\
{[\mathrm{kN} / \mathrm{mm}]}\end{array}$ & $\begin{array}{c}\text { Shear } \\
\text { reactionmodulus } \\
\text { K } \\
{[\mathrm{MPa} / \mathrm{mm}]}\end{array}$ \\
\hline \multirow{3}{*}{ SMA 11/AC B 22 } & 0 & 43.2 & 2.4 & 2.3 & 25.6 & 1.4 \\
& 2.5 & 39.2 & 2.5 & 2.4 & 20.4 & 1.2 \\
& 5.0 & 37.0 & 2.1 & 2.5 & 20.8 & 1.2 \\
\hline \multirow{3}{*}{ AC B 22/AC T 32 } & 0 & 43.6 & 2.5 & 1.8 & 30.2 & 1.7 \\
& 2.5 & 44.3 & 2.5 & 1.9 & 29.5 & 1.7 \\
& 5.0 & 43.6 & 2.5 & 1.9 & 29.2 & 1.7 \\
\hline \multirow{3}{*}{ AC T 32/AC S 22 } & 0 & 26.0 & 1.5 & 0.9 & 30.5 & 1.7 \\
& 2.5 & 27.6 & 1.6 & 1.0 & 31.4 & 1.8 \\
& 5.0 & 19.3 & 1.1 & 0.8 & 26.8 & 1.5 \\
\hline In SMA 11 & 0 & 29.5 & 1.7 & 4.4 & 11.3 & 0.6 \\
& 2.5 & 26.0 & 1.5 & 3.2 & 12.9 & 0.7 \\
& 5.0 & 29.3 & 1.7 & 4.2 & 12.8 & 0.7 \\
\hline In AC B 22 & 0 & 36.6 & 2.1 & 3.0 & 21.6 & 1.2 \\
& 2.5 & 33.6 & 1.9 & 3.0 & 21.2 & 1.2 \\
& 5.0 & 35.8 & 2.0 & 2.9 & 21.5 & 1.2 \\
\hline In AC T 32 & 0 & 39.8 & 2.3 & 2.4 & 25.3 & 1.4 \\
& 2.5 & 40.6 & 2.3 & 2.2 & 28.8 & 1.6 \\
& 5.0 & 42.0 & 2.4 & 2.4 & 27.7 & 1.6 \\
\hline
\end{tabular}

Regarding the in-layer shear forces no significant systematic influence of the gap width could be observed: In the SMA, the mean maximum shear forces for $0 \mathrm{~mm}$ and $5.0 \mathrm{~mm}$ are identical. The value for a $2.5 \mathrm{~mm}$ gap is slightly smaller. This behaviour can also be found for the second layer (AC B 22), while for the AC T 32 layer the mean shear force increases with increasing gap width. 


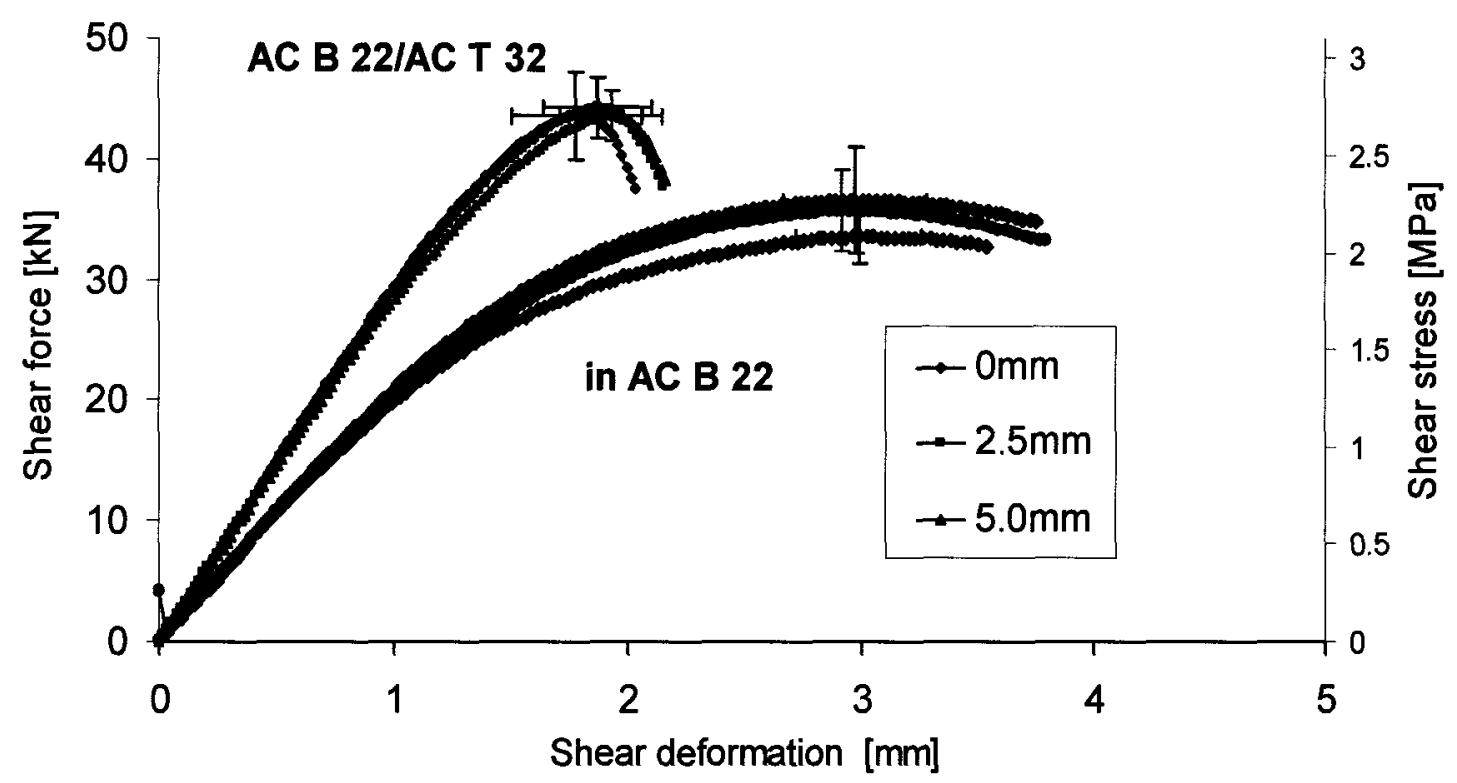

Figure 4.31: Mean shear force-deformation curves AC-B22/AC-T322 with standard deviation for gap widths of $0 \mathrm{~mm}, 2.5 \mathrm{~mm}$ and $5 \mathrm{~mm}$

This process takes place during the whole shear test but becomes more dominant with increasing load. Hence, this type of behaviour is based on a successive process with ductile appearance. The interlayer shear behaviour, on the other hand, is governed by the adhesion of two planes, which means that the whole plane has to be moved at once to produce shear failure. After local adjustment at the beginning of the test, which was eliminated in this study by using the tangent and horizontal shifting the curve as described in Chapter 3, the interlayer system tends to react stiff and failure occurs almost suddenly without large deformations. 
2.5 and $5.0 \mathrm{~mm}$ gaps, while for the in-layer testing of the SMA 11 and AC B 22 no difference could be found.

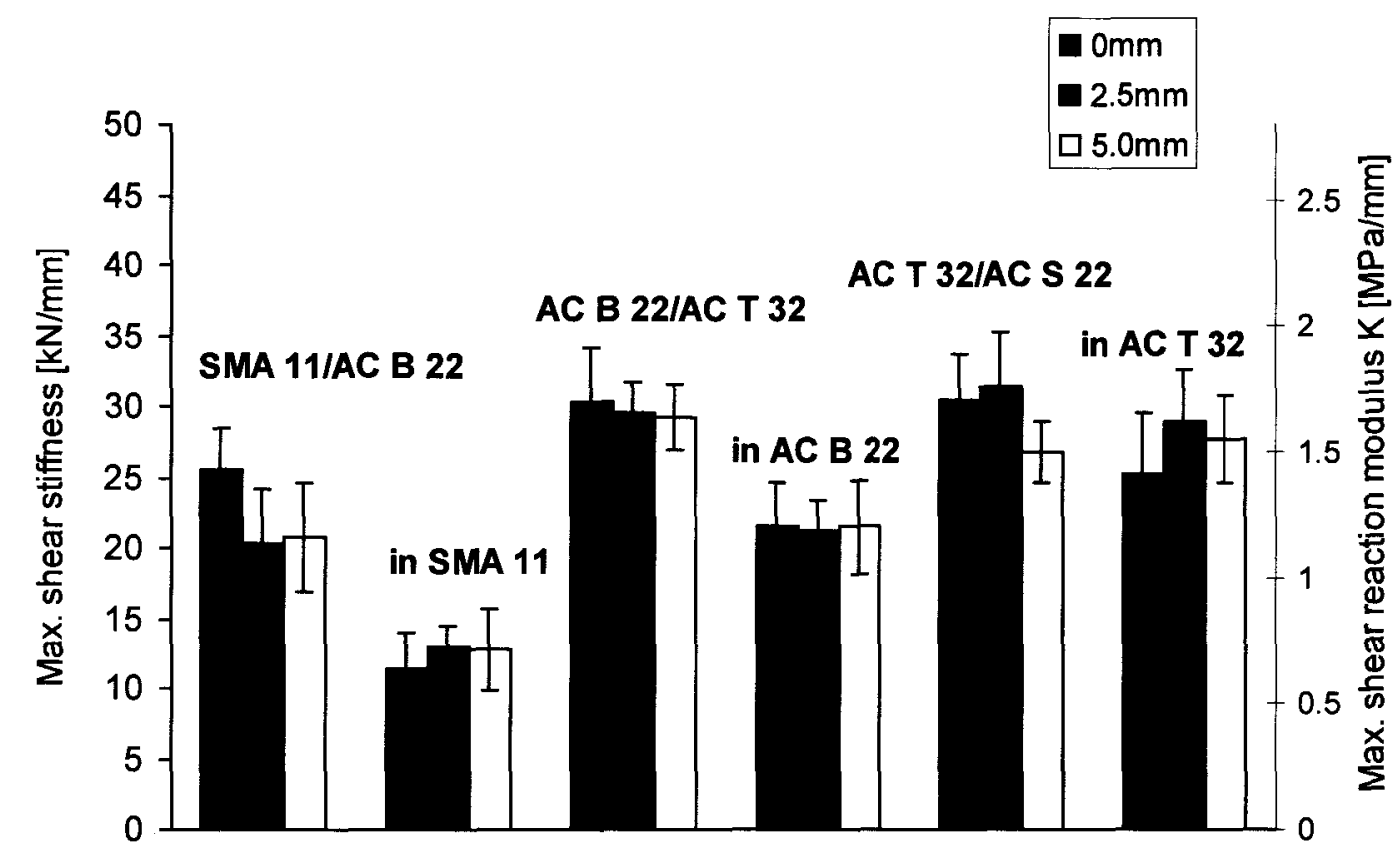

Figure 4.29: Mean values of the maximum interlayer and in-layer stiffness and shear reaction modulus with gap widths of $0 \mathrm{~mm}, 2.5 \mathrm{~mm}$ and $5.0 \mathrm{~mm}$, mean value and standard deviation

\subsubsection{Interlayer and in-layer shear behaviour}

In Figure 4.30, the mean shear force - shear deformation curves for the interlayer testing between the stone mastic asphalt surface course SMA 11 and the asphalt concrete binder course AC B 22 as well as the in-layer testing in the SMA 11 surface course layer are depicted. Figure 4.31 shows the same curves for the $\mathrm{AC} B / \mathrm{AC} T$ interlayer and the $\mathrm{AC} \mathrm{B}$ 22 in-layer testing. 
Regarding the difference of interlayer and in-layer shear behaviour, the qualitative difference between the curves is noteworthy: In-layer curves are flatter (less stiff) and show more deformation than interlayer curves. Further, the scatter of deformation is larger than the one of shear force respectively shear stress.

It has been found earlier (Raab and Partl, 1999) that the interlayer adhesion behaviour between surface and binder courses is often less ductile (and therefore stiffer) than the in-layer shear behaviour of the pavement. This has been explained by the fundamental difference between both shear behaviours. The in-layer shear properties depend on the micro-structural interlock of the components. Due to the inhomogeneities of the material and depending on compaction and composition, the interlock and contact forces between the individual components are only fully mobilised if some deformation and reorientation of the aggregates within the material has been possible.

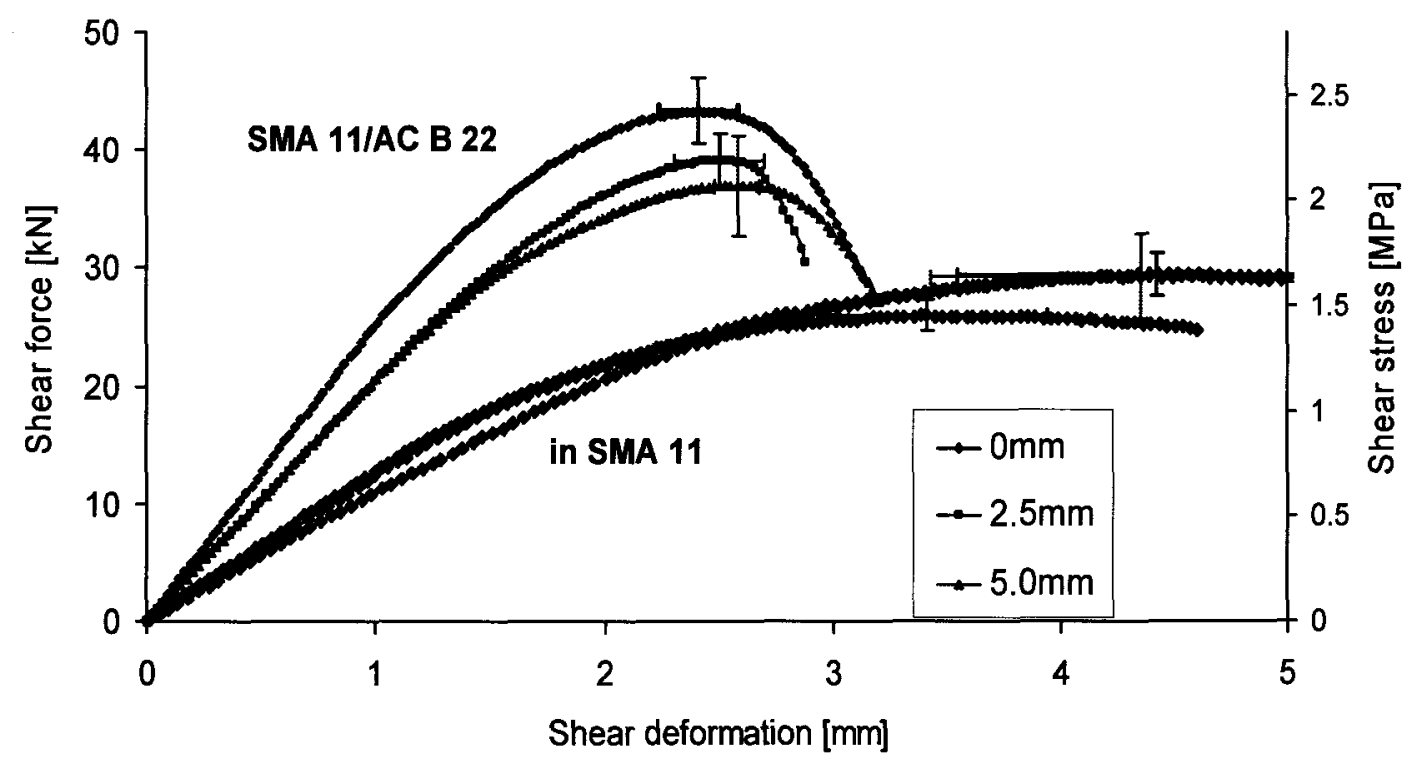

Figure 4.30: Mean shear force-deformation curves SMA 11/AC-B 22 with standard deviation for gap widths of $0 \mathrm{~mm}, 2.5 \mathrm{~mm}$ and $5 \mathrm{~mm}$ 


\section{CHAPTER 5}

\section{Data Mining Investigation}

\subsection{Description of datasets}

\subsubsection{Introduction}

The data mining investigation is to take advantage of previous work which was done by the author of this thesis over the course of more than 15 years and led to the databases which were retrieved from different research projects, experiments and road pavement evaluations between 1993 and 2009 and used for the utilisation of artificial neural network ANN for the analysis of interlayer shear properties. The different datasets are presented in Sections 5.2 while the ANN analysis can be found in Section 6.2.

Within the above mentioned projects the interlayer bonding properties of newly constructed road pavements, laboratory pavements and pavement constructed under lablike conditions in the field, data on performance of interlayer bond with aging and trafficking were determined. All testing was performed in the same laboratory using comparable equipment. The testing can be divided into the following 5 datasets shown in Table 5.1. 
Table 5.1: Datasets for ANN

\begin{tabular}{|l|l|l|}
\hline No. & \multicolumn{1}{|c|}{ Titel } & \multicolumn{1}{|c|}{ Description } \\
\hline 1 & New Road & Newly constructed asphalt pavements, not in service \\
\hline 2 & LTPP Road & In service asphalt pavements (min. 10 years) \\
\hline 3 & Combi Road & Semi rigid (Combi) asphalt/concrete pavements \\
\hline 4 & Lab Pavement & Indoor laboratory small scale asphalt slabs \\
\hline 5 & RILEM Pavement & Outdoor large scale asphalt slabs \\
\hline
\end{tabular}

For each test specimen of every dataset the material characteristics as well as the results for shear force, shear stress, shear deformation at $F_{\max }$, shear stiffness $S$, shear reaction modulus $\mathrm{K}$ and secant modulus $\mathrm{M}$ are given in the Appendix $\mathrm{A}$.

\subsubsection{New Road}

In the mid 1990s the Swiss Federal Laboratories Empa was appointed by the Swiss Federal Road Administration (ASTRA) to evaluate a simple, practice oriented and standardisable test method for interlayer bond assessment between the top and the second layer of asphalt pavements (Raab and Partl, 1999, Partl and Raab, 1999).

The test method should be suitable as quality assurance (QA) tool for inspection immediately after pavement construction. In the course of this research project, a number of Swiss pavements constructed between 1993 and 1997 were investigated, providing a representative selection of materials used in Switzerland for heavy traffic roads during that period of time. In the course of the project only the bond between first (surface) and second layer should be evaluated. Since the construction took place before the European Standards became effective, all surface courses had been constructed according the old 
Swiss Standard (Swiss Standard SN 640431a, 1988). Figure 5.1 shows the location of all test sites in Switzerland and Table 5.2 gives an overview of all test sites, their structures, mixtures and the temperature of testing.

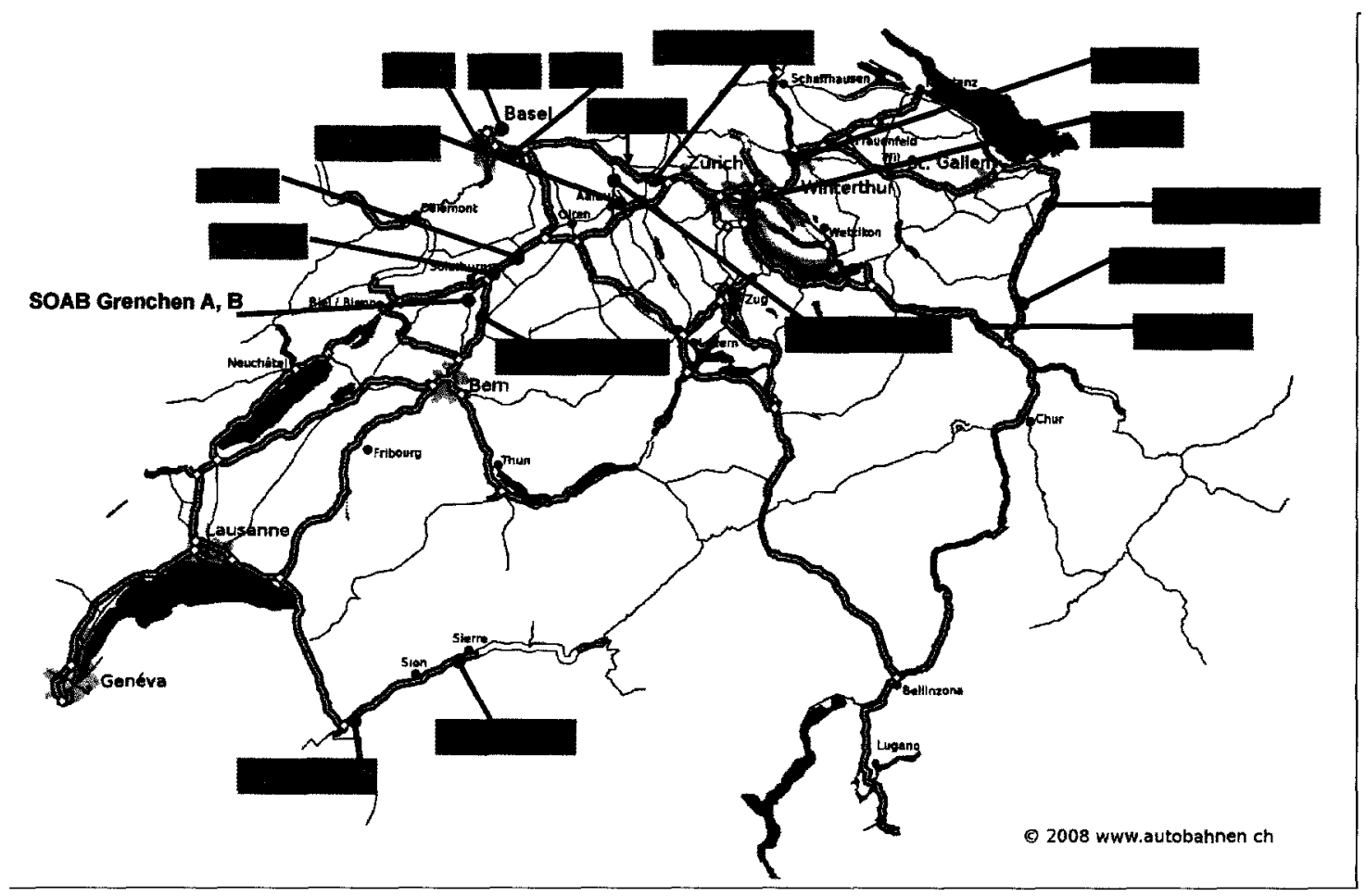

Figure 5.1: Location of Swiss test sites

(Source: Raab and Partl, 1999)

Most pavement surface courses consisted either of mastic asphalt (SMA) or asphalt concrete (AC): Nine pavements had stone mastic asphalt (SMA) and seven road sections had asphalt concrete (AC) surface courses. In addition, three coring sites with special surface courses, i.e. mastic asphalt (MA), hot-rolled asphalt (HR) and porous asphalt (PA) were included. The surface courses were placed either on asphalt concrete 
layers (AC) with a nominal maximum aggregate size of $10,16,22$ or $32 \mathrm{~mm}$ or on mastic asphalt (MA) with a maximum aggregate size of $16 \mathrm{~mm}$ each.

Figures 5.2 to 5.6 show the gradation curve limits for all new first and second layers according to the Swiss standards SN EN 640430, 2008 for asphalt concrete and SN EN 640441, 2008, for mastic asphalt.

The investigated asphalt pavements were either new constructions or rehabilitations of first and second layers. Therefore, all surface and second layers apart from three binder courses and one upper base layer were totally new. In two cases, pavements with new surface courses on unknown old base and binder courses were investigated. According to a binder extraction analysis in the lab, the mixture type of these unknown layers could be evaluated to be most probably AC 10 according to the Swiss standard from 1976 (Swiss Standard SN 640431, 1976). It is important to note, that the composition of binder courses was equal to the composition of base courses since at that time the Swiss construction practise did not distinguish between binder and base courses. In order to avoid confusion, all notations in Table 5.2 are according to the new Swiss standard, SN EN 640430, 2008 for asphalt concrete and SN EN 640441, 2008 for mastic asphalt. 
Table 5.2: New road pavements

\begin{tabular}{|l|l|l|c|c|}
\hline Name & Material & & \multicolumn{2}{|c|}{ Test temperature } \\
\hline & Layer 1 & Layer 2 & $20^{\circ} \mathrm{C}$ & $40^{\circ} \mathrm{C}$ \\
\hline BSG & SMA 11 & AC 22 & $\mathrm{x}$ & $\mathrm{x}$ \\
\hline BSM & SMA 11 & AC 32 & $\mathrm{x}$ & $\mathrm{x}$ \\
\hline BSS & SMA 11 & AC 32 & $\mathrm{x}$ & $\mathrm{x}$ \\
\hline AGSMA-95 & SMA 11 & AC 22 & $\mathrm{x}$ & $\mathrm{x}$ \\
\hline AGSMA-96 & SMA 11 & AC 22 & $\mathrm{x}$ & $\mathrm{x}$ \\
\hline ZHWall & SMA 11 & AC 16 & $\mathrm{x}$ & $\mathrm{x}$ \\
\hline WallisSMA & SMA 11 & AC 22 & $\mathrm{x}$ & $\mathrm{x}$ \\
\hline SOSMA & SMA 11 & AC 32 & $\mathrm{x}$ & - \\
\hline ZHTöss & SMA 11 & AC 16 & $\mathrm{x}$ & $\mathrm{x}$ \\
\hline SOAB & AC 11 & AC 32 & $\mathrm{x}$ & $\mathrm{x}$ \\
\hline AGHotroll & HR 11 & AC 22 & $\mathrm{x}$ & $\mathrm{x}$ \\
\hline AGGA & MA 11 & MA 16 & $\mathrm{x}$ & $\mathrm{x}$ \\
\hline WallisDRA & PA 11 & AC 16 & $\mathrm{x}$ & $\mathrm{x}$ \\
\hline SGMontlingen & SMA 11 & AC 22 & $\mathrm{x}$ & - \\
\hline SOABWasseramt & AC 11 & AC 32 & $\mathrm{x}$ & $\mathrm{x}$ \\
\hline SOABGrenchenA & AC 11 & AC 22 & $\mathrm{x}$ & - \\
\hline SOABGrenchenB & AC 11 & AC 22 & $\mathrm{x}$ & - \\
\hline SGABBuchs & AC 16 & AC 10 & $\mathrm{x}$ & - \\
\hline SGABFlums & AC 16 & AC 10 & $\mathrm{x}$ & - \\
\hline AGDensbüren & AC 11 & AC 16 & $\mathrm{x}$ & - \\
\hline
\end{tabular}



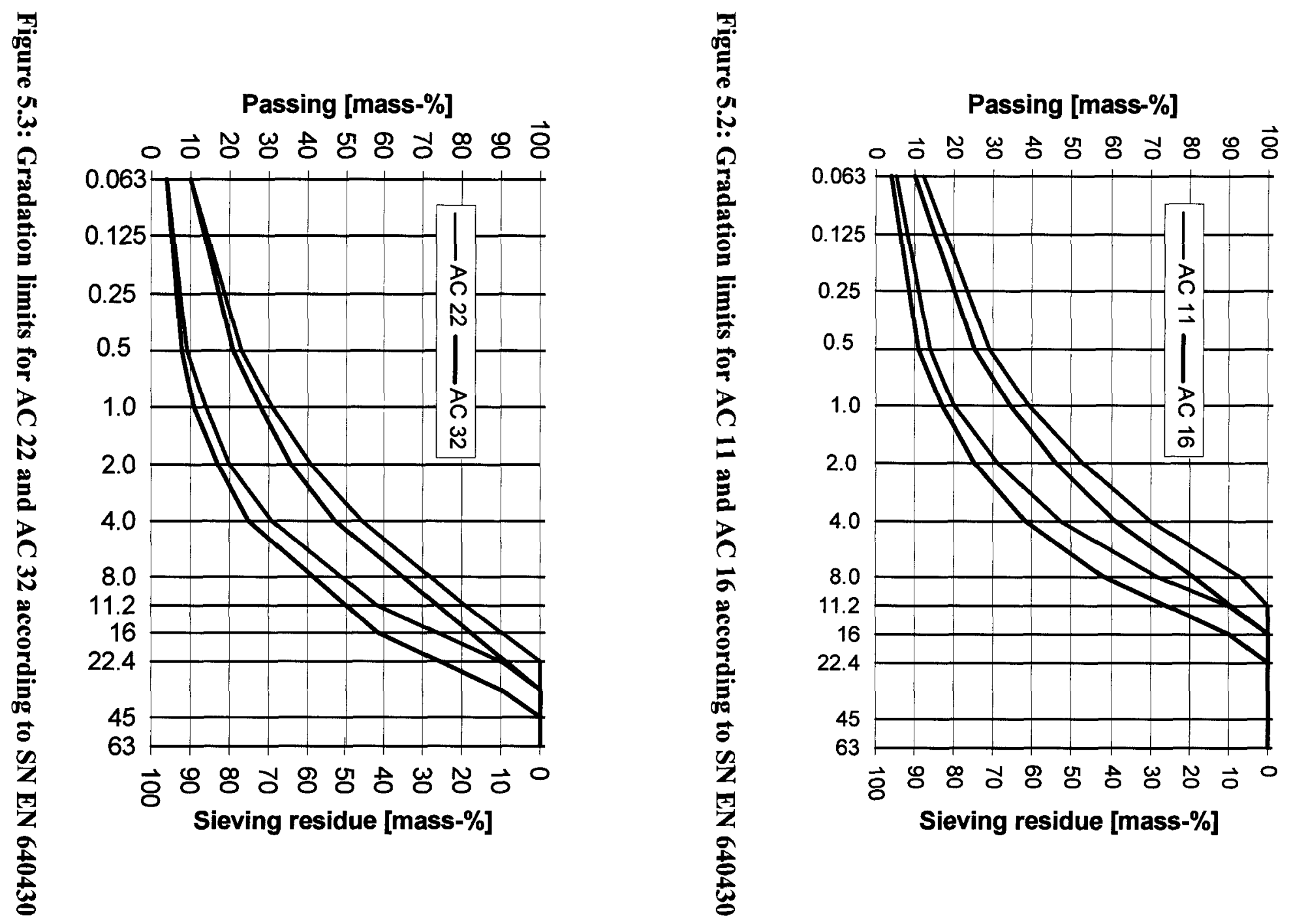

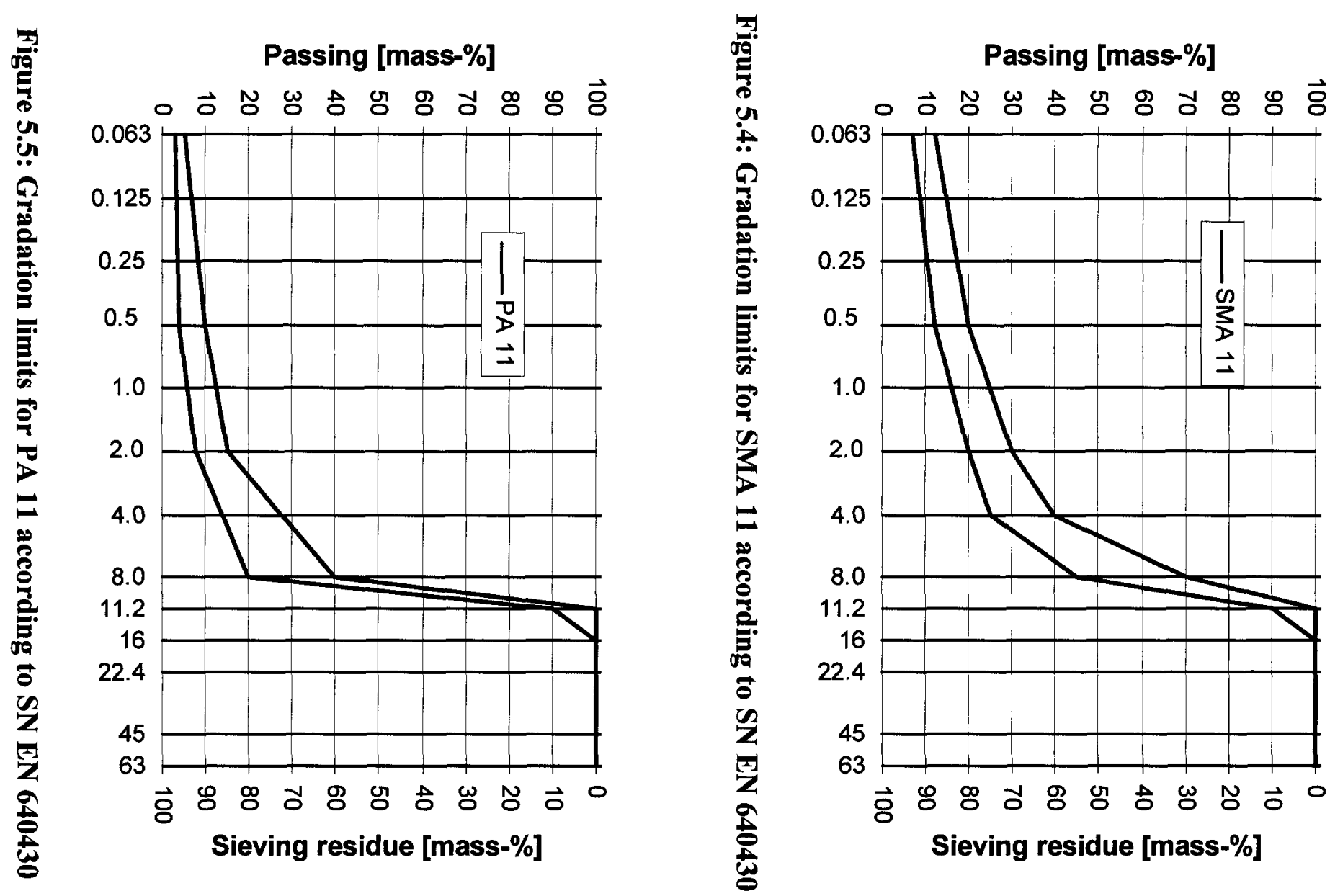


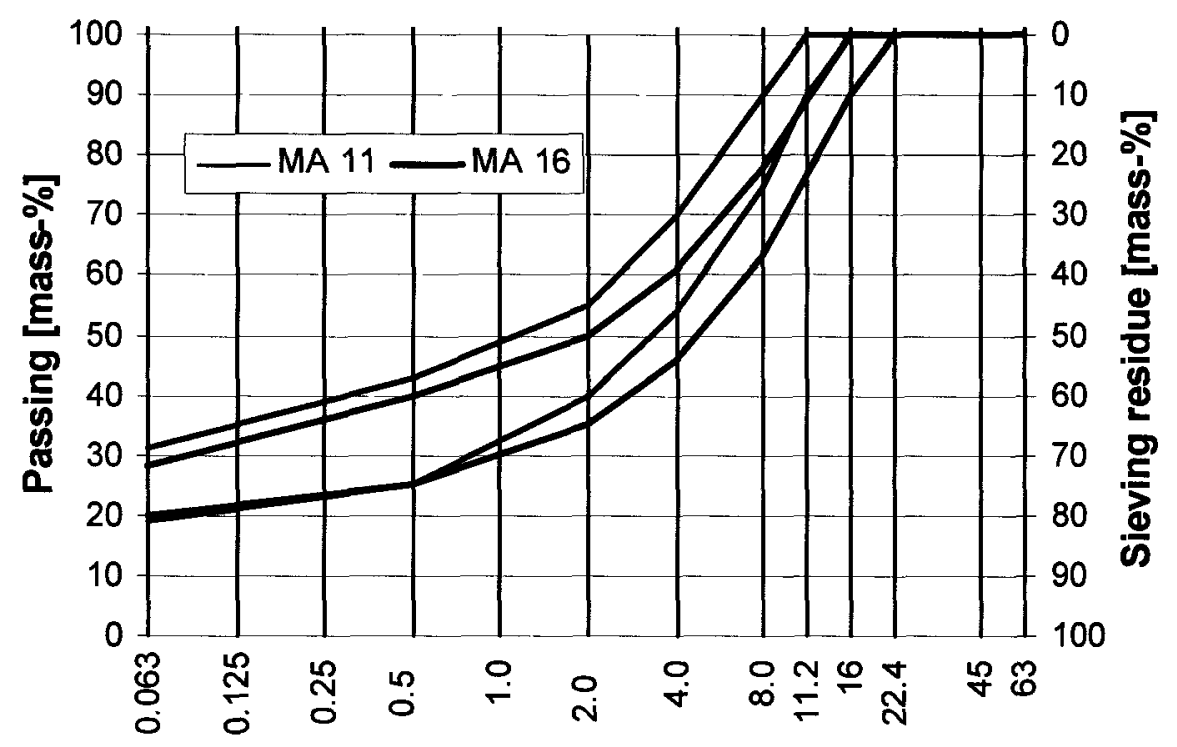

Figure 5.6: Gradation for MA 11 and MA 16 according to SN EN 640441

All new asphalt pavement mixes (1. and 2. layers) were analysed in the laboratory determining aggregate size distribution, binder content, Marshall values (stability, flow, air void content) and binder properties (penetration, softening point ring and ball). Furthermore, the air void content of the pavement layers (mean value) and the tack coat type was given.

For this investigation, at each test site, 40 cores were taken directly after construction of the pavement or pavement rehabilitation. From these cores, interlayer shear tests between the first and second layer were performed at temperatures of $20^{\circ} \mathrm{C}$ and $40^{\circ} \mathrm{C}$ using the LPDS shear device. In addition to the maximum shear force, the maximum shear stress, the maximum shear deformation, the maximum shear stiffness $\mathrm{S}$ and the maximum shear reaction modulus $\mathrm{K}$ were determined for all cores. 


\subsubsection{LTPP-Road}

For a long time, apart from two preliminary investigations in 1999 and 2001 on a limited database (Raab and Partl, 2007, 2008, 2009, Stöckert, 2001), little performance data concerning interlayer bonding were available, until in 2003 the Swiss Federal Laboratories EMPA was appointed by the Swiss Federal Road Administration (ASTRA) to conduct a project aimed at the performance of interlayer bonding over time.

Based on the research project from 1999 (Raab and Partl, 1999) and the results directly after construction of more than 1000 cores from 20 different pavements, a decade later the long-term bonding properties of remaining 14 pavements could be determined again. The bonding properties determined with the Layer Parallel Direct Shear Test (LPDS) according to Leutner at a temperature of $20^{\circ} \mathrm{C}$ of 14 high volume roads from the years 1993 to 1997 were compared to the values for the same road sections determined in 2006.

From the remaining pavements, seven had stone mastic asphalt (SMA) and four asphalt concrete (AC) surface courses. All three coring sites with special surface courses, i.e. mastic asphalt (MA), hot-rolled asphalt (HR) and porous asphalt (PA) could also be included.

For many of the road sections, traffic data, e.g. the average daily traffic in vehicles (ADT) and the percentage of heavy vehicles ( $>3.5 \mathrm{t}$ ), were also available (Swiss Traffic Survey 2005, 2006). 
Table 5.3 shows the remaining road sections with information on the material of the first and second layer and the traffic data.

Table 5.3: Sites with pavement characteristics and traffic data

(Source: Raab and Partl, 2008)

\begin{tabular}{|c|c|c|c|c|}
\hline Name & \multicolumn{2}{|c|}{ Material } & \multicolumn{2}{c|}{ Traffic } \\
\hline & Layer 1 & Layer 2 & $\begin{array}{c}\text { ADT } \\
{[\text { veh/d] }}\end{array}$ & $\begin{array}{c}>3.5 \mathrm{t} \\
{[\% !}\end{array}$ \\
\hline BSM & SMA 11 & AC 22 & - & buses \\
\hline BSS & SMA 11 & AC 32 & $18^{\prime} 300$ & 9.8 \\
\hline AGSMA-96 & SMA 11 & AC 22 & $32^{\prime} 700$ & 7.6 \\
\hline ZHWall & SMA 11 & AC 16 & $94^{\prime} 990$ & 4.4 \\
\hline WallisSMA & SMA 11 & AC 22 & $19^{\prime} 800$ & 4.4 \\
\hline SOSMA & SMA 11 & AC 32 & $31^{\prime} 450$ & 5.5 \\
\hline SOAB & AC 11 & AC 32 & $77^{\prime} 890$ & 11.1 \\
\hline AGHotroll & HR 11 & AC 22 & $9^{\prime}, 800$ & 2.6 \\
\hline AGGA & MA 11 & MA 16 & $32^{\prime} 700$ & 7.6 \\
\hline WallisDRA & PA 11 & AC 16* & $31^{\prime} 500$ & 4.6 \\
\hline SGMontlingen & SMA 11 & AC 22 & $28^{\prime} 050$ & 5.8 \\
\hline SOABWasseramt & AC 11 & AC 32 & $64^{\prime} 230$ & 8.2 \\
\hline SGABBuchs & AC 16 & AC 10 & - & - \\
\hline SGABFlums & AC 16 & AC 10 & - & - \\
\hline
\end{tabular}

The coring for the investigation of the long-term pavement performance study was conducted a few meters away from the original coring site. For every road section, 5 cores were taken inside and another 5 outside the wheel track. From these cores interlayer shear tests between the first and second layer were performed at $20^{\circ} \mathrm{C}$ using the LPDS shear device. In addition to the maximum shear force, the shear stress and shear 
deformation as well as the shear stiffness values $\mathrm{S}$ and $\mathrm{K}$, as described earlier, were determined for all cores.

Complementary to the mixture analysis from the earlier investigation, this time the air void content of each core was determined (see Appendix A).

\subsubsection{Combi Road}

The first motorway constructions in Europe used to be concrete pavements consisting of jointed slabs. After more than thirty years of service, their riding quality had come to an intolerable state and therefore, more and more of these concrete structures had to be rehabilitated. This was mostly done using asphalt concrete overlays in order to ensure safety and riding comfort.

Many of the above mentioned old concrete structures also showed severe damage in form of cracks. Here, rehabilitations with asphalt overlays and intermediate layer consisting of steel mesh, geotextiles or a bituminous treatment were applied to prevent the cracks from reappearing in the top asphalt layer. Although the method seemed very promising, in practice, it showed difficulties and problems with the interlayer bonding, especially when intermediate layers were used. After some negative experience, the Swiss Federal Road Administration (ASTRA) launched a research project on the interlayer shear properties of these structures (Raab and Partl, 2006, Werner et al., 2007).

Before its rehabilitation, a concrete motorway near Bern was divided into 6 different test sections which were prepared and constructed according to Table 5.4 using different intermediate layers. Only sections 5 and 6 did not have intermediate layers, here 
the asphalt overlay was directly placed on the concrete surface. All constructions and structures in Table 5.4 are in accordance to the Swiss Standard SN 6407347, 2009.

The asphalt concrete overlay consisted of either asphalt concrete AC 11 or stone mastic asphalt SMA 11 with the polymer modified bitumen PmB-E 50/70-65 and had a thickness of $45 \mathrm{~mm}$. The gradation limits for SMA 11 and AC 11 according to the Swiss standard SN EN 640430 are depicted in Figure 5.7.

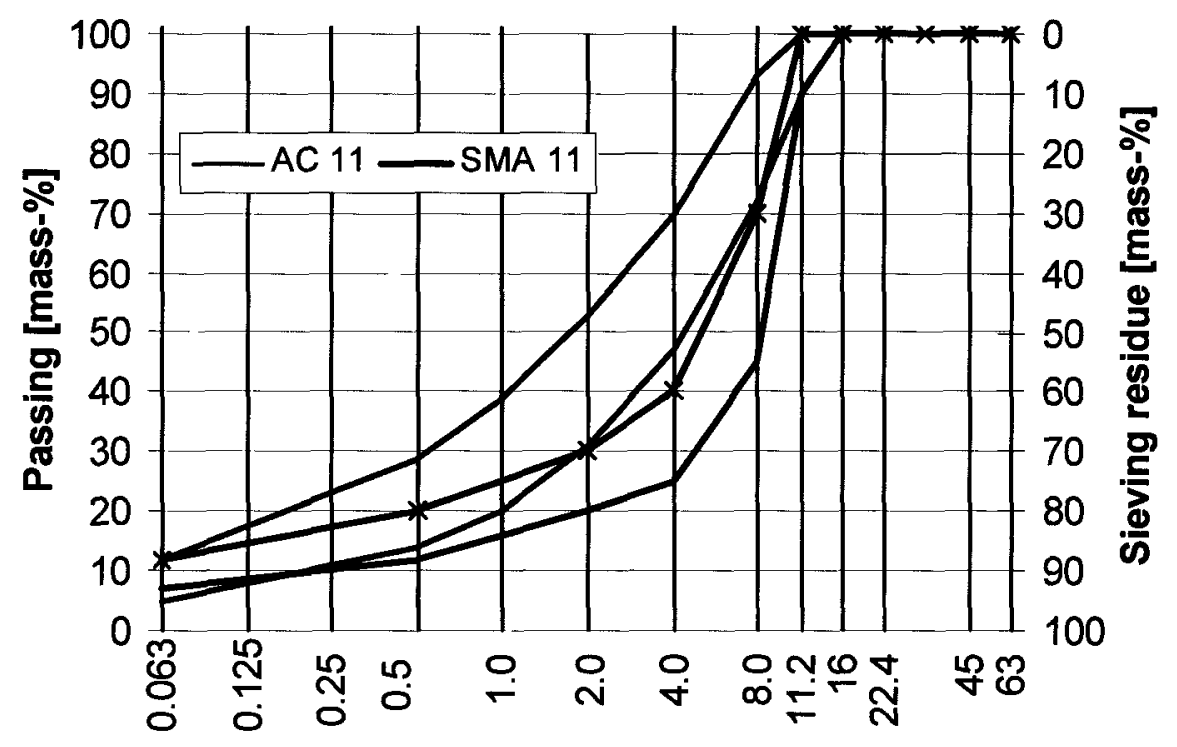

Figure 5.7 :Gradation limits for AC 11 and SMA 11 according to SN EN 640430 
Table 5.4: Test sections with different intermediate layers

\begin{tabular}{|c|c|}
\hline Sections & Preparation of concrete surface, Intermediate layer \\
\hline Section 1 & $\begin{array}{l}\text { - } 0-10 \mathrm{~mm} \text { fine milling and cleaning with compressed air } \\
\text { - surface treatment with highly polymer modified bitumen } \\
\text { - gravel } 8 / 11 \mathrm{~mm} \text { (compacted and removal of surplus gravel) } \\
\end{array}$ \\
\hline Section 2 & $\begin{array}{l}\text { - } 0-10 \mathrm{~mm} \text { fine milling and cleaning with compressed air } \\
\text { - tack coat consisting of a polymer modified bituminous emulsion } \\
\text { - pre-bituminised glass fibre grid }\end{array}$ \\
\hline Section 3 & $\begin{array}{l}\text { - } 0-10 \mathrm{~mm} \text { fine milling and cleaning with compressed air } \\
\text { - tack coat consisting of a polymer modified bituminous emulsion, } \\
\text { - pre-bituminised carbon fibre grid } \\
\text { - } \text { prebituminised gravel } 3 / 6 \mathrm{~mm} \text { (compacted, removal of surplus gravel) }\end{array}$ \\
\hline Section 4 & $\begin{array}{l}\text { - } 0-10 \mathrm{~mm} \text { fine milling and cleaning with compressed air } \\
\text { - tack coat for concrete pavement } \\
\text { - surface treatment with highly polymer modified bitumen } \\
\text { - glass gridseal } \\
\text { application of broken and washed gravel } 8 / 11 \mathrm{~mm}\end{array}$ \\
\hline Section 5 & $\begin{array}{l}\text { - } 0-10 \mathrm{~mm} \text { fine milling and cleaning with compressed air } \\
\text { - tack coat for concrete pavement }\end{array}$ \\
\hline Section 6 & $\begin{array}{l}\text { no fine milling, cleaning with compressed air } \\
\text { - tack coat for concrete pavement }\end{array}$ \\
\hline
\end{tabular}

Shortly after the rehabilitation, cores with a diameter of $150 \mathrm{~mm}$ were taken in order to test the interlayer bond with the LPDS test device. All tests were conducted at a temperature of $20^{\circ} \mathrm{C}$.

In the course of the investigation, the change in interlayer bond properties could be evaluated by repeated coring and bond testing after half a year and after one year. The test program is shown in Table 5.5: 
Table 5.5: Number of core and test date for all test sections

\begin{tabular}{|c|c|c|c|}
\hline Test section & June 2005 (new) & November 2005 & June 2006 \\
\hline 1 & 4 cores & 2 cores & 5 cores \\
\hline 2 & 4 cores & 2 cores & 4 cores \\
\hline 3 & 4 cores & 3 cores & 4 cores \\
\hline 4 & 4 cores & 3 cores & 5 cores \\
\hline 5 & 4 cores & 3 cores & 5 cores \\
\hline 6 & 4 cores & 3 cores & 6 cores \\
\hline
\end{tabular}

\subsubsection{Lab Pavement}

Tack coats have been used in road construction for many years to improve the bond between the different pavement layers. Although the benefit of using tack coats is not debated (Uzan, et al., 1978, Hachiya et al., 1997, Mohammad, 2002, Recasens, et al., 2003, Canestrari, et al., 2005) it is not clear how much tack coats effectively contribute to the bonding properties. In most cases tack coats are applied empirically based on the practical experience of contractors and consultants. Parameters, such as surface roughness (fine milling, no fine milling), cleanness of the underlying base course surface and the age of the underlying layer play an important role (Mrawira and Damunde, 1999, Raab and Partl, 2007), although their influence is often neglected in reality.

In order to account for these deficiencies a laboratory study (Raab and Partl, 2007, Raab and Partl, 2006) was conducted in which a cationic tack coat was used between two layered specimens. The specimens were produced with a roller compactor and the adhesion of cores taken from the slabs was evaluated by means of direct LPDS at a temperature of $20^{\circ} \mathrm{C}$. 
Different parameters such as surface roughness (fine milling, no fine milling) and the influence of curing time were investigated and their influence on the bond between the layers was determined. To evaluate the limits of the application of tack coats, dirt and moisture was applied between the two layers before and after the application of a tack coat. Table 5.6 gives an overview of the produced laboratory specimens.

Table 5.6: Laboratory pavement specimens

\begin{tabular}{|c|c|c|c|}
\hline Slab No. & Parameter & $\begin{array}{l}\text { Tack } \\
\text { coat }\end{array}$ & $\begin{array}{l}\text { Treatment of base layer } \\
\text { surface and other remarks }\end{array}$ \\
\hline 1 & Original state & HC $50^{*}$ & No treatment \\
\hline 2 & Polymer modified tack coat & HCP 60 & No treatment \\
\hline 3 & Surface Roughness & None & $\begin{array}{l}\text { Fine milling of base layer } \\
\text { surface }\end{array}$ \\
\hline 4 & Surface Roughness & HC 50 & $\begin{array}{l}\text { Fine milling of base layer } \\
\text { surface }\end{array}$ \\
\hline 5 & Cleanness & HC 50 & $\begin{array}{c}\text { Dirt (filler) was applied } \\
\text { before tack coat application }\end{array}$ \\
\hline 6 & Cleanness & HC 50 & $\begin{array}{c}\text { Dirt (filler) was applied after } \\
\text { tack coat application }\end{array}$ \\
\hline 7 & Cleanness and dryness & HC 50 & $\begin{array}{l}\text { Wet dirt (filler) was applied } \\
\text { before tack coat application }\end{array}$ \\
\hline 8 & Cleanness and dryness & HC 50 & $\begin{array}{l}\text { Wet dirt (filler) was applied } \\
\text { after tack coat application }\end{array}$ \\
\hline 9 & Curing time and age & HC 50 & $\begin{array}{c}\text { Slab was stored outside for } 2 \\
\text { months (summer conditions) } \\
\text { before testing }\end{array}$ \\
\hline 10 & $\begin{array}{l}\text { Curing time and age } \\
\text { (comparison) }\end{array}$ & HC 50 & $\begin{array}{l}\text { Slab was cored and directly } \\
\text { tested after construction }\end{array}$ \\
\hline
\end{tabular}

* designation according to European Standard EN 13808, 2005

Although the investigation was a laboratory study, the slab construction was performed as close to reality as possible. Therefore, the slab roller compactor constructed by the MMLS company at the University of Stellenbosch, South Africa, was used. The 
compactor (Figure 5.8) consisted of a steel roller with a width of about $910 \mathrm{~mm}$, a diameter of about $350 \mathrm{~mm}$ and a metal frame with a rail on which the steel roller could be displaced horizontally. In the vertical direction a winder enabled the steel roller to be moved; furthermore an automatic vibration system was applied. During compaction, the steel roller was sprayed with water and prior to compaction was heated with a heater reflector. The steel roller was pushed manually back and forth in the longitudinal direction of the slab. A piece of concrete within the metal frame served as base for compaction.

For the construction of the asphalt slabs a wooden frame with the dimension of $0.95 \mathrm{~m}$ by $1.08 \mathrm{~m}$ was applied and the hot mixture was filled into it and compacted to a thickness of $40 \mathrm{~mm}$.

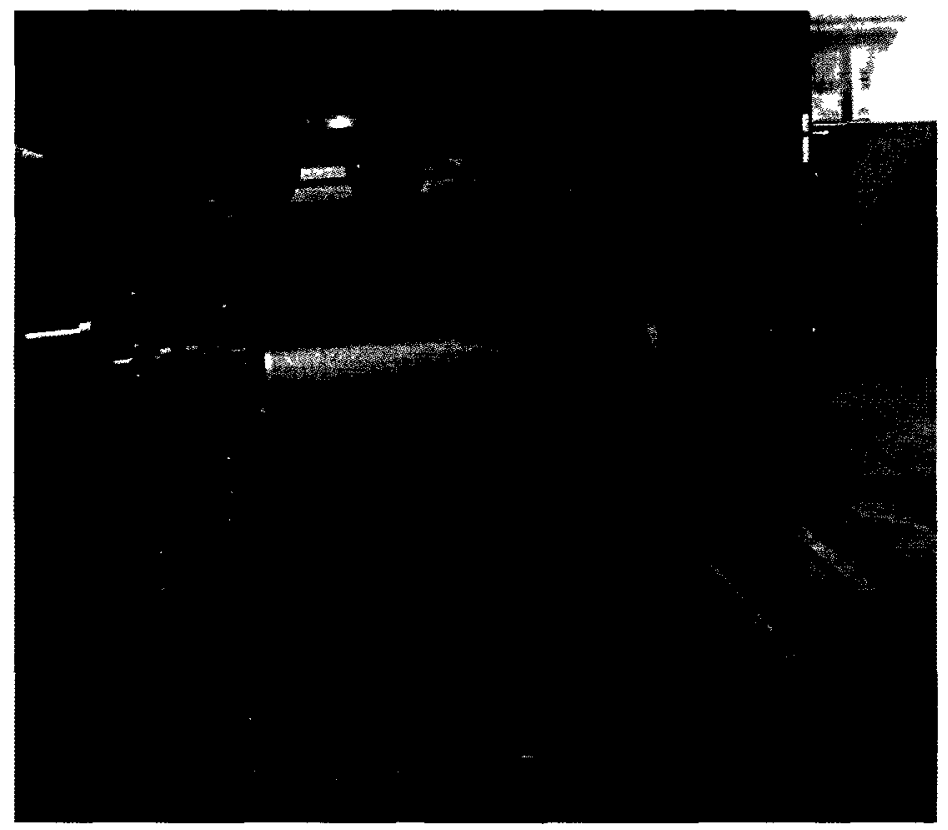

Figure 5.8: Slab Roller compactor

The slabs were constructed in two layers. The base layer which consisted of asphalt concrete AC 22 had a thickness of $60 \mathrm{~mm}$, while the surface layer consisted of 
asphalt concrete AC11 according to the Swiss Standard SN EN 640430 and had a thickness of $40 \mathrm{~mm}$. Both mixtures consisted of an unmodified penetration grade binder 50/70. Table 5.7 presents the material characteristics and Figures 5.9 and 5.10 show the gradations curves.

Table 5.7: Material characteristics of AC 11 and AC 22

\begin{tabular}{|l|c|c|}
\hline & Layer 1 & Layer 2 \\
\hline Material & AC 11 & AC 22 \\
\hline Binder content [mass-\%] & 5.4 & 4.5 \\
\hline Density [kg/m ${ }^{3}$ ] & 2545 & 2510 \\
\hline Air voids, Marshall [vol-\%] & 2.3 & 4.7 \\
\hline Stability, Marshall [kN] & - & 11.5 \\
\hline Flow, Marshall [mm] & - & 2.4 \\
\hline
\end{tabular}

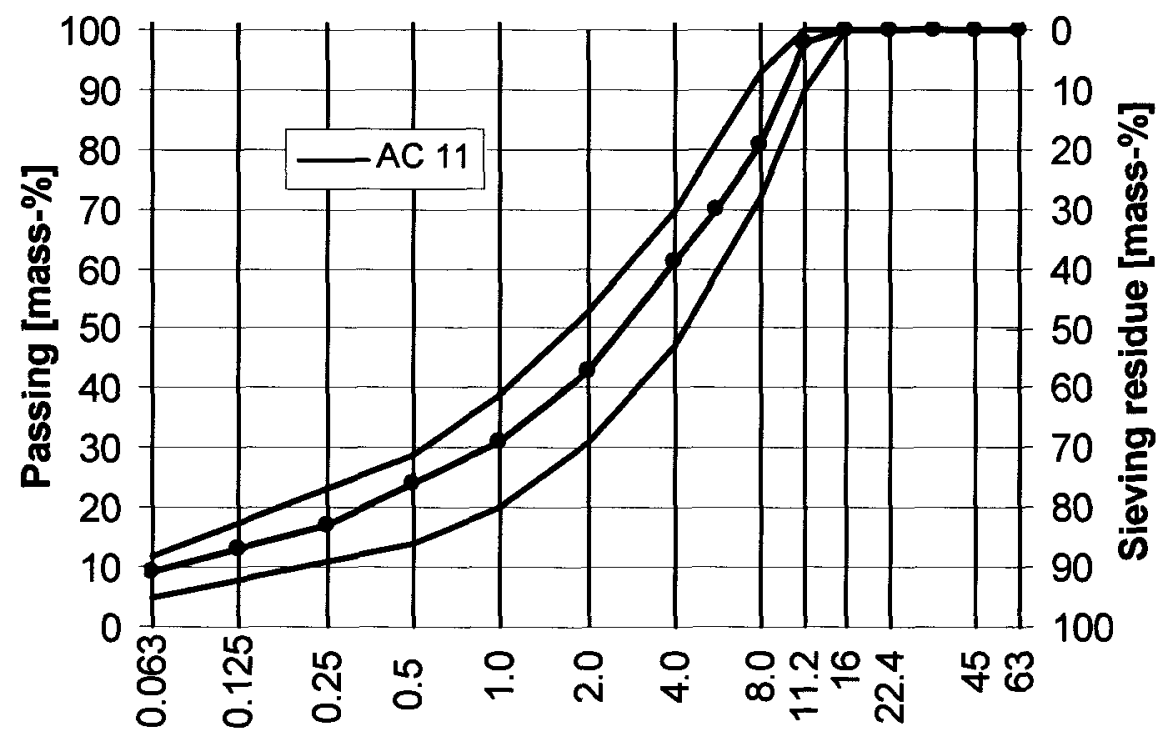

Figure 5.9: Gradation with limits for AC 11 according to SN EN 640430 


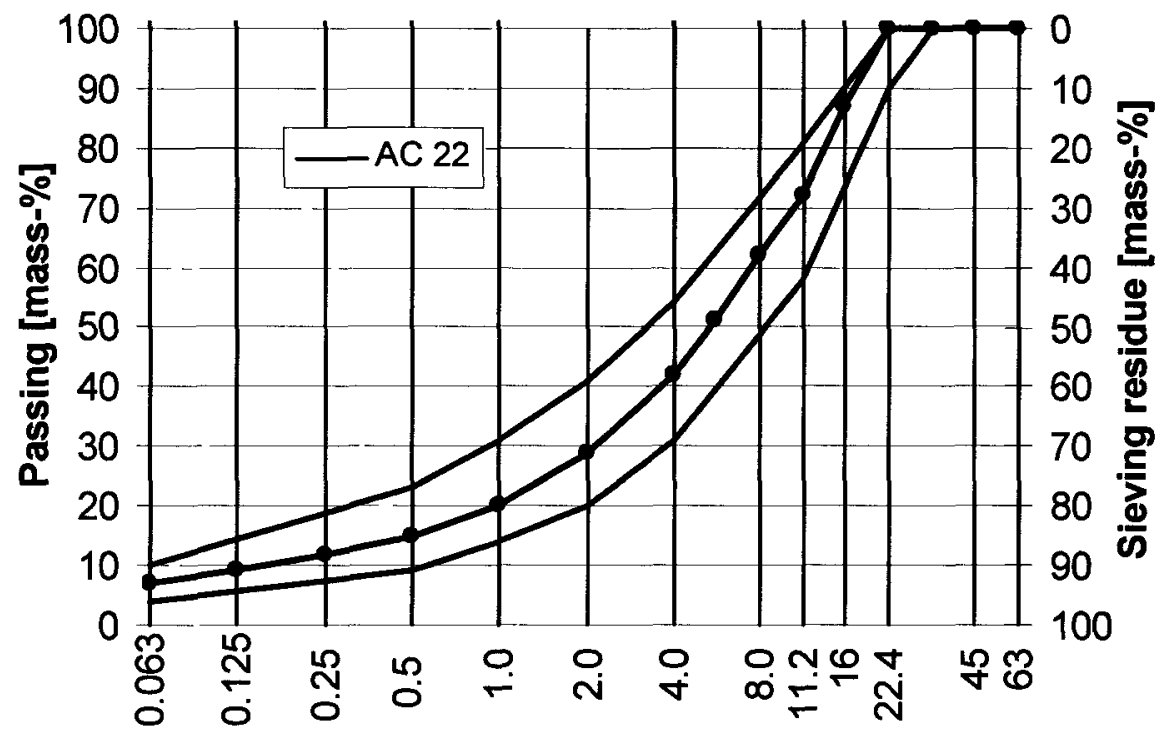

Figure 5.10: Gradation with limits for AC 22 according to SN EN 640430

The slabs had a dimension of $0.99 \mathrm{~m} \times 0.86 \mathrm{~m}$. After the construction of the base layer $200 \mathrm{~g} / \mathrm{m} 2$ of tack coat were sprayed on the surface on one side of the slab using a spray gun and the surface layer was applied thereafter. The tack coat was an unmodified bituminous cationic emulsion $\mathrm{HC} 50$ with a residual bitumen content of $50 \%$ according to the European standard, EN 13808 (European Standard EN 13808, 2005). For the investigation of the influence of polymer modified tack coats, in one case, a tack coat HCP 60 with a residual bitumen content of $60 \%$ and a polymer modification was used. Here, the total application rate was also $200 \mathrm{~g} / \mathrm{m} 2$. The tack coat was weighted on a scale and evenly distributed over the surface using a spray gun. Two days after construction, 12 cores were taken on either side of the slab (with and without tack coat) as shown in Figure 5.11. 


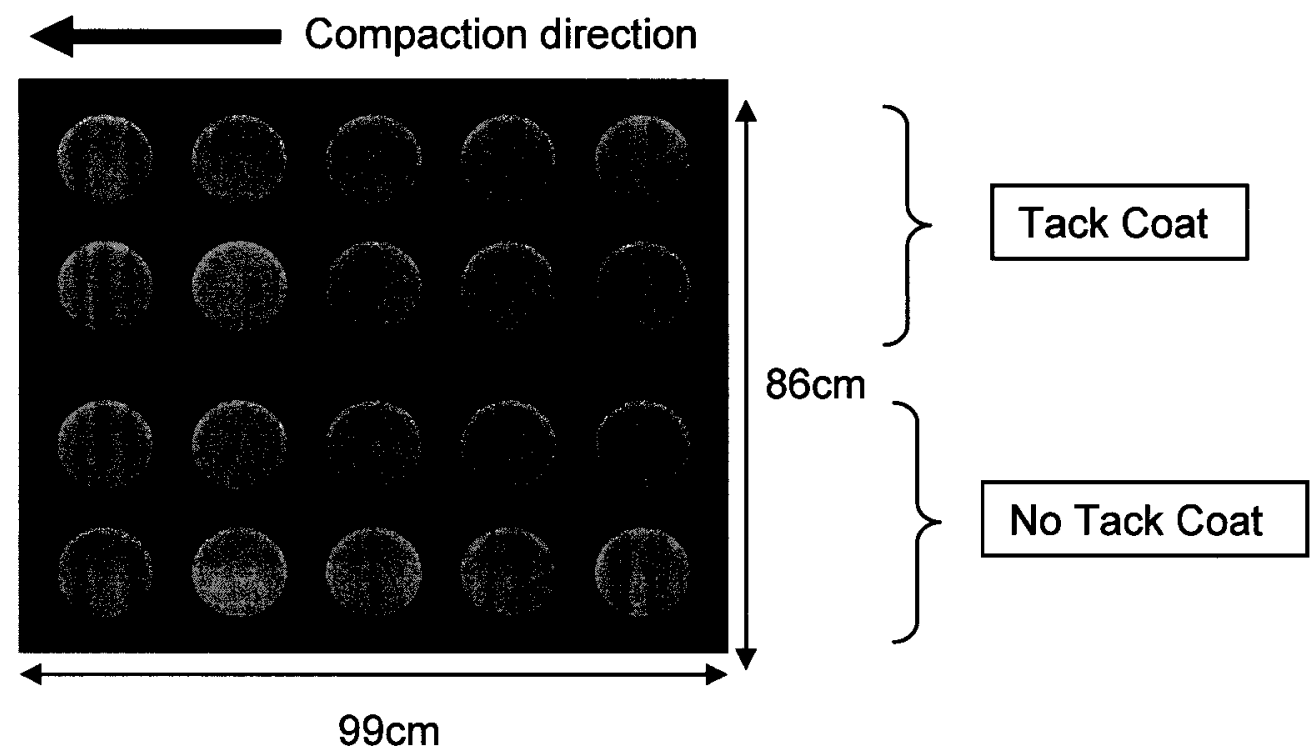

Figure 5.11: Schematic drawing of coring schema

In this project, the air void content of each core was determined. The values are listed in the tables of the Appendix A.

\subsubsection{RILEM Pavement}

Another source of data was retrieved during the interlaboratory test program initiated by RILEM TC 206 ATB TG 4 (Piber et al., 2009) in the year 2008.

Within this program, research and materials testing institutions from Europe and North America were asked to perform interlayer bond tests on pre-selected and defined material under certain test conditions using their specific shear test equipment.

For this interlaboratory test, the University della Marche in Ancona constructed a trial pavement of $3.50 \mathrm{~m}$ by $21.0 \mathrm{~m}$ with two asphalt concrete layers. The lower layer had a thickness of $50 \mathrm{~mm}$ and consisted of an asphalt mixture type AC 16 with a penetration 
grade bitumen 70/100 (EN 13108-1). The upper layer was $30 \mathrm{~mm}$ thick and produced with an asphalt mixture type $\mathrm{AC} 11$ containing the same bitumen. The whole pavement was divided in 3 parts of $7.0 \mathrm{~m}$, as shown in Figure 5.12, and for each section a different interface treatment was applied:

- $\quad$ Pavement section NE : No tack coat,

Pavement section ME : Polymer modified emulsion

- Pavement section CE : Conventional cationic emulsion.

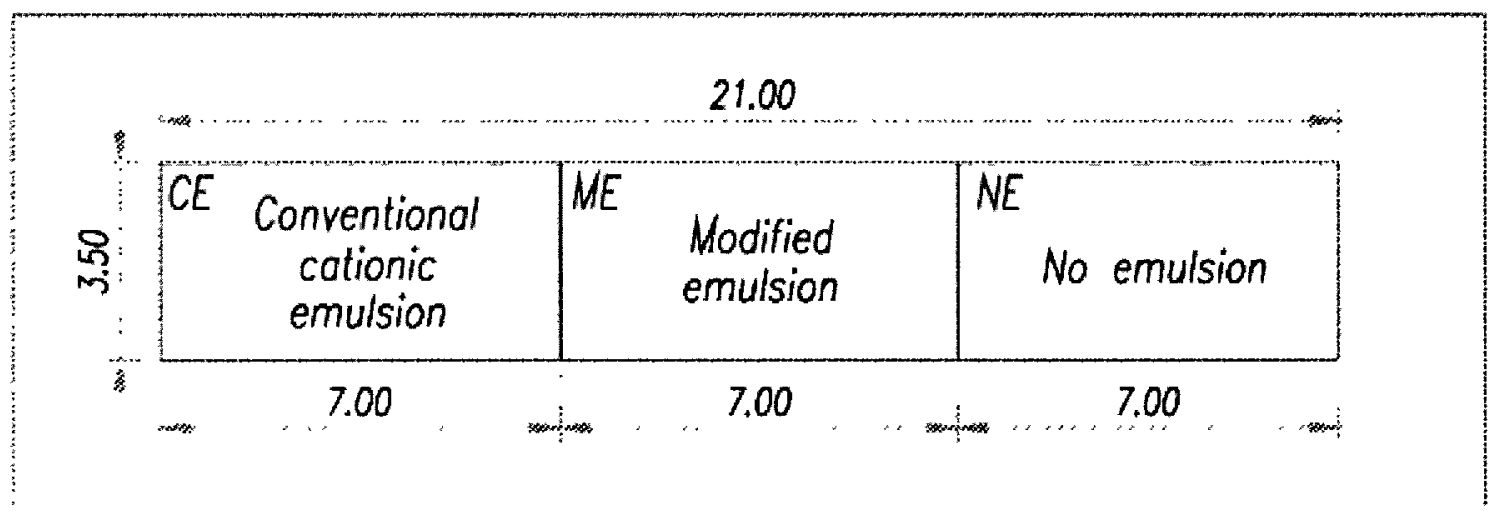

Figure 5.12: Schematic view of the RILEM trial pavement

(Source: Ferrotti, 2007)

Figure 5.13 shows the finished trial pavement. As described by Ferrotti and Piber (Ferrotti, 2007, Piber et al., 2009), the pavement construction included the following steps:

- In a first step, the unbound material was compacted in order to provide a regular and even base.

- In a second step, the binder course consisting of asphalt concrete AC 16 was placed and compacted to a thickness of $50 \mathrm{~mm}$. 
- A fortnight later, both tack coats with an application rate of $150 \mathrm{~g} / \mathrm{m}^{2}$ residual bitumen were applied with a brush.

After a curing time of six hours, the surface course consisting of asphalt concrete AC 11 was laid and compacted to a thickness of $30 \mathrm{~mm}$.

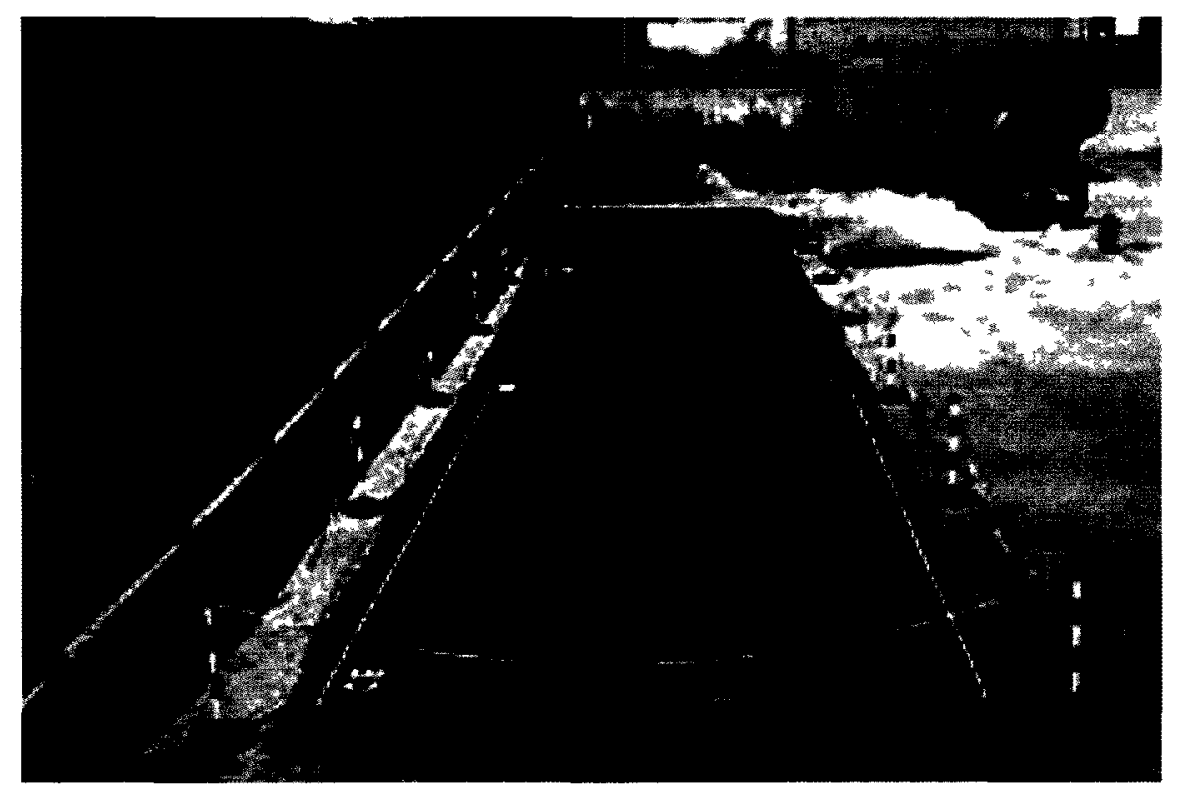

Figure 5.13: RILEM trial pavement in summer 2005

(Source: Ferrotti, 2007)

Cores were taken from the pavement sections with different interface types and sent out for testing at different temperatures and deformation rates (see Figure 5.14). For every test condition (temperature and deformation rate) 7 cores were distributed to the different organisations. The cores had a diameter of $143 \mathrm{~mm}$. 


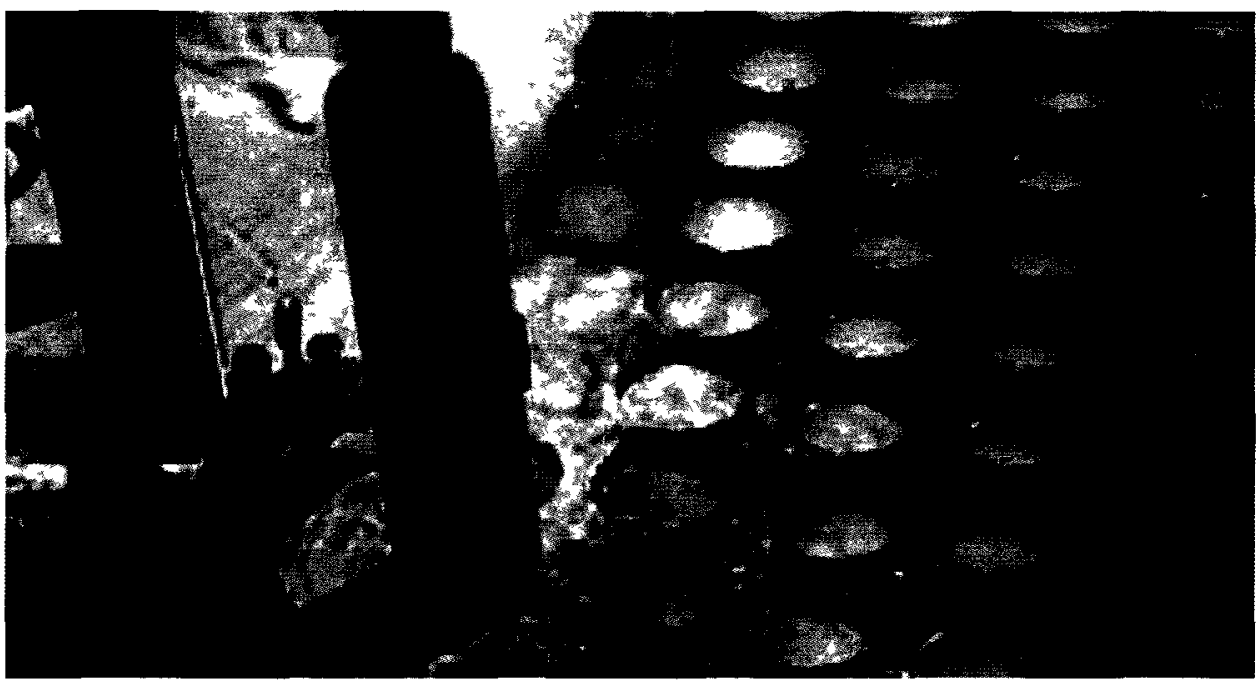

Figure 5.14: Coring the test specimens

(Source: Ferrotti, 2007 and Piber, 2009)

The material characterisation of the two asphalt pavement layers is given in Table 5.8 and Figures 5.15 and 5.16.

Table 5.8: Mixture characteristics of the RILEM trial pavement

\begin{tabular}{|l|c|c|}
\hline & Layer 1 & Layer 2 \\
\hline Material & AC 11 & AC 16 \\
\hline Aggregate type & Basalt & Limestone \\
\hline Binder content [mass-\%] & 5.2 & 4.6 \\
\hline Density [kg/m $\left.{ }^{3}\right]$ & 2475 & 2503 \\
\hline Penetration [mm $\left.\mathrm{mm}^{-1}\right]$ & 78 & 78 \\
\hline
\end{tabular}


Passing [mass-\%]

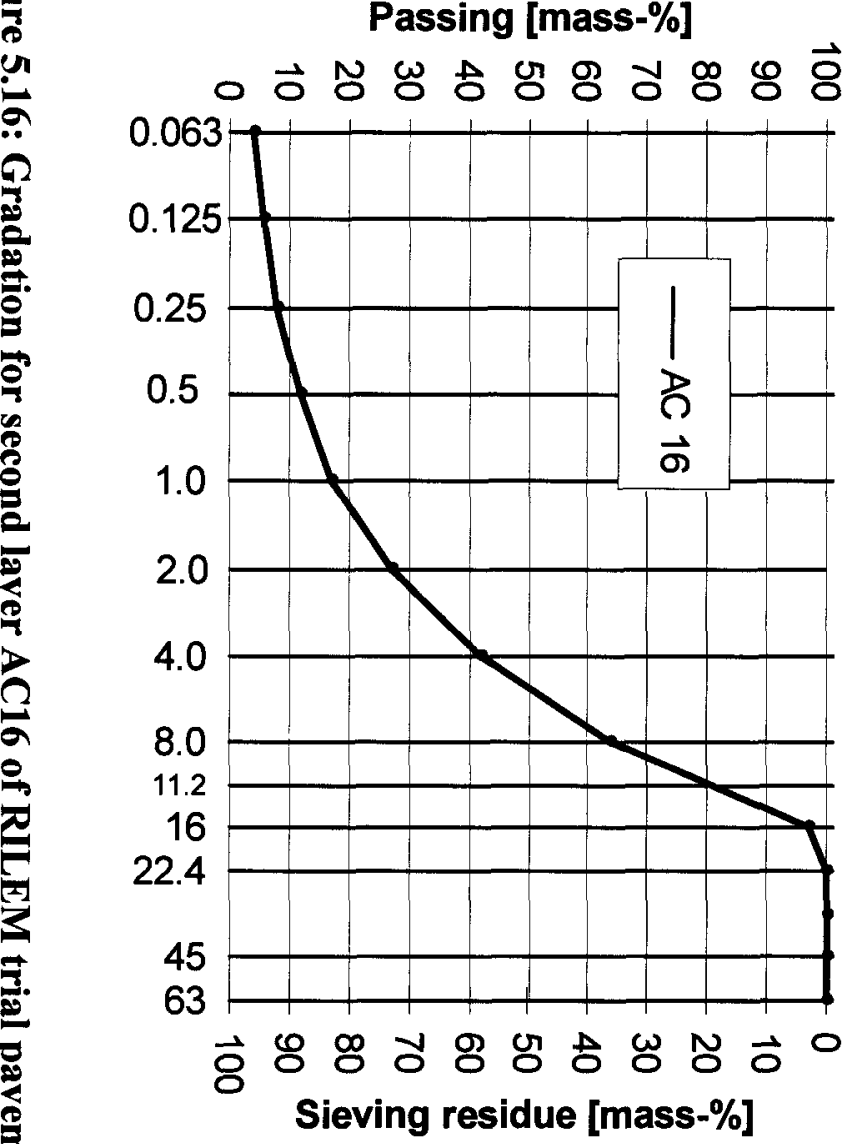

Passing [mass-\%]

으 Nㅜㅇ
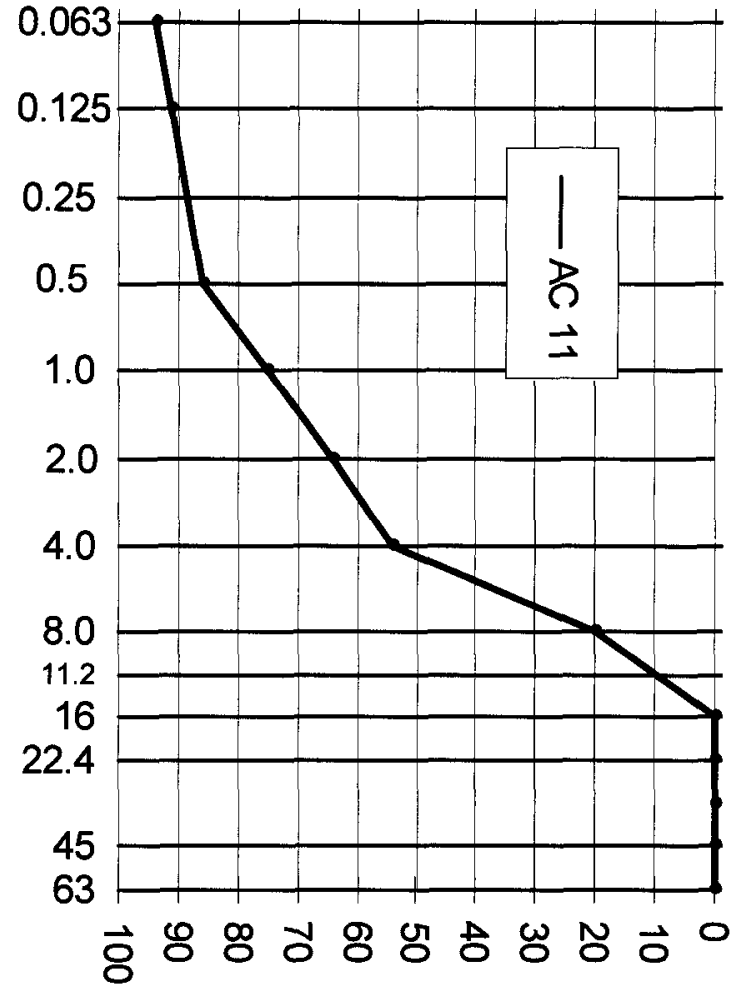

Sieving residue [mass-\%] 
In the course of that RILEM project, Empa had the possibility to test the 3 different interface types (tack coat conditions) at 5 different temperatures $\left(10^{\circ} \mathrm{C}, 20^{\circ} \mathrm{C}\right.$, $25^{\circ} \mathrm{C}, 30^{\circ} \mathrm{C}$ and $40^{\circ} \mathrm{C}$ ) and 2 different deformation rates $(50 \mathrm{~mm} / \mathrm{min}$ and $200 \mathrm{~mm} / \mathrm{min})$. Additionally, pavement ME was tested again 1.5 years later in order to evaluate the influence of aging. Table 5.9 depicts the testing program.

Table 5.9: Testing program

\begin{tabular}{|l|c|c|c|}
\hline & Pavement NE & Pavement ME & Pavement CE \\
\hline Tack coat type & none & $\begin{array}{c}\text { polymer modified. } \\
\text { emulsion }\end{array}$ & cationic emulsion \\
\hline Temperature $\left[{ }^{\circ} \mathrm{C}\right]$ & $10,20,25,30,40$ & $10,20,25,30,40$ & $10,20,25,30,40$ \\
\hline $\begin{array}{l}\text { Deformation rate } \\
{[\mathrm{mm} / \mathrm{min}]}\end{array}$ & 50,200 & 50,200 & 50,200 \\
\hline Date of testing & 2006 & 2006 & 2006 \\
\hline
\end{tabular}

In addition to the material characteristics given in Table 5.8, the air void content of each core was determined and is shown in the Appendix A.

\subsection{Utilisation of Artificial Neural Network ANN for the Analysis of Interlayer Shear Properties}

\subsubsection{Outline}

In this thesis artificial intelligence in form of artificial neural network (ANN) is applied to predict interlayer shear properties using different datasets determined by the author of the thesis. While Section 5.1 was intended to give information on these datasets including 
information on the construction, material and testing, Section 5.2 presents some explanation of artificial neural networks and their technique focussing on the used evaluation software Alyuda Neurointelligence (C 2001-2009 Neo Digital). In this section, the databases from Section 5.1 will be discussed concerning their relevance for ANN because understanding and gathering data is one of the most important steps in knowledge discovery using ANN techniques.

The outline of the ANN evaluation for interlayer bond problems reads as follows and is summarised in Figure 5.17. The yellow parts can be found in Section 6.2.

After an introductory part, a general section giving definition and basic information on artificial neural networks ANN will follow, including a short review on recent literature.

A broader literature review is not given for two reasons:

1. In her thesis Miradi (Miradi, 2009) provides an detailed up to date literature review on the use of knowledge discovery in the field of road pavements using artificial neural networks and other artificial intelligence tools.

2. There is no literature available in the field of interlayer bonding and artificial neural network. 


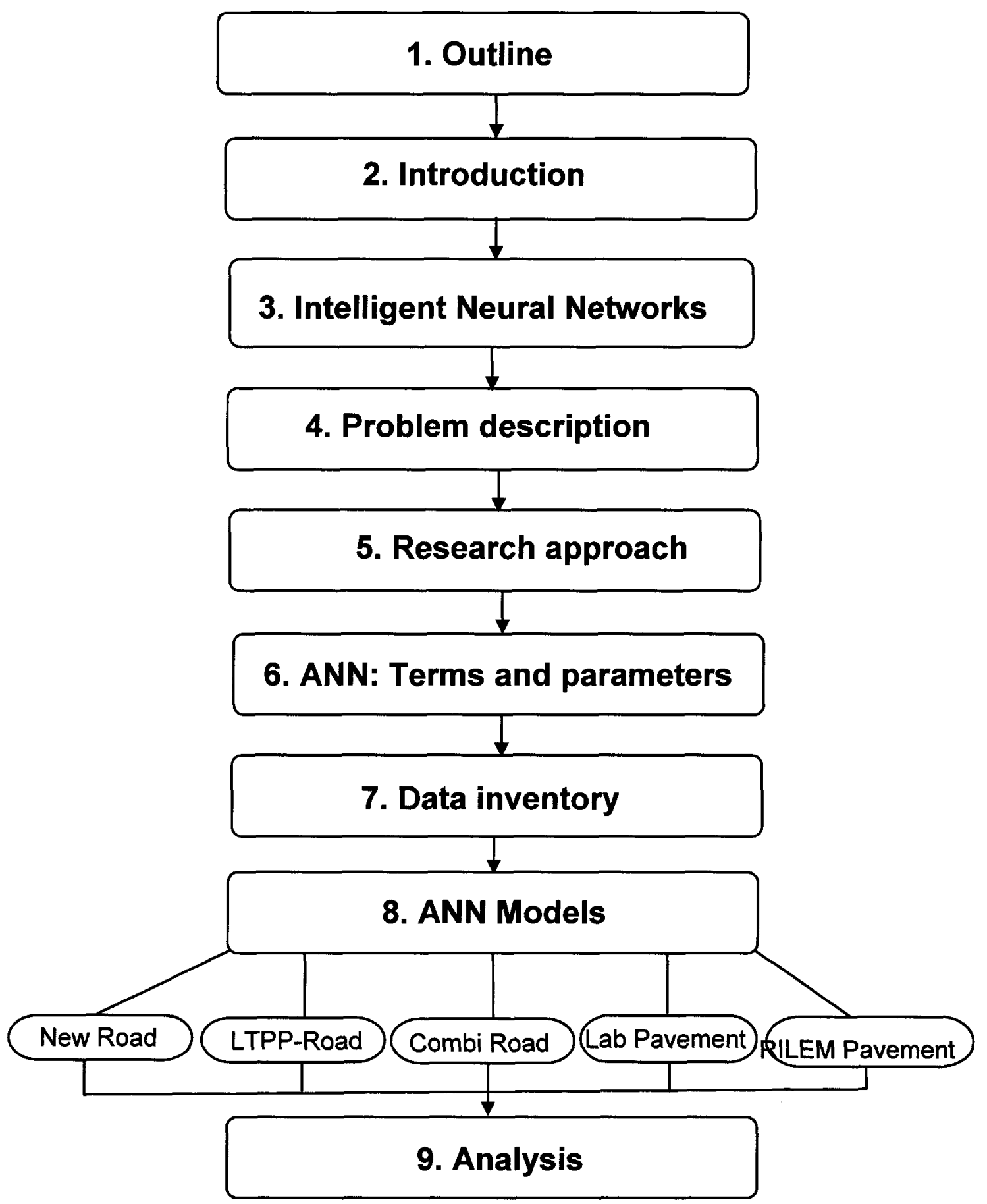

Figure 5.17: Outline for the utilisation of Artificial Neural Network ANN for the Analysis of Interlayer Shear Properties (described in Section 5.2 and Section 6.2) 
Then, problem description and the research approach are presented. Next, ANN terms and parameters will be explained, firstly in general and secondly with regards to the Alyuda Neurointelligence software used in this thesis. The evaluation software Alyuda Neurointelligence was chosen because it represents a commonly available tool which can easily be adapted to a specific problem. In a pre-evaluation Alyuda Neurointelligence was compared to other software and found to be more clear and user friendly. Besides these advantages it offers features, such as the response graphs, which are not part of other software.

Further, the data inventory reports on the preparation of the available databases described in Section 5.1.

Section 6.2 describes the ANN models and the prediction of the bond properties when applying ANN to the different datasets. In addition, the analysis and a summary of the main findings can be found.

\subsubsection{Use of artificial neural network}

During resent years, data collection has gained more and more importance in various fields and disciplines. This also applies for pavement engineering, especially the field of pavement management, where data collection has always been an essential tool for analysis and interpretation of field and laboratory findings.

In order to organise data and to discover knowledge from data, new approaches, so called knowledge discovery techniques with artificial neuronal networks (ANN), were introduced in the 1950s. According to Fayyad (Fayyad et al., 1996) knowledge discovery 
is the nontrivial process of identifying valid, novel, potentially useful, and ultimately understandable patterns in data. ANN is a mathematical or computational model that tries to simulate the structure of biological neural networks. It consists of an interconnected group of artificial neurons and process information using a connectionist approach to computation (Haykin, 1999).

As opposed to other areas in science and economy, where computational tools in the field of artificial intelligence were used for discovering knowledge from an increasing amount of data, this was rarely the case in pavement engineering. Here, for a long period of time, data collection and evaluation was rather based on empirical or statistical methods. Recently, Miradi (Miradi, 2009) pointed out that artificial intelligence application and pavement engineering are completely different fields and experts from these field still have little awareness of each other.

In her thesis Miradi (Miradi, 2009) performed an artificial intelligence based knowledge discovery study of data on asphalt road pavement problems, in particular, ravelling, cracking and rutting as well as stiffness of cement treated bases. She could show that even without special knowledge of asphalt pavements the correct use of artificial intelligence tools can lead to meaningful results and findings.

The aim is to apply artificial intelligence in form of artificial neural network (ANN) for knowledge discovery from pavement engineering data in the field of interlayer bonding.

The advantage of using artificial neural network ANN for modelling and evaluation purposes lies in the fact that ANN is capable of processing large amounts of data sets. It is also possible to work with subsets of data and in case of missing data; 
ANN can be used to predict such data. As opposed to statistical analysis, when a model has to be determined, ANN determines the model based on a learning or training process. Furthermore, in most cases it is unknown if the relationship between the variables is a linear one or not. Therefore, ANN being a non-linear statistical data modelling tool has a clear advantage over statistical linear regression analysis. Although ANN does not deliver an equation it can be utilised to determine most critical and influencing variables. For many problems these influencing parameters or variables are not known in detail or they can not be assessed completely. In case of multi regression analysis, MRA, their knowledge is indispensable while ANN has the potential to identify the most important ones. Another advantage of ANN is the fact that it needs less computational time compared with MRA.

As opposed to Miradi's thesis (Miradi, 2009) which approached the problem from a mathematical side, this thesis deals with the practical application of artificial neural networks (ANN). This means that the focus is on the practical use of ANN and its application for databases on interlayer bonding in order to find pattern within the data and to predict certain interlayer bond properties. Nevertheless, it is for sake of clarity inevitable to explain some of the most important term of artificial neural networks and describe their techniques.

\subsubsection{Relevance of ANN for interlayer bonding}

Although during recent years the bonding characteristics between asphalt pavement layers have been discussed in a remarkable number of conference and journal papers, master or $\mathrm{PhD}$ theses and other publications (e.g. Ziari and Khabiri, 2007, 
Tschegg et al., 2007, Leng et al., 2008, Mohammad et al., 2009), large scale data collection in this field has not been within high priority research focus, so far.

This is partly due to the fact that, as mentioned in Chapter 2, the bond between asphalt pavement layers has not been part of the standardisation and normalisation for a long period of time. Hence, recommendations and guidelines were simply requiring "sufficient" bond between asphalt pavements layers (Swiss standard, SN 640431, 1976). In most cases no generally valid value was specified with the result that local administrations and organisations were left to define their own limiting numbers. Even after the establishment of interlayer bond requirements, when field cores had to be taken for evaluating interlayer bond characteristics, the evaluated values were determined locally and mostly not integrated in databases or analysed in relation to other pavement information such as pavement structure, air void content or type of tack coat etc. Therefore, artificial intelligence tools such as artificial neural networks could not be used for knowledge discovery from interlayer bonding data.

\subsubsection{Knowledge discovery using artificial intelligence}

In her thesis, Miradi (Miradi, 2009) elaborates on the definition of knowledge discovery by Fayyad (Fayyad et al., 1996) in the way that the term process implies that knowledge discovery is not a single action, but is comprised of a number of steps. Figure 5.18 shows the different steps involved in knowledge discovery as it is given by Fayyad (Fayyad et al., 1996) 


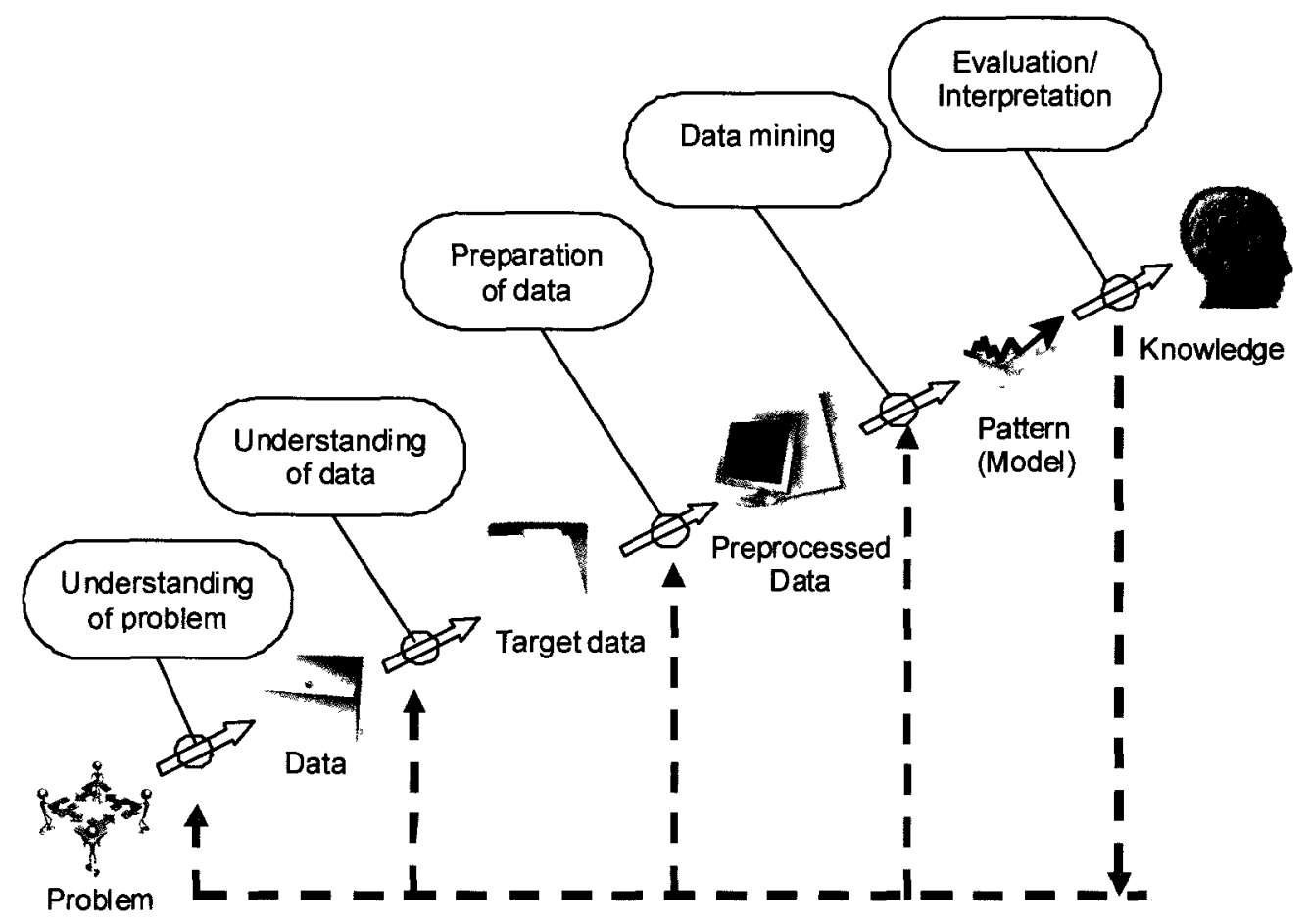

Figure 5.18: Steps of knowledge discovery according to Fayyad

(Source: Fayyad et al., 1996, Miradi, 2009)

Furthermore, the term nontrivial states that this process is not a straightforward computation, but consist of a search. According to Miradi the data is a set of observations (measurements, values) and the term pattern means finding a structure or model applicable to the dataset (Miradi, 2009).

\subsubsection{Artificial neural networks (ANN)}

\subsubsection{General}

Neural networks, as used in artificial intelligence approaches, have traditionally been viewed as simplified models of neural processing in the brain, even though the relation 
between these models and biological architecture and functioning of the brain is debated (Rojas, 1996, Brown, 1991).

An artificial neural network (ANN) is an interconnected group of artificial neurons that uses a mathematical or computational model for information processing. In most cases an ANN is an adaptive system that changes its structure based on external or internal information that flows through the network during the learning or training phase. Neural networks are non-linear statistical data modelling tools. They can be used to model complex relationships between inputs and outputs or to find patterns in data (Haykin, 1999, Tapkin, 2010).

As compared to the traditional multiple stepwise regression models, the ANN is a model free estimator. Hence, it does not require the knowledge of the form of functions ( , models) to begin with the analysis (Xiao et al., 2010) and it offers the potential for capturing complicated nonlinear relationships between the input and output variables.

However, the main disadvantage of the ANN approach is the inability to extrapolate results when the inputs are outside the range of values used to develop it (Martínez and Angelone, 2010). In literature, ANN techniques were often found to be more powerful in predicting output variables compared to classical statistical regression models (Gesoglu et al., 2010).

Artificial neural networks (ANN) are one of the most powerful data mining techniques and with the rapid evolution of computers and their enhanced ability to process enormous mounds of data the interest in the field has increased dramatically during resent years. In the wake of that development the number of literature publications 
concerning this subject is tremendous (for example Engelbrecht, 2007, Fayyad, et al., 1996, Haykin, 1999, Rojas, 1996, Abraham, 2005).

According to Engelbrecht (Engelbrecht, 2007), an artificial neural network (ANN) is a layered network of artificial neurons. Each artificial neuron (AN) receives information from input variables or from other artificial neurons. This information is gathered and transmitted to all connected artificial neurons (see Figure 5.3, left). Input information is accounted with positive or negative numerical weights associated with each connection to the AN. An ANN may consist of an input layer, hidden layer(s), and an output layer as shown in Figure 5.19, right. Hidden layers are used for additional computing.

The most commonly used ANN is a feed forward ANN called FANN. In this type of ANN each artificial neuron is only connected to the artificial neuron in the next layer and its output is fed forward to the next layer in the direction from input to output (Miradi, 2009).
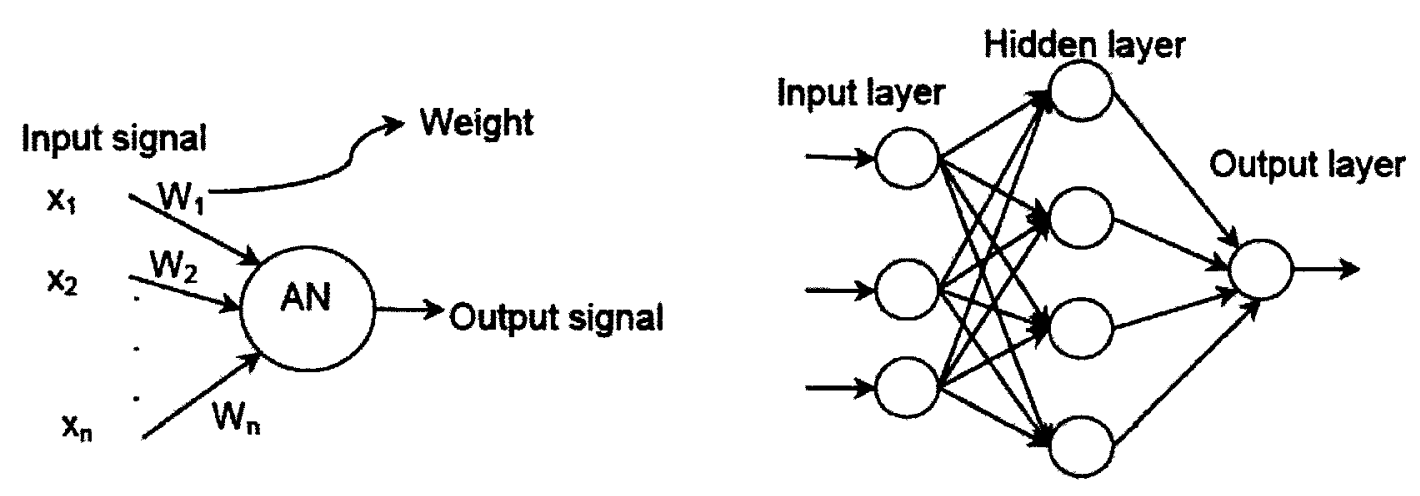

where: $x_{1}-x_{n}$ are the input signals and $W_{1}-W_{n}$ the weights

Figure 5.19: Schematic of an artificial neuron (left) and a three layer ANN (right)

(Source: Miradi, 2009) 


\subsubsection{Review of recent literature}

Regarding recent literature (between 2009 and May 2010) on ANN concerning the field of pavements the main work has been devoted to the prediction of binder and mixture properties. Most studies are very practical and often compare ANN to other modelling tools such as statistical linear regression.

In a quite theoretical work Oeser (Oeser and Freitag, 2009) used an ANN based concept for modelling the rheological behaviour of asphalt. Oeser showed that ANN could be used to replace fractional dashpots in rheological models.

Tapkin (Tapkin, 2010) conducted a practical study for which he investigated the fatigue life of bituminous mixtures with fly ashes using ANN: In his work. Tapkin used the experimental laboratory data for different types of fly ashes as filler replacement in dense bituminous mixtures. According to his studies, the fatigue lives of the mixtures could be predicted with ANN in an acceptable manner. Tapkin compared different network architectures with one, two and three hidden layers. Looking at the results he concluded that a one hidden layered artificial neural networks and backpropagation learning algorithm was sufficient for the fatigue life prediction.

The aim of another research (Xiao et al., 2010) was the application of ANN for predicting the penetration index of binders after long term aging. During the same study, ANN was compared to statistical regression models and it was found to predict the penetration index more accurately. For the prediction a one hidden layered ANN and backpropagation in the Levenberg-Marquart algorithm was used.

A Turkish study (Gesoglu et al., 2010) aimed to model the mechanic properties of rubberised concretes by ANN and genetic programming (GEP). Both methods were 
found to provide a high prediction capability, while the prediction through a statistical linear regression was comparatively low. As in previous studies, a one layered backpropagation network was applied.

\subsubsection{Problem description (interlayer bonding)}

Artificial neural networks are valuable in place of conventional physical models for analysing complex relationships involving multiples variables (Xia et al., 2010). The bond between asphalt pavements is influenced by such a great variety of different parameters or variables.

Figure 5.20 names some of the most important variables for a durable bond between asphalt pavement layers. By listing the different parameters separately, it becomes clear that they are numerous and related by many interactions. For example, mineral aggregate size, binder properties and mixture composition are influenced by the chosen pavement type, since these parameters $b$ are responsible of the friction and the interlocking properties.

The number and complexity of parameters influencing interlayer bonding makes it difficult to quantify the contribution of the different parameters to the measured bonding properties and to find a physical model predicting the shear bond properties such as shear force, maximum shear stress with deformation or shear stiffness. This is even true for qualitative principles. For example, whereas the decrease of the interlayer bond with rising temperature is a well-known fact, the influence of other factors (e.g. influence of tack coat, geometry of the interface etc.) is either unknown to full extent or intensely 
debated among researchers and practitioners (Uzan et al., 1978, Romanoschi and Metcalf, 2002, Raab and Partl, 2004, Ziari and Khabiri, 2007).

Another problem is the above mentioned non-existence of generally acknowledged and openly accessible databases for interlayer bonding.

Furthermore, openly accessible databases are lacking interlayer bond performance data, since the evaluation of the shear bond between asphalt layers is usually determined using cores, which are directly taken after construction and before the road is opened to traffic. 


\section{Durable bond between layers}

Layer (surface-binder course, binder-base coarse, base-base-course)

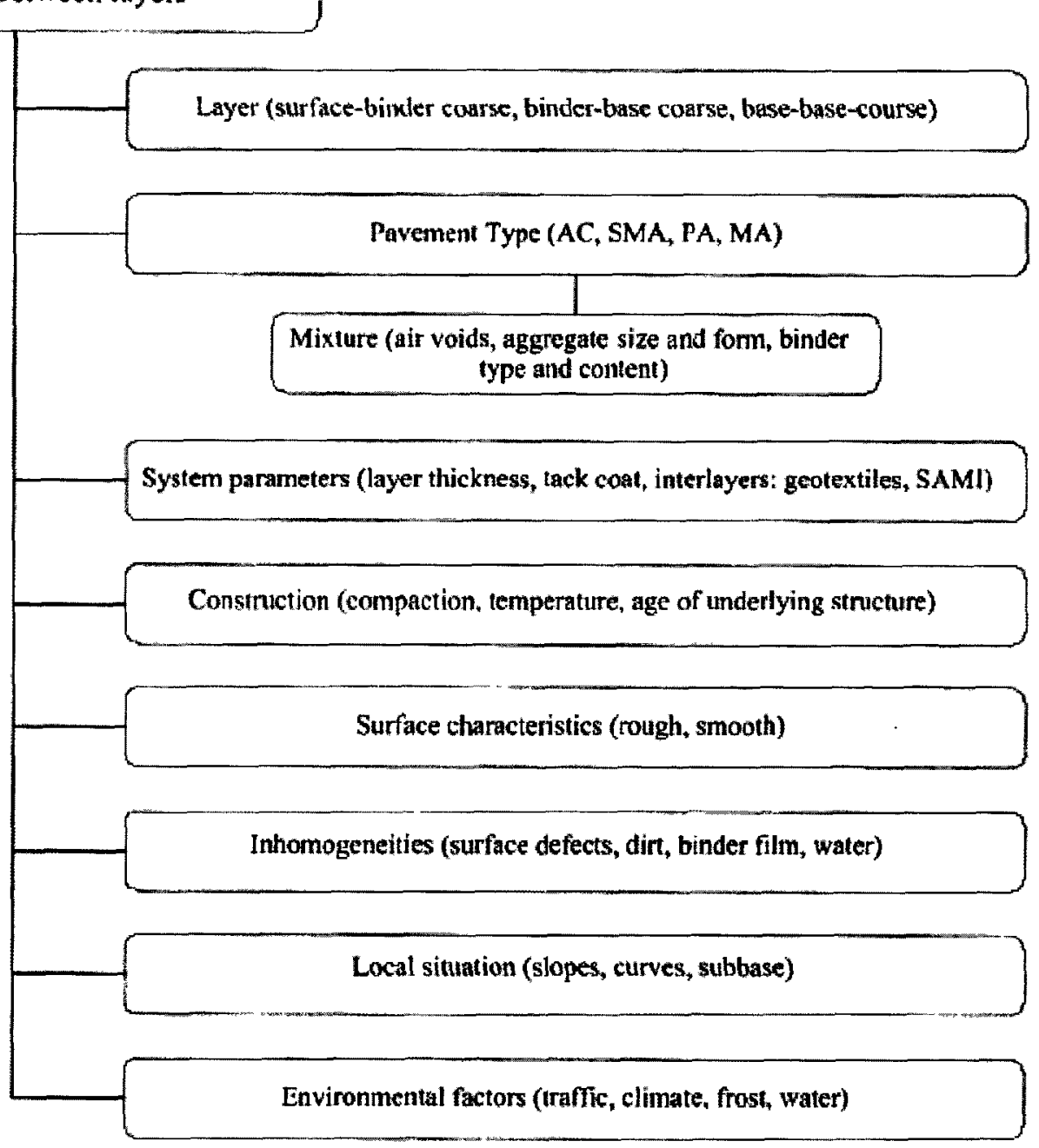

Figure 5.20: Factors influencing a durable bond between asphalt pavement layers

(Source: Raab et al., 2009) 


\subsubsection{Research approach}

A simplified flow chart of the step-by-step research approach is presented in Figure 5.21 and described in the following sections.

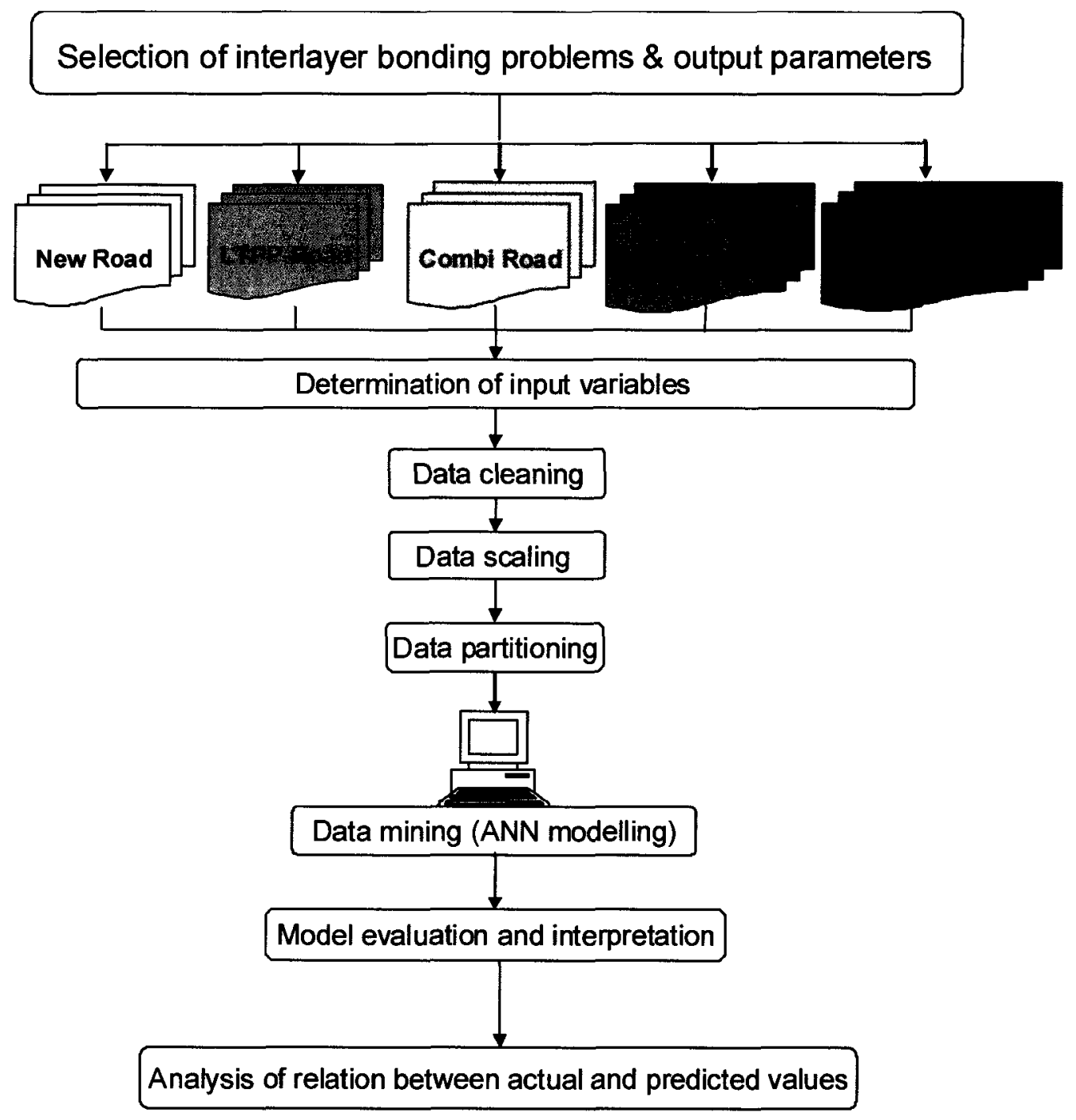

Figure 5.21: Research steps 


\subsubsection{Data selection for interlayer bonding problems}

Before ANN calculations can be conducted, the available data have to be gathered and prepared. Regarding the gathering and selection of data in this study, five different datasets as shown below were available. These datasets are taken partly from road pavements constructed for real traffic (datasets 1,2 and 3) and partly from pavements that were either produced in the laboratory (dataset 4) or under lab-like conditions on an open-air field (site) such as the data for dataset 5 .

All datasets are presented and discussed in greater detail in Section 5.1.

\subsubsection{Determination of output parameters}

The available output parameters from interlayer shear tests according to Chapter 3.1, are the following:

- $\quad$ maximum shear forces $\mathrm{F}_{\max }[\mathrm{kN}]$, which can be converted into the maximum nominal shear stress $\tau_{\max }[\mathrm{MPa}]$

- $\quad$ shear deformation at maximum shear stress $\mathrm{w}[\mathrm{mm}]$

- maximum shear stiffness $\mathrm{S}[\mathrm{kN} / \mathrm{mm}]$, which can be converted into the shear reaction modulus $\mathrm{K}[\mathrm{MPa} / \mathrm{mm}]$

- $\quad$ secant modulus $\mathrm{M}$ and the

- $\quad$ dissipated energy $\mathrm{W}_{\text {diss, }}$, which can be calculated from the fracture energy $\mathrm{W}_{\text {frac }}$ and the elastic energy $W_{\text {elast }}$.

For this investigation the three output parameters:

- $\quad$ max. shear force $\mathrm{F}[\mathrm{kN}]$

- $\quad$ shear deformation at maximum shear stress $\mathrm{w}[\mathrm{mm}]$ and 
- $\quad$ max. shear stiffness $\mathrm{S}[\mathrm{kN} / \mathrm{mm}]$

were chosen for prediction.

It was decided to take max. shear force and the max. shear stiffness instead of the max. shear stress and the shear reaction modulus, since all tested cores had the same diameter of $150 \mathrm{~mm}$. Nevertheless, from the predicted shear force and stiffness parameters, shear stress and shear reaction modulus can be calculated. As mentioned in Chapter 3, secant modulus and energy were not included.

\subsubsection{Determination of input variables}

Regarding the input variables it is important to choose the ones which have the biggest impact on the output.

The selection of the chosen input variables is given in Tables 5.12 to 5.16 (see Section 5.2.7)

\subsubsection{Data cleaning}

Another step in data preparation is data cleaning. This means that the datasets should neither contain missing data nor outliers or wrong types of values. In case of missing data the values are removed, or the missing values are substituted, where it was possible to determine input values such as mixtures characteristics according to standards or regulations.

\subsubsection{Data scaling}

After data cleaning, data scaling is done. This is a procedure which allows eliminating any incompatibility of data caused by the different units which may affect the accuracy of the ANN model. Data cleaning is done with a scaling feature implemented in the ANN software, as described later (see Section 5.6.2). 


\subsubsection{Data partitioning}

Before the evaluation, the dataset is divided in two subsets, the training and the test set. The training set, about $85 \%$ of the dataset, is used for training and the test set, about $15 \%$ of the data, is used for testing the evaluated model.

The Alyuda Neurointelligence software used in this research divides each dataset into three subsets: the training set, the validation set and the test set. The training set is a part of the input dataset used for neural network training, i.e. for the adjustment of network weights. The validation set is a part of the data used to tune network topology or network parameters other than weights. For example, it is used to define the number of hidden units or to detect the moment when the neural network performance started to deteriorate. The software uses the validation set for calculating generalisation loss and retaining the best network (the network with the lowest error on validation set). The test set is a part of the dataset used only to test how well the neural network will perform on new data. The test set is used after the network is ready trained, to test what errors will occur during future network application. The test set is not used during training and thus can be considered as consisting of new data entered by the user for the neural network application.

In addition to the data participation by the software, it was decided to separate a small part of the dataset to have an additional test set, the so called query set, which can be used to query and validate the determined network. This was done prior to feeding the datasets into the software, which means that several lines of data were excluded and put together in the so-called query set file. The procedure how these query sets were selected is explained in Section 5.8. 


\subsubsection{Data mining (ANN modelling)}

The first step in data mining means answering the question what kind of data mining is going to be carried out. There are two main tasks in data mining:

1. Function approximation or regression analysis, which predict the value of a continuous output parameter on the basis of a certain input dataset, and

2. Classification task which can predict a class label of the input object.

Since the aim of this research is the prediction of continuous output parameters such as maximum shear force, shear deformation at maximum stress and maximum shear stiffness on the basis of input parameters such as temperature, mixture characteristics or aging and traffic information, regression analysis for artificial neural network was performed.

\subsubsection{Model evaluation and interpretation}

As described earlier, a part of the dataset (about 15\% of all data) and the additional test set (about $10 \%$ of the whole dataset) will be used to test the network or, in other words, to evaluate the performance of the developed model.

This is done by minimising the error $\mathrm{E}$. If the error of the test set is smaller than a chosen threshold, the model has a good performance, see equation 5.1:

$$
E=\sum_{i=1}^{n}\left(y_{\imath}-v_{t}\right)^{2}
$$

where $y_{i}$ and $v_{i}$ are respectively the output calculated by ANN and the actual output for $n$ data points

In her dissertation, Miradi (Miradi, 2009) shows this process in a graph (see Figure 5.22). 


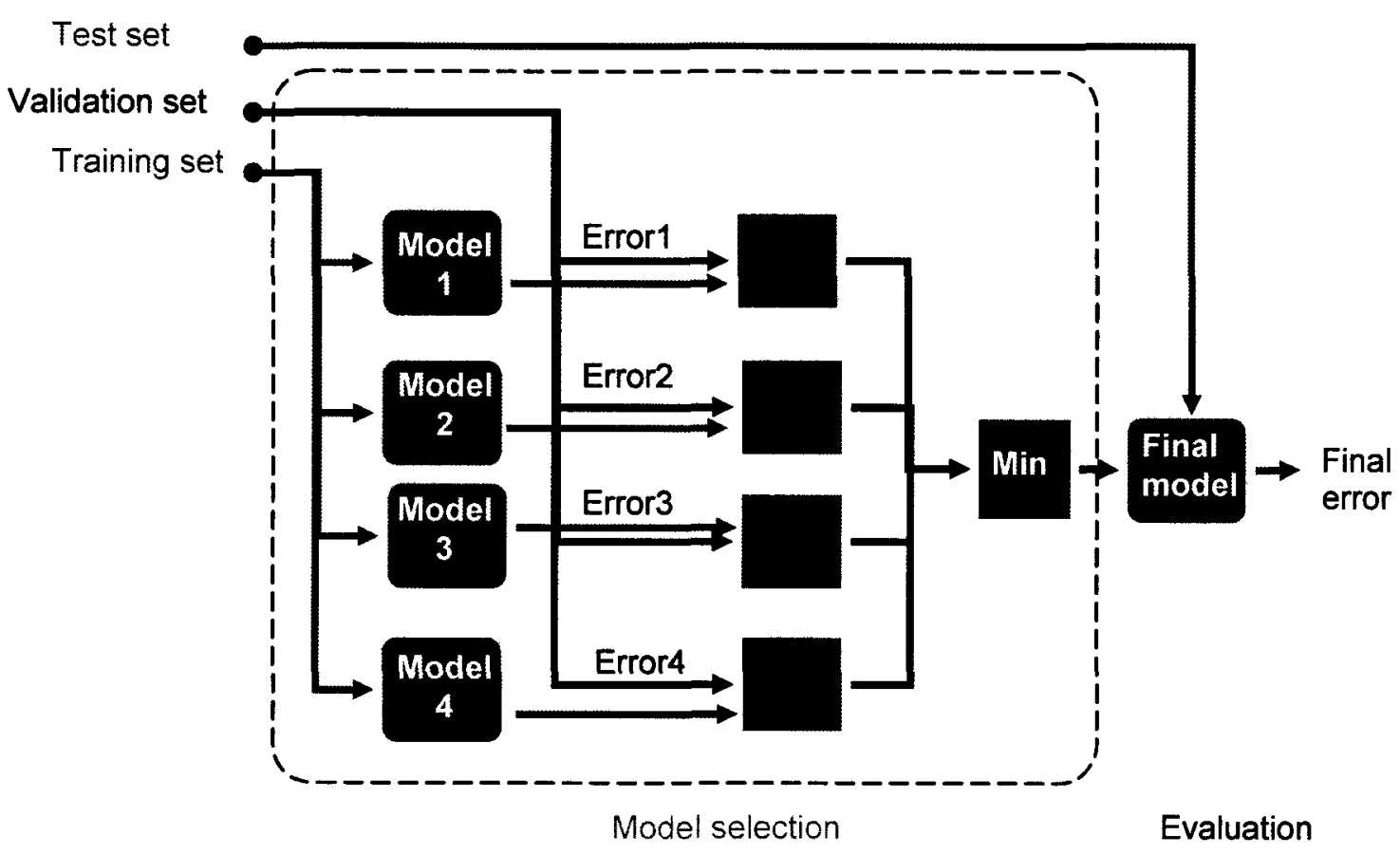

Figure 5.22: Evaluation of the developed model

(Source: Miradi, 2009)

The "quality" of a neural network training is given by the absolute relative error ARE or the absolute error $\mathrm{AE}$, which is calculated by subtracting the current output values with the target output values of the neural network. Additionally, the statistical ratio R-squared that provides a measure of how well future outcomes are likely to be predicted by the model is calculated by the actual versus the predicted values.

This statistical ratio R-squared should not be confused with $\mathrm{R}^{2}$ from linear regression, which is also given for training and test set. 
The model output is examined with so called response graphs, which display the response of the neural network output while one input is varied with the other inputs held constant.

\subsubsection{Analysis of relationship between actual and predicted values}

With an additional query test set, a linear regression is performed between the actual and the predicted values and the linear regression coefficient $\mathrm{R}^{2}$ are calculated.

\subsubsection{ANN: Definitions and techniques}

\subsubsection{Introduction}

The purpose of this section is to explain the definitions and techniques of artificial neural network (ANN) in general and to show the features and applications for the software Alyuda Neurointelligence.

Since this dissertation is aimed at practical application of artificial neural networks it concentrates on basic explanations in order to help the reader, who is unfamiliar with the topic, to understand the principles. Many of the information is taken from existing literature (e.g. Miradi, 2009, Haykin, 1999) or from the Alyuda Neurointelligence manual (C 2001-2009 Neo Digital). For detailed information and more complete overviews on ANN the reader is referred to the following publications (for example Engelbrecht, 2007, Fayyad, et al., 1996, Haykin, 1999, Rojas, 1996, Abraham, 2005, Kriesel, 2007).

The structure of this section corresponds to the steps described in section 5.2.5. 


\subsubsection{Data cleaning}

The software has an inbuilt feature to detect data anomalies. The user can then decide how to treat them.

In cases of missing values for output data, the whole row of data was eliminated in this research. In some cases, output data were only missing for one output parameter (such as shear stiffness). In this case, the data line was eliminated for the evaluation of shear stiffness while it was used for the evaluation of shear force and shear deformation.

In case of missing input data (variables) it had to be decided whether the data could be inserted by values known from standards or guidelines, for example, mixture characteristics or traffic data, or if the whole line of data had to be eliminated.

Wrong type values resulting from human error (e.g. typos) could either be corrected or had to be eliminated.

Outliers are values that can be just extreme cases, measurement errors or other anomalies. Hence, each single outlier has to be examined and it has to be decided if it can be used or has to be eliminated. The software often detected values for extreme cases and characterised them as outliers. Here, it was decided to accept these data (e.g. high binder and low air void content in case of mastic asphalt) when the given data were consistent with reality and therefore should be included in the evaluation. In other cases, unreasonably high or low data were either corrected when the correct value could be retrieved or eliminated when this was not possible.

\subsubsection{Data scaling}

In the software numeric columns are automatically scaled during data preprocessing using the following formulas (see Alyuda Neurointelligence software manual): 
$S F=\frac{\left(S R_{\max }-S R_{\min }\right)}{\left(x_{\text {max }}-x_{\text {min }}\right)}$

(equation 5.2)

$x_{s}=S R_{\min }+\left(x-x_{\min }\right) * S F$

(equation 5.3)

where:

$\mathrm{SF}=$ scaling factor

$\mathrm{SR}_{\min }=$ lower scaling range limit

$\mathrm{SR}_{\max }=$ upper scaling range limit

$\mathrm{x}=$ actual numerical value

$\mathrm{x}_{\mathrm{min}}=$ minimum actual value of the column

$\mathbf{x}_{\max }=$ maximum actual value of the column

$\mathrm{x}_{\mathrm{S}}=$ scaled value

For input columns the scaling range is $[-1,1]$. For the target column the scaling range depends on activation function of the output layer according to Table 5.10:

Table 5.10: Range of output layer activation functions

\begin{tabular}{|l|l|}
\hline Output layer activation function & range \\
\hline Linear & {$[-1 . .1]$} \\
\hline Logistic & {$[0 . .1]$} \\
\hline Hyperbolic Tangent & {$[-1 . .1]$} \\
\hline
\end{tabular}


A simple example shows how the above cited equations are used. For this example the air void content variable with a value of 5 vol- $\%$ from a dataset with the minimum value of 3 vol- $\%$ and a maximum value of 8 vol- $\%$ is considered.

Scaling in the range of $[-1,1]$ results in a scaled value of -0.2 .

$$
\begin{aligned}
& \mathrm{SR}_{\text {min }}=-1, \mathrm{SR}_{\text {max }}=1, \mathrm{x}_{\text {min }}=3, \mathrm{x}_{\max }=8, \mathrm{x}=5 \\
& S F=\frac{(1-(-1))}{(8-3)}=0.4 \\
& \mathrm{X}_{S}=-1+0.4(5-3)=-0.2
\end{aligned}
$$

The input variables are not always numerical but sometimes categorical which means that such a variable has at least two categories (e.g. tack coat type, intermediate layer type). In case of categorical variables, scaling is called encoding. Categorical variables can be encoded using one-of- $\mathrm{N}$, binary or numeric encodings.

One-of- $\mathrm{N}$ encoding means that a variable with $\mathrm{N}$ distinct categories (values) is encoded into a set of $\mathrm{N}$ numeric variables, with one variable for each category. For example, for the tack coat variable with values "No tack", "Modified tack" and "Unmodified tack", "No tack" will be represented as $\{1,0,0\}$, "Modified tack" as $\{0,1,0\}$, and "Unmodified tack" as $\{0,0,1\}$.

Binary encoding means that a variable with $\mathrm{N}$ distinct categories (values) is encoded into a set of $M$ binary variables, where $M$ is equal to the length of a binary number needed to represent $\mathrm{N}$ distinct values. For example, the intermediate layer variable with values "Intermediate layer 1", "Intermediate layer 2", "Intermediate layer 
3", "Intermediate layer 4," and "No Intermediate layer" will be encoded into 3 binary variables and "Intermediate layer 1 " will be represented as $\{0,0,0\}$, "Intermediate layer $2 "$ as $\{0,0,1\}$, "Intermediate layer $3 "$ as $\{0,1,0\}$, "Intermediate layer " 4 as $\{0,1,1\}$, and "No Intermediate layer" as $\{1,0,0\}$.

Numeric encoding means that a variable with $\mathrm{N}$ distinct categories (values) is encoded into one numeric variable, with one integer value assigned for each category. For example, for the tack coat variable with values "No tack", "Modified tack" and "Unmodified tack", "No tack" will be represented as $\{1\}$, "Modified tack" as $\{2\}$, and "Unmodified tack" as $\{3\}$.

\subsubsection{Determination of input variables}

Input variable selection is a very important step since the choice of the variables influences the quality of the model prediction. Sometimes it is possible that a variable seems to be important for the software, while this importance can physically not be explained and is opposed to the findings in reality. Therefore, it is important not only to rely on machine-aided search mechanisms, but also to include experimental knowledge and engineering judgement.

On the one hand, including more variables may have a negative effect on data mining since for example more data points are needed to ensure statistical validity, on the other hand, including more variables can increase the knowledge and may help to examine the model output (e.g. produce response graphs).

For this research, before applying the ANN technique engineering judgment and experience were applied to ensure that most critical variables were selected. This step 
was completed by testing the existence of any significant influence per each variable and those which failed the test were removed from any further analysis.

\subsubsection{Data mining with Artificial Neural Networks: ANN Structure}

As described in Section 5.2.3, artificial neural networks are composed of different artificial neurons (ANs), which are the information processing units. Figure 5.23 shows the model of such an artificial neuron (Haykin, 1999). The artificial neuron (AN) receives information inputs from the environment or from other neurons. These inputs are entered and fed through connections characterised by their own weights. A linear adder sums up all weighted input signals. The activation function has the task to convert the input to the output and to limit the amplitude of the AN output. According to Figure 5.23 the artificial neuron also includes a bias $b_{k}$, which can increase or decrease the input of the activation function $\left(v_{k}\right)$ depending on whether it is positive or negative.

Haykin (Haykin, 1999) describes the output of an artificial neuron in a mathematical way as follows:

$y_{k}=F\left(\sum_{j=1}^{m} w_{k j} x_{j}+b_{k}\right)$

where $\mathrm{x}_{1}, \mathrm{x}_{2}, \ldots \mathrm{x}_{\mathrm{m}}$ are the input variables, $\mathrm{w}_{\mathrm{k} 1}, \mathrm{w}_{\mathrm{k} 2}, \ldots \mathrm{w}_{\mathrm{km}}$ the weighted connections, $\sum_{j=1}^{m}$ the linear adder, $b_{k}$ is the bias, $F($.$) is the activation function and y_{k}$ the output. 


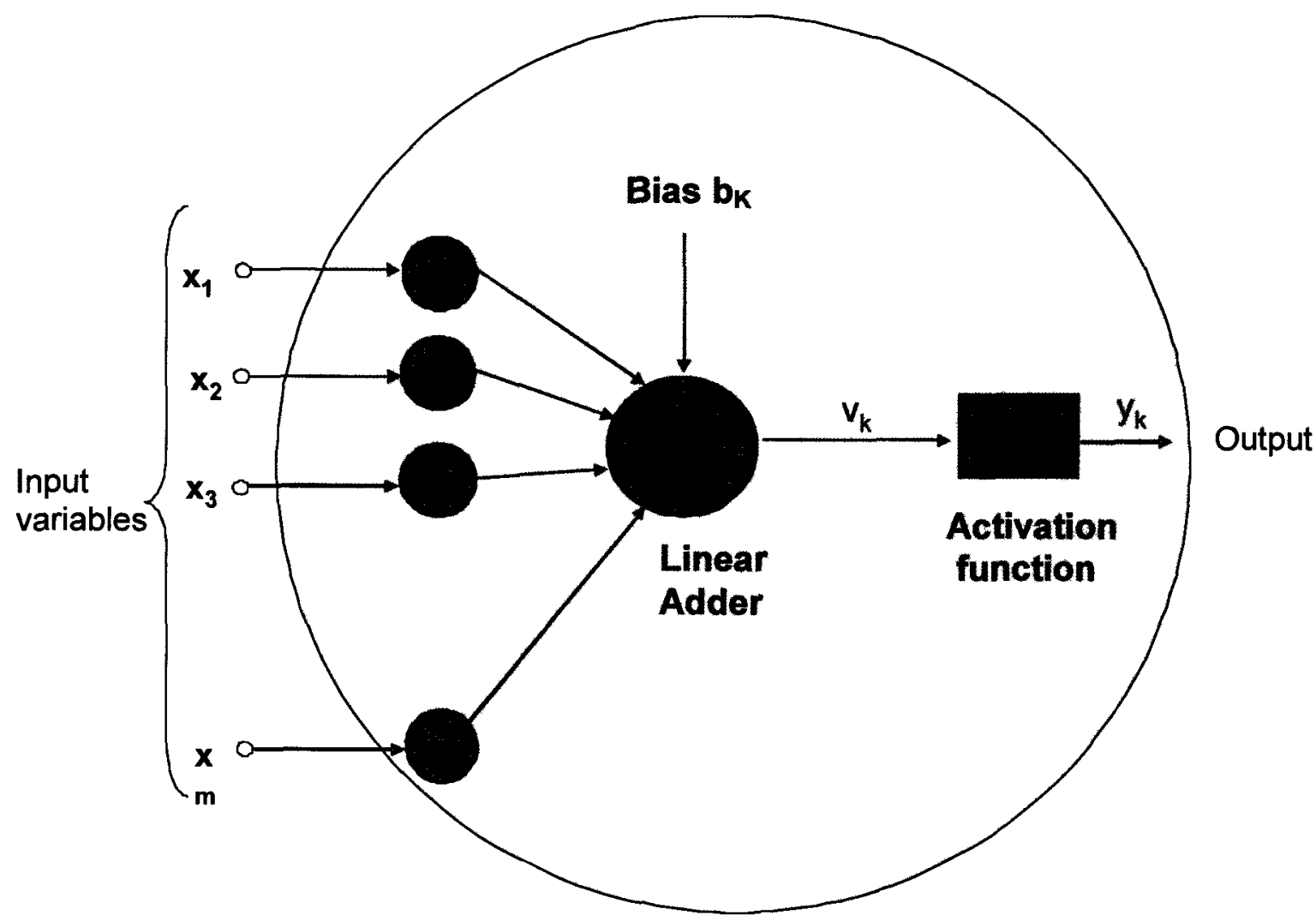

Figure 5.23: Schematic of an artificial neuron

(Source: Haykin, 1999, Miradi, 2009)

\subsubsection{Activation function}

The activation function $\mathrm{F}($.$) is responsible for the nonlinearity, since without activation$ function there would be only a linear sum. It is the nonlinear activation function that allows artificial neural networks to compute nontrivial problems using only a small number of nodes.

The applied software supports 3 activation functions for regression analysis:

Linear: This function produces its input as its output or, in other words, just passes the activation level directly as the output. 
Logistic or Log-sigmoid: This function as shown in Figure 5.24(a) has a sigmoid curve and is calculated using the following formula where $B$ is the slope parameter of the function:

$$
F(x)=\frac{1}{1+e^{-\beta x}}
$$

Hyperbolic tangent: This function (see Figure 5.24(b)) also has a sigmoid curve where $B$ defines the shape of the function. Because of its symmetry it is often found to perform better than the logistic function and it is calculated using the following formula:

$$
F(x)=\frac{e^{\beta x}-e^{-\beta x}}{e^{\beta x}+e^{-\beta x}}
$$

(equation 5.6)

(a)

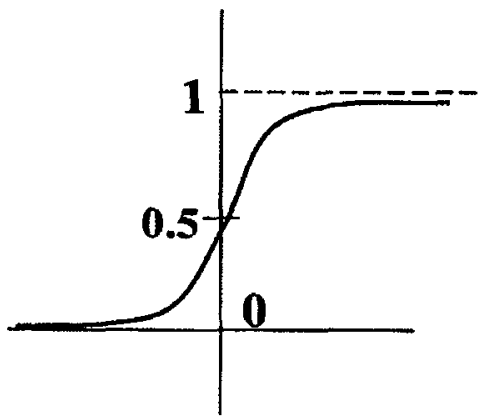

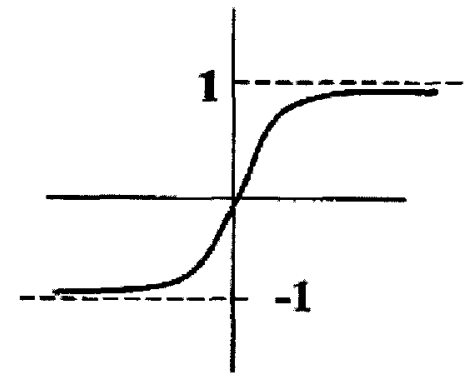

(b)

Figure 5.24 - Logistic function (a) and Hyperbolic tangent function (b)

For the presented research it was found that for the chosen learning algorithm (see section 5.2.7.6) the hyperbolic tangent function gave the lowest prediction error and was therefore chosen as activation function for both hidden and output layer.

\subsubsection{Learning algorithm}

Learning algorithms are used to model complex relationships between inputs and outputs and to find patterns in data. In most cases an ANN is an adaptive system that changes its 
structure based on external or internal information that flows through the network during the learning phase. During this learning or training process the weights are gradually changed in order to achieve an output with a minimal error and get the best convergence for the predicted value. The learning ability of an ANN is achieved through the application of a learning or training algorithm. Based on the way ANN is trained, the learning algorithms can be either supervised or unsupervised learning.

In supervised learning, input-output pairs are presented to the ANN, which has to learn to associate each input to its corresponding and desired output. Unsupervised learning is a human's ability some ANNs have. Humans can learn by experience. ANNs based on unsupervised learning learn in the same way. The data given to these learning algorithms contain no output and the algorithm discovers a pattern from the data (Miradi, 2009). In this research a supervised learning algorithm was selected.

The applied software allows the application of the following learning algorithms which are also the most commonly used ones:

1. Backpropagation

2. Quick propagation

3. Conjugate Gradient Descent

4. Quasi-Newton

5. Levenberg-Marquardt

According to the literature (Miradi, 2009, Haykin, 1999) there is no single best training algorithm for neural networks. The choice of a training algorithm has to be based 
on the characteristics of the problem. The following simple rules proved to be quite effective for most practical purposes (see Alyuda Neurointelligence program manual):

- If the network has a small number of weights (usually, up to 300), LevenbergMarquardt algorithm is efficient. Levenberg-Marquardt often performs considerably faster than other algorithms and finds better optima than other algorithms. But its memory requirements are proportional to the square of the number of weights. Another Levenberg-Marquardt limitation is that it is specifically designed to minimize the sum of squares error and cannot be used for other types of network error.

- If the networks has a moderate number of weights, Quasi-Newton and Limited Memory Quasi-Newton algorithms are efficient. But their memory requirements are also proportional to the square of the number of weights.

- If the network has a large number of weights, it is recommended to use Conjugate Gradient Descent.

- Backpropagation and Quick propagation can be used for networks of any size. Backpropagation algorithm is the most popular algorithm for training of FANN and is often used by researchers and practitioners.

After several trials which proved most of the above mentioned algorithms to work well after adjusting the training algorithm's parameters, backpropagation was selected, since it seemed to perform well for the given databases. This algorithm was further chosen since in the field of pavement engineering and material science backpropagation was found to have a very good performance (Miradi, 2009, Gesoglu et al., 2010, Xiao et al., 2010, Miradi et al., 2008, Ghaffari et al., 2006).

In backpropagation the initial weights are chosen to small random values. Then, one data point from the training set is taken and the ANN output is calculated. The ANN output is then compared to the actual output value by determining the error resulting in an 
update of the weights. This process is repeated until the network reaches a determined level of accuracy, thus producing the adequate output for all data points in the training set.

\subsubsection{Optimisation of learning parameters}

\section{Initial weights}

The chosen initial weights strongly influence the convergence of the learning algorithm of an ANN (Miradi, 2009). Normally they are initialised at small random values in order to avoid that the activation function becomes saturated from the very beginning and the solution will be trapped in a local minimum or in a flat plateau close to the starting point (Pantic, 2001).

There are two main approaches for weight adjustment: online and batch. The number of weight updates of the two methods for the same number of data presentations is very different. The online method modifies and updates the weights for each input data, while the batch method computes the weight update for each input data, but stores these values during one repetition through the training set. At the end, after all input data samples have been presented, all the contributions are added, and only then the weights will be updated (Abraham, 2005).

For the present research the batch method was found to have a clearly better convergence and a lower prediction error than the on-line method.

\section{Determination of optimum number of hidden layers and neurons}

The number of hidden layers and hidden neurons influences the convergence and the performance of a FANN. Explicitly, the number of hidden neurons affects how well the network is able to separate the data. On the one hand, a large number of hidden neurons 
will ensure correct learning and a good prediction of the data the network has been trained on. On the other hand, the network's performance on new data and its ability to generalise may be compromised. With too few hidden neurons, the network may be unable to learn the relationships amongst the data and the error will never fall below an acceptable level (Abraham, 2005).

Concerning the number of hidden layers, Miradi proved that one single hidden layer is sufficient for a FANN (see Miradi, 2009, p. 100).

Concerning the number of hidden neurons, they must be determined through a trial and error procedure by changing their number and looking for the smallest error.

The applied software has an inbuilt search feature for the network architecture and the number of hidden neurons. According to the literature there are also a few common rules: The smallest number of neurons that yields satisfactory results should be used (Xiao, 2010) and in most cases the maximum number of hidden units is rarely required to exceed the number of inputs by more than four times (Alyuda Neurointelligence manual).

For the present research, an architecture search for hidden neurons using the inbuilt architecture search feature was conducted (exhaustive search), while the number of hidden layer was set to one. This led o the finding that a good convergence could be achieved for different numbers of hidden neurons and that the number of hidden neurons also varied for the different datasets. Regarding the above mentioned rules it was decided to take the smallest number of hidden neurons which proved to have a good convergence of the network. 


\section{Determination of optimum learning rate and momentum coefficient}

For backpropagation, two other parameters, the learning rate and the momentum coefficient need to be defined for network training. The learning rate is an adjustable factor that controls the speed of the learning process. With a faster learning rate, the ANN model will learn faster. However, if the learning rate is too high, the oscillations of weight changes can impede the convergence of the error surface, and may lead to overshooting a near-optimal weight factor. In contrast, if the learning rate is too slow, the ANN model may be caught in a local error minimum instead of the global minimum (Ghaffari, 2006, Miradi, 2009).

The momentum is used in weight updating for backpropagation ANN to avoid local minima and to reduce oscillation of weight change. To obtain faster learning without oscillation, the weight change is related to the previous weight change to provide a smooth effect. The momentum coefficient determines the proportion of the last weight change that is added into the new weight change. The following simplified relationship presented by Erb (1993) points out the effects of these two parameters on the weight adjustment:

new weight change $=\eta \times$ error $+\beta \times$ last weight change

(equation 5.7)

where, $\eta$ is the learning rate and $\beta$ stands for the momentum coefficient

According to the literature there is no general rule to choose the learning rate, and in most cases it is done experimentally for each particular problem. In order to determine the best values for learning rate $\eta$ and momentum coefficient $\beta$, a grid search is 
recommended by Haykin (Haykin, 1999). This can be done by varying the values for learning rate $\eta$ and momentum coefficient $\beta$ in 0.1 intervals between 0 and 1 (Miradi, 2009, Haykin, 1999, Ghaffari, 2006).

For the presented research, a trial and error search was done, varying the values for $\eta$ and $\beta$ between 0 and 1 in intervals of 0.1 . This method led to the finding that a good convergence could be achieved for different close by combinations of values for $\eta$ and $\beta$ and that the values for $\eta$ and $B$ also varied for the different datasets.

\subsubsection{Developing ANN models - summary}

The single steps for developing ANN models are summarised below:

1) Determine input and output parameters

2) Prepare data (data cleaning and scaling, data partitioning)

3) Determine network architecture (number of layers and neurons per layer)

4) Chose activation function and learning algorithm

5) Find learning rate and momentum coefficient

6) Train network. Stop training, if the decrease in prediction error is small or if the overall changes in the weights are small.

7) Test the trained model using the test set

8) Choose another activation function, learning algorithm and parameters and start training again.

9) Try various training parameters (activation function, learning algorithm etc.) and select the one that gives lowest prediction error. 


\subsubsection{Data inventory}

\subsubsection{General}

As discussed earlier, the interlayer bond is a mechanical property that is critical for enhancing the long term performance of asphalt pavements and at the same time it is very complex to determine the main variables that govern its behaviour in the field. In this thesis it was decided that utilising an approach based on ANN technique and rich database would provide an excellent opportunity to analyse and determine those main governing variables. Clearly, the interlayer bond will depend on physical and mechanical properties of the main constituents of the asphalt mixtures, the characteristics of the interface, the mechanical properties of the pavement structure and the external factors that affect the pavement structure itself. Finally, the value of the bond itself will depend very much on the testing method and conditions. Table 5.11 illustrates a list of the variables which are expected to govern the general behaviour of the bond. The list consists of four major variable sets which includes nineteen different main variables. It is beyond the scope of this research to measure the contribution of each variable to the interlayer bond especially when there are five different pavement types considered for this study. Subsequently, for each pavement type a set of variables associated with the specific characteristics of the four sets was developed and their contribution was examined utilising the ANN technique. Tables 5.12 to 5.16 provide the prepared lists of variables for each of the pavement type considered in the analysis. 
Table 5.11: List of general variables influencing the interlayer bond

\begin{tabular}{|c|c|c|c|}
\hline $\begin{array}{c}\text { Mixture } \\
\text { characteristics }\end{array}$ & $\begin{array}{c}\text { Binder } \\
\text { characteristics }\end{array}$ & $\begin{array}{c}\text { Pavement } \\
\text { characteristics }\end{array}$ & $\begin{array}{c}\text { Testing } \\
\text { condition }\end{array}$ \\
\hline Mixture type & $\begin{array}{c}\text { Binder type } \\
\text { (laboratory mix } \\
\text { design) }\end{array}$ & Type of Pavement & Temperature \\
\hline $\begin{array}{c}\text { Nom. max. } \\
\text { aggregate size }\end{array}$ & $\begin{array}{c}\text { Penetration } \\
\text { (field recovery) }\end{array}$ & Layer thickness & $\begin{array}{c}\text { Deformation } \\
\text { rate }\end{array}$ \\
\hline $\begin{array}{c}\text { Aggregate } \\
\text { gradation }\end{array}$ & $\begin{array}{c}\text { Softening Point } \\
\text { (field recovery) }\end{array}$ & Air void content & \\
\hline Binder content & Tack coat & \\
\hline Marshall stability & & Age & \\
\hline Marshall flow & & Traffic & \\
\hline & & Convironmental \\
Constions \\
\end{tabular}

The variables and their values or ranges considered for the newly constructed pavement or New Road are shown in Table 5.12. As can be noted from the Table, the developed matrix to perform the analysis becomes extremely large when one attempts to consider all its elements. For economic and time constrains it was important to reduce the size of the considered matrix of variables. Therefore, before applying the ANN technique, engineering judgment and experience were applied to ensure that most critical variables were selected. This step was completed by testing the existence of any significant influence per each variable and those which failed the test were removed from any further analysis. 
This technique was applied on all five road types and the results of utilising the ANN technique are given in Tables 6.2, 6.4, 6.6, 6.8 and 6.10.

\subsubsection{Data from New Road}

The database from New Road represents the largest database available for ANN modelling. As explained earlier in this project, the interlayer shear properties between the top and second layer of either new road pavement constructions or rehabilitations were determined. This meant that normally for each road pavement evaluation between 7 and 10 cores were tested at $20^{\circ} \mathrm{C}$ and $40^{\circ} \mathrm{C}$ respectively. In three cases tests were only conducted at $20^{\circ} \mathrm{C}$. The deformation rate was $50 \mathrm{~mm} / \mathrm{min}$. For all individual layers mixture, binder and pavement type was known. Further, lab testing was carried out in order to determine mixture, binder and pavement parameters, such as nom. max. aggregate size, aggregate gradation, binder content, Marshall stability and flow, air void content and layer thickness. Additionally, penetration and softening point ring and ball were determined from the recovered binder.

Table 5.12 shows all variables and their values or ranges for New Road. All parameters in bold show those parameters for which information were available and values provided a certain range (e.g. it is not possible to have the deformation rate as a variable when testing is done at one rate only). 
Table 5.12: List of variables influencing interlayer bond of New Road

\begin{tabular}{|c|c|c|c|c|c|c|}
\hline \multirow{2}{*}{\multicolumn{2}{|c|}{$\begin{array}{c}\begin{array}{c}\text { Mixture } \\
\text { characteristics }\end{array} \\
\text { Mixture type }\end{array}$}} & \multirow{2}{*}{\multicolumn{2}{|c|}{$\begin{array}{c}\text { Binder } \\
\text { characteristics }\end{array}$}} & \multicolumn{2}{|c|}{$\begin{array}{c}\text { Pavement } \\
\text { characteristics }\end{array}$} & \multirow{3}{*}{$\begin{array}{c}\begin{array}{c}\text { Testing } \\
\text { condition }\end{array} \\
\text { Temperature } \\
20^{\circ} \mathrm{C}, 40^{\circ} \mathrm{C}\end{array}$} \\
\hline & & & & Layer & hickness & \\
\hline Layer 1 & Layer 2 & Layer 1 & Layer 2 & Layer 1 & Layer 2 & \\
\hline $\begin{array}{l}\text { MA } \\
\text { AC } \\
\text { SMA } \\
\text { PA } \\
\end{array}$ & $\begin{array}{l}\text { MA } \\
\text { AC }\end{array}$ & $\begin{array}{c}55 / 70 \\
60 / 70 \\
80 / 100 \\
\mathrm{PmB} \\
\end{array}$ & $\begin{array}{c}55 / 70 \\
60 / 70 \\
80 / 100 \\
\text { PmB } \\
\end{array}$ & $30-55 \mathrm{~mm}$ & $35-100 \mathrm{~mm}$ & \\
\hline \multicolumn{2}{|c|}{$\begin{array}{c}\text { Nom. max. aggregate } \\
\text { size }\end{array}$} & \multicolumn{2}{|c|}{ Penetration } & \multicolumn{2}{|c|}{ Air void content } & $\begin{array}{c}\text { Deformation } \\
\text { rate } \\
50 \mathrm{~mm} / \mathrm{min} \\
\end{array}$ \\
\hline Layer 1 & Layer 2 & Layer 1 & Layer 2 & Layer 1 & Layer 2 & \\
\hline $\begin{array}{l}11 \mathrm{~mm} \\
16 \mathrm{~mm}\end{array}$ & $\begin{array}{l}16 \mathrm{~mm} \\
22 \mathrm{~mm} \\
32 \mathrm{~mm}\end{array}$ & $30-90$ & $30-90$ & $1 \%-20 \%$ & $2 \%-7.8 \%$ & \\
\hline \multicolumn{2}{|c|}{ Aggregate gradation } & \multicolumn{2}{|c|}{$\begin{array}{c}\text { Softening Point } \\
\text { Ring+Ball }\end{array}$} & \multirow{3}{*}{\multicolumn{2}{|c|}{$\begin{array}{c}\text { Tack coat } \\
\text { non mod. tack } \\
\text { polym. mod. tack }\end{array}$}} & \\
\hline Layer 1 & Layer 2 & Layer 1 & Layer 2 & & & \\
\hline $\begin{array}{c}\text { Passing \% } \\
ø 8: 56-87 \\
\emptyset 2: 7-56 \\
ø 0.09: 2-26\end{array}$ & $\begin{array}{c}\text { Passing \% } \\
\varnothing 8: 56-80 \\
\varnothing 2: 25-47 \\
\varnothing 0.09: 5-26\end{array}$ & $56-65$ & $53-60$ & & & \\
\hline \multicolumn{2}{|c|}{ Binder content } & & & \multirow{3}{*}{\multicolumn{2}{|c|}{$\begin{array}{c}\text { Age: } \\
0 \text { years }\end{array}$}} & \\
\hline Layer 1 & Layer 2 & & & & & \\
\hline $4.5-7.8 \%$ & $3.5 \%-7 \%$ & & & & & \\
\hline \multicolumn{2}{|c|}{ Marshall stability } & & & \multirow{3}{*}{\multicolumn{2}{|c|}{$\begin{array}{c}\text { Traffic: } \\
\text { new, no traffic }\end{array}$}} & \\
\hline Layer 1 & Layer 2 & & & & & \\
\hline $8-16$ & $9-20$ & & & & & \\
\hline \multicolumn{2}{|c|}{ Marshall flow } & & & \multirow{3}{*}{\multicolumn{2}{|c|}{$\begin{array}{l}\text { Pavement type: } \\
\text { asphalt/asphalt }\end{array}$}} & \\
\hline Layer 1 & Layer 2 & & & & & \\
\hline $2-5.3 \mathrm{~mm}$ & $2-4.5 \mathrm{~mm}$ & & & & & \\
\hline
\end{tabular}

\subsubsection{Data from LTPP-Road}

The second database was retrieved about 10 years later from a repeated interlayer shear property investigation of the pavements from the New Road database. Since the investigated pavement structure had not been new any longer and had been under traffic 
for about 10 years the traffic data, such as average daily traffic (number of vehicles) and the percentage of heavy traffic (vehicles with a weight of more than $3.5 \mathrm{t}$ ) were available for additional input variables. In order to be able to profit from the additional input variables, traffic and age, the LTPP Road and the New Road databases have to be put together for ANN evaluation.

Table 5.13 shows all variables and their values or ranges for LTPP Road.

Table 5.13: List of variables influencing interlayer bond of LTPP Road

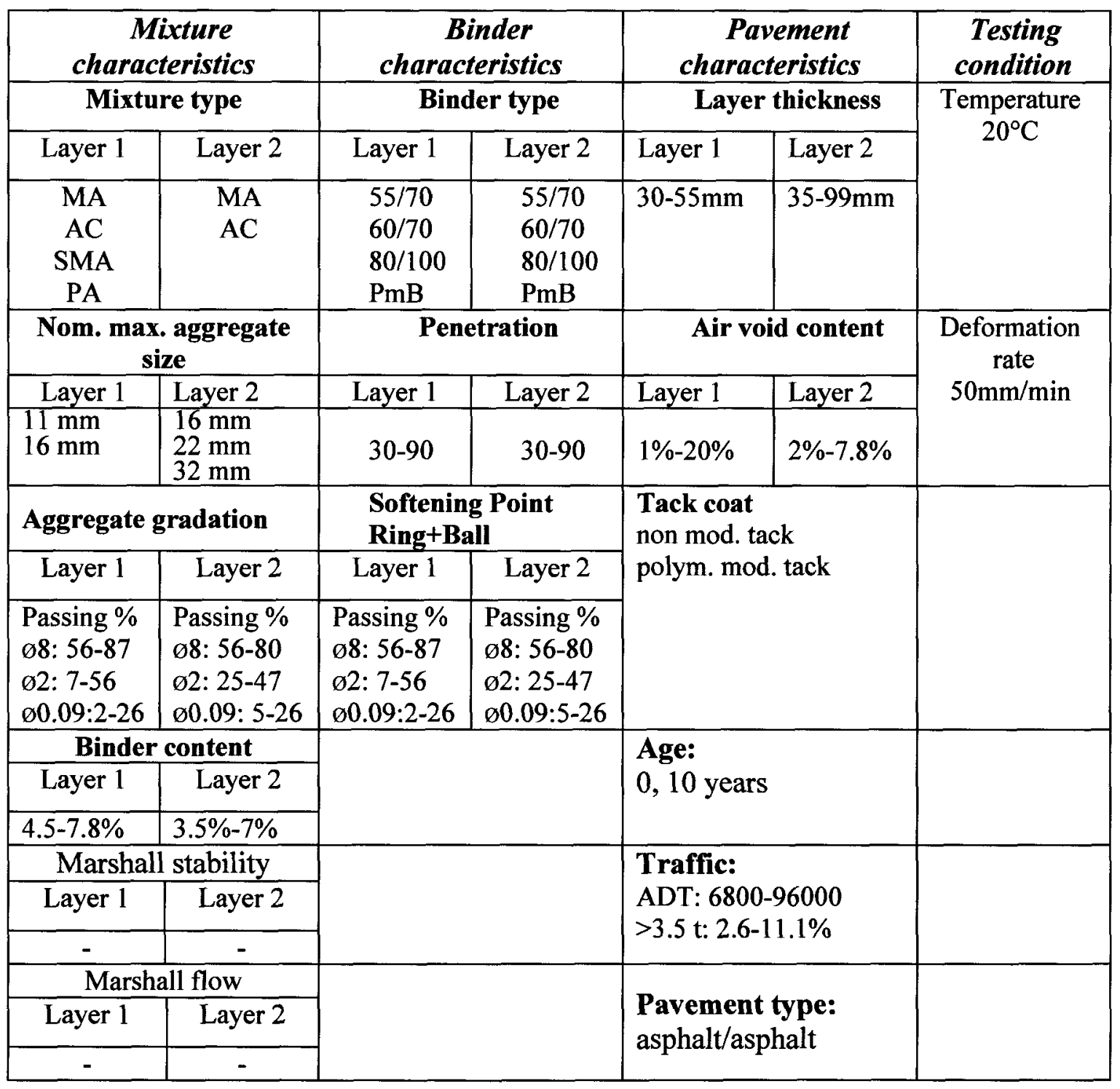




\subsubsection{Data from Combi Road}

The data from the Combi Road database which was evaluated in this research were retrieved from interlayer shear testing of rehabilitated concrete pavements of a motorway. These pavements had been rehabilitated with and without different intermediate layer such as bituminous treatments or geotextiles and an asphalt overlay of either asphalt concrete AC or stone mastic asphalt SMA (see also Chapter 5.1.4).

For performance evaluation, testing directly after construction (June 2005) was repeated after 0.5 (November 2005) and 1 year (June 2006) respectively.

Since, in this investigation the material properties of the second layer, which consisted of concrete, made no sense, its properties, were not taken into consideration.

Table 5.14 shows all variables and their values or ranges for Combi Road. 
Table 5.14: List of variables influencing interlayer bond of Combi Road

\begin{tabular}{|c|c|c|c|c|c|c|}
\hline \multirow{2}{*}{\multicolumn{2}{|c|}{$\begin{array}{c}\begin{array}{c}\text { Mixture } \\
\text { characteristics }\end{array} \\
\text { Mixture type }\end{array}$}} & \multirow{2}{*}{\multicolumn{2}{|c|}{$\begin{array}{c}\text { Binder } \\
\text { characteristics }\end{array}$}} & \multicolumn{2}{|c|}{$\begin{array}{c}\text { Pavement } \\
\text { characteristics }\end{array}$} & \multirow{3}{*}{$\begin{array}{c}\begin{array}{c}\text { Testing } \\
\text { condition }\end{array} \\
\text { Temperature } \\
20^{\circ} \mathrm{C}\end{array}$} \\
\hline & & & & Laye & ickness & \\
\hline Layer 1 & Layer 2 & Layer 1 & Layer 2 & Layer 1 & Layer 2 & \\
\hline $\begin{array}{c}\text { AC } \\
\text { SMA }\end{array}$ & Concrete & $55 / 70$ & - & $40 \mathrm{~mm}$ & $60 \mathrm{~mm}$ & \\
\hline \multicolumn{2}{|c|}{$\begin{array}{c}\begin{array}{c}\text { Nom. max. aggregate } \\
\text { size }\end{array} \\
\end{array}$} & \multicolumn{2}{|c|}{ Penetration } & \multicolumn{2}{|c|}{ Air void content } & $\begin{array}{l}\text { Deformation } \\
\text { rate }\end{array}$ \\
\hline Layer 1 & Layer 2 & Layer 1 & Layer 2 & Layer 1 & Layer 2 & $50 \mathrm{~mm} / \mathrm{min}$ \\
\hline $11 \mathrm{~mm}$ & - & 60 & & $1 \%-20 \%$ & & \\
\hline \multicolumn{2}{|c|}{ Aggregate gradation } & \multicolumn{2}{|c|}{$\begin{array}{l}\text { Softening Point } \\
\text { Ring+Ball }\end{array}$} & \multirow{3}{*}{\multicolumn{2}{|c|}{$\begin{array}{l}\text { Tack coat } \\
\text { Poly. mod. tack }\end{array}$}} & \\
\hline Layer 1 & Layer 2 & Layer 1 & Layer 2 & & & \\
\hline $\begin{array}{l}\text { Passing \% } \\
\varnothing 8: 53-70 \\
\varnothing 2: 24-35 \\
\varnothing 0.09: 9 \\
\end{array}$ & $\begin{array}{c}\text { Passing \% } \\
- \\
- \\
- \\
\end{array}$ & 54 & - & & & \\
\hline \multicolumn{2}{|c|}{ Binder content } & & & \multirow{3}{*}{\multicolumn{2}{|c|}{$\begin{array}{l}\text { Age: } \\
0,1,2 \text { years }\end{array}$}} & \\
\hline Layer 1 & Layer 2 & & & & & \\
\hline $5.6 \%$ & - & & & & & \\
\hline \multicolumn{2}{|c|}{ Marshall stability } & & & \multirow{3}{*}{\multicolumn{2}{|c|}{$\begin{array}{l}\text { Traffic: } \\
\text { not known }\end{array}$}} & \\
\hline Layer 1 & Layer 2 & & & & & \\
\hline 14 & - & & & & & \\
\hline \multicolumn{2}{|c|}{ Marshall flow } & & & \multirow{3}{*}{\multicolumn{2}{|c|}{$\begin{array}{l}\text { Pavement type: } \\
\text { asphalt/concrete }\end{array}$}} & \\
\hline Layer 1 & Layer 2 & & & & & \\
\hline \multirow[t]{2}{*}{$2.8 \mathrm{~mm}$} & - & & & & & \\
\hline & & & & \multicolumn{2}{|c|}{$\begin{array}{l}\text { Intermediate layer } \\
1=\text { bit. treatment } \\
2=\text { glass fibre grid } \\
3=\text { carbon fibre grid } \\
4=\text { bit. treatment }+ \\
\text { glass fibre grid } \\
5=\text { none } \\
6=\text { none, fine milling }\end{array}$} & \\
\hline
\end{tabular}




\subsubsection{Data from Lab Pavement}

The Lab Pavement database was collected during an investigation on the influence of tack coat using laboratory specimens. As described in Chapter 5.1.5., all specimens were prepared in the same manner varying at the interface in terms of tack coat, surface roughness (fine milling or no fine milling), conditioning and surface cleanness/dryness. Since the specimens were cored from slabs constructed in the laboratory, the amount of tests for one condition was normally 12 , in case of surface roughness even 24 . Table 5.15 shows all variables and their values or ranges considered for Lab Pavement.

Table 5.15: List of variables influencing interlayer bond of Lab Pavement

\begin{tabular}{|c|c|c|c|c|c|c|}
\hline \multirow{2}{*}{\multicolumn{2}{|c|}{$\begin{array}{c}\text { Mixture } \\
\text { characteristics } \\
\text { Mixture type }\end{array}$}} & \multirow{2}{*}{\multicolumn{2}{|c|}{$\begin{array}{c}\text { Binder } \\
\text { characteristics }\end{array}$}} & \multicolumn{2}{|c|}{$\begin{array}{c}\text { Pavement } \\
\text { characteristics }\end{array}$} & \multirow{3}{*}{$\begin{array}{c}\begin{array}{r}\text { Testing } \\
\text { condition }\end{array} \\
\text { Temperature } \\
20^{\circ} \mathrm{C}\end{array}$} \\
\hline & & & & Lay & ickness & \\
\hline Layer 1 & Layer 2 & Layer 1 & Layer 2 & Layer 1 & Layer 2 & \\
\hline $\mathrm{AC}$ & $\mathrm{AC}$ & $55 / 70$ & $55 / 70$ & $40 \mathrm{~mm}$ & $60 \mathrm{~mm}$ & \\
\hline \multicolumn{2}{|c|}{$\begin{array}{l}\text { Nom. max. aggregate } \\
\text { size }\end{array}$} & \multicolumn{2}{|c|}{ Penetration } & \multicolumn{2}{|c|}{ Air void content } & $\begin{array}{l}\text { Deformation } \\
\text { rate }\end{array}$ \\
\hline Layer 1 & Layer 2 & Layer 1 & Layer 2 & Layer 1 & Layer 2 & $50 \mathrm{~mm} / \mathrm{min}$ \\
\hline $11 \mathrm{~mm}$ & $22 \mathrm{~mm}$ & 65 & 60 & $2.5-8.5 \%$ & $3.5-7.8 \%$ & \\
\hline \multicolumn{2}{|c|}{ Aggregate gradation } & \multicolumn{2}{|c|}{$\begin{array}{l}\text { Softening Point } \\
\text { Ring+Ball }\end{array}$} & \multirow{3}{*}{\multicolumn{2}{|c|}{$\begin{array}{l}\text { Treatment } \\
0=\text { no treatment } \\
1=\text { fine milling } \\
2=\text { dirt, applied before } \\
3=\text { dirt, applied before } \\
\text { 4=dirt, moisture, before } \\
5=\text { dirt, moisture, after }\end{array}$}} & \\
\hline Layer 1 & Layer 2 & Layer 1 & Layer 2 & & & \\
\hline $\begin{array}{l}\text { Passing \% } \\
\varnothing 8: 82 \\
\varnothing 2: 40 \\
\varnothing 0.09: 9.8\end{array}$ & $\begin{array}{l}\text { Passing \% } \\
\varnothing 8: 62 \\
\varnothing 2: 30 \\
\varnothing 0.09: 7.5\end{array}$ & 54 & 60 & & & \\
\hline \multicolumn{2}{|c|}{ Binder content } & & & \multirow{3}{*}{\multicolumn{2}{|c|}{$\begin{array}{l}\text { Tack coat } \\
\text { none } \\
\text { non mod. tack } \\
\text { poly. mod. tack }\end{array}$}} & \\
\hline Layer 1 & Layer 2 & & & & & \\
\hline $5.6 \%$ & - & & & & & \\
\hline \multicolumn{2}{|c|}{ Marshall stability } & & & \multirow{3}{*}{\multicolumn{2}{|c|}{$\begin{array}{l}\text { Age: } \\
0,2 \text { months }\end{array}$}} & \\
\hline Layer 1 & Layer 2 & & & & & \\
\hline 14 & - & & & & & \\
\hline \multicolumn{2}{|c|}{ Marshall flow } & & & \multirow{3}{*}{\multicolumn{2}{|c|}{$\begin{array}{l}\text { Pavement type: } \\
\text { asphalt/asphalt }\end{array}$}} & \\
\hline Layer 1 & Layer 2 & & & & & \\
\hline $2.8 \mathrm{~mm}$ & & & & & & \\
\hline
\end{tabular}




\subsubsection{Data from RILEM Pavement}

The data for the RILEM Pavement database came from an interlaboratory study on interlayer shear and tack coats. As described in Chapter 5.1.6 a pavement section was constructed and divided into 3 sections with different tack coats. The data used of the ANN evaluation were all determined at Empa with the LPDS test equipment described in Section 3.1. For interlayer shear testing temperature and the deformation rate were varied. For all test conditions 7 specimens each were tested.

Table 5.16 shows all variables and their values or ranges considered for RILEM Pavement.

Table 5.16: List of variables influencing interlayer bond of RILEM Pavement

\begin{tabular}{|c|c|c|c|c|c|c|}
\hline \multicolumn{2}{|c|}{$\begin{array}{c}\text { Mixture } \\
\text { characteristics }\end{array}$} & \multicolumn{2}{|c|}{$\begin{array}{c}\text { Binder } \\
\text { characteristics }\end{array}$} & \multicolumn{2}{|c|}{$\begin{array}{c}\text { Pavement } \\
\text { characteristics }\end{array}$} & $\begin{array}{c}\text { Testing } \\
\text { condition }\end{array}$ \\
\hline \multicolumn{2}{|c|}{ Mixture type } & \multicolumn{2}{|c|}{ Binder type } & \multicolumn{2}{|c|}{ Layer thickness } & Temperature \\
\hline Layer 1 & Layer 2 & Layer 1 & Layer 2 & Layer 1 & Layer 2 & $20,25,30$ \\
\hline $\mathrm{AC}$ & $\mathrm{AC}$ & $55 / 70$ & $55 / 70$ & $40 \mathrm{~mm}$ & $60 \mathrm{~mm}$ & $40^{\circ} \mathrm{C}$ \\
\hline \multicolumn{2}{|c|}{ Nom. max. aggregate size } & \multicolumn{2}{|c|}{ Penetration } & \multicolumn{2}{|c|}{ Air void content } & Deformation \\
\hline Layer 1 & Layer 2 & Layer 1 & Layer 2 & Layer 1 & Layer 2 & $50 \mathrm{~mm} / \mathrm{min}$ \\
\hline $11 \mathrm{~mm}$ & $16 \mathrm{~mm}$ & 78 & 78 & $2.5-8.5 \%$ & $3.5-7.8 \%$ & $200 \mathrm{~mm} / \mathrm{min}$ \\
\hline \multicolumn{2}{|c|}{ Aggregate gradation } & \multicolumn{2}{|c|}{$\begin{array}{c}\text { Softening Point } \\
\text { Ring+Ball } \\
\end{array}$} & \multirow{3}{*}{\multicolumn{2}{|c|}{$\begin{array}{l}\text { Tack coat } \\
\text { None } \\
\text { Non mod. tack } \\
\text { Poly. mod. tack }\end{array}$}} & \\
\hline Layer 1 & Layer 2 & Layer 1 & Layer 2 & & & \\
\hline $\begin{array}{l}\text { Passing \% } \\
\varnothing 8: 80 \\
\varnothing 2: 38 \\
\varnothing 0.09: 7 \\
\end{array}$ & $\begin{array}{l}\text { Passing \% } \\
\emptyset 8: 65 \\
\varnothing 2: 28 \\
\varnothing 0.09: 6 \\
\end{array}$ & - & - & & & \\
\hline \multicolumn{2}{|c|}{ Binder content } & & & \multirow{3}{*}{\multicolumn{2}{|c|}{$\begin{array}{l}\text { Age: } \\
0,1.5 \text { years }\end{array}$}} & \\
\hline Layer 1 & Layer 2 & & & & & \\
\hline $5.2 \%$ & $4,6 \%$ & & & & & \\
\hline \multicolumn{2}{|c|}{ Marshall stability } & & & \multirow{3}{*}{\multicolumn{2}{|c|}{ Traffic: none }} & \\
\hline Layer 1 & Layer 2 & & & & & \\
\hline- & - & & & & & \\
\hline \multicolumn{2}{|c|}{ Marshall flow } & & & \multirow{3}{*}{\multicolumn{2}{|c|}{$\begin{array}{l}\text { Pavement type: } \\
\text { asphalt/asphalt }\end{array}$}} & \\
\hline Layer 1 & Layer 2 & & & & & \\
\hline - & - & & & & & \\
\hline
\end{tabular}




\section{CHAPTER 6}

\section{Interpretation and Analysis of Results}

\subsection{Influence of the tested parameters on the}

\section{measured interlayer bond}

\subsubsection{Idealisation of the bond (testing program 1)}

As far as the optimum combination of ball sizes is concerned, s/b produced the highest shear stress values, a fact that is true also in case of no binder. This phenomenon can be explained as shown in Figure 6.1 by an interlocking effect and a higher 'roughness' of the interface caused by the construction of the specimens:
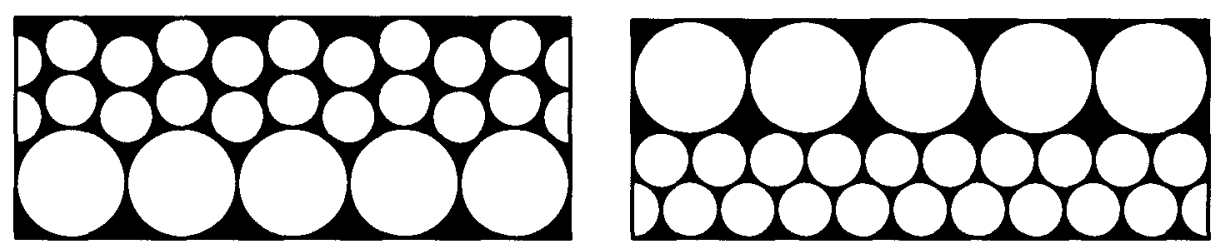

Figure 6.1: Comparison of interlock in case of the two specimen structures, left: small/big (s/b), right: big/small (b/s)

When, in case of $s / b$, the base layer with big steel balls was produced and the second layer of small steel balls is placed, the hot steel balls sink into the gaps between the big balls displacing the bitumen. In case of the other combinations, especially for $\mathrm{b} / \mathrm{s}$, this is not possible, since there are no gaps which can be filled other than with bitumen. 
In case of $b / b$ and $s / s$, the situation is intermediate, since some filling of the gaps, i.e. some interlock, is possible.

The interlocking effect was also observed after the shear tests for the combination $\mathrm{s} / \mathrm{b}$.

Here, the interface of the separated specimen parts showed small steel balls from the top layer between the big balls on the bottom shear plane (see Figure 6.2).

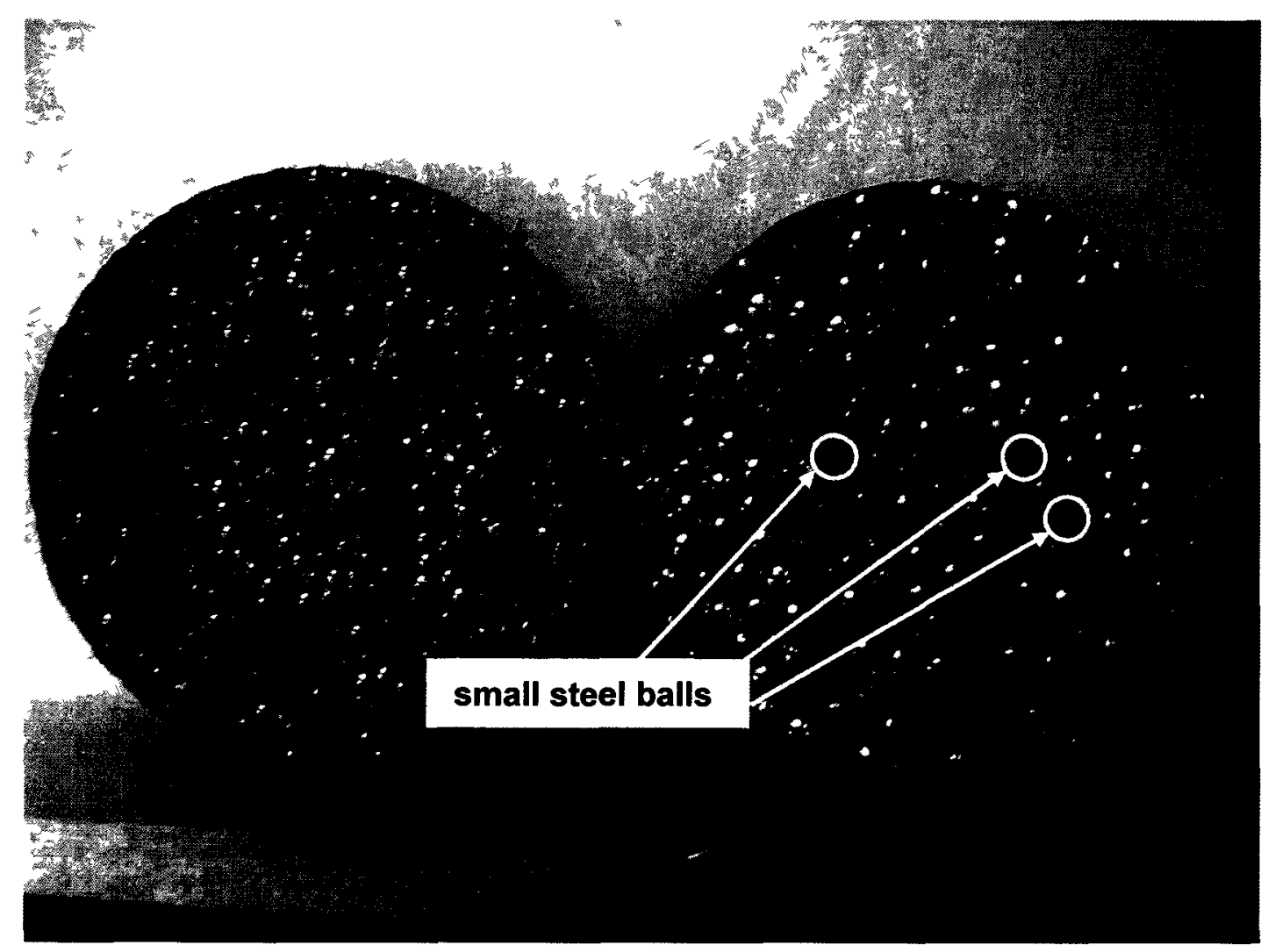

Figure 6.2: Small/big specimen after LPDS test; left: small steel balls, right: big steel balls with some small steel balls remaining from top layer

This finding can also be explained by some simple geometrical assumptions: 
As shown in Figure 6.3, roughness increases with increasing diameter of the steel balls. Hence, the shear resistance in terms of roughness capacity $R$ is assumed to increase with increasing diameter $\mathrm{D}$ of the lower steel balls, since bigger diameters produce deeper cavities and therefore more roughness. In this case, the roughness capacity $\mathrm{R}$ is a function $f_{1}$ of the lower steel ball diameter $D$ (see equation 6.1)

$R=f_{1}(D)$ (equation 6.1)

where $\mathrm{D}=$ diameter of lower steel balls
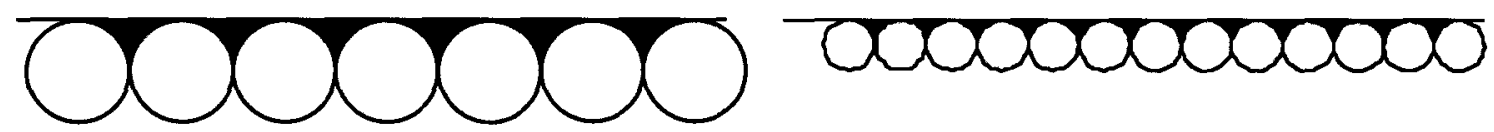

Figure 6.3: Comparison of roughness in case of the two specimen structures, left: big steel balls, right: small steel balls

The opposite is true, when looking at the upper steel balls with a diameter d. Here, the roughness capacity $\mathrm{R}$ increases with decreasing diameter of the upper steel balls, because the smaller the diameter (down to a certain extent, i.e. $\mathrm{d}^{*}$ ), the better the cavities can be filled. The equation for the roughness capacity $R$ of the upper layer is the following:

$R=f_{2}(1 / d)$

(equation 6.2)

where $d=$ diameter of upper steel balls 
Including both steel ball diameters the total roughness capacity $\mathrm{R}^{\prime}$ for $\mathrm{d}>\mathrm{d}^{*}$ can be defined in its simplest form as:

$R^{\prime}=f_{1}(D) f_{2}(1 / d)=f(D / d)$

(equation 6.3)

For the steel ball combinations $s / s$ and $b / b$ this means that $D / d=1$. For the combination $s / b$ with $d=D / 2=2$, a better roughness capacity is obtained, while for the combination $b / s$ with $d=2 D$ the roughness capacity becomes worse, determined by a value of $\mathrm{D} / \mathrm{d}=0.5$.

That the assumption $R^{\prime}=f(D / d)$ can only be true for a certain relationship of $D$ and $\mathrm{d}$ is shown in Figure 6.4. As depicted in this schematic drawing, the roughness capacity curve ranges between the two extreme points with low shear resistance. Point 1: very big diameter $\mathrm{D}$ and very small diameters $\mathrm{d}$ and Point 2 : very small diameters $\mathrm{D}$ and very big diameter $\mathrm{d}$. Between these extreme points the roughness capacity reaches a peak for a certain diameter $d^{*}$. When the upper diameters $d$ becomes smaller than $d^{*}$, the steel balls become so small that their centre is below the shear plane. Therefore, these steel balls loose their interlocking capacity, i.e. the roughness capacity declines (see Figure 6.4). With the selected ratio of steel balls it is assumed that $d>d^{*}$. Hence, equation 6.3 is valid in this rage. 


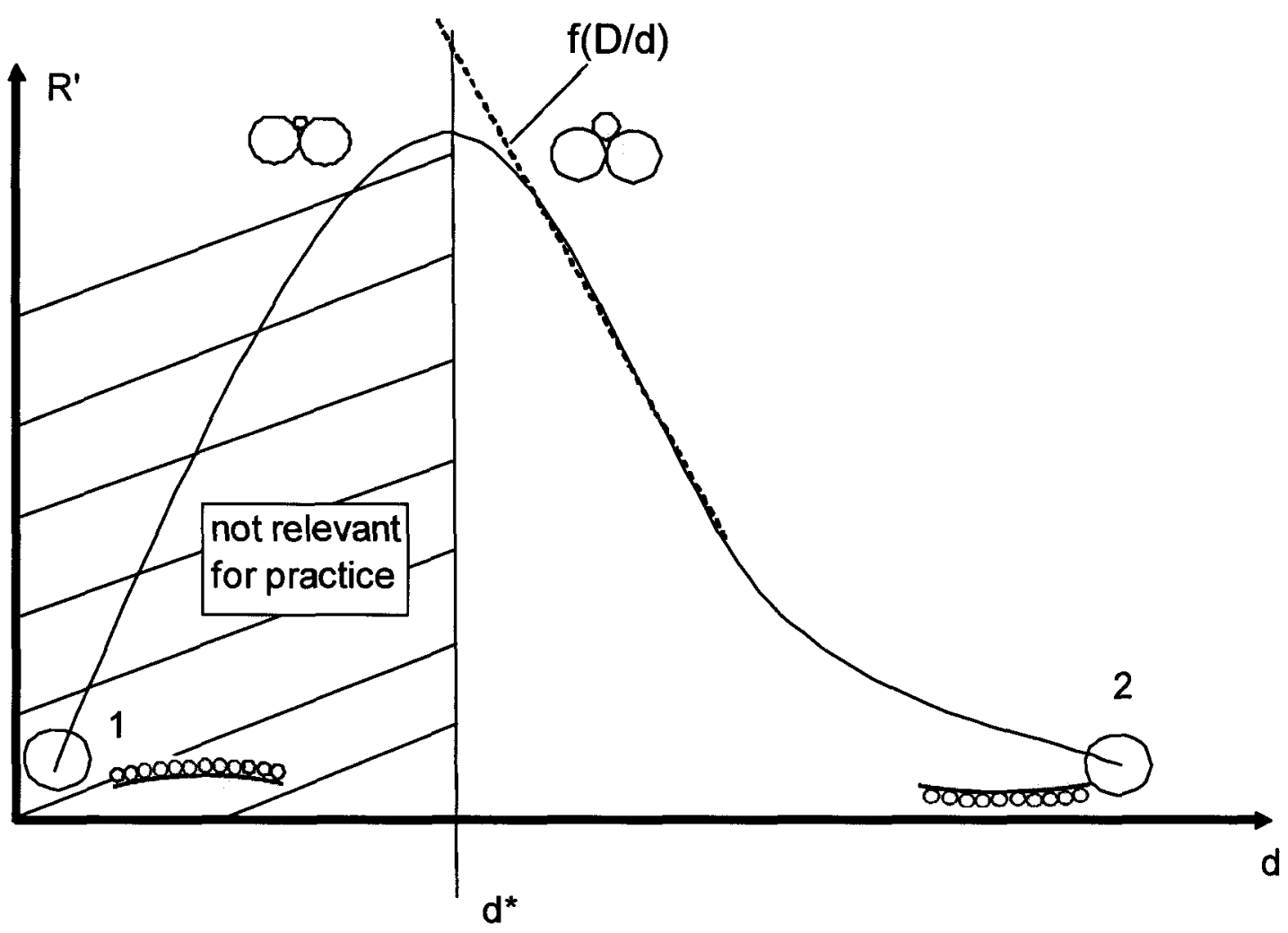

Figure 6.4: Schematic drawing of the roughness capacity curve

These assumptions are quite simple and neglect certain facts. It is obvious that due to different dilatancy effects an extremely fine steel ball interface has another roughness capacity than an interface with larger steel balls. In addition one has also to account for the fact that geometrical parameters are not sufficient to describe the shear failure and the influence of binder is neglected. Nevertheless, since in this study the different parameters for a more detailed model could not be determined, the simple $R^{\prime}=(D / d)$ for $d>d^{*}$ is considered sufficient. 
The shear failure behaviour can be divided into two major parts, the cohesive part, mainly governed by the binder properties and the adhesive part between steel balls and binder which is influenced by the adhesion strength and the roughness (see Figure 4.6).

For assessing the influence of the different steel ball sizes it is assumed, that no direct friction between the steel balls is possible, since a small binder film between steel balls can always be found. Further, the cohesive part will be neglected, because the speed is considered so slow, that no cohesive forces can develop.

In case of shear failure the total shear force that is needed to overcome all adhesive bonds can be calculated as follows:

$\mathrm{F}=\mathrm{A} \tau$ (equation 6.4)

where $\tau$ is the failure shear stress to overcome the adhesion bond and A is the area in the interface where adhesive bond failure occurred, i.e. when in Figure 6.2 the steel ball surfaces became visible.

With Coulomb's law from equation 3.6 and assuming the initial friction $\mathrm{c}_{0}$ to be zero, the equation for $\tau$ and $\mathrm{F}$ are the following:

$\tau=\sigma_{\mathrm{n}} \mu_{\mathrm{r}}$

(equation 6.5)

$\mathrm{F}=\mathrm{A} \sigma_{\mathrm{n}} \mu_{\mathrm{r}}$

(equation 6.6) 
where $\mu_{\mathrm{r}}$ is the friction or roughness coefficient, $\sigma_{\mathrm{n}}$ the adhesion between steel and bitumen and $\mathrm{A}$ the fracture area.

Assuming that the roughness coefficient can be expressed by the roughness capacity $R^{\prime}$, i.e. $\mu_{r}=R^{\prime}=f(D / d)$, and further assuming $f(D / d)$ being linear, the following equation is obtained:

$F=A \sigma_{n} f(D / d)$

(equation 6.7)

In order to calculate the adhesive bond failure areas A, fracture surfaces were visually interpreted and plots of the cross section were drawn as shown in Figure 6.5, showing the blank (white) areas of the steel balls. These blank areas, can be assumed as the areas where steel balls became free of binder, i.e. the binder lost complete adhesion. The calculations for the mean blank areas can be found in Table 6.1. 

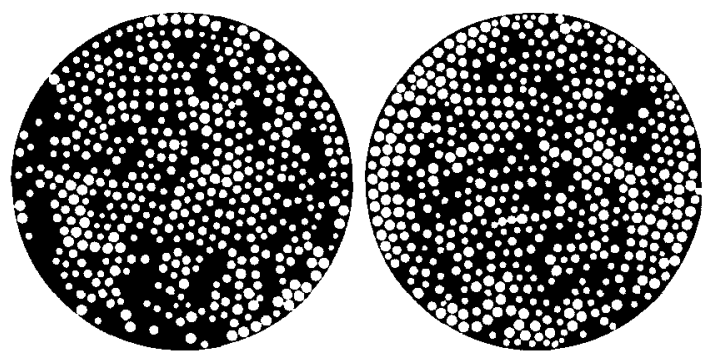

(a)
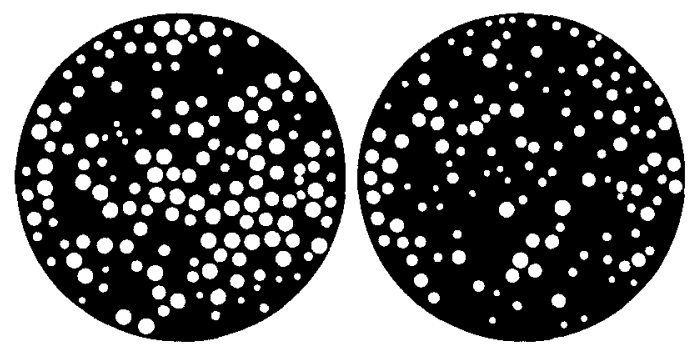

(b)
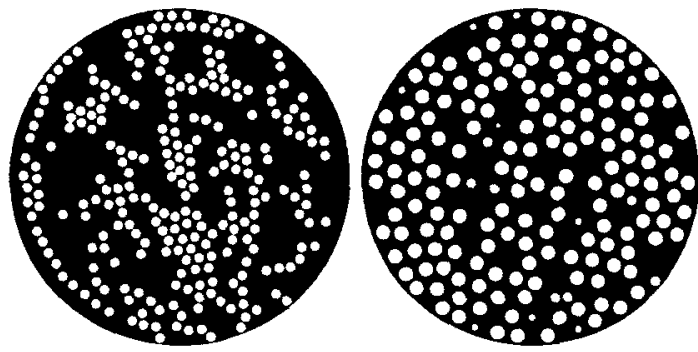

(c)

Figure 6.5: Fracture surfaces after LPDS testing (slow), (a) small/small, (b) big/big and (c) small/big

Table 6.1: Area in \% of total cross section area under the shear force-displacement curves (shear box) for all steel ball combinations with and without binder

\begin{tabular}{|c|c|c|c|}
\hline White area $\mathrm{A}[\%]$ & $\mathrm{s} / \mathrm{s}$ & $\mathrm{b} / \mathrm{b}$ & $\mathrm{s} / \mathrm{b}$ \\
\hline left & 34.5 & 26.8 & 26 \\
right & 41.0 & 16.4 & 34 \\
\hline mean & $\mathbf{3 8}$ & $\mathbf{2 2}$ & $\mathbf{3 0}$ \\
\hline
\end{tabular}


Neglecting $\sigma_{\mathrm{n}}$, and normalising $\mathrm{A}$ with $\mathrm{A}_{0}\left(\mathrm{~A}_{0}=\right.$ area for the combination $\left.\mathrm{s} / \mathrm{s}\right)$ the following resistances are obtained for the different steel ball combinations:

$$
F_{s s}=\frac{38}{38} \cdot \frac{1}{1}=1, F_{b b}=\frac{22}{38} \cdot \frac{1}{1}=0.58, F_{s b}=\frac{60}{38} \cdot \frac{2}{1}=1.58 \text { and } F_{b s}=\frac{30}{38} \cdot \frac{1}{2}=0.4
$$

From LPDS testing and normalisation for, one obtains the following values:

$\mathrm{s} / \mathrm{s}=1, \mathrm{~b} / \mathrm{b}=0.94, \mathrm{~s} / \mathrm{b}=1.08$ and $\mathrm{b} / \mathrm{s}=0.86$.

Although, this calculated ranking is not identical with the true ranking from LPDS testing, the results prove the finding, leading to a similar ranking for the different steel ball combinations as shown in Figure 6.6. Note, that the ranking in Figure 6.6 is only valid for $\mathrm{d}>\mathrm{d}^{*}$.

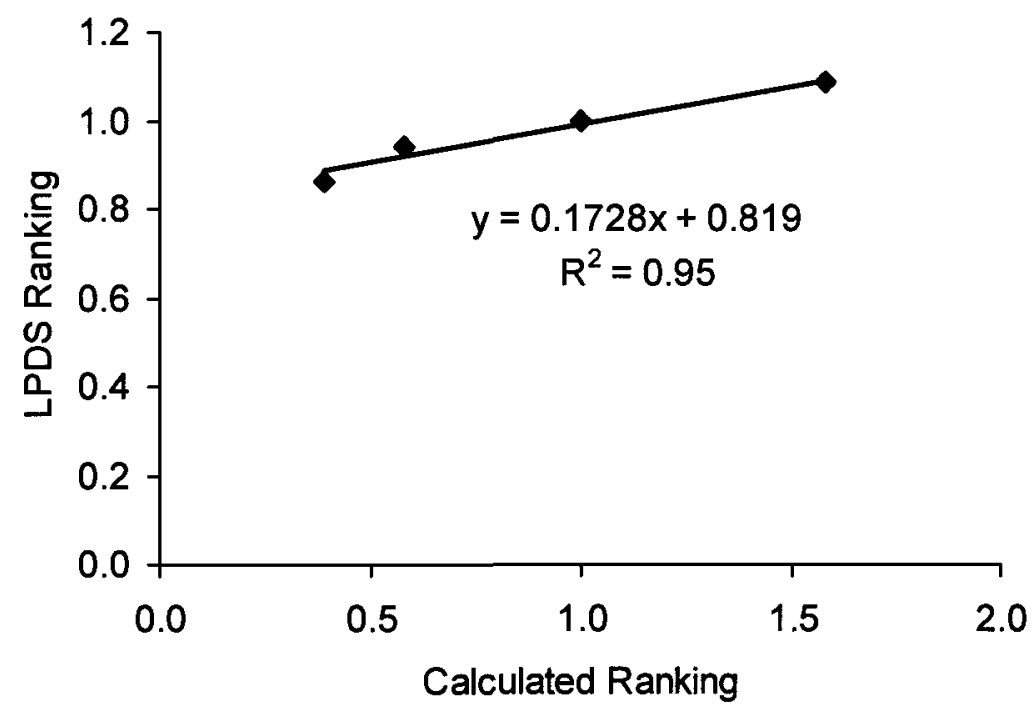

Figure 6.6: Comparison of calculated ranking and LPDS ranking for the different steel ball combinations 
In summary this investigation showed the following findings:

- With LPDS testing it was possible to determine a clear ranking in shear stress for the different steel ball combinations: The highest shear force values were received for the combination small/big, where good interlocking between the steel balls was observed. Secondly, the combination small/small followed, while the combinations big/big and big/small achieved the lowest shear force results. This ranking remained the same when testing at a significantly lower deformation rate of $2.5 \mathrm{~mm} / \mathrm{min}$.

- It is interesting to note, that the slower deformation rate had less influence on the magnitude of the measured shear forces, whereas the shear stiffness was reduced to half its magnitude when testing with a deformation rate of $50 \mathrm{~mm} / \mathrm{min}$ compared to a deformation rate of $2.5 \mathrm{~mm} / \mathrm{min}$.

- $\quad$ By using Shear Box testing with a normal stress of $0.1 \mathrm{MPa}$, it was possible to determine a clear ranking in shear force for the different steel ball combinations: The highest shear force values were received for the combination small/big. Secondly, the combination small/small followed, while the combination big/big achieved the lowest shear force results. This ranking changed slightly, when a normal stress of $0.4 \mathrm{MPa}$ was applied. In this case the combination $\mathrm{b} / \mathrm{b}$ received higher values, than the combination small/small.

- Shear Box testing with higher normal stresses results for all combinations of steel balls in higher shear stress. The potential of an increase is higher in case of lower 
initial values (testing with a normal stress of $0.1 \mathrm{MPa}$ ). The shear deformation and the shear stiffness for the combination small/small were not affected by the amplitude of the normal stress. Whereas, the shear stiffness at $0.1 \mathrm{MPa}$ was bigger for the combination big/big and smaller for the combination small/big compared to testing with $0.4 \mathrm{MPa}$.

- For both LPDS and Shear Box testing, shear deformation was not significantly different for the different steel ball combinations.

- When testing the different steel ball combinations without binder, the combination small/big receives the highest shear stress values, while a distinction between the other two combinations is more difficult.

- As expected, adding binder improves the potential to attain higher shear force (stress) values and according to Coulomb's law the cohesion led to a medium increase in shear stress of about $1 \mathrm{MPa}$, whereas the dependency of maximum stress on the normal stress remains basically unchanged.

- The comparison between Shear Box with a normal stress of 0.1 MPa and LPDS testing with a deformation rate of $2.5 \mathrm{~mm} / \mathrm{min}$ let to the same ranking for the different steel ball combinations. The higher shear stress values for Shear Box testing can be attributed to the normal stress of $0.1 \mathrm{MPa}$.

- Although Shear Box and LPDS testing lead to a similar ranking, the shear force shear deformation curves for both tests are totally different revealing a different shear mechanism. While in the LPDS test failure occurs suddenly leading to an immediate drop of the shear force, failure in the shear box test develops more 
gradually. Typical for Shear Box tests the force still remains at a residual value after the peak (maximum) had been reached.

- As compared to the maximum shear force in LPDS testing which is reached after 1.5 and $2 \mathrm{~mm}$, in Shear Box testing the deformation at maximum shear force lies between 2.8 and $4 \mathrm{~mm}$. When testing at a deformation rate of $2.5 \mathrm{~mm} / \mathrm{min}$ the maximum shear stress is lower for LPDS testing.

- $\quad$ For the combination $\mathrm{s} / \mathrm{b}$, the shear force values from Shear Box testing are approx. $20 \%$ higher than those from LPDS testing. For the combination s/s values the shear force for Shear Box testing was a slightly lower than for LPDS testing, while for the combination $\mathrm{b} / \mathrm{b}$ both test results are in very good agreement.

- The ranking of the maximum shear forces, for different steel ball combinations obtained by LPDS testing is in agreement with a ranking based on simple geometrical and optical evaluations.

\subsubsection{Effect of moisture (testing program 2)}

From the investigation it becomes clear that moisture generally has a negative influence on the interlayer shear bond of asphalt pavements.

Apart from LPDS testing of pavement 2, all pavements in this investigation water conditioning shows a decrease in shear force and shear stiffness. The measured decrease is neither the same for all pavements and interfaces, nor for all test methods and conditioning cases. While the first interface of pavement 1 in the Shear Box shows only a slight decrease in shear force, when tested after water conditioning of $40^{\circ} \mathrm{C}$, the LPDS result reveals a decrease after water conditioning of about $20 \%$. A decrease of $20 \%$ in 
shear force can also be found in Shear Box testing for pavement 2, when LPDS testing even leads to an increase in shear force.

When considering the water conditioning of $60^{\circ} \mathrm{C}$, which was only done for LPDS testing, this conditioning proved even more severe for all pavements and interfaces which resulted in larger decrease in shear force of $15 \%$ to $25 \%$ and shear stiffness of $14 \%$ to $30 \%$. This is also true for pavement 2 . The finding that for this pavement the shear force for water conditioning at $60^{\circ} \mathrm{C}$ is still nearly higher than for the unconditioned test series reveals that there may have been some problems with the reference data (no water).

Testing pavements 1 and 3 at $40^{\circ} \mathrm{C}$ after short time water conditioning combined with pressure, produces interesting results. When the air void content in the upper layer is high (here: higher than 10 vol-\%), condition No. $4\left(40^{\circ} \mathrm{C}\right.$ short term water conditioning combined with pressure) has a similar influence as long-term water conditioning at $40^{\circ} \mathrm{C}$ (Condition No. 2), while for normal air void contents in the upper layer (around 4 to 5 vol-\%), condition No. 4 proves to be the most severe test condition regarding its influence on shear force and stiffness. This finding can be explained by the fact that the applied pressure is released through the air voids and therefore has a smaller influence on shear stress and shear stiffness than for denser upper layers. In order to achieve the same effect as for pavements with dense upper layers, it is important to seal the cores during pressure conditioning.

Contrary to the findings from earlier research (Raab and Partl, 2004), when it was found that the reduction in shear force caused by long term water storage of $75 \mathrm{~h}$ at $40^{\circ} \mathrm{C}$ was equal to short term water storage at $40^{\circ} \mathrm{C}$ of $8 \mathrm{~h}$ combined with a pressure of $0.05 \mathrm{MPa}$, in this investigation, the combined moisture/pressure treatment of pavements 
with dense upper layers had a more severe impact on the decrease of shear stress and stiffness.

In summary this investigation showed the following findings:

- Water conditioning at $40^{\circ} \mathrm{C}$ or $60^{\circ} \mathrm{C}$ generally has a negative effect on the interlayer shear bond leading to decreases in shear force and shear stiffness since it penetrates into the structure weakening the bond between the layers.

- For $72 \mathrm{~h}$ water conditioning at $40^{\circ} \mathrm{C}$ the decrease in shear force in the investigated pavement interfaces lies between $2 \%$ and $20 \%$.

- $\quad 72 \mathrm{~h}$ water conditioning at $60^{\circ} \mathrm{C}$ is an even more severe treatment leading to reductions in shear force of $15 \%$ to $25 \%$ and in shear stiffness of $14 \%$ to $30 \%$.

- For pavements with an upper layer air void content of about 5 vol- $\%$ the largest reduction in shear force and shear stiffness up to more than $30 \%$ can be found for a $5 \mathrm{~h}$ water conditioning combined with a pressure of $0.05 \mathrm{MPa}$.

- For pavements with an upper layer air void content $>10$ vol-\%, 5h water conditioning combined with a pressure of $0.05 \mathrm{MPa}$ is a less serve treatment since it allows the applied pressure to be released through the air voids. For these pavements this treatment has a similar effect on shear force and stiffness as $72 \mathrm{~h}$ water conditioning at $40^{\circ} \mathrm{C}$. In order to achieve an influence comparable to the pavements with dense upper layers the cores need to be sealed during the conditioning. 
- In order to avoid cumbersome specimen preparation and difficulties with variable air void contents, it is recommended to test the influence of water conditioning on the interlayer shear properties by $72 \mathrm{~h}$ water storage at $60^{\circ} \mathrm{C}$.

- A comparison between this specific ETH Shear Box and LPDS testing at different deformation rates $(2.5 \mathrm{~mm} / \mathrm{min}$ and $50 \mathrm{~mm} / \mathrm{min})$ gives a factor of 1.5 to convert maximum shear stress from Shear Box testing into maximum shear stress from LPDS testing.

\subsubsection{Effect of low temperature (testing program 2)}

It is a well-known fact that shear testing is highly temperature dependent, in which testing at high temperature leads to lower shear force and stiffness values whereas lower temperatures generally result in higher values.

The results from the investigation of the effect of low temperatures on the interlayer bond showed the following:

- As visible in Figures 4.24 to 4.27 shear force and in most cases shear stiffness values are highest when testing is performed at a temperature of $0^{\circ} \mathrm{C}$ compared to testing at $-20^{\circ} \mathrm{C}$. This observation was contributed to the fact that bond defects or weaknesses at a temperature of $0^{\circ}$ are still compensated by the stiffness or strength of the material compared to testing at lower temperatures when the material becomes so brittle that any bond defect will leas to failure.

- Interlayer bond defects or weaknesses are more obvious when testing is performed at very low temperature of $-20^{\circ} \mathrm{C}$. Therefore, the ranking of shear force and shear stiffness for different interlayers can change when tested at $-20^{\circ} \mathrm{C}$ 
instead of $+20^{\circ} \mathrm{C}$ and shear testing at one temperature $\left(20^{\circ} \mathrm{C}\right.$ as requested for Leutner shear testing) is not sufficient. Hence, standards, where only one temperature is considered should be reviewed in that sense.

- Shear forces between the lower layers of a pavement is less influenced by the test temperature compared to the one between the first and the second layer. This finding can be contributed to the fact that, lower layers are composed of larger aggregates and lower binder contents and shear force therefore mainly depends on the aggregate interlock.

- As observed in earlier investigations, the in-layer stiffness of a surface course layer is lower than the one of the first interlayer (interlayer between first and second layer). Often, interlayer curves can be found between the corresponding in-layer curves of the single layers, often tending to be closer to the one with lower shear stiffness.

- Traffic, not exceeding the design limits, leads to higher shear forces and shear stiffnesses for a pavement compared to an untrafficked one. Hence, the finding that the interlayer bond properties of intact and well designed asphalt pavements in terms of shear force and stiffness increase over time could be supported by the results of the study.

\subsubsection{Effect of gap width (testing program 2)}

\subsubsection{General Considerations}

From Figures 4.28 and 4.29 the gap width appears to be less critical for in-layer than for interlayer shear tests. Assuming that a properly produced asphalt layer material by itself 
should have a better internal micro-structural interlock than the interlock expected between the two layers, this finding suggests that the better the interlock between the layers or within the asphalt layer material, the lesser is the influence of the gap width on the shear test results. This means that in cases of comparatively poor interlayer bond, the gap width may well influence the results and can therefore not be ignored. Standardisation should therefore opt for narrow gap width tolerances.

Considering the influence of the gap width, in case of this study, the interlock between AC B 22/AC T 32 (layer with small on layer with large maximum aggregate size) appears better than the between $\mathrm{AC} \mathrm{T} \mathrm{32/AC} \mathrm{S} 22$ (layer with large on layer with small maximum aggregate size). This confirms findings with the model material (steel balls). Likewise the influence of the gap width would imply that the interlock between SMA 11 and AC B 22 despite small on big maximum aggregate size is relatively weak. This may be due to the fact that SMA has a thicker binder film than the AC and a gap graded gradation that does not interlock so ideally with the AC. The reduced ability to interlock also shows up when the in-layer results for SMA are compared with the two other AC in-layer shear properties (AC B 22 and AC T 32), with SMA providing clearly lower force and stiffness values than $\mathrm{AC}$.

\subsubsection{Optical measurements}

The difference between interlayer and in-layer testing are depicted in Figure 6.9 showing optical measurements of the shear testing (Raab and Partl, 1999). These optical measurements (see Figures 6.7 and 6.8) had been conducted to determine the vertical and horizontal deformation during the shear test and compare the deformation behaviour of interlayer and in-layer testing. In order to be able to measure several points on the test 
specimen at the same time, the markings drawn on the specimen (Figure 4.34) were taken with a camera during the shearing action with a camera. In this process, the analogue force signal was blend in by using a mirror so that it was possible to correlate the measured deformation and the effective force. In Figure 6.7 the test setup of the optical measurement is shown.

During shear testing, the specimens suffer displacements not only in the vertical in-plane shear direction but also in the horizontal or axial direction. This is due to dilatancy and load eccentricity effects. Optical measurements performed on a pavement with SMA 11 surface and an AC 22 asphalt concrete base course at $20^{\circ} \mathrm{C}$ showed that at maximum shear load the horizontal displacement was about four to three times smaller than the vertical displacements (Partl and Raab, 1999). For the interlayer shear tests, the horizontal displacements were in the order of $0.06 \mathrm{~mm}$ which was about $60 \%$ of the corresponding in-layer values. In addition, the measurements showed that after the starting phase of the shear test, the vertical displacements were distributed quite evenly over the cross section of the specimen. Note the difference of the fracture pattern in Figure 6.9 between interlayer and in-layer test. The interlayer shear fracture occurred in the adhesion plane and a narrow fracture zone of about $4 \mathrm{~mm}$ width was observed. For inlayer shear a dispersed fracture with a fracture zone width of about twice the maximum aggregate size $(22 \mathrm{~mm})$ was observed.

The difference between the sizes of the two fracture zones demonstrates clearly the influence of changing the gap width. 

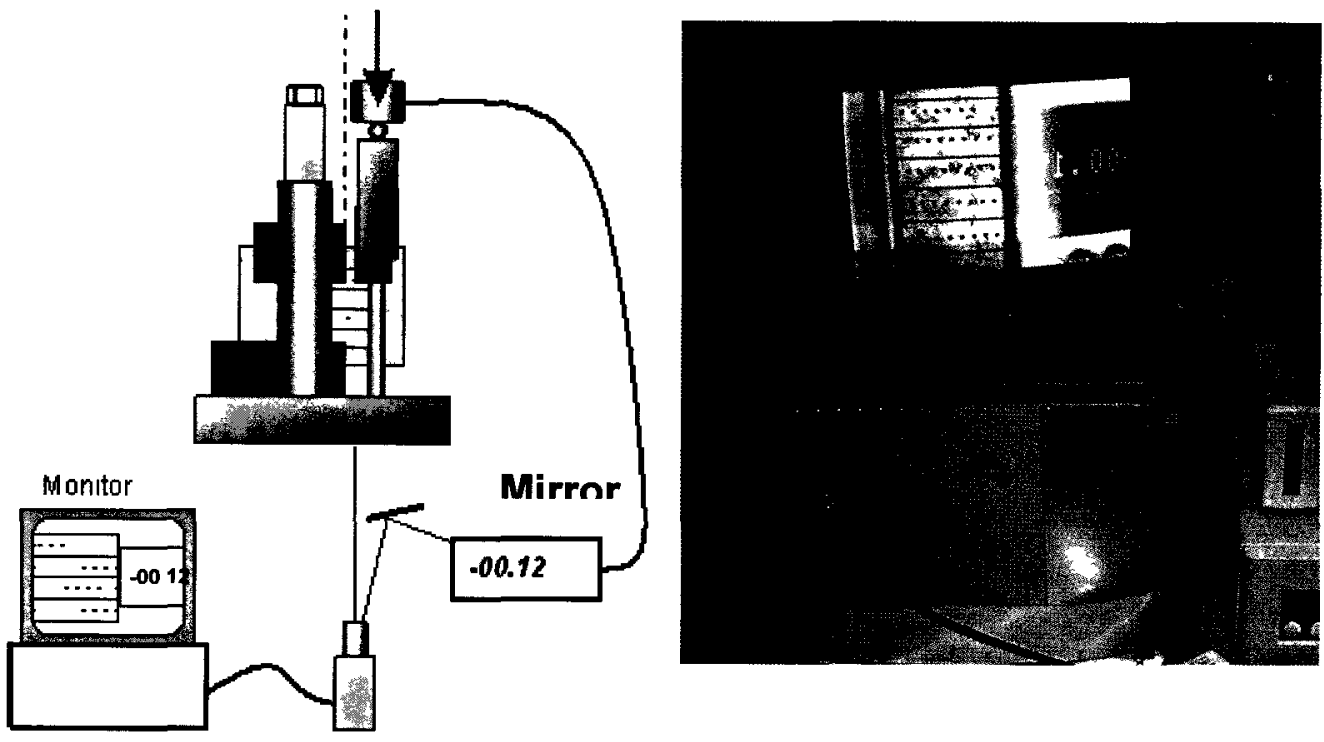

Figure 6.7: Schematic drawing of test set-up (left), Photograph of image processing unit (right)

Shear plane
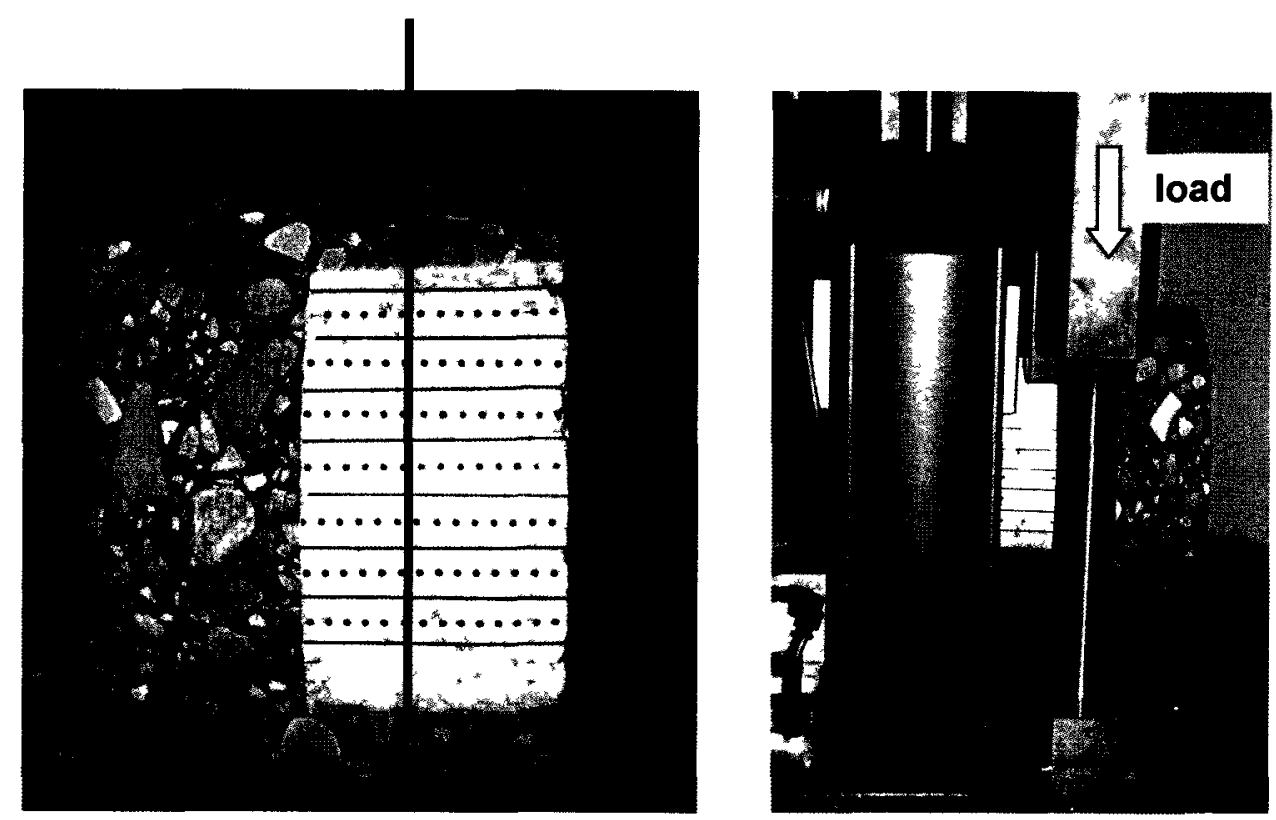

Figure 6.8: LPDS test device: Test specimen with markings for optical measurements in the shearing zone (left). To the right specimen fixed in the test device 


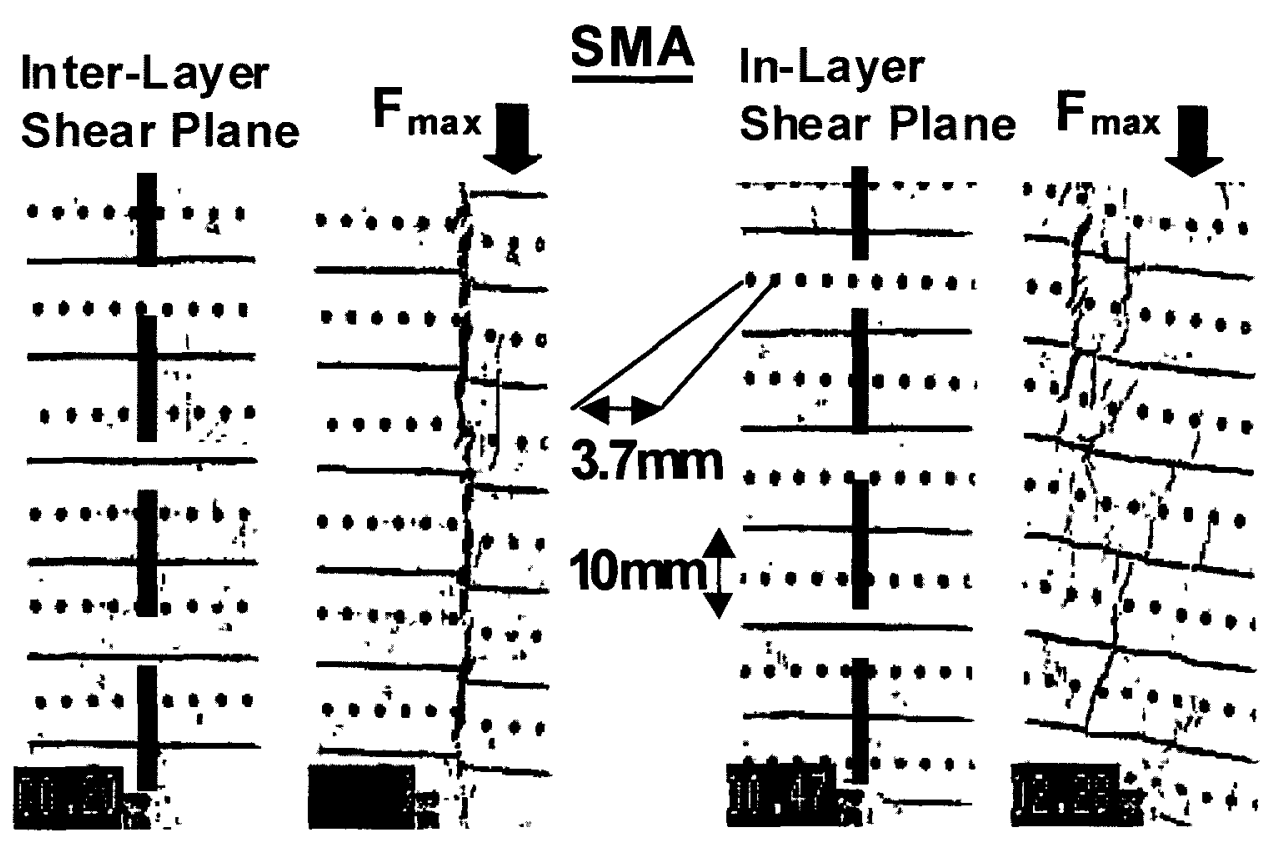

Figure 6.9: Optical measurements during inter-layer and in-layer shear testing of a pavement with SMA 11 surface and AC 22 base courses at $20^{\circ} \mathrm{C}$. View of the situation at the start of the test and when cracks appear

(Source: Raab and Partl, 1999)

In this investigation the shear stiffness value in the interlayer is also always higher than the in-layer stiffness value, a fact that had been already found for surface and binder courses in an earlier investigation (Raab and Partl, 1999, Partl and Raab, 1999). Unlike, the findings in this earlier paper, the maximum interlayer shear stresses are considerable higher than the in-layer shear stresses of the upper layer. However, the findings regarding the stiffness were confirmed.

In summary this investigation showed the following findings:

- For interlayer shear testing, the gap width between the shearing rings of the Leutner device does have an influence on the interlayer shear test results, 
especially in cases when the material characteristics of the two layers are different. Here, an increasing gap width leads to decreasing maximum shear force and shear stiffness value up to $34 \%$. If the layer material characteristics are similar, the gap width is less important.

- By increasing the gap width, one increases also the eccentricity resulting in a combined bending-shear stress situation.

- By increasing the gap width, the shear plane becomes less defined and failure tends to occur at the weakest point rather than at the exact interface. Therefore, regarding a standardisation of interlayer shear testing, a gap width of $5 \mathrm{~mm}$ may lead to results which reflect combined inlayer and interlayer properties and is therefore not recommended.

- In order to simplify and optimise the testing (more tolerance in the shear plane and less difficulty to perfectly align the interface to the shear plane, especially for specimens having irregular interfaces) a gap width slightly larger than $0 \mathrm{~mm}$ would be sufficient. So far, the gap width of existing devices does not exceed $2.5 \mathrm{~mm}$. This value should not be increased.

- In case of good interlock the influence of the gap width appears small. On the other hand, this means that in cases of comparatively poor interlayer bond, the gap width may well influence the results and can therefore not be ignored. Standardisation should therefore opt for narrow gap width tolerances.

- As already found in earlier research, there is a qualitative difference between interlayer and in-layer shear force - shear deformation curves, suggesting that the 
interlayer adhesion behaviour at $20^{\circ} \mathrm{C}$ is less ductile (and therefore stiffer) than the in-layer shear behaviour of the pavements. Optical measurements showed that for the interlayer shear tests the horizontal displacements during shear testing were about $60 \%$ of the corresponding in-layer values. Optical measurements further reveal the difference in the fracture pattern between interlayer and in-layer test. While interlayer shear fracture occurred in the adhesion plane with a narrow fracture zone of about $4 \mathrm{~mm}$ width, in-layer shear produced a dispersed fracture with a fracture zone width of about twice the maximum aggregate size.

- Interlayer shear force and the stiffness value of two pavement layers are mostly considerably higher, than the in-layer shear force and stiffness value of the upper pavement layer.

- Mixes with smaller maximum aggregate on mixes with bigger maximum aggregate appear to have a better interlock than mixes with bigger aggregate on mixes with smaller maximum aggregate. This confirms findings with the model material (steel balls).

\subsection{ANN Models}

\subsubsection{Model from New Road}

Data preparation includes different steps such as input variable selection, data cleaning, data scaling and data partitioning (see Chapter 5.2). The database from new road pavements is the largest and therefore the main database in the ANN investigation. Before data cleaning the number of data points was more than 300 . 


\subsubsection{Determination of input variables}

From the input variables listed in Table 5.2 the ones shown in Table 6.2 were taken into account. It was found that the passing through the sieves of $8 \mathrm{~mm}, 2 \mathrm{~mm}$ and the filler $(<0.09 \mathrm{~mm}$ or $0.063 \mathrm{~mm})$ were better indicators than just the nominal maximum aggregate size, while including the whole aggregate gradation would have overloaded the number of input factors unnecessarily.

Table 6.2: Input variables for New Road

\begin{tabular}{|c|c|c|}
\hline Index & Input variables, designation for tables in Appendix A & Unit/type \\
\hline 1 & Temperature, T* & ${ }^{\circ} \mathrm{C}$ \\
\hline 2 & Void 1, void content of layer 1, AV1* & vol-\% \\
\hline 3 & Void 2, void content of layer 2, AV2* & vol-\% \\
\hline 4 & Binder 1, binder content of layer 1, BC1* & mass-\% \\
\hline 5 & Binder 2, binder content of layer 2, BC2* & mass-\% \\
\hline 6 & Aggregate passing through sieve 8 mm, layer 1, 8_1* & mass \%-passing \\
\hline 7 & Aggregate passing through sieve 8 mm, layer 2,8_2* & mass \%-passing \\
\hline 8 & Aggregate passing through sieve 2 mm, layer 1,2_1* & mass \%-passing \\
\hline 9 & Aggregate passing through sieve 2 mm, layer 2,2_2* & mass \%-passing \\
\hline 10 & Aggregate passing through sieve 0.09 mm, layer 1, Fil_1* & mass \%-passing \\
\hline 11 & Aggregate passing through sieve 0.09 mm, layer 2, Fil_2* & mass \%-passing \\
\hline
\end{tabular}

* abbreviations used in tables in Appendix A 
When executing an inbuilt feature selection mode in the software (exhaustive search), temperature, $8 \_2$ and Fil_2 were determined to be the most important variables with a fitness of $56.1 \%$, while the combination of all input variables gained a fitness of $55.6 \%$. It was therefore decided to take all 11 input variables, since in this way, more information could be retrieved using the response graph feature.

\subsubsection{Data cleanings}

For data cleaning, the database had to be checked for missing values and outliers.

Regarding missing values, in some cases, air void contents or binder content as well as the gradation were not available. Hence, the values could be supplemented by values taken from the Swiss standards (see also Section 5.1).

The software qualified all mastic asphalt data as outlier, since their filler content was extremely high. Here, it was decided to accept these data, because the values were correct for mastic asphalt and this asphalt type should be included in the evaluation.

\subsubsection{Data scaling}

Since all input variables were numerical data, scaling was done in the range of $[-1,1]$, according to the method explained in Section 5. 2.6.3.

\subsubsection{Data partitioning}

Before feeding the data into the ANN program it was decided to reduce it by $10 \%$ of the data and take these data as an independent test or query file. In case of the New Road database, 30 data were excluded. The 30 data values were taken from every section and if possible, from testing at both temperatures $20^{\circ} \mathrm{C}$ and $40^{\circ} \mathrm{C}$. In order to show that the selection of data can have an influence on the quality of prediction for the max. shear force $F_{\max }$, this procedure was done in two different ways: For a first file, data with the 
best target values (e.g. data with representative results) were chosen (force_red), while for a second file, data were picked randomly (every 10th value, therefore the names force_red10). For the other output values, shear deformation at $F_{\max }$ and max. shear stiffness $S_{\max }$, only the unbiased method (def_red10, stiff_red10) was applied.

The remaining data were fed into the program and partitioned into a training set ( $68 \%$ of data), a validation set ( $16 \%$ of data) and a test set (16\% of data).

\subsubsection{Data mining (modelling)}

Network parameter determination

Network parameter determination includes the network architecture, i.e. the number of hidden neurons, the determination of the activation function and the learning algorithm including learning rate and momentum coefficient.

For all three output parameters the same network architecture or number of hidden layers was used. Since it was found that the result did not differ too much when using different numbers of hidden neurons, the minimum number, which gave a good prediction, was determined to be 5 . Therefore, the network structure depicted in Figure 6.10 was used: 
11-5-1

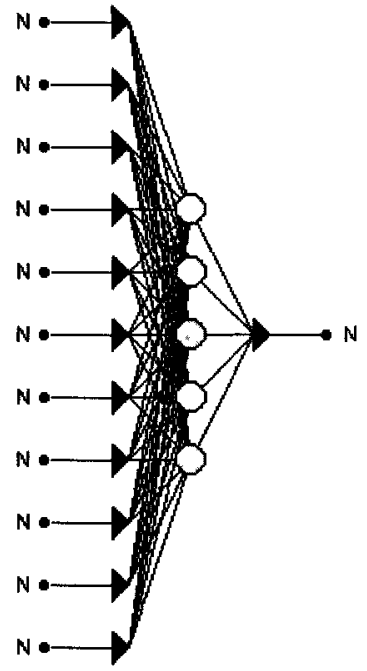

Figure 6.10: Network architecture used for data mining from New Road

As mentioned earlier batch backpropagation was chosen as learning algorithms, while the activation function for both, hidden and output layer was found to be a hyperbolic tangent. It was decided to have a learning rate $\eta=0.2$ and a momentum coefficient $\beta=0.9$.

\subsubsection{Evaluation}

The results for the prediction of the output values in the ANN software are shown in Table 6.3. 
Table 6.3: Test results for all output parameters for data from New Road

\begin{tabular}{|l|c|c|c|c|}
\hline & Avg. training error & Avg. validation error & Avg. test error & R-squared \\
\hline $\mathrm{F}_{\text {max_} \_}$red10 & 2.52 & 2.62 & 2.18 & 0.89 \\
\hline $\mathrm{F}_{\text {max_red }}$ & 2.54 & 2.63 & 2.34 & 0.89 \\
\hline $\mathrm{W}_{\text {max_ }}$ red10 & 0.64 & 0.59 & 0.61 & 0.11 \\
\hline $\mathrm{S}_{\text {max_}}$ red10 & 2.13 & 1.87 & 1.99 & 0.78 \\
\hline
\end{tabular}

The scatter plots in Figures 6.11 to 6.13 show the prediction plots for training (left) and testing (right) for the output parameters.

In these figures, the left $\mathrm{x}$-axis represents the actual (target) force, deformation or stiffness values while the first $y$-axis shows the predicted value of the output variables. For the max. shear force $F_{\max }$ and shear stiffness $S_{\max }$, the second $y$-axis depicts the predicted max. shear stress $\tau_{\max }$ and the max. shear reaction modulus $\mathrm{K}_{\max }$. The red line on the plot is the so-called line of equality. The closer the points are located to this line, the better the prediction. In addition a linear regression is calculated giving the equation and the linear regression coefficient $\mathrm{R}^{2}$. 

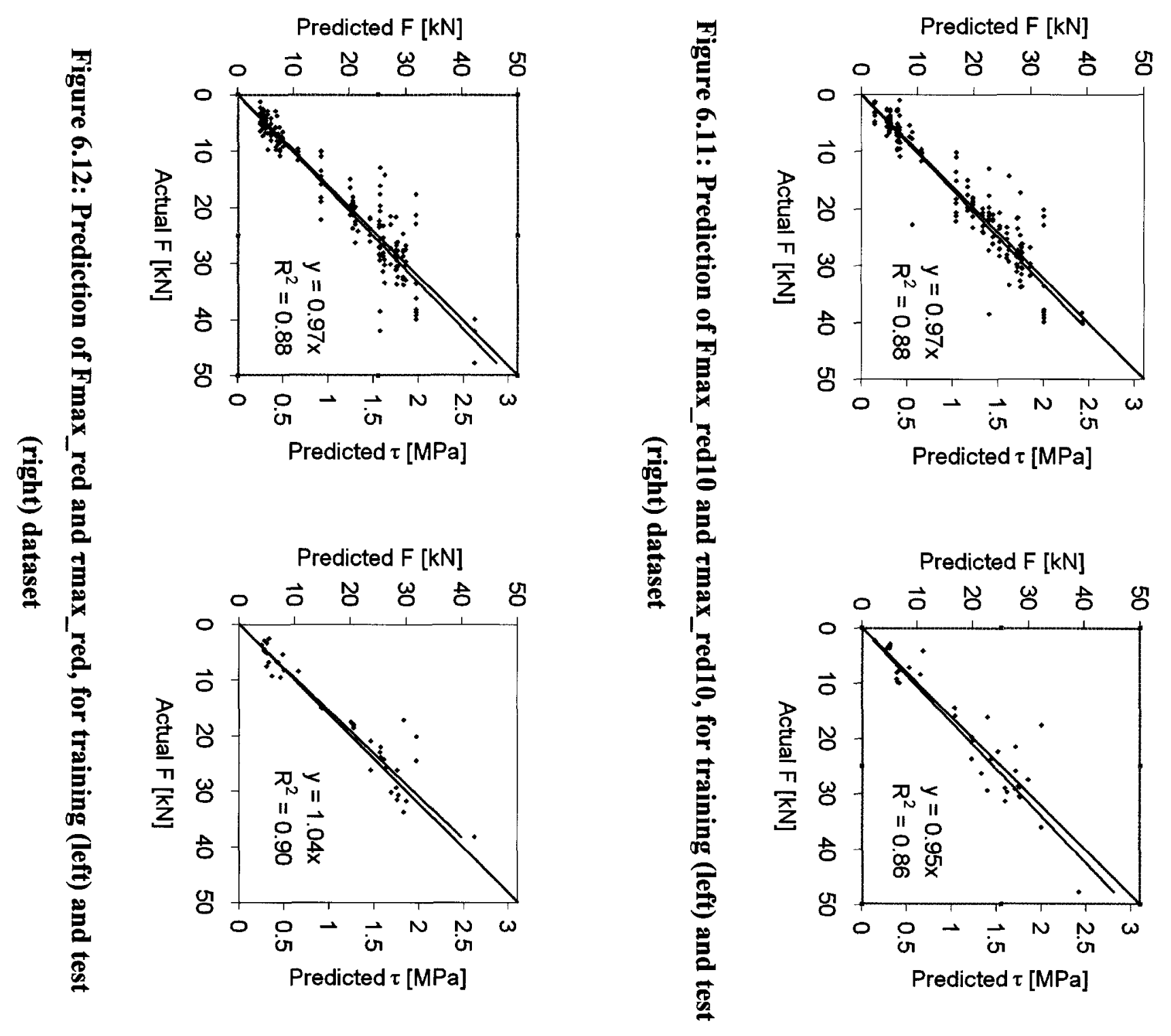

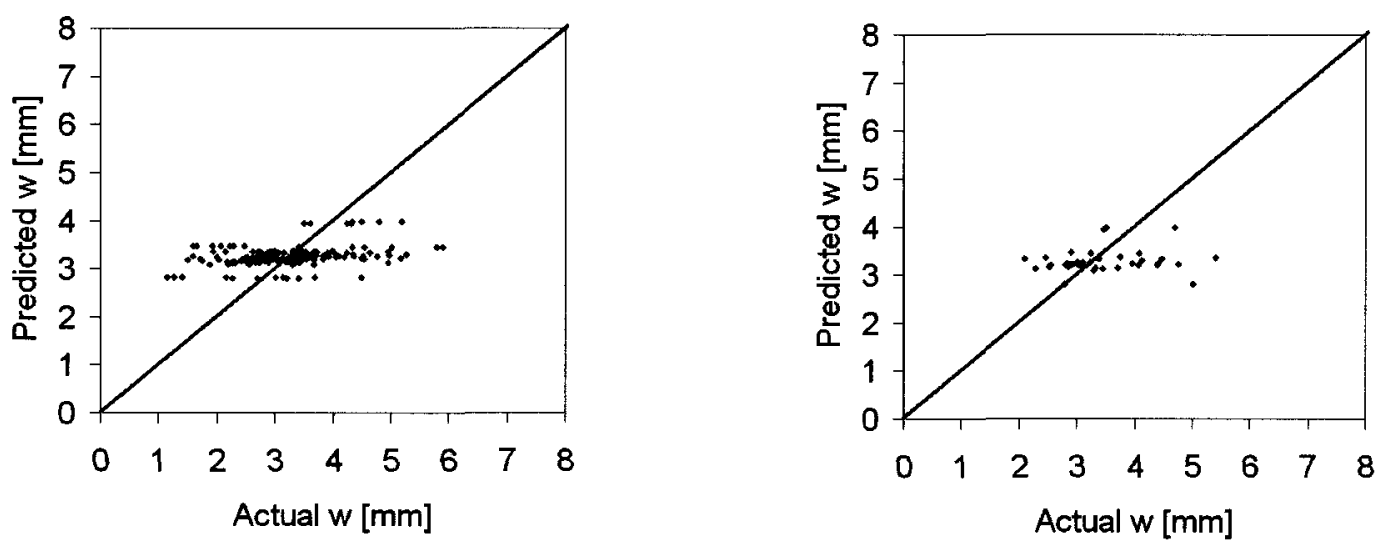

Figure 6.13: Prediction of $w \_$red10 at Fmax for training (left) and test (right) dataset
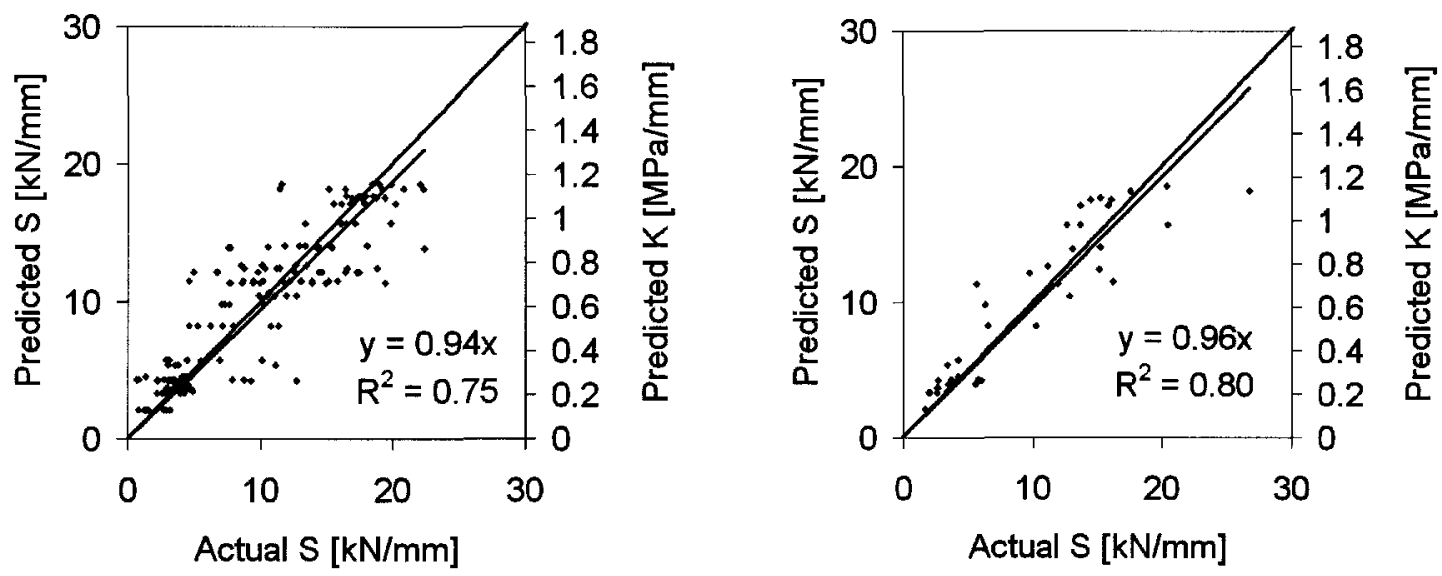

Figure 6.14: Prediction of Smax_red10 and Kmax_red 10 for training (left) and test (right) dataset

From Figures 6.11 to 6.14 it becomes clear that for the output variable max. shear force $F_{\max }$ and max. shear stiffness $S_{\max }$ a good prediction is possible, while the ANN computation of the third output variable, shear deformation $\mathrm{w}_{\max }$ at $\mathrm{F}_{\max }$, does not lead to a model, which is able to predict its values in a sufficient way. Not only, do the R- 
squared values of 0.89 and 0.79 give an acceptable prediction of shear force, shear stress and stiffness, the linear regression coefficients $\mathrm{R}^{2}$ show also very high values and the slopes of the regression lines are close to 1 and the regression curve goes through the origin of the coordinate system as it is expected to do.

\subsubsection{Analysis of relation between actual and predicted values}

Figure 6.15 to 6.18 show the prediction for the output variables using the independent query files for validating the determined network.

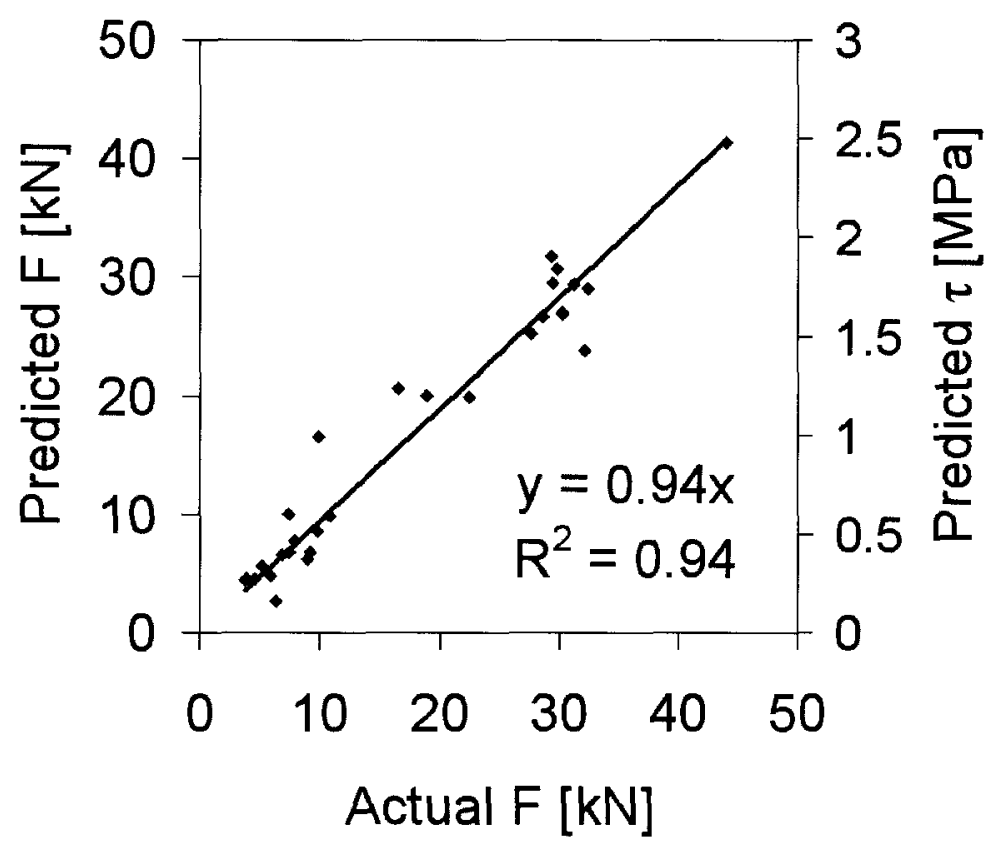

Figure 6.15: Prediction of Fmax_red10 and $\tau \max \_$red10 for independent query test dataset red10 


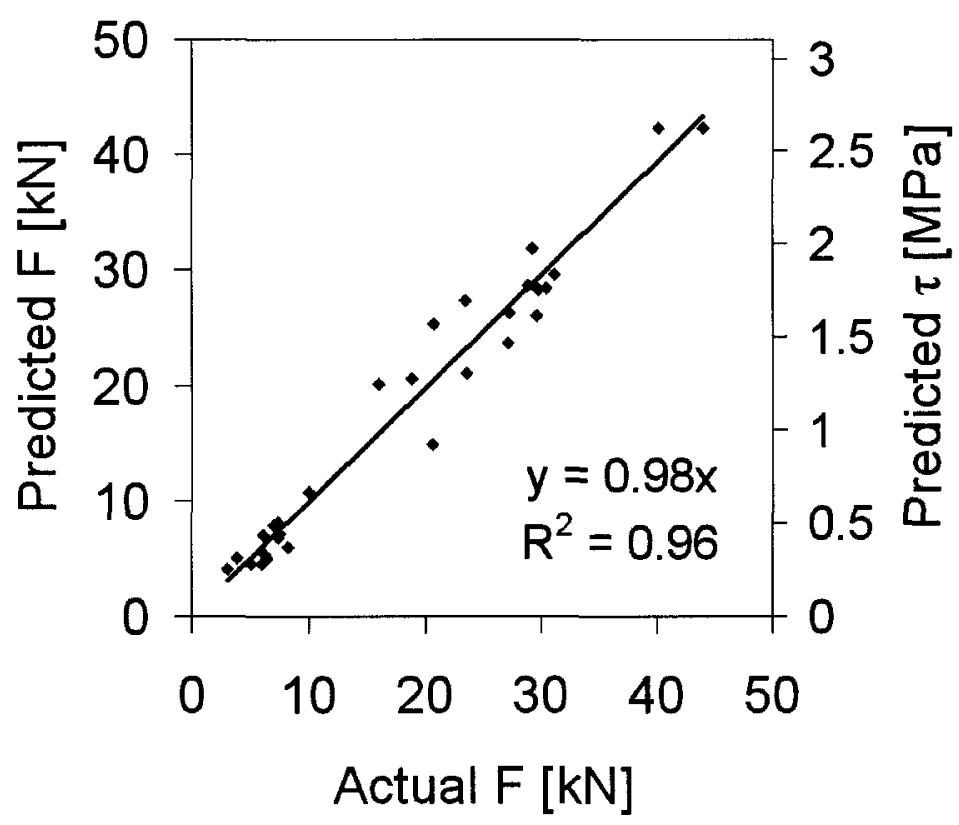

Figure 6.16: Prediction of max. shear force Fmax_red and $\tau$ max_red for independent query test dataset red10

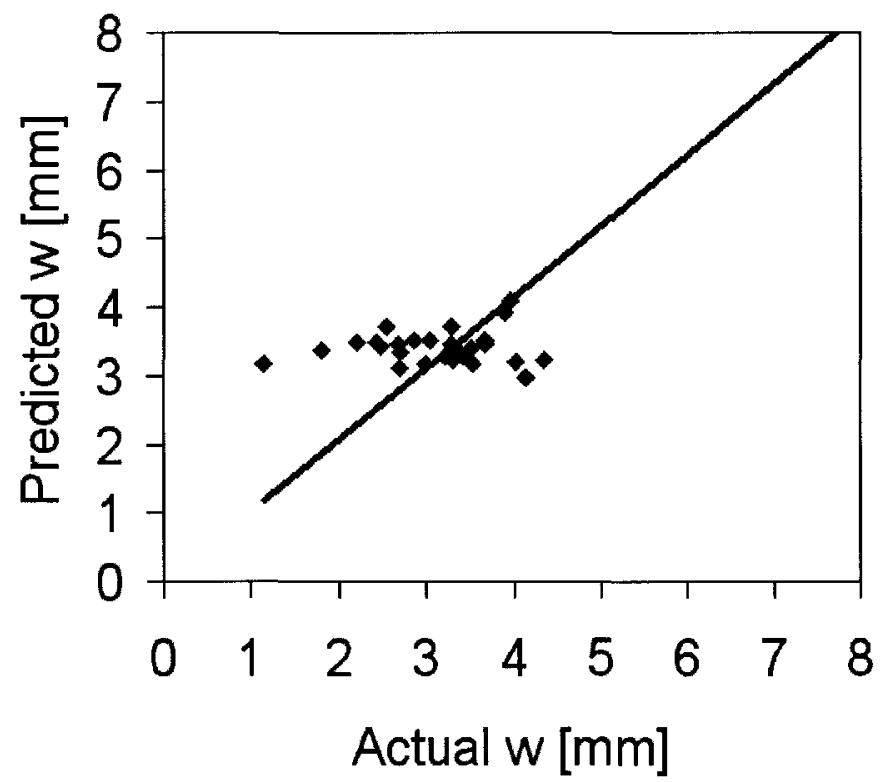

Figure 6.17: Prediction of max. shear deformation wmax_red10 for independent test dataset red10 


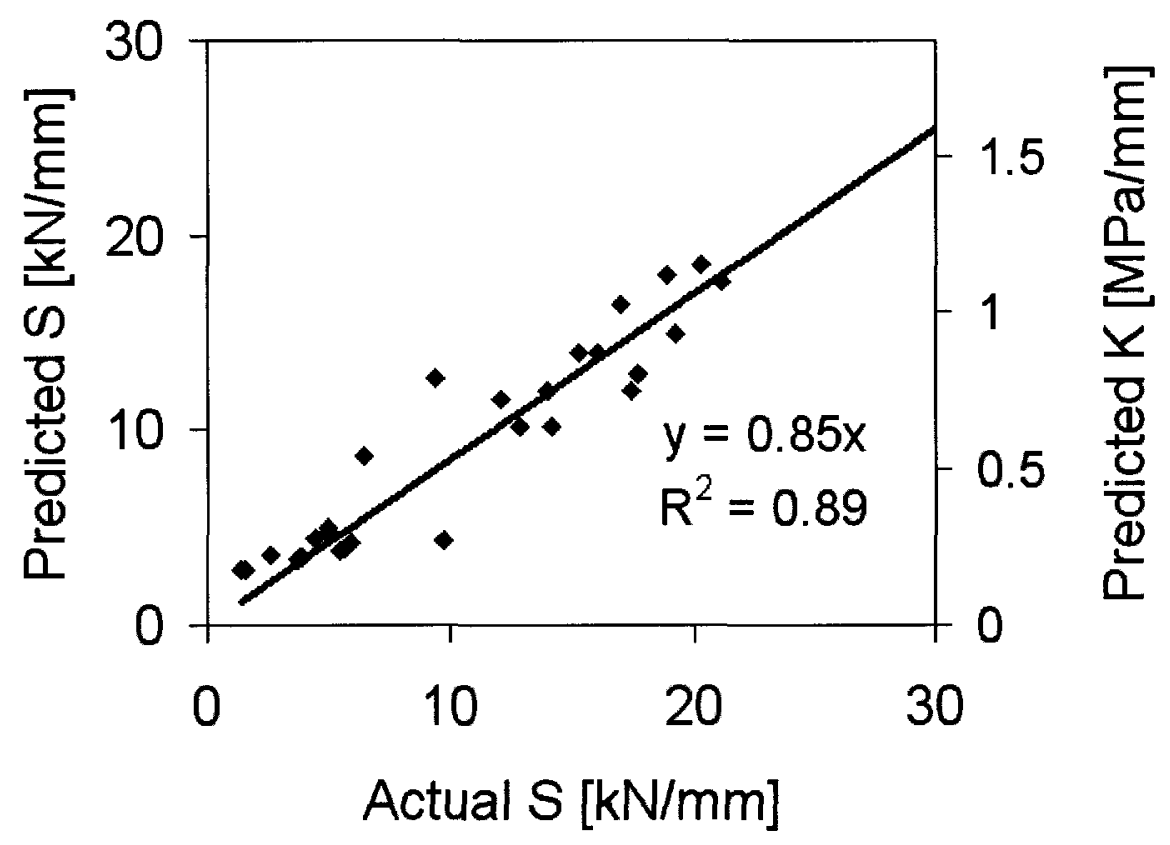

Figure 6.18: Prediction of max. shear stiffness Smax_red10 for independent test dataset red10

In Figures 6.15 to 6.18 , again shear force, shear stress and shear stiffness show excellent correlation with $\mathrm{R}^{2}$ values of 0.94 and 0.88 respectively, while for the shear deformation a linear correlation in the form $y=a x+b$ with $b=0$ is not possible. The slope of the regression line is for the shear force and shear stress close to 1 , in case of shear stiffness and shear reaction modulus it is a bit lower, revealing some other influence in the data.

When comparing the results for the max. shear force and shear stress in Figures 6.15 and 6.16, it is obvious that even for the test file red10 the ANN model leads to a very good value prediction with $R^{2}$ of 0.94 and a trend line with a slope that is close to 1 . 
Another tool for the interpretation of ANN results is the so-called response graph. The response graph displays the response of the model output by varying one of the variables, while keeping the other input variables constant. The constant value for each variable is the mean value of that variable in the dataset. The mean value for the temperature was $27.4^{\circ} \mathrm{C}$. The mean values for the air void content of the first and second layer 6.0 and 4.7 vol-\% respectively. For the binder content of first and second layers mean values of 6.3 and 4.4 mass-\% were found. Regarding the aggregates passing on the $8 \mathrm{~mm}$ sieve, mean values of 71.4 and 59.5 mass- $\%$ were obtained, while the passing on the $2 \mathrm{~mm}$ sieve reached mean values of 32 and 29.7 mass- $\%$ and the passing for the $0.09 \mathrm{~mm}$ filler sieve was 9.4 and 8.0 mass- $\%$.

Figure 6.19 gives the response graphs for all eleven input variables. It was decided to show the response graphs for max. shear force and max. shear stress since here physical dependencies are known best. For some input variables the response graph for max. shear stiffness and max. shear reaction modulus are also given.

As shown in Figure 6.19a, the max. shear force and stress decrease with increasing temperature from $20^{\circ} \mathrm{C}$ to $40^{\circ} \mathrm{C}$. The same applies for the max. shear force and stress with increasing air void content of the first layer (b). The situation gets different, for the air void content of the second layer, where an increase in air void content goes with an increase of max. shear force and stress (c). While the first two findings are in agreement with practical experience, the finding that the shear force increases with increasing air void content of the second layer is debatable. Here, the range of air void content is probably too small for determining a clear dependency and one has to keep in mind that the increase in shear force is also very small. Regarding the air void content 
another explanation could be found in the difference between first and second layer. Is the difference in air void content in the case of the first layer mainly based on differences in the asphalt concept, with mastic, asphalt with very low air void content on the one hand and porous asphalt with very high air void content on the other hand, the air void content of the second layer lies within a certain range since these layers are all constructed according to the concept of asphalt concrete. In case of the air void content of the second layer, other effects of roughness and interlock could be dominant.

While the binder content of the first layer is in such a small range, that any change in shear force can be neglected, the increase of max. shear force with increasing binder content of the second layer could be contributed to the fact that the increase of binder can be seen as a sort of "tack coat" leading to an increased adhesion.

For the passing through the $8 \mathrm{~mm}$ and $2 \mathrm{~mm}$ sieve of the first layer, the decreases in maximum shear force and stress are very small and therefore negligible (f), (h). In case of the second layer, max. shear force and stress are more depending on the amount passing these sieves. For the $8 \mathrm{~mm}$ sieve the increasing of amount passing results in a decrease of maximum shear force and stress, which means that the max. shear force and stress increases when the second layer consist of a smaller maximum aggregates $(\mathrm{g})$. This finding is not always in agreement with practical experience. The result regarding the passing through the $2 \mathrm{~mm}$ further indicates that this layer should be finer in order to achieve higher max. shear forces and stresses (i). Regarding practical experience this 
迥

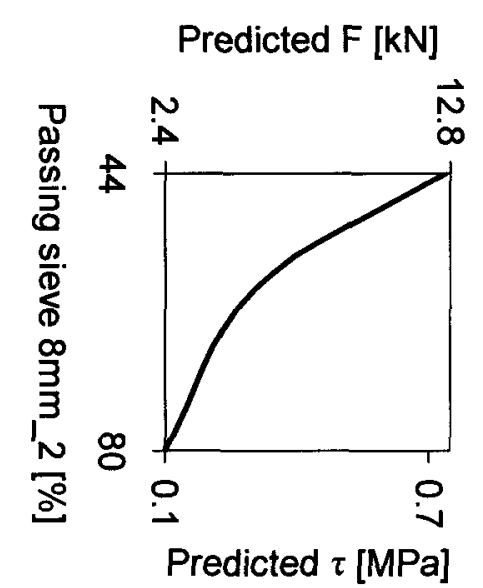

동

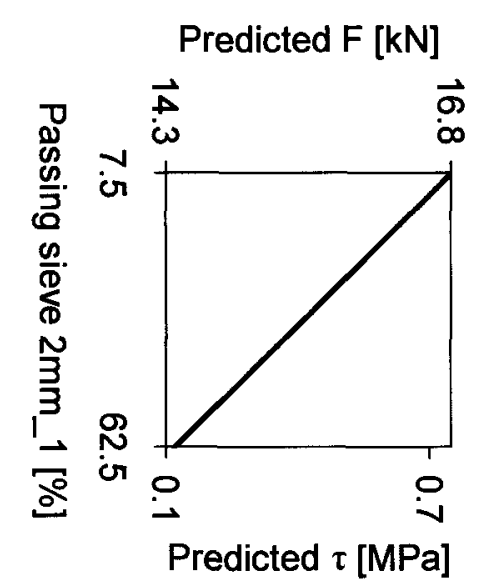

(3)

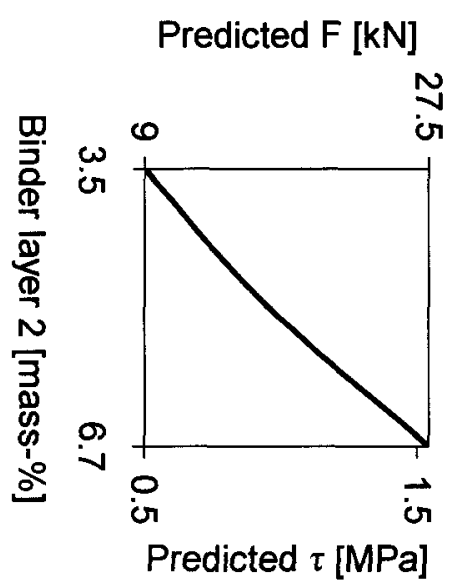

$\Theta$

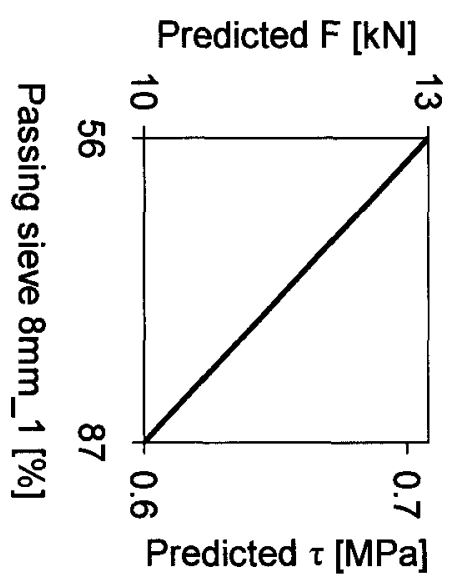

อ

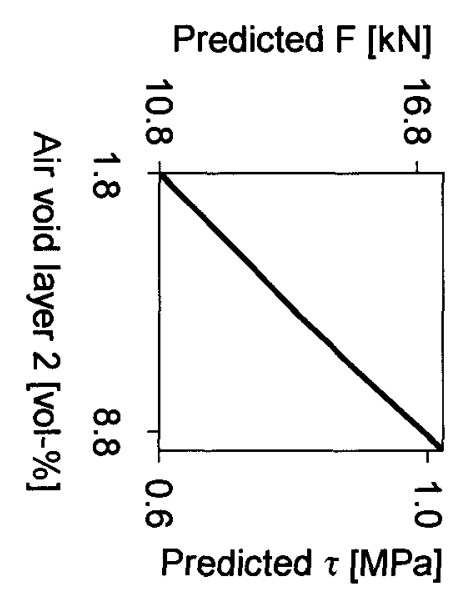

잉

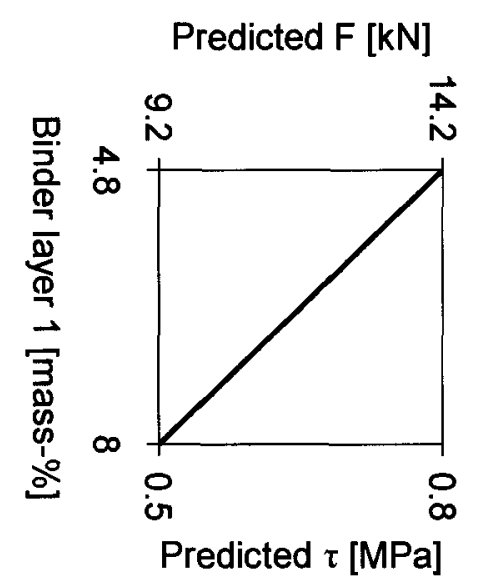

$\widehat{\infty}$

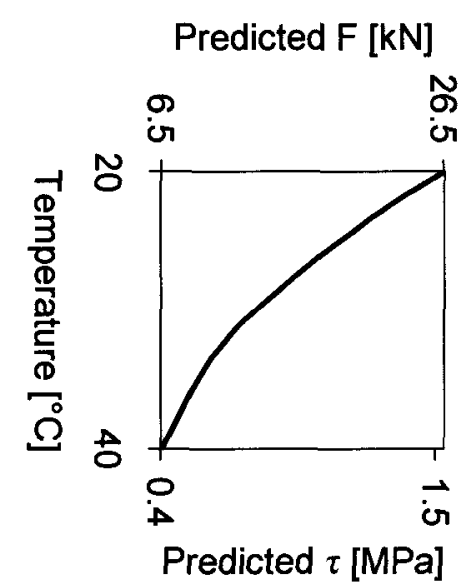

త્ర

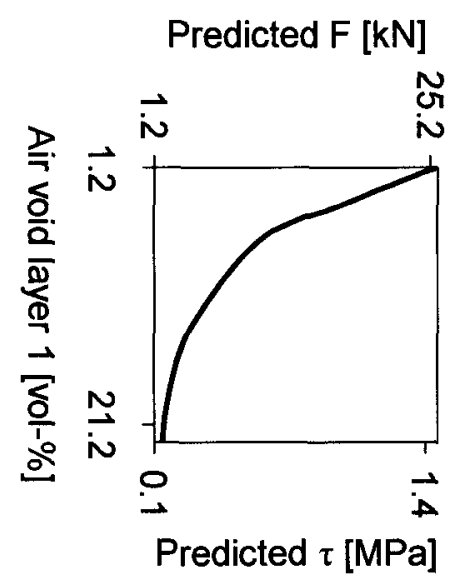




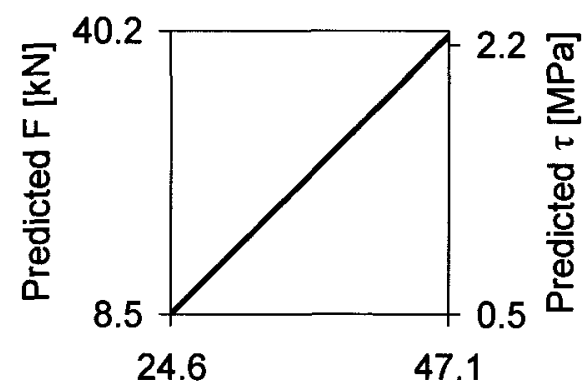

(i)

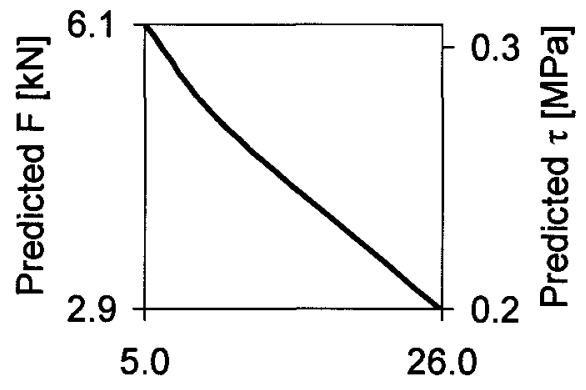

(k)

Passing sieve 0.09mm_2 [\%]

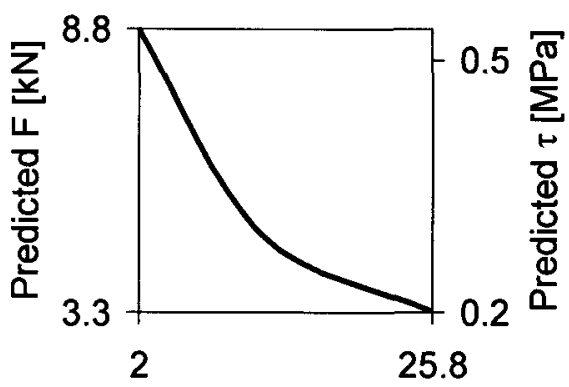

(j)

Figure 6.19: Response graphs of the input variables as a function of max. shear force and max. shear stress: temperature (a), air void content first and second layer (b), (c), binder content first and second layer (d), (e), passing-\% for first and second layer and the sieve $8 \mathrm{~mm}, 2 \mathrm{~mm}$ and $0.09 \mathrm{~mm}(\mathrm{f})$ - (k)

finding depends on the type of the asphalt mixture and the combination of first and second layer and can therefore not be generalised.

The result for the passing through the filler sieve of the first layer, where a decrease of max. shear force is found with higher filler contents, is clearly in disagreement with the finding that the mastic asphalt surface courses achieve the highest max. shear forces and stress of all datasets from New Road (j). In contrast, the opposite 
finding for the filler content of the second layer corresponds with the results for a second layers consisting of mastic asphalt $(\mathrm{k})$.

\subsubsection{Model from LTPP-Road}

\subsubsection{Determination of input variables}

Since the performance can only be evaluated when comparing the data from new in situ pavements with the results after ten years, for this evaluation both databases had to be combined, which resulted in a database of more than 400 data points.

Regarding the input variables, the following ones have to be taken into account in addition to the variables taken for the evaluation of the database for new road pavements (Chapter 5.7.1):

- $\quad$ Age

- $\quad$ Average daily traffic

- $\quad$ Percentage of heavy vehicles $>3.5 t$

Based on the previous evaluations and in order not to have too many input variables, the variables were reduced to nine input variables. The test temperature had to be excluded, since all performance data were only determined for the temperature of $20^{\circ} \mathrm{C}$. The binder contents for the first and second layer were not included because their range was very small and therefore, their evaluation did not give important information. The air void content was also neglected because the values for the LTPP road data were not comparable to the values of the new road data. In the LTPP investigation air voids had been determined for every single core, while for New Road the air void content 
represents a global value for the whole pavement. Table 6.4 depicts all input variables for data from LTPP-Road.

\section{Table 6.4: Input variables for LTPP-Road}

\begin{tabular}{|c|l|l|}
\hline Index & Input variable, designation for tables in Appendix A & Unit/type \\
\hline 1 & Traffic, average daily traffic, ADT* & vehicles \\
\hline 2 & Percentage of heavy vehicles $>3.5 \mathrm{t}$ & $\%$ \\
\hline 3 & Age & years \\
\hline 4 & Aggregate passing through sieve $8 \mathrm{~mm}$, layer, 8_1* & mass \%-passing \\
\hline 5 & Aggregate passing through sieve $8 \mathrm{~mm}$, layer 2, 8_2* & mass \%-passing \\
\hline 6 & Aggregate passing through sieve 2 mm, layer 1,2_1* & mass \%-passing \\
\hline 7 & Aggregate passing through sieve 2 mm, layer 2,2_2* & mass \%-passing \\
\hline 8 & Aggregate passing through sieve 0.09 mm, layer 1, Fil_1* & mass \%-passing \\
\hline 9 & Aggregate passing through sieve 0.09 mm, layer 2, Fil_2* & mass \%-passing \\
\hline
\end{tabular}

* abbreviations used in tables in Appendix A

When executing an inbuilt feature selection mode in the software (exhaustive search) traffic and the aggregates passing through sieve $2 \mathrm{~mm}$ were determined to be the most important variables. These variables produced a fitness of $50.6 \%$, while the combination of all input variables gained a fitness of $50.4 \%$. It was therefore decided to take all 9 input variables, since in this way more information could be retrieved with the response graph feature. The other reason was that the program made selection did not prove to be based on physical reasons. 


\subsubsection{Data mining (modelling)}

Network parameter determination

For all output parameters the same network architecture and number of hidden layers was used. Since it was found that the result did not differ too much when using different numbers of hidden neurons, the minimum number, which gave a good prediction, was determined to be 5 (see Figure 6.20)

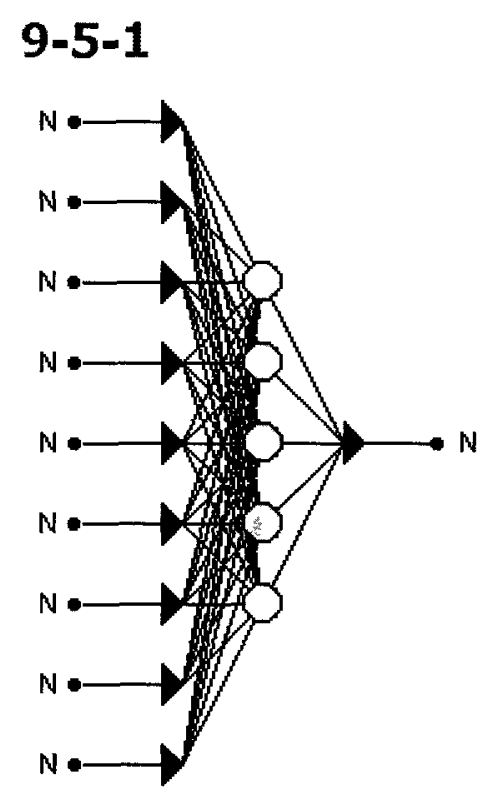

Figure 6.20: Network architecture used for data mining for LTPP-Road

Again, batch backpropagation was chosen as learning algorithms, while the activation function for both, hidden and output layer was found to be a hyperbolic tangent. For the other parameters, it was decided to have a learning rate $\eta=0.4$ and a momentum coefficient $\beta=0.9$. 


\subsubsection{Evaluation}

The results for the prediction of the output values in the ANN program are shown in Table 6.5 and in Figures 6.21 to 6.23 .

Table 6.5: Test results for all output variables for LTPP-Road

\begin{tabular}{|l|c|c|c|c|}
\hline & Avg. training error & Avg. validation error & Avg. test error & R-squared \\
\hline F $_{\text {max }}$ red & 3.39 & 3.92 & 3.14 & 0.75 \\
\hline $\mathrm{w}_{\text {max }}$ red & 0.46 & 0.32 & 0.50 & 0.52 \\
\hline $\mathrm{S}_{\text {max }}$ red & 2.49 & 2.94 & 2.38 & 0.74 \\
\hline
\end{tabular}
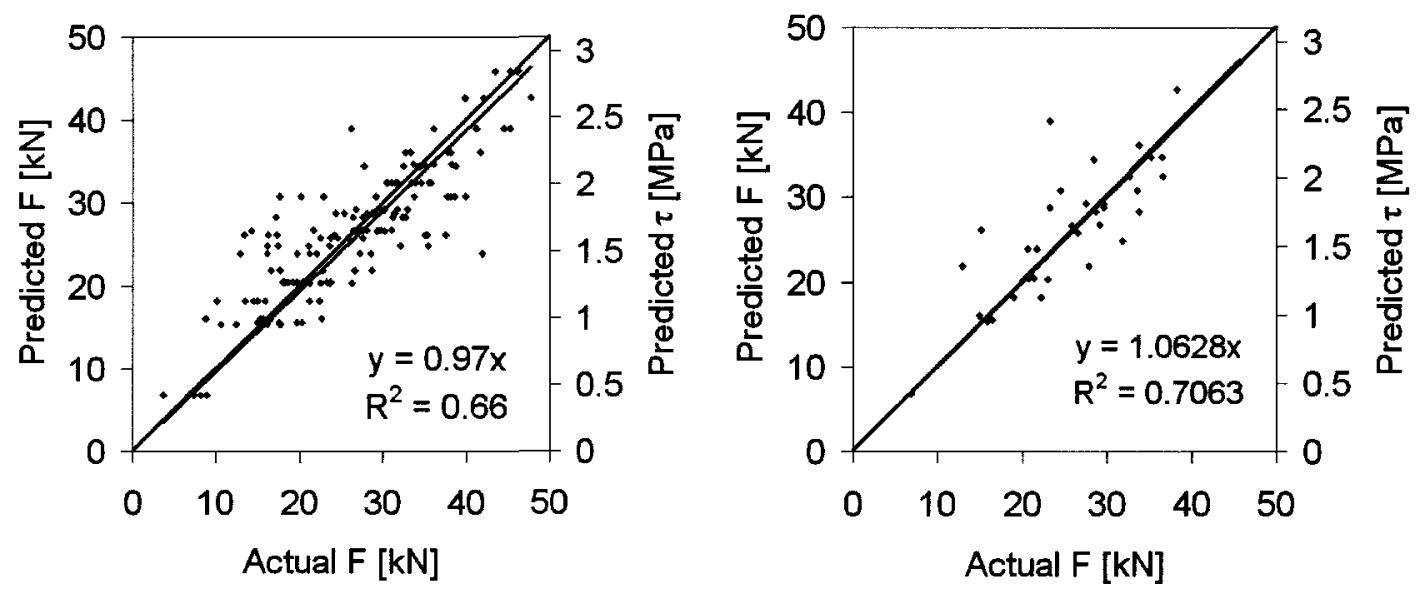

Figure 6.21: Prediction of Fmax and $\tau \max$, for training (left) and test (right) dataset 

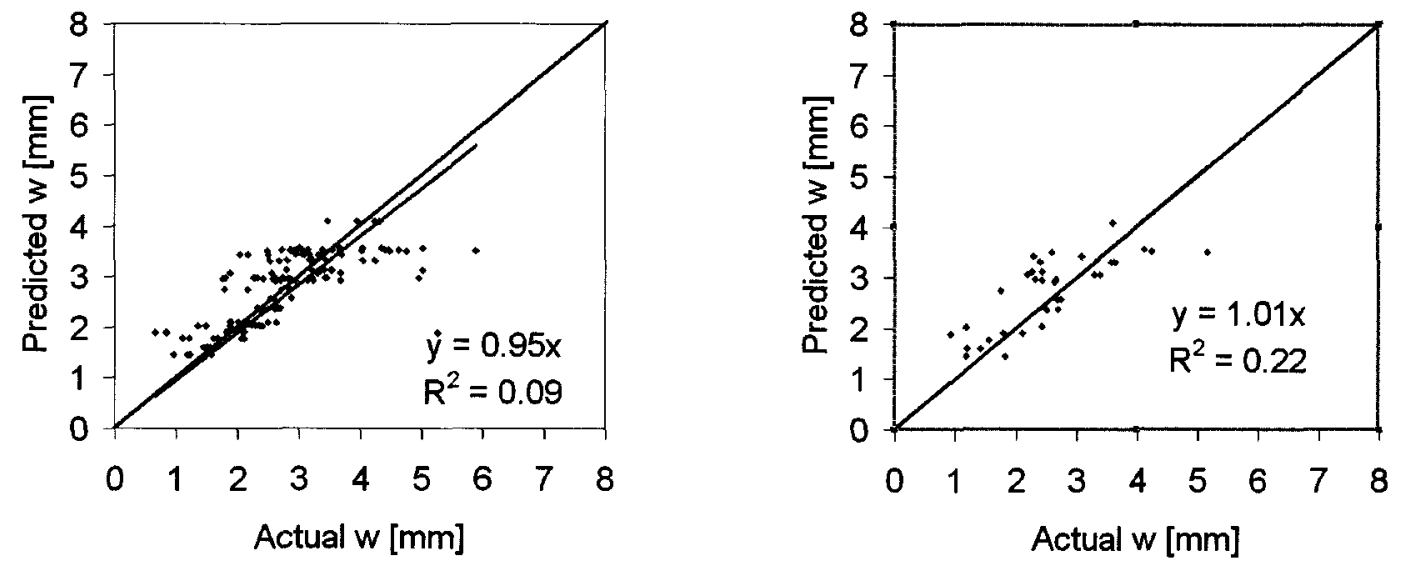

Figure 6.22: Prediction of $w$ at Fmax for training (left) and test (right) dataset
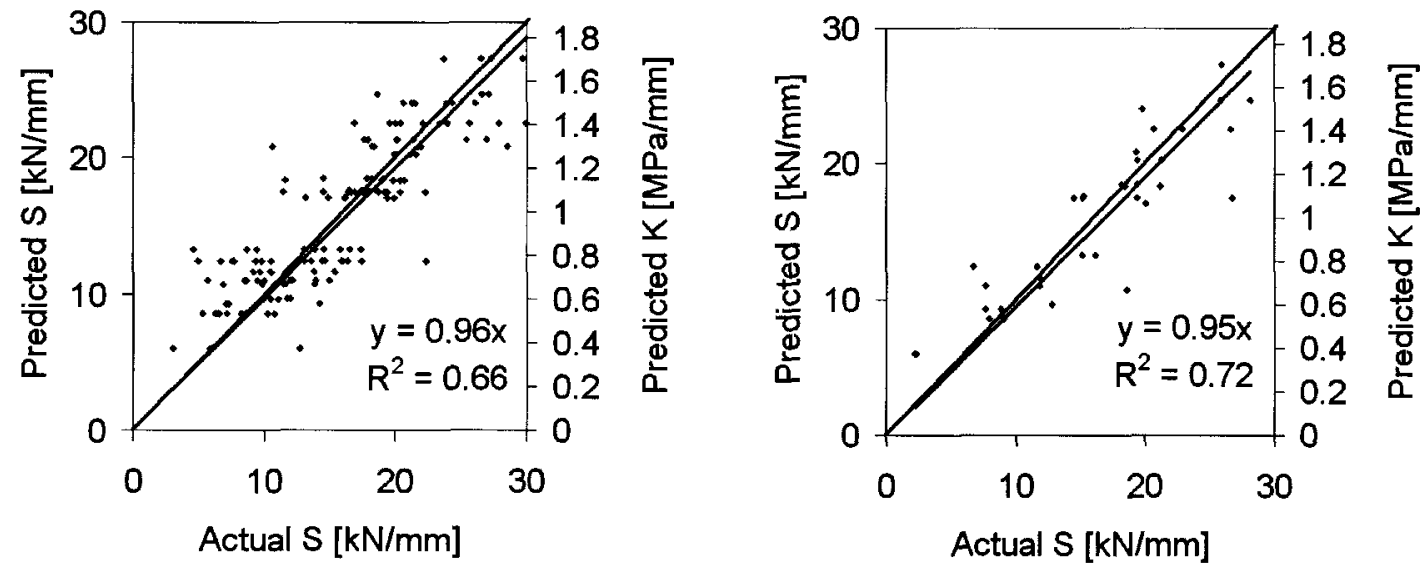

Figure 6.23: Prediction of Smax and Kmax for training (left) and test (right) dataset

From Figures 6.21 to 6.23 it becomes clear that for the output variable max. shear force $F_{\max }$ and max. shear stiffness $S_{\max }$ a prediction is possible with $R$-squared values of 0.75 and 0.74 . For this database even the prediction for the third output variable shear deformation $\mathrm{w}$ at $\mathrm{F}_{\max }$ is possible, although the $\mathrm{R}$-squared value with 0.52 is clearly not very high. This finding can be contributed to the fact that with age the deformation at 
$\mathrm{F}_{\max }$ becomes smaller and the distinction between the new and aged values becomes clearer.

For the linear regression the findings are similar: For all regression lines a slope very close to 1 is found, although the linear regression coefficients $R^{2}$ are not high. For max. shear force and max. shear stiffness they receive values of 0.66 for training and 0.72

for testing. In case of the shear deformation at $F_{\max }, \mathrm{R}^{2}$ is very low $(0.09$ for training and 0.22 for testing).

It is interesting to note, that in the LTPP data, as opposed to New Road data, a weak correlation for the max. shear deformation at $F_{\max }$ can be found. This correlation might be attributed to the fact that in case of LTPP data, overall the shear deformation data are lying within a less wide range and the amount of similar or comparable data (new/old) increased.

\subsubsection{Analysis of relation between actual and predicted values}

Figure 6.24 to 6.26 show the prediction for the output variables using the independent additional query files for validating the network. 


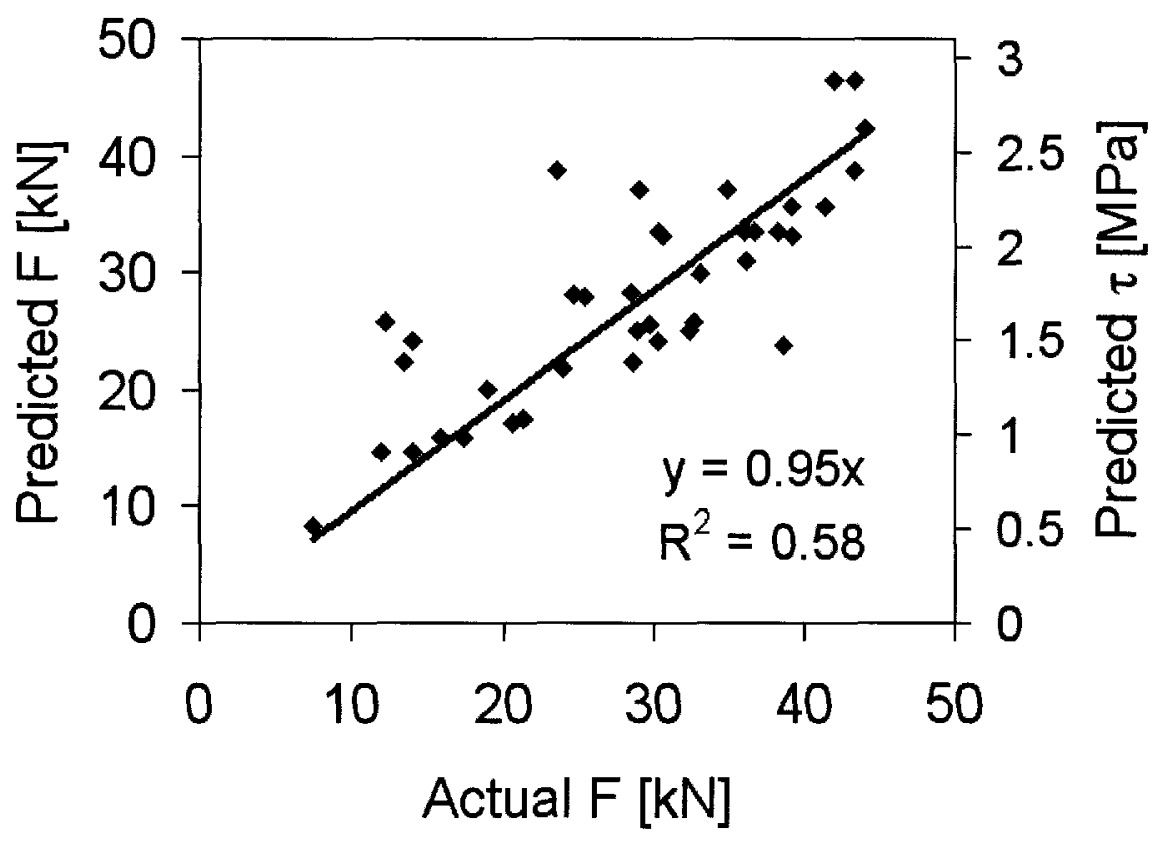

Figure 6.24: Prediction of Fmax and $\tau$ max, for independent query test dataset

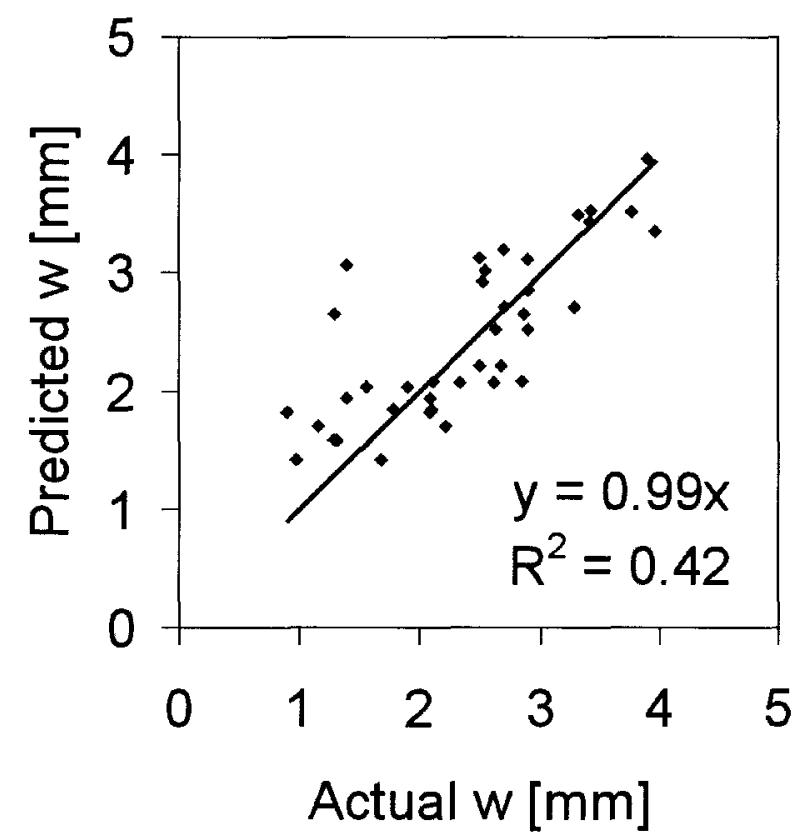

Figure 6.25: Prediction of $w$ at Fmax for independent query test dataset 


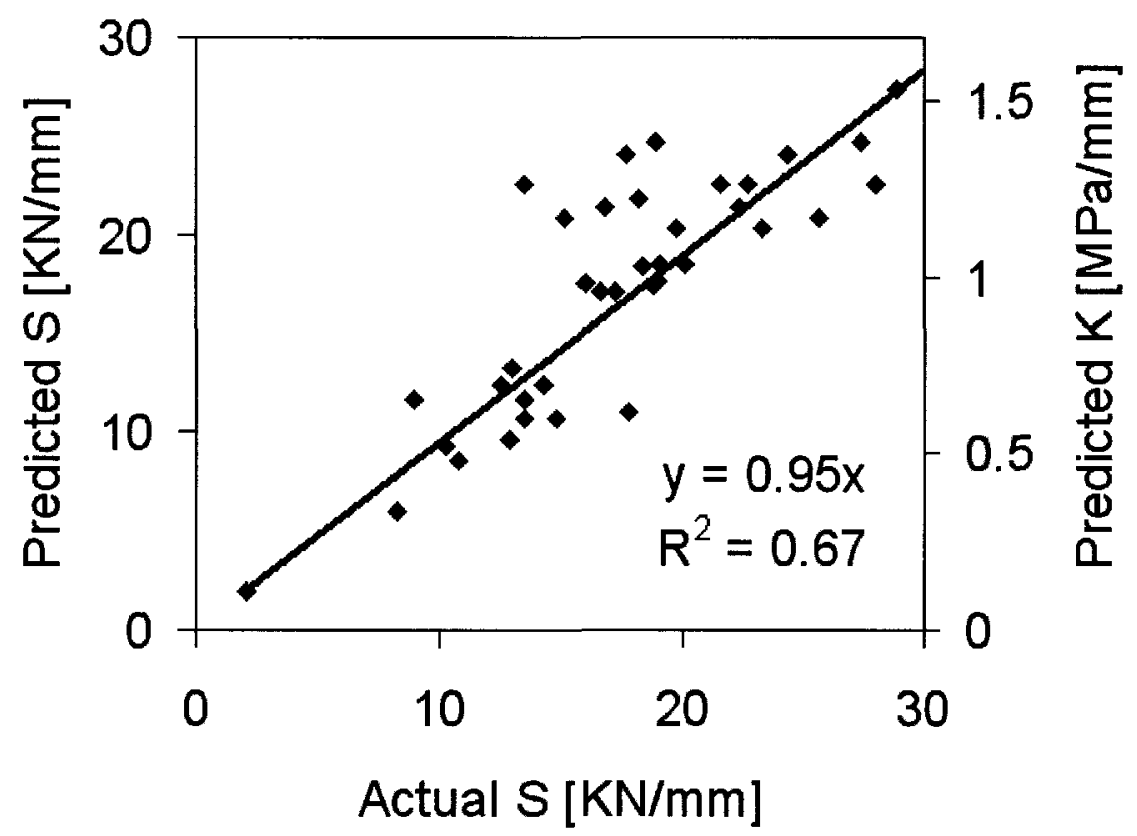

Figure 6.26: Prediction of Smax and Kmax for independent query test dataset

Similar findings can be drawn from Figures 6.24 to 6.26. However, here shear force and shear stiffness show only weak correlations with $R^{2}$ values of 0.58 and 0.62 respectively, while the $\mathrm{R}^{2}$ of the linear correlation for the shear deformation is only 0.42 , partly due to the fact that, for physical reason again, the regression line was forced through the origin of the axis. On the other hand, the slope of the linear regression line was for all output variables close to 1 . That the prediction for LTPP Road is not so good compared to New Road can be explained by the fact that LTPP-Road is a combination of two datasets which differ regarding the time of testing.

The response graphs as a function of max. shear force and shear stress are presented in Figure 6.27. The mean value for the average daily traffic was 17570 , the mean value for the percentage of heavy vehicles was 2.9 and for the age 4.5 years. 
Regarding the gradation, passing through the $8 \mathrm{~mm}$ sieve achieved mean values of 70.8 mass- $\%$ and 62.9 mass- $\%$, while the passing through the $2 \mathrm{~mm}$ sieve reached mean values of 31.3 mass- $\%$ and 30.8 mass- $\%$ and the passing for the $0.09 \mathrm{~mm}$ filler sieve was 9.5 mass- $\%$ and 8.2 mass- $\%$. As expected these values are quite similar to those from New Road.

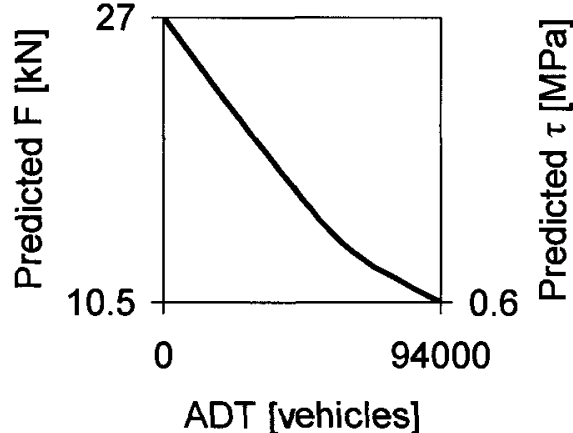

(a)

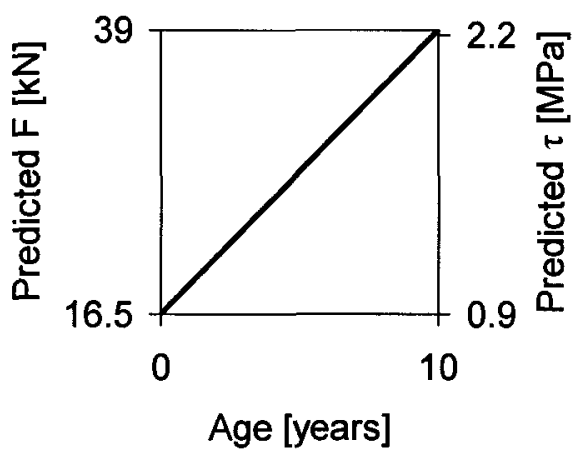

(c)

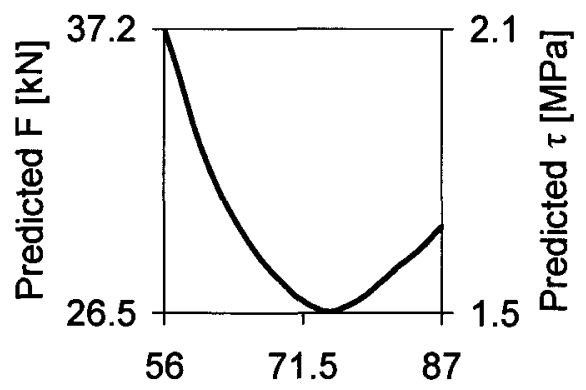

(d)

Passing sieve 8mm_1 [\%]

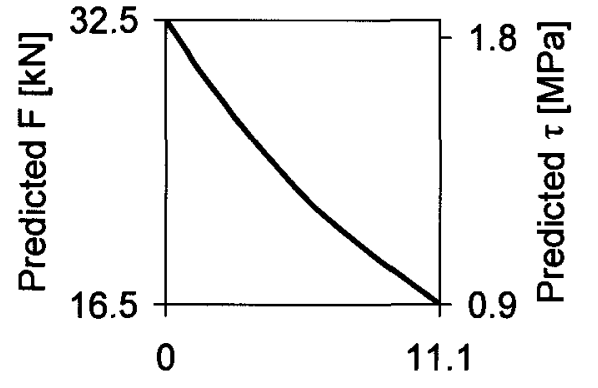

(b) 


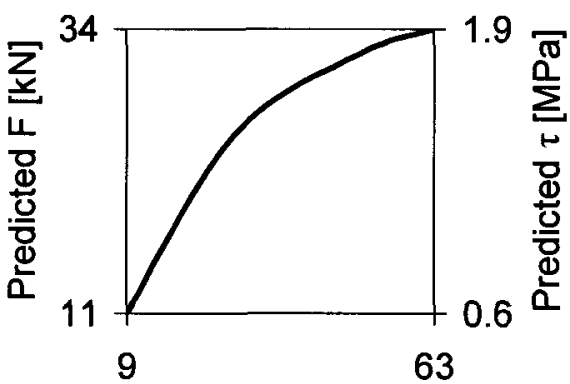

(f)

Passing sieve $2 \mathrm{~mm} \_1$ [\%]

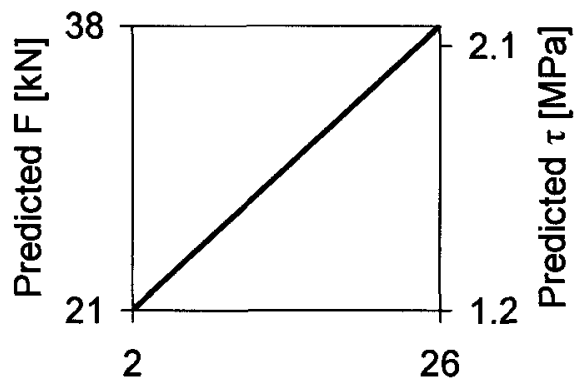

(h)

Passing sieve $0.09 \mathrm{~mm} \_1$ [\%]

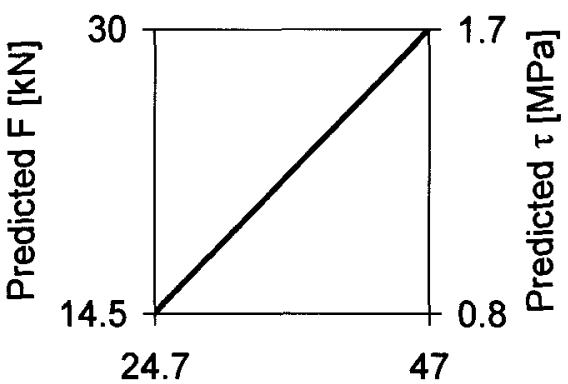

Passing sieve 2mm_2 [\%]

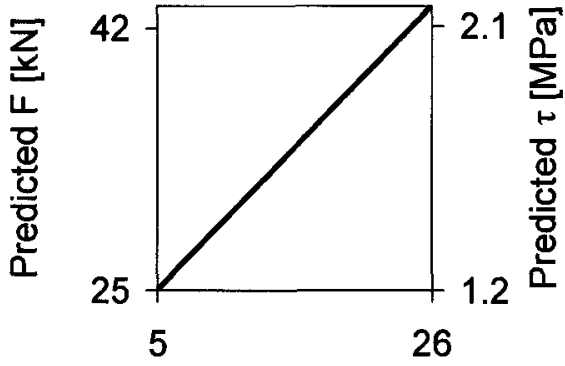

Passing sieve 0.09mm_2 [\%]

Figure 6.27: Response graphs of the input variables as a function of max. shear force and max. shear stress: average daily traffic ADT (a), percentage of vehicles $>3.5 \mathrm{t}$ (b), age (c), aggregates passing the sieve $8 \mathrm{~mm}, 2 \mathrm{~mm}$ and $0.09 \mathrm{~mm}$ for first and second layer (d) - (i)

As shown in Figure 6.27a, the shear force decreases with increasing average daily traffic. The same applies for increasing percentage of heavy vehicles (b). The situation gets different, when looking at the age, where an increase in age by 10 years leads to an increase of shear force and shear stress (c). The findings for the average daily traffic, the percentage of heavy vehicles and the age are in agreement with practical experience. The results in a paper by Raab (Raab and Partl, 2008) clearly states that while the shear force of intact pavements increases with age, very high levels of daily traffic and high 
percentages of heavy vehicles can lead to pavement deterioration combined with a decrease in shear force and shear stress. In this investigation it was found that very high levels of daily traffic and high percentages of heavy vehicles can cause damage to the pavement, which results in a decrease of shear forces and stresses mainly in the wheel path. In most cases the pavement deterioration is visible (ruts, cracks), but when the pavement is subjected to very high levels of ADT over a long period of time, shear properties were found to decrease without the pavement showing visible defects.

Regarding the first layer the passing through the $8 \mathrm{~mm}$ sieve, a decrease in shear force can be seen in (d), when the amount of passing is increased from 55 to 76 mass-\%, while the shear force increases again when the amount increases to 87 mass-\%. For the second layer, the situation is similar, although the decrease in shear force and stress is less distinct, when increasing the passing from 44 mass- $\%$ to 69 mass- $\%$ and a negligible increase to $25 \mathrm{kN}$ when the amount increases to 80 mass-\% (e). In case of first and second layer the passing through the $2 \mathrm{~mm}$ sieve, the shear force increases, when increasing the amount passing (f) and (g). For the passing through the $8 \mathrm{~mm}$ and $2 \mathrm{~mm}$ sieves of both layers an interpretation and a comparison with the in situ behaviour is more difficult, since detailed practical experience is lacking and the changes in shear force and stress may depend either on the material or on the time of testing (new or LTPP data).

For the filler sieve of the first and second layer an increase in the amount passing corresponds to an increase in shear force and shear stress (h) and (i). By combining two databases (New Road and LTPP-Road), there seem to be sufficient data for pavements 
with high filler contents. Hence, the ANN model is able to predict an increase in shear force and stress with increasing filler contents for both layers.

Figure 6.28 the response graphs as a function of max. shear stiffness and shear reaction modulus for the input variables ADT (a), vehicles $>3.5 \mathrm{t}$ (b) and age (c).

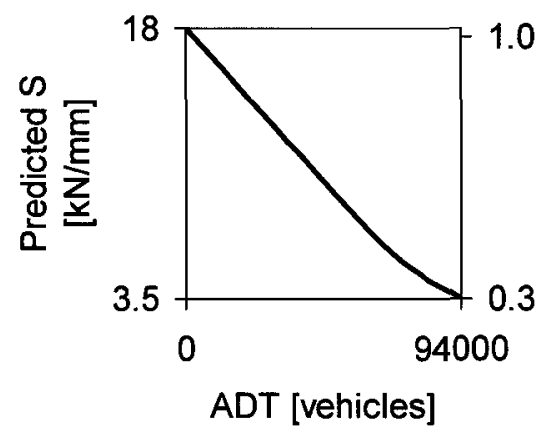

(a)

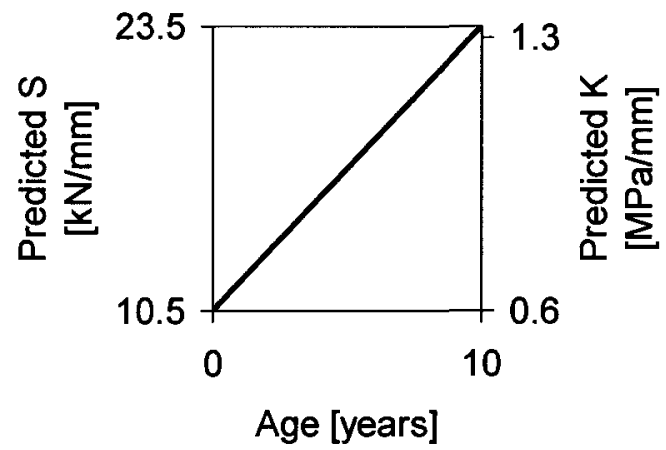

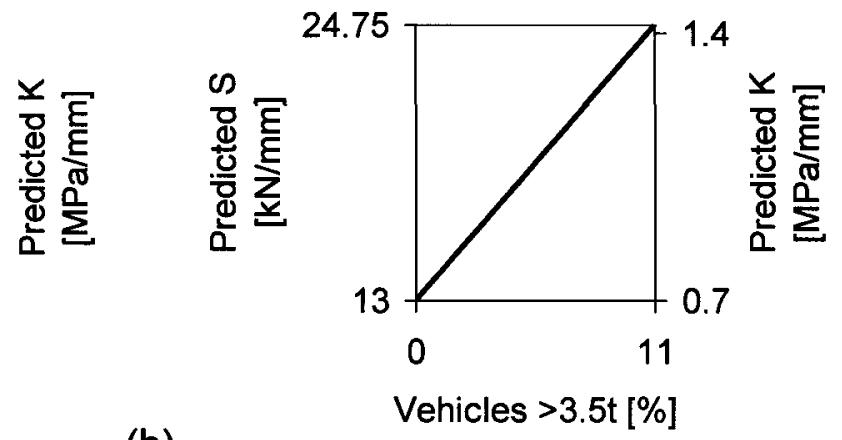

(b)

(c)

Figure 6.28: Response graphs of the input variables as a function of max. shear stiffness and shear reaction modulus: average daily traffic ADT (a), percentage of vehicles $>3.5 t$ (b) and age (c)

The increase of maximum shear stiffness and shear reaction modulus with age corresponds to the findings for max. shear force and shear stress. In case of an increasing amount of vehicles $>3.5 t$ an increase in stiffness is found although the max. shear force and stress decrease. This finding is still logical since a decrease in max. shear force and 
stress of aged pavements is not necessarily combined with decreasing stiffness (see also Raab and Partl, 2008). The increase of shear stiffness and shear reaction modulus with decreasing ADT also corresponds to the findings for shear force and shear stiffness. Here again, the negative effect of excessive traffic leading to pavement deterioration is reflected in the ADT response graph.

\subsubsection{Model from Combi Road}

\subsubsection{Determination of input variables}

Regarding the input variables the situation for this database is different. On the on hand we have a two layered pavement, where the second layer consists of concrete. On the other hand we have only two different types of asphalt surface courses which are only different in terms of gradation but not regarding their binder and air void content. This reduces the input variables to the gradation values $8 \_1,2 \_1$ and Fil_1. Another drawback regarding this database lies in the fact that it is very small, that means after the reduction for a separate query file, there were only 55 data points available.

Additional parameters to be taken into account are: The type of intermediate layer or surface treatment (fine milling) and the age, since the evaluation was done at different times.

Table 6.6 shows all input variables for data from concrete/asphalt pavements with different intermediate layer: 
Table 6.6: Input variables for data from Combi Road

\begin{tabular}{|c|l|l|}
\hline Index & Input variable, designation for tables in Appendix A & Unit/type \\
\hline 1 & Type of intermediate layer(1-6) & Categorical value \\
\hline 2 & Age & years \\
\hline 3 & Aggregate passing through sieve 8 mm, layer, 8_1* & mass \%-passing \\
\hline 4 & Aggregate passing through sieve 2 mm, layer 1, 2_1* & mass \%-passing \\
\hline 5 & Aggregate passing through sieve 0.09 mm, layer 1, Fil_1* & mass \%-passing \\
\hline
\end{tabular}

* abbreviations used in tables in Appendix A

\subsubsection{Data mining (modelling)}

Network parameter determination

For the maximum shear force output parameter the network architecture depicted in Figure 6.29 with a number of 6 hidden neurons was used. For the other parameters it was decided to have a learning rate $\eta=0.1$ and a momentum coefficient $\beta=0.9$.

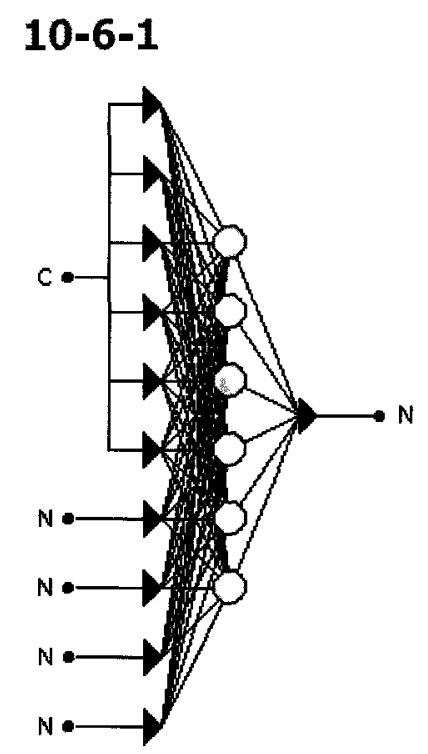

Figure 6.29: Network architecture used for data mining for Combi-Road 


\subsubsection{Evaluation}

The results for the prediction of the output value maximum shear force $F_{\max }$ in the ANN program are shown in Table 6.7.

Table 6.7: Test results for all output variables for data from Combi Road

\begin{tabular}{|l|c|c|c|c|}
\hline & Avg. training error & Avg. validation error & Avg. test error & R-squared \\
\hline$F_{\text {max } \_ \text {red }}$ & 2.38 & 2.44 & 3.45 & 0.26 \\
\hline
\end{tabular}

When executing the modelling for the max. shear force $F_{\max }$, it was found that a prediction in case of the Combi Road database was not possible. Therefore, only the result for one output variable is shown. The scatter plot in Figure 6.30 shows the prediction plot of training (left) and test set (right) for max. shear force $F_{\max }$ output variable.
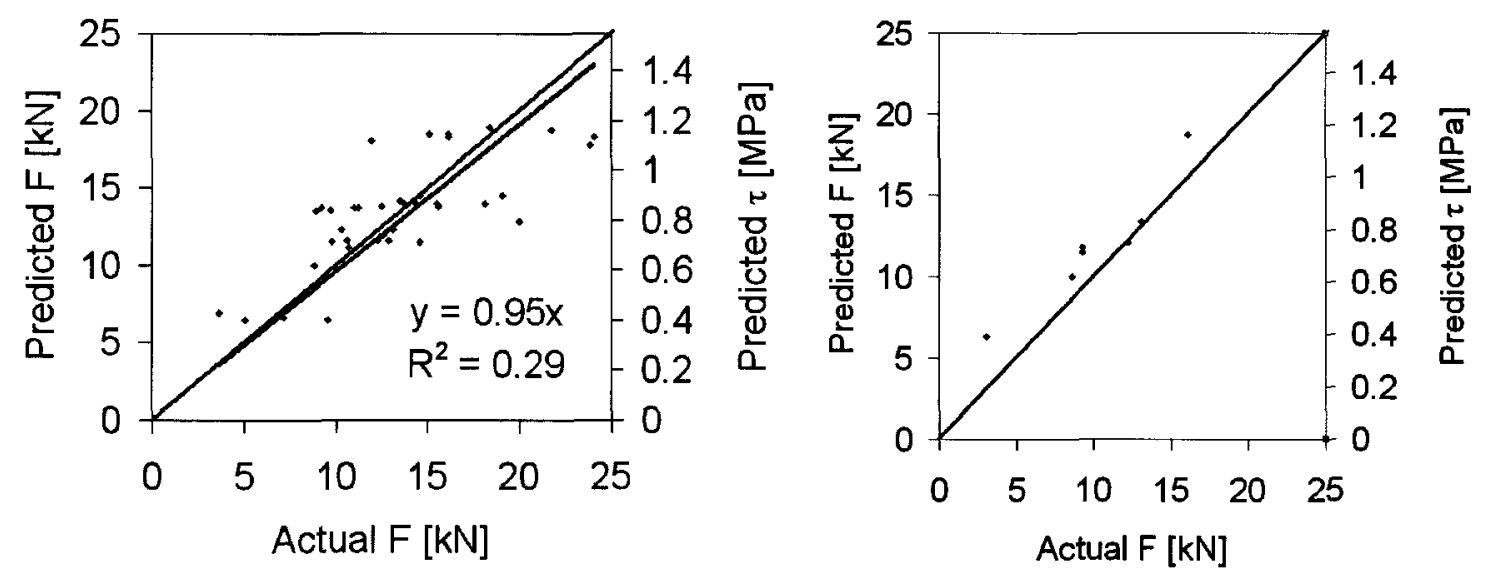

Figure 6.30: Prediction of Fmax and $\tau$ max, for training (left) and test (right) dataset 


\subsubsection{Analysis of relation between actual and predicted values}

Figure 6.31 depicts the prediction for the output variable using the independent query test dataset.

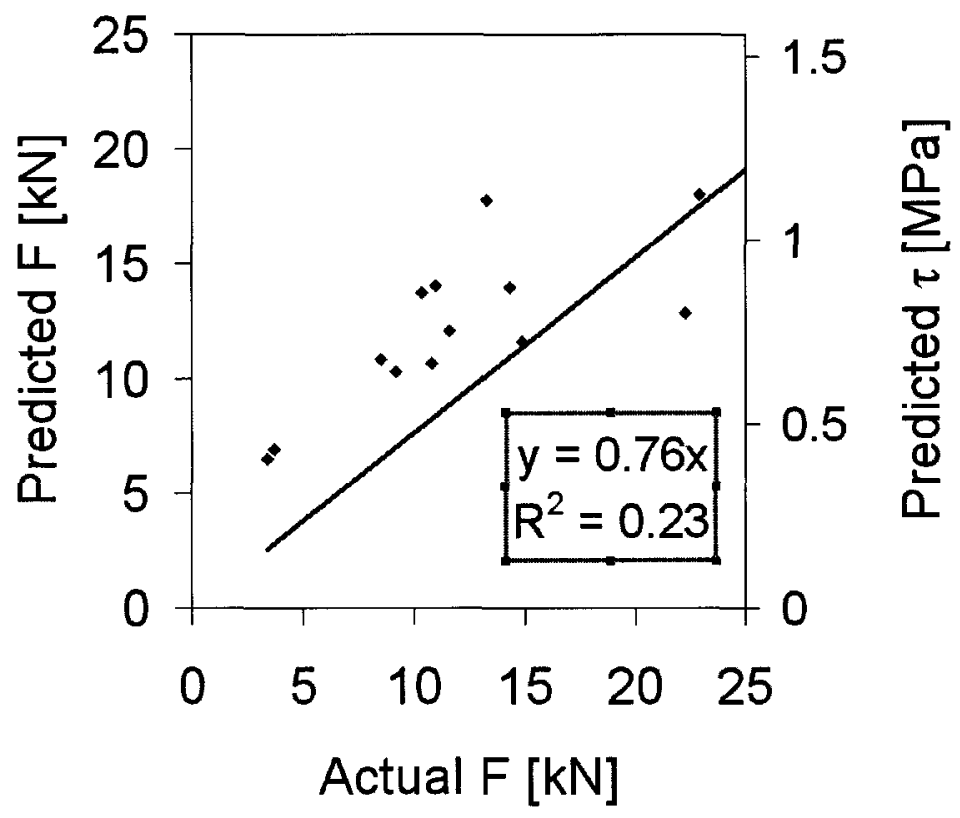

Figure 6.31: Prediction of max. shear force Fmax and max. shear stress and $\tau$ max, for independent query test dataset

When looking at Figures 6.30 and 6.31 it becomes clear that for the output variable max. shear force $F_{\max }$ a prediction is not possible. The reason can be found in the database which is on the one hand very small with sometimes only two values for a certain set of data (material or test condition). Furthermore, the data are not distinct enough regarding certain input variables such as age. 


\subsubsection{Model from Lab Pavement}

\subsubsection{Data mining (modelling)}

Since the material in this database is the same for all specimens, the number of material related input variables is very limited. It was only possible to include the air void content of both layers which was determined for every single specimen and individual layer. Further, the following input variables were integrated in the evaluation (see Table 6.8):

- $\quad$ Type of tack coat

- $\quad$ Treatment and

- $\quad$ Age

The reduced database consisted of more than 150 data points.

Table 6.8: Input variables for Lab Pavement

\begin{tabular}{|c|l|l|}
\hline Index & Input variable, designation for tables in Appendix A & Unit/type \\
\hline 1 & Type of tack coat, Tack coat & categorical value \\
\hline 2 & Treatment & categorical value \\
\hline 3 & Age & years \\
\hline 4 & Void 1, void content of layer 1, AV1* & vol-\% \\
\hline 5 & Void 2, void content of layer 2, AV2* & vol-\% \\
\hline
\end{tabular}

* abbreviations used in tables in Appendix A 


\subsubsection{Data mining (modelling)}

Network parameter determination

For all three output parameters the same network architecture with a number of 3 hidden neurons was used. For the other parameters it was determined to have a learning rate $\eta=$ 0.2 and a momentum coefficient $\beta=0.9$. The network structure is depicted in Figure 6.32:

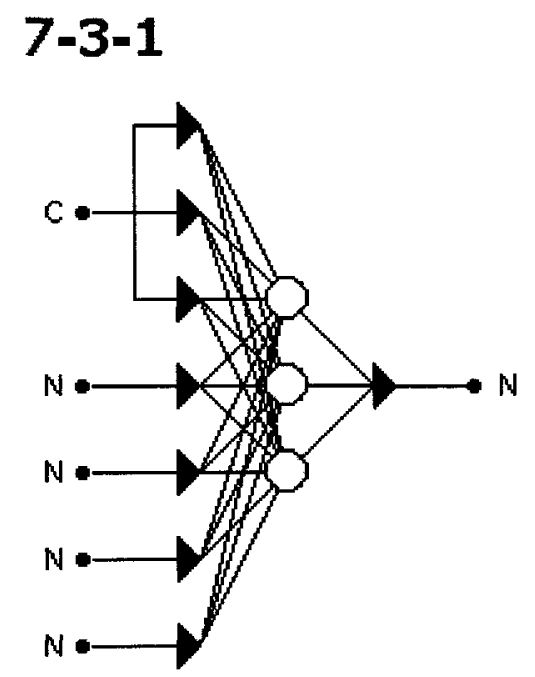

Figure 6.32: Network architecture for data from laboratory pavements using cationic tack coats

\subsubsection{Evaluation}

The results for the prediction of the output values in the ANN program are shown in Table 6.9. 
Table 6.9: Test results for all output variables for Lab Pavement

\begin{tabular}{|l|c|c|c|c|}
\hline & Avg. training error & Avg. validation error & Avg. test error & R-squared \\
\hline $\mathrm{F}_{\text {max_red }}$ & 4.47 & 4.56 & 3.56 & 0.86 \\
\hline $\mathrm{w}_{\text {max }}$ red & 0.20 & 0.22 & 0.19 & 0.78 \\
\hline $\mathrm{S}_{\text {max }}$ red & 3.78 & 3.99 & 4.31 & 0.58 \\
\hline
\end{tabular}

Figures 6.33 to 6.35 (Scatter plots) show the prediction plots of the test set for the 3 output variables max. shear force $F_{\max }$, max. shear deformation $w$ at $F_{\max }$ and max. shear stiffness $S_{\max }$.
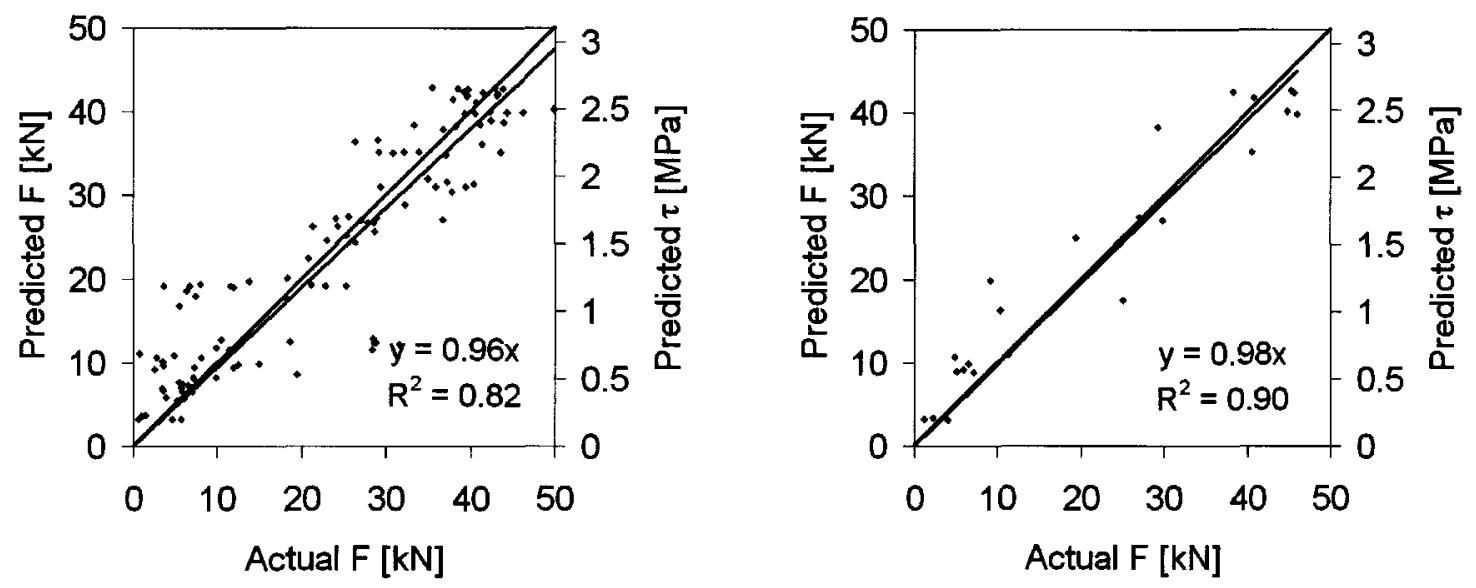

Figure 6.33: Prediction of Fmax and $\tau$ max, for training (left) and test (right) dataset 

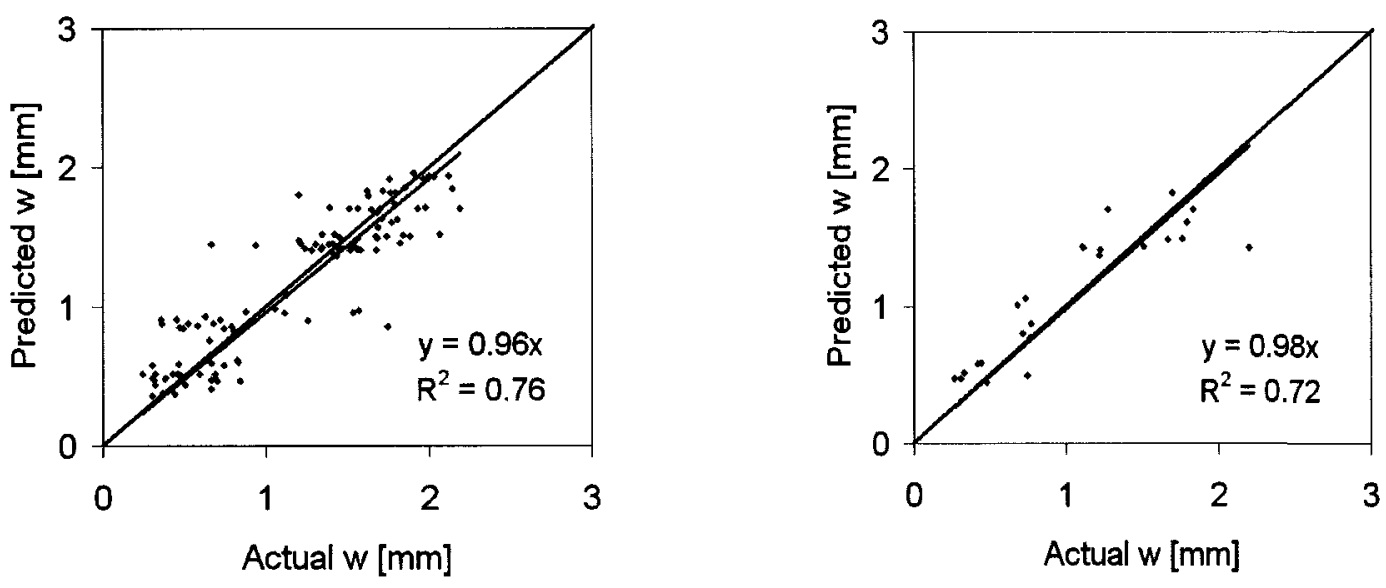

Figure 6.34: Prediction of $w$ at Fmax for training (left) and test (right) dataset
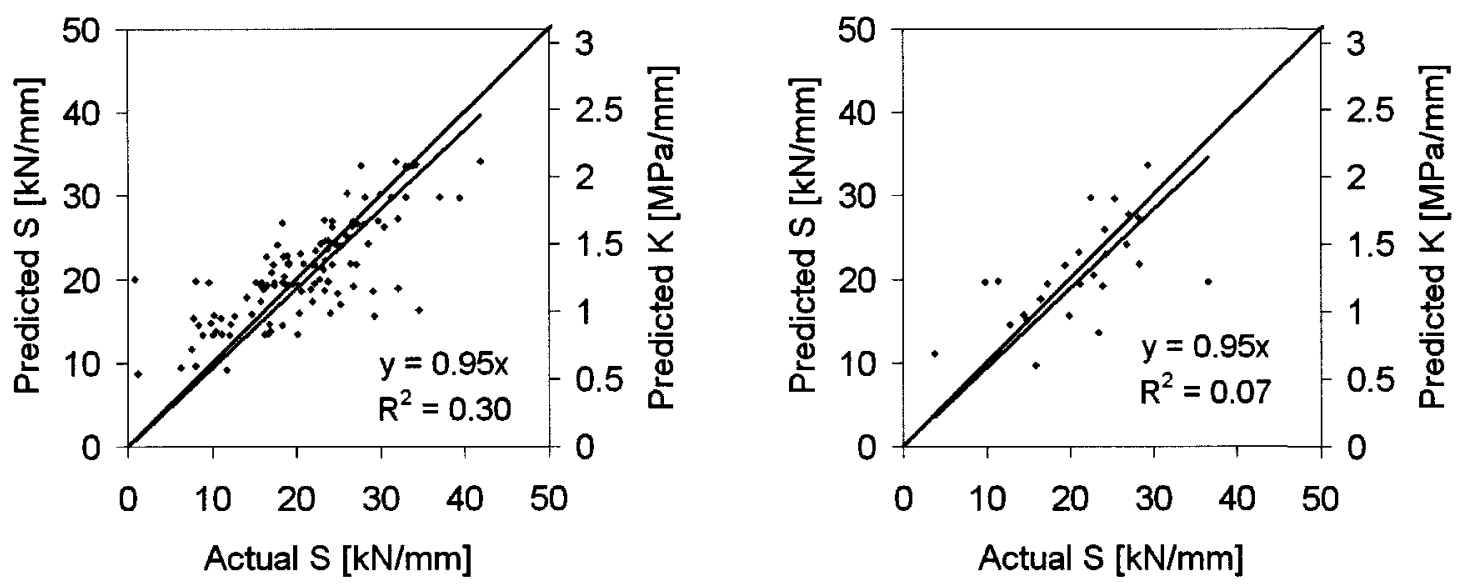

Figure 6.35: Prediction of Smax and Kmax for training (left) and test (right) dataset

Table 6.9 and Figures 5.33 to 5.35 show that for the output variable max. shear force $F_{\max }$ a good and for the output variable shear deformation $w$ at $F_{\max }$ a more or less acceptable prediction with $\mathrm{R}$-squared values of 0.86 and 0.78 is possible, while the output variable max. shear stiffness $S_{\max }$ can only predicted with a $R$-squared value of 0.58. Regarding the linear regression, the slope of the regression line is close to 1 for all output variables, while the regression coefficient for the max. shear stiffness is very low with $\mathrm{R}^{2}$ values of 0.30 (training) and 0.07 (testing). 


\subsubsection{Analysis of relation between actual and predicted values}

Figures 6.36 to 6.38 show the prediction for the 3 output variables using the independent additional query files for validating the network.

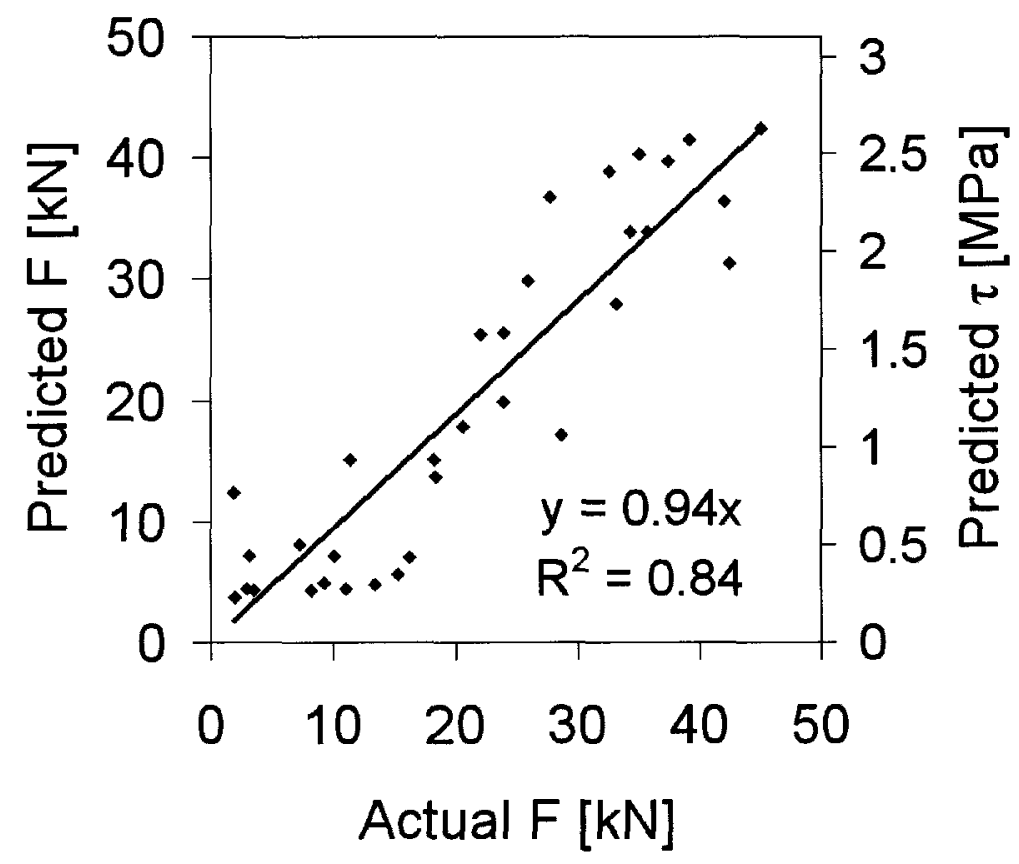

Figure 6.36: Prediction of Fmax and $\tau \max$, for independent query test dataset 


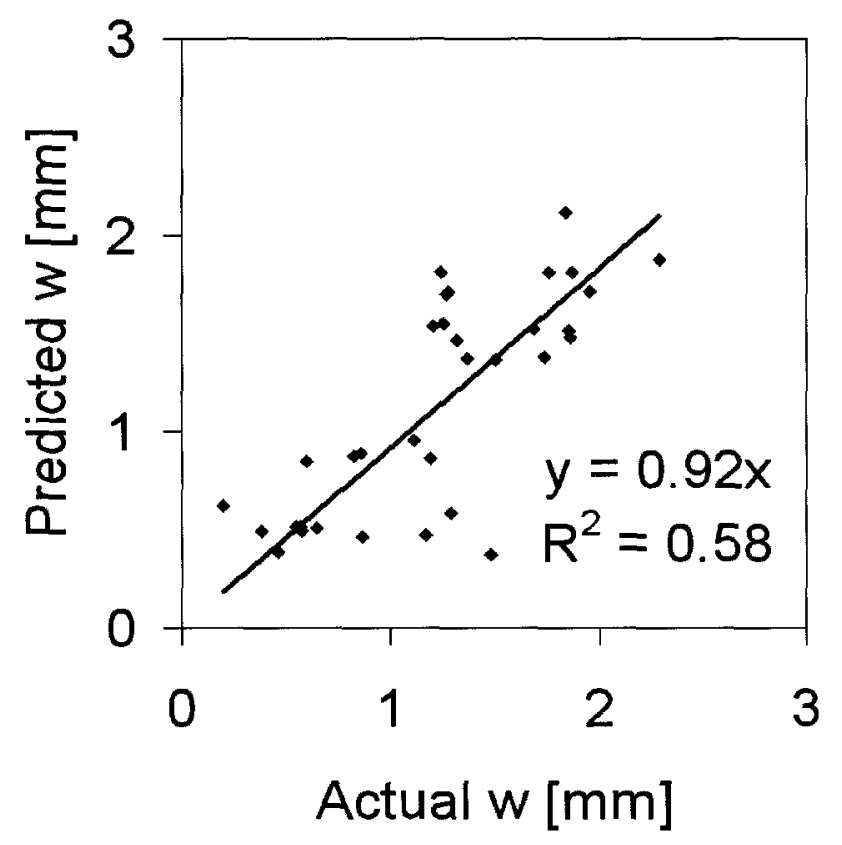

Figure 6.37: Prediction w at Fmax for independent query test dataset

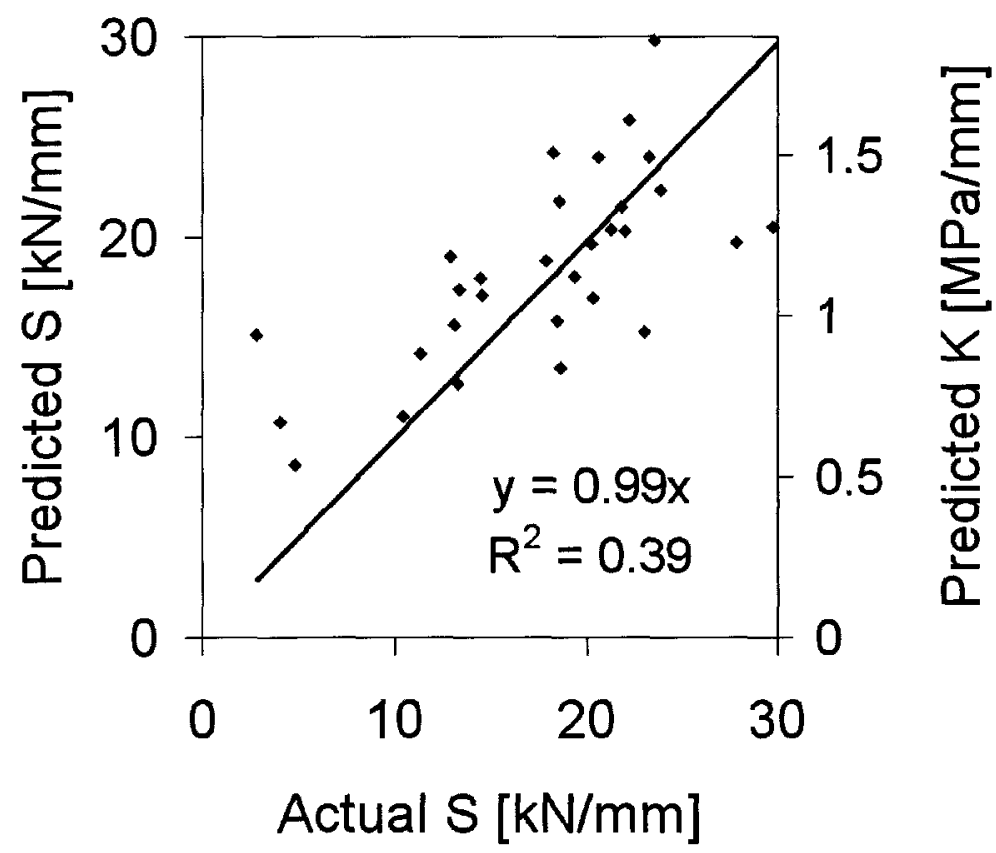

Figure 6.38: Prediction of Smax and Kmax for independent query test dataset 
Similar findings can be drawn from Figures 6.36 to 6.38 . Here, again shear force shows good and shear deformation acceptable correlations with $R^{2}$ values of 0.84 and 0.58 respectively, while the $\mathrm{R}^{2}$ of the linear correlation for the shear stiffness is only 0.39 . Nevertheless, the slopes of the regression lines are close to 1 for all output variables.

Figure 6.39 gives the response graphs for the three numerical input variables, age (a), air void content of the first (b) and air void content of the second layer (c). The mean value for the air void content of the first layer was 4.6 vol- $\%$, and for the second layer 6.3 vol- $\%$.

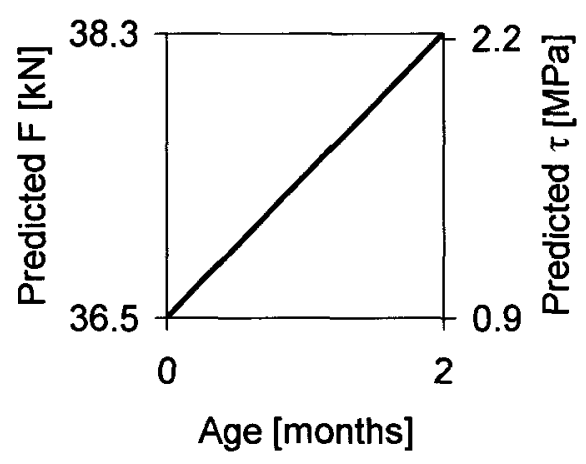

(a) Age [months]

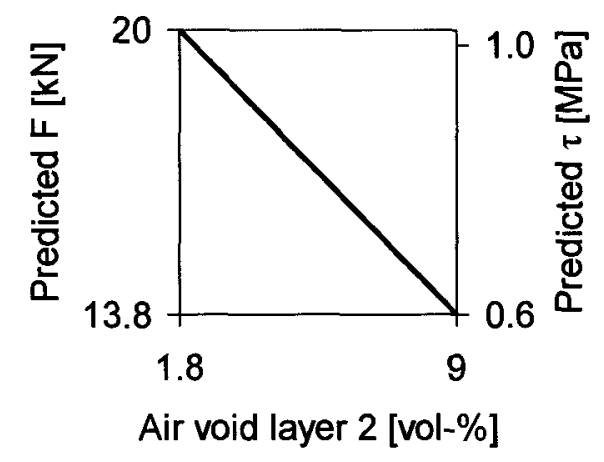

(c)

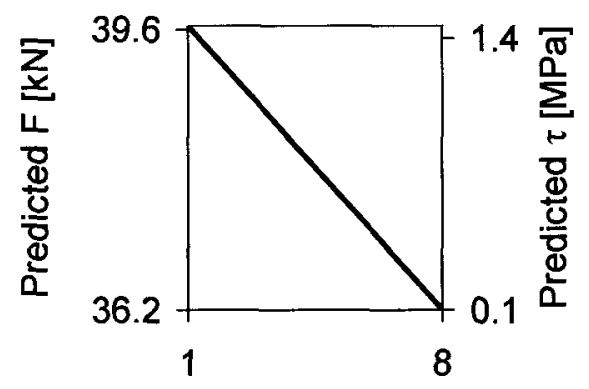

(b)

Figure 6.39: Response graphs of the input variables as a function of max. shear force and max. shear stress: age (a), air void content of the first (b) and air void content of the second layer (c) 
The finding that aging leads to an increase in shear force is in good agreement with the conclusions in the research project on tack coats (Raab and Partl, 2007). For an increase of the air void contents of first layer and second layer the response graphs show also an decrease in shear force. Although in the previous mentioned research project (Raab and Partl, 2007) a direct relationship between air void content and the magnitude of shear force could not be found, in case of high ( 8 to 9 vol-\%) air voids an decrease in shear force was determined.

Figure 6.40 shows the response graph for the input variable age as a function of the maximum shear stiffness and the max. shear reaction modulus.

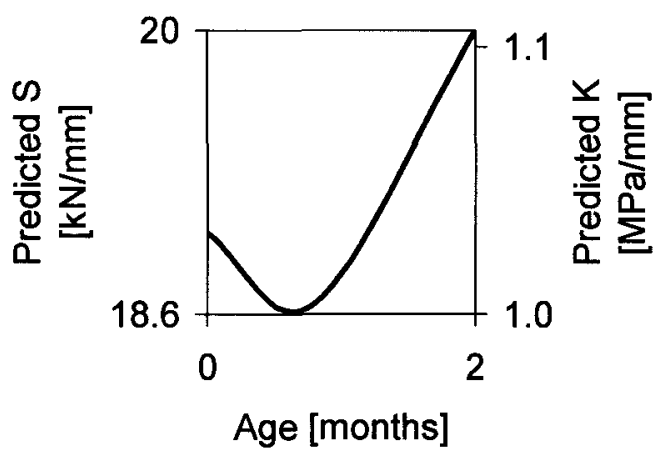

Figure 6.40: Response graphs of the input variable age as a function of max. shear stiffness and max. shear reaction modulus

\subsubsection{Model from RILEM Pavement}

\subsubsection{Determination of input variables}

Since the material in this database is the same for all specimens, the number of material related input variables is very limited. It was only possible to include the air void content 
of both layers which was determined for every single specimen and individual layer. On the other hand, the tests parameters temperature and deformation rate had been varied and therefore could be taken as input variables. Further, the input variables:

- Type of tack coat and

- Age

could be integrated in the evaluation. The reduced database consisted of more than 120 data points. For the additional independent query file data for all test conditions and for all tack coat types were taken. Since every dataset consisted of 7 data points always the last data point was taken for the additional query file.

Table 6.10 shows all input variables for RILEM Pavement:

Table 6.10: Input variables for RILEM Pavement

\begin{tabular}{|c|l|l|}
\hline Index & \multicolumn{1}{|c|}{ Input variable, designation for tables in Appendix A } & Unit/type \\
\hline 1 & Type of tack coat, Tack coat* & categorical value \\
\hline 2 & Age & years \\
\hline 3 & Temperature, T* & ${ }^{\circ} \mathrm{C}$ \\
\hline 4 & Deformation rate & $\mathrm{mm} / \mathrm{min}$ \\
\hline 5 & Void 1, void content of layer $1, \mathrm{AV} 1^{*}$ & vol-\% \\
\hline 6 & Void 2, void content of layer 2, AV2* & vol-\% \\
\hline
\end{tabular}

* abbreviations used in tables in Appendix A 


\subsubsection{Data mining (modelling)}

Network parameter determination

For all three output parameters, the same network architecture with a number of 4 hidden neurons was used. For the other parameters best results were found with a learning rate $\eta$ $=0.2$ for force and stiffness and 0.4 for deformation. The momentum coefficient $\beta=0.9$ was taken for all output variables. The network structure is depicted in Figure 6.41:

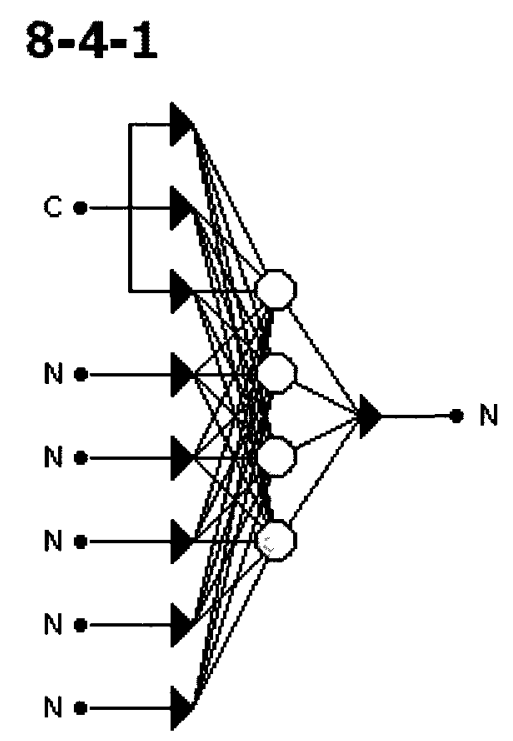

Figure 6.41: Network architecture for RILEM Pavement

\subsubsection{Evaluation}

The results for the prediction of the output values in the ANN program are shown in Table 6.11 . 
Table 6.11: Test results for all output variables for RILEM Pavement

\begin{tabular}{|l|c|c|c|c|}
\hline & Avg. training error & Avg. validation error & Avg. test error & R-squared \\
\hline $\mathrm{F}_{\text {max_red7 }}$ & 1.99 & 2.14 & 2.49 & 0.95 \\
\hline $\mathrm{W}_{\text {max }}$ red7 & 0.31 & 0.35 & 0.47 & 0.82 \\
\hline $\mathrm{S}_{\text {max_red7 }}$ & 2.58 & 3.00 & 3.47 & 0.97 \\
\hline
\end{tabular}

Figures 6.42 to 6.44 (Scatter plots) show the prediction plots of the training and test set for the 3 output variables max. shear force $F_{\max }$, max. shear deformation $w$ at $F_{\max }$ and max. shear stiffness $S_{\max }$.
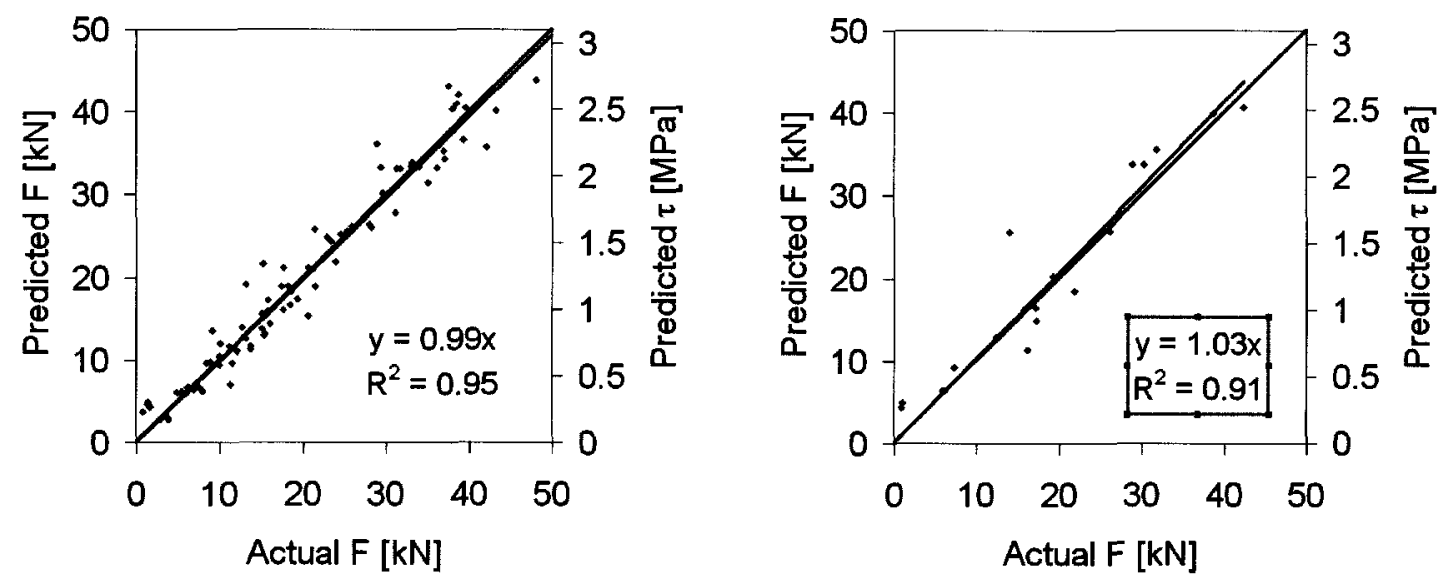

Figure 6.42: Prediction of Fmax and $\tau \max$, for training (left) and test (right) dataset 

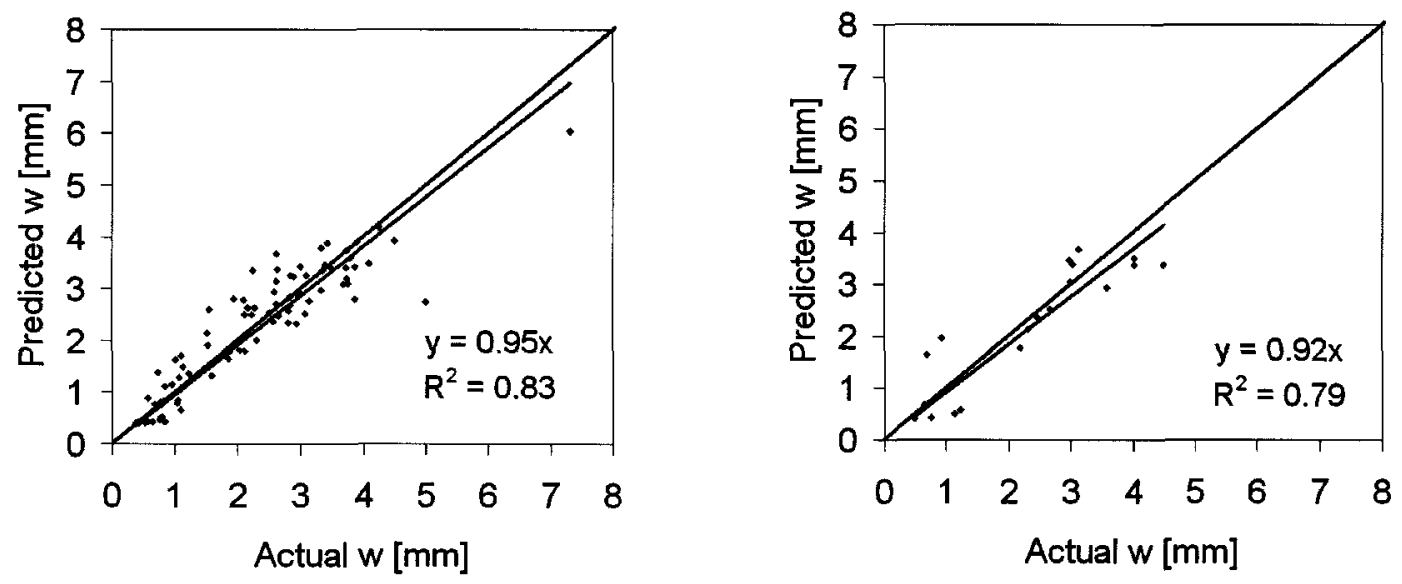

Figure 6.43: Prediction of $w$ at Fmax for training (left) and test (right) dataset
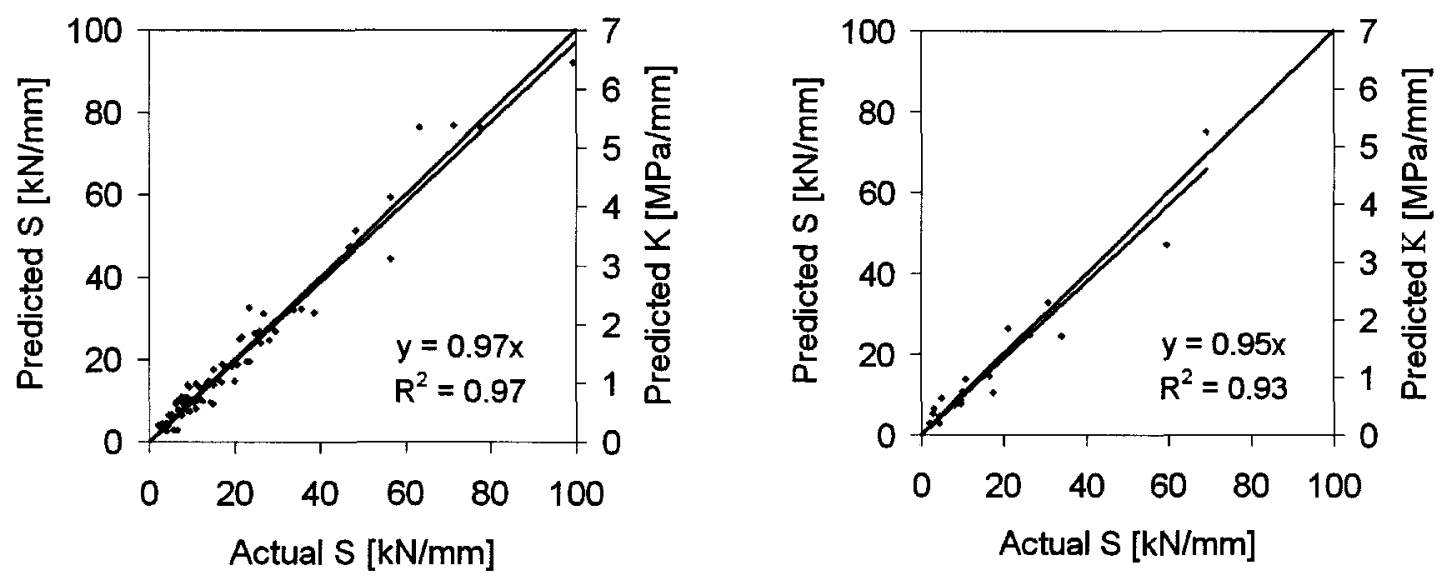

Figure 6.44: Prediction of Smax and Kmax for training (left) and test (right) dataset

Table 6.11 and Figures 6.42 to 6.44 show that for the output variable max. shear force $F_{\max }$ and max. shear stiffness a very good prediction with $R$-squared values of 0.95 and 0.97 is possible. The prediction for the output variable $w$ at $F_{\max }$ is with a $R$-squared value of 0.82 also not too bad. Regarding the linear regression, the slope of the regression line is close to 1 for all output variables, while the regression coefficient for the max. 
shear force and stiffness is very high with $\mathrm{R}^{2}$ values of min. 0.91 and around 0.80 for the max. shear deformation at $\mathrm{F}_{\max }$.

\subsubsection{Analysis of relation between actual and predicted values}

Figures 6.45 to 6.46 show the prediction for the output variables using the additional independent query files for validating the network.

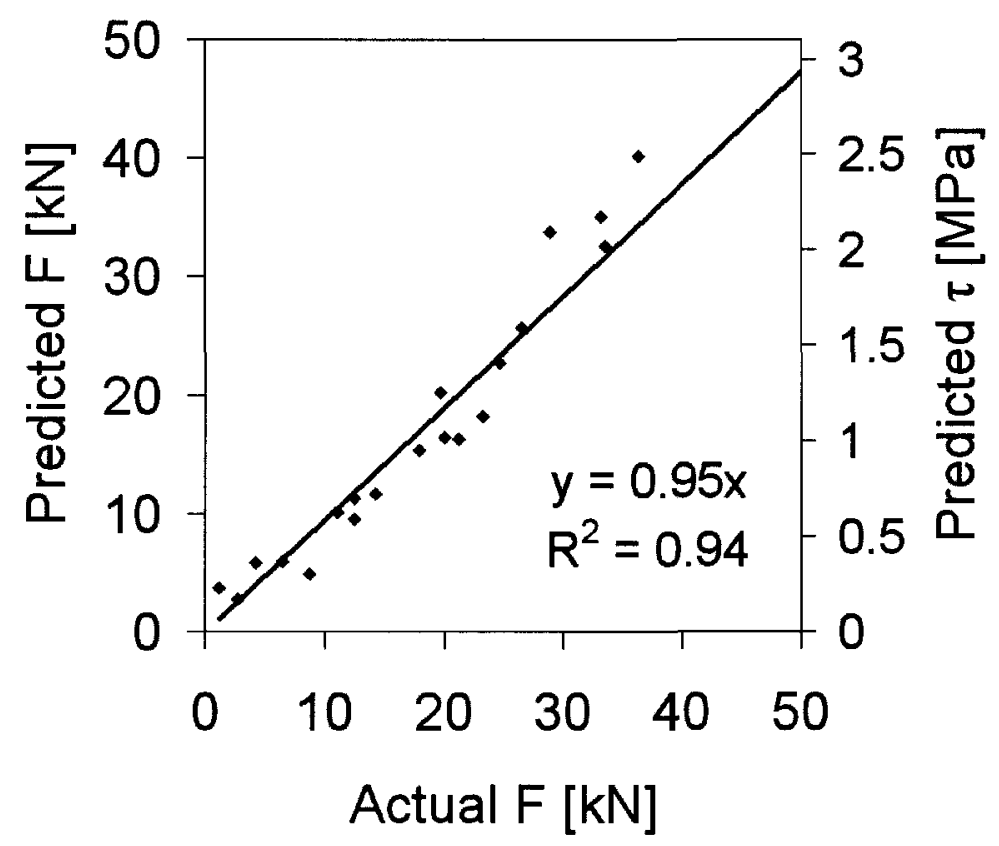

Figure 6.45: Prediction of Fmax and $\tau$ max, for independent query test dataset 


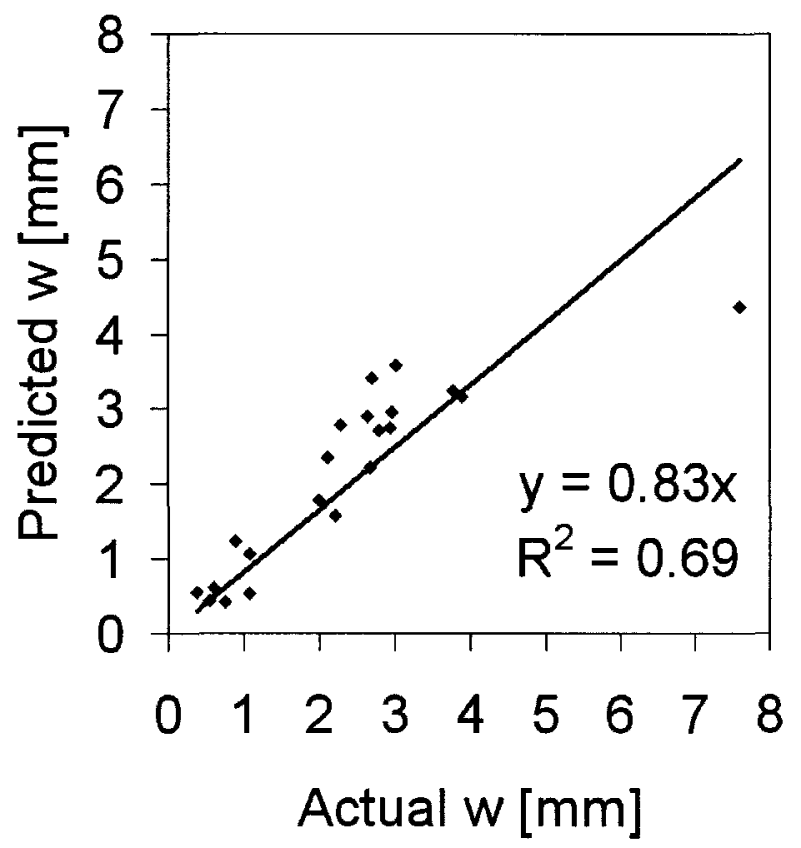

Figure 6.46: Prediction of $w$ at Fmax for independent query test dataset

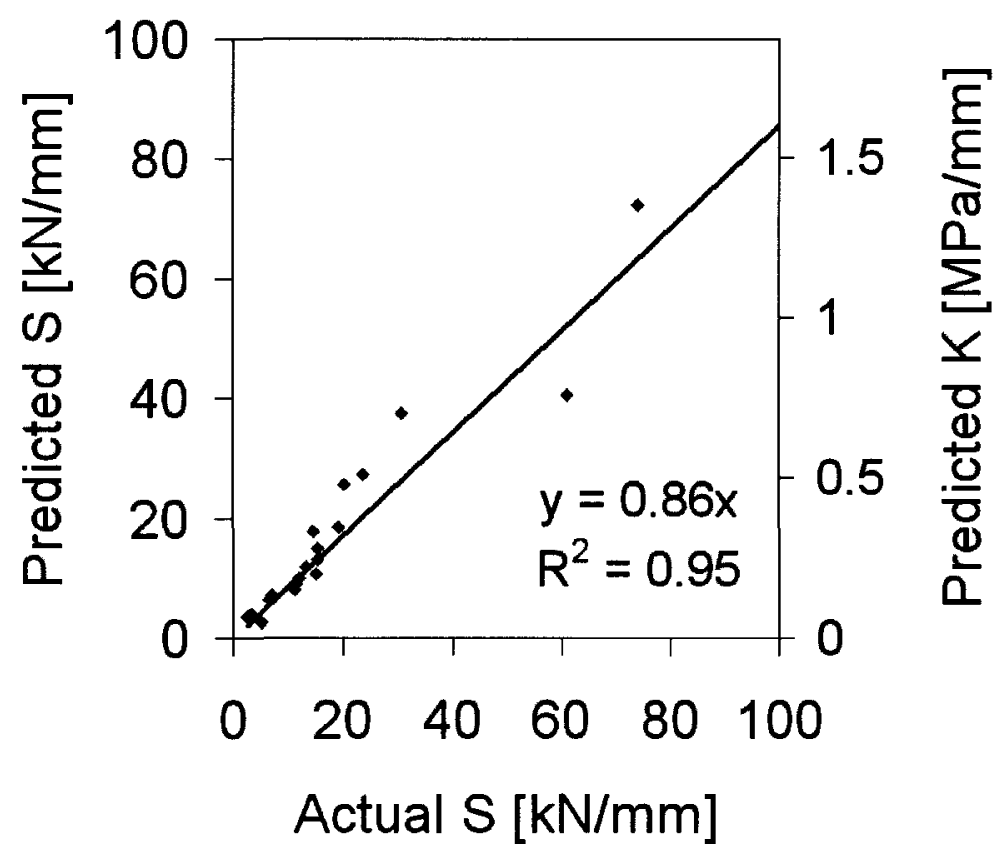

Figure 6.47: Prediction of Smax and Kmax for independent query test dataset 
Similar findings can be drawn from Figures 6.45 to 6.47 . Here, again shear force shows good and shear stiffness give good correlations with $\mathrm{R}^{2}$ values of 0.94 and 0.95 respectively, while the $\mathrm{R}^{2}$ of the linear correlation for the shear deformation is with 0.69 still acceptable. The slope of all regression lines are close to 1 .

Figure 6.48 presents the response graphs as a function of max. shear force and max. shear stress for the three numerical input variables, temperature (a), deformation rate (b), age (c), air void content of the first (d) and air void content of the second layer (e), while Figure 6.49 displays the response graphs as a function of max. shear stiffness and shear reaction modulus for the numerical input variables temperature (a), deformation rate (b) and age (c).

The response graphs for this evaluation are in good agreement with the practical experience. As seen also for the database of New Road, max. shear force and stress decreases with increasing temperature. The study on RILEM Pavement could further show that an increase in deformation rate leads to an increase in max. shear force and stress, a finding that was also observed in the model material investigation and can be explained with the viscoelastic behaviour of asphalt pavements.

The finding, that aging (storage) leads to an increase in shear force is in good agreement with the results from the investigation on cationic tack coats shown in Section 6.2.4. Regarding the air void content, however, the range of investigated air voids is so small that the decrease in shear force is also only marginal.

Similar findings can be drawn from the response graphs in function of max. shear stiffness and shear reaction modulus for the numerical input variables temperature, deformation rate and age (see Figure 6.49). The decrease of max. shear stiffness with 
rising temperature and the increase of max. shear stiffness with increasing deformation rate and age, states earlier findings (Raab and Partl, 2008) and in case of the deformation rate correspond to the evaluations of the idealisation of the bond.

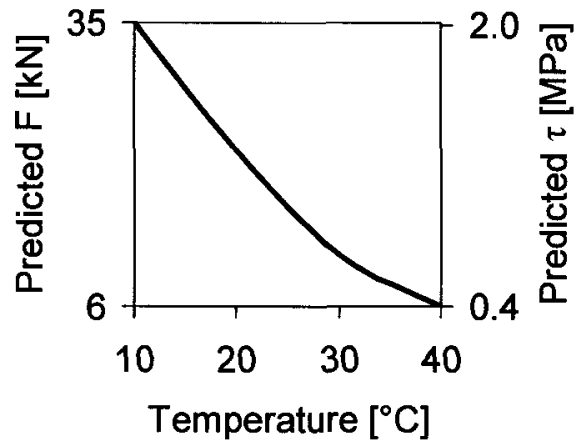

(a)

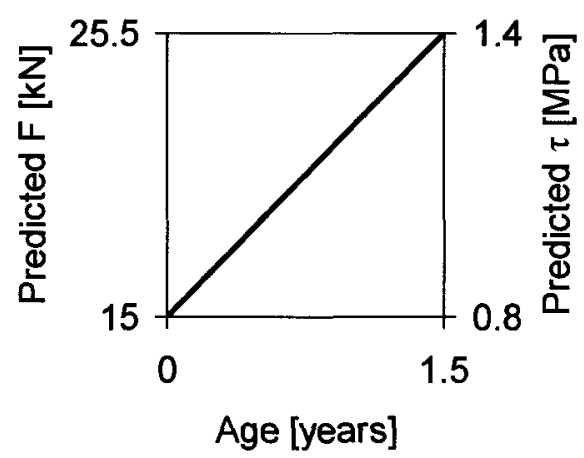

(c)

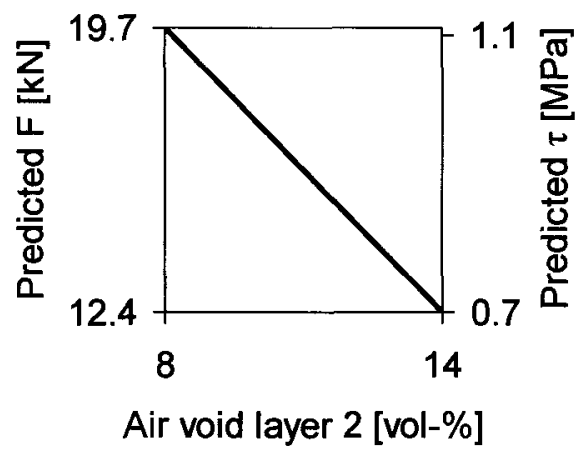

(e)

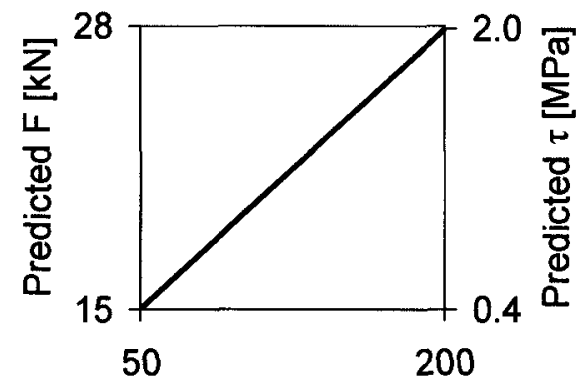

(b)

Deformation Rate [mm/min]

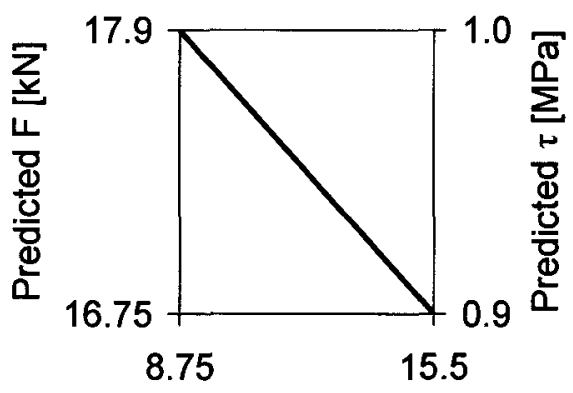

(d)

Figure 6.48: Response graphs of the input variables as a function of max. shear force and max. shear stress: temperature (a), deformation rate (b), age (c), air void content of the first (d) and air void content of the second layer (e) 


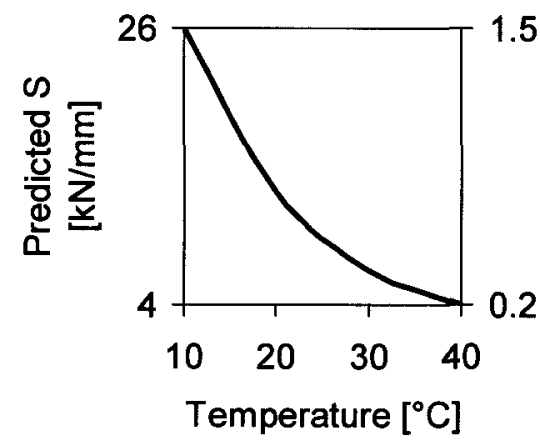

(a)
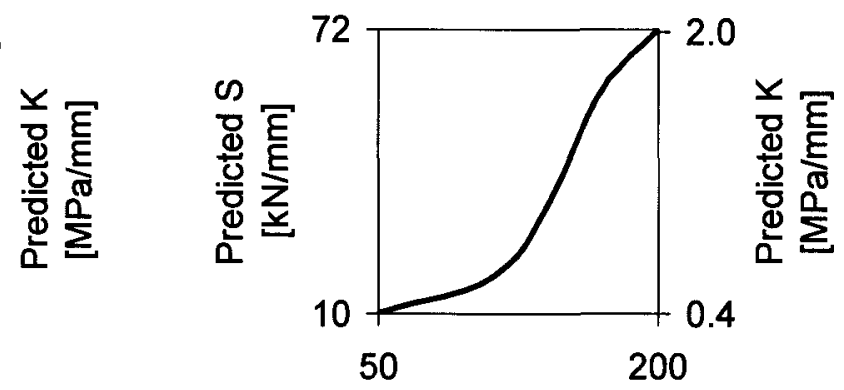

(b)

Deformation Rate [mm/min]

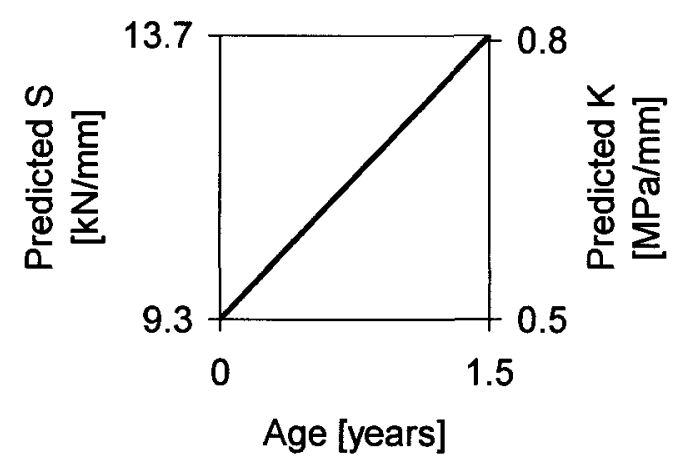

(c)

Figure 6.49: Response graphs of the input variables as a function of max. shear stiffness and max. shear reaction modulus: temperature (a), deform. rate (b) and age (c)

\subsubsection{Comparison between the different datasets}

A comparison between the different databases is not easy because not many of the input variables are identical. A comparison can be done for the input parameters temperature from New Road and RILEM Pavement and for the parameters age from LTPP-Road and RILEM Pavement, although one has to keep in mind that the age differs between 1.5 and 10 years. Further, the air void content of first and second layer can be compared between New Road and RILEM Pavement. Here, it is important to note, that in case of the RILEM Pavement databases the air void content was determined for the same or a very similar 
asphalt type while for the New Road database, the air void content varies over a wide range of material.

Table 6.12 shows the normalised response graphs for the input variables max. shear force and stress as well as the ones for max. shear stiffness and shear reaction modulus.

The normalised response graphs in Table 6.12 show a good concordance for the values between the individual databases. The normalisation on the maximum shear force or shear stiffness visualises the range of the results. In case of increasing temperature generally a decrease of max. shear force and stress can be found. The same applies for max. shear stiffness and reaction modulus. For the parameter temperature, the normalisation visualises the wide range of the results within the database and importance of the parameter temperature and its great influence on the results.

For the parameter age, an increase of output parameters with increasing age seems also logical. Here, the normalisation clearly differentiates between the short term effect in case of Lab pavement and RILEM pavement ( 2 months and 1.5 years) and the long term effect in case of LTPP Pavement (10 years). While for influence of 2 months aging can be neglected the long term aging reveals the importance of the parameter age and its influence on maximum shear stress and shear stiffness. 
Table 6.12: Comparison of normalised response graphs as a function of max. shear force and stress and max. shear stiffness and shear reaction modulus

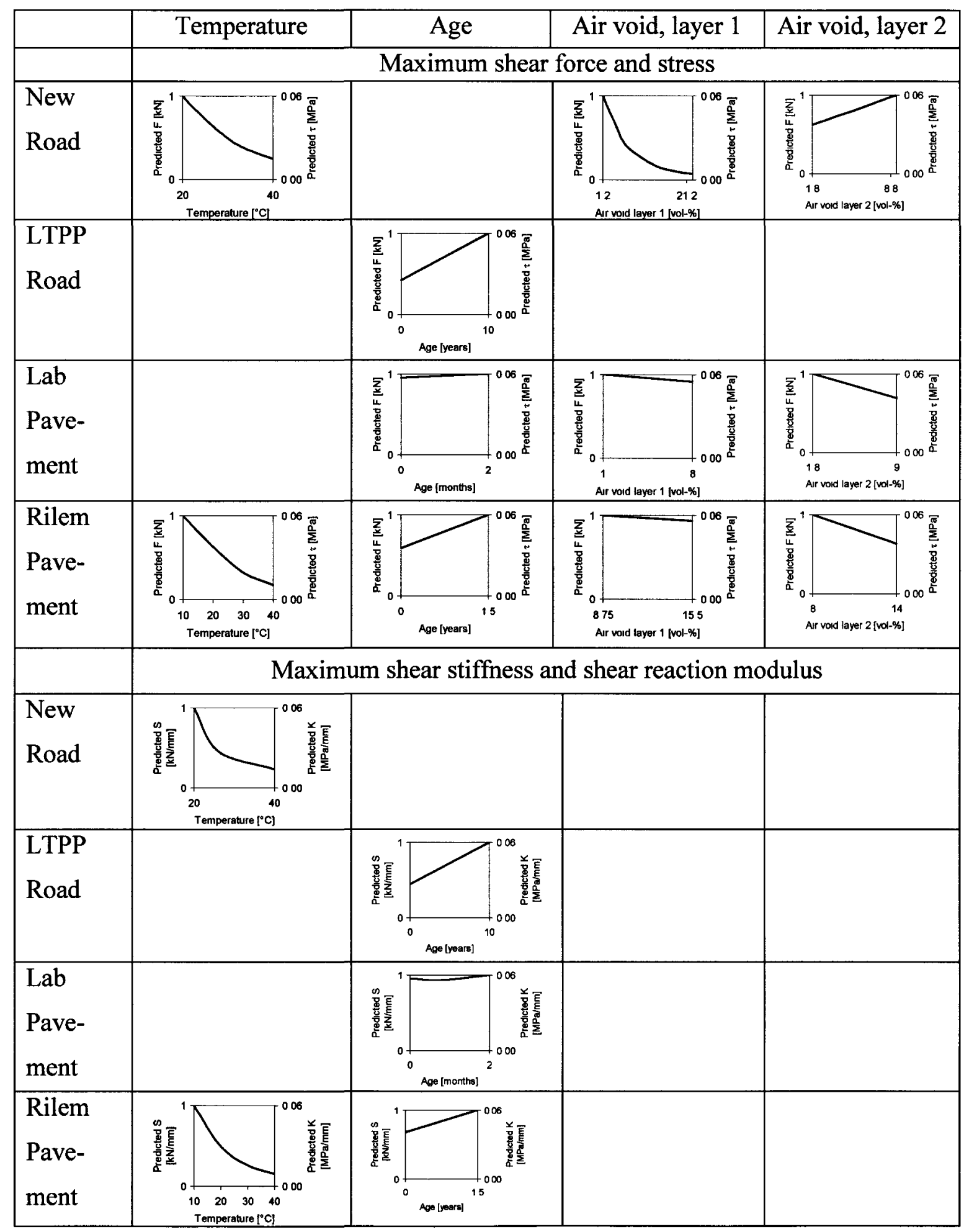


The response graphs for the air void content of the first layer show all the same tendency although in case of Lab and RILEM Pavement the range is very small since the differences in air void content of the first layer is small within the data.

Only, regarding the air void content of the second layer the findings from New Road and Lab Pavement or RILEM Pavement are controversial. Here, it was concluded earlier that the response graph for New Road was not necessarily in agreement with practical findings and that the change in maximum shear force and shear stress for all three databases lies only in a limited range.

\subsubsection{Summary}

The results and findings in this Chapter are presented following the steps of knowledge discovery presented in Table 5.21: Understanding the problem, understanding the data, data preparation, data mining (modelling) and evaluation/interpretation of the results.

\subsubsection{Understanding of the problem}

The goal of the research presented in this Chapter was the prediction of interlayer shear bond properties using artificial neural network (ANN). The study proved that:

1. Despite the huge number of parameters influencing the interlayer bonding, ANN techniques can be used to predict interlayer shear bond properties such as maximum shear force, deformation at maximum shear force and maximum shear stiffness.

\subsubsection{Understanding of the data}

In order to conduct ANN evaluations suitable and large databases are necessary. For the evaluation presented here, five different databases were available and examined for ANN 
evaluation. From this process the following conclusions can be drawn and some recommendations given:

1. Not all investigated databases were suitable for data mining (modelling) with ANN, since the prediction was dependent on the kind of input data in a database.

2. The quality and reliability of the input data could be ensured, since all parameter data had been determined either according to the same standards or with the same procedures and in most cases even with the same laboratory equipment. Hence, the quality of the data was considered comparable.

3. Regarding the data collection, it is therefore essential to pay attention to the quality of data. In case of data collection by different laboratories and institutions the consistency and coherency of data has to be ensured.

4. The collected data have to be relevant, applicable for the investigation and comparable when in case of combining different databases. During this investigation, when combining the database for New Road pavements with the database of LTPP road pavements, the air void content had to be excluded since in one case it was determined for every core, but in the other case it was represented only by a global value.

5. A crucial factor is the amount of data for different sections within a database. Regarding data from Combi Road with different intermediate layers, it could be shown, that a certain number of data points for one characteristic is indispensable of ANN evaluation (see Chapter 5.7.3). 


\subsubsection{Data preparation}

Data cannot be directly taken from the databases, since they have to be prepared for ANN use. Hence, data cleaning is the first step for avoiding both, missing or wrong type values and outliers.

This step of data preparation is important, since the program used in this investigation is not capable of dealing with such values. This means:

1. Good knowledge of the data and their characteristics is needed when performing data preparation and dealing with outliers. For the database of new road pavements, the air void and filler content values for mastic asphalt were determined as outliers because they were found to be just extreme cases in this investigation.

2. In addition, sufficient data for one type of material must be available. Otherwise the ANN is not able to predict the behaviour matching practical experience and real behaviour (see response graphs for filler content for new road pavements).

3. Data scaling is important in order to avoid incompatibility of units among the variables which may affect the model output and its accuracy.

4. Regarding the input variables, in some cases, engineering judgement and practical knowledge is indispensable when choosing the important variables.

5. Data partition has to happen before data mining. According to the findings of this research, it is recommended to create an additional independent query test file. In order to have the most reliable output, the data for this query file should be chosen randomly, but should take into account every investigated characteristic. 


\subsubsection{Data mining (modelling)}

Since it was clear from the beginning that ANN should be used, there was no question regarding the data mining technique. Nevertheless,

1. It is important to choose the best combination of activation function and learning algorithm. For an application of a given ANN program this can be done by trial and error.

2. Regarding the choice of input variables, as mentioned earlier, engineering judgement, should not be neglected. The same applies for the output variables. Output variables have to be selected in such a way that they are depending on the input variables. In this Chapter it was shown, that not all output variables can be predicted with sufficient quality and accuracy. For example, in case of data from New Road, the shear deformation at maximum shear force was less distinct and therefore could not be predicted very well. Whereas for Lab Pavements the shear stiffness and the shear reaction modulus were less predictable.

\section{Data evaluation and interpretation}

Data evaluation was done with the help of an independent query test set for each database. Further, response graphs as offered by the Alyuda Neurointelligence program were used. Overall the following conclusions can be drawn:

1. For most of the investigated databases (four out of five) ANN modelling is an excellent tool for predicting interlayer shear properties such as maximum shear force, shear deformation at maximum shear force and maximum shear stiffness. 
2. Although not all of these shear property parameters performed with the same quality and accuracy, all three properties are valuable and predictable information for interlayer bonding. Overall, max. shear force, shear stress, shear stiffness and shear reaction modulus could be predicted better than shear deformation at max. shear stress.

3. For an evaluation of the response graphs it is important that the range of the investigated input variables is not too small and that their values do influence the output variable apparently.

4. Further, the number of data points with certain variable characteristics have to be big enough to show an influence in the response graphs.

5. Comparing the response graphs of a variable (e.g. temperature, age etc.) for different databases generally shows a good agreement.

The findings and conclusions from the models of the different databases are the following:

\subsubsection{New Road}

1. Regarding the 3 output parameters the best predictions was found for the max. shear force followed by the max. shear stiffness with $\mathrm{R}^{2}$ values of 0.94 and 0.88 for the independent query test set. A prediction for the max. shear deformation was not possible, since the deformation data seemed to be too diverse within the database.

2. The quality of prediction for the independent query database depends on the selection of these data. In order to obtain more valuable information, it is 
recommended to choose the data for an independent query test set randomly and unbiased.

3. The response graphs for the predicted max. shear force and the temperature as well as the air void content of the first layer are in good qualitative agreement with practical experience, while for other variables, due to deficiencies explained above, a connection with practical experience is not possible.

\subsubsection{LTPP-Road}

1. For this database, a combination of New Road with its performance data a prediction of max. shear force and max. shear stiffness is not as accurate as for the first database alone. This results in $\mathrm{R}^{2}$ values of 0.58 and 0.62 . The prediction for the max. shear deformation even becomes better than for the new pavements $\left(\mathrm{R}^{2}=\right.$ $0.42)$

2. The response graphs for the prediction of the max. shear force supports findings from another study (Raab and Partl, 2007, Raab and Partl, 2008) where it was concluded that aging had a positive effect on the max. shear force, while the pavement can deteriorates leading to a decrease in shear force when the average daily traffic and the percentage of heavy vehicles becomes very large.

\subsubsection{Combi Road}

1. For the database from concrete/asphalt pavements with different intermediate layer a prediction for the output variable shear force is not possible.

This result is due to the fact that the database is very small (less than 100 data points) and that the data are not distinct enough regarding certain input variables such as age. Further, not only the number of overall data points is 
limited, but also the number of data for a certain material or test condition is extremely small.

\subsubsection{Lab Pavement}

1. Here, ANN prediction for max. shear force is good resulting in an $\mathrm{R}^{2}$ value of 0.84 for the independent test set, while the prediction of shear deformation at max. shear force with a value of 0.58 and the prediction of max. shear stiffness with an $\mathrm{R}^{2}$ of only 0.39 are more difficult.

2. The result graphs are in good agreement with findings from the research project on cationic tack coats (Raab and Partl, 2007), where aging was found to produce an increase in shear force and shear stiffness.

3. Since this database consisted of data derived from a laboratory study, the material characteristics did not change and therefore could not be taken as input variables, which makes it difficult to have enough independent input variables for ANN modelling.

\subsubsection{RILEM Pavement}

1. In case of this database a very good prediction for the output variables max. shear force and max. shear stiffness, with $\mathrm{R}^{2}$ values of 0.94 and 0.95 was determined. The prediction for and the max. shear deformation was also possible and an $R^{2}$ value of 0.69 was found.

2. The response graphs for the max. shear force confirmed the well known relationship between decreasing temperature and increasing deformation rate with increasing max. shear forces. 


\subsubsection{Overall findings and remarks}

1. As the response graphs from the different databases for the parameters "temperature", "age", "deformation rate", "air void content of the 1. layer" and "traffic" show, the model evaluation is mostly in very good agreement with findings from practical experience and from other research.

2. It is only possible to draw response graphs for numerical but not for categorical input parameters. Therefore, it is helpful to collect numerical instead of categorical parameters or to convert categorical parameters into numerical. 


\section{CHAPTER 7}

\section{Conclusions and Recommendations}

\subsection{Introduction}

The main objective of this thesis was to develop a framework for the standardisation of the interlayer bond between asphalt layers. Figure 7.1 shows a flow chart of the developed framework.

In order to develop such a framework it is essential to understand the mechanisms that govern the interlayer bond. In the research presented in the thesis this was done with an extensive literature review followed by a comprehensive experimental modelling by using an idealised model material.

From theses investigations it was found that for laboratory testing; the direct shear device was preferable over other methods such as torque testing. Regarding the relative aggregate size a combination of small aggregates in the top layer and bigger aggregates in the bottom layer was found to be most beneficial for the bond strength.

Furthermore, the effects of the critical parameters have to be determined and quantified. This objective was achieved during an parametric experimental study which investigated the effect of moisture, temperature and the gap width between the shearing rings on the bond strength. 


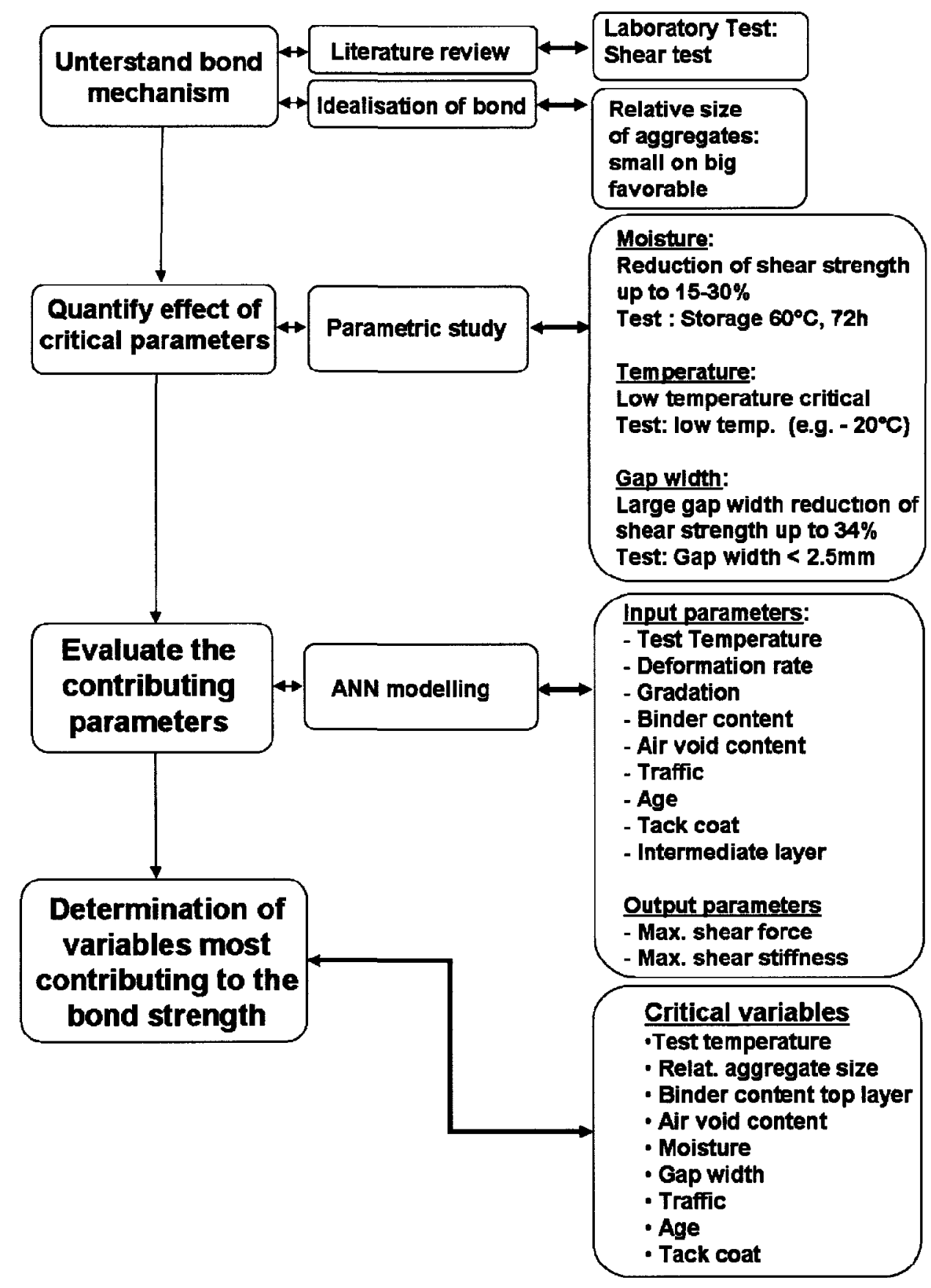

Figure 7.1: Developed framework for standardisation of interlayer bond of asphalt pavements 
Moisture was found to reduce the bond strength between 15 and $30 \%$. Since the reduction is governed by the water storage temperature and duration, this thesis suggests that testing should be done after $72 \mathrm{~h}$ of water storage at a temperature of $60^{\circ} \mathrm{C}$. Low temperature was detected to be critical, especially in case of weak bond and bond defects. Therefore, this thesis suggests as part of the testing standards to consider additional testing at low temperature (e.g. $-20^{\circ} \mathrm{C}$ ). Large gap width between the shearing rings resulted in shear strength reductions up to $34 \%$. This thesis therefore, proposes a maximum gap width between the shearing rings of $2.5 \mathrm{~mm}$.

After understanding the mechanisms and the effects of the critical parameters, a predictive model (ANN modelling) was used to evaluate the contributing variables and to predict their influences on the bond.. It was found that using the input variables listed in Figure 7.1 the output variables i.e., maximum shear force and maximum shear stiffness can be predicted with sufficient accuracy.

Subsequently, the results show that the variables most contributing to the shear strength are the following:

- Test temperature

- $\quad$ Relative aggregate size

- $\quad$ Binder content

- $\quad$ Air void content

- $\quad$ Moisture

- $\quad$ Gap width

- $\quad$ Traffic

- $\quad$ Age 
- Tack coat

Furthermore, the following conclusions and recommendations are supported by the results and analysis provided earlier.

\subsection{Literature Review}

- The interlayer bond between the layers of asphalt pavements has to be strong in order to minimise stresses and strains and to prevent layers from sliding on one another leading to pavement failure.

- The fact that good bond between the layers of an asphalt pavement is a key factor for durable and long-lasting pavements has become more widely accepted during recent years and led to interlayer bond testing as a subject of study and the development of many different test methods and procedures to evaluate the bond between pavement layers over the last decades.

- The results of the literature review suggested that laboratory shear testing provides a good and effective method to determine the interlayer bond of asphalt pavements, whereby direct shear test devices are commonly preferred to torque test devices.

- For the construction of test devices, it is important to keep the test set-up and the installation of test specimens simple and straight forward. 
- For the comparison of different test devices, it is indispensable that test parameters, such as torque moment and deformation rate or normal load, and test set-ups are comparable.

- $\quad$ Torque test devices are found to offer a good possibility for in situ testing and testing of thin asphalt surfaces, which is rather difficult with direct shear testing.

- It is important to compare the test results of interlayer shear bond with outcome of different devices and methods in a detailed and careful way. Inter-laboratory testing, such as the recently performed by RILEM is considered an excellent tool for promoting standardisation and normalisation internationally.

\subsection{Interlayer shear data and properties}

- It is helpful to consider other interlayer shear bond properties (e.g. max. shear stiffness, fracture energy etc.) instead of maximum values of shear force, since the interlayer shear behaviour in reality can not be characterised when total damage occur which may lead to bond failure. Clearly, the stiffness provides a better means to estimate the bond especially at relatively small deformations values. The quality and accuracy of any evaluation or modelling attempt such as the utilisation of the ANN technique in modelling or other evaluations depends very much on the availability and accessibility to reliable and complete databases, containing information on material characteristics, pavement construction, test conditions and other important parameters. 


\subsection{Utilisation of Artificial Neural Network ANN for the Analysis of Interlayer Shear Properties}

- $\quad$ ANN techniques can be used to predict interlayer shear bond properties such as maximum shear force, deformation at maximum shear stress, and maximum shear stiffness. The ANN models developed in this thesis are able to predict maximum shear force and shear stiffness with a reasonable accuracy. The predictions can be improved by increasing the quality and quantity of the database. Another advantage of ANN method is that when data from other sources are compatible with the databases used in this work, including such data to the present one will enhance the prediction abilities of developed ANN models.

- It is important to note that interlayer bond properties can not be predicted with the same quality and accuracy when ANN is utilised. Maximum shear force can be predicted best, followed by maximum shear stiffness, while shear deformation at maximum shear stress is a less representative of the bond property. The results of this investigation showed that indeed not all databases are suitable for data mining (modelling) with ANN due to their limited quantity and poor quality.

- It is useful to ensure the quality and reliability of the input data by determining all data parameters either by following the same standards or applying the same test procedures.

- $\quad$ Engineering judgement and practical knowledge are indispensable when choosing the important variables for using the ANN technique. Therefore, plausibility checks are necessary. 
- According to the findings of this research, it is recommended to create an additional independent query test file. In order to have the most reliable output, the data for these query files should be chosen randomly, but taking into account every investigated characteristic, such as different materials, different temperatures or intermediate layers etc.

- For reliable use and application of the response graphs it is important to consider variables with realistic ranges. Also, ensure that their values will have measureable influence on the predicted output. Furthermore, the number of data points describing certain variable characteristics must be large enough to show an influence in the predicted response graphs. Based on the research carried out in this thesis, it is recommended to have at least 10 data point for each input variable and variable characteristic.

- It was noted that when the above mentioned requirements were fulfilled, comparison of the response graphs of variables (e.g. temperature, age etc.) for different databases generally gave good agreement with practical and experimental findings from other research results.

\subsection{Idealisation of the bond}

- The test results showed that the bond between asphalt pavement layers does not depend only on the adhesion properties of the binder but also on the interlock and therefore on the geometrical surface conditions of the interface between the two layers. The idealised model material which consisted of steel balls (representing 
the aggregates) filled with $10 / 20$ penetration graded bitumen showed that it is possible to determine a clear ranking in terms of shear force or bond performance for the four different steel ball combinations. This conclusion is very important since it provides useful information concerning best design practice for enhanced bond properties.

- The results of the LPDS testing showed that the highest bond values are received for the combination small/big (Ø5 mm and $\varnothing 10 \mathrm{~mm}$ steel balls), where good interlocking between the steel balls was observed. Secondly, the combination small/small followed, while the combinations big/big and big/small achieved the lowest bond results. This ranking remains the same when testing is performed at a significantly lower deformation rate of $2.5 \mathrm{~mm} / \mathrm{min}$. These results suggest that an optimal combination of adhesion and interlock is able to enhance the bond and provide better bond properties than interfaces dominated by either adhesion or interlock.

- Shear Box and LPDS testing led to a similar ranking of the maximum shear forces for the different steel ball combinations. But their shear force - shear deformation curves were totally different, revealing a different shear mechanism. While in the LPDS test failure occurred suddenly, leading to an immediate drop of the shear force, failure in the Shear Box test developed more gradually. Typical for Shear Box tests the force still remained at a residual value after the peak (maximum) had been reached. Both tests are laboratory tests which do not fully cover the 
actual situation of a real pavement. But each test reflects a different situation and stress mode that can be found on a real road.

- The results of comparing the shear force values obtained from both test methods for the different combinations showed that Shear Box test results in the case of the combination of $\mathrm{s} / \mathrm{b}$ was $20 \%$ higher than the value obtained from LPDS testing. On the other hand, the Shear Box test results for the combination s/s were slightly lower than those obtained from the LPDS testing, while the results of the combination $\mathrm{b} / \mathrm{b}$ both test methods gave similar results which were in very good agreement.

- The ranking of the bond properties, i.e. the maximum shear force, for different steel ball combinations obtained by LPDS testing is in agreement with a ranking based on simple geometrical and optical evaluations.

\subsection{Influence of moisture on the interlayer bond of asphalt pavements}

- As expected water conditioning at $40^{\circ} \mathrm{C}$ or $60^{\circ} \mathrm{C}$ has a negative effect on the interlayer shear bond leading to reduced shear force and shear stiffness.

- $\quad$ For $72 \mathrm{~h}$ water conditioning at $40^{\circ} \mathrm{C}$ the reduction in shear force and shear stiffness at the investigated pavement interfaces (SMA/AC and MR/AC) was found to be between $2 \%$ and $20 \%$ respectively $0 \%$ and $15 \%$, while $72 \mathrm{~h}$ water conditioning at $60^{\circ} \mathrm{C}$ led to reductions in shear force of $15 \%$ to $25 \%$ and in shear stiffness of $14 \%$ to $30 \%$. 
- For pavements with an upper layer air void content of about 5 vol-\% the largest reduction in shear force and shear stiffness up to more than $30 \%$ can be found for a $5 \mathrm{~h}$ water conditioning combined with a pressure of $0.05 \mathrm{MPa}$.

- For pavements with an upper layer air void content $>10$ vol-\%, 5h water conditioning combined with a pressure of $0.05 \mathrm{MPa}$ is a less serve treatment since it allows the applied pressure to be released through the air voids. For these pavements this treatment has a similar effect on shear force and stiffness as $72 \mathrm{~h}$ water conditioning at $40^{\circ} \mathrm{C}$. In order to achieve an influence comparable to the pavements with dense upper layers the cores need to be sealed during the conditioning.

- In order to avoid cumbersome specimen preparation and difficulties with variable air void contents, it is recommended to test the influence of water conditioning on the interlayer shear properties after $72 \mathrm{~h}$ water storage at $60^{\circ} \mathrm{C}$ and not using pressure.

\subsection{Influence of low temperature on interlayer bonding}

- The investigation confirms that shear testing is highly temperature dependent, in which testing at high temperature leads to lower shear force and stiffness values whereas lower temperatures generally result in higher values.

- Shear force and in most cases shear stiffness values are higher when testing was performed at a temperature of $0^{\circ} \mathrm{C}$ compared to a temperature of $-20^{\circ} \mathrm{C}$. 
- The ranking of shear force and shear stiffness for different interlayers was found to change when tested at $-20^{\circ} \mathrm{C}$ instead of $+20^{\circ} \mathrm{C}$. Further, interlayer bond defects or weaknesses seem to appear more obvious when testing is performed at very low temperature of $-20^{\circ} \mathrm{C}$, therefore bond testing at one temperature $\left(20^{\circ} \mathrm{C}\right.$ as requested for Leutner shear testing) may not be sufficient and additional testing at low temperatures should be considered in the standards in case of ambient temperature only.

- The investigation supports the results from earlier studies (Raab and Partl, 2008) that the interlayer bond properties such as shear force and stiffness of intact and well designed asphalt pavements increase over time. Hence, traffic, not exceeding the design limits, lead to higher shear forces for a trafficked pavement compared to an untrafficked one.

\subsection{Influence of the gap width between the shearing rings on interlayer shear bond testing}

- For interlayer bond testing, the gap width between the shearing rings of the Leutner device has an influence on the interlayer shear test results, especially in cases when the material characteristics of the two layers were different. Here, an increasing gap width was found to decreasing maximum shear force and shear stiffness value up to $34 \%$. If the layer material characteristics are similar the gap width is less important.

- $\quad$ By increasing the gap width, shear eccentricity increases resulting in a combined bending-shear force situation. With increased gap width, the shear plane becomes 
less defined and failure tended to occur at the weakest point rather than at the exact interface. Therefore, regarding a standardisation of interlayer shear testing a gap width of $5 \mathrm{~mm}$ leads to results which reflect combined in-layer and interlayer properties.

- In case of good interlock the influence of the gap width is small. On the other hand this means that in cases of comparatively poor interlayer bond, the gap width may well influence the results and can therefore not be ignored. Standardisation should therefore opt for narrow gap width tolerances of $2.5 \mathrm{~mm}$ or less.

- In order to simplify and optimise the testing (more tolerance in the shear plane and less difficulty to perfectly align the interface to the shear plane, especially for specimens having irregular interfaces) a gap width slightly larger than $0 \mathrm{~mm}$ and up to $2.5 \mathrm{~mm}$ is considered acceptable.

\subsection{Summary}

The findings of this research provide important guidelines for pavement engineers and researchers who are attempting to develop effective methods and procedures for reducing rutting, surface cracking and other distress modes observed in the field. Furthermore, current design methods do not consider the contribution of the bond between layers on the long term performance due to lack of data and information on the subject. Clearly, the research presented in this thesis provides useful information related to how the bond will influence the long term performance of the roads. 
The main objective of this thesis was to develop a framework for the standardisation of the interlayer bond between asphalt layers. This objective could be obtained as summarised below:

- Performing a comprehensive experimental investigation to measure the interlayer bond generated a unique and huge database for the interlayer shear bond of asphalt pavements.

- Using this database made it possible to analyse and predict the relationship between the measured bond and the critical influencing factors. The ANN models developed in this thesis are able to predict the bond values with a reasonable accuracy. In the framework for standardisation another advantage of the applied ANN method is that when data from other sources are compatible with the databases used in this work, including such data to the present one will not only enhance the prediction abilities of developed ANN models but will allow other researchers or professionals to use them. This fact will encourage the application of artificial intelligence tools and emphasise the importance of artificial intelligent modelling and data collection for the field of pavement engineering.

- The phenomenological understanding of the mechanisms of interlayer bonding in terms of the geometrical surface conditions of the interface could be improved by using a model material. Test results reveal a direct influence of geometrical surface conditions and aggregate size combination on the quantity of the shear bond and give a clear ranking of bond values. 
- The parameter study in testing program 2 was able to quantify the influence of some of the most influencing factors such as moisture, temperature and gap width. Here, moisture and very low temperatures $\left(-20^{\circ} \mathrm{C}\right)$ were detected to be critical for the interlayer bond weakening the structure resulting in a decrease of the bond properties.

- The evaluation of the datasets used for the data mining investigation showed that the influence of age and traffic is beneficial for the shear bond, as long as the traffic volume does not exceeding the design limits causing damage to the pavement.

- The test results from semi rigid asphalt/concrete pavement with intermediate layers proved the intermediated layer to be responsible for weakening the bond between the pavement layers.

- Regarding the information for standardisation, it was shown that the construction of test equipment has a direct influence on the quantity of the measured bond. Here, a gap width between the shearing rings of less than $2.5 \mathrm{~mm}$ was found to be best for testing.

\subsection{Recommendation for future research}

Regarding the further development of interlayer bond testing, standardisation and normalisation on an international level, it is crucial to come to commonly accepted and evaluated test methods and procedures. Since, different countries have been developing and using their own test devices and set-ups over a long period of time, the discussion on 
the most suitable ones should be encouraged. Research is therefore needed not only for establishing and developing common standards and methods but also, to improve the phenomenological understanding of the mechanisms in interlayer shear testing. The results and conclusions presented in this thesis emphasised the importance of comparing the results obtained from different test methods and the need to carefully evaluate specific test configurations such as the gap width between the shearing rings.

Concerning the phenomenological understanding of the mechanisms of interlock in interlayer shear testing, further studies have to investigate the question of "the" optimum aggregate combination as an optimisation of the combination small/big in more detail. In further studies this should be done combining experimental tests and theoretical modelling (e.g. discrete element method).

It is important to note, that it will not be possible to transcribe the findings with the model material from this study to asphalt specimens on a 1:1 scale. On the one hand, the ideally round and one-size steel balls are different than the graded, crushed mineral aggregates, on the other hand the hard binder properties are different to those of the mastic composed of binder and filler in a real mix. Nevertheless, it will be of great interest to compare the results with the findings from real asphalt pavements. Having said this, it is recommended to investigate the influence and impact of an optimum aggregate combination between two layers using real asphalt mixes instead of model material. In a first step it is recommended to do the testing for a mastic (filler and binder) material.

The parameter study on the influence of moisture and temperature on the interlayer bonding provided first results taking into account only a limited amount of data. Here, further investigations have to be conducted in order to confirm the findings 
and to decide if additional interlayer bond testing should be conducted at temperatures other than $20^{\circ} \mathrm{C}$.

The aim of this study was not only to predict results for interlayer bond problems using artificial neural network modelling, but it was also to emphasise the importance of artificial intelligent modelling and data collection for the field of pavement engineering, especially interlayer bonding. In this context, definitely more research and effort is needed, so that openly accessible databases will be available and might provide a basis for future artificial intelligence modelling.

The objective of the present study was to perform laboratory testing to measure the bond between asphalt layers and establish. In future research it is important to relate the bond values to the performance of real pavements. Therefore it is of great interest to determine the shear between the pavement layers under different climatic conditions and for different traffic situations using in situ measurements of the relative movements between the pavement layers. It is important to consider that interlayer bonding on real roads is influenced not only by climate and traffic, but also by the geometry of the road. Therefore the interlayer bond is more critical for curves, slopes or acceleration/braking sections (i.e. before traffic lights), when the impact of traffic induced shear becomes even more relevant. Compaction of the pavement is another crucial factor. In this thesis it could be clearly demonstrated that moisture penetrating into the pavement through construction or service induced cracks leads to a weakening of the pavement. Future studies should further investigate such effects and demonstrate how insufficient bond can lead to pavement damage in form of cracking and rutting and how better bonding can be achieved when compaction and construction is paid more attention. In this context the 
influence of pavement reinforcement in form of intermediate layers between the layers of asphalt pavements which was found to be critical for good bond values also need further investigation. 


\section{References}

Abd El Halim, A.O., Rickards, I., Haas R., Nabi, R. 1997. Evaluation of Design and Construction Effects on Asphalt Pavement Performance through a Portable In-

Situ Shear Test Device. $8^{\text {th }}$ International Conference on Asphalt Pavements, Volume 2, pp 1311-1327.

Abd El Halim, A.O. 2004. An In-Situ Shear Test Facility for Asphalt Concrete Pavements. NCHRP IDEA Project \#87 Final Report, 2004.

Abraham, A. 2005. Artificial Neural Networks. Handbook of Measuring System Design, edited by Peter H. Sydenham and Richard Thorn.@2005 John Wiley \& Sons, Ltd. ISBN: 0-470-02143-8.

Ascher, D., Wellner F. 2007. Untersuchungen zur Wirksamkeit des Haftverbundes und dessen Auswirkungen auf die Lebensdauer von Asphaltbefestigungen [Investigation of the effectiveness of bonding and its influence on the service life of asphalt pavements]. Technical University of Dresden, Germany, Report No. $13589 \mathrm{BR} / 1$.

Birgisson, B., Roque R., Page, G. 2003. Evaluation of water damage using hot mix asphalt fracture mechanics AAPT proceedings.

Bocci M., Canestrari F. 1997. Influence of the old pavement surface conditions on the effectiveness of tack coat emulsions. $2^{\text {nd }}$ World Congress on Emulsions, Bordeaux, France.

Bondt de, A.H. 1999. Anti-reflective Cracking Design of (Reinforced) Asphaltic Overlays. PhD. Thesis, Delft University of Technology. 
Brown A. 1991. Nerve Cells and Nervous Systems, Springer-Verlag, Berlin, Germany.

Canestrari, F., Ferrotti, G., Partl, M.N. Santagata, E. 2005 Advanced Testing and Characterization of Interlayer Shear Resistance. Transportation Research Record No. 1929, pp 68-78, Washington D.C., USA.

Canestrari F., Santagata E. 2005. Temperature effects on the shear behaviour of tack coat emulsions used in flexible pavements. International Journal of Pavement Engineering, Vol. 6/1, pp 39-46.

Choi, Y., Collop, A., Airey, G., Elliot, R. 2005. A comparison between interface properties measured using the Leutner test and the torque test. Journal of Association of Asphalt Paving Technologists, Vol. 74B. ISSN 1553-5576.

Choi, Y., Sutanto M., Collop, A., Airey G. 2005a. Bond between asphalt layers. Project Report to the UK Highways Acency, Scott Wilson Pavement Engineering LtD.

Crispino, M, Festa, B, Giannattasio, P, Nicolosi, V. 1997. Evaluation of the interaction between the asphalt concrete layers by a new dynamic test. $8^{\text {th }}$ International Conference on the Structural Design of Asphalt Pavements. Washington State University, Seattle, pp 741-754.

Diakhate, M., Phelipot, A., Millien, A., Petit, C. 2006. Shear fatigue behaviour of tack coats in pavements. Road Materials and Pavement Design Vol. 7, pp 201-222.

Diakhate, M., Millien, A., .Phelipot-Mardelé A., Pouteau, B., Goacolou, H. 2007. Comparison of direct shear and torque tests for determining viscoelastic behaviour of tack coats. International Conference of Advanced Characterisation of Pavement and Soil Engineering Materials, Athens, Greece. 
Di Benedetto, H., de la Roche, C., 1998, State of the art on stiffness modulus and fatigue of bituminous mixtures. Rilem Report No. 17, Bituminous Binders and Mixes, edited by L. Francken.

EMPA-Test Report No. 51872, 1985, (not for public use)

Engelbrecht, A. P. 2007. Computational Intelligence: An Introduction, Wiley.

Erb, R.J., 1993. Introduction to backpropagation neural network computation. Pharm. Res. 10, pp 165-170.

Fayyad, U., Piatetsky-Shapiro, G., Smyth, P. 1996. From Data Mining to Knowledge Discovery in Databases. American Association for Artificial Intelligence.

Ferrotti, G. 2007. Experimental Characterisation of Interlayer Shear Resistance in Flexible Pavements. PhD Thesis, University della Marche, Ancona, Italy.

Ghaffari, A., Abdollahi, H., Khoshayand, M. R., Soltani Bozchalooi, Dadgar, A., RafieeTherani, M. 2006. Performance comparison of neural networl training algorithms in modelling of bimodal drug delivery. Science Direct. International Journal of Pharmaceutics 327, pp 126-138.

Gesoglu, M., Güneyisi, E., Özturan, T, Özbay, E., 2010. Modelling the mechanical properties of rubberized concretes by neural network and genetic programming, Material and Structures 43, pp 31-45.

Goodman R. E., Taylor R. L., Brekke T. L. 1968. A Model for the Mechanics of Jointed Rock, Journal of the Soil Mechanics and Foundations Division. American Society of Civil Engineers, Vol.94, pp 637-658. 
Goodman, S. N. 2000. Design, Development and Validation of the In-Situ Shear Stiffness Test (InSiSST). Facility for Asphalt Concrete Pavements. Master Thesis, Carleton University.

Haykin, S. 1999. Neural Networks: A Comprehensive Foundation, Prentice Hall, ISBN 0-13-273350-1.

Hicks, R.G. 1991. Moisture Damage in Asphalt Concrete. National Cooperative Highway Research Program, NCHRP, Synthesis of Highway Practice Report No. 175, Transportation Research Board, TRB, National Research Council, NRC, Washington D.C, USA.

Kandhal, P.S. 1992. Moisture susceptibility of HMA mixes: Identification of problem and recommended solutions. NCAT, Report No. 92-01.

Kiggundu, B. M., Roberts, F., L. 1988. Stripping in HMA Mixtures: State-of-the-Art and Critical Review on Test Methods. National Centre for Asphalt Technology, NCAT, Report No. 88-2, Auburn University, AL, USA.

Kriesel D. 2007. A Brief Introduction to Neural Networks, available at http://www.dkriesel.com.

Kim, H., Arraigada, M., Raab, C. Partl, M.N. 2010. Numerical and Experimental Analysis for the Interlayer Behavior of Double-Layered Asphalt Pavement Specimens. Journal of Materials in Civil Engineering-ASCE.

Kruntcheva, M. R, Collop A. C., Thom, N. H. 2006. Properties of asphalt concrete layer interfaces, Journal of Materials in Civil Engineering 18 (3), pp 467-471.

La Roche de C. 1996. Module de rigidité et comportement en fatigue des enrobés bitumineux. PhD Thesis, University of Lyon, France. 
Leng, Z., Hasan, O., Al-Qadi, I. L. and Carpenter, S. H. (2008). Interface Bonding between HMA and Various PCC Surfaces. Laboratory Assessment. TRB, Washington, USA.

Leutner, R. 1979. Untersuchungen des Schichtenverbunds beim bituminösen Oberbau. Fachartikel. Bitumen 3/1979, (in German)

Lieberman, J., Raab, C., 2001. The Effects of Water on the Shear Strength of Asphalt. EMPA-Report No. 840851/1.

Little, D., N., Jones D. R., 2003. Chemical and mechanical process of moisture damage in hot-mix asphalt pavements. National Seminar on Moisture Sensitivity of Asphalt Pavements, San Diego, California, USA.

Mallick, R., Gould J, Bhattacharjee S, Regimand A, James L, Brown E. 2003. Development of a rational procedure for evaluation of moisture susceptibility of asphalt. TRB annual meeting. Washington, USA.

Martínez, F., Angelone, S., 2010. The Estimation of the Dynamic Modulus of Asphalt Mixtures Using Artificial Neural Networks. $11^{\text {th }}$ International Conference on Asphalt Pavement s, ISAP, Nagoya, Japan.

Millien, A., Petit C., Rosier J. 1996. Comportement au cisaillement des couches d'accrochage dans les chaussées. Rapport interne Laboratoire 3MsGC, Université de Limoges, France.

Miradi M. 2009. Knowledge discovery and pavement performance, PhD Dissertation, Deft, University of Technology, Delft, The Netherlands.

Miradi, M., Molenaar, A. A. A., van de Ven, M. F. C. 2009. Performance Modelling of Porous Asphalt Concrete using Artificial Intelligence. Road Materials and 
Pavement design. ICAM 2009. DOI: 10.3166/RMPD.10HS.263-280@2009 Lavoisier, Paris, France.

Mirò Recasens R., Pérez Jiménez F., Borras Gonzalez J. M. 2003. Evaluation of the effect of tack coats. LCB shear test. $6^{\text {th }}$ RILEM Symposium PTEBM'03, Zurich, Switzerland, pp 550-556.

Mohammad L.N., Raqib M.A., Wu Z., Huang B. 2002. Measurement of interlayer bond strength through shear tests. $3^{\text {rd }}$ International Conference bituminous mixtures and pavements, Thessaloniki, Greece.

Mohammad, L. N., Bae A., Elseifi, M. 2009. Effect of Tack coat materials and application rate on the interface shear strength. $6^{\text {th }}$ International Conference on Maintenance and Rehabilitation of Pavements and Technological Control Mairepav6, Torino, Italy, Vol II, pp 636-645.

Mostafa, A. Abd El Halim, A. O. Hassan, Y., Scarlett J. 2003. Laboratory testing of moisture susceptibility of asphalt concrete mixes - an overview, Proceedings of $3^{\text {rd }}$ International Symposium on Maintenance and Rehabilitation of Pavements and Technological Control, Minho University, Guimarães, Portugal, pp 359-368

Mrawira, D., Damunde, D. 1999. Revisiting the effectiveness of tack coats in HMA overlays: The shear strength of tack coats in young overlays. $14^{\text {th }}$ Annual Conference, Canadian Technical Asphalt Association.

Oeser, M., Freitag, S. 2009. Neural networks in rheology: Theory and application. $7^{\text {th }}$ International RILEM Symposium ATCBM09 on Advanced Testing and Characterization of Bituminous Materials, Rhodes, Greece, Vol 1, pp 949-958. 
Pantic, M. 2001. Facial expression analysis by computational intelligence techniques. $\mathrm{PhD}$ Thesis, University of Technology, Delft, The Netherlands.

Partl, M.N., Canestrari, F., Grilli, A., Gubler, R. 2008. Characterization of Water Sensitivity of Asphalt Mixtures with Coaxial Shear Test. International Journal of Road Materials and Pavement Design, JRMPD, Hermes Science Publications, Vol 9/2, pp 247-278.

Partl, M.N., Raab. C. 1999. Shear Adhesion between Top Layers of Fresh Asphalt Pavements in Switzerland. $7^{\text {th }}$ Conf. on Asphalt Pavements for Southern Africa, CAPSA '99, Victory Falls, Zimbabwe, pp 5.130-5.137.

Petit, C., Laveissiere, D., Millien, A. 2002. Modelling of reflective cracking in pavements: fatigue under shear stresses. $3^{\text {rd }}$ International Symposium on 3D Finite Element for Pavement Analysis, Design and Research, Amsterdam, Netherlands.

Piber, H., Canestrari, F., Ferrotti, G., Lu, X., Millien, A., Partl, M.N., Petit, C., PhelipotMardelle, A., Raab, C. 2009. RILEM Interlaboratory Test on Interlayer Bonding of Asphalt Pavements. $7^{\text {th }}$ International RILEM Symposium ATCBM09 on Advanced Testing and Characterization of Bituminous Materials, Rhodes, Greece Volume 2, pp 1181-1189.

Potts, D. M., Dounias, G. T., Vaughan, P. R. 1987. Finite Element Analysis of the Direct Shear Box Test. Geotechnique, The Institution of Civil Engineers, London, UK, Vol. 37 (1), pp 11-23.

Raab, C.; Partl, M. N. 1999. Methoden zur Beurteilung des Schichtenverbunds von Asphaltbelägen [Methods to determine the bond of asphalt pavements]. ASTRAProject FA 12/94, Report No 442. 
Raab, C., 1999a. Vorbereitung zur Untersuchung des Schichtenverbunds [Preparation for the investigation of interlayer bonding]. EMPA-Report No. 1421689, Duebendorf, Switzerland (in German).

Raab, C., Partl, M. N. 2004. Effect of tack coats on interlayer shear bond of pavements. $8^{\text {th }}$ Conference of Asphalt Pavements for Southern Africa (CAPSA'04), Sun City, South Africa, Document Transformation Technologies cc. 847-855. ISBN 1-92001718-6.

Raab, C., Partl, M. N. 2004a. Einfluß und Wirkung von Dünnschichtbelägen auf die InSitu-Eigenschaften von Asphaltoberbauten. Eidgenössisches Departement für Umwelt, Verkehr, Energie und Kommunikation, Bundesamt für Strassen. Report No 1075 (in German).

Raab, C., Partl, M. N. 2005. Determination of the Mechanical Resistance of Thin Surfacings on Asphalt Pavements. $4^{\text {th }}$ International Conference on Maintenance and Rehabilitation of Pavements and Technological Control, Belfast, Northern Ireland.

Raab, C., Partl, M. N. 2006. Adhesion Testing of Rehabilitated Concrete Pavements. $10^{\text {th }}$ International Conference on Asphalt Pavements, Paper No. 79, 1 Quebec, Canada.

Raab, C., Partl, M.N. 2007. Langzeiterfassung des Schichtenverbunds - Relation zwischen Prüfwert nach Einbau und Langzeitverhalten. Eidgenössisches Departement für Umwelt, Verkehr, Energie und Kommunikation, Bundesamt für Strassen. FA 2005/503 auf Antrag der VSS, Report No. 1195. 
Raab, C., Partl, M.N. 2007a. Prüfung von Haftklebern. Eidgenössisches Departement für Umwelt, Verkehr, Energie und Kommunikation, Bundesamt für Strassen. FA 1999/277 auf Antrag der VSS, Report No. 1196.

Raab, C.; Partl, M. N. 2008. Investigation on Long-Term Interlayer Bonding of Asphalt Pavements. The Baltic Journal of Road and Bridge Engineering. Vol. 3 No. 2, pp $65-70$.

Raab, C., Partl, M.N. 2008a. Influence of Tack Coats on the Adhesion Properties of Asphalt Pavements. $4^{\text {th }}$ Int. Gulf Conference on Roads, Dohar, Qatar. Efficient Transportation and Pavement Systems, Editors: Al Qadi, I., Sayed T., Alnuaimi N. A. and Masad, E., ISBN 978-0-415-48979-9, pp 517-527.

Raab, C., Partl, M.N. 2009. Interlayer Bonding of Binder, Base and Subbase Layers of Asphalt Pavements. Long-Term Performance, Construction \& Building Materials Vol 23, No 8, pp 2926-2931.

Raab, C., Partl, M.N. 2009a. Laboratory Study on Interlayer Bonding Using Cationic Tack Coats $7^{\text {th }}$ International RILEM Symposium ATCBM09 on Advanced Testing and Characterization of Bituminous Materials, Rhodes, Greece, Volume 1, pp 312.

Raab, C., Partl, M.N. 2009b. Long-Term Interlayer Shear Performance of Base and Subbase Layers in Asphalt Pavements. $6^{\text {th }}$ International Conference on Maintenance and Rehabilitation of Pavements and Technological Control Mairepav6, Torino, Italy, Vol II, pp 646-653. 
Raab, C., Partl, M.N. Abd El Halim A.O. 2009. Evaluation of Interlayer Shear Bond Devices for Asphalt Pavements. Baltic Journal of Road and Bridge Engineering. Vol 4 No 4, pp 176-195.

Raab, C., Partl, M.N., Abd El Halim A.O. 2010. Effect of gap width on interlayer shear bond results. International Journal of Pavement research and Technology IJPRT Reference No. IJPRT-09544(3), Volume 3 No 2, pp 79-85.

Rabiot, D., Morizur M. 1996. Polymermodified bitumen emulsions an advantage for various road applications. Euroasphalt and Eurobitumen Congress, Strasbourg, France, 1996.

Riedweg, S., Partl, M. N. 1999. Einarbeitung in die TVIST. EMPA Report 840584-1. Swiss Laboratories for Materials Testing and Research, Duebendorf, Switzerland, 2004, (in German).

Rojas, R. 1996. Neural Networks - A Systematic Introduction. Springer-Press, Berlin, New-York, 1996.

Romanoschi S.A., Metcalf J.B., 2001. Characterization of Asphalt Concrete Layer Interfaces. Transportation Research Record, No. 1778, pp 132-139, Washington D.C., USA.

Romanoschi, S. A., Metcalf J. B. 2002. The characterization of pavement layer interfaces. [CD-ROM]. $9^{\text {th }}$ International Conference on Asphalt Pavements, Copenhagen, Denmark.

Saada, A. S., Townsend, F. C. 1981. State of the art: Laboratory strength testing of soils. Lab. Shear Strength of Soils. Philadelphia, US, ASTM Special Technical Publication 740, pp 7-77. 
Sanders, P. J., Brown, S. F., Thom N. H. 1999. Reinforced asphalt for crack and rut control. $7^{\text {th }}$ Conference on Asphalt Pavements for Southern Africa, CAPSA '99, Victory Falls, Zimbabwe, Document Transformation Technologies pp. 847-855.

Santagata E., Canestrari F. (1994). Tensile and shear tests of interfaces in asphalt mixes: a new prospective on their failure criteria. 2nd International Symposium - Ulster, Northern Ireland.

Sholar, G. A., Page G.C., Musselman J.A., Upshaw P.B., Moseley H.L. 2004. Preliminary Investigation of a Test Method to Evaluate Bond Strength of Bituminous Tack Coats. Journal of the Association of Asphalt Paving Technologists, Vol. 73, pp 771-801.

Sokolov, K., Gubler, R., and Partl, M.N. 2005. Extended numerical modeling and application of the coaxial shear test for asphalt pavements. Materials and Structures, 279, pp 515-522.

Sousa, J. B., Weissmann, S. L., Deacon, J. A., Harvey, J., Paulsen, G., Monismith, C. L. 1994. Permanent Deformation Response of Asphalt Aggregate Mix Part III, Strategic Highway Research SHRP A-415, Editor: Harrigan, E. T. Washington D.C., USA.

Stöckert, U. 2001: Schichtenverbund - Prüfung und Bewertungshintergrund. Straße + Autobahn, 11/2001, pp 624-631 (in German).

Sutanto, M. 2009. Assessment of Bond between Asphalt Layers. PhD Thesis, Nottingham University, Great Britain.

Tapkin, S. 2010. Estimation of Fatigue Lives of Fly Ash Modified Bituminous Mixtures Based on Artificial Neural Networks, submitted to Materials and Structures. 
Tschegg, E. K., Macht, J., Jamek, M.; Steigenberger, J. 2007. Mechanical and fracturemechanical properties of asphalt-concrete interfaces. ACI Materials Journal 104, pp 474-480.

Uzan J., Livneh M., and Eshed Y. 1978, Investigation of adhesion properties between asphaltic concrete layers. Asphalt Paving Technology, Vol.47, Lake Buena Vista, Florida, pp 495-521.

Velske, S. 1978. Versuche zur Prüfung der Standfestigkeit von Walzasphalt. [Experiments of testing the stability of compacted asphalt]. Fachbeitrag: Das stationäre Mischwerk, 4/1978, pp 14-17 (in German).

Werner, R., Scazziga, I., Raab, C., Partl, M.N. 2007. Kombinierte Beläge Belagsüberzüge auf Betonbeläge und Kompositbeläge. Eidgenössisches Departement für Umwelt, Verkehr, Energie und Kommunikation, Bundesamt für Strassen. FA 2001/501 auf Antrag der VSS, Report No. 1180.

West, R.C., Zhang, J.; Moore, J. 2005. Evaluation of bond strength between pavement layers. National Center for Asphalt Technology, NCAT Report 05-08.

Zahw, M. A., 1995. Development of testing framework for evaluation of rutting resistance of asphalt mixes. PhD Thesis, Carleton University, Ottawa, Canada.

Ziari, H. and Khabiri, M.M. 2007. Interface Condition Influence on prediction of Flexible Pavement Life. Journal of Civil Engineering and Management. Vol Xlll, No 1, pp 76-78, ISSN 1392-3730 print, ISSN 1822-3605 online.

Xiao, F., Amirkhanian, S.N. and Juang, H. C. 2010. An Artificial Neural network Approach to Developing Long-Term Aging Models of Asphalt Binders, submitted to Materials and structures. 


\section{Standards and Guidelines}

Austrian Standard, ÖNORM B 3639-1. Asphalt for road construction and related purposes - testing - shear resistance in contact surfaces of asphalt layers, 1997.

British Board of Agreement. Guidelines Document for the Assessment and Certification of Thin Surfacing Systems for Highways. SG3/05/234, British Board of Agreement, Watford, UK, 2004

German Guideline, ALP A-StB part 4. Examination of interlayer bonding with the Leutner shear test, 1999.

European Standard, EN 12697-48. Bituminous mixtures - Test methods for hot mix asphalt - Part 48: Interlayer Bonding, 2009

European Standard, EN 12697-5. Bituminous mixtures - Test methods for hot mix asphalt - Part 5: Determination of the maximum density, 2009

European Standard, EN 12697-6. Bituminous mixtures - Test methods for hot mix asphalt - Part 6: Determination of bulk density of bituminous specimens, 2007

European Standard, EN 13108-1. Bituminous mixtures - Material specifications - Part 1: Asphalt Concrete, 2006

European Standard, EN 13108-6. Bituminous mixtures - Material specifications - Part 6: Mastic Asphalt, 2006

European Standard, EN 13808,. Bitumen and bituminous binders - Framework for specifying cationic bituminous emulsions 2005

Italian Standard, UNI/TS 11214. Caratterizzazione prestazionale a taglio delle interfacce - Metodo di prova ASTRA, 2007 
Swiss Standard SN 640420. Asphalt, Grundnorm, erein Schweizerischer Straßenfachleute VSS, Zürich, 2008

Swiss Standard, SN 640430b. Walzasphalt, Konzeption, Ausführung und Anforderungen an die eingebauten Schichten. Verein Schweizerischer Straßenfachleute VSS, Zürich, 2008

Swiss Standard, Schweizer Norm SN 640431. Asphaltbetonbeläge, Konzeption, Anforderungen, Ausführungen. Verein Schweizerischer Straßenfachleute VSS, Zürich, 1976

Swiss Standard, Schweizer Norm SN 640431a. Asphaltbetonbeläge, Konzeption, Anforderungen, Ausführungen. Verein Schweizerischer Straßenfachleute VSS, Zürich, 1988

Swiss Standard, Schweizer Norm SN 640431b. Asphaltbetonbeläge, Konzeption, Anforderungen, Ausführungen. Verein Schweizerischer Straßenfachleute VSS, Zürich, 1997

Swiss Standard, Schweizer Norm SN 640440. Gussasphalt, Konzeption, Ausführung und Anforderungen an die eingebauten Schichten. Verein Schweizerischer Straßenfachleute VSS, Zürich, 2008

Swiss Standard, Schweizer Norm SN 670205 NA, EN 13808-2005. Bitumen und bitumenhaltige Bindemittel, Rahmenwerk für die Spezifizierung kationischer bitumenhaltigen Emulsionen, Verein Schweizerischer Straßenfachleute VSS, Zürich, 2007 
Swiss Standard, Schweizer Norm SN 671961. Bituminöses Mischgut, Bestimmung des Schichtenverbunds (nach Leutner), Verein Schweizerischer Straßenfachleute VSS, 2000.

Swiss Standard, Schweizer Norm SN 671 965a. Bituminöses Mischgut, Dichte, Verein Schweizerischer Straßenfachleute VSS, Zürich, 1971 


\section{Appendix A}

\section{Data from Data Mining Investigation (ANN)}

\section{A.1 Data}

Tables A1 to A5 show the test condition, selected material properties and the LPD interlayer shear results for all datasets used for ANN modelling.

Abbreviations in Tables A1 - A5:

$\mathrm{T}=$ test temperature

$\mathrm{AV} 1=$ air void content layer 1

$\mathrm{AV} 2=$ air void content layer 2

$\mathrm{BC} 1=$ binder content layer 1

$\mathrm{BC} 2=$ binder content layer

$8 \_1$ = aggregates passing through sieve $8 \mathrm{~mm}$, layer 1

$8 \_2=$ aggregates passing through sieve $8 \mathrm{~mm}$, layer 1

$2 \_1$ = aggregates passing through sieve $2 \mathrm{~mm}$, layer 1

$2 \_2=$ aggregates passing through sieve $2 \mathrm{~mm}$, layer 2

Fil $1=$ aggregates passing through sieve $0.09 \mathrm{~mm}$, layer 1

Fil 2 = aggregates passing through sieve $8 \mathrm{~mm}$, layer 1

ADT $=$ average daily traffic

$>3.5 \mathrm{t}=$ percentage of heavy vehicles $>3.5 \mathrm{t}$ 
Table A.1: New Road -1

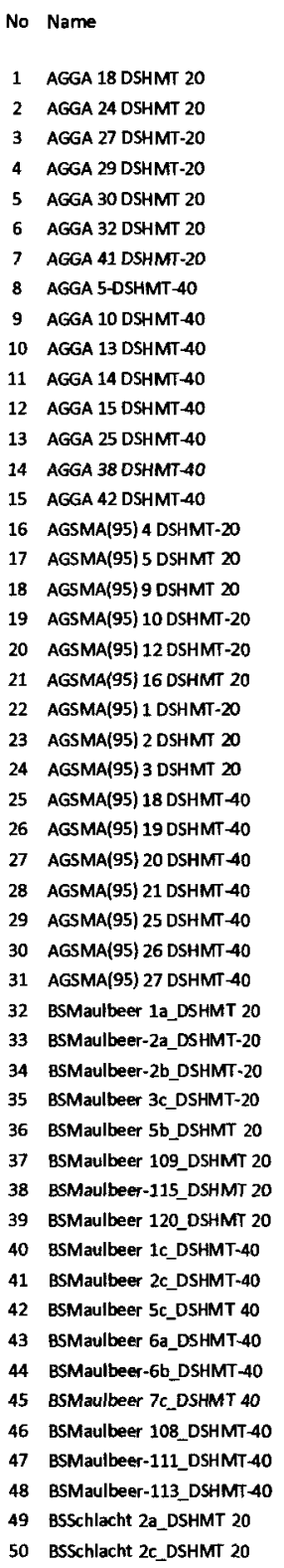

\begin{tabular}{|c|c|c|c|c|c|c|c|c|c|c|}
\hline & $\begin{array}{l}\text { AV } 1 \\
{[\%]}\end{array}$ & $\begin{array}{l}\text { AV } 2 \\
\text { [\%] }\end{array}$ & $\begin{array}{l}\mathrm{BC} 1 \\
{[\%]}\end{array}$ & $\begin{array}{l}\mathrm{BC} 2 \\
{[\%]}\end{array}$ & $\begin{array}{l}\text { 8_1 } \\
{[\%]}\end{array}$ & $\begin{array}{l}8 \_2 \\
{[\%]}\end{array}$ & $\begin{array}{l}2 \_1 \\
{[\%]}\end{array}$ & $\begin{array}{l}2 \_2 \\
{[\%]}\end{array}$ & $\begin{array}{l}F_{1}{ }_{1} 1 \\
{[\%]}\end{array}$ & [\%] \\
\hline & 12 & 18 & 72 & 67 & 868 & 739 & 557 & 472 & 256 & \\
\hline & 12 & 18 & 72 & 67 & 868 & 739 & 557 & 472 & 256 & 259 \\
\hline & 12 & & 2 & 67 & 868 & 739 & 557 & 472 & 256 & 5 \\
\hline & 12 & 18 & 72 & 67 & 868 & 739 & 557 & 472 & 256 & 259 \\
\hline & 12 & 8 & 72 & 67 & 858 & 739 & 557 & 472 & 256 & 259 \\
\hline & 12 & 18 & 72 & 67 & 868 & 739 & 557 & 472 & 256 & 259 \\
\hline & 12 & 18 & 72 & 67 & 868 & 739 & 557 & 472 & 256 & 259 \\
\hline & 12 & & 72 & 67 & 868 & 739 & 557 & 472 & 256 & 259 \\
\hline & 12 & 18 & 72 & 67 & 868 & 739 & 557 & 472 & 256 & 259 \\
\hline & 12 & 18 & 72 & 67 & 868 & 739 & 557 & 472 & 256 & 259 \\
\hline & 12 & 18 & 72 & 67 & 868 & 739 & 557 & 472 & 256 & 259 \\
\hline & 12 & 18 & 72 & 67 & 868 & 739 & 557 & 472 & 256 & 259 \\
\hline & 12 & 18 & 72 & 67 & 868 & 739 & 557 & 472 & 256 & 259 \\
\hline & 12 & 18 & 72 & 67 & 868 & 739 & 557 & 472 & 256 & 259 \\
\hline & 12 & 18 & 72 & 67 & 868 & 739 & 557 & 472 & 256 & 259 \\
\hline & 35 & 4 & 68 & 44 & 636 & 635 & 246 & 305 & 105 & 0 \\
\hline & 35 & 43 & 68 & 44 & 636 & 635 & 246 & 305 & 105 & 0 \\
\hline & 35 & 43 & 68 & 44 & 636 & 635 & 246 & 305 & 105 & 90 \\
\hline & 35 & 4 & 68 & 44 & 636 & 635 & 246 & 305 & 105 & 10 \\
\hline & 35 & 43 & 68 & 44 & 636 & 635 & 246 & 305 & 105 & 10 \\
\hline & 35 & 43 & 68 & 44 & 636 & 635 & 246 & 305 & 105 & 90 \\
\hline & 35 & 43 & 68 & 44 & 636 & 635 & 246 & 305 & 105 & 90 \\
\hline & 35 & 43 & 68 & 44 & 636 & 635 & 246 & 305 & 105 & 90 \\
\hline & 35 & 4 & 68 & 44 & 636 & 635 & 246 & 305 & 105 & 90 \\
\hline & 35 & 43 & 68 & 44 & 636 & 635 & 246 & 305 & 105 & 90 \\
\hline & 35 & 43 & 68 & 44 & 636 & 635 & 246 & 305 & 105 & 90 \\
\hline & 35 & 4 & & 44 & 636 & 635 & 246 & 305 & 105 & 10 \\
\hline & 35 & 43 & 68 & 44 & 636 & 635 & 246 & 305 & 105 & 90 \\
\hline & 35 & 43 & 68 & 44 & 636 & 635 & 246 & 305 & 105 & 90 \\
\hline & 35 & 4 & & 44 & 636 & 635 & 246 & 305 & 105 & 90 \\
\hline & 35 & 43 & 68 & 44 & 636 & 635 & 246 & 305 & 105 & 90 \\
\hline & 49 & 41 & & 42 & 677 & 583 & 226 & 295 & 70 & 87 \\
\hline & 49 & 41 & 76 & 42 & 677 & 583 & 226 & 295 & 70 & 87 \\
\hline & 49 & 41 & 76 & 42 & 677 & 583 & 226 & 295 & 70 & 87 \\
\hline & 49 & 41 & 76 & 42 & 677 & 583 & 226 & 295 & 70 & 87 \\
\hline & 49 & 41 & 76 & 42 & 677 & 583 & 226 & 295 & 70 & 87 \\
\hline & 49 & 41 & 8 & 42 & 677 & 583 & 226 & 295 & 70 & 87 \\
\hline & 49 & 41 & & 42 & 677 & 583 & 226 & 295 & 70 & 8.7 \\
\hline & 49 & 41 & 76 & 42 & 677 & 583 & 226 & 295 & 70 & 87 \\
\hline & 49 & 41 & 76 & 42 & 677 & 583 & 226 & 295 & 70 & 87 \\
\hline & 49 & 4 & 7 & 42 & 677 & 583 & 226 & 295 & 70 & 87 \\
\hline & 49 & 41 & 76 & 42 & 677 & 583 & 226 & 295 & 70 & 87 \\
\hline & 49 & 41 & 76 & 42 & 677 & 583 & 226 & 295 & 70 & 7 \\
\hline & 49 & 41 & 76 & 42 & 677 & 583 & 226 & 295 & 70 & 87 \\
\hline & 49 & 41 & 76 & 42 & 677 & 583 & 226 & 295 & 70 & 87 \\
\hline & 49 & 4 & 76 & 42 & 677 & 583 & 226 & 295 & 70 & 87 \\
\hline & 49 & 41 & 76 & 42 & 677 & 583 & 226 & 295 & 70 & 87 \\
\hline & 49 & 41 & 76 & 42 & 677 & 583 & 226 & 295 & 70 & 87 \\
\hline & 78 & 38 & 60 & 49 & 559 & 500 & 256 & 262 & 84 & 63 \\
\hline & 78 & 38 & 60 & 49 & 559 & 500 & 256 & 262 & 84 & 63 \\
\hline
\end{tabular}

\begin{tabular}{|c|c|c|c|c|c|}
\hline$\stackrel{F}{F}$ & $\stackrel{\tau}{\tau}$ & $\stackrel{w}{w}$ & $\begin{array}{c}\mathrm{S} \\
{[\mathrm{KN} / \mathrm{mm}]}\end{array}$ & $\begin{array}{c}\mathrm{K} \\
{[\mathrm{MPa} / \mathrm{mm}]}\end{array}$ & $\begin{array}{c}M \\
{[K N / m m]}\end{array}$ \\
\hline 440 & 25 & 39 & 189 & 11 & 113 \\
\hline 421 & 24 & 42 & 165 & 09 & 99 \\
\hline 398 & 23 & 35 & 179 & 10 & 114 \\
\hline 401 & 23 & 40 & 140 & 08 & 101 \\
\hline 399 & 23 & 36 & 185 & 10 & 110 \\
\hline 383 & 22 & 35 & 152 & 09 & 110 \\
\hline 478 & 27 & 43 & 174 & 10 & 111 \\
\hline 101 & 06 & 52 & 38 & 02 & 19 \\
\hline 95 & 05 & 48 & 41 & 02 & 20 \\
\hline 108 & 06 & 65 & 5.5 & 03 & 17 \\
\hline 104 & 06 & 38 & 43 & 02 & 27 \\
\hline 101 & 06 & 43 & 4.5 & 03 & 23 \\
\hline 102 & 06 & 47 & 35 & 02 & 22 \\
\hline 84 & 05 & 45 & 42 & 02 & 19 \\
\hline 116 & 07 & 35 & 56 & 03 & 33 \\
\hline 297 & 17 & 40 & 143 & 08 & 75 \\
\hline 267 & 15 & 41 & 131 & 07 & 66 \\
\hline 258 & 15 & 25 & 224 & 13 & 102 \\
\hline 272 & 15 & 27 & 116 & 07 & 102 \\
\hline 302 & 17 & 34 & 160 & 09 & 88 \\
\hline 334 & 19 & 42 & 154 & 09 & 79 \\
\hline 264 & 15 & 33 & 106 & 06 & 80 \\
\hline 142 & 08 & 36 & 77 & 04 & 40 \\
\hline 293 & 17 & 42 & 76 & 04 & 70 \\
\hline 40 & 02 & 21 & 40 & 02 & 19 \\
\hline 67 & 04 & 42 & 26 & 01 & 16 \\
\hline 56 & 03 & 35 & 38 & 02 & 16 \\
\hline 37 & 02 & 28 & 3.3 & 02 & 13 \\
\hline 64 & 04 & 24 & 93 & 05 & 26 \\
\hline 51 & 03 & 31 & 37 & 02 & 17 \\
\hline 63 & 04 & 30 & 34 & 02 & 21 \\
\hline 304 & 17 & 36 & 112 & 06 & 85 \\
\hline 288 & 16 & 41 & 87 & 05 & 70 \\
\hline 307 & 17 & 45 & 103 & 06 & 68 \\
\hline 289 & 16 & 30 & 114 & 06 & 96 \\
\hline 324 & 18 & 28 & 166 & 09 & 115 \\
\hline 291 & 16 & 34 & 188 & 11 & 85 \\
\hline 277 & 16 & 48 & 151 & 09 & 58 \\
\hline 262 & 15 & 34 & 104 & 06 & 78 \\
\hline 92 & 05 & 31 & 56 & 03 & 30 \\
\hline 81 & 05 & 26 & 4.5 & 03 & 31 \\
\hline 51 & 03 & 54 & 29 & 02 & 09 \\
\hline 65 & 04 & 29 & 5.5 & 03 & 22 \\
\hline 51 & 03 & 21 & 42 & 02 & 24 \\
\hline 83 & 05 & 35 & 52 & 03 & 23 \\
\hline 81 & 05 & 29 & 101 & 06 & 28 \\
\hline 70 & 04 & 37 & 31 & 02 & 19 \\
\hline 73 & 04 & 19 & 69 & 04 & 37 \\
\hline 247 & 14 & 29 & 187 & 11 & 85 \\
\hline 312 & 18 & 27 & 203 & 12 & 116 \\
\hline
\end{tabular}


Table A.1: New Road - continued 2

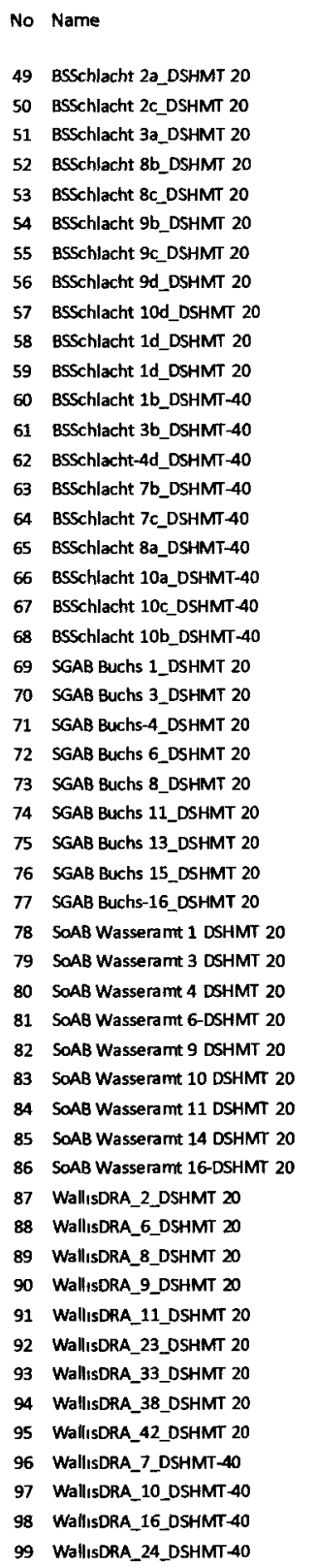

\begin{tabular}{|c|c|c|c|c|c|c|c|c|c|c|c|c|c|c|c|c|}
\hline $\begin{array}{l}\mathrm{T} \\
{\left[{ }^{\circ} \mathrm{C}\right]}\end{array}$ & $\begin{array}{l}\text { AV } 1 \\
{[\%]}\end{array}$ & $\begin{array}{l}\text { AV } 2 \\
\text { [\%] }\end{array}$ & $\begin{array}{l}\mathrm{BC} 1 \\
{[\%]}\end{array}$ & $\begin{array}{l}\text { BC 2 } \\
{[\%]}\end{array}$ & $\begin{array}{l}8 \_1 \\
{[\%]}\end{array}$ & $\begin{array}{l}8 \_2 \\
{[\%]}\end{array}$ & $\begin{array}{l}2 \_1 \\
{[\%]}\end{array}$ & $\begin{array}{l}2-2 \\
{[\%]}\end{array}$ & $\begin{array}{l}\text { Fil_1 } 1 \\
{[\%]}\end{array}$ & $\begin{array}{l}\text { FIl_2 } \\
{[\%]}\end{array}$ & $\begin{array}{c}F \\
{[k N]}\end{array}$ & $\begin{array}{c}\tau \\
{[\mathrm{MPa}]}\end{array}$ & $\stackrel{w}{w}[\mathrm{~mm}]$ & $\begin{array}{c}\mathrm{s} \\
{[\mathrm{KN} / \mathrm{mm}]}\end{array}$ & $\begin{array}{c}\mathrm{K} \\
{[\mathrm{MPa} / \mathrm{mm}]}\end{array}$ & $\begin{array}{c}M \\
{[\mathrm{KN} / \mathrm{mm}]}\end{array}$ \\
\hline 200 & 78 & 38 & 60 & 49 & 559 & 500 & 256 & 262 & 84 & 63 & 247 & 14 & 29 & 187 & 11 & 85 \\
\hline 200 & 78 & 38 & 60 & 49 & 559 & 500 & 256 & 262 & 84 & 63 & 312 & 18 & 27 & 203 & 12 & 116 \\
\hline 200 & 78 & 38 & 60 & 49 & 559 & 500 & 256 & 262 & 84 & 63 & 276 & 16 & 28 & 152 & 09 & 97 \\
\hline 200 & 78 & 38 & 60 & 49 & 559 & 500 & 256 & 262 & 84 & 63 & 279 & 16 & 37 & 208 & 12 & 76 \\
\hline 200 & 78 & 38 & 60 & 49 & 559 & 500 & 256 & 262 & 84 & 63 & 287 & 16 & 32 & 175 & 10 & 89 \\
\hline 200 & 78 & 38 & 60 & 49 & 559 & 500 & 256 & 262 & 84 & 63 & 264 & 15 & 29 & 164 & 09 & 92 \\
\hline 200 & 78 & 38 & 60 & 49 & 559 & 500 & 256 & 262 & 84 & 63 & 172 & 10 & 26 & 115 & 06 & 66 \\
\hline 200 & 78 & 38 & 60 & 49 & 559 & 500 & 256 & 262 & 84 & 63 & 328 & 19 & 31 & 192 & 11 & 104 \\
\hline 200 & 78 & 38 & 60 & 49 & 559 & 500 & 256 & 262 & 84 & 63 & 338 & 19 & 29 & 223 & 13 & 115 \\
\hline 200 & 78 & 38 & 60 & 49 & 559 & 500 & 256 & 262 & 84 & 63 & 338 & 19 & 28 & 223 & 13 & 121 \\
\hline 200 & 78 & 38 & 60 & 49 & 559 & 500 & 256 & 262 & 84 & 63 & 324 & 18 & 26 & 268 & 15 & 123 \\
\hline 400 & 78 & 38 & 60 & 49 & 559 & 500 & 256 & 262 & 84 & 63 & 97 & 06 & 40 & 5.0 & 03 & 25 \\
\hline 400 & 78 & 38 & 60 & 49 & 559 & 500 & 256 & 262 & 84 & 63 & 76 & 04 & 31 & 41 & 02 & 25 \\
\hline 400 & 78 & 38 & 60 & 49 & 559 & 500 & 256 & 262 & 84 & 63 & 108 & 06 & 48 & 4.0 & 02 & 23 \\
\hline 400 & 78 & 38 & 60 & 49 & 559 & 500 & 256 & 262 & 84 & 63 & 73 & 04 & 39 & 4.3 & 02 & 19 \\
\hline 401 & 78 & 38 & 60 & 49 & 559 & 500 & 256 & 262 & 84 & 63 & 99 & 06 & 29 & 4.3 & 02 & 34 \\
\hline 400 & 78 & 38 & 60 & 49 & 559 & 500 & 256 & 262 & 84 & 63 & 10 & 01 & 16 & 1.4 & 01 & 06 \\
\hline 400 & 78 & 38 & 60 & 49 & 559 & 500 & 256 & 262 & 84 & 63 & 85 & 05 & 36 & 4.5 & 03 & 23 \\
\hline 400 & 78 & 38 & 60 & 49 & 559 & 500 & 256 & 262 & 84 & 63 & 95 & 05 & 44 & 48 & 03 & 22 \\
\hline 400 & 78 & 38 & 60 & 49 & 559 & 500 & 256 & 262 & 84 & 63 & 56 & 03 & 26 & 29 & 02 & 22 \\
\hline 200 & 36 & 32 & 60 & 49 & 678 & 800 & 318 & 350 & 77 & 70 & 284 & 16 & 25 & 184 & 10 & 113 \\
\hline 200 & 36 & 32 & 60 & 49 & 678 & 800 & 318 & 350 & 77 & 70 & 294 & 17 & 26 & 212 & 12 & 114 \\
\hline 200 & 36 & 32 & 60 & 49 & 678 & 800 & 318 & 350 & 77 & 70 & 292 & 16 & 24 & 206 & 12 & 120 \\
\hline 200 & 36 & 32 & 60 & 49 & 678 & 800 & 318 & 350 & 77 & 70 & 276 & 16 & 28 & 204 & 12 & 97 \\
\hline 200 & 36 & 32 & 60 & 49 & 678 & 800 & 318 & 350 & 77 & 70 & 217 & 12 & 28 & 116 & 07 & 76 \\
\hline 200 & 36 & 32 & 60 & 49 & 678 & 800 & 318 & 350 & 77 & 70 & 281 & 16 & 28 & 184 & 10 & 102 \\
\hline 200 & 36 & 32 & 60 & 49 & 678 & 800 & 318 & 350 & 77 & 70 & 311 & 18 & 24 & 221 & 12 & 128 \\
\hline 200 & 36 & 32 & 60 & 49 & 678 & 800 & 318 & 350 & 77 & 70 & 285 & 16 & 18 & 198 & 11 & 162 \\
\hline 200 & 36 & 32 & 60 & 49 & 678 & 800 & 318 & 350 & 77 & 70 & 297 & 17 & 29 & 189 & 11 & 104 \\
\hline 200 & 58 & 43 & 57 & 40 & 862 & 508 & 381 & 253 & 85 & 52 & 240 & 14 & 3.4 & 129 & 07 & 70 \\
\hline 200 & 58 & 43 & 57 & 40 & 862 & 508 & 381 & 253 & 85 & 52 & 230 & 13 & 41 & 120 & 07 & 56 \\
\hline 200 & 58 & 43 & 57 & 40 & 862 & 508 & 381 & 253 & 85 & 52 & 225 & 13 & 32 & 128 & 07 & 71 \\
\hline 200 & 58 & 43 & 57 & 40 & 862 & 508 & 381 & 253 & 85 & 52 & 263 & 15 & 30 & 127 & 07 & 87 \\
\hline 200 & 58 & 43 & 57 & 40 & 862 & 508 & 381 & 253 & 85 & 52 & 213 & 12 & 44 & 111 & 06 & 49 \\
\hline 200 & 58 & 43 & 57 & 40 & 862 & 508 & 381 & 253 & 85 & 52 & 235 & 13 & 41 & 117 & 07 & 57 \\
\hline 200 & 58 & 43 & 57 & 40 & 862 & 508 & 381 & 253 & 85 & 52 & 199 & 11 & 37 & 105 & 06 & 54 \\
\hline 200 & 58 & 43 & 57 & 40 & 862 & 508 & 381 & 253 & 85 & 52 & 206 & 12 & 50 & 9.9 & 06 & 41 \\
\hline 198 & 58 & 43 & 57 & 40 & 862 & 508 & 381 & 253 & 85 & 52 & 242 & 14 & 53 & 106 & 06 & 46 \\
\hline 199 & 226 & 77 & 57 & 49 & 636 & 700 & 69 & 330 & 20 & 70 & 76 & 04 & 27 & 82 & 05 & 28 \\
\hline 200 & 226 & 77 & 57 & 49 & 636 & 700 & 69 & 330 & 20 & 70 & 37 & 02 & 32 & 31 & 02 & 12 \\
\hline 199 & 226 & 77 & 57 & 49 & 636 & 700 & 69 & 330 & 20 & 70 & 69 & 04 & 28 & 28 & 02 & 25 \\
\hline 200 & 226 & 77 & 57 & 49 & 636 & 700 & 69 & 330 & 20 & 70 & 89 & 05 & 24 & 59 & 03 & 37 \\
\hline 201 & 226 & 77 & 57 & 49 & 636 & 700 & 69 & 330 & 20 & 70 & 58 & 03 & 35 & 23 & 01 & 17 \\
\hline 200 & 226 & 77 & 57 & 49 & 636 & 700 & 69 & 330 & 20 & 70 & 81 & 05 & 23 & 127 & 07 & 36 \\
\hline 200 & 226 & 77 & 57 & 49 & 636 & 700 & 69 & 330 & 20 & 70 & 68 & 04 & 34 & 60 & 03 & 20 \\
\hline 200 & 226 & 77 & 57 & 49 & 636 & 700 & 69 & 330 & 20 & 70 & 73 & 04 & 50 & 2.2 & 01 & 15 \\
\hline 200 & 226 & 77 & 57 & 49 & 636 & 700 & 69 & 330 & 20 & 70 & 61 & 03 & 35 & 37 & 02 & 17 \\
\hline 400 & 226 & 77 & 57 & 49 & 636 & 700 & 69 & 330 & 20 & 70 & 23 & 01 & 22 & 35 & 02 & 10 \\
\hline 400 & 226 & 77 & 57 & 49 & 636 & 700 & 69 & 330 & 20 & 70 & 39 & 02 & 37 & 5.8 & 03 & 10 \\
\hline 400 & 226 & 77 & 57 & 49 & 636 & 700 & 69 & 330 & 20 & 70 & 36 & 02 & 13 & 32 & 02 & 29 \\
\hline 400 & 226 & 77 & 57 & 49 & 636 & 700 & 69 & 330 & 20 & 70 & 31 & 02 & 11 & 54 & 03 & 27 \\
\hline
\end{tabular}


Table A.1: New Road - continued 3

No Name

101 Wall ISDRA_28_DSHMT-40 102 Wall ISDRA_29_DSHMT 40 103 WallisDRA_34_DSHMT 40

104 WallISDRA_35_DSHMT-40 105 WallsSDRA_36_DSHMT-40 106 WallisSMA 2 DSHMT 20 107 WallisSMA_4_DSHMT 20 108 WallisSMA_5_DSHMT 20 109 WallisSMA_8_DSHMT 20 110 WallisSMA_9_DSHMT-20 111 WallISSMA_10_DSHMT 20 112 WallısSMA_11_DSHMT 20 113 WallisSMA_14_DSHMT 20 114 WallisSMA_18_DSHMT 20 115 WallisSMA_19_DSHMT-20 116 WallisSMA_32_DSHMT-20 117 WallisSMA_35_DSHMT 20 118 WallISSMA 37 DSHMT-20 119 WallISSMA_39_DSHMT-20 120 WaltISSMA_42_DSHMT-20 121 WallisSMA_22_DSHMT-40 122 WallisSMA_25_DSHMT-40 123 WalltsSMA_7_DSHMT-40 124 WallisSMA_1_DSHMT-40 125 WallisSMA_12_DSHMT 40 126 WallıSSMA_15_DSHMT-40 127 WallısSMA_16_DSHMT-40 128 WallisSMA_26_DSHMT-40 129 WallisSMA_27_DSHMT-40 130 WallisSMA_29_DSHMT 40 131 WallisSMA_3_DSHMT-40 132 WallisSMA_33_DSHMT-40 133 WallisSMA_38_DSHMT-40 134 Wall IsSMA_40_DSHMT 40 135 ZHWall_1a_DSHMT_20

136 ZHWall_1c_DSHMT_20 137 ZHWall_1d_DSHMT_20 138 ZHWall_te_DSHMT 20 139 ZHWall_2b_DSHMT_20 140 ZHWall_2c_DSHMT_20 141 ZHWall_2e_DSHMT_20 142 ZHWall_3C_DSHMT_20 143 ZHWall_3e_DSHMT_20 144 ZHWall_4b_DSHMT_20 145 ZHWall_4d_DSHMT_20 146 ZHWall_4e_DSHMT_2O 147 ZHWall_Se_DSHMT_20 148 ZHWall_6d_DSHMT_20 149 ZHWall_lb_DSHMT_40 150 ZHWall $1 \mathrm{~g}$ DSHMT 40
$T \quad A V 1$
$A V 2$

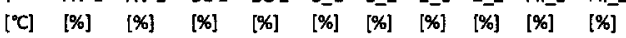
$\begin{array}{lllllllllll}400 & 226 & 77 & 57 & 49 & 636 & 700 & 69 & 330 & 20 & 70\end{array}$ $\begin{array}{lllllllllll}400 & 226 & 77 & 57 & 49 & 636 & 700 & 69 & 330 & 20 & 70\end{array}$ $\begin{array}{lllllllllll}400 & 226 & 77 & 57 & 49 & 636 & 700 & 69 & 330 & 20 & 70\end{array}$ $\begin{array}{lllllllllll}400 & 226 & 77 & 57 & 49 & 636 & 700 & 69 & 330 & 20 & 70\end{array}$ $\begin{array}{lllllllllll}400 & 226 & 77 & 57 & 49 & 636 & 700 & 69 & 330 & 20 & 70\end{array}$ $\begin{array}{lllllllllll}200 & 49 & 39 & 60 & 40 & 617 & 598 & 228 & 255 & 74 & 60\end{array}$ $\begin{array}{lllllllllll}200 & 49 & 39 & 60 & 40 & 617 & 598 & 228 & 255 & 74 & 60\end{array}$ $\begin{array}{lllllllllll}200 & 49 & 39 & 60 & 40 & 617 & 598 & 228 & 255 & 74 & 60\end{array}$ $\begin{array}{lllllllllll}200 & 49 & 39 & 60 & 40 & 617 & 598 & 228 & 255 & 74 & 60\end{array}$ $\begin{array}{lllllllllll}200 & 49 & 39 & 60 & 40 & 617 & 598 & 228 & 255 & 74 & 60\end{array}$ $\begin{array}{lllllllllll}200 & 49 & 39 & 60 & 40 & 617 & 598 & 228 & 255 & 74 & 60\end{array}$ $\begin{array}{lllllllllll}200 & 49 & 39 & 60 & 40 & 617 & 598 & 228 & 255 & 74 & 60\end{array}$ $\begin{array}{lllllllllll}200 & 49 & 39 & 60 & 40 & 617 & 598 & 228 & 255 & 74 & 60\end{array}$ $\begin{array}{lllllllllll}200 & 49 & 39 & 60 & 40 & 617 & 598 & 228 & 255 & 74 & 60\end{array}$ $\begin{array}{lllllllllll}200 & 49 & 39 & 60 & 40 & 617 & 598 & 228 & 255 & 74 & 60\end{array}$ $\begin{array}{lllllllllll}200 & 49 & 39 & 60 & 40 & 617 & 598 & 228 & 255 & 74 & 60\end{array}$ $\begin{array}{lllllllllll}200 & 49 & 39 & 60 & 40 & 617 & 598 & 228 & 255 & 74 & 60\end{array}$ $\begin{array}{lllllllllll}200 & 49 & 39 & 60 & 40 & 617 & 598 & 228 & 255 & 74 & 60\end{array}$ $\begin{array}{lllllllllll}200 & 49 & 39 & 60 & 40 & 617 & 598 & 228 & 255 & 74 & 60\end{array}$ $\begin{array}{lllllllllll}200 & 49 & 39 & 60 & 40 & 617 & 598 & 228 & 255 & 74 & 60\end{array}$ $\begin{array}{lllllllllll}400 & 49 & 39 & 60 & 40 & 617 & 598 & 228 & 255 & 74 & 60\end{array}$ $\begin{array}{lllllllllll}400 & 49 & 39 & 60 & 40 & 617 & 598 & 228 & 255 & 74 & 60\end{array}$ $\begin{array}{lllllllllll}400 & 49 & 39 & 60 & 40 & 617 & 598 & 228 & 255 & 74 & 60\end{array}$ $\begin{array}{lllllllllll}400 & 49 & 39 & 60 & 40 & 617 & 598 & 228 & 255 & 74 & 60\end{array}$ $\begin{array}{lllllllllll}400 & 49 & 39 & 60 & 40 & 617 & 598 & 228 & 255 & 74 & 60\end{array}$ $\begin{array}{lllllllllll}400 & 49 & 39 & 60 & 40 & 617 & 598 & 228 & 255 & 74 & 60\end{array}$ $\begin{array}{lllllllllll}398 & 49 & 39 & 60 & 40 & 617 & 598 & 228 & 255 & 74 & 60\end{array}$ $\begin{array}{lllllllllll}400 & 49 & 39 & 60 & 40 & 617 & 598 & 228 & 255 & 74 & 60\end{array}$ $\begin{array}{lllllllllll}400 & 49 & 39 & 60 & 40 & 617 & 598 & 228 & 255 & 74 & 60\end{array}$ $\begin{array}{lllllllllll}400 & 49 & 39 & 60 & 40 & 617 & 598 & 228 & 255 & 74 & 60\end{array}$ $\begin{array}{lllllllllll}400 & 49 & 39 & 60 & 40 & 617 & 598 & 228 & 255 & 74 & 60\end{array}$ $\begin{array}{lllllllllll}400 & 49 & 39 & 60 & 40 & 617 & 598 & 228 & 255 & 74 & 60\end{array}$ $\begin{array}{lllllllllll}401 & 49 & 39 & 60 & 40 & 617 & 598 & 228 & 255 & 74 & 60\end{array}$ $\begin{array}{lllllllllll}400 & 49 & 39 & 60 & 40 & 617 & 598 & 228 & 255 & 74 & 60\end{array}$ $\begin{array}{lllllllllll}200 & 25 & 21 & 57 & 49 & 648 & 704 & 209 & 335 & 139 & 80\end{array}$ $\begin{array}{lllllllllll}200 & 25 & 21 & 57 & 49 & 648 & 704 & 209 & 335 & 139 & 80\end{array}$ $\begin{array}{lllllllllll}200 & 25 & 21 & 57 & 49 & 648 & 704 & 209 & 335 & 139 & 80\end{array}$ $\begin{array}{lllllllllll}200 & 25 & 21 & 57 & 49 & 648 & 704 & 209 & 335 & 139 & 80\end{array}$ $\begin{array}{lllllllllll}200 & 25 & 21 & 57 & 49 & 648 & 704 & 209 & 335 & 139 & 80\end{array}$ $\begin{array}{lllllllllll}200 & 25 & 21 & 57 & 49 & 648 & 704 & 209 & 335 & 139 & 80\end{array}$ $\begin{array}{lllllllllll}200 & 25 & 21 & 57 & 49 & 648 & 704 & 209 & 335 & 139 & 80\end{array}$ $\begin{array}{lllllllllll}200 & 25 & 21 & 57 & 49 & 648 & 704 & 209 & 335 & 139 & 80\end{array}$ $\begin{array}{lllllllllll}200 & 25 & 21 & 57 & 49 & 648 & 704 & 209 & 335 & 139 & 80\end{array}$ $\begin{array}{lllllllllll}200 & 25 & 21 & 57 & 49 & 648 & 704 & 209 & 335 & 139 & 80\end{array}$ $\begin{array}{lllllllllll}200 & 25 & 21 & 57 & 49 & 648 & 704 & 209 & 335 & 139 & 80\end{array}$ $\begin{array}{lllllllllll}200 & 25 & 21 & 57 & 49 & 648 & 704 & 209 & 335 & 139 & 80\end{array}$ $\begin{array}{lllllllllll}200 & 25 & 21 & 57 & 49 & 648 & 704 & 209 & 335 & 139 & 80\end{array}$ $\begin{array}{lllllllllll}200 & 25 & 21 & 57 & 49 & 648 & 704 & 209 & 335 & 139 & 80\end{array}$ $\begin{array}{lllllllllll}400 & 25 & 21 & 57 & 49 & 648 & 704 & 209 & 335 & 139 & 80\end{array}$ $\begin{array}{lllllllllll}400 & 25 & 21 & 57 & 49 & 648 & 704 & 209 & 335 & 139 & 80\end{array}$

\begin{tabular}{|c|c|c|c|c|c|}
\hline$\underset{[\mathrm{kN}]}{\mathrm{F}}$ & $\begin{array}{c}\tau \\
{[\mathrm{MPa}]}\end{array}$ & $\underset{[\mathrm{mm}]}{w}$ & $\begin{array}{c}\mathrm{S} \\
{[\mathrm{KN} / \mathrm{mm}]}\end{array}$ & $\begin{array}{c}K \\
{[\mathrm{MPa} / \mathrm{mm}]}\end{array}$ & $\stackrel{M}{M}$ \\
\hline 14 & 01 & 45 & 08 & 00 & 03 \\
\hline 12 & 01 & 30 & 07 & 00 & 04 \\
\hline 32 & 02 & 42 & 37 & 02 & 08 \\
\hline 52 & 03 & 31 & 87 & 05 & 16 \\
\hline 47 & 03 & 14 & 79 & 04 & 33 \\
\hline 189 & 11 & 29 & 130 & 07 & 65 \\
\hline 208 & 12 & 27 & 146 & 08 & 76 \\
\hline 196 & 11 & 23 & 102 & 06 & 86 \\
\hline 182 & 10 & 23 & 87 & 05 & 79 \\
\hline 189 & 11 & 18 & 174 & 10 & 104 \\
\hline 237 & 13 & 34 & 158 & 09 & 69 \\
\hline 232 & 13 & 35 & 139 & 08 & 67 \\
\hline 214 & 12 & 32 & 162 & 09 & 67 \\
\hline 180 & 10 & 23 & 166 & 09 & 80 \\
\hline 182 & 10 & 50 & 46 & 03 & 37 \\
\hline 204 & 12 & 27 & 131 & 07 & 77 \\
\hline 192 & 11 & 23 & 122 & 07 & 83 \\
\hline 186 & 11 & 23 & 94 & 05 & 81 \\
\hline 205 & 12 & 2.3 & 152 & 09 & 90 \\
\hline 188 & 11 & 26 & 139 & 08 & 72 \\
\hline 61 & 03 & 22 & 48 & 03 & 27 \\
\hline 53 & 03 & 30 & 26 & 01 & 18 \\
\hline 56 & 03 & 32 & 37 & 02 & 18 \\
\hline 37 & 02 & 33 & 29 & 02 & 11 \\
\hline 26 & 01 & 32 & 27 & 02 & 08 \\
\hline 28 & 02 & 25 & 34 & 02 & 12 \\
\hline 50 & 03 & 26 & 45 & 03 & 20 \\
\hline 30 & 02 & 28 & 30 & 02 & 10 \\
\hline 41 & 02 & 25 & 26 & 01 & 16 \\
\hline 37 & 02 & 26 & 39 & 02 & 14 \\
\hline 43 & 02 & 33 & 41 & 02 & 13 \\
\hline 60 & 03 & 31 & 41 & 02 & 19 \\
\hline 33 & 02 & 26 & 37 & 02 & 13 \\
\hline 47 & 03 & 31 & 29 & 02 & 15 \\
\hline 176 & 10 & 39 & 77 & 04 & 45 \\
\hline 385 & 22 & 33 & 178 & 10 & 116 \\
\hline 213 & 12 & 30 & 94 & 05 & 71 \\
\hline 239 & 14 & 27 & 119 & 07 & 88 \\
\hline 207 & 12 & 34 & 86 & 05 & 61 \\
\hline 285 & 26 & 43 & 121 & 07 & 67 \\
\hline 419 & 24 & 44 & 194 & 11 & 95 \\
\hline 273 & 15 & 29 & 139 & 08 & 95 \\
\hline 197 & 11 & 35 & 8.5 & 05 & 56 \\
\hline 129 & 07 & 45 & 77 & 04 & 29 \\
\hline 161 & 09 & 46 & 57 & 03 & 35 \\
\hline 221 & 13 & 32 & 118 & 07 & 70 \\
\hline 217 & 12 & 31 & 99 & 06 & 71 \\
\hline 294 & 17 & 36 & 149 & 08 & 83 \\
\hline 45 & 03 & 34 & 28 & 02 & 13 \\
\hline 40 & 02 & 43 & 1.5 & 01 & 09 \\
\hline
\end{tabular}


Table A.1: New Road - continued 4

\begin{tabular}{|c|c|c|c|c|c|c|c|c|c|c|c|c|c|c|c|c|}
\hline $\begin{array}{l}T \\
{\left[{ }^{\circ} \mathrm{C}\right]}\end{array}$ & $\begin{array}{l}\text { AV } 1 \\
\text { [\%] }\end{array}$ & $\begin{array}{l}\text { AV } 2 \\
\text { [\%] }\end{array}$ & $\begin{array}{l}B C 1 \\
{[\%]}\end{array}$ & $\begin{array}{l}B C 2 \\
{[\%]}\end{array}$ & $\begin{array}{l}8 \_1 \\
{[\%]}\end{array}$ & 8_2 & [\%] & $\begin{array}{l}2 \_2 \\
{[\%]}\end{array}$ & $\begin{array}{l}\text { Fil_1 } \\
\text { [\%] }\end{array}$ & $\begin{array}{l}\text { Fil_2 } \\
{[\%]}\end{array}$ & $\begin{array}{c}\mathrm{F} \\
{[\mathrm{kN}]}\end{array}$ & $\begin{array}{c}\tau \\
{[\mathrm{MPa}]}\end{array}$ & $\stackrel{w}{w}$ & $\begin{array}{c}\mathrm{S} \\
{[\mathrm{KN} / \mathrm{mm}]}\end{array}$ & $\begin{array}{c}\mathrm{K} \\
{[\mathrm{MPa} / \mathrm{mm}]}\end{array}$ & $\stackrel{M}{M}$ \\
\hline 400 & 25 & 21 & 57 & 49 & 648 & 704 & 209 & 335 & 139 & 80 & 47 & 03 & 58 & 17 & 01 & 08 \\
\hline 400 & 25 & 21 & 57 & 49 & 648 & 704 & 209 & 335 & 139 & 80 & 25 & 01 & 41 & 0.9 & 00 & 06 \\
\hline 400 & 25 & 21 & 57 & 49 & 648 & 704 & 209 & 335 & 139 & 80 & 28 & 02 & 38 & 1.5 & 01 & 07 \\
\hline 400 & 25 & 21 & 57 & 49 & 648 & 704 & 209 & 335 & 139 & 80 & 44 & 02 & 43 & 1.3 & 01 & 10 \\
\hline 400 & 25 & 21 & 57 & 49 & 648 & 704 & 209 & 335 & 139 & 80 & 37 & 02 & 45 & 11 & 01 & 08 \\
\hline 400 & 25 & 21 & 57 & 49 & 648 & 704 & 209 & 335 & 139 & 80 & 33 & 02 & 59 & 1.3 & 01 & 06 \\
\hline 400 & 25 & 21 & 57 & 49 & 648 & 704 & 209 & 335 & 139 & 80 & 72 & 04 & 50 & 2.9 & 02 & 14 \\
\hline 400 & 25 & 21 & 57 & 49 & 648 & 704 & 209 & 335 & 139 & 80 & 48 & 03 & 32 & 21 & 01 & 15 \\
\hline 400 & 25 & 21 & 57 & 49 & 648 & 704 & 209 & 335 & 139 & 80 & 55 & 03 & 33 & 32 & 02 & 17 \\
\hline 400 & 25 & 21 & 57 & 49 & 648 & 704 & 209 & 335 & 139 & 80 & 46 & 03 & 59 & 14 & 01 & 08 \\
\hline 200 & 48 & 38 & 49 & 43 & 735 & 800 & 332 & 350 & 77 & 70 & 254 & 14 & 25 & 160 & 09 & 100 \\
\hline 200 & 48 & 38 & 49 & 43 & 735 & 800 & 332 & 350 & 77 & 70 & 281 & 16 & 33 & 194 & 11 & 85 \\
\hline 200 & 48 & 38 & 49 & 43 & 735 & 800 & 332 & 350 & 77 & 70 & 232 & 13 & 22 & 166 & 09 & 106 \\
\hline 200 & 48 & 38 & 49 & 43 & 735 & 800 & 332 & 350 & 77 & 70 & 296 & 17 & 33 & 194 & 11 & 90 \\
\hline 200 & 48 & 38 & 49 & 43 & 735 & 800 & 332 & 350 & 77 & 70 & 314 & 18 & 34 & 187 & 11 & 92 \\
\hline 200 & 48 & 38 & 49 & 43 & 735 & 800 & 332 & 350 & 77 & 70 & 243 & 14 & 19 & 176 & 10 & 130 \\
\hline 200 & 48 & 38 & 49 & 43 & 735 & 800 & 332 & 350 & 77 & 70 & 287 & 16 & 33 & 145 & 08 & 87 \\
\hline 200 & 48 & 38 & 49 & 43 & 735 & 800 & 332 & 350 & 77 & 70 & 290 & 16 & 37 & 169 & 10 & 79 \\
\hline 200 & 67 & 40 & 64 & 35 & 705 & 443 & 233 & 247 & 95 & 60 & 213 & 12 & 29 & 103 & 06 & 74 \\
\hline 200 & 67 & 40 & 64 & 35 & 705 & 443 & 233 & 247 & 95 & 60 & 165 & 09 & 24 & 142 & 08 & 69 \\
\hline 200 & 67 & 40 & 64 & 35 & 705 & 443 & 233 & 247 & 95 & 60 & 149 & 08 & 28 & 77 & 04 & 53 \\
\hline 200 & 67 & 40 & 64 & 35 & 705 & 443 & 233 & 247 & 95 & 60 & 176 & 10 & 37 & 73 & 04 & 48 \\
\hline 200 & 67 & 40 & 64 & 35 & 705 & 443 & 233 & 247 & 95 & 60 & 161 & 09 & 32 & 7.0 & 04 & 50 \\
\hline 200 & 67 & 40 & 64 & 35 & 705 & 443 & 233 & 247 & 95 & 60 & 197 & 11 & 32 & 8.8 & 05 & 62 \\
\hline 200 & 67 & 40 & 64 & 35 & 705 & 443 & 233 & 247 & 95 & 60 & 203 & 11 & 38 & 63 & 04 & 53 \\
\hline 400 & 67 & 40 & 64 & 35 & 705 & 443 & 233 & 247 & 95 & 60 & 97 & 06 & 50 & 40 & 02 & 20 \\
\hline 400 & 67 & 40 & 64 & 35 & 705 & 443 & 233 & 247 & 95 & 60 & 63 & 04 & 37 & 33 & 02 & 17 \\
\hline 400 & 67 & 40 & 64 & 35 & 705 & 443 & 233 & 247 & 95 & 60 & 25 & 01 & 27 & 31 & 02 & 09 \\
\hline 400 & 67 & 40 & 64 & 35 & 705 & 443 & 233 & 247 & 95 & 60 & 29 & 02 & 25 & 20 & 01 & 12 \\
\hline 400 & 67 & 40 & 64 & 35 & 705 & 443 & 233 & 247 & 95 & 60 & 68 & 04 & 83 & 26 & 01 & 08 \\
\hline 400 & 67 & 40 & 64 & 35 & 705 & 443 & 233 & 247 & 95 & 60 & 70 & 04 & 41 & 3.2 & 02 & 17 \\
\hline 400 & 67 & 40 & 64 & 35 & 705 & 443 & 233 & 247 & 95 & 60 & 67 & 04 & 33 & 31 & 02 & 20 \\
\hline 400 & 67 & 40 & 64 & 35 & 705 & 443 & 233 & 247 & 95 & 60 & 34 & 02 & 27 & 3.0 & 02 & 12 \\
\hline 200 & 97 & 62 & 55 & 40 & 821 & 518 & 373 & 268 & 71 & 63 & 207 & 12 & 34 & 108 & 06 & 60 \\
\hline 200 & 97 & 62 & 55 & 40 & 821 & 518 & 373 & 268 & 71 & 63 & 101 & 06 & 25 & 46 & 03 & 40 \\
\hline 200 & 97 & 62 & 55 & 40 & 821 & 518 & 373 & 268 & 71 & 63 & 182 & 10 & 32 & 8.2 & 05 & 57 \\
\hline 200 & 97 & 62 & 55 & 40 & 821 & 518 & 373 & 268 & 71 & 63 & 221 & 13 & 37 & 79 & 04 & 60 \\
\hline 200 & 97 & 62 & 55 & 40 & 821 & 518 & 373 & 268 & 71 & 63 & 189 & 11 & 31 & 66 & 04 & 61 \\
\hline 200 & 97 & 62 & 55 & 40 & 821 & 518 & 373 & 268 & 71 & 63 & 151 & 09 & 32 & 6.3 & 04 & 47 \\
\hline 200 & 97 & 62 & 55 & 40 & 821 & 518 & 373 & 268 & 71 & 63 & 99 & 06 & 21 & 6.4 & 04 & 48 \\
\hline 200 & 97 & 62 & 55 & 40 & 821 & 518 & 373 & 268 & 71 & 63 & 22.4 & 13 & 33 & 114 & 06 & 67 \\
\hline 200 & 97 & 62 & 55 & 40 & 821 & 518 & 373 & 268 & 71 & 63 & 145 & 08 & 30 & 71 & 04 & 49 \\
\hline 200 & 97 & 62 & 55 & 40 & 821 & 518 & 373 & 268 & 71 & 63 & 135 & 08 & 22 & 108 & 06 & 62 \\
\hline 200 & 97 & 62 & 55 & 40 & 821 & 518 & 373 & 268 & 71 & 63 & 109 & 06 & 31 & 5.3 & 03 & 36 \\
\hline 200 & 97 & 62 & 55 & 40 & 821 & 518 & 373 & 268 & 71 & 63 & 149 & 08 & 23 & 103 & 06 & 65 \\
\hline 200 & 97 & 62 & 55 & 40 & 821 & 518 & 373 & 268 & 71 & 63 & 212 & 12 & 32 & 91 & 05 & 66 \\
\hline 200 & 97 & 62 & 55 & 40 & 821 & 518 & 373 & 268 & 71 & 63 & 159 & 09 & 31 & 86 & 05 & 51 \\
\hline 400 & 97 & 62 & 55 & 40 & 821 & 518 & 373 & 268 & 71 & 63 & 56 & 03 & 33 & 26 & 01 & 17 \\
\hline 400 & 97 & 62 & 55 & 40 & 821 & 518 & 373 & 268 & 71 & 63 & 71 & 04 & 44 & 2.2 & 01 & 16 \\
\hline 400 & 97 & 62 & 55 & 40 & 821 & 518 & 373 & 268 & 71 & 63 & 74 & 04 & 30 & 39 & 02 & 25 \\
\hline
\end{tabular}


Table A.1: New Road - continued 5

No Name

201 SOAB-13 DSHMT-40

202 SOAB-23_DSHMT-40

203 SOAB-27_DSHMT-40

204 SOAB-29_DSHMT-40

205 SOAB-3_DSHMT-4O

206 SOAB-30 DSHMT-40

207 SOAB-5_DSHMT-40

208 SOAB-6_DSHMT-4O

209 SOAB, GrenchenA 2aDSHMT 20

210 SOAB, GrenchenA 3aDSHMT 20

211 SOAB, GrenchenA GaDSHMT-20

212 SOAB, GrenchenA 7 aDSHMT-20

213 SOAB,GrenchenA 8aDSHMT 20

214 SOAB, GrenchenA 11aDSHMT 20

215 SOAB, GrenchenA 13aDSHMT 20

216 SOAB,GrenchenA 16aDSHMT 20

217 SOAB,GrenchenB 1 b_DSHMT-20

218 SOAB, GrenchenB 2b DSHMT-20

219 SOAB, GrenchenB 3b_DSHMT 20

220 SOAB, GrenchenB 5b DSHMT 20

221 SOAB,GrenchenB 6b DSHMT 20

222 SOAB,GrenchenB 7b_DSHMT 20

224 SOAB,GrenchenB 14b_DSHMT-20 20053 225 SOAB,GrenchenB $16 \mathrm{~b}$ DSSHMT-20

226 BSGrenz 3a"_DSHMT 20

227 BSGrenz 3b_DSHMT-20

228 BSGrenz 3c_DSHMT-20

229 BSGrenz 3d_DSHMT 20

230 BSGrenz 4a DSHMT-20

231 BSGrenz 4b_DSHMT 20

232 BSGrenz 4c DSHMT 20

233 BSGrenz 4d_DSHMT 20

234 BSGrenz 5a_DSHMT-20

235 BSGrenz 5b_DSHMT 20

236 BSGrenz 5c_DSHMT-20

237 BSGrenz 5d_DSHMT 20

238 BSGrenz 6b_OSHMT 20

239 BSGrenz 7a_DSHMT 20

240 BSGrenz 1a DSHMT-40

241 BSGrenz 1b_OSHMT-40

242 BSGrenz 1c DSHMT-40

243 BSGrenz 1d_DSHMT-40

244 BSGrenz 2a_DSHMT-40

245 BSGrenz 2c_DSHMT-40

246 AGHotroll 1 DSHMT 20

247 AGHotroll 10 DSHMT 20

248 AGHotroll 11 DSHMT 20

249 AGHotroll 2 DSHMT-20

250 AGHotroll 26 DSHMT 20

\begin{tabular}{|c|c|c|c|c|c|c|c|c|c|}
\hline & AV 1 & AV 2 & $B C 1$ & $B C 2$ & 8_1 & 8_2 & 2_1 & $2{ }^{2} 2$ & Fil_1 \\
\hline 400 & 97 & 62 & 55 & 40 & 821 & 518 & 373 & 268 & 71 \\
\hline 400 & 97 & 62 & 55 & 40 & 821 & 518 & 373 & 268 & 71 \\
\hline 400 & 97 & 62 & 55 & 40 & 821 & 518 & 373 & 268 & 71 \\
\hline 0 & 97 & 62 & 55 & 40 & 821 & 518 & 373 & 268 & 71 \\
\hline 900 & 97 & 62 & 55 & 40 & 821 & 518 & 373 & 268 & 71 \\
\hline 400 & 97 & 62 & 55 & 40 & 821 & 518 & 373 & 268 & 71 \\
\hline 100 & 97 & 62 & 55 & 40 & 821 & 518 & 373 & 268 & 71 \\
\hline 400 & 97 & 62 & 55 & 40 & 821 & 518 & 373 & 268 & 71 \\
\hline 00 & 56 & 51 & 58 & 43 & 847 & 545 & 420 & 280 & 71 \\
\hline 200 & 56 & 51 & 58 & 43 & 847 & 545 & 420 & 280 & 71 \\
\hline 200 & 56 & 51 & 58 & 43 & 847 & 545 & 420 & 280 & 71 \\
\hline 200 & 56 & 51 & 58 & 43 & 847 & 545 & 420 & 280 & 71 \\
\hline 200 & 56 & 51 & 58 & 43 & 847 & 545 & 420 & 280 & 71 \\
\hline 200 & 56 & 51 & 58 & 43 & 847 & 545 & 420 & 280 & 71 \\
\hline 200 & 56 & 51 & 58 & 43 & 847 & 545 & 420 & 280 & 71 \\
\hline 200 & 56 & 51 & 58 & 43 & 847 & 545 & 420 & 280 & 71 \\
\hline 200 & 53 & 85 & 59 & 41 & 841 & 501 & 432 & 262 & 118 \\
\hline 200 & 53 & 85 & 59 & 41 & 841 & 501 & 432 & 262 & 118 \\
\hline 200 & 53 & 85 & 59 & 41 & 841 & 501 & 432 & 262 & 118 \\
\hline 200 & 53 & 85 & 59 & 41 & 841 & 501 & 432 & 262 & 118 \\
\hline 200 & 53 & 85 & 59 & 41 & 841 & 501 & 432 & 262 & 118 \\
\hline 200 & 53 & 85 & 59 & 41 & 841 & 501 & 432 & 262 & 118 \\
\hline 200 & 53 & 85 & 59 & 41 & 841 & 501 & 432 & 262 & 118 \\
\hline 200 & 53 & 85 & 59 & 41 & 841 & 501 & 432 & 262 & 118 \\
\hline 200 & 53 & 85 & 59 & 41 & 841 & 501 & 432 & 262 & 118 \\
\hline 200 & 57 & 45 & 63 & 38 & 665 & 440 & 219 & 250 & 79 \\
\hline 200 & 57 & 45 & 63 & 38 & 665 & 440 & 219 & 250 & 79 \\
\hline 200 & 57 & 45 & 63 & 38 & 665 & 440 & 219 & 250 & 79 \\
\hline 200 & 57 & 45 & 63 & 38 & 665 & 440 & 219 & 250 & 79 \\
\hline 200 & 57 & 45 & 63 & 38 & 665 & 440 & 219 & 250 & 79 \\
\hline 200 & 57 & 45 & 63 & 38 & 665 & 440 & 219 & 250 & 79 \\
\hline 200 & 57 & 45 & 63 & 38 & 665 & 440 & 219 & 250 & 79 \\
\hline 200 & 57 & 45 & 63 & 38 & 665 & 440 & 219 & 250 & 79 \\
\hline 200 & 57 & 45 & 63 & 38 & 665 & 440 & 219 & 250 & 79 \\
\hline 200 & 57 & 45 & 63 & 38 & 665 & 440 & 219 & 250 & 79 \\
\hline 200 & 57 & 45 & 63 & 38 & 665 & 440 & 219 & 250 & 79 \\
\hline 200 & 57 & 45 & 63 & 38 & 665 & 440 & 219 & 250 & 79 \\
\hline 200 & 57 & 45 & 63 & 38 & 665 & 440 & 219 & 250 & 79 \\
\hline 400 & 57 & 45 & 63 & 38 & 665 & 440 & 219 & 250 & 79 \\
\hline 400 & 57 & 45 & 63 & 38 & 665 & 440 & 219 & 250 & 79 \\
\hline 400 & 57 & 45 & 63 & 38 & 665 & 440 & 219 & 250 & 79 \\
\hline 400 & 57 & 45 & 63 & 38 & 665 & 440 & 219 & 250 & 79 \\
\hline 400 & 57 & 45 & 63 & 38 & 665 & 440 & 219 & 250 & 79 \\
\hline 400 & 57 & 45 & 63 & 38 & 665 & 440 & 219 & 250 & 79 \\
\hline 400 & 57 & 45 & 63 & 38 & 665 & 440 & 219 & 250 & 79 \\
\hline 200 & 26 & 92 & 78 & 43 & 856 & 604 & 630 & 302 & 99 \\
\hline 200 & 26 & 92 & 78 & 43 & 856 & 604 & 630 & 302 & 99 \\
\hline 200 & 26 & 92 & 78 & 43 & 856 & 604 & 630 & 302 & 99 \\
\hline 200 & 26 & 92 & 78 & 43 & 856 & 604 & 630 & 302 & 99 \\
\hline & 26 & 92 & 78 & 43 & 856 & 604 & 630 & 302 & 99 \\
\hline
\end{tabular}

$\begin{array}{ccc}F & \tau & w \\ 93 & 05 & 45 \\ 58 & 03 & 31 \\ 29 & 02 & 17 \\ 58 & 03 & 41 \\ 95 & 05 & 33 \\ 66 & 0.4 & 38 \\ 98 & 06 & 34\end{array}$

$\begin{array}{llll}72 & 04 & 38 & 29\end{array}$

$\begin{array}{llll}234 & 13 & 37 & 101\end{array}$

$\begin{array}{lllll}301 & 17 & 28 & 15\end{array}$

$\begin{array}{llll}215 & 12 & 28 & 127\end{array}$

$\begin{array}{llll}303 & 17 & 32 & 134\end{array}$

$\begin{array}{llll}216 & 12 & 42 & 111\end{array}$

$\begin{array}{llll}230 & 13 & 20 & 169\end{array}$

$\begin{array}{llll}273 & 15 & 35 & 86\end{array}$

$259 \quad 15 \quad 44 \quad 9 A$

$\begin{array}{llll}249 & 14 & 15 & 338\end{array}$

$\begin{array}{llll}260 & 15 & 31 & 133\end{array}$

$\begin{array}{llll}262 & 15 & 26 & 18\end{array}$

$\begin{array}{llll}321 & 18 & 43 & 177\end{array}$

$209 \quad 12 \quad 20 \quad 152$

$\begin{array}{llll}237 & 13 & 33 & 129\end{array}$

$\begin{array}{llll}27 & 15 & 33 & 14\end{array}$

$\begin{array}{llll}218 & 12 & 25 & 15\end{array}$

$\begin{array}{llll}220 & 12 & 31 & 118\end{array}$

$\begin{array}{llll}293 & 17 & 30 & 198\end{array}$

$\begin{array}{llll}304 & 17 & 33 & 15\end{array}$

$\begin{array}{llll}310 & 18 & 28 & 165\end{array}$

$\begin{array}{llll}337 & 19 & 31 & 204\end{array}$

$\begin{array}{lll}323 & 18 & 31\end{array}$

$\begin{array}{llll}315 & 18 & 34 & 172\end{array}$

$290 \quad 16 \quad 29 \quad 16$

$\begin{array}{llll}285 & 16 & 32 & 133\end{array}$

$\begin{array}{llll}304 & 17 & 35 & 17\end{array}$

$\begin{array}{llll}262 & 15 & 35 & 124\end{array}$

$\begin{array}{llll}280 & 16 & 32 & 137\end{array}$

$\begin{array}{llll}268 & 15 & 28 & 160\end{array}$

$\begin{array}{llll}263 & 15 & 33 & 126\end{array}$

$\begin{array}{llll}227 & 13 & 36 & 112\end{array}$

$\begin{array}{llll}75 & 04 & 33 & 44\end{array}$

$\begin{array}{llll}65 & 04 & 35 & 3.0\end{array}$

$\begin{array}{llll}77 & 04 & 67 & 31\end{array}$

$\begin{array}{llll}77 & 04 & 34 & 35\end{array}$

$\begin{array}{llll}91 & 05 & 50 & 38\end{array}$

$\begin{array}{llll}82 & 05 & 37 & 34\end{array}$

$\begin{array}{llll}361 & 20 & 38 & 126\end{array}$

$\begin{array}{lll}335 & 19 & 35\end{array}$

$\begin{array}{llll}213 & 12 & 37 & 98\end{array}$

$\begin{array}{llll}337 & 19 & 29 & 136\end{array}$

$\begin{array}{llll}292 & 17 & 40 & 94\end{array}$

\begin{tabular}{|c|c|}
\hline K & $M$ \\
\hline 02 & 20 \\
\hline 02 & 19 \\
\hline 02 & 17 \\
\hline 01 & 14 \\
\hline 03 & 29 \\
\hline 01 & 17 \\
\hline 02 & 29 \\
\hline 02 & 19 \\
\hline 06 & 64 \\
\hline 09 & 107 \\
\hline 07 & 76 \\
\hline 08 & 93 \\
\hline 06 & 51 \\
\hline 10 & 114 \\
\hline 05 & 79 \\
\hline 05 & 59 \\
\hline 19 & 166 \\
\hline 08 & 85 \\
\hline 10 & 102 \\
\hline 10 & 74 \\
\hline 09 & 103 \\
\hline 07 & 71 \\
\hline 08 & 82 \\
\hline 09 & 88 \\
\hline 07 & 71 \\
\hline 11 & 97 \\
\hline 09 & 92 \\
\hline 09 & 112 \\
\hline 12 & 108 \\
\hline 11 & 103 \\
\hline 10 & 93 \\
\hline 09 & 100 \\
\hline 08 & 88 \\
\hline 10 & 87 \\
\hline 07 & 74 \\
\hline 08 & 86 \\
\hline 09 & 95 \\
\hline 07 & 80 \\
\hline 06 & 63 \\
\hline 02 & 23 \\
\hline 02 & 19 \\
\hline 02 & 12 \\
\hline 02 & 23 \\
\hline 02 & 18 \\
\hline 02 & 22 \\
\hline 07 & 96 \\
\hline 08 & 97 \\
\hline 06 & 58 \\
\hline 08 & 115 \\
\hline 05 & 72 \\
\hline
\end{tabular}


Table A.1: New Road - continued 6

No Name

251 AGHotroll 28 DSHMT 20 252 AGHotroll 3 DSHMT 20

253 AGHotroll 35 DSHMT 20 254 AGHot roll 36 DSHMT 20

255 AGHotroll 37 DSHMT 20 256 AGHot roll 4 DSHMT 20

257 AGHotroll 5 DSHMT 20

258 AGHotroll 6 DSHMT 20

259 AGHot roll 8 DSHMT 20

260 AGHotroll 14 DSHMT 40

261 AGHotroll 24 DSHMT-40

262 AGHot roll 31 DSHMT-40

263 AGHotroll 32 DSHMT-40

264 AGHotroll 38 DSHMT 40

265 AGHotroll 41 DSHMT 40

266 AGSMA(96)-4 DsHMT 20

267 AGSMA(96) 6 DSHMT 20

268 AGSMA(96)-7 DSHMT 20

269 AGSMA(96)-12 DSHMT 20

270 AGSMA(96)-13 DsHMT 20

271 AGSMA(96)-15 DSHMT 20

272 AGSMA(96)-18 DsHMT 20

273 AGSMA(96)-20 DsHMT 20

274 AGSMA(96)-22 DsHMT 20

275 AGSMA(96)-24 DSHMT 20

276 AGSMA(96) 26 DSHMT 20

277 AGSMA(96)-11 DsHMT 40

278 AGSMA(96)-14 DSHMT-40

279 AGSMA(96) 16 DSHMT-40

280 AGSMA(96)-21 DsHMT 40

281 AGSMA(96) 23 DSHMT 40

282 AGSMA(96) 25 DsHMT-40

283 AGSMA(96) 29 DsHMT-40

284 AGSMA(96) 30 DsHMT 40

285 MontlingenM13SMAHMT22

286 MontlingenM14SMAHMT23

287 MontlingenM9SMAHMT24

288 MontlingenM15SMAHMT25

289 MontlingenM156SMAHMT26

290 MontlingenM11SMAHMT 27

291 MontlingenM12SMAHMT28

292 MontlingenM3SMAHMT 29

\begin{tabular}{|c|c|c|c|c|c|c|c|c|c|c|c|c|c|c|c|c|}
\hline$T$ & AV 1 & AV 2 & $B C 1$ & $B C 2$ & 8_1 & 8_2 & 2_1 & $2 \_2$ & Fil_1 & FII_2 & $F$ & $\tau$ & $w$ & 5 & K & $\mathbf{M}$ \\
\hline 200 & 26 & 92 & 78 & 43 & 856 & 604 & 630 & 302 & 99 & 86 & 228 & 13 & 48 & 67 & 04 & 48 \\
\hline 200 & 26 & 92 & 78 & 43 & 856 & 604 & 630 & 302 & 99 & 86 & 399 & 23 & 30 & 159 & 09 & 134 \\
\hline 200 & 26 & 92 & 78 & 43 & 856 & 604 & 630 & 302 & 99 & 86 & 202 & 11 & 52 & 68 & 04 & 39 \\
\hline 200 & 26 & 92 & 78 & 43 & 856 & 604 & 630 & 302 & 99 & 86 & 246 & 14 & 45 & 97 & 06 & 55 \\
\hline 200 & 26 & 92 & 78 & 43 & 856 & 604 & 630 & 302 & 99 & 86 & 176 & 10 & 59 & 50 & 03 & 30 \\
\hline 200 & 26 & 92 & 78 & 43 & 856 & 604 & 630 & 302 & 99 & 86 & 392 & 22 & 26 & 174 & 10 & 150 \\
\hline 200 & 26 & 92 & 78 & 43 & 856 & 604 & 630 & 302 & 99 & 86 & 382 & 22 & 25 & 173 & 10 & 153 \\
\hline 200 & 26 & 92 & 78 & 43 & 856 & 604 & 630 & 302 & 99 & 86 & 386 & 22 & 29 & 164 & 09 & 134 \\
\hline 200 & 26 & 92 & 78 & 43 & 856 & 604 & 630 & 302 & 99 & 86 & 378 & 21 & 29 & 144 & 08 & 131 \\
\hline 400 & 26 & 92 & 78 & 43 & 856 & 604 & 630 & 302 & 99 & 86 & 80 & 04 & 32 & 49 & 03 & 25 \\
\hline 400 & 26 & 92 & 78 & 43 & 856 & 604 & 630 & 302 & 99 & 86 & 88 & 05 & 40 & 49 & 03 & 22 \\
\hline 400 & 26 & 92 & 78 & 43 & 856 & 604 & 630 & 302 & 99 & 86 & 54 & 03 & 30 & 34 & 02 & 18 \\
\hline 400 & 26 & 92 & 78 & 43 & 856 & 604 & 630 & 302 & 99 & 86 & 71 & 04 & 33 & 33 & 02 & 21 \\
\hline 400 & 26 & 92 & 78 & 43 & 856 & 604 & 630 & 302 & 99 & 86 & 74 & 04 & 35 & 30 & 02 & 21 \\
\hline 400 & 26 & 92 & 78 & 43 & 856 & 604 & 630 & 302 & 99 & 86 & 77 & 04 & 38 & 32 & 02 & 21 \\
\hline 200 & 35 & 44 & 78 & 43 & 856 & 604 & 630 & 302 & 99 & 86 & 271 & 15 & 19 & 202 & 11 & 140 \\
\hline 200 & 35 & 44 & 78 & 43 & 856 & 604 & 630 & 302 & 99 & 86 & 259 & 15 & 26 & 182 & 10 & 101 \\
\hline 200 & 35 & 44 & 78 & 43 & 856 & 604 & 630 & 302 & 99 & 86 & 230 & 13 & 21 & 168 & 09 & 112 \\
\hline 200 & 35 & 44 & 78 & 43 & 856 & 604 & 630 & 302 & 99 & 86 & 224 & 13 & 16 & 137 & 08 & 140 \\
\hline 200 & 35 & 44 & 78 & 43 & 856 & 604 & 630 & 302 & 99 & 86 & 275 & 16 & 22 & 170 & 10 & 128 \\
\hline 200 & 35 & 44 & 78 & 43 & 856 & 604 & 630 & 302 & 99 & 86 & 207 & 12 & 25 & 125 & 07 & 84 \\
\hline 200 & 35 & 44 & 78 & 43 & 856 & 604 & 630 & 302 & 99 & 86 & 283 & 16 & 29 & 161 & 09 & 98 \\
\hline 200 & 35 & 44 & 78 & 43 & 856 & 604 & 630 & 302 & 99 & 86 & 270 & 15 & 26 & 179 & 10 & 106 \\
\hline 200 & 35 & 44 & 78 & 43 & 856 & 604 & 630 & 302 & 99 & 86 & 234 & 13 & 17 & 155 & 09 & 142 \\
\hline 200 & 35 & 44 & 78 & 43 & 856 & 604 & 630 & 302 & 99 & 86 & 230 & 13 & 23 & 158 & 09 & 100 \\
\hline 200 & 35 & 44 & 78 & 43 & 856 & 604 & 630 & 302 & 99 & 86 & 283 & 16 & 22 & 178 & 10 & 127 \\
\hline
\end{tabular}

$\begin{array}{lllllllllllll}300 & 35 & 44 & 78 & 43 & 856 & 604 & 630 & 302 & 99 & 86 & 42 & 02\end{array}$

$\begin{array}{lllllllllllll}400 & 35 & 44 & 78 & 43 & 856 & 604 & 630 & 302 & 99 & 86 & 45 & 03\end{array}$

$\begin{array}{lllllllllllll}400 & 35 & 44 & 78 & 43 & 856 & 604 & 630 & 302 & 99 & 86 & 59 & 03\end{array}$

$\begin{array}{lllllllllll}400 & 35 & 44 & 78 & 43 & 856 & 604 & 630 & 302 & 99 & 86\end{array}$

$\begin{array}{lllllllllllll}400 & 35 & 44 & 78 & 43 & 856 & 604 & 630 & 302 & 99 & 86 & 47 & 03\end{array}$

$\begin{array}{lllllllllllll}400 & 35 & 44 & 78 & 43 & 856 & 604 & 630 & 302 & 99 & 86 & 39 & 02\end{array}$

$\begin{array}{lllllllllllll}400 & 35 & 44 & 78 & 43 & 856 & 604 & 630 & 302 & 99 & 86 & 33 & 02\end{array}$

$\begin{array}{lllllllllllll}200 & 40 & 45 & 60 & 40 & 564 & 589 & 187 & 305 & 84 & 88 & 330 & 19\end{array}$

$\begin{array}{lllllllllllll}200 & 40 & 45 & 60 & 40 & 564 & 589 & 187 & 305 & 84 & 88 & 268 & 15\end{array}$

$\begin{array}{lllllllllllll}200 & 40 & 45 & 60 & 40 & 564 & 589 & 187 & 305 & 84 & 88 & 275 & 16\end{array}$

$\begin{array}{lllllllllllll}200 & 40 & 45 & 60 & 40 & 564 & 589 & 187 & 305 & 84 & 88 & 329 & 19\end{array}$

$\begin{array}{lllllllllllll}200 & 40 & 45 & 60 & 40 & 564 & 589 & 187 & 305 & 84 & 88 & 296 & 17\end{array}$

$\begin{array}{lllllllllllll}200 & 40 & 45 & 60 & 40 & 564 & 589 & 187 & 305 & 84 & 88 & 298 & 17\end{array}$

$\begin{array}{llllllllllllll}200 & 40 & 45 & 60 & 40 & 564 & 589 & 187 & 305 & 84 & 88 & 302 & 17\end{array}$

$\begin{array}{lllllllllllll}200 & 40 & 45 & 60 & 40 & 564 & 589 & 187 & 305 & 84 & 88 & 317 & 18\end{array}$ 
Table A.2: LTPP-Road -1

\begin{tabular}{|c|c|c|c|c|c|c|c|c|c|c|c|c|c|c|c|c|c|c|c|c|}
\hline No & Name & $\begin{array}{l}\text { AV } 1 \\
{[\%]}\end{array}$ & $\begin{array}{l}\text { AV } 2 \\
{[\%]}\end{array}$ & $\begin{array}{l}\mathrm{BC} 1 \\
{[\%]}\end{array}$ & $\begin{array}{l}B C 2 \\
{[\%]}\end{array}$ & ADT & $\begin{array}{l}<35 T \\
{[\%]}\end{array}$ & $\begin{array}{l}\text { Age } \\
{[y]}\end{array}$ & $\begin{array}{l}8 \_1 \\
{[\%]}\end{array}$ & $\begin{array}{l}8 \_2 \\
{[\%]}\end{array}$ & $\begin{array}{l}2-1 \\
{[\%]}\end{array}$ & $\begin{array}{l}2{ }^{2} \\
{[\%]}\end{array}$ & $\begin{array}{l}F_{11} 1 \\
{[\%]}\end{array}$ & $\begin{array}{l}\text { Fil_2 } \\
{[\%]}\end{array}$ & $\begin{array}{c}\mathbf{F} \\
{[\mathrm{kN}]}\end{array}$ & $\begin{array}{c}\tau \\
{[\mathrm{MPa}]}\end{array}$ & $\underset{[\mathrm{mm}]}{w}$ & $\begin{array}{c}S \\
{[\mathrm{KN} / \mathrm{mm}]}\end{array}$ & $\begin{array}{c}K \\
{[\mathrm{MPa} / \mathrm{mm}]}\end{array}$ & $\begin{array}{c}M \\
{[\mathrm{KN} / \mathrm{mm}]}\end{array}$ \\
\hline 1 & AGGAR 1_1 & 09 & 21 & 72 & 67 & 32700 & 76 & 100 & 868 & 739 & 557 & 472 & 256 & 259 & 433 & 2.5 & 33 & 189 & 11 & 132 \\
\hline 2 & AGGAR 2 1 & 07 & 21 & 72 & 67 & 32700 & 76 & 100 & 868 & 739 & 557 & 472 & 256 & 259 & 46.1 & 2.6 & 29 & 186 & 11 & 161 \\
\hline 3 & AGGAR 3_1 & 06 & 23 & 72 & 67 & 32700 & 76 & 100 & 868 & 739 & 557 & 472 & 256 & 259 & 449 & 2.5 & 31 & 195 & 11 & 145 \\
\hline 4 & AGGAR 4_1 & 07 & 21 & 72 & 67 & 32700 & 76 & 100 & 86.8 & 739 & 557 & 472 & 256 & 259 & 435 & 2.5 & 25 & 266 & 15 & 171 \\
\hline 5 & AGGAR5_1 & 07 & 22 & 72 & 67 & 32700 & 76 & 100 & 868 & 739 & 557 & 472 & 256 & 259 & 456 & 2.6 & 27 & 259 & 15 & 170 \\
\hline 6 & AGGA M 1_1 & 11 & 24 & 72 & 67 & 32700 & 76 & 100 & 868 & 739 & 557 & 472 & 256 & 259 & 419 & 24 & 27 & 274 & 16 & 155 \\
\hline 7 & AGGA M 2_1 & 07 & 24 & 72 & 67 & 32700 & 76 & 100 & 868 & 739 & 557 & 472 & 256 & 259 & 453 & 26 & 26 & 266 & 15 & 175 \\
\hline 8 & AGGA M 3_1 & 08 & 24 & 72 & 67 & 32700 & 76 & 100 & 868 & 739 & 557 & 472 & 256 & 259 & 470 & 27 & 27 & 247 & 14 & 172 \\
\hline 9 & AGGA M 4_1 & 08 & 2.5 & 72 & 67 & 32700 & 76 & 100 & 868 & 739 & 557 & 472 & 256 & 259 & 46.2 & 2.6 & 25 & 271 & 15 & 182 \\
\hline 10 & AGGA M 5_1 & 08 & 25 & 72 & 67 & 32700 & 76 & 100 & 868 & 739 & 557 & 472 & 256 & 259 & 45.6 & 2.6 & 27 & 282 & 16 & 166 \\
\hline 11 & AGSMAR 1_1(95) & 31 & 35 & 68 & 44 & $32^{\prime} 700$ & 76 & 100 & 636 & 635 & 246 & 305 & 105 & 90 & 36.6 & 21 & 21 & 289 & 16 & 174 \\
\hline 12 & AGSMAR 2_1 & 25 & 39 & 68 & 44 & $32^{\prime} 700$ & 76 & 100 & 636 & 635 & 246 & 305 & 105 & 90 & 30.6 & 17 & 18 & 313 & 18 & 169 \\
\hline 13 & AGSMAR 3_1 & 25 & 36 & 68 & 44 & 32700 & 76 & 100 & 636 & 635 & 246 & 305 & 105 & 90 & 35.5 & 2.0 & 21 & 265 & 15 & 168 \\
\hline 14 & AGSMAR 4_1 & 26 & 3.5 & 68 & 44 & 32700 & 76 & 100 & 636 & 635 & 246 & 305 & 105 & 90 & 334 & 19 & 20 & 255 & 14 & 168 \\
\hline 15 & AGSMAR 5_1 & 34 & 34 & 68 & 44 & $32^{\prime} 700$ & 76 & 100 & 636 & 635 & 246 & 305 & 105 & 90 & 315 & 1.8 & 19 & 301 & 17 & 170 \\
\hline 16 & AGSMAM 1_1 & 32 & 31 & 68 & 44 & 32700 & 76 & 100 & 636 & 635 & 246 & 305 & 105 & 90 & 36.0 & 2.0 & 18 & 340 & 19 & 202 \\
\hline 17 & AGSMAM 2_1 & 34 & 31 & 68 & 44 & $32^{\prime} 700$ & 76 & 100 & 636 & 635 & 246 & 305 & 105 & 90 & 390 & 22 & 21 & 273 & 15 & 184 \\
\hline 18 & AGSMAM 3_1 & 32 & 29 & 68 & 44 & $32 ' 700$ & 76 & 100 & 636 & 635 & 246 & 305 & 105 & 90 & 36.6 & 21 & 18 & 259 & 15 & 198 \\
\hline 19 & AGSMAM 4_1 & 33 & 31 & 68 & 44 & $32^{\prime} 700$ & 76 & 100 & 636 & 635 & 246 & 305 & 105 & 90 & 358 & 2.0 & 18 & 297 & 17 & 200 \\
\hline 20 & AGSMAM 5_1 & 29 & 29 & 68 & 44 & 32700 & 76 & 100 & 636 & 635 & 246 & 305 & 105 & 90 & 304 & 17 & 18 & 237 & 13 & 168 \\
\hline 21 & BS1_1R & 33 & 26 & 60 & 49 & $18^{\prime} 350$ & 98 & 100 & 559 & 500 & 256 & 262 & 84 & 63 & 141 & 0.8 & 12 & 168 & 09 & 122 \\
\hline 22 & BS2_1R & 38 & 28 & 60 & 49 & $18^{\prime} 350$ & 98 & 100 & 55.9 & 500 & 255 & 262 & 84 & 63 & 16.1 & 0.9 & 12 & 176 & 10 & 133 \\
\hline 23 & BS3_1R & 25 & 22 & 60 & 49 & $18^{\prime} 350$ & 98 & 100 & 559 & 500 & 256 & 262 & 84 & 63 & 175 & 10 & 11 & 179 & 10 & 157 \\
\hline 24 & BS4_1R & 23 & 33 & 60 & 49 & 181350 & 98 & 100 & 559 & 500 & 256 & 262 & 84 & 63 & 236 & 13 & 16 & 201 & 11 & 151 \\
\hline 25 & BS5_1R & 29 & 32 & 60 & 49 & $18 ' 350$ & 98 & 100 & 559 & 500 & 256 & 262 & 84 & 63 & 21.1 & 12 & 16 & 201 & 11 & 131 \\
\hline 26 & BS1_1M & 24 & 22 & 60 & 49 & $18+350$ & 98 & 100 & 559 & 500 & 256 & 262 & 84 & 63 & 302 & 17 & 22 & 223 & 13 & 136 \\
\hline 27 & BS2_1M & 24 & 2 & 60 & 49 & $18^{\prime} 350$ & 98 & 100 & 559 & 500 & 256 & 262 & 84 & 63 & 322 & 1.8 & 21 & 269 & 15 & 152 \\
\hline 28 & BS3_1M & 25 & 21 & 60 & 49 & $18^{\prime} 350$ & 98 & 100 & 559 & 500 & 256 & 262 & 84 & 63 & 354 & 20 & 22 & 208 & 12 & 159 \\
\hline 29 & BS4_IM & 24 & 19 & 60 & 49 & $18 ' 350$ & 98 & 100 & 559 & 500 & 256 & 262 & 84 & 63 & 354 & 20 & 17 & 213 & 12 & 212 \\
\hline 30 & BS5_1M & 29 & 2 & 60 & 49 & $18^{\prime} 350$ & 98 & 100 & 559 & 500 & 256 & 262 & 84 & 63 & 318 & 1.8 & 2.1 & 254 & 14 & 154 \\
\hline 31 & SG-Buchs-R 1 & 41 & 31 & 60 & 49 & 28050 & 58 & 100 & 678 & 800 & 318 & 350 & 77 & 70 & 391 & 22 & 23 & 2439 & 14 & 167 \\
\hline 32 & SG-Buchs-R-2 & 39 & 34 & 60 & 49 & 28050 & 58 & 100 & 678 & 800 & 318 & 350 & 77 & 70 & 353 & 20 & 21 & 2429 & 14 & 165 \\
\hline 33 & SG-Buchs-R-3 & 34 & 36 & 60 & 49 & 28050 & 58 & 100 & 678 & 800 & 318 & 350 & 77 & 70 & 344 & 1.9 & 2.1 & 261 & 15 & 167 \\
\hline 34 & SG-Buchs-R-4 & 36 & 29 & 60 & 49 & 28050 & 58 & 100 & 67.8 & 800 & 318 & 350 & 77 & 70 & 345 & 20 & 21 & 2587 & 15 & 168 \\
\hline 35 & SG-Buchs-R 5 & 40 & 31 & 60 & 49 & 28050 & 58 & 100 & 678 & 800 & 318 & 350 & 77 & 70 & 32.5 & 18 & 24 & 1975 & 11 & 134 \\
\hline 36 & SG-Buchs-M 1 & 40 & 3.3 & 60 & 49 & 28050 & 58 & 100 & 678 & 800 & 318 & 350 & 77 & 70 & 304 & 17 & 26 & 1761 & 10 & 116 \\
\hline 37 & SG-Buchs-M 2 & 39 & 31 & 60 & 49 & 28050 & 58 & 100 & 678 & 800 & 318 & 350 & 77 & 70 & 28.4 & 16 & 24 & 2126 & 12 & 121 \\
\hline 38 & SG-Buchs-M 3 & 36 & 40 & 60 & 49 & 28050 & 58 & 100 & 67.8 & 800 & 318 & 350 & 77 & 70 & 38.7 & 2.2 & 23 & 2385 & 13 & 169 \\
\hline 39 & SG-Buchs-M 4 & 34 & 4.3 & 60 & 49 & 28050 & 58 & 100 & 678 & 800 & 318 & 350 & 77 & 70 & 277 & 16 & 23 & 2149 & 12 & 121 \\
\hline 40 & SG-Buchs-M 5 & 35 & 34 & 60 & 49 & 28050 & 58 & 100 & 678 & 800 & 318 & 350 & 77 & 70 & 28.5 & 16 & 22 & 2059 & 12 & 128 \\
\hline 41 & so-Wasseramt R-1 & 65 & 47 & 57 & 40 & $64^{\prime} 230$ & 82 & 100 & 862 & 508 & 381 & 253 & 85 & 52 & 122 & 07 & 09 & 1513 & 09 & 135 \\
\hline 42 & so-Wasseramt R-2 & 61 & 49 & 57 & 40 & $64^{\prime} 230$ & 82 & 100 & 862 & 508 & 381 & 253 & 85 & 52 & 134 & 0.8 & 08 & 182 & 10 & 157 \\
\hline 43 & SO-Wasseramt-R 3 & 63 & 46 & 57 & 40 & $64^{\prime} 230$ & 82 & 100 & 862 & 508 & 381 & 253 & 85 & 52 & 16.3 & 09 & 09 & 1833 & 10 & 175 \\
\hline 44 & so-Wasseramt-R-4 & 6 & 45 & 57 & 40 & $64^{\prime} 230$ & 82 & 100 & 862 & 508 & 381 & 253 & 85 & 52 & 172 & 1.0 & 07 & 329 & 19 & 258 \\
\hline 45 & So-Wasseramt-R-5 & 63 & 4.2 & 57 & 40 & $64^{\prime} 230$ & 82 & 100 & 862 & 508 & 381 & 253 & 85 & 52 & 152 & 09 & 08 & 2168 & 12 & 180 \\
\hline 46 & so-Wasseramt M 1 & 54 & 36 & 57 & 40 & 64230 & 82 & 100 & 862 & 508 & 381 & 253 & 85 & 52 & 326 & 18 & 21 & 2568 & 15 & 156 \\
\hline 47 & so-Wasseramt M 2 & 46 & 34 & 57 & 40 & $64^{\prime} 230$ & 82 & 100 & 862 & 508 & 381 & 253 & 85 & 52 & 307 & 17 & 23 & 1932 & 11 & 134 \\
\hline 48 & so-Wasserarnt $M 3$ & 57 & 35 & 57 & 40 & $64^{\prime} 230$ & 82 & 100 & 862 & 508 & 381 & 253 & 85 & 52 & 350 & 2.0 & 21 & 2193 & 12 & 167 \\
\hline 49 & SO-Wasserarnt M-4 & 4 & 34 & 57 & 40 & $64^{\prime} 230$ & 82 & 100 & 862 & 508 & 381 & 253 & 85 & 52 & 376 & 21 & 19 & 2854 & 16 & 203 \\
\hline 50 & SO-Wasseramt-M 5 & 35 & 34 & 57 & 40 & $64^{\prime} 230$ & 82 & 100 & 862 & 508 & 381 & 253 & 85 & 52 & 353 & 2.0 & 17 & 3099 & 18 & 206 \\
\hline
\end{tabular}


Table A.2: LTPP-Road -continued 2

\begin{tabular}{|c|c|c|c|c|c|c|c|c|c|c|c|c|c|c|c|c|c|c|c|c|}
\hline No & Name & $\begin{array}{l}\text { AV } 1 \\
{[\%]}\end{array}$ & $\begin{array}{l}A V 2 \\
{[\%]}\end{array}$ & $\begin{array}{l}\text { BC } 1 \\
{[\%]}\end{array}$ & $\begin{array}{l}\mathrm{BC} 2 \\
{[\%]}\end{array}$ & ADT & $\begin{array}{l}<35 T \\
{[\%]}\end{array}$ & $\begin{array}{l}\text { Age } \\
\text { [y] }\end{array}$ & $\begin{array}{l}\text { 8_1 } \\
{[\%]}\end{array}$ & $\begin{array}{l}8,2 \\
{[\%]}\end{array}$ & $\begin{array}{l}2 \_1 \\
{[\%]}\end{array}$ & $\begin{array}{l}2-2 \\
{[\%]}\end{array}$ & $\begin{array}{l}\text { Fil_1 } \\
{[\%]}\end{array}$ & $\begin{array}{l}\text { Fil_2 } \\
{[\%]}\end{array}$ & $\begin{array}{c}\mathrm{F} \\
{[\mathrm{kN}]}\end{array}$ & $\begin{array}{c}\tau \\
{[\mathrm{MPa}]}\end{array}$ & $\stackrel{w}{w}$ & $\begin{array}{c}S \\
{[\mathrm{KN} / \mathrm{mm}]}\end{array}$ & $\begin{array}{c}\mathrm{K} \\
{[\mathrm{MPa} / \mathrm{mm}]}\end{array}$ & $\begin{array}{c}M \\
{[\mathrm{KN} / \mathrm{mm}]}\end{array}$ \\
\hline 51 & VS-N9 RB-1-C & 23 & 7.5 & 57 & 49 & $31 ' 500$ & 46 & 100 & 636 & 700 & 69 & 330 & 20 & 70 & 11.9 & 07 & 19 & 89 & 05 & 63 \\
\hline 52 & VS-N9 RB-2CC & 23 & 74 & 57 & 49 & 31500 & 46 & 100 & 636 & 700 & 69 & 330 & 20 & 70 & 159 & 0.9 & 15 & 154 & 09 & 107 \\
\hline 53 & VS-NG RB $3-C$ & 23 & 7.8 & 57 & 49 & $31^{\prime} 500$ & 46 & 100 & 63.6 & 700 & 69 & 330 & 20 & 70 & 12.5 & 07 & 20 & 97 & 05 & 62 \\
\hline 54 & VS-N9 RB 4-C & 23 & 7.8 & 57 & 49 & $31^{\prime} 500$ & 46 & 100 & 636 & 700 & 69 & 330 & 20 & 70 & 16.1 & 0.9 & 19 & 105 & 06 & 86 \\
\hline 55 & VS-N9 RB-5-C & 23 & 79 & 57 & 49 & $31 ' 500$ & 46 & 100 & 63.6 & 700 & 69 & 330 & 20 & 70 & 178 & 1.0 & 24 & 92 & 05 & 74 \\
\hline 56 & VS-N9 RB-1-NC & 23 & 82 & 57 & 49 & $31^{\prime} 500$ & 46 & 100 & 63.6 & 700 & 69 & 330 & 20 & 70 & 141 & 0.8 & 16 & 135 & 08 & 90 \\
\hline 57 & VS-N9 RB-2-NC & 23 & 75 & 57 & 49 & $31^{\prime} 500$ & 46 & 100 & 636 & 700 & 69 & 330 & 20 & 70 & 177 & 10 & 14 & 157 & 09 & 131 \\
\hline 58 & VS-N9 RB 3-NC & 23 & 79 & 57 & 49 & 31500 & 46 & 100 & 63.6 & 700 & 69 & 330 & 20 & 70 & 10.6 & 0.6 & 12 & 138 & 08 & 90 \\
\hline 59 & VS-N9-RB-4-NC & 23 & 8.3 & 57 & 49 & $31^{\prime} 500$ & 46 & 100 & 636 & 700 & 69 & 330 & 20 & 70 & 155 & 0.9 & 21 & 117 & 07 & 75 \\
\hline 60 & VS-N9 RB-5-NC & 23 & 79 & 57 & 49 & $31 ' 500$ & 46 & 100 & 636 & 700 & 69 & 330 & 20 & 70 & 149 & 0.8 & 16 & 105 & 06 & 93 \\
\hline 61 & Vs-N9 R-1C & 26 & 4.5 & 60 & 40 & 19800 & 44 & 100 & 617 & 598 & 228 & 255 & 74 & 60 & 391 & 22 & 27 & 197 & 11 & 146 \\
\hline 62 & VS-N9 R 2C & 3 & 4 & 60 & 40 & $19 ' 800$ & 44 & 100 & 617 & 598 & 228 & 255 & 74 & 60 & 352 & 20 & 26 & 199 & 11 & 134 \\
\hline 63 & VS-N9 R-3C & 27 & 46 & 60 & 40 & $19 ' 800$ & 44 & 100 & 617 & 598 & 228 & 255 & 74 & 60 & 33.6 & 1.9 & 27 & 194 & 11 & 125 \\
\hline 64 & VS-N9 R-4C & 31 & 5.4 & 60 & 40 & $19^{\circ} 800$ & 44 & 100 & 617 & 598 & 228 & 255 & 74 & 60 & 348 & 2.0 & 27 & 196 & 11 & 129 \\
\hline 65 & VS-N9 R 5C & 26 & 51 & 60 & 40 & $19 ' 800$ & 44 & 100 & 617 & 598 & 228 & 255 & 74 & 60 & 38.2 & 22 & 27 & 201 & 11 & 144 \\
\hline 66 & VS-N9 M 1NC & 24 & 4 & 60 & 40 & $19 ' 800$ & 44 & 100 & 617 & 598 & 228 & 255 & 74 & 60 & 41.4 & 2.3 & 25 & 233 & 13 & 165 \\
\hline 67 & WSNG-M-2NC & 27 & 44 & 60 & 40 & $19^{\prime} 800$ & 44 & 100 & 617 & 598 & 228 & 255 & 74 & 60 & 36.5 & 21 & 27 & 215 & 12 & 136 \\
\hline 68 & VS-N9 M 3NC & 3 & 44 & 60 & 40 & $19 ' 800$ & 44 & 100 & 617 & 598 & 228 & 255 & 74 & 60 & 36.1 & 2.0 & 25 & 212 & 12 & 145 \\
\hline 69 & VS-N9 M-4NC & 68 & 6.3 & 60 & 40 & $19^{\prime} 800$ & 44 & 100 & 617 & 598 & 228 & 255 & 74 & 60 & 34.9 & 20 & 23 & 208 & 12 & 151 \\
\hline 70 & VS-NG M-5NC & 36 & 59 & 60 & 40 & $19 ' 800$ & 44 & 100 & 617 & 598 & 228 & 255 & 74 & 60 & 337 & 19 & 22 & 211 & 12 & 154 \\
\hline 71 & ZH Wallisellen-R-1 & 58 & 57 & 57 & 49 & $94^{\prime} 990$ & 44 & 100 & 64.8 & 704 & 209 & 335 & 139 & 80 & 158 & 0.9 & 13 & 135 & 08 & 122 \\
\hline 72 & $\mathrm{ZH}$ Wallisellen-R 2 & 29 & 54 & 57 & 49 & $94^{\prime} 990$ & 44 & 100 & 64.8 & 704 & 209 & 335 & 139 & 80 & 153 & 09 & 12 & 138 & 08 & 127 \\
\hline 73 & ZH-Wallisellen $\mathrm{R} 3$ & 56 & 5.2 & 57 & 49 & 94990 & 44 & 100 & 64.8 & 704 & 209 & 335 & 139 & 80 & 156 & 09 & 13 & 140 & 08 & 123 \\
\hline 74 & $\mathrm{ZH}$ Wallisellen R-4 & 58 & 51 & 57 & 49 & 94990 & 44 & 100 & 64.8 & 704 & 209 & 335 & 139 & 80 & 88 & 0.5 & 15 & 69 & 04 & 57 \\
\hline 75 & ZH-Wallsellen-R 5 & 56 & 5.3 & 57 & 49 & $94 ' 990$ & 44 & 100 & 64.8 & 704 & 209 & 335 & 139 & 80 & 164 & 09 & 16 & 114 & 06 & 100 \\
\hline 76 & ZH Wallsellen M-1 & 66 & 53 & 57 & 49 & 94990 & 44 & 100 & 648 & 704 & 209 & 335 & 139 & 80 & 175 & 10 & 13 & 148 & 08 & 133 \\
\hline 77 & $\mathrm{ZH}-$ Walissellen-M-2 & 67 & 51 & 57 & 49 & 94990 & 44 & 100 & 648 & 704 & 209 & 335 & 139 & 80 & 13.2 & 07 & 14 & 98 & 06 & 93 \\
\hline 78 & ZH Wallisellen-M-3 & 68 & 4.9 & 57 & 49 & $94^{\prime} 990$ & 44 & 100 & 64.8 & 704 & 209 & 335 & 139 & 80 & 149 & 0.8 & 16 & 108 & 06 & 96 \\
\hline 79 & ZH-Wallisellen $\mathrm{M}-4$ & 66 & 54 & 57 & 49 & $94^{\prime} 990$ & 44 & 100 & 648 & 704 & 209 & 335 & 139 & 80 & 16.6 & 09 & 15 & 116 & 07 & 109 \\
\hline 80 & $\mathrm{ZH}-$ Walliselten-M-S & 67 & 58 & 57 & 49 & $94^{\prime} 990$ & 44 & 100 & 64.8 & 704 & 209 & 335 & 139 & 80 & 22.6 & 1.3 & 15 & 186 & 10 & 156 \\
\hline 81 & SG-flums-R-1 & 45 & 6 & 49 & 43 & 35000 & 55 & 100 & 735 & 800 & 332 & 350 & 77 & 70 & 38.2 & 22 & 21 & 216 & 12 & 181 \\
\hline 82 & SG-flums-R-2 & 53 & 5.8 & 49 & 43 & 35000 & 55 & 100 & 73.5 & 800 & 332 & 350 & 77 & 70 & 339 & 1.9 & 19 & 279 & 16 & 179 \\
\hline 83 & SG-flums-R-3 & 45 & 67 & 49 & 43 & 35000 & 55 & 100 & 735 & 800 & 332 & 350 & 77 & 70 & 356 & 2.0 & 20 & 256 & 14 & 176 \\
\hline 84 & SG-flums-R-4 & 64 & 56 & 49 & 43 & 35000 & 55 & 100 & 735 & 800 & 332 & 350 & 77 & 70 & 346 & 20 & 19 & 266 & 15 & 183 \\
\hline 85 & SG-flums-R 5 & 4 & 5.8 & 49 & 43 & 35000 & 55 & 100 & 73.5 & 800 & 332 & 350 & 77 & 70 & 317 & 18 & 19 & 254 & 14 & 169 \\
\hline 86 & SG-flums-M 1 & 36 & 59 & 49 & 43 & 35000 & 55 & 100 & 73.5 & 800 & 332 & 350 & 77 & 70 & 302 & 17 & 29 & 227 & 13 & 106 \\
\hline 87 & SGflums M 2 & 3 & 4 & 49 & 43 & 35000 & 55 & 100 & 73.5 & 800 & 332 & 350 & 77 & 70 & 31.1 & 18 & 22 & 239 & 14 & 143 \\
\hline 88 & SGflums-M 3 & 31 & 41 & 49 & 43 & 35000 & 55 & 100 & 73.5 & 800 & 332 & 350 & 77 & 70 & 326 & 1.8 & 25 & 199 & 11 & 131 \\
\hline 89 & SGFlums-M-4 & 34 & 41 & 49 & 43 & 35000 & 55 & 100 & 73.5 & 800 & 332 & 350 & 77 & 70 & 278 & 1.6 & 26 & 204 & 12 & 106 \\
\hline 90 & SG-flums-M-5 & 38 & 61 & 49 & 43 & 35000 & 55 & 100 & 73.5 & 800 & 332 & 350 & 77 & 70 & 306 & 17 & 25 & 194 & 11 & 123 \\
\hline 98 & SO-SMA-R 1 & 39 & 2.8 & 64 & 35 & $31^{\prime} 450$ & 55 & 100 & 70.5 & 443 & 233 & 247 & 95 & 60 & 28.8 & 1.6 & 26 & 172 & 10 & 109 \\
\hline 99 & SO-SMA R 2 & 35 & 2.6 & 64 & 35 & $31^{\prime} 450$ & 55 & 100 & 705 & 443 & 233 & 247 & 95 & 60 & 237 & 1.3 & 23 & 199 & 11 & 101 \\
\hline 100 & SO-SMA R 3 & 39 & 24 & 64 & 35 & 31450 & 55 & 100 & 705 & 443 & 233 & 247 & 95 & 60 & 258 & 15 & 25 & 194 & 11 & 103 \\
\hline
\end{tabular}


Table A.2: LTPP-Road -continued 3

\begin{tabular}{|c|c|c|c|c|c|c|c|c|c|c|c|c|c|c|c|c|c|c|c|c|}
\hline No & Name & $\begin{array}{l}\text { AV } 1 \\
{[\%]}\end{array}$ & $\begin{array}{l}\text { AV } 2 \\
{[\%]}\end{array}$ & $\begin{array}{l}\mathrm{BC} 1 \\
{[\%]}\end{array}$ & $\begin{array}{l}\text { BC } 2 \\
{[\%]}\end{array}$ & ADT & $\begin{array}{l}<35 T \\
{[\%]}\end{array}$ & $\begin{array}{l}\text { Age } \\
\text { [y] }\end{array}$ & $\begin{array}{l}\text { 8_1 } \\
{[\%]}\end{array}$ & $\begin{array}{l}8 \_2 \\
{[\%]}\end{array}$ & 2_1 & $\begin{array}{l}2-2 \\
{[\%]}\end{array}$ & $\begin{array}{l}\text { Fil_1 } \\
{[\%]}\end{array}$ & $\begin{array}{l}\text { FII_2 } \\
{[\%]}\end{array}$ & $\underset{[\mathbf{k N}]}{\mathbf{F}}$ & $\begin{array}{c}\tau \\
\text { [MPa] }\end{array}$ & $\begin{array}{c}w \\
{[\mathrm{~mm}]}\end{array}$ & $\begin{array}{c}\mathrm{S} \\
{[\mathrm{KN} / \mathrm{mm}]}\end{array}$ & $\begin{array}{c}\mathrm{K} \\
{[\mathrm{MPa} / \mathrm{mm}]}\end{array}$ & $\begin{array}{c}M \\
{[\mathrm{KN} / \mathrm{mm}]}\end{array}$ \\
\hline 101 & SO-SMA R-4 & 35 & 28 & 64 & 35 & $31^{\prime} 450$ & 55 & 100 & 70.5 & 443 & 233 & 247 & 95 & 60 & 276 & 1.6 & 25 & 196 & 11 & 111 \\
\hline 102 & SO-SMA R 5 & 39 & 28 & 64 & 35 & $31^{\prime} 450$ & 55 & 100 & 70.5 & 443 & 233 & 247 & 95 & 60 & 26.6 & 1.5 & 24 & 201 & 11 & 112 \\
\hline 103 & SO-SMA M-1 & 44 & 37 & 64 & 35 & $31^{\prime} 450$ & 55 & 100 & 70.5 & 443 & 233 & 247 & 95 & 60 & 32.4 & 1.8 & 29 & 167 & 09 & 111 \\
\hline 104 & SO-SMA M-2 & 37 & 37 & 64 & 35 & $31^{\prime} 450$ & 55 & 100 & 70.5 & 443 & 233 & 247 & 95 & 60 & 246 & 14 & 25 & 162 & 09 & 98 \\
\hline 105 & SO-SMA M-3 & 43 & 3.8 & 64 & 35 & $31^{\prime} 450$ & 55 & 100 & 70.5 & 443 & 233 & 247 & 95 & 60 & 226 & 1.3 & 27 & 148 & 08 & 85 \\
\hline 106 & SO-SMA M-4 & 36 & 32 & 64 & 35 & $31^{+} 450$ & 55 & 100 & 70.5 & 443 & 233 & 247 & 95 & 60 & 24.6 & 14 & 24 & 161 & 09 & 102 \\
\hline 107 & SO-SMA M-5 & 41 & 3 & 64 & 35 & $31: 450$ & 55 & 100 & 70.5 & 443 & 233 & 247 & 95 & 60 & 258 & 1.5 & 26 & 131 & 07 & 99 \\
\hline 108 & SO-AB-R 1 & 32 & 62 & 55 & 40 & 77890 & 111 & 100 & 821 & 518 & 373 & 268 & 71 & 63 & 28.6 & 1.6 & 17 & 201 & 11 & 170 \\
\hline 109 & SO-AB-R-2 & 29 & 62 & 55 & 40 & 77890 & 111 & 100 & 821 & 518 & 373 & 268 & 71 & 63 & 278 & 1.6 & 18 & 194 & 11 & 152 \\
\hline 110 & SO-AB-R-3 & 30 & 6.2 & 55 & 40 & 77890 & 111 & 100 & 821 & 518 & 373 & 268 & 71 & 63 & 28.7 & 1.6 & 19 & 191 & 11 & 149 \\
\hline 111 & SO-AB-R-4 & 32 & 6.2 & 55 & 40 & 77890 & 111 & 100 & 821 & 518 & 373 & 268 & 71 & 63 & 26.7 & 1.5 & 16 & 194 & 11 & 169 \\
\hline 112 & SO-AB-R-5 & 37 & 6.2 & 55 & 40 & $7 r 890$ & 111 & 100 & 821 & 518 & 373 & 268 & 71 & 63 & 22.8 & 1.3 & 15 & 178 & 10 & 152 \\
\hline 113 & SO-AB-M-1 & 30 & 6.2 & 55 & 40 & 77890 & 111 & 100 & 821 & 518 & 373 & 268 & 71 & 63 & 13.5 & 0.8 & 10 & 191 & 11 & 138 \\
\hline 114 & SO-AB-M-2 & 26 & 62 & 55 & 40 & 77890 & 111 & 100 & 821 & 518 & 373 & 268 & 71 & 63 & 129 & 07 & 10 & 182 & 10 & 135 \\
\hline 115 & SO-AB-M-3 & 28 & 62 & 55 & 40 & 77890 & 111 & 100 & 821 & 518 & 373 & 268 & 71 & 63 & 171 & 10 & 12 & 182 & 10 & 139 \\
\hline 116 & SO-AB-M-4 & 31 & 62 & 55 & 40 & 77890 & 111 & 100 & 821 & 518 & 373 & 268 & 71 & 63 & 177 & 10 & 12 & 167 & 09 & 150 \\
\hline 117 & SO-AB-M-S & 28 & 62 & 55 & 40 & 77890 & 111 & 100 & 821 & 518 & 373 & 268 & 71 & 63 & 165 & 0.9 & 12 & 145 & 08 & 139 \\
\hline 118 & AGHRR 1_1 & 31 & 5.5 & 78 & 43 & $6^{\prime} 800$ & 26 & 100 & 85.6 & 604 & 630 & 302 & 99 & 86 & 236 & 1.3 & 13 & 1351 & 08 & 182 \\
\hline 119 & AGHRR 2_1 & 30 & 61 & 78 & 43 & $6^{\prime} 800$ & 26 & 100 & 85.6 & 604 & 630 & 302 & 99 & 86 & 36.1 & 20 & 27 & 1954 & 11 & 133 \\
\hline 120 & AGHRR 3_1 & 33 & 71 & 78 & 43 & $6+800$ & 26 & 100 & 85.6 & 604 & 630 & 302 & 99 & 86 & 304 & 17 & 22 & 2063 & 12 & 141 \\
\hline 121 & AGHRR 4_1 & 39 & 6.5 & 78 & 43 & $6^{\prime} 800$ & 26 & 100 & 856 & 604 & 630 & 302 & 99 & 86 & 26.2 & 1.5 & 18 & 2334 & 13 & 148 \\
\hline 122 & AGHRR 5_1 & 37 & 68 & 78 & 43 & $6 ' 800$ & 26 & 100 & 856 & 604 & 630 & 302 & 99 & 86 & 232 & 1.3 & 17 & 1685 & 10 & 133 \\
\hline 123 & AGHRM1_1 & 32 & 4.5 & 78 & 43 & $6^{\prime} 800$ & 26 & 100 & 856 & 604 & 630 & 302 & 99 & 86 & 433 & 24 & 29 & 2798 & 16 & 151 \\
\hline 124 & AGHRM2_1 & 28 & 4.6 & 78 & 43 & $6 ' 800$ & 26 & 100 & 856 & 604 & 630 & 302 & 99 & 86 & 453 & 2.6 & 27 & 2994 & 17 & 167 \\
\hline 125 & AGHRM3_1 & 31 & 4.6 & 78 & 43 & 6' 800 & 26 & 100 & 85.6 & 604 & 630 & 302 & 99 & 86 & 471 & 27 & 30 & 2207 & 12 & 159 \\
\hline 126 & AGHRM4_1 & 29 & 4.5 & 78 & 43 & $6^{\prime} 800$ & 26 & 100 & 85.6 & 604 & 630 & 302 & 99 & 86 & 412 & 2.3 & 28 & 2177 & 12 & 145 \\
\hline 127 & AGHRM 5_1 & 35 & 4.5 & 78 & 43 & $6^{\prime} 800$ & 26 & 100 & 856 & 604 & 630 & 302 & 99 & 86 & 44.5 & 2.5 & 29 & 229 & 13 & 156 \\
\hline 128 & BM1_1R & 68 & 44 & 76 & 42 & & bus & 10 & 677 & 583 & 226 & 295 & 70 & 87 & 277 & 16 & 1364 & 243 & 14 & 203 \\
\hline 129 & BM2_1R & 68 & 4.4 & 76 & 42 & & bus & 10 & 677 & 583 & 226 & 295 & 70 & 87 & 23.7 & 1.3 & 1471 & 226 & 13 & 161 \\
\hline 130 & BM3_1R & 68 & 44 & 76 & 42 & & bus & 10 & 677 & 583 & 226 & 295 & 70 & 87 & 248 & 14 & 1569 & 205 & 12 & 158 \\
\hline 131 & BM4_1R & 68 & 44 & 76 & 42 & & bus & 10 & 677 & 583 & 226 & 295 & 70 & 87 & 39.1 & 2.2 & 2.24 & 184 & 10 & 175 \\
\hline 132 & BM5_1R & 68 & 4.4 & 76 & 42 & & bus & 10 & 677 & 583 & 226 & 295 & 70 & 87 & 270 & 15 & 2129 & 216 & 12 & 127 \\
\hline 133 & BM1_1M & 68 & 44 & 76 & 42 & & bus & 10 & 677 & 583 & 226 & 295 & 70 & 87 & 38.2 & 2.2 & 2214 & 276 & 16 & 172 \\
\hline 134 & BM2_1M & 68 & 44 & 76 & 42 & & bus & 10 & 677 & 583 & 226 & 295 & 70 & 87 & 350 & 20 & 2109 & 226 & 13 & 166 \\
\hline 135 & BM3_1M & 68 & 44 & 76 & 42 & & bus & 10 & 677 & 583 & 226 & 295 & 70 & 87 & 295 & 17 & 2225 & 205 & 12 & 133 \\
\hline 136 & BM4_1M & 68 & 4.4 & 76 & 42 & & bus & 10 & 677 & 583 & 226 & 295 & 70 & 87 & 271 & 1.5 & 1792 & 184 & 10 & 151 \\
\hline 137 & BM5_1M & 68 & 4.4 & 76 & 42 & & bus & 10 & 677 & 583 & 226 & 295 & 70 & 87 & 34.3 & 19 & 2063 & 216 & 12 & 166 \\
\hline 138 & SG-Mont R 1 & 38 & 38 & 60 & 40 & 28050 & 58 & 100 & 56.4 & 589 & 187 & 305 & 84 & 88 & 348 & 20 & 14 & 302 & 17 & 250 \\
\hline 139 & SG-Mont R 2 & 42 & 37 & 60 & 40 & 28050 & 58 & 100 & 56.4 & 589 & 187 & 305 & 84 & 88 & 38.1 & 2.2 & 16 & 293 & 17 & 243 \\
\hline 140 & SG-Mont $\mathrm{R} 3$ & 41 & 3.8 & 60 & 40 & 28050 & 58 & 100 & 564 & 589 & 187 & 305 & 84 & 88 & 417 & 24 & 09 & 325 & 18 & 442 \\
\hline 141 & SG-Mont R-4 & 4 & 39 & 60 & 40 & 28050 & 58 & 100 & 564 & 589 & 187 & 305 & 84 & 88 & 333 & 19 & 17 & 277 & 16 & 201 \\
\hline 142 & SG-Mont R-5 & 38 & 4.8 & 60 & 40 & 28050 & 58 & 100 & 564 & 589 & 187 & 305 & 84 & 88 & 334 & 19 & 19 & 229 & 13 & 179 \\
\hline 143 & $S G-M o n t-M 1$ & 39 & 5.5 & 60 & 40 & 28050 & 58 & 100 & 564 & 589 & 187 & 305 & 84 & 88 & 290 & 16 & 21 & 182 & 10 & 138 \\
\hline 144 & SG-Mont-M-2 & 37 & 71 & 60 & 40 & 28050 & 58 & 100 & 564 & 589 & 187 & 305 & 84 & 88 & 33.8 & 1.9 & 20 & 215 & 12 & 167 \\
\hline 145 & SG-Mont-M 3 & 39 & 61 & 60 & 40 & 28050 & 58 & 100 & 56.4 & 589 & 187 & 305 & 84 & 88 & 382 & 2.2 & 18 & 264 & 15 & 211 \\
\hline 146 & SG-Mont M-4 & 4 & 6.6 & 60 & 40 & 28050 & 58 & 100 & 56.4 & 589 & 187 & 305 & 84 & 88 & 32.7 & 1.9 & 21 & 194 & 11 & 154 \\
\hline 147 & SG-Mont-M-5 & 42 & 54 & 60 & 40 & 28050 & 58 & 100 & 564 & 589 & 187 & 305 & 84 & 88 & 378 & 21 & 20 & 256 & 15 & 189 \\
\hline
\end{tabular}


Table A.3: Combi Road-1

\begin{tabular}{|c|c|c|c|c|c|c|c|c|c|c|c|c|}
\hline No & Name & $\begin{array}{l}\text { Interlayer } \\
\text { type }\end{array}$ & $\begin{array}{c}\text { Age } \\
\text { [years] }\end{array}$ & $\begin{array}{c}8 \mathrm{~mm} \\
{[\%]}\end{array}$ & $\begin{array}{c}2 \mathrm{~mm} \\
{[\%]}\end{array}$ & $\begin{array}{l}\text { Filler } \\
{[\%]}\end{array}$ & $\underset{[\mathrm{kN}]}{\mathrm{F}}$ & $\stackrel{\tau}{\boldsymbol{t}}[\mathrm{MPa}]$ & $\underset{[\mathrm{mm}]}{\mathrm{w}}$ & $\begin{array}{c}\mathrm{S} \\
{[\mathrm{KN} / \mathrm{mm}]}\end{array}$ & $\begin{array}{c}\mathrm{K} \\
{[\mathrm{MPa} / \mathrm{mm}]}\end{array}$ & $\begin{array}{c}M \\
{[\mathrm{kN} / \mathrm{mm}]}\end{array}$ \\
\hline 2 & 12 (135) & 1 & 00 & 85 & 450 & 90 & 112 & 06 & 36 & 35 & 02 & 31 \\
\hline 4 & $14(161)$ & 1 & 00 & 65 & 25.0 & 100 & 125 & 07 & 39 & 38 & 02 & 32 \\
\hline 5 & $21(235)$ & 2 & 00 & 65 & 250 & 100 & 34 & 02 & 27 & 13 & 01 & 13 \\
\hline 8 & $24(253)$ & 2 & 00 & 85 & 450 & 90 & 18 & 01 & 20 & 08 & 00 & 09 \\
\hline 9 & 31 & 3 & 00 & 85 & 450 & 90 & 149 & 08 & 35 & 48 & 03 & 42 \\
\hline 10 & 32 & 3 & 00 & 65 & 250 & 100 & 106 & 06 & 20 & 77 & 04 & 54 \\
\hline 11 & 33 & 3 & 00 & 65 & 250 & 100 & 129 & 07 & 26 & 57 & 03 & 49 \\
\hline 16 & 44 & 4 & 00 & 65 & 250 & 100 & 86 & 05 & 33 & 39 & 02 & 26 \\
\hline 17 & 51 & 5 & 00 & 85 & 450 & 90 & 133 & 08 & 14 & 101 & 06 & 94 \\
\hline 18 & 52 & 5 & 00 & 85 & 450 & 90 & 239 & 14 & 13 & 198 & 11 & 189 \\
\hline 19 & 53 & 5 & 00 & 65 & 250 & 100 & 151 & 09 & 11 & 128 & 07 & 137 \\
\hline 20 & 54 & 5 & 00 & 65 & 250 & 100 & 162 & 09 & 15 & 114 & 06 & 107 \\
\hline 21 & 61 & 0 & 00 & 85 & 450 & 90 & 223 & 13 & 10 & 236 & 13 & 218 \\
\hline 22 & 62 & 0 & 00 & 85 & 450 & 90 & 200 & 11 & 13 & 186 & 11 & 158 \\
\hline 23 & 63 & 0 & 00 & 65 & 250 & 100 & 131 & 07 & 11 & 130 & 07 & 120 \\
\hline 24 & 64 & 0 & 00 & 65 & 250 & 100 & 180 & 10 & 18 & 129 & 07 & 100 \\
\hline 32 & 42 & 4 & 1.0 & 85 & 450 & 90 & 151 & 09 & 08 & 204 & 12 & 195 \\
\hline 33 & 43 & 4 & 1.0 & 65 & 250 & 100 & 107 & 06 & 22 & 91 & 05 & 49 \\
\hline 34 & 51 & 5 & 10 & 85 & 450 & 90 & 229 & 13 & 07 & 312 & 18 & 346 \\
\hline 35 & 52 & 5 & 10 & 85 & 45.0 & 90 & 120 & 07 & 03 & 412 & 23 & 390 \\
\hline 36 & 53 & 5 & 10 & 65 & 250 & 100 & 218 & 12 & 06 & 392 & 22 & 356 \\
\hline 37 & 54 & 5 & 1.0 & 65 & 250 & 100 & 161 & 09 & 04 & 410 & 23 & 375 \\
\hline 38 & 61 & 0 & 1.0 & 85 & 450 & 90 & 299 & 17 & 08 & 404 & 23 & 370 \\
\hline 39 & 62 & 0 & 10 & 85 & 450 & 90 & 136 & 08 & 06 & 242 & 14 & 223 \\
\hline 40 & 63 & 0 & 10 & 65 & 250 & 100 & 92 & 05 & 07 & 140 & 08 & 128 \\
\hline 41 & 11 & 1 & 2.0 & 85 & 450 & 90 & 143 & 08 & 12 & 142 & 08 & 115 \\
\hline 42 & 12 & 1 & 20 & 65 & 250 & 100 & 146 & 08 & 18 & 146 & 08 & 81 \\
\hline 43 & 13 & 1 & 2.0 & 85 & 450 & 90 & 144 & 08 & 16 & 143 & 08 & 93 \\
\hline 44 & 14 & 1 & 20 & 65 & 250 & 100 & 191 & 11 & 10 & 191 & 11 & 190 \\
\hline 45 & 15 & 1 & 20 & 85 & 450 & 90 & 137 & 08 & 15 & 137 & 08 & 90 \\
\hline 46 & 21 & 2 & 2.0 & 65 & 250 & 100 & 37 & 02 & 10 & 39 & 02 & 36 \\
\hline 47 & 22 & 2 & 2.0 & 85 & 450 & 90 & 118 & 07 & 07 & 175 & 10 & 165 \\
\hline 48 & 23 & 2 & 2.0 & 65 & 25.0 & 100 & 37 & 02 & 12 & 109 & 06 & 31 \\
\hline 49 & 24 & 2 & 20 & 85 & 450 & 90 & 72 & 04 & 08 & 44 & 02 & 8.8 \\
\hline 50 & 31 & 3 & 2.0 & 85 & 450 & 90 & 116 & 07 & 20 & 65 & 04 & 5.8 \\
\hline
\end{tabular}




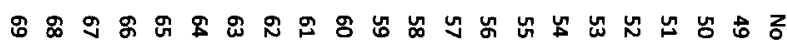

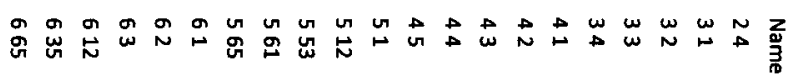

०000000

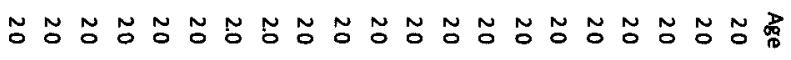

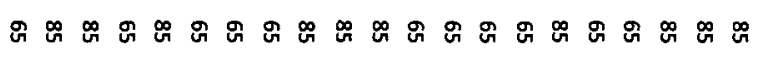
颌

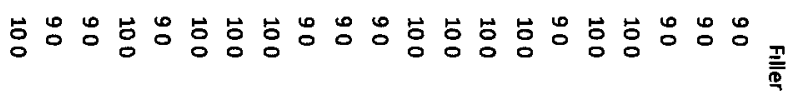

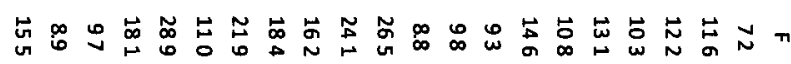

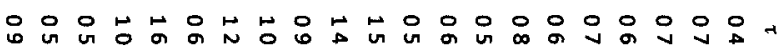

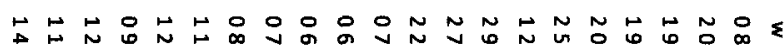

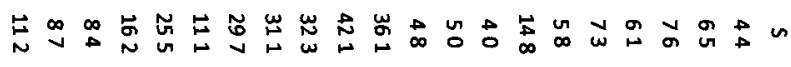

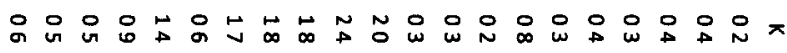

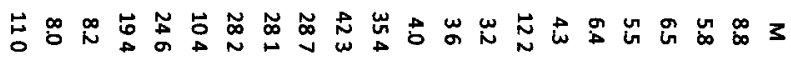


Table A.4: Lab Pavement-1

\begin{tabular}{|c|c|c|c|c|c|c|c|c|c|c|c|c|}
\hline No & Name & Tack coat & Treatment & $\begin{array}{c}\text { Age } \\
\text { [months] }\end{array}$ & $\begin{array}{l}\text { AV 1 } \\
\text { [\%] }\end{array}$ & $\begin{array}{l}\text { AV } 2 \\
{[\%]}\end{array}$ & $\underset{[\mathrm{kN}]}{F}$ & $\begin{array}{c}\tau \\
{[\mathrm{MPa}]}\end{array}$ & $\underset{[m m]}{w}$ & $\begin{array}{c}\mathrm{S} \\
{[\mathrm{KN} / \mathrm{mm}]}\end{array}$ & $\begin{array}{c}\mathrm{K} \\
{[\mathrm{MPa} / \mathrm{mm}]}\end{array}$ & $\begin{array}{c}M \\
{[\mathrm{KN} / \mathrm{mm}]}\end{array}$ \\
\hline 1 & 301 & 0 & 0 & 0 & 55 & 65 & 325 & 18 & 19 & 222 & 13 & 174 \\
\hline 2 & 302 & 0 & 0 & 0 & 41 & 67 & 411 & 23 & 17 & 321 & 18 & 240 \\
\hline 3 & 303 & 0 & 0 & 0 & 37 & 68 & 439 & 25 & 21 & 269 & 15 & 205 \\
\hline 4 & 304 & 0 & 0 & 0 & 34 & 69 & 424 & 24 & 18 & 303 & 17 & 229 \\
\hline 5 & 305 & 0 & 0 & 0 & 45 & 67 & 293 & 17 & 17 & 183 & 10 & 172 \\
\hline 6 & 306 & 0 & 0 & 0 & 6.5 & 65 & 290 & 16 & 12 & 253 & 14 & 242 \\
\hline 7 & 307 & 0 & 0 & 0 & 6.2 & 63 & 339 & 19 & 16 & 234 & 13 & 208 \\
\hline 8 & 308 & 0 & 0 & 0 & 45 & 66 & 383 & 22 & 21 & 266 & 15 & 185 \\
\hline 9 & 309 & 0 & 0 & 0 & 43 & 67 & 333 & 19 & 16 & 243 & 14 & 205 \\
\hline 10 & 310 & 0 & 0 & 0 & 49 & 66 & 367 & 21 & 18 & 242 & 14 & 205 \\
\hline 11 & 311 & 0 & 0 & 0 & 49 & 67 & 369 & 21 & 18 & 304 & 17 & 209 \\
\hline 12 & 312 & 0 & 0 & 0 & 7 & 69 & 277 & 16 & 18 & 182 & 10 & 158 \\
\hline 13 & 253 & 0 & 0 & 1 & 54 & 73 & 343 & 19 & 17 & 233 & 13 & 204 \\
\hline 14 & 254 & 0 & 0 & 1 & 31 & 7 & 263 & 15 & 12 & 241 & 14 & 219 \\
\hline 15 & 255 & 0 & 0 & 1 & 45 & 69 & 339 & 19 & 17 & 228 & 13 & 203 \\
\hline 16 & 256 & 0 & 0 & 1 & 37 & 79 & 414 & 23 & 16 & 280 & 16 & 251 \\
\hline 17 & 257 & 0 & 0 & 1 & 46 & 73 & 405 & 23 & 17 & 285 & 16 & 233 \\
\hline 18 & 258 & 0 & 0 & 1 & 52 & 73 & 371 & 21 & 18 & 236 & 13 & 202 \\
\hline 19 & 259 & 0 & 0 & 1 & 47 & 72 & 436 & 25 & 20 & 248 & 14 & 219 \\
\hline 20 & 260 & 0 & 0 & 1 & 46 & 69 & 292 & 17 & 18 & 178 & 10 & 166 \\
\hline 21 & 261 & 0 & 0 & 1 & 48 & 7 & 308 & 17 & 15 & 248 & 14 & 212 \\
\hline 22 & 262 & 0 & 0 & 1 & 48 & 76 & 321 & 18 & 13 & 267 & 15 & 239 \\
\hline 23 & 263 & 0 & 7 & 1 & 6 & 7 & 341 & 19 & 14 & 275 & 16 & 240 \\
\hline 24 & 264 & 0 & 7 & 1 & 54 & 72 & 357 & 20 & 19 & 206 & 12 & 193 \\
\hline 25 & 289 & 1 & 0 & 0 & 85 & 64 & 239 & 14 & 12 & 202 & 11 & 193 \\
\hline 26 & 290 & 1 & 0 & 0 & 62 & 68 & 308 & 17 & 16 & 218 & 12 & 187 \\
\hline 27 & 291 & 1 & 0 & 0 & 5 & 7 & 378 & 21 & 17 & 264 & 15 & 224 \\
\hline 28 & 292 & 1 & 0 & 0 & 54 & 68 & 313 & 18 & 17 & 208 & 12 & 183 \\
\hline 29 & 293 & 1 & 0 & 0 & 51 & 67 & 359 & 20 & 18 & 222 & 13 & 199 \\
\hline 30 & 294 & 1 & 0 & 0 & 53 & 64 & 355 & 20 & 17 & 243 & 14 & 211 \\
\hline 31 & 295 & 1 & 0 & 0 & 66 & 65 & 294 & 17 & 18 & 172 & 10 & 164 \\
\hline 32 & 296 & 1 & 0 & 0 & 48 & 63 & 349 & 20 & 20 & 193 & 11 & 177 \\
\hline 33 & 297 & 1 & 0 & 0 & 36 & 69 & 395 & 22 & 22 & 208 & 12 & 180 \\
\hline 34 & 298 & 1 & 0 & 0 & 38 & 67 & 404 & 23 & 16 & 282 & 16 & 258 \\
\hline 35 & 299 & 1 & 0 & 0 & 47 & 65 & 372 & 21 & 18 & 271 & 15 & 208 \\
\hline 36 & 300 & 1 & 0 & 0 & 6.7 & 71 & 260 & 15 & 13 & 212 & 12 & 205 \\
\hline 37 & 241 & 1 & 0 & 1 & 93 & 83 & 420 & 24 & 23 & 218 & 12 & 183 \\
\hline 38 & 242 & 1 & 0 & 1 & 54 & 79 & 379 & 21 & 18 & 273 & 15 & 215 \\
\hline 39 & 243 & 1 & 0 & 1 & 43 & 79 & 431 & 24 & 20 & 272 & 15 & 216 \\
\hline 40 & 244 & 1 & 0 & 1 & 4 & 77 & 432 & 24 & 21 & 267 & 15 & 204 \\
\hline 41 & 245 & 1 & 0 & 1 & 41 & 85 & 407 & 23 & 19 & 280 & 16 & 213 \\
\hline 42 & 246 & 1 & 0 & 1 & 37 & 85 & 422 & 24 & 19 & 296 & 17 & 220 \\
\hline 43 & 247 & 1 & 0 & 1 & 59 & 81 & 406 & 23 & 19 & 259 & 15 & 213 \\
\hline 44 & 248 & 1 & 0 & 1 & 47 & 77 & 396 & 22 & 18 & 266 & 15 & 225 \\
\hline 45 & 249 & 1 & 0 & 1 & 46 & 74 & 397 & 22 & 20 & 245 & 14 & 202 \\
\hline 46 & 250 & 1 & 0 & 1 & 36 & 75 & 456 & 26 & 20 & 282 & 16 & 228 \\
\hline 47 & 251 & 1 & 0 & 1 & 39 & 75 & 466 & 26 & 20 & 282 & 16 & 233 \\
\hline 48 & 252 & 1 & 0 & 1 & 38 & 76 & 424 & 24 & 18 & 298 & 17 & 231 \\
\hline 49 & 97 & 0 & 1 & 0 & 52 & 55 & 331 & 19 & 17 & 239 & 13 & 191 \\
\hline 50 & 98 & 0 & 1 & 0 & 46 & 61 & 367 & 21 & 20 & 233 & 13 & 181 \\
\hline
\end{tabular}


Table A.4: Lab Pavement-2

\begin{tabular}{|c|c|c|c|c|c|c|c|c|c|c|c|c|}
\hline No & Name & Tack coat & Treatment & $\begin{array}{c}\text { Age } \\
\text { [months] }\end{array}$ & $\begin{array}{l}\text { AV } 1 \\
{[\%]}\end{array}$ & $\begin{array}{l}\text { AV2 } \\
{[\%]}\end{array}$ & $\stackrel{\mathrm{F}}{\mathrm{F}}$ & 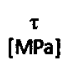 & $\begin{array}{c}w \\
{[m m]}\end{array}$ & $\begin{array}{c}\mathrm{S} \\
{[\mathrm{KN} / \mathrm{mm}]}\end{array}$ & $\begin{array}{c}\mathrm{K} \\
{[\mathrm{MPa} / \mathrm{mm}]}\end{array}$ & $\begin{array}{c}M \\
{[\mathrm{KN} / \mathrm{mm}]}\end{array}$ \\
\hline 51 & 99 & 0 & 1 & 0 & 53 & 6 & 248 & 14 & 16 & 164 & 09 & 158 \\
\hline 52 & 100 & 0 & 1 & 0 & 49 & 6 & 270 & 15 & 16 & 190 & 11 & 174 \\
\hline 53 & 101 & 0 & 1 & 0 & 51 & 6 & 279 & 16 & 13 & 234 & 13 & 209 \\
\hline 54 & 102 & 0 & 1 & 0 & 59 & 62 & 287 & 16 & 14 & 235 & 13 & 199 \\
\hline 55 & 103 & 0 & 1 & 0 & 58 & 59 & 213 & 12 & 13 & 170 & 10 & 158 \\
\hline 56 & 104 & 0 & 1 & 0 & 33 & 58 & 322 & 18 & 17 & 231 & 13 & 192 \\
\hline 57 & 105 & 0 & 1 & 0 & 43 & 61 & 289 & 16 & 14 & 238 & 13 & 207 \\
\hline 58 & 106 & 0 & 1 & 0 & 44 & 6 & 270 & 15 & 15 & 210 & 12 & 183 \\
\hline 59 & 107 & 0 & 1 & 0 & 47 & 6 & 298 & 17 & 16 & 205 & 12 & 189 \\
\hline 60 & 108 & 0 & 1 & 0 & 6 & 89 & 239 & 14 & 13 & 220 & 12 & 191 \\
\hline 61 & 109 & 0 & 1 & 0 & 6.8 & 67 & 224 & 13 & 13 & 184 & 10 & 175 \\
\hline 62 & 110 & 0 & 1 & 0 & 44 & 62 & 278 & 16 & 15 & 191 & 11 & 180 \\
\hline 63 & 111 & 0 & 1 & 0 & 41 & 62 & 256 & 14 & 12 & 243 & 14 & 207 \\
\hline 64 & 112 & 0 & 1 & 0 & 43 & 65 & 285 & 16 & 15 & 223 & 13 & 194 \\
\hline 65 & 113 & 0 & 1 & 0 & 46 & 6 & 240 & 14 & 11 & 248 & 14 & 217 \\
\hline 66 & 114 & 0 & 1 & 0 & 62 & 63 & 253 & 14 & 15 & 190 & 11 & 167 \\
\hline 67 & 115 & 0 & 1 & 0 & 77 & 71 & 207 & 12 & 12 & 186 & 11 & 170 \\
\hline 68 & 116 & 0 & 1 & 0 & 6.2 & 67 & 230 & 13 & 17 & 141 & 08 & 137 \\
\hline 69 & 117 & 0 & 1 & 0 & 53 & 68 & 221 & 13 & 13 & 185 & 10 & 168 \\
\hline 70 & 118 & 0 & 1 & 0 & 51 & 63 & 243 & 14 & 14 & 193 & 11 & 173 \\
\hline 71 & 119 & 0 & 1 & 0 & 6.1 & 65 & 194 & 11 & 11 & 190 & 11 & 175 \\
\hline 72 & 120 & 0 & 1 & 0 & 69 & 64 & 263 & 15 & 14 & 228 & 13 & 190 \\
\hline 73 & 121 & 1 & 1 & 0 & 48 & 57 & 206 & 12 & 09 & 279 & 16 & 241 \\
\hline 74 & 122 & 1 & 1 & 0 & 29 & 66 & 141 & 08 & 09 & 165 & 09 & 151 \\
\hline 75 & 123 & 1 & 1 & 0 & 29 & 64 & 115 & 07 & 07 & 183 & 10 & 162 \\
\hline 76 & 124 & 1 & 1 & 0 & 45 & 64 & 63 & 04 & 06 & 95 & 05 & 100 \\
\hline 77 & 125 & 1 & 1 & 0 & 77 & 65 & 55 & 03 & 05 & 106 & 06 & 118 \\
\hline 78 & 126 & 1 & 1 & 0 & 68 & 63 & 57 & 03 & 07 & 80 & 05 & 78 \\
\hline 79 & 127 & 1 & 1 & 0 & 33 & 55 & 182 & 10 & 08 & 236 & 13 & 219 \\
\hline 80 & 128 & 1 & 1 & 0 & 26 & 59 & 91 & 05 & 06 & 157 & 09 & 156 \\
\hline 81 & 129 & 1 & 1 & 0 & 31 & 64 & 66 & 04 & 05 & 172 & 10 & 146 \\
\hline 82 & 130 & 1 & 1 & 0 & 39 & 61 & 36 & 02 & 04 & 98 & 06 & 101 \\
\hline 83 & 131 & 1 & 1 & 0 & 66 & 64 & 250 & 14 & 17 & 151 & 09 & 143 \\
\hline 84 & 132 & 1 & 1 & 0 & 66 & 7 & 115 & 06 & 08 & 129 & 07 & 140 \\
\hline 85 & 133 & 1 & 1 & 0 & 49 & 6 & 242 & 14 & 11 & 238 & 13 & 228 \\
\hline 86 & 134 & 1 & 1 & 0 & 3 & 59 & 138 & 08 & 08 & 200 & 11 & 179 \\
\hline 87 & 135 & 1 & 1 & 0 & 35 & 63 & 118 & 07 & 07 & 186 & 11 & 175 \\
\hline 88 & 136 & 1 & 1 & 0 & 39 & 59 & 79 & 04 & 05 & 158 & 09 & 152 \\
\hline 89 & 137 & 1 & 1 & 0 & 6.6 & 6 & 73 & 04 & 08 & 97 & 05 & 93 \\
\hline 90 & 138 & 1 & 1 & 0 & 77 & 7 & 103 & 06 & 07 & 174 & 10 & 152 \\
\hline 91 & 139 & 1 & 1 & 0 & 1.6 & 57 & 184 & 10 & 09 & 227 & 13 & 211 \\
\hline 92 & 140 & 1 & 1 & 0 & 51 & 56 & 252 & 14 & 16 & 174 & 10 & 161 \\
\hline 93 & 141 & 1 & 1 & 0 & 54 & 55 & 228 & 13 & 11 & 221 & 13 & 210 \\
\hline 94 & 142 & 1 & 1 & 0 & 55 & 54 & 211 & 12 & 11 & 212 & 12 & 189 \\
\hline 95 & 143 & 1 & 1 & 0 & 72 & 6 & 182 & 10 & 11 & 195 & 11 & 172 \\
\hline 96 & 144 & 2 & 1 & 0 & 71 & 67 & 184 & 10 & 11 & 178 & 10 & 166 \\
\hline 97 & 49 & 2 & 0 & 0 & 41 & 21 & 374 & 21 & 10 & 342 & 19 & 374 \\
\hline 98 & 50 & 2 & 0 & 0 & 3.7 & 21 & 393 & 22 & 12 & 365 & 21 & 322 \\
\hline 99 & 51 & 2 & 0 & 0 & 35 & 21 & 383 & 22 & 13 & 330 & 19 & 293 \\
\hline 100 & 52 & 2 & 0 & 0 & 36 & 19 & 405 & 23 & 17 & 338 & 19 & 242 \\
\hline
\end{tabular}


Table A.4: Lab Pavement-3

\begin{tabular}{|c|c|c|c|c|c|c|c|c|c|c|c|c|}
\hline No & Name & Tack coat & Treatment & $\begin{array}{c}\text { Age } \\
\text { [months] }\end{array}$ & $\begin{array}{l}\text { AV } 1 \\
{[\%]}\end{array}$ & $\begin{array}{l}\text { AV } 2 \\
{[\%]}\end{array}$ & $\underset{[k N]}{F}$ & $\stackrel{\tau}{\tau}$ & $\begin{array}{c}w \\
{[\mathrm{~mm}]}\end{array}$ & $\begin{array}{c}\mathrm{S} \\
{[\mathrm{KN} / \mathrm{mm}]}\end{array}$ & $\begin{array}{c}\mathrm{K} \\
{[\mathrm{MPa} / \mathrm{mm}]}\end{array}$ & $\begin{array}{c}M \\
{[\mathrm{KN} / \mathrm{mm}]}\end{array}$ \\
\hline 101 & 53 & 2 & 0 & 0 & 2.7 & 19 & 429 & 24 & 12 & 262 & 15 & 351 \\
\hline 102 & 54 & 2 & 0 & 0 & 34 & 21 & 453 & 26 & 15 & 419 & 24 & 300 \\
\hline 103 & 55 & 2 & 0 & 0 & 34 & 24 & 397 & 22 & 12 & 277 & 16 & 325 \\
\hline 104 & 56 & 2 & 0 & 0 & 31 & 18 & 385 & 22 & 12 & 334 & 19 & 317 \\
\hline 105 & 57 & 2 & 0 & 0 & 2.8 & 2 & 355 & 20 & 14 & 327 & 19 & 248 \\
\hline 106 & 58 & 2 & 0 & 0 & 32 & 22 & 438 & 25 & 14 & 317 & 18 & 311 \\
\hline 107 & 59 & 2 & 0 & 0 & 34 & 21 & 436 & 25 & 15 & 342 & 19 & 284 \\
\hline 108 & 60 & 2 & 0 & 0 & 34 & 24 & 350 & 20 & 17 & 271 & 15 & 207 \\
\hline 109 & 61 & 2 & 0 & 0 & 23 & 25 & 450 & 25 & 19 & 235 & 13 & 233 \\
\hline 110 & 62 & 2 & 0 & 0 & 2.7 & 2 & 426 & 24 & 18 & 294 & 17 & 232 \\
\hline 111 & 63 & 2 & 0 & 0 & 27 & 22 & 448 & 25 & 13 & 300 & 17 & 333 \\
\hline 112 & 64 & 2 & 0 & 0 & 25 & 21 & 499 & 28 & 20 & 294 & 17 & 253 \\
\hline 113 & 65 & 2 & 0 & 0 & 3 & 23 & 423 & 24 & 14 & 260 & 15 & 305 \\
\hline 114 & 66 & 2 & 0 & 0 & 3.3 & 23 & 393 & 22 & 22 & 281 & 16 & 180 \\
\hline 115 & 67 & 2 & 0 & 0 & 3 & 22 & 443 & 25 & 16 & 253 & 14 & 284 \\
\hline 116 & 68 & 2 & 0 & 0 & 32 & 19 & 405 & 23 & 15 & 312 & 18 & 269 \\
\hline 117 & 69 & 2 & 0 & 0 & 32 & 2 & 460 & 26 & 13 & 224 & 13 & 362 \\
\hline 118 & 70 & 2 & 0 & 0 & 3 & 21 & 462 & 26 & 13 & 393 & 22 & 364 \\
\hline 119 & 71 & 2 & 0 & 0 & 3 & 21 & 479 & 27 & 13 & 370 & 21 & 377 \\
\hline 120 & 72 & 0 & 1 & 0 & 3 & 23 & 392 & 22 & 13 & 330 & 19 & 309 \\
\hline 121 & 146 & 1 & 2 & 0 & 5 & 83 & 315 & 18 & 18 & 233 & 13 & 173 \\
\hline 122 & 147 & 1 & 2 & 0 & 43 & 84 & 285 & 16 & 16 & 296 & 17 & 181 \\
\hline 123 & 148 & 1 & 2 & 0 & 43 & 82 & 288 & 16 & 21 & 205 & 12 & 139 \\
\hline 124 & 149 & 1 & 2 & 0 & 62 & 93 & 283 & 16 & 19 & 239 & 13 & 151 \\
\hline 125 & 150 & 1 & 2 & 0 & 56 & 95 & 301 & 17 & 18 & 267 & 15 & 170 \\
\hline 126 & 151 & 1 & 2 & 0 & 74 & 98 & 113 & 06 & 07 & 203 & 11 & 170 \\
\hline 127 & 152 & 1 & 2 & 0 & 36 & 9 & 104 & 06 & 07 & 161 & 09 & 149 \\
\hline 128 & 153 & 1 & 2 & 0 & 42 & 76 & 186 & 11 & 12 & 168 & 09 & 152 \\
\hline 129 & 154 & 1 & 2 & 0 & 4 & 54 & 284 & 16 & 15 & 218 & 12 & 185 \\
\hline 130 & 155 & 1 & 2 & 0 & 47 & 86 & 328 & 19 & 17 & 295 & 17 & 189 \\
\hline 131 & 158 & 0 & 2 & 0 & 33 & 81 & 27 & 02 & 03 & 114 & 06 & 102 \\
\hline 132 & 159 & 0 & 2 & 0 & 4 & 84 & 6.5 & 04 & 03 & 216 & 12 & 208 \\
\hline 133 & 160 & 0 & 2 & 0 & 42 & 64 & 114 & 06 & 04 & 321 & 18 & 295 \\
\hline 134 & 161 & 0 & 2 & 0 & 45 & 62 & 120 & 07 & 05 & 291 & 16 & 250 \\
\hline 135 & 162 & 0 & 2 & 0 & 58 & 89 & 194 & 11 & 07 & 345 & 20 & 284 \\
\hline 136 & 163 & 0 & 2 & 0 & 47 & 93 & 51 & 03 & 03 & 164 & 09 & 171 \\
\hline 137 & 164 & 0 & 2 & 0 & 32 & 76 & 07 & 00 & 07 & 08 & 00 & 10 \\
\hline 138 & 165 & 0 & 2 & 0 & 46 & 83 & 35 & 02 & 03 & 99 & 06 & 114 \\
\hline 139 & 166 & 0 & 2 & 0 & 47 & 6 & 9.8 & 06 & 04 & 248 & 14 & 232 \\
\hline 140 & 167 & 0 & 2 & 0 & 53 & 84 & 87 & 05 & 04 & 251 & 14 & 230 \\
\hline 141 & 170 & 1 & 3 & 0 & 26 & 52 & 4.8 & 03 & 05 & 110 & 06 & 98 \\
\hline 142 & 171 & 1 & 3 & 0 & 53 & 62 & 72 & 04 & 04 & 203 & 11 & 172 \\
\hline 143 & 172 & 1 & 3 & 0 & 51 & 53 & 119 & 07 & 07 & 198 & 11 & 183 \\
\hline 144 & 173 & 1 & 3 & 0 & 45 & 63 & 149 & 08 & 07 & 240 & 14 & 209 \\
\hline 145 & 174 & 1 & 3 & 0 & 38 & 54 & 204 & 12 & 08 & 292 & 17 & 255 \\
\hline 146 & 175 & 1 & 3 & 0 & 2.6 & 45 & 81 & 05 & 08 & 142 & 08 & 106 \\
\hline 147 & 176 & 1 & 3 & 0 & 2.4 & 52 & 4.8 & 03 & 07 & 78 & 04 & 65 \\
\hline 148 & 177 & 1 & 3 & 0 & 4 & 59 & 34 & 02 & 04 & 102 & 06 & 94 \\
\hline 149 & 178 & 1 & 3 & 0 & 45 & 54 & 7.9 & 04 & 07 & 126 & 07 & 110 \\
\hline 150 & 179 & 1 & 3 & 0 & 48 & 63 & 124 & 07 & 13 & 109 & 06 & 99 \\
\hline
\end{tabular}




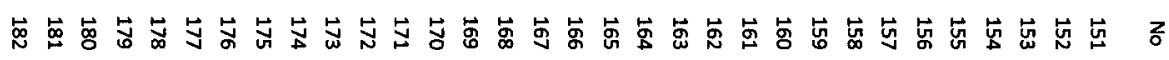

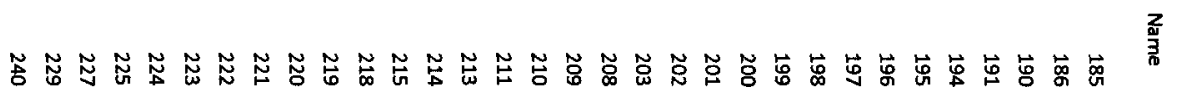

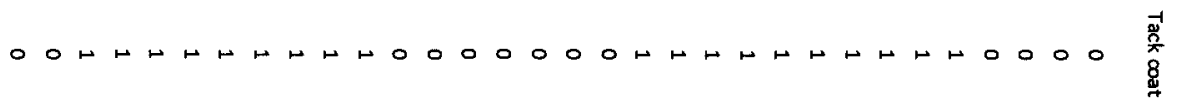

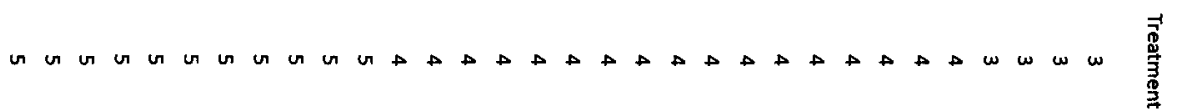

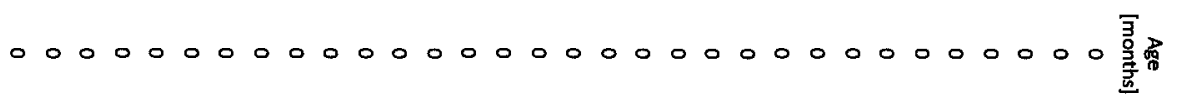

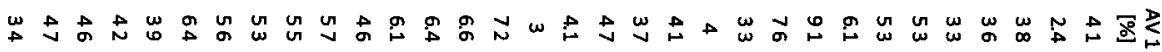
舟

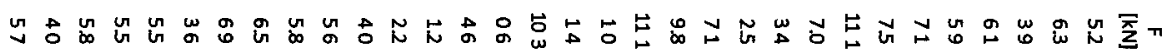

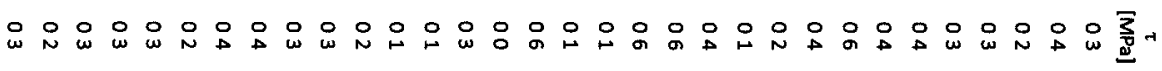

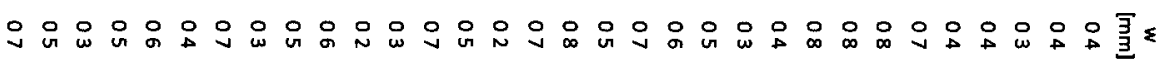

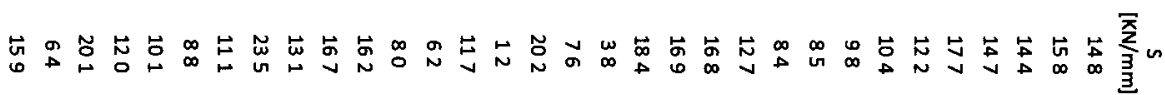

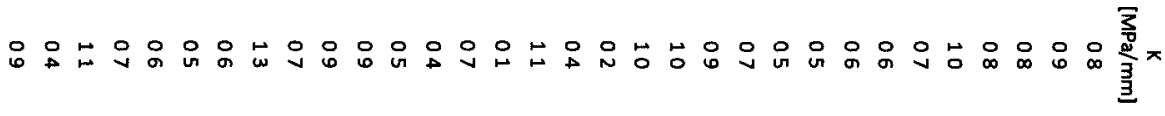

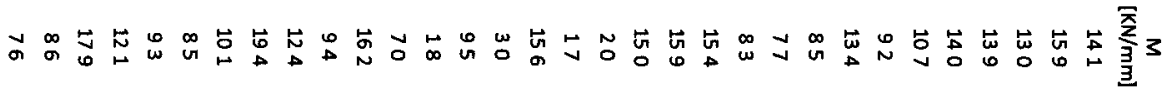


Table A.5: RILEM Pavement -1

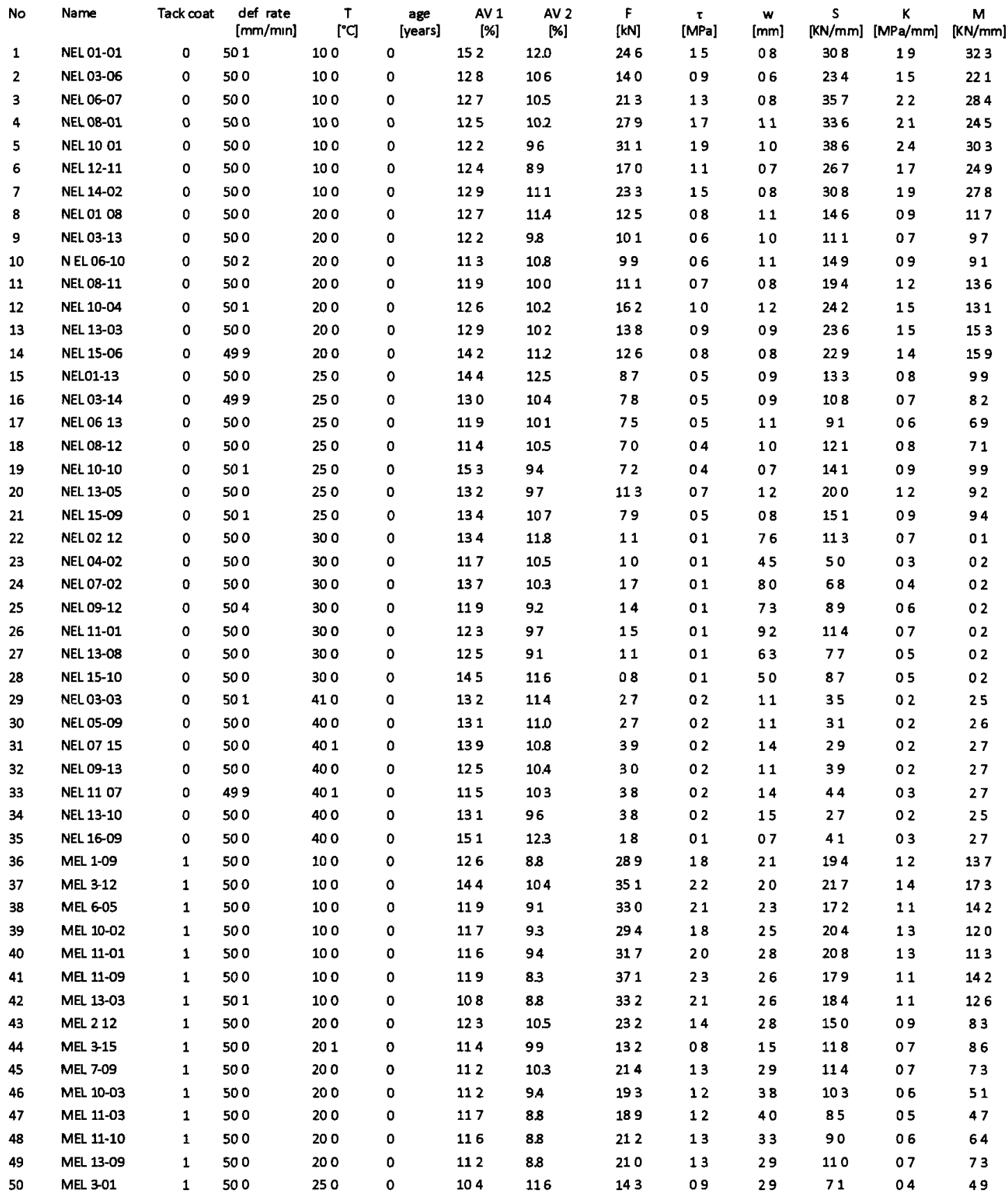


Table A.5 :RILEM Pavement -continued 2

\begin{tabular}{|c|c|c|c|c|c|c|c|c|c|c|c|c|c|}
\hline No & Name & Tack coat & $\begin{array}{l}\text { def rate } \\
{[\mathrm{mm} / \mathrm{mın}]}\end{array}$ & $\begin{array}{c}T \\
{\left[{ }^{\circ} \mathrm{C}\right]}\end{array}$ & $\begin{array}{c}\text { age } \\
\text { [years] }\end{array}$ & $\begin{array}{c}\text { AV } 1 \\
{[\%]}\end{array}$ & $\begin{array}{c}\text { AV } 2 \\
{[\%]}\end{array}$ & $\stackrel{\underset{F}{F}}{[\mathrm{kN}]}$ & $\begin{array}{c}\tau \\
{[\mathrm{MPa}]}\end{array}$ & $\begin{array}{c}w \\
{[\mathrm{~mm}]}\end{array}$ & $\begin{array}{c}\mathrm{S} \\
{[\mathrm{KN} / \mathrm{mm}]}\end{array}$ & $\begin{array}{c}\mathrm{K} \\
{[\mathrm{MPa} / \mathrm{mm}]}\end{array}$ & 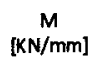 \\
\hline 51 & MEL 4.08 & 1 & 500 & 250 & 0 & 88 & 100 & 150 & 09 & 30 & 68 & 04 & 51 \\
\hline 52 & MEL 8-08 & 1 & 500 & 250 & 0 & 94 & 106 & 153 & 10 & 30 & 95 & 06 & 51 \\
\hline 53 & MEL 10-06 & 1 & 500 & 250 & 0 & 87 & 100 & 127 & 08 & 28 & 86 & 05 & 45 \\
\hline 54 & MEL 11-04 & 1 & 500 & 250 & 0 & 76 & 89 & 133 & 08 & 44 & 56 & 03 & 30 \\
\hline 55 & MEL $11-14$ & 1 & 500 & 250 & 0 & 92 & 104 & 154 & 10 & 26 & 88 & 05 & 60 \\
\hline 56 & MEL 14-04 & 1 & 500 & 250 & 0 & 92 & 105 & 155 & 10 & 36 & 68 & 04 & 43 \\
\hline 57 & MEL 3-02 & 1 & 500 & 300 & 0 & 101 & 93 & 111 & 07 & 30 & 66 & 04 & 37 \\
\hline 58 & MEL 4-12 & 1 & 500 & 300 & 0 & 109 & 102 & 73 & 05 & 28 & 35 & 02 & 26 \\
\hline 59 & MEL \&12 & 1 & 500 & 300 & 0 & 111 & 9.5 & 115 & 07 & 33 & 53 & 03 & 35 \\
\hline 60 & MEL 10-08 & 1 & 500 & 300 & 0 & 123 & 9.2 & 84 & 05 & 33 & 51 & 03 & 25 \\
\hline 61 & MEL 11-08 & 1 & 500 & 301 & 0 & 114 & 93 & 85 & 05 & 45 & 30 & 02 & 19 \\
\hline 62 & MEL 12-04 & 1 & 500 & 300 & 0 & 114 & 93 & 89 & 06 & 39 & 32 & 02 & 23 \\
\hline 63 & MEL 14-05 & 1 & 501 & 300 & 0 & 119 & 9.5 & 99 & 06 & 38 & 44 & 03 & 26 \\
\hline 64 & MEL 3-08 & 1 & 500 & 400 & 0 & 109 & 10.5 & 43 & 03 & 27 & 26 & 02 & 16 \\
\hline 65 & MEL 5-12 & 1 & 500 & 400 & 0 & 114 & 100 & 56 & 03 & 34 & 20 & 01 & 16 \\
\hline 66 & MEL 909 & 1 & 501 & 400 & 0 & 113 & 103 & 62 & 04 & 30 & 23 & 01 & 21 \\
\hline 67 & MEL 10-13 & 1 & 500 & 400 & 0 & 106 & 97 & 59 & 04 & 42 & 24 & 01 & 14 \\
\hline 68 & MEL 11-08-1 & 1 & 500 & 400 & 0 & 118 & 99 & 59 & 04 & 38 & 26 & 02 & 15 \\
\hline 69 & MEL 12-05 & 1 & 500 & 401 & 0 & 113 & 106 & 54 & 03 & 37 & 25 & 02 & 15 \\
\hline 70 & MEL 15-09 & 1 & 500 & 400 & 0 & 125 & 96 & 49 & 03 & 37 & 18 & 01 & 13 \\
\hline 71 & CEL 01-08 & 2 & 500 & 100 & 0 & 137 & 104 & 331 & 21 & 20 & 202 & 13 & 165 \\
\hline 72 & CEL 05-13 & 2 & 500 & 101 & 0 & 120 & 104 & 370 & 23 & 22 & 262 & 16 & 168 \\
\hline 73 & CE $10-02$ & 2 & 500 & 100 & 0 & 141 & 9.5 & 289 & 18 & 22 & 216 & 13 & 130 \\
\hline 74 & CEL $10-20$ & 2 & 500 & 100 & 0 & 132 & 86 & 389 & 24 & 18 & 340 & 21 & 211 \\
\hline 75 & CE $11-16$ & 2 & 500 & 100 & 0 & 128 & 94 & 393 & 24 & 19 & 282 & 18 & 209 \\
\hline 76 & CEl 13.05 & 2 & 500 & 100 & 0 & 129 & 102 & 319 & 20 & 17 & 213 & 13 & 192 \\
\hline 77 & CEL 15-20 & 2 & 500 & 100 & 0 & 127 & 100 & 422 & 26 & 23 & 263 & 16 & 183 \\
\hline 78 & CEL $02-13$ & 2 & 499 & 201 & 0 & 124 & 103 & 197 & 12 & 26 & 153 & 10 & 75 \\
\hline 79 & CEL 05-15 & 2 & 500 & 200 & 0 & 117 & 99 & 177 & 11 & 39 & 94 & 06 & 46 \\
\hline 80 & CEL $10-05$ & 2 & 500 & 200 & 0 & 132 & 100 & 206 & 13 & 26 & 132 & 08 & 78 \\
\hline 81 & CEL 11-01 & 2 & 501 & 200 & 0 & 128 & 90 & 199 & 12 & 33 & 110 & 07 & 60 \\
\hline 82 & CEL 12-04 & 2 & 500 & 200 & 0 & 119 & 96 & 152 & 09 & 19 & 87 & os & 78 \\
\hline 83 & CFL 13-07 & 2 & 500 & 200 & 0 & 122 & 9.5 & 239 & 15 & 27 & 126 & 08 & 90 \\
\hline 84 & CEL 16-11 & 2 & 500 & 250 & 0 & 129 & 94 & 212 & 13 & 23 & 119 & 07 & 93 \\
\hline 85 & CE 03-08 & 2 & 500 & 250 & 0 & 129 & 104 & 173 & 11 & 40 & 147 & 09 & 43 \\
\hline 86 & CE 06-11 & 2 & 500 & 250 & 0 & 123 & 100 & 206 & 13 & 31 & 143 & 09 & 66 \\
\hline 87 & CE 10.08 & 2 & 500 & 250 & 0 & 132 & 93 & 172 & 11 & 33 & 102 & 06 & 51 \\
\hline 88 & CE 11-02 & 2 & 500 & 250 & 0 & 128 & 88 & 157 & 10 & 26 & 175 & 11 & 60 \\
\hline 89 & Cé 12-17 & 2 & 500 & 250 & 0 & 129 & 90 & 183 & 11 & 30 & 81 & 05 & 61 \\
\hline 90 & CEL 13-08 & 2 & 500 & 250 & 0 & 123 & 91 & 185 & 12 & 30 & 121 & 08 & 62 \\
\hline 91 & CE $16-13$ & 2 & 501 & 250 & 0 & 130 & 96 & 176 & 11 & 22 & 124 & 08 & 79 \\
\hline 92 & CEL 03-09 & 2 & 500 & 300 & 0 & 125 & 102 & 125 & 08 & 38 & 65 & 04 & 33 \\
\hline 93 & CEL 06-15 & 2 & 500 & 300 & 0 & 128 & 100 & 138 & 09 & 41 & 74 & 05 & 34 \\
\hline 94 & CEL 10.09 & 2 & 500 & 300 & 0 & 132 & 91 & 124 & 08 & 39 & 80 & 05 & 32 \\
\hline 95 & CE 11-11 & 2 & 500 & 300 & 0 & 129 & 92 & 132 & 08 & 30 & 94 & 06 & 44 \\
\hline 96 & CE 13-02 & 2 & 500 & 300 & 0 & 127 & 83 & 91 & 06 & 23 & 86 & 05 & 39 \\
\hline 97 & CE 14-08 & 2 & 500 & 300 & 0 & 139 & 106 & 121 & 08 & 26 & 75 & 05 & 46 \\
\hline 98 & CE 17-18 & 2 & 500 & 300 & 0 & 126 & 102 & 142 & 09 & 34 & 100 & 06 & 42 \\
\hline 99 & CEI 04-14 & 2 & 500 & 400 & 0 & 129 & 127 & 65 & 04 & 39 & 52 & 03 & 17 \\
\hline 100 & CEL 09-10 & 2 & 500 & 400 & 0 & 138 & 119 & 60 & 04 & 31 & 56 & 03 & 19 \\
\hline
\end{tabular}


Table A.5: RILEM Pavement -continued 3

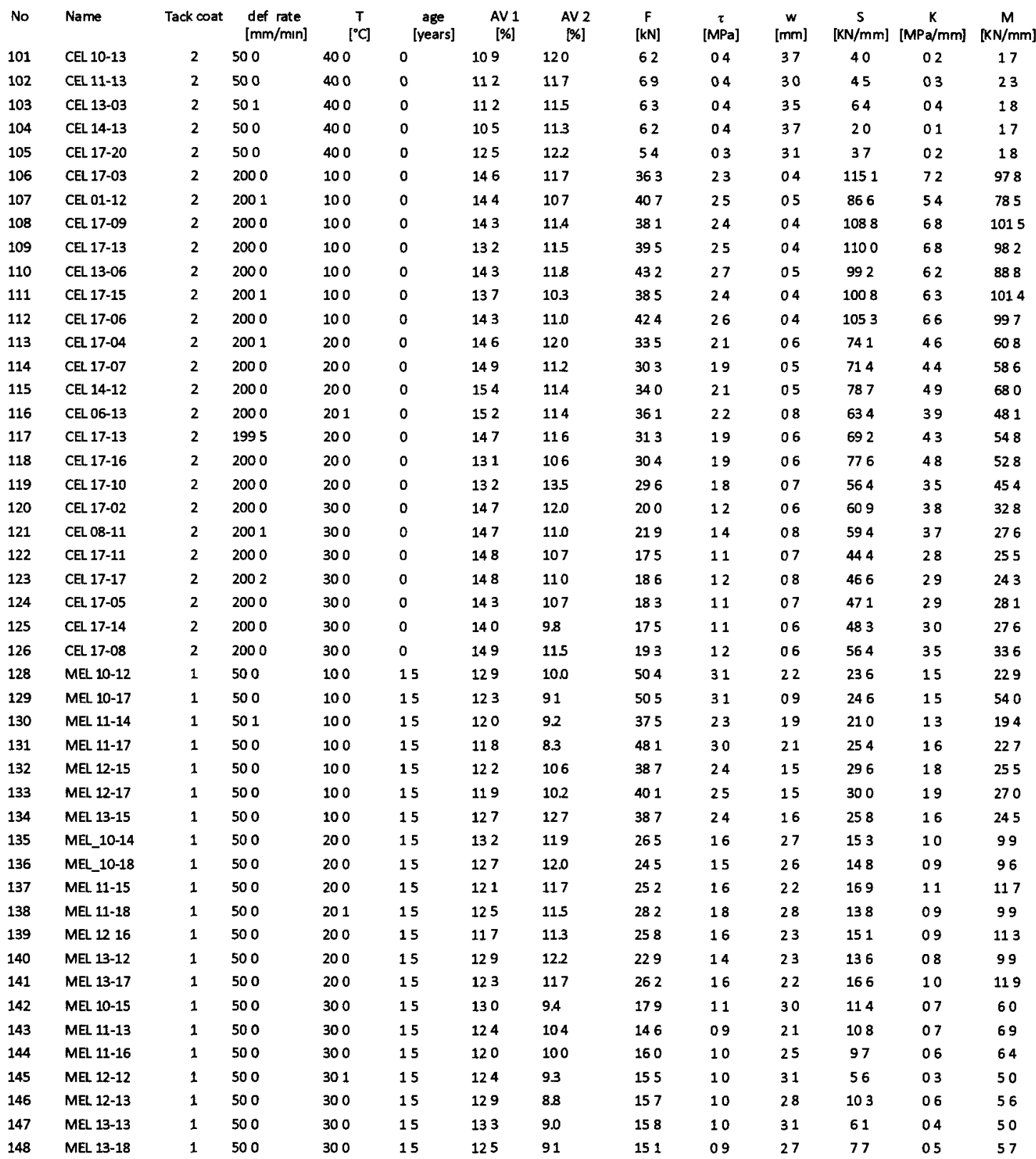




\section{Appendix B}

\section{Data from testing program 2 (influence of moisture)}

\section{B.1 Data}

Tables B1 to B7 show the LPDS and Shear Box individual test results for the different moisture conditions. If the air void content was determined, these values are also given. 
Table B.1: Pavement 1, first interface, results of Shear Box testing, single values

$\begin{array}{ccccccc}\begin{array}{c}\mathrm{F}_{\text {ShearBox }} \\ {[\mathrm{kN}]}\end{array} & \begin{array}{c}\tau_{\text {ShearBox }} \\ {[\mathrm{MPa}]}\end{array} & \begin{array}{c}\mathrm{W}_{\text {ShearBox }} \\ {[\mathrm{mm}]}\end{array} & \begin{array}{c}\mathrm{S}_{\text {ShearBox }} \\ {[\mathrm{kN} / \mathrm{mm}]}\end{array} & \begin{array}{c}\mathrm{K}_{\text {Shear Box }} \\ {[\mathrm{MPa}]}\end{array} & \sigma[\mathrm{MPa}] & \text { Conditioning } \\ 11.62 & 1.51 & 3.26 & 5.12 & 0.3 & 0 & \text { no } \\ 8.99 & 1.17 & 3.57 & 3.08 & 0.2 & 0 & \text { no } \\ 10.24 & 1.33 & 4.09 & 3.36 & 0.2 & 0 & \text { no } \\ 7.56 & 0.98 & 3.14 & 3.02 & 0.2 & 0 & \text { no } \\ 7.87 & 1.02 & 3.68 & 2.89 & 0.2 & 0 & \text { no } \\ 8.59 & 1.12 & 2.68 & 3.84 & 0.2 & 0 & \text { no } \\ 8.01 & 1.04 & 3.48 & 2.9 & 0.2 & 0 & \text { no } \\ 10.21 & 1.33 & 3.79 & 3.63 & 0.2 & 0 & \text { no } \\ & & & & & & \\ 8.01 & 1.04 & 2.83 & 3.12 & 0.2 & 0.1 & \text { no } \\ 8.86 & 1.15 & 2.52 & 3.94 & 0.2 & 0.1 & \text { no } \\ 8.27 & 1.07 & 2.4 & 4.27 & 0.2 & 0.1 & \text { no } \\ 9.1 & 1.18 & 2.76 & 3.7 & 0.2 & 0.1 & \text { no } \\ 10.33 & 1.34 & 3.21 & 3.87 & 0.2 & 0.1 & \text { no } \\ & & & & & & \\ 9.92 & 1.29 & 2.8 & 4.43 & 0.3 & 0.4 & \text { no } \\ 10.61 & 1.38 & 3.17 & 4.34 & 0.2 & 0.4 & \text { no } \\ 8.43 & 1.09 & 2.58 & 4.68 & 0.3 & 0.4 & \text { no } \\ 12.92 & 1.68 & 3.93 & 4.6 & 0.3 & 0.4 & \text { no } \\ 11.37 & 1.48 & 3.27 & 4.61 & 0.3 & 0.4 & \text { no } \\ 9.69 & 1.26 & 2.89 & 4.37 & 0.2 & 0.4 & \text { no } \\ & & & & & & \\ 11.67 & 1.52 & 3.94 & 3.83 & 0.2 & 0.1 & \text { water } 40^{\circ} \mathrm{C} \\ 7.19 & 0.93 & 4.15 & 2.51 & 0.1 & 0.1 & \text { water } 40^{\circ} \mathrm{C} \\ 11.16 & 1.45 & 4.1 & 3.87 & 0.2 & 0.1 & \text { water } 40^{\circ} \mathrm{C} \\ 6.8 & 0.88 & 3.35 & 2.76 & 0.2 & 0.1 & \text { water } 40^{\circ} \mathrm{C} \\ 7.41 & 0.96 & 3.89 & 2.71 & 0.2 & 0.1 & \text { water } 40^{\circ} \mathrm{C} \\ 8.86 & 1.15 & 4.12 & 2.6 & 0.1 & 0.1 & \text { water } 40^{\circ} \mathrm{C} \\ 8.05 & 1.05 & 3.66 & 2.73 & 0.2 & 0.1 & \text { water } 40^{\circ} \mathrm{C}\end{array}$


Table B.2: Pavement 2, first interface, results of Shear Box testing, single values

\begin{tabular}{|c|c|c|c|c|c|c|}
\hline $\begin{array}{c}\mathrm{F}_{\text {ShearBox }} \\
{[\mathrm{kN}]}\end{array}$ & $\begin{array}{c}\tau_{\text {ShearBox }} \\
{[\mathrm{MPa}]}\end{array}$ & $\begin{array}{c}\text { W }_{\text {ShearBox }} \\
{[\mathrm{mm}]}\end{array}$ & $\begin{array}{c}\mathrm{S}_{\text {ShearBox }} \\
{[\mathrm{kN} / \mathrm{mm}]}\end{array}$ & $\begin{array}{c}\mathrm{K}_{\text {Shear Box }} \\
{[\mathrm{MPa}]}\end{array}$ & $\sigma[\mathrm{MPa}]$ & Conditioning \\
\hline 9.96 & 1.29 & 3.32 & 3.39 & 0.2 & 0 & no \\
\hline 8.36 & 1.09 & 2.72 & 3.79 & 0.2 & 0 & no \\
\hline 10.07 & 1.31 & 3.18 & 3.8 & 0.2 & 0 & no \\
\hline 10.42 & 1.35 & 2.9 & 4.13 & 0.2 & 0 & no \\
\hline 8.41 & 1.09 & 2.75 & 3.41 & 0.2 & 0 & no \\
\hline 8.19 & 1.06 & 2.47 & 3.56 & 0.2 & 0 & no \\
\hline 8.86 & 1.13 & 3.2 & 2.92 & 0.2 & 0.1 & no \\
\hline 8.97 & 1.16 & 3.79 & 2.52 & 0.1 & 0.1 & no \\
\hline 11.73 & 1.52 & 4.48 & 2.87 & 0.2 & 0.1 & no \\
\hline 10.18 & 1.32 & 3.64 & 3.05 & 0.2 & 0.1 & no \\
\hline 11.31 & 1.47 & 3.31 & 3.76 & 0.2 & 0.1 & no \\
\hline 11.13 & 1.45 & 4.54 & 2.61 & 0.1 & 0.1 & no \\
\hline 10.03 & 1.3 & 3.14 & 3.56 & 0.2 & 0.4 & no \\
\hline 12 & 1.56 & 3.03 & 4.83 & 0.3 & 0.4 & no \\
\hline 9.86 & 1.28 & 4.02 & 3.25 & 0.2 & 0.4 & no \\
\hline 10.65 & 1.38 & 3.07 & 4.04 & 0.2 & 0.4 & no \\
\hline 8.23 & 1.07 & 3.9 & 2.44 & 0.1 & 0.1 & water $40^{\circ} \mathrm{C}$ \\
\hline 7.02 & 0.91 & 2.86 & 2.84 & 0.2 & 0.1 & water $40^{\circ} \mathrm{C}$ \\
\hline 7.15 & 0.93 & 2.52 & 3.25 & 0.2 & 0.1 & water $40^{\circ} \mathrm{C}$ \\
\hline 7.97 & 1.03 & 3.2 & 2.68 & 0.2 & 0.1 & water $40^{\circ} \mathrm{C}$ \\
\hline 6.83 & 0.89 & 3.43 & 2.51 & 0.1 & 0.1 & water $40^{\circ} \mathrm{C}$ \\
\hline 6.57 & 0.85 & 2.56 & 2.98 & 0.2 & 0.1 & water $40^{\circ} \mathrm{C}$ \\
\hline 8.3 & 1.08 & 4.26 & 2.1 & 0.1 & 0.1 & water $40^{\circ} \mathrm{C}$ \\
\hline
\end{tabular}


Table B.3: Pavement 1, first interface, results of LPDS testing, single values

Name

$\underset{[\mathrm{kN}]}{\mathrm{F}} \quad[\mathrm{M}$

$[\mathrm{MPa}]$
W $[\mathrm{mm}$
$\mathrm{K}$ $[\mathrm{kN} / \mathrm{mm}$
AV 1

[Vol-\%]
AV 2

[Vol-\%]

Condition 1 , no water

$\begin{array}{llllllll}\text { WL1 } & 32.6 & 1.8 & 2.4 & 19.3 & 1.1 & 9.5 & 5.0 \\ \text { WL2 } & 32.0 & 1.8 & 2.6 & 16.7 & 0.9 & 9.1 & 5.0 \\ \text { WL3 } & 30.5 & 1.7 & 2.45 & 19.1 & 1.1 & 9.1 & 4.4 \\ \text { WL4 } & 30.3 & 1.7 & 3.0 & 14.5 & 0.8 & 9.4 & 4.7 \\ \text { WL5 } & 27.3 & 1.5 & 2.7 & 16.2 & 0.9 & 9.5 & 2.1\end{array}$

Condition 2, water $40^{\circ} \mathrm{C}$

$\begin{array}{llllllll}\text { WL13 } & 26.9 & 1.5 & 3.2 & 18.2 & 1.0 & 10.1 & 5.2 \\ \text { WL14 } & 28.6 & 1.6 & 2.4 & 19.3 & 1.1 & 9.8 & 4.8 \\ \text { WL15 } & 23.9 & 1.4 & 2.4 & 19.5 & 1.1 & 9.8 & 5.4 \\ \text { WL16 } & 22.3 & 1.3 & 2.7 & 14.7 & 0.8 & 10.4 & 5.3 \\ \text { WL17 } & 25.3 & 1.4 & 2.9 & 19.5 & 1.1 & 10.0 & 4.5\end{array}$

Condition 3, water $60^{\circ} \mathrm{C}$

$\begin{array}{llllllll}\text { W6 } & 23.1 & 1.3 & 2.3 & 15.5 & 0.9 & 10.9 & 4.7 \\ \text { W7 } & 20.8 & 1.2 & 1.8 & 18.6 & 1.1 & 10.7 & 4.5 \\ \text { W8 } & 21.9 & 1.2 & 2.3 & 13.0 & 0.7 & 10.6 & 5.1 \\ \text { W9 } & 24.6 & 1.4 & 2.3 & 14.1 & 0.8 & 10.1 & 5.2 \\ \text { W10 } & 22.6 & 1.3 & 1.8 & 19.2 & 1.1 & 10.1 & 6.1 \\ \text { WL11 } & 23.8 & 1.3 & 2.6 & 15.5 & 0.9 & 11.0 & 4.8\end{array}$

Condition 4, water $40^{\circ} \mathrm{C}$, pressure 0.5 bar

$\begin{array}{llllllll}\text { WL12 } & 25.3 & 1.4 & 2.1 & 12.1 & 0.7 & 10.2 & 4.8 \\ \text { WL19 } & 24.6 & 1.4 & 2.4 & 18.3 & 1.0 & 12.5 & 5.5 \\ \text { WL20 } & 26.8 & 1.5 & 2.6 & 17.0 & 1.0 & 11.6 & 5.0 \\ \text { WL22 } & 26.1 & 1.5 & 2.7 & 19.6 & 1.1 & 10.4 & 5.4\end{array}$


Table B.4: Pavement 1, second interface, results of LPDS testing, single values

Name

$$
\begin{array}{ccccccc}
\mathrm{F} & \tau & \mathrm{w} & \mathrm{S} & \mathrm{K} & \mathrm{AV} \mathrm{1} & \mathrm{AV} \mathrm{2} \\
{[\mathrm{kN}]} & {[\mathrm{MPa}]} & {[\mathrm{mm}]} & {[\mathrm{kN} / \mathrm{mm}]} & {[\mathrm{MPa} / \mathrm{mm}]} & {[\mathrm{Vol}-\%]} & {[\mathrm{Vol}-\%]}
\end{array}
$$

Condition 1 , no water

$\begin{array}{llllllll}\text { WL1_2 } & 24.5 & 1.4 & 2.0 & 19.6 & 1.1 & 5.0 & 4.4 \\ \text { WL7_2 } & 32.4 & 1.8 & 2.2 & 26.2 & 1.5 & 4.5 & 5.1 \\ \text { WL15_2 } & 24.0 & 1.4 & 2.2 & 14.8 & 0.8 & 5.4 & 4.2 \\ \text { WL18_2 } & 28.5 & 1.6 & 1.8 & 29.7 & 1.7 & 4.5 & 7.6\end{array}$

Condition 2, water $40^{\circ} \mathrm{C}$

$\begin{array}{llllllll}\text { WL12 } & 25.2 & 1.4 & 2.2 & 20.9 & 1.2 & 4.8 & 4.0 \\ \text { WL19 } & 25.5 & 1.4 & 2.0 & 21.2 & 1.2 & 5.5 & 4.4 \\ \text { WL20 } & 26.1 & 1.5 & 2.3 & 17.9 & 1.0 & 5.0 & 4.4 \\ \text { WL21 } & 24.8 & 1.4 & 2.5 & 16.8 & 1.0 & 5.4 & 4.3\end{array}$

Condition 3 , water $60^{\circ} \mathrm{C}$

$\begin{array}{llllllll}\text { WL4_2 } & 21.7 & 1.2 & 2.6 & 17.3 & 1.0 & 4.7 & 4.9 \\ \text { WL9_2 } & 24.9 & 1.4 & 2.6 & 13.1 & 0.7 & 5.2 & 4.5 \\ \text { WL13_2 } & 20.4 & 1.2 & 2.2 & 13.9 & 0.8 & 5.2 & 4.4 \\ \text { WL16_2 } & 20.7 & 1.2 & 2.1 & 17.3 & 1.0 & 5.3 & 4.7 \\ \text { WL4_2 } & 21.7 & 1.2 & 2.6 & 17.3 & 1.0 & 4.7 & 4.9\end{array}$

Condition 4, water $40^{\circ} \mathrm{C}$, pressure 0.5 bar

$\begin{array}{llllllll}\text { WL3_2 } & 19.6 & 1.1 & 1.8 & 16.2 & 0.9 & 5.0 & 5.1 \\ \text { WL5_2 } & 12.7 & 0.7 & 1.9 & 12.7 & 0.7 & 5.3 & 4.7 \\ \text { WL8_2 } & 22.8 & 1.2 & 2.2 & 15.1 & 0.9 & 5.1 & 4.9 \\ \text { WL10_2 } & 20.8 & 1.2 & 2.1 & 15.5 & 0.9 & 6.1 & 4.8 \\ \text { WL17_2 } & 15.9 & 0.9 & 1.8 & 14.0 & 0.8 & 5.5 & 4.9\end{array}$


Table B.5: Pavement 2, first interface, results of LPDS testing, single values

Name

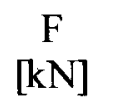

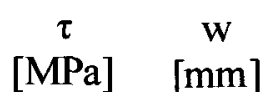

$\mathrm{S}$

$\mathrm{K}$

AV 1

AV 2

$[\mathrm{kN}]$

$[\mathrm{kN} / \mathrm{mm}] \quad[\mathrm{MPa} / \mathrm{mm}]$

[Vol-\%]

[Vol-\%]

Condition 1 , no water

$\begin{array}{llllllll}\text { WS13 } & 30.5 & 1.7 & 2.3 & 19.3 & 1.1 & 11.0 & 1.4 \\ \text { WS12 } & 28.4 & 1.6 & 2.6 & 19.8 & 1.1 & 11.7 & 1.8 \\ \text { WS11 } & 35.3 & 2.0 & 2.4 & 25.0 & 1.4 & 14.5 & 2.7 \\ \text { WS14 } & 34.2 & 1.9 & 2.4 & 26.5 & 1.5 & 11.6 & 2.5 \\ \text { WS18x } & 35.6 & 2.0 & 2.5 & 18.5 & 1.0 & 12.2 & 2.6\end{array}$

Condition 2 , water $40^{\circ} \mathrm{C}$

$\begin{array}{llllllll}\text { WS6 } & 33.3 & 1.9 & 2.4 & 26.6 & 1.5 & 11.7 & 1.6 \\ \text { WS7 } & 41.2 & 2.3 & 2.7 & 22.4 & 1.3 & 11.3 & 1.7 \\ \text { WS8 } & 38.6 & 2.2 & 3.0 & 18.5 & 1.0 & 10.9 & 1.3 \\ \text { WS9 } & 36.0 & 2.0 & 2.8 & 19.2 & 1.1 & 11.7 & 1.9 \\ \text { WS10 } & 37.0 & 2.1 & 2.5 & 19.8 & 1.1 & 11.6 & 2.7 \\ \text { Condition 3, } & \text { water } 60^{\circ} \mathrm{C} & & & & & & \\ \text { WS1 } & 32.3 & 1.8 & 3.2 & 20.2 & 1.1 & 10.9 & 1.8 \\ \text { WS2 } & 34.0 & 1.9 & 2.7 & 20.8 & 1.2 & 10.8 & 1.7 \\ \text { WS3 } & 36.1 & 2.0 & 2.6 & 22.5 & 1.3 & 11.0 & 1.8 \\ \text { WS4 } & 27.5 & 1.6 & 2.1 & 21.4 & 1.2 & 10.9 & 1.9 \\ \text { WS5 } & 37.0 & 2.1 & 2.5 & 19.8 & 1.1 & 10.5 & 2.1\end{array}$


Table B.6: Pavement 3, first interface, results of LPDS testing, single values

Name

$$
\begin{array}{ccccccc}
\mathrm{F} & \tau & \mathrm{w} & \mathrm{S} & \mathrm{K} & \mathrm{AV} \mathrm{1} & \mathrm{AV} \mathrm{2} \\
{[\mathrm{kN}]} & {[\mathrm{MPa}]} & {[\mathrm{mm}]} & {[\mathrm{kN} / \mathrm{mm}]} & {[\mathrm{MPa} / \mathrm{mm}]} & {[\mathrm{Vol}-\%]} & {[\mathrm{Vol}-\%]}
\end{array}
$$

Condition 1, no water

$\begin{array}{llllllll}20 \_1 & 31.2 & 1.8 & 2.1 & 24.0 & 1.4 & 11.5 & 4.4 \\ 21 \_1 & 39.6 & 2.2 & 1.9 & 31.8 & 1.8 & 9.5 & 4.3 \\ 22 \_1 & 30.6 & 1.7 & 1.8 & 23.6 & 1.3 & 10.1 & 4.7 \\ 24 \_1 & 34.5 & 2.0 & 1.8 & 25.0 & 1.4 & 10.7 & 4.4 \\ 25 \_1 & 29.9 & 1.7 & 1.8 & 22.9 & 1.3 & 10.2 & 4.1\end{array}$

Condition 2, water $40^{\circ} \mathrm{C}$

$\begin{array}{llllllll}31 \_1 & 37.7 & 2.1 & 2.2 & 26.5 & 1.5 & 9.9 & 3.9 \\ 29 \_1 & 30.6 & 1.7 & 2.3 & 21.4 & 1.2 & 10.9 & 4.2 \\ 32 \_1 & 26.8 & 1.5 & 2.1 & 18.7 & 1.1 & 11.1 & 4.3 \\ 26 \_1 & 28.4 & 1.6 & 1.8 & 22.9 & 1.3 & 8.1 & 4.2 \\ 30 \_1 & 40.6 & 2.3 & 2.3 & 31.1 & 1.8 & 8.4 & 4.5 \\ 33 \_1 & 38.8 & 2.2 & 2.4 & 21.4 & 1.2 & 8.6 & 4.2\end{array}$

Condition 3, water $60^{\circ} \mathrm{C}$

$\begin{array}{llllllll}13 \_1 & 29.6 & 1.7 & 2.4 & 15.5 & 0.9 & 8 & 4.3 \\ 14 \_1 & 37.2 & 2.1 & 2.7 & 21.8 & 1.2 & 9.8 & 4.8 \\ 16 \_1 & 14.4 & 0.8 & 1.2 & 14.2 & 0.8 & 10.3 & 4.3 \\ 15 \_1 & 20.3 & 1.1 & 2.0 & 13.9 & 0.8 & 18.8 & 4.2 \\ 7 \_1 & 37.8 & 2.1 & 2.3 & 22.2 & 1.3 & 9.7 & 4.1 \\ 8 \_1 & 30.3 & 1.7 & 2.2 & 14.9 & 0.8 & 9.8 & 4\end{array}$

Condition 4 , water $40^{\circ} \mathrm{C}$, pressure 0.5 bar

$\begin{array}{llllllll}34 \_1 & 34.5 & 2.0 & 1.9 & 29.5 & 1.7 & 9.2 & 4.5 \\ 35 \_1 & 33.5 & 1.9 & 2.0 & 23.8 & 1.3 & 9.2 & 4.9 \\ 36 \_1 & 30.6 & 1.7 & 1.8 & 26.8 & 1.5 & 9.2 & 4.5 \\ 37 \_1 & 25.3 & 1.4 & 2.2 & 15.3 & 0.9 & 10.6 & 4.2 \\ 38 \_1 & 43.0 & 2.4 & 2.4 & 23.1 & 1.3 & 9.4 & 4.6 \\ 39 \_1 & 22.2 & 1.3 & 2.6 & 11.2 & 0.6 & 12.2 & 5.0\end{array}$


Table B.7: Pavement 3, second interface, results of LPDS testing, single values

Name

$$
\begin{array}{ccccccc}
\mathrm{F} & \tau & \mathrm{w} & \mathrm{S} & \mathrm{K} & \mathrm{AV} \mathrm{1} & \mathrm{AV} \mathrm{2} \\
{[\mathrm{kN}]} & {[\mathrm{MPa}]} & {[\mathrm{mm}]} & {[\mathrm{kN} / \mathrm{mm}]} & {[\mathrm{MPa} / \mathrm{mm}]} & {[\mathrm{Vol}-\%]} & {[\mathrm{Vol}-\%]}
\end{array}
$$

Condition 1 , no water

$\begin{array}{llllllll}20 \_2 & 40.1 & 2.3 & 1.7 & 28.4 & 1.6 & 4.4 & 4.3 \\ 21 \_2 & 35.9 & 2.0 & 1.3 & 30.2 & 1.7 & 3.9 & 5.7 \\ 22 \_2 & 31.4 & 1.8 & 1.3 & 27.8 & 1.6 & 4.3 & 3.3 \\ 23 \text { 2 } & 38.4 & 2.2 & 1.9 & 25.9 & 1.5 & 4.7 & 6.1 \\ 24 \_2 & 28.2 & 1.6 & 1.4 & 26.5 & 1.5 & 4.6 & 12.4 \\ 25 \_2 & 37.2 & 2.1 & 1.6 & 24.8 & 1.4 & 4.0 & 5.2\end{array}$

Condition 2, water $40^{\circ} \mathrm{C}$

$\begin{array}{llllllll}\text { 31_2 } & 30.7 & 1.7 & 1.2 & 29.4 & 1.7 & 3.6 & 4.5 \\ \text { 29_2 } & 31.2 & 1.8 & 1.6 & 21.4 & 1.2 & 3.6 & 4.2 \\ \text { 32_2 } & 33.1 & 1.9 & 1.6 & 26.8 & 1.5 & 4.1 & 3.9 \\ 26 \_2 & 37.3 & 2.1 & 1.2 & 37.5 & 2.1 & 4.2 & 5.8 \\ 30 \_2 & 40.2 & 2.3 & 1.6 & 30.7 & 1.7 & 4.0 & 7.1 \\ \text { 33_2 } & 30.4 & 1.7 & 1.5 & 25.9 & 1.5 & 4.2 & 7.3\end{array}$

Condition 3 , water $60^{\circ} \mathrm{C}$

$\begin{array}{llllllll}\text { 13_2 } & 40.1 & 2.3 & 1.7 & 29.1 & 1.6 & 4.8 & 6.4 \\ 14 \_2 & 35.9 & 2.0 & 1.3 & 24.3 & 1.4 & 4.6 & 5.7 \\ 16 \_2 & 31.4 & 1.8 & 1.3 & 32.9 & 1.9 & 3.9 & 3.8 \\ 15 \_2 & 38.4 & 2.2 & 1.9 & 25.1 & 1.4 & 4.2 & 6.1 \\ \text { 7_2 } & 28.2 & 1.6 & 1.4 & 19.9 & 1.1 & 3.7 & 5.7 \\ \text { 8_2 } & 37.2 & 2.1 & 1.6 & 26.7 & 1.5 & 4.2 & 5.0\end{array}$

Condition 4 , water $40^{\circ} \mathrm{C}$, pressure 0.5 bar

$\begin{array}{llllllll}34 \_2 & 19.7 & 1.1 & 1.5 & 15.7 & 0.9 & 4.8 & 6.0 \\ 35 \_2 & 18.1 & 1.0 & 1.4 & 16.5 & 0.9 & 5.1 & 4.1 \\ 36 \_2 & 26.3 & 1.5 & 1.0 & 29.8 & 1.7 & 4.9 & 3.5 \\ 37 \_2 & 22.9 & 1.3 & 0.9 & 29.8 & 1.7 & 5.0 & 4.3 \\ 39 \_2 & 27.4 & 1.5 & 1.9 & 20.0 & 1.1 & 4.6 & 4.1\end{array}$

